\title{
Sedimentology and numerical modelling of aeolian sediment dispersal, McMurdo Sound, southwest Ross Sea, Antarctica
}

by

Jane Margaret Chewings

A thesis

submitted to the Victoria University of Wellington

in partial fulfilment of the requirements for the degree of

Master of Science in Geology.

Antarctic Research Centre

Victoria University of Wellington 



\section{Abstract}

Large volumes of aeolian sand and dust are deflated from unconsolidated till deposits, and supraglacial debris surrounding McMurdo Sound, Antarctica. This material is transported offshore with windblown snow onto extensive winter-formed sea ice in the southwest Ross Sea, and is subsequently released into the water-column during summer sea ice breakup. Aeolian sediment samples were collected from a $\sim 600 \mathrm{~km}^{2}$ area of sea ice in western McMurdo Sound to determine the magnitude of deposition and identify sediment sources. A new 2-dimensional numerical aeolian sediment transport model (NaMASTE) tuned specifically for the McMurdo Sound area, was used to explore the ability of the local wind system to move sediment from source areas to sea ice and to determine the pattern and extent of aeolian sediment dispersal to the southwest Ross Sea. Debris deposits on the McMurdo Ice Shelf debris bands are the most dominant sediment source for the area. Unconsolidated deposits between Cape Bernacchi and Spike Cape, and the Taylor Valley mouth are significant secondary deposits. Mass accumulation rates varied between $0.15 \mathrm{~g} \mathrm{~m}^{-2} \mathrm{y}^{-1}$ and $54.6 \mathrm{~g} \mathrm{~m}^{-2} \mathrm{y}^{-1}$, equating to a background aeolian sediment accumulation rate, excluding extremely high values, of $1.14 \pm 0.59 \mathrm{~g} \mathrm{~m}^{-2} \mathrm{y}^{-1}$ for the McMurdo Sound coastal sea ice zone. This is $3 \mathbf{- 5}$ orders of magnitude more than global background dust fallout for the Ross Sea. Modal grain size is very-fine sand to coarse silt. Notably, much of this material is distributed in localised, high sand content plumes that are oriented downwind from source, with finer deposits found outside these zones. An average seafloor linear sedimentation rate of $0.2 \mathrm{~cm} \mathrm{ky}^{-1}$ is calculated for McMurdo Sound, which is minor compared to biogenic sedimentation for the region. This equates to $\sim 0.7 \mathrm{Gg}$ $\mathrm{y}^{-1}$ aeolian sediment entering McMurdo Sound during sea ice melt. Application of NaMASTE successfully simulated the general aeolian sediment distribution pattern. Testing of model variables suggests that aeolian material is mainly transported during strong ( $>20 \mathrm{~m} \mathrm{~s}^{-1}$ ) wind events. Modelling also suggests aeolian material from McMurdo Sound can be transported north to the Drygalski Ice Tongue, $\sim 250 \mathrm{~km}$ from source, but only in very trace quantities. 


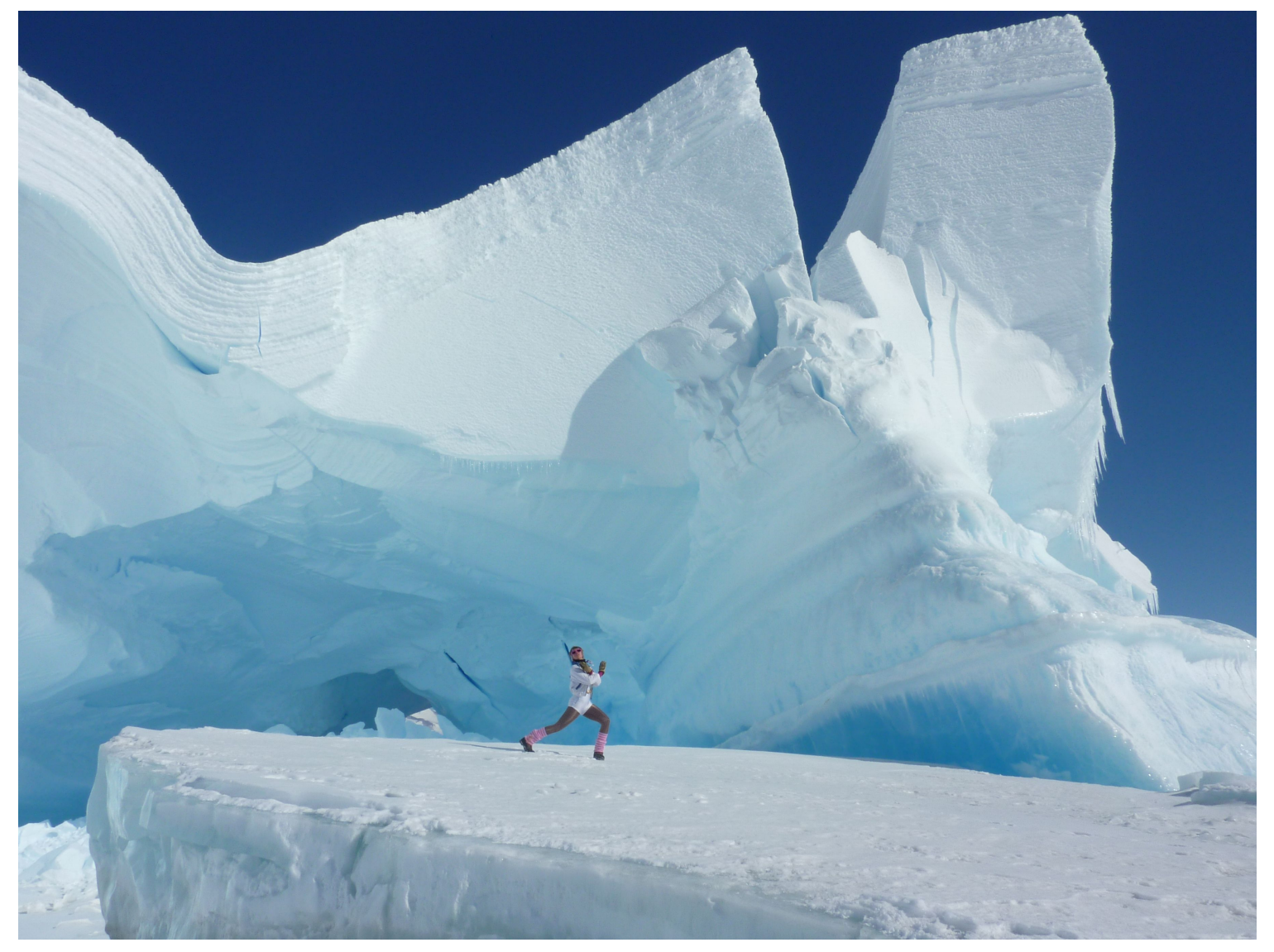

The author on a stranded iceberg performing an interpretive dance about the journey of an aeolian particle on the sea ice. New Harbour, McMurdo Sound, Antarctica (November 2010). 


\section{Acknowledgments}

This thesis is dedicated to my parents and grandparents who nurtured and encouraged an enquiring mind.

Financial assistance for this thesis was received from the 2012 Dominion Post Masters by thesis Scholarship (Antarctic Research); the Geoscience Society of New Zealand 2012 Hastie Research Award; and the Antarctic Research Centre, Victoria University of Wellington (VUW). Funding for the fieldwork component was received from the New Zealand Ministry of Science and Innovation through the Past Antarctic Climate and Future Implications (ANDRILL-NZ) Programme (contract C05X1001), under the leadership of Dr. Richard Levy, GNS Science, New Zealand. Operations and logistics support in the field was received from Antarctica New Zealand (Event: K001-D). Laboratory work was partially conducted at the National Ice Core Research Facility, GNS Science, Lower Hutt, New Zealand. All other laboratory work was carried out at the School of Geography, Enivironment and Earth Sciences (VUW). A grant to support the writing of the findings of this study into a scientific paper has been received from the Antarctic Research Centre (VUW) Endowed Development Fund.

I am grateful to have had the guidance of my supervisors: Drs. Cliff Atkins, Gavin Dunbar and Nicholas Golledge. Their shared enthusiasm for the project was greatly appreciated. Individual thanks go to: Cliff, for offering me this opportunity, taking me to the ice, and making sure I got home, for your time spent on admin and money finding, for keeping me on track, and for your welcome sense of humour. Gavin, for being a details man and a taskmaster, for your lab expertise, for your rigorous revisions of the manuscript, and for your sage anecdotes. Nick, for

writing a model specifically for simulating aeolian sediment transport over sea ice in McMurdo Sound and the SW Ross Sea, for your patience, encouragement, and kindness in helping with many small details.

There are many people who have shown an interest in and supported this research, and whose kind words have spurred me on: Prof. Peter Barrett has shown his interest in the project from the outset and his legacy of work in McMurdo Sound provided the foundation from which this project has grown. Prof. Tim Naish, AProf. Mike Hannah, Prof. Lionel Carter, Dr. Richard Levy, and Dr. Nancy Bertler, as well as Tamsin Falconer, Michelle Dow, and Louise Soulsby, provided ongoing support and encouragement both professionally and personally, for which I am very grateful. Dr. Brent Alloway provided companionship in the field, ongoing support, and beautiful photographs of our trip. Go Team ADD! Holly Winton 
provided instruction and method refinements of the filtration of dust samples and supporting data. Dr. Margaret Harper provided expertise that I was very fortunate to be able to draw on for diatom identification. Hannah Christensen and Prof. Ian Hawes, assisted in identifying the bryophitic moss remains. Molly Miller and Beverley Walker from Vanderbilt University Tennessee, provided anecdotal observations for New Harbour of the katabatic event in the field, and made us a much appreciated cup of tea. Alex Pyne kindly shared his local knowledge of the sea ice in McMurdo Sound. Simon Cox and Mark Rattenbury, GNS Science, generously provided me early access to the Southern Victoria Land QMAP. Dr. Julie Vry, assisted with mineral identification and other aspects of petrographic microscopy. Bella Duncan provided anecdotal observations of aeolian transport at Minna Bluff. Additional technical expertise was provided by Ashley Pocock, Andrew Mellanby, Adrian Benson and Aleksandr Beliaev. Staff and students of the ARC and SGEES provided friendship and collegiality, which made the task of a first, major research project all the more enjoyable. My office buddies, past and present, in particular Liz Cairns, Jess Dallas, Annika Greve, and Rob Holt, provided a huge amount of support in many ways. Ben Hines and Sanne Maas gave generously of their time to help with formatting and proofreading. Dr. Kate Sinclair, Rebecca Pyne, Dr. Katja Riedel, Daniel Emanuelsson and Andrea Tuohy, provided superb, white-suited company in the ice core lab. Dr. Marcus Vandergoes provided employment, encouragement and advice, which helped to steer me into postgraduate research.

On a more personal note, I am also fortunate to have many dear friends who kept in contact when I disappeared up the hill, cooked me dinner, bought me drinks, encouraged me, who still get excited to hear about my geeky dust project, and who inspire me by their own endeavours and incredible lives. Amy R. accompanied me on many adventures in the moutains that helped to inspire my passion for rocks. Angela understood I had to study science rather than run a business, and baked us ANZAC bikkies for in the field. Rebekah bought me many dinners and enlisted me for my first official Antarctic outreach. Kate supported me in numerous ways, not least by putting a roof over my head when I needed it. The Real Hot Bitches Dance Troupe kept me real, and inspired me to dance on ice. Carmel collected me at 6.30am to go swimming, cheered me on, and provided generous use of her car for getting me to the ice core lab. Julia, Anna, and Simon provided many evenings of cooked meals, fish feeding, beers, support, understanding, and encouragment to "do good science". May one of your children become an earth scientist, study dust, and reference this thesis.

Finally, my wonderfully supportive family and my incredibly patient and loving significant other Matt Price, always encouraged me and provided their unswerving support of my academic endeavours. 


\section{Contents}

$\begin{array}{lll}1 & \text { Introduction } & 1\end{array}$

1.1 Overview . . . . . . . . . . . . . . . . . . . . . . 1

1.2 Aeolian sediment in Antarctica . . . . . . . . . . . . . . . . . . . 2

1.2.1 Aeolian sediment dispersal to the Ross Sea . . . . . . . . . . . 2

1.3 Research scope, aims and objectives . . . . . . . . . . . . . . 3

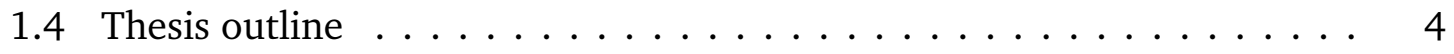

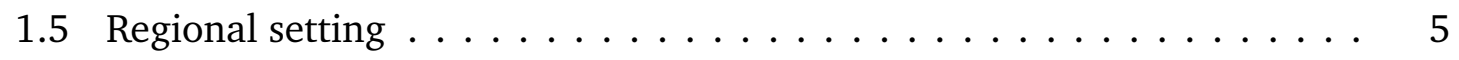

1.5 .1 Geography . . . . . . . . . . . . . . . . . 5

1.5 .2 Geology . . . . . . . . . . . . . . . . . 7

1.5.3 Wind regime, meteorology and climate . . . . . . . . . . . 9

1.5 .4 Oceanography and sea ice . . . . . . . . . . . . 16

I Physical processes and observations 21

2 Aeolian sediment entrainment and transport 23

2.1 Physical requirements for aeolian processes . . . . . . . . . . . . 23

2.1 .1 Sediment transporting wind systems . . . . . . . . . . . . . 23

2.1 .2 Aeolian sediment. . . . . . . . . . . . . . . . . . 24

2.1 .3 The wind profile . . . . . . . . . . . . . . . . . 25

2.2 Aeolian sediment transport thresholds . . . . . . . . . . . . . . . . . 29

$2.2 .1 \quad$ Particle forces . . . . . . . . . . . . . . . . . . . . . . . . . 29

2.2 .2 The threshold of particle motion . . . . . . . . . . . . . . 29

2.2 .3 Settling of a particle $\ldots \ldots \ldots \ldots$. . . . . . . . . . . 31

2.2 .4 Complicating effects for application of entrainment

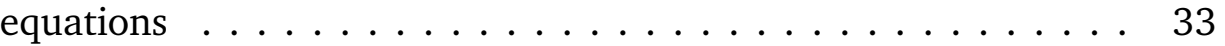

2.3 Modes of aeolian transport . . . . . . . . . . . . . . . . . 33

2.3 .1 Saltation, suspension and creep . . . . . . . . . . . . . 33

2.3 .2 Sediment transport rates $\ldots \ldots \ldots \ldots \ldots$

2.4 Aeolian processes in cold environments $\ldots \ldots \ldots$. . . . . . . . . 37

2.4 .1 Niveo-aeolian processes . . . . . . . . . . . . . . . 37 
2.4 .2 Temperature and humidity effects . . . . . . . . . . . . 38

2.5 Aeolian processes in McMurdo Sound . . . . . . . . . . . . . . . . 39

2.5 .1 Aeolian sediment supply . . . . . . . . . . . . . . . . . . 39

2.5 .2 Aeolian transport . . . . . . . . . . . . . . . . . . 39

2.5 .3 Aeolian sediment deposition . . . . . . . . . . . . . . . 40

2.6 Summary of aeolian sediment entrainment and transport . . . . . . . . . 42

$3 \quad$ Sea ice sedimentology methods 43

3.1 Sampling locations and rationale $\ldots \ldots \ldots \ldots \ldots$. . . . . . . . 43

3.2 Field methods . . . . . . . . . . . . . . . . . . . . . . . . 44

3.2.1 Sampling methodology . . . . . . . . . . . . . . . . . . 44

3.2 .2 Sample storage and transport . . . . . . . . . . . . . . . . . 47

3.2 .3 General weather observations . . . . . . . . . . . . . . . . 47

3.3 Sediment mass determination . . . . . . . . . . . . . . . . . . . 48

3.4 Provenance determination by smear slide analysis . . . . . . . . . . . . . 51

3.5 Grain size analysis $\ldots \ldots \ldots \ldots \ldots \ldots$. . . . . . . . . . . . 52

4 Results of sea ice sedimentology

4.1 Spatial patterns of aeolian sediment mass accumulation rates . . . . . . 55

4.2 Aeolian sediment provenance. . . . . . . . . . . . . . . . . . . 61

4.3 Patterns in aeolian sediment grain size . . . . . . . . . . . . . . . . 67

4.3 .1 General features of grain size distribution . . . . . . . . . . 67

4.3 .2 Spatial patterns in grain size data $\ldots \ldots \ldots$. . . . . . . . . . . . . . . . . . .

4.4 Summary of empirical results . . . . . . . . . . . . . . . . . 72

\begin{tabular}{lll}
\hline II & Physical process modelling & 75
\end{tabular}

5 Numerical modelling of aeolian sediment dispersal

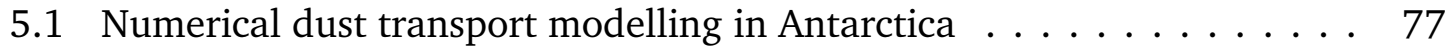

5.2 Model development for this thesis $\ldots \ldots \ldots \ldots \ldots \ldots$. . . . . . . . 78

5.2 .1 Context and aims . . . . . . . . . . . . . . . . . 79

5.3 Aeolian sediment transport modelling . . . . . . . . . . . . . . . . 79

5.3.1 Seminal empirical studies of aeolian sediment transport. . . . . . 79

5.4 Model description . . . . . . . . . . . . . . . . . . . . . . . 80

5.4 .1 Model domain and input data . . . . . . . . . . . . . . . 80

5.4 .2 Considerations for modelling physical processes . . . . . . . . . 88

5.4 .3 Constants and model variables . . . . . . . . . . . . . . 88

5.4 .4 Model physics . . . . . . . . . . . . . . . . . . . . . . 90

5.4 .5 Sources of error and uncertainty $\ldots \ldots \ldots$. . . . . . . . . 91 
5.4 .6 Runtime outputs . . . . . . . . . . . . . . . . . . . 92

5.5 Experimental approach for this study . . . . . . . . . . . . . . . 92

$5.5 .1 \quad$ Sensitivity testing . . . . . . . . . . . . . . . . 92

$5.5 .2 \quad$ Predictive modelling . . . . . . . . . . . . . . . 95

$\begin{array}{lll}6 & \text { Modelling results } & 99\end{array}$

6.1 Sensitivity testing . . . . . . . . . . . . . . . . . . . . . . 99

$6.1 .1 \quad$ Entrainment coefficient $(A) \ldots \ldots \ldots$. . . . . . . . . . 99

6.1 .2 Sorting coefficient $(\delta) \ldots \ldots \ldots \ldots \ldots 10 \ldots \ldots$

6.1 .3 Roughness amplitude $(\lambda) \ldots \ldots \ldots$. . . . . . . . 102

6.1 .4 Retention factor $(R)$. . . . . . . . . . . . . . . . . . 104

6.1 .5 Sediment supply rate $(M) \ldots \ldots \ldots \ldots$. . . . . . . . 105

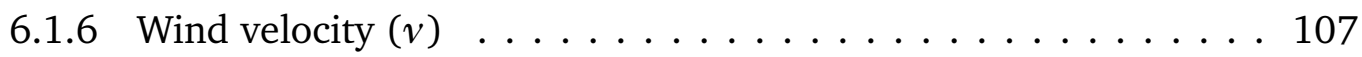

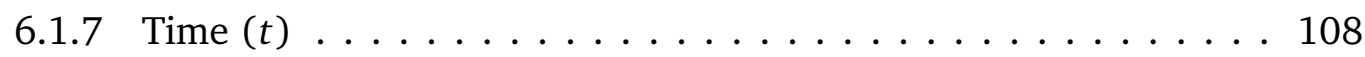

6.2 Predictive modelling . . . . . . . . . . . . . . . . . . . . . . . . . . . . . 109

6.3 Summary of modelling results . . . . . . . . . . . . . . . . 115

III Synthesis of empirical and modelling findings $\quad 117$

\begin{tabular}{|lll}
\hline 7 & McMurdo Sound aeolian sediment dispersal & 119
\end{tabular}

7.1 What are the sources of aeolian sediment in McMurdo Sound? . . . . . . . . . . . . . . . . . . . . . . . . . . . . . 119

7.2 How extensive is aeolian sediment dispersal from McMurdo Sound in the southwest Ross Sea? . . . . . . . . . . . . . . . . . . . . . . . . . . 125

7.3 What is the flux of dust from McMurdo Sound sources to the seafloor? . . . . . . . . . . . . . . . . . . . . . . . . . 129

8 Conclusions and future work 135

8.1 Conclusions . . . . . . . . . . . . . . . . . . . . . . 135

8.2 Future work . . . . . . . . . . . . . . . . . . . 136

\begin{tabular}{ll|}
\hline IV Appendices & 139
\end{tabular}

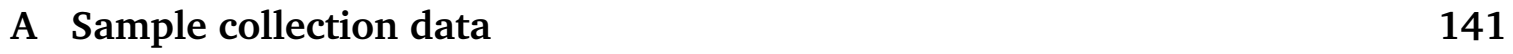

\begin{tabular}{lll}
\hline B & Mass accumulation data & 153
\end{tabular}

\begin{tabular}{lll}
\hline C Grain size data & 167
\end{tabular}

\begin{tabular}{lll}
\hline Smear slide analysis data & 181
\end{tabular} 


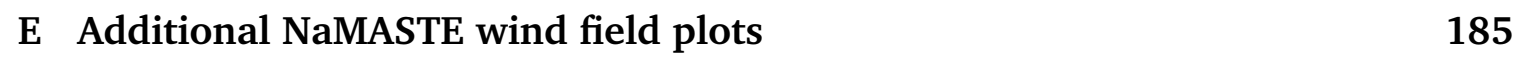

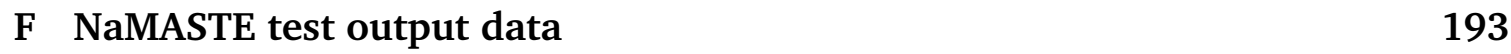

\begin{tabular}{lll}
\hline G NaMASTE sensitivity test variable values & 205
\end{tabular}

\begin{tabular}{|lll}
\hline$H$ & NaMASTE predictive test output data (selected) & 207
\end{tabular}

\begin{tabular}{|lll}
\hline I NaMASTE predictive test variable values & 211
\end{tabular}

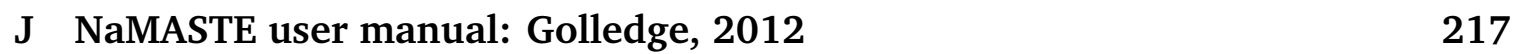




\title{
List of Abbreviations and Symbols
}

\author{
Greek Letters and Mathematical Symbols
}

$\delta \quad$ sorting coefficient; an empirical coefficient used in aeolian sand transport

flux calculations describing the degree of sorting of source sediment (after Bagnold, 1941)

$\lambda \quad$ amplitude of surface roughness elements (NaMASTE)

ln natural logarithm

$\mu \quad$ absolute viscosity; a function of fluid composition and temperature

$\nabla \quad$ del; vector differential operator, denotes the gradient of a scalar field or vector field

a partial derivative of a function of several variables

$\pi \quad \mathrm{pi} ; \approx 3.14159$

$\Psi \quad$ specific gas constant

$\mathrm{R}^{2} \quad$ statistical coefficient of determination; the proportion of variation in the $y$ values that is explained by the regression line ( $x$ values)

$\rho \quad$ fluid density

$\rho_{a} \quad$ air density

$\rho_{p}$ or $\sigma$ particle (grain) density

$\tau_{0} \quad$ shear stress

$v \quad$ kinematic viscosity of the air 


\section{Letter Abbreviations}

A entrainment coefficient; empirical coefficient describing threshold conditions of a grain on a bed prior to entrainment

cf. latin:confer: compare, similar to

d grain diameter

$D \quad$ experimental standard grain diameter $(250 \mu \mathrm{m})$

d model grain size (NaMASTE)

$g \quad$ acceleration due to gravity

$H \quad$ sediment concentrated in transit layer (NaMASTE)

$h \quad$ accumulated sediment concentration (NaMASTE)

K Prandtl-von Kármán constant; a measure of the slope of the logarithmic wind velocity profile

$k^{\prime} \quad$ focus height; corresponds to height of $O^{\prime}$

$M \quad$ source sediment supply rate (NaMASTE)

n.b. latin: notabene; note well, pay particular attention to

$O^{\prime} \quad$ focus at which wind velocity profiles diverge

$P \quad$ air pressure

$p \quad$ absolute air pressure

$Q \quad$ net flux of sediment

$q_{s l t} \quad$ flux of sediment transported in saltation

$q_{\text {sus }} \quad$ flux of sediment transported in suspension

$R \quad$ retention factor (NaMASTE)

Re Reynold's number; a measure of a certain quality of fluid flow

$R e_{p} \quad$ particle friction Reynold's number

$T$ temperature

$t \quad$ time

$U \quad$ wind (fluid) velocity ( $v$ in NaMASTE)

$u_{*}$ or $V^{*} \quad$ wind shear velocity

$u_{* t}$ or $v t$ entrainment threshold velocity

$u_{f} \quad$ terminal or settling velocity

$U_{v e l} \quad$ wind velocity along horizontal dimension $x$ (NaMASTE)

$V_{\text {vel }} \quad$ wind velocity along horizontal dimension $y$ (NaMASTE)

$z \quad$ height above surface at which velocity measurement is taken

$z_{0} \quad$ surface roughness height 


\section{Text Abbreviations}

\begin{tabular}{|c|c|}
\hline ALM & $\begin{array}{l}\text { aqueous liquid module; Beckman Coulter LS } 13320 \text { laser sizer sample } \\
\text { processing module }\end{array}$ \\
\hline AMPS & $\begin{array}{l}\text { Antarctic Mesoscale Prediction System; an experimental real time weather } \\
\text { prediction capability }\end{array}$ \\
\hline ANDRILL & ANtarctic geological DRILLing project \\
\hline AWS & automatic weather station \\
\hline $\mathrm{CO}_{2}$ & carbon dioxide \\
\hline CIROS & Cenozoic Investigations of the Ross Sea; geological drilling project \\
\hline CR & $\begin{array}{l}\text { Cape Roberts; first base camp for field team K001-D in 2010, also used as } \\
\text { sample identification prefix }\end{array}$ \\
\hline CRP & Cape Roberts Project; geological drilling project \\
\hline DVDP & Dry Valleys Drilling Project; geological drilling project \\
\hline $\mathrm{E}$ & East, cardinal direction \\
\hline EVP & Erebus Volcanic Province; province of MVG \\
\hline GPS & geographic positioning system \\
\hline K001-D & Antarctica New Zealand field event code, 'K' for Kiwi, 'D' for dust \\
\hline MAF & Ministry of Agriculture and Fisheries (New Zealand) \\
\hline MAR & mass accumulation rate \\
\hline MDV & McMurdo Dry Valleys; geographic region \\
\hline MLM & $\begin{array}{l}\text { micro liquid module; Beckman Coulter LS 13-320 laser sizer sample pro- } \\
\text { cessing module }\end{array}$ \\
\hline MODIS & Moderate Resolution Imaging Spectroradiometer project (NASA-EO) \\
\hline MP & $\begin{array}{l}\text { Marble Point; second base camp for field team K001-D in 2010, also used } \\
\text { as sample identification prefix }\end{array}$ \\
\hline MS & meteorological station \\
\hline MSSTS & McMurdo Sound Sediment and Tectonic Study; geological drilling project \\
\hline MVG & $\begin{array}{l}\text { McMurdo Volcanics Group; volcanic provinces located in the western Ross } \\
\text { Sea area }\end{array}$ \\
\hline $\mathrm{N}$ & North, cardinal direction \\
\hline NaMASTE & Numerical Model for Aeolian Sediment Transport and Evolution \\
\hline $\mathrm{NaN}$ & Not a Number; indicates no output for model grid point (NaMASTE) \\
\hline NASA-EO & National Aeronautics and Space Administration - Earth Observatory (USA) \\
\hline RSD & Ross Sea Drift; moraine deposit found in McMurdo Sound area \\
\hline S & South, cardinal direction \\
\hline snap & snapshot; relates to AMPS static wind field (NaMASTE) \\
\hline SWE & strong wind event \\
\hline SWS & surface weather station \\
\hline USGS & United States Geological Survey \\
\hline TAM & Transantarctic Mountains \\
\hline W & West, cardinal direction \\
\hline
\end{tabular}




\section{Units of Measurement}

${ }^{\circ} \mathrm{C}$ degrees Celcius; unit of temperature, the freezing point of water at one atmosphere is $0^{\circ} \mathrm{C}=-273.15^{\circ} \mathrm{K}$

$\mathrm{cm}$ centimetre; unit of length, equivalent to one hundreth of a metre

$\mathrm{g}$ gram; unit of mass, equivalent to one thousanth of a kilogram

Gg gigagram; unit of mass equivalent to one billion grams

h hour; unit of time, equivalent to 60 minutes

$\mathrm{hPa}$ hectopascal; unit of air pressure, equivalent to one hundred pascals

${ }^{\circ} \mathrm{K}$ degrees Kelvin; SI base unit of temperature, equivalent to ${ }^{\circ} \mathrm{C}+273.15$

kg kilogram; SI unit of mass

$\mathrm{km} \quad$ kilometre; unit of length, equivalent to one thousand metres

$\mathrm{kPa} \quad$ kilopascal; unit of air pressure, equivalent to one thousand pascals

ky kiloyear; unit of time, equivalent to one thousand years

$\mathrm{m} \quad$ metre; base SI unit of length

$\mathrm{m} \Omega$ milliohm; unit of electrical resistance, equivalent to one thousandth of an ohm

MPa megapascal; unit of air pressure, equivalent to one million pascals

$\mu \mathrm{m} \quad$ micron; unit of length, equivalent to one millionth of a metre

$\mathrm{Pa} \quad$ pascal; SI base unit of pressure, equivalent to one Newton per square metre

s second; SI base unit of time, equivalent to one sixtieth of a minute

$\mathrm{Tg}$ teragram; unit of mass, equivalent to one trillion grams

y year; unit of time, equivalent to $\sim 8,760$ hours 


\section{List of Figures}

1.1 Location map of McMurdo Sound in the southwest Ross Sea. . . . . . . . 6

1.2 Geology of the McMurdo Sound region, including cover deposits and aeolian sediment sample sites. . . . . . . . . . . . . . . 8

1.3 Multi-year wind direction and velocity data for locations surrounding McMurdo Sound. . . . . . . . . . . . . . . . . . . . . . . . . 11

1.4 Map showing predominant wind flowlines for McMurdo Sound. . . . . . 12

1.5 Annual distribution of strong wind events at McMurdo Station, 1979-

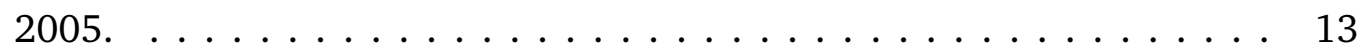

1.6 Mean wind field streamlines over the surface of Antarctica. . . . . . . . . 14

1.7 Spatial gradient of snow accumulation in Taylor and Wright Valleys. . . . 15

1.8 Mean monthly air temperature and relative humidity for McMurdo Sound 16

1.9 Map of McMurdo Sound showing ocean circulation. . . . . . . . . . . . 17

1.10 Satellite images showing the seasonal break-up of sea ice, and a large phytoplankton bloom, in the southwest Ross Sea . . . . . . . . . . . . 19

2.1 Cumulative grain size frequency curves of global atmospheric dust samples.. . . . . . . . . . . . . . . . . . 25

2.2 A comparison of (non-dimensional) velocity profiles . . . . . . . . . 26

2.3 Wind velocity profiles over both a stationary and a mobile sand bed . . . 27

2.4 The relation between particle size and the threshold velocity for move-

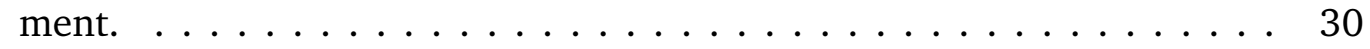

2.5 Modes of transport of quartz spheres of different diameters at different wind shear velocities. . . . . . . . . . . . . . . . . . . 32

2.6 Modes of aeolian transport: saltation, suspension and creep. . . . . . . . 34

2.7 Schematic diagram showing saltation splash . . . . . . . . . . . . 35

2.8 Saltation over differing surfaces. . . . . . . . . . . . . . . . 35

2.9 The characteristic saltation path showing vertical and horizontal components of grain velocity relative to the ground. . . . . . . . . . . 36

2.10 Windblown snow streamers over sea ice and snow/sediment streamers over gravelly till, 31 October $2010 . \ldots \ldots$. . . . . . . . . 41 
3.1 Event K001-D sampling sites, 2010 field season, western McMurdo Sound. 45

3.2 Millipore vacuum filtration system. . . . . . . . . . . . . . . . . . 49

3.3 Potential contaminant of sediment samples appearing as a white residue. 50

3.4 Replicate runs to show accuracy of Beckman Coulter LS 13 320. . . . . . 53

4.1 Sediment mass accumulation rates found in western McMurdo Sound snow samples. . . . . . . . . . . . . . . . . . . . . . . . . 57

$4.2 \quad$ Distribution of aeolian sediment mass accumulation rates. . . . . . . . . 58

4.3 Areas of highest and lowest sediment mass accumulation rates. . . . . . . 59

4.4 Graph showing frequency distribution of mass accumulation rates. . . . 60

4.5 Photograph of smear slide CR-J11 showing sample composition and tex-

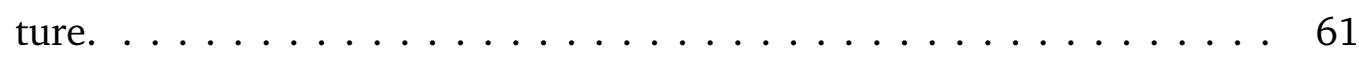

4.6 Plot of volcanic glass abundance for the field area. . . . . . . . . . . . . 63

4.7 Photographs of biogenic grains and within aeolian sediment samples. . . 65

4.8 Histogram of aeolian sediment grain size data from western McMurdo Sound. . . . . . . . . . . . . . . . . . . . 69

4.9 Four transects showing fining away from the coast. . . . . . . . . 70

4.10 Contour map showing percent sand in each sample. . . . . . . . . . 71

5.1 Relative contribution from three Southern Hemisphere sources to dust deposition in southern high latitudes. . . . . . . . . . . . . . 78

5.2 Antarctic Mesoscale Prediction System (AMPS) domains. . . . . . . . . . 82

5.3 NaMASTE model domain. . . . . . . . . . . . . . . . . . 83

5.4 NaMASTE model four year annual mean wind field for McMurdo Sound. 85

5.5 NaMASTE model moderate strength wind field for McMurdo Sound.. . . 86

5.6 NaMASTE model 16 May 2004 katabatic storm event wind field for McMurdo Sound. . . . . . . . . . . . . . . . . . . . 87

5.7 Flow diagram showing methodology used for sensitivity testing of NaMASTE model variables . . . . . . . . . . . . . . . . . . . 94

5.8 Distribution of southerly winds at Pegasus North AWS during 2010. . . . 96

6.1 Effect of entrainment coefficient on accumulation. . . . . . . . . . . . . 100

6.2 Effect of source material sorting on accumulation. . . . . . . . . . . . 102

6.3 Effect of surface roughness on accumulation. . . . . . . . . . . . 103

6.4 Effect of snow capture/ retention on accumulation. . . . . . . . . . . . . 105

6.5 Effect of sediment supply rate on accumulation. . . . . . . . . . . . . . . . . . . . . . . . . 106

6.6 Effect of wind strength on accumulation. . . . . . . . . . . . . . . . . . . . . . . . . . . . . . . . . .

6.7 Effect of time on accumulation. . . . . . . . . . . . . . . . . . . . 109

6.8 NaMASTE best fit predictive plot of aeolian sediment dispersal for McMurdo Sound and the southwest Ross Sea. . . . . . . . . . . . . . . 111 
6.9 NaMASTE alternative predictive plots of aeolian sediment dispersal for McMurdo Sound and the southwest Ross Sea. . . . . . . . . . . . . . 114

7.1 Satellite image of the McMurdo Ice Shelf debris bands. . . . . . . . . . . . 121

7.2 MAR distribution and storm dominated wind flow. . . . . . . . . . . . . 122

7.3 Percentage sand with storm dominated wind flow. . . . . . . . . . . . . 124

7.4 Modelled dust deposition for the globe. . . . . . . . . . . . . . . . . 126

7.5 Relationship between observed MAR and distance from McMurdo Ice Shelf. . . . . . . . . . . . . . . . . . . . . . . . . . 127

7.6 Schematic cross section of McMurdo Sound illustrating sediment inputs. 129 


\section{List of Tables}

2.1 Aerodynamic properties of natural surfaces. . . . . . . . . . . . . . . . 28

2.2 Density and kinematic viscosity of air in terms of temperature at a pressure of $0.099 \mathrm{MPa} . \ldots \ldots \ldots \ldots$

3.1 Summary of types of sample collected and methods used in collection: Event K001-D - 2010 field season. . . . . . . . . . . . . . . . . . . . 46

4.1 K001-D 2010-2011 McMurdo Sound field season sample collection and lab analysis statistics . . . . . . . . . . . . . . . 55

4.2 Compositional features of aeolian sediment samples. . . . . . . . . . . 62

4.3 Diatoms found in aeolian sediment samples, as identified from 31 smear slides. . . . . . . . . . . . . . . . . . . . . . 66

5.1 Summary of NaMASTE model environment. . . . . . . . . . . . . . . . 84

5.2 Physical constants used in the NaMASTE. . . . . . . . . . . . . . . . . 89

5.3 NaMASTE model variables. . . . . . . . . . . . . . . . . . . . . . . . . 89

5.4 Summary of NaMASTE model physics. . . . . . . . . . . . . . . . . . 91

5.5 NaMASTE model variables and used in sensitivity testing . . . . . . . . 93

6.1 Range of velocities within static wind fields. . . . . . . . . . . . . . . 107

6.2 Test variables used to predict for a "best fit" to the distribution found in the empirical data. . . . . . . . . . . . . . . . . . . 110

6.3 Observed accumulation and modelled accumulation for corresponding locations. . . . . . . . . . . . . . . . . . . . . . . 113

7.1 Aeolian sediment accumulation rates at various locations on the Antarctic continent. . . . . . . . . . . . . . . . . . . . . 120

7.2 $\quad$ Aeolian sediment accumulation rates and deposition estimates for the Southern Ocean and southwest Ross Sea. . . . . . . . . . . . . . . . . . 132

7.3 Sedimentation rates for aeolian and other sources of sediment. . . . . . . 133 


\section{Chapter 1 Introduction}

\subsection{Overview}

Aeolian (windblown) sediment has recently been highlighted as an emerging core theme in Earth system science with the "dust cycle" being positioned alongside other global bio-geochemical cycles such as the energy cycle and carbon cycle (Kohfeld and Tegen, 2007; Shao et al., 2011). Aeolian material plays an integral part in the world's atmospheric, terrestrial, oceanic and cryospheric processes, with an estimated 2,000 Mt emitted into the atmosphere and subsequently rained out each year. Although $75 \%$ of this material accumulates on land (Ravi et al., 2011; Shao et al., 2011), the $25 \%$ that rains out over the oceans is particularly important because; 1) changes in the flux to the ocean are captured in the stratigraphic record and are a proxy for environmental change (e.g. Bloemendal and deMenocal, 1989), and 2) of the potential for this material to provide otherwise limited micronutrients for marine phytoplankton production (e.g. Sedwick and DiTullio, 1997), which in turn affects $\mathrm{CO}_{2}$ drawdown by biomass in the oceans (Prospero et al., 1983; Kohfeld and Tegen, 2007; McTainsh and Strong, 2007; Mahowald et al., 2011; Shao et al., 2011; Schulz et al., 2012).

The largest aeolian sediment sources are poorly vegetated desert regions that lie under sub-tropical high-pressure systems (e.g. Sahara). Cold deserts found at the polar regions, although minor in terms of source area, also lack vegetation and have high wind speeds, which enhance erosion, ensuring aeolian processes are very active in these latitudes (Prospero et al., 2002; Kohfeld and Tegen, 2007). Indeed, the absence of fluvial processes, particularly in Antarctica, means ice and wind are the dominant agents of erosion and sediment transport (Anderson et al., 1984; Malin, 1992; Marchant and Head, 2007).

The southwest Ross Sea region of Antarctica is isolated from sources of global dust such as central Australia and Patagonia, soures of dust to the East Antarctic Ice Sheet; 
however local dust appears to be important as the flux of aeolian sediment to this ocean sector during sea ice melt has been closely linked to changes in biological productivity by previous workers (e.g. Sedwick and DiTullio, 1997; Arrigo et al., 2003; Leventer, 2003; Sedwick et al., 2011). These characteristics mean the region is well suited to a quantitative study of aeolian sediment flux into the sea.

The recognition that windblown material contributes directly and indirectly to biogeochemical cycling and to marine sedimentation is not new (Windom, 1969; Prospero et al., 1983; Volk and Hoffert, 1985); however, the processes involved, particularly for the polar oceans, the rate of supply, and the relative importance of windblown sediment to biomass productivity, are poorly constrained (e.g. Arrigo et al., 2010; Sedwick et al., 2011; Tagliabue et al., 2011; Alderkamp et al., 2012; Boyd et al., 2012; Gerringa et al., 2012; Schulz et al., 2012; Smetacek et al., 2012). This study contributes new aeolian sediment accumulation and particle size observations and numerical modelling to improve our understanding of aeolian transport pathways, processes and distribution within the southwest Ross Sea sector of the Antarctic continental margin.

\subsection{Aeolian sediment in Antarctica}

\subsubsection{Aeolian sediment dispersal to the Ross Sea}

McMurdo Sound in the southwest Ross Sea is bordered by large, ice-free exposures of weathered rock and unconsolidated sediment. This supply of erodible sediment, the lack of vegetation and abundant wind make it one of the few areas in Antarctica where aeolian processes can transport sediment directly onto sea ice and into the ocean. Visible dusty plumes on sea ice have helped to identify aeolian sediment sources in McMurdo Sound (e.g. Bentley, 1979; Atkins and Dunbar, 2009). Despite this, aeolian sediment datasets for this region are few, generally covering small spatial areas, and reflecting differing research questions and collection methods. For example, paleodust in ice or firn cores (Delmonte et al., 2010b); chemistry of dust from snow pits in relation to terrestrial ecological activity (e.g.Witherow et al., 2006) and paleo-climate variability (e.g. Bertler et al., 2006); and geomorphic studies (e.g. Speirs et al., 2008).

Early sedimentological investigations in McMurdo Sound were considerably advanced by the Dry Valley's Drilling Project (DVDP), 1972-1976 (Barrett et al., 1975). DVDP-15 $\left(77^{\circ} 28.4^{\prime} \mathrm{S}, 164^{\circ} 25.5^{\prime} \mathrm{E}\right)$ was the first off-shore sedimentary core retrieved from McMurdo Sound, reaching $65 \mathrm{~m}$ below sea floor. Core material graded down core from 
modern, poorly sorted, slightly gravelly medium sand to (probably) late Pliocene-age well sorted, fine basaltic sands. Grab samples of the modern seafloor sediments were compared to core textures. This led workers to the interpretation that a significant section of the DVDP-15 core reflected seasonal deposition from settling through suspension of sediment deposited by wind or released from melting sea ice (Barrett et al., 1975; Barnes et al., 1976; Barrett and Treves, 1981; Barrett et al., 1995). By studying seafloor sediments, early workers proposed that aeolian sediment, mainly fine to very-fine sand, is the most significant contributor to nearshore sedimentation in McMurdo Sound (Barrett et al., 1983) and for the nearby Terra Nova Bay polynya (Hughes and Krissek, 1985); however, no quantitative study to date has been carried out to confirm these conclusions at a regional scale.

Localised studies of aeolian processes, landforms and sediments surrounding McMurdo Sound have occurred in various sites ranging from: deglaciated valleys and inland dune fields (Malin, 1986; Lancaster, 2002; Lancaster et al., 2010; Wilson, 2003; Speirs et al., 2008; Bristow et al., 2010; Deuerling, 2010; Šabacká et al., 2012); on low-elevation glaciers (Ayling and McGowan, 2006; Witherow et al., 2006; Bull, 2009; Schuck, 2009; Fortner et al., 2011); on coastal sea ice (Bentley, 1979; Barrett et al., 1983; Atkins and Dunbar, 2009; Winton, 2011); and on nearby ice shelves (Dunbar et al., 2009). While some of these projects provide context and observations relevant to this study, none have aimed to understand the importance of aeolian sediment dispersal on a scale applicable to the broader southwest Ross Sea marine environment.

\subsection{Research scope, aims and objectives}

That sea ice in McMurdo Sound acts as a natural sediment trap also makes it possible to sample seasonal-annual aeolian sediment accumulation throughout the area. From this, a minimum mass flux to ocean surface waters can be calculated and a distribution pattern investigated. By numerically modelling regional wind fields and their capacity to move aeolian sediment from source areas onto sea ice, it is possible to predict aeolian sediment dispersal for a larger area by matching model outputs to empirical data and extrapolating beyond the field area.

This study aims to understand the origin, transport and deposition of aeolian sediment to the southwest Ross Sea from sources surrounding McMurdo Sound. It presents a modern, regionally representative, empirical dataset of aeolian sediment accumulation on sea ice. It also links this dataset to local point sources for aeolian sediment and uses local wind field data to constrain transport pathways. These empirical data are then 
used to project aeolian sediment distribution to the broader Ross Sea region using a simple, 2D-numerical aeolian sediment transport model (Golledge, 2012). Empirical and modelling findings are used to discuss potential contribution to sedimentation in the southwest Ross Sea.

Key research questions for this thesis are:

- What is the source and distribution of windblown sediment within McMurdo Sound, Antarctica?

- How is sediment moved and dispersed by mesoscale wind flow from McMurdo Sound to the southwest Ross Sea region?

\subsection{Thesis outline}

This thesis comprises three parts. The first describes and interprets the distribution of aeolian sediment on sea ice in McMurdo Sound. The second utilises a sediment transport model to provide insight into the physical mechanisms behind the patterns observed in Part I. A final, third part synthesises the results of these two complementary components.

Chapter 1 offers an introduction to the subject and the regional setting of the study area. In Part I: Chapter 2 outlines the physical processes of aeolian sediment transport, empirical observations and analysis, and offers further detail on this topic specific to the field area. Chapter 3 comprises the methodology, and Chapter 4 the results, of the first part of this study. In Part II: Chapter 5 provides details of the numerical model and modelling approach used for the second part, followed by results in Chapter 6 . Finally in Part III: Chapter 7 presents a synthesis of results of the empirical data and modelling outlined in Chapters 3 to 7 , discussing and drawing conclusions from the findings under three 'key question' headings. Chapter 8 summarises the key findings of the research and offers thoughts on directions of future research beyond this thesis. Additional data can be found in Appendices A to J. 


\subsection{Regional setting}

\subsubsection{Geography}

\section{McMurdo Sound}

McMurdo Sound is situated between $77^{\circ} \mathrm{S}$ and $78^{\circ} \mathrm{S}$, and $163^{\circ} \mathrm{E}$ and $166^{\circ} \mathrm{E}$ in the southwest Ross Sea, lying off the coast of Southern Victoria Land (Figure 1.1). It is bound to the west by the McMurdo Dry Valleys (MDV) region, the largest $(4,800$ $\mathrm{km}^{2}$; Doran, 2002) ice-free area on the Antarctic continent, and to the south and east by outcropping Erebus Volcanic Province, one of three that comprise the McMurdo Volcanics Group (MVG) (referred to throughout this study as MVG) (Kyle et al., 1990). As summarised in Barrett et al. (1983), the sound is $\sim 50 \mathrm{~km}$ wide, with a western shelf (average depth $200 \mathrm{~m}$ ), an eastern slope $\left(\sim 1^{\circ}\right)$, and an elongate, north-south trending, glaci-marine basin (average depth $900 \mathrm{~m}$ ). To the north the sound opens to the Ross Sea. To the south the sound continues beneath the McMurdo Ice Shelf, a peripheral extension of the Ross Ice Shelf, which overides the southern-most MVG volcanic islands and peninsulas (Denton and Marchant, 2000; Aitken et al., 2012). This comparatively small $\left(\sim 1,500 \mathrm{~km}^{2}\right)$ ice shelf is unusual in its high rate of surface ablation (43-411 $\mathrm{mm} \mathrm{y}^{-1}$ ), minimal calving and large amounts of surface debris, probably present throughout the Holocene (Glasser et al., 2006). 


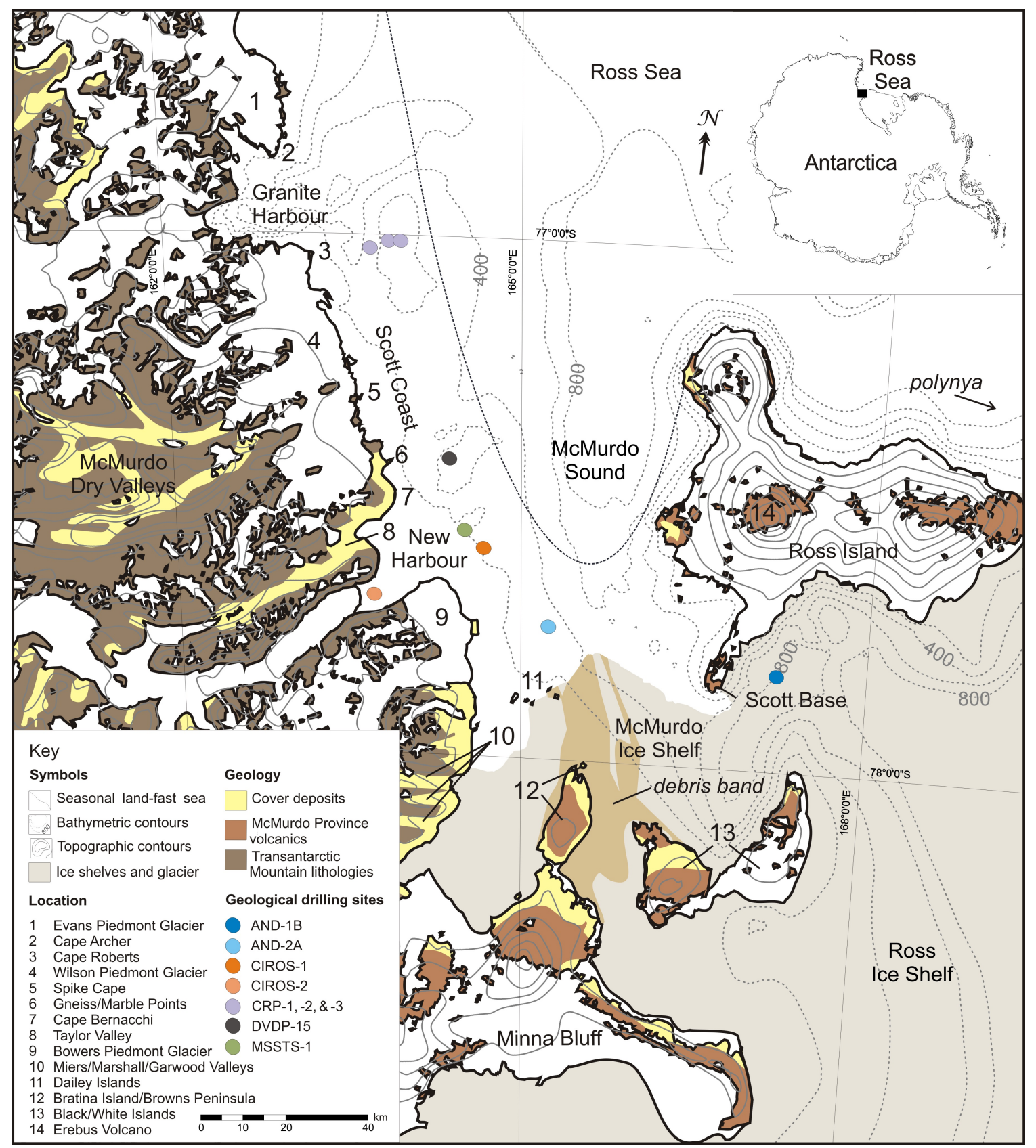

Figure 1.1: Location map showing McMurdo Sound in the southwest Ross Sea and surrounds. Inset: Location of McMurdo Sound on the Antarctic coastline. 


\section{McMurdo Dry Valleys}

Historically referred to as the "McMurdo Oasis", the MDV collectively comprise the largest, contiguous ice-free area of the $\sim 2 \%$ exposed Antarctic bedrock (Drewry et al., 1982). Valleys trend northeast-southwest and topographic highs are typically $\sim 2,000$ $\mathrm{m}$ in elevation, increasing to more than $4,000 \mathrm{~m}$ in the nearby Royal Society Range. The MDV region has remained largely ice-free since at least the middle Miocene, with high-elevation bedrock topography diverting drainage paths of ice sheet outlet glaciers (Sugden et al., 1999; Denton and Marchant, 2000); however, between latitudes $76^{\circ} \mathrm{S}$ and $79^{\circ} \mathrm{S}$, seven large glaciers flow from Taylor Dome on the western side of the Transantarctic Mountains (TAM) into the valleys and surrounds including the Mackay and Ferrar outlet glaciers which terminate in Granite Harbour and New Harbour, respectively. Smaller valley and cold-based glaciers are also present, but affect little erosion in the modern environment (Atkins et al., 2002; Marchant and Head, 2007; Atkins and Dickinson, 2007). Rock outcrops and gravel beaches make up about a third of McMurdo Sound's coastline (Barrett et al., 1983). MDV outcropping geology is outlined in Subsection 1.5.2. Piedmont and valley glaciers terminate in many of the larger valleys, such as Victoria and Wright, essentially rendering them closed sedimentary systems as the relatively coarse (sand and gravel) surface sediment exposed there is not transported over these topographic features. In contrast, the Miers, Marshall, Garwood and Taylor valleys remain open to the coast and are potential sources of windblown sediment onto the sea ice in McMurdo Sound.

\subsubsection{Geology}

\section{Location and lithology of unconsolidated sediment}

The geology of the TAM outcropping in Southern Victoria Land is relatively simple. As summarised by Gunn and Warren (1962); Craddock (1970); Barrett et al. (1995); Denton and Marchant (2000) and more recently Cox et al. (2012), the regional geology has been subdivided into several broadscale groupings based on age and lithology (Figure 1.2). Meta-sediments and granitic-granodioritic basement rocks are overlain by $\sim 2 \mathrm{~km}$ of broadly horizontal, largely terrestrial sediments sourced from the East Antarctic craton and eastern Ross Sea (Devonian to Triassic, Beacon Supergroup). Jurassic Ferrar Dolerite intrude this sequence, forming massive sills that total 1,000 m in thickness (Sugden and Denton, 2004). Their resistance to erosion forms the plateau topography typical of the TAM. Whereas, recent MVG eruptives interrupt the Victoria Land coastline, forming basaltic islands and peninsulas (Kyle et al., 1990). 


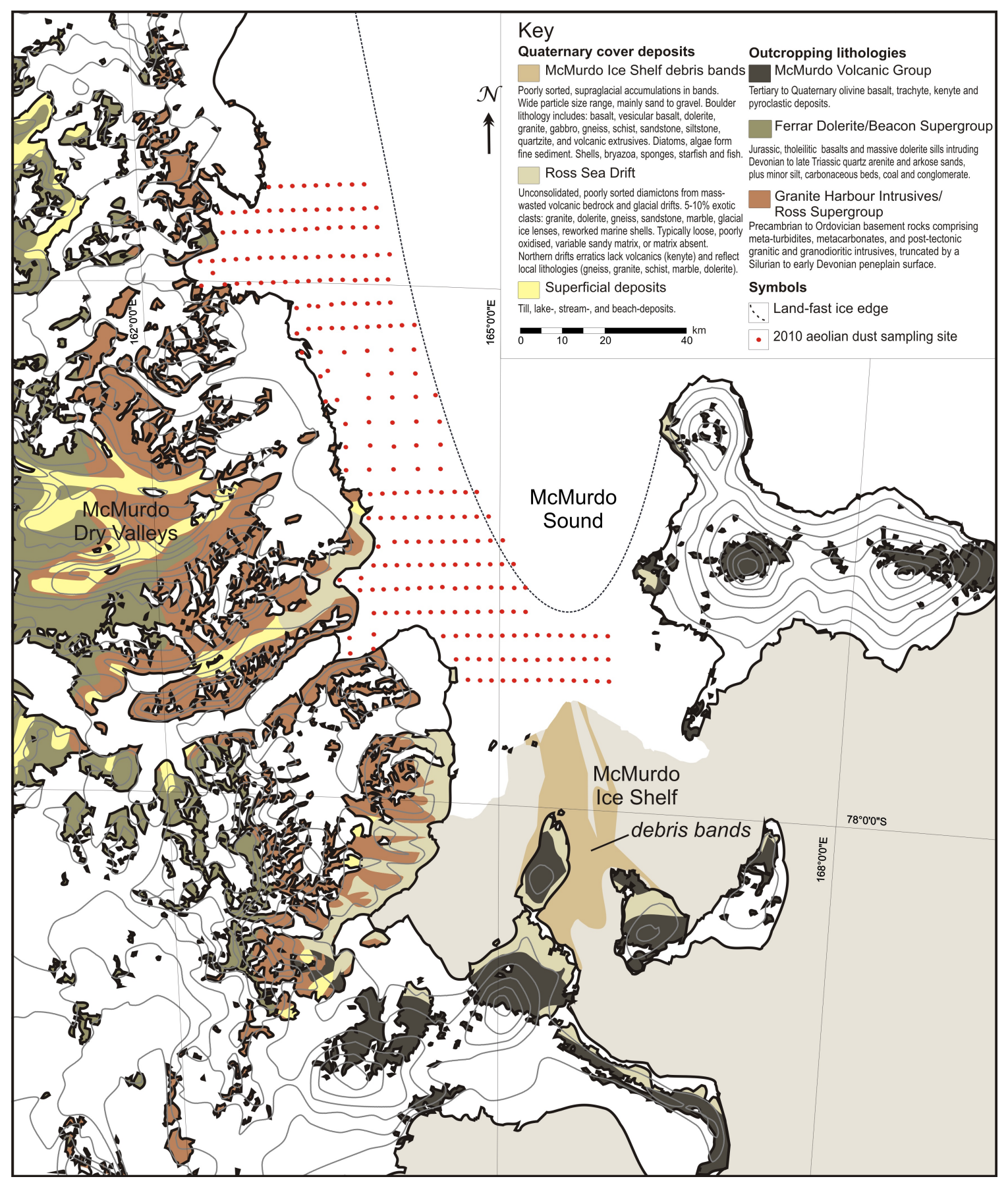

Figure 1.2: Geology of the McMurdo Sound region, including cover deposits and 2010 aeolian sediment sample sites (this study) on sea ice attached to the Scott Coast, western McMurdo Sound. Descriptions after Gunn and Warren, 1962; Craddock, 1970; Kellogg et al., 1990; Kyle et al., 1990; Barrett et al., 1995; Denton and Hughes, 2000; Glasser et al., 2006; Cox et al., 2012 


\section{Cover deposits potentially erodible by wind}

Surficial cover deposits of glacial, fluvial and tidal origin are found in exposed valleys and coastal areas. Diamicton deposits, known as the Ross Sea Drift (RSD), mantle the southern-most Victoria Land valley mouths and MVG exposures (Figure 1.2). These deposits, detailed in Denton and Marchant (2000), derive from the Ross Ice Sheet's westward advance into McMurdo Sound during the Last Glacial Maximum.

On the McMurdo Ice Shelf surface, accumulations of sediment, known as the McMurdo Ice Shelf debris bands or the "dirty ice", form surficial bands between Black Island and Brown Peninsula, around Bratina Island and beyond to the ice shelf edge (refer Figure 1.1 and Figure 1.2). The majority of this material is thought to be a remnant of debris transported by a paleo-ice tongue during the Last Glacial Maximum, while a lesser portion of the debris has worked its way through the ice shelf by advection. This occurs due to basal adfreezing of sediments to anchor ice in shallows where the ice shelf grounds and surface ablation carries seafloor debris up through the ice shelf to the surface (Debenham, 1920; Kellogg et al., 1990; Hawes and Howard-Williams, 2003; Glasser et al., 2006).

The debris exhibits a wide range of particle sizes. Gravel lag deposits are common, serving to protect the sands and silts lying underneath from wind erosion. A small portion of the fine grained fraction is non-lithogenic, comprising diatoms and algae originating from surficial meltwater ponds (Kellogg et al., 1990). Icebergs carrying supraglacial debris of similar composition to the McMurdo Ice Shelf debris bands have also been observed along the western margin of the sound (Barrett et al., 1983; this study).

\subsubsection{Wind regime, meteorology and climate}

\section{Atmospheric circulation}

The Ross Sea is one of the most active cyclogenetic regions in the world (Parish et al., 2006). A confluence of three dissimilar air masses occurs over the Ross Ice Shelf and Ross Sea region; 1) very cold, dry air from the East Antarctic continental plateau to the west, 2) cold and somewhat moister air from the low-lying Ross Ice Shelf to the south, and 3) relatively warm, moist maritime air from the Ross Sea to the north (Monaghan et al., 2005).

As summarised by van den Broeke and van Lipzig (2003) and Seefeldt et al. (2007), atmospheric circulation within the region is characterised by barrier, katabatic, and 
light winds, with strong seasonal variability. Barrier winds are generated by cyclonic circulation over the Ross Ice Shelf or southern Ross Sea, creating a strong southerly air flow along the TAM. Katabatic winds for the Ross Sea region result from surface-level cold air drainage from the continental plateau through the TAM. Light katabatics $<5 \mathrm{~m} \mathrm{~s}^{-1}$, are strongly directional from the south, often extending for hundreds of kilometres over the Ross Ice Shelf; however, valley topography can locally enhance wind velocities. Strong katabatics are typically $>5 \mathrm{~m} \mathrm{~s}^{-1}$ and can be associated with large differences in surface temperature between the Ross Ice Shelf and the polar plateau. Light winds $\left(<4 \mathrm{~m} \mathrm{~s}^{-1}\right)$ are not influenced by topography, have weak pressure gradients but are generally more variable than katabatics, manifesting as sea breezes in the McMurdo Sound vicinity.

Due to McMurdo Sound's position between the major topographic obstacles of the TAM (Mt Lister 4,025 m) and Ross Island (Mt Erebus 3,794 m), orographic effects exert an important influence on near-surface wind circulation (Monaghan et al., 2005) (Figure 1.3 and Figure 1.4). The southerly- to southwesterly-dominant air flow typically deflects around the complex local topography, flowing around Minna Bluff and splitting around Ross Island, creating localised synoptic cyclogenesis for the area (Stearns, 1997; Seefeldt et al., 2003; Chenoli et al., 2012). Some climatic seasonality (e.g. Southern Annular Mode; Speirs et al., 2012) and diurnally forced variability in wind direction and intensity have been noted for the region (McKendry and Lewthwaite, 1992; Doran, 2002; Šabacká et al., 2012; Speirs et al., 2012). 


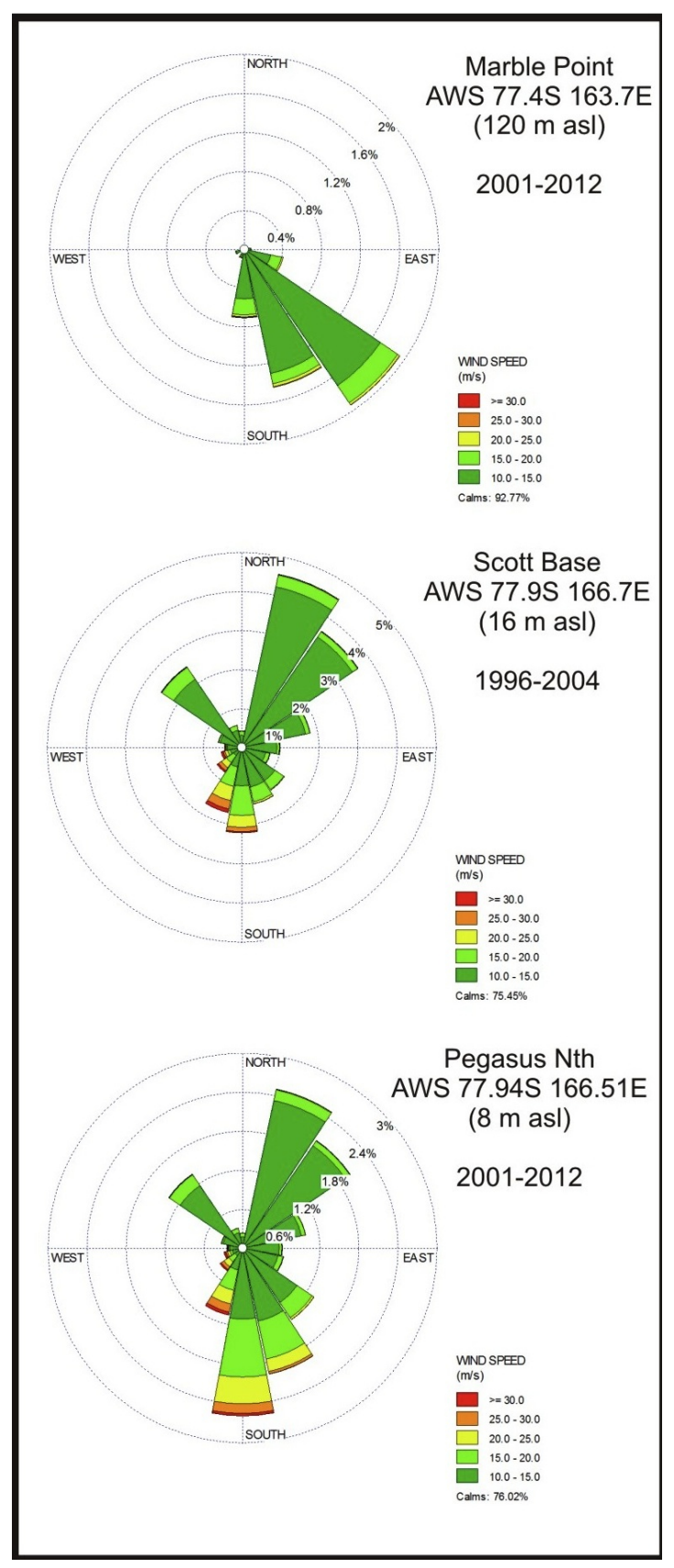

(a)

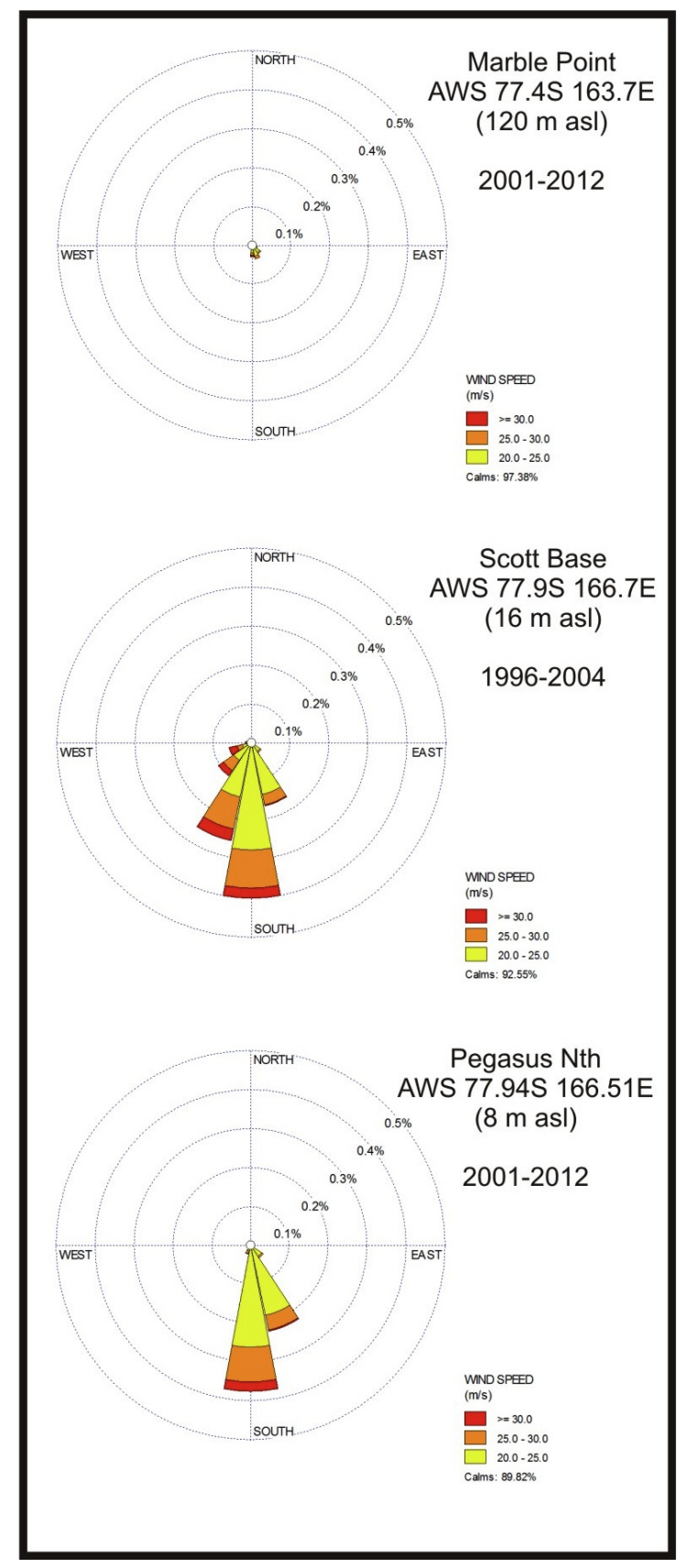

(b)

Figure 1.3: Multi-year wind direction and velocity data for locations surrounding McMurdo Sound. Panels show: a) winds $>10 \mathrm{~m} \mathrm{~s}^{-1}$, and b) winds $>20 \mathrm{~m} \mathrm{~s}^{-1}$. Data are $1 \mathrm{~h}$ observations from Marble Point, automatic weather station, Scott Base surface weather station, and Pegasus North automatic weather station. Station locations provided in Figure 1.4. Wind flowlines modified from Ayling (2001). Scott Base data: CliFlo archive, http://cliflo.niwa.co.nz. Pegasus North and Marble Point data: AWS archive, http://amrc.ssec.wisc.edu/aws/. 


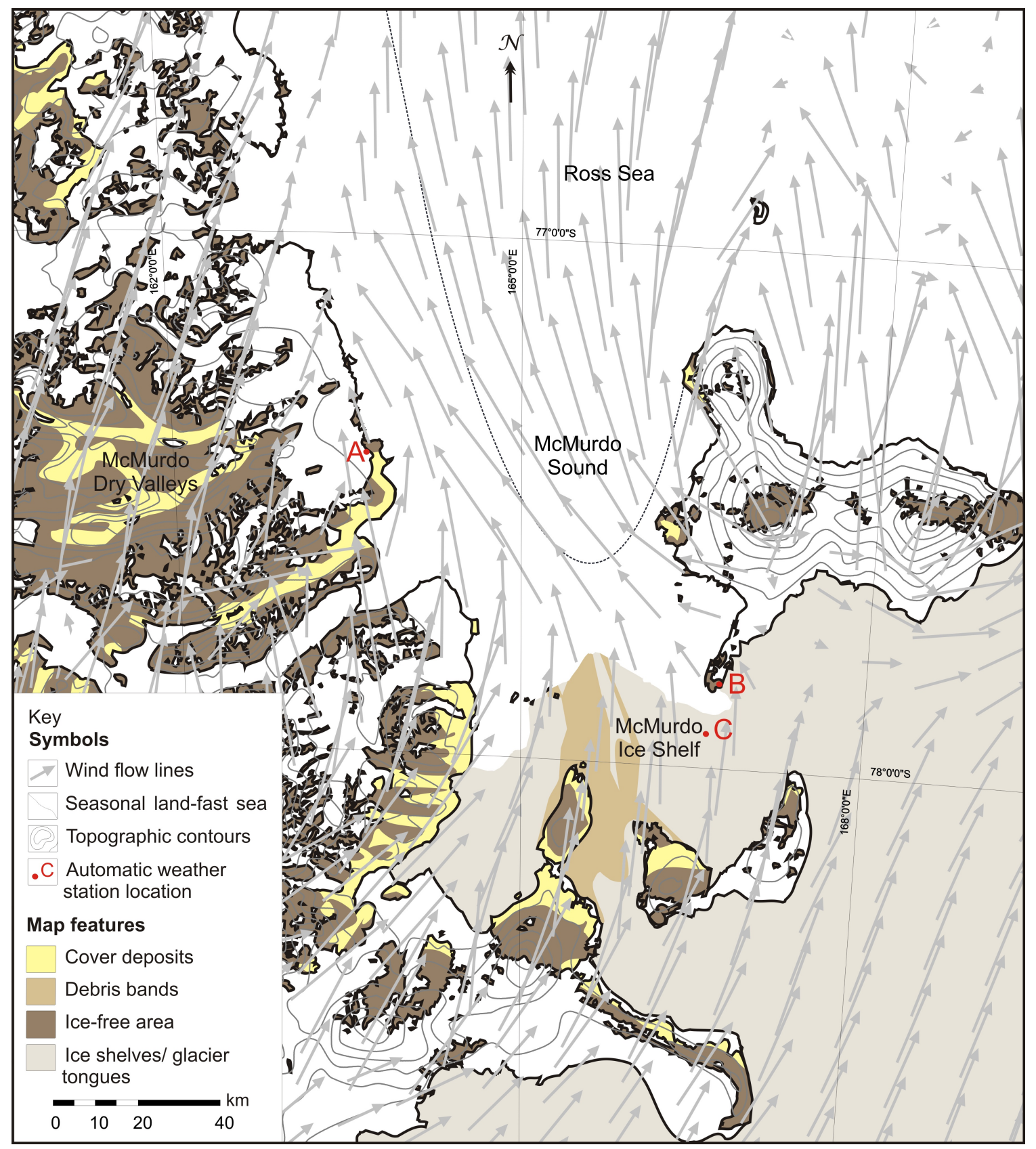

Figure 1.4: Map showing predominant wind flowlines for McMurdo Sound with locations of weather stations used in Figure 1.3. A=Marble Point; B=Scott Base; and, C=Pegasus North. Wind flow-lines supplied to show predominant wind flow for McMurdo Sound, modified from Ayling (2001). Northeasterly winds at Scott Base due to orographic deflection around Ross Island. 


\section{Strong wind events in McMurdo Sound and the Dry Valleys}

Wind speeds throughout the region, particularly for katabatic air flow, frequently exceed average sediment and blown snow entrainment threshold velocities (Speirs et al., 2008; Knuth et al., 2010). Although McMurdo Sound's coastal area experiences mean annual wind speeds of $<5 \mathrm{~m} \mathrm{~s}^{-1}$ (Ayling and McGowan, 2006), strong wind speed events (SWE) $>15 \mathrm{~m} \mathrm{~s}^{-1}$ are common particularly during the winter months (Holmes et al., 2000; van den Broeke and van Lipzig, 2003) and have been known to reach $71.5 \mathrm{~m} \mathrm{~s}^{-1}$ (Steinhoff et al., 2008). Increased storm frequency during winter also corresponds to greater sediment transport during winter months (Dunbar et al., 2009). Figure 1.5 shows the annual distribution and strong seasonality of SWE for the region. The most SWE for the region result from katabatic air flow from the continental plateau and the Ross Ice Shelf (Figure 1.6).

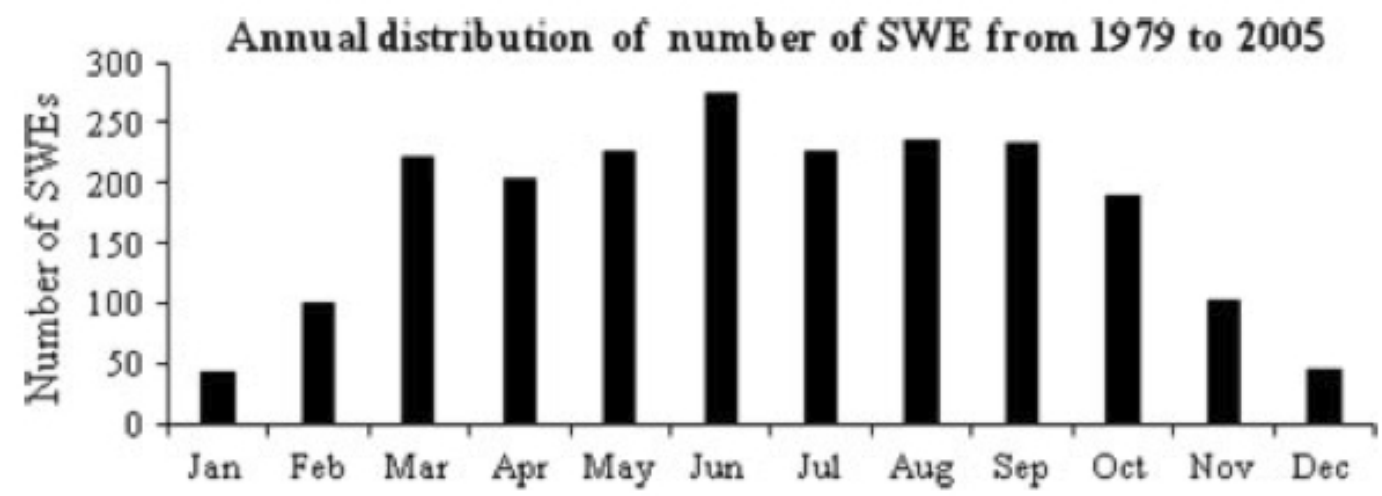

Figure 1.5: Annual distribution of the number of strong wind events (SWE) for the period 1979-2005 for McMurdo Station based on a threshold of a single six hourly observation with a wind speed greater than a Beaufort scale $6\left(>13.9 \mathrm{~m} \mathrm{~s}^{-1}\right)$. From Chenoli et al. (2012).

Katabatic wind events in the Ross Sea region are directionally constant from the south (Seefeldt et al., 2003). In McMurdo Sound, the steepness of topography can locally modify synoptic and mesoscale systems to increase wind speeds to velocities more typical of areas on the continent that experience the most extreme katabatic winds (e.g. annual mean surface wind speeds at Terra Nova Bay, Northern Victoria Land and Cape Denison, Adelie Land, are $16.6 \mathrm{~m} \mathrm{~s}^{-1}$ and $19.5 \mathrm{~m} \mathrm{~s}^{-1}$, respectively; Parish and Bromwich, 1987; Bromwich, 1989) (Steinhoff et al., 2008). In the MDV, throughout the year net radiation losses produce cool dense air on the continental plateau that can be channelled into the valleys generating strong, westerly-southwesterly, down-valley winds (Speirs et al., 2010, 2012; Steinhoff et al., 2012). During such events adiabatic 


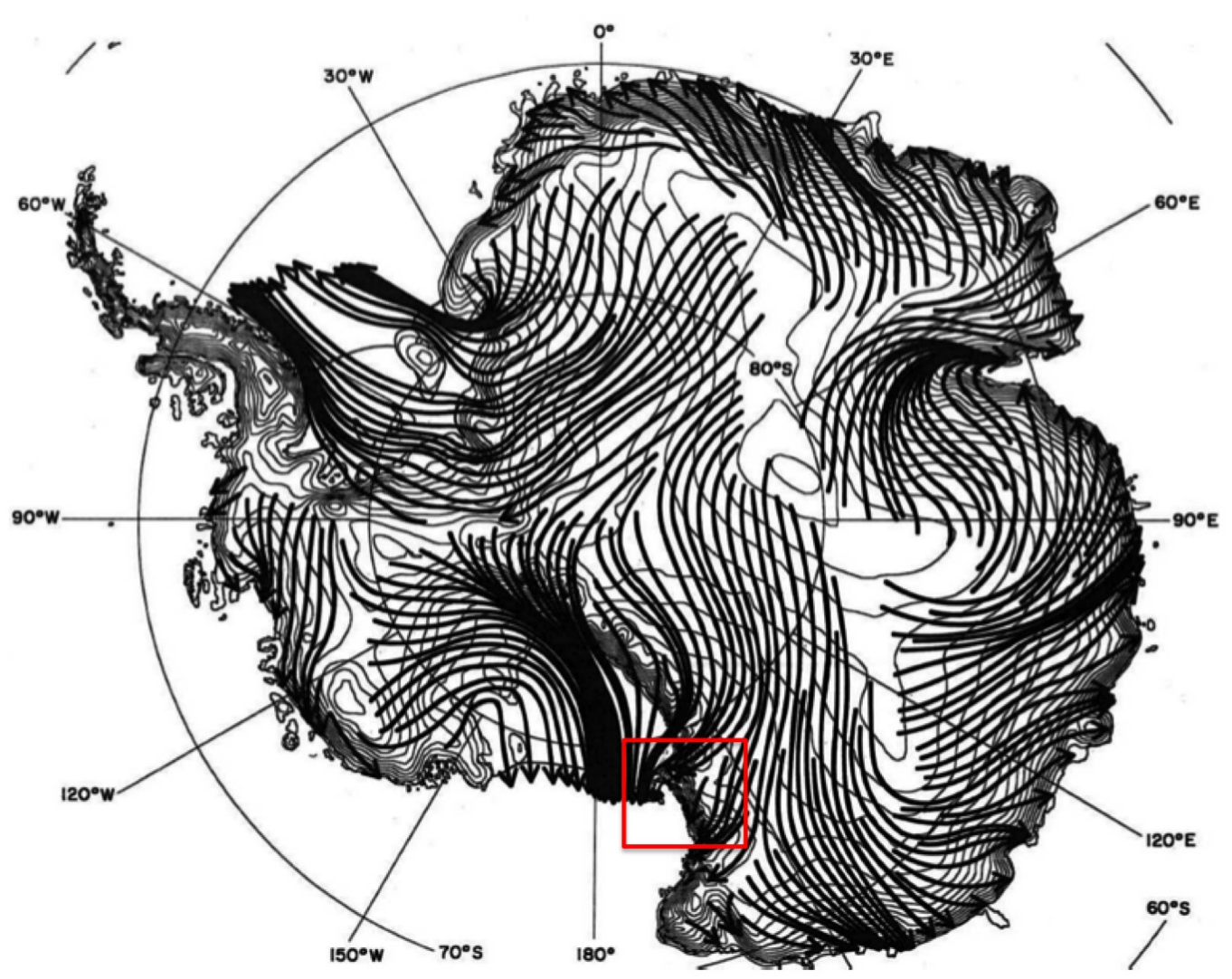

Figure 1.6: Mean wind field streamlines over the surface of the Antarctic continent and ice shelves for a 1-year period from June 2003-May 2004, Antarctic Mesoscale Prediction System archive. $30 \mathrm{~km}$ resolution, approximately $13 \mathrm{~m}$ above ground level (agl) at sea level and $7 \mathrm{~m}$ agl over the high interior of Antarctica. Red box indicates the location of McMurdo Sound, SW Ross Sea. From Parish and Bromwich (2007).

warming can increase local air temperatures by $30^{\circ} \mathrm{C}$ (to $0-+15^{\circ} \mathrm{C}$, for annual average air temperatures) in less than a few hours, which can affect frozen surfaces (Nylen et al., 2004; Fountain et al., 2010). Intense down-valley winds are more common during the winter months (March-September), while lighter easterly sea breezes dominate during the summer (October-March) (Doran, 2002; Šabacká et al., 2012; Speirs et al., 2012).

\section{Precipitation}

Due to the region's sub-zero temperatures precipitation falls as snow (Doran, 2002; Fountain et al., 2010). Snowfall can impact upon aeolian sediment supply, transport and deposition by altering surface snow cover and blown snow concentrations, as snowfall frequently occurs with high wind speed events (McKenna-Neuman, 1993; Seppälä, 2004; Knuth et al., 2010). Low snowfall in the MDV (annually $<50 \mathrm{~mm}$ 
water equivalent; Doran, 2002) is due to a precipitation shadow exerted by topography (Monaghan et al., 2005). Precipitation dramatically decreases with distance inland from the coast (Figure 1.7), with sublimation effects reducing the amount of snowfall that reaches the ground (Fountain et al., 2010). At the coast greater snowfall occurs during winter than summer (Fountain et al., 2010), with blowing and drifting snow also playing an important role in surface snow accumulation (Knuth et al., 2010).

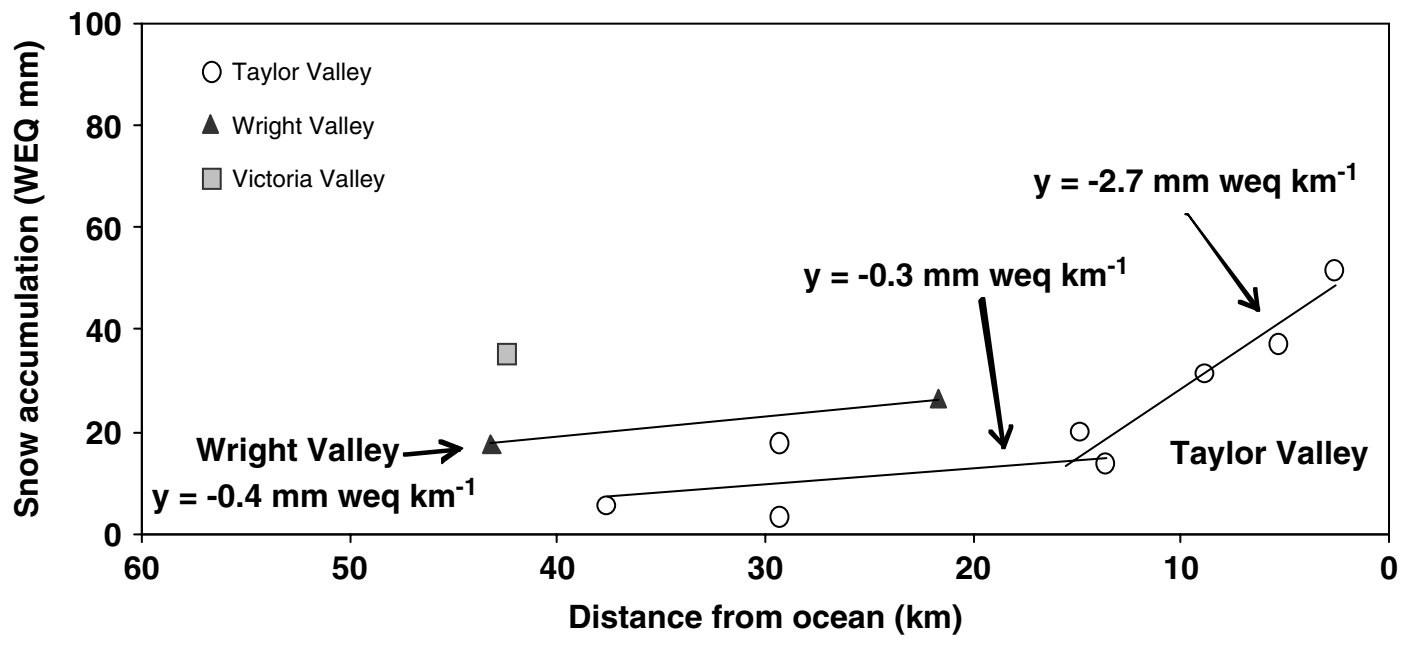

Figure 1.7: Spatial gradient of snow accumulation in Taylor and Wright Valleys for 2004 (weq=water equivalent). From Fountain et al. (2010).

\section{Temperature and humidity}

McMurdo Sound mean monthly air temperature at sea level varies between $-4.7^{\circ} \mathrm{C}$ in January to $-30^{\circ} \mathrm{C}$ in August (Keys, 1980; Sinclair, 1982) (Figure 1.8). In the MDV temperatures extremes range between $+10^{\circ} \mathrm{C}$ and $-65^{\circ} \mathrm{C}$, with annual averages ranging between -14.8 to $-30^{\circ} \mathrm{C}$ (Doran, 2002). However, locally mean daily temperatures can be highly variable, such as that between Scott Base and its neighbour McMurdo Station, which is on average $3^{\circ} \mathrm{C}$ warmer due to being more sheltered from the dominant southerly air flow (Sinclair, 1982).

Mean annual humidity in the MDV shows a gradient from coastal to inland areas (Doran, 2002) corresponding to a higher snowfall at the coast, as mentioned above. Humidity values for two locations in McMurdo Sound are shown in Figure 1.8. Areas with highest humidity, temperature and snowfall also have the wettest soil (Howard-Williams et al., 2010). Freezing of water vapour and pore water may bond sediments, increasing cohesion and related entrainment thresholds (Seppälä, 2004). 


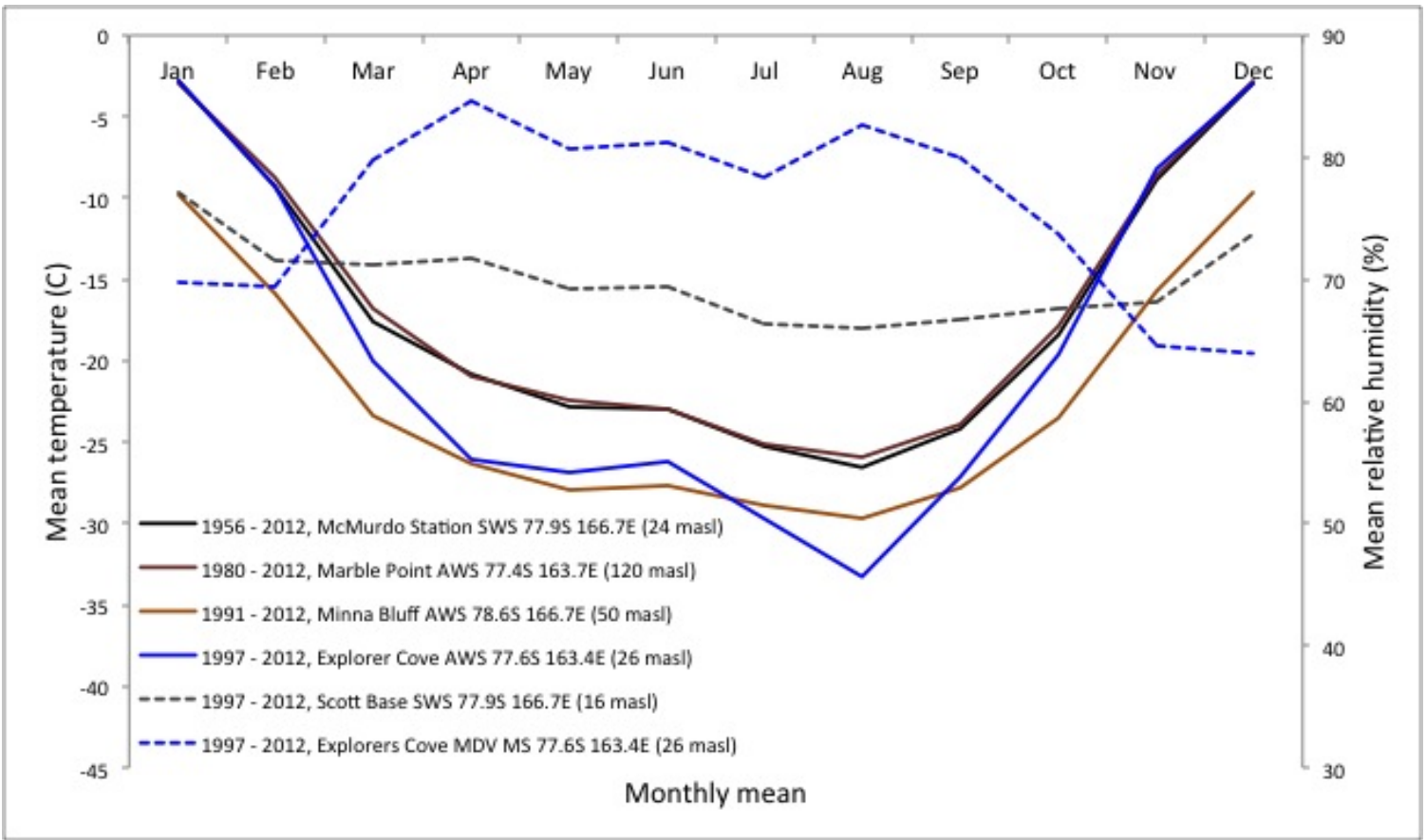

Figure 1.8: Mean monthly air temperature in degrees celcius for four locations (solid lines) and mean monthly relative humidity for two locations (dashed lines) in McMurdo Sound. N.b. Where the air temperature is $\leq 0^{\circ} \mathrm{C}$, the degree of saturation relative to observed humidity is defined with respect to ice (Keys, 1980; Doran, 2002). AWS=automatic weather station, SWS=surface weather station, MDV MS=McMurdo Dry Valleys meteorological station. Data sources: Global Change Master Directory, Met-READER (Turner et al., 2005); CliFlo archive, http://cliflo.niwa.co.nz; MDV Long Term Ecological Project archive (Doran, 2002).

\subsubsection{Oceanography and sea ice}

\section{Ocean circulation}

Sparse oceanographic and hydrographic data exists for the region. However, recent oceanographic modelling suggests the dominant oceanic circulation in the Ross Sea is from east to west with low current velocities over the continental shelf and below the Ross Ice Shelf (Rickard et al., 2010). In the McMurdo Sound area ocean circulation is thought to be cyclonic, flowing southwards along the eastern margin of the sound, travelling beneath the McMurdo Ice Shelf and returning northwards along the western margin (Figure 1.9).

Below the ice shelves and along the continental shelf current velocities are low. In McMurdo Sound, currents are strongly controlled by tides. In the southeastern sector 


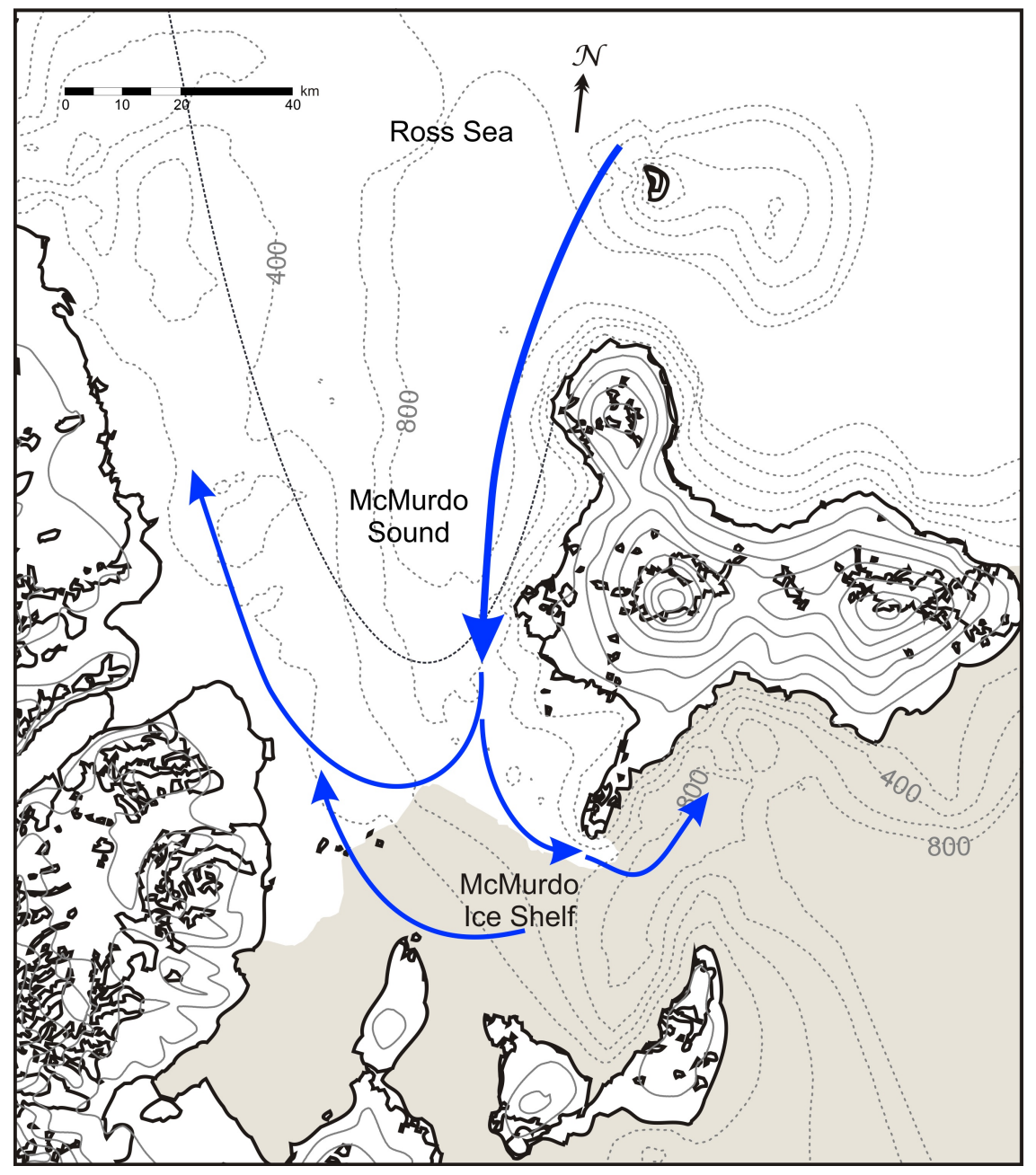

Figure 1.9: $\quad$ Map of McMurdo Sound showing local ocean circulation (blue arrows). Bathymetry is shown in meters below sea level. Dashed line shows seasonal land-fast sea ice edge. After Robinson et al. (2010).

of the sound a depth averaged flow of between 0.03-0.09 $\mathrm{m} \mathrm{s}^{-1}$ (depending on location) enters the sub-ice shelf cavity, peaking at $0.25 \mathrm{~m} \mathrm{~s}^{-1}$, but increasing to a maximum of $0.6 \mathrm{~m} \mathrm{~s}^{-1}$ during spring tides (Robinson, 2004; Robinson et al., 2010)). On the shallow western side of the sound beneath the seasonal land-fast sea ice velocities are lower, with a maximum of $\sim 0.12 \mathrm{~m} \mathrm{~s}^{-1}$ within the water column, and $<0.02 \mathrm{~m} \mathrm{~s}^{-1}$ on the seafloor (Barrett et al., 1983). Tidal currents may combine with geostrophic flow to move fine sediment from the western shelf to the deeper basins. However, due to its depth and sea ice cover, wind-driven currents affect little, if any, sediment transport in the sound (Bartek and Anderson, 1991).

\section{Sea ice in McMurdo Sound and the Ross Sea}

The southern Ross Sea produces almost twice its own area in sea ice each winter $\left(3.5 \times 10^{6} \mathrm{~km}^{2}\right.$ ) (Kwok, 2005; Drucker et al., 2011). Around 80\% of Antarctic pack ice is first-year ice and the Ross Sea is one of the few sectors where perennial sea ice persists (Barber and Masson, 2007). Sea ice concentration and area begins to increase rapidly in the southeast Ross Sea in late February, growing westwards and northwards, 
with the Ross Sea closing completely in late March-early April (Falconer and Pyne, 2000). The cyclonic circulation of sea ice, with influx from the east, and a strong northwesterly outflux, is related to strong air flow off the Ross Ice Shelf and sea ice production in the Ross Sea Polynya which creates strong, northward ice export (Kwok, 2005; Comiso et al., 2011).

McMurdo Sound's relatively shallow water depths on its western side, and buffering from the volcanic islands to the south, encourages the development of a 20-22 km wide fast ice platform (ice frozen to the shoreline) along the coast. This land-fast sea ice starts to develop in May and continues to grow until around mid-October, with multi-year accumulations persisting in the most sheltered coastline areas. Fast-ice thicknesses are generally $>1.7 \mathrm{~m}$. Two winter climate states, 'calm' and 'stormy', affect sea ice growth, stability, subsequent breakout timing, and extent in McMurdo Sound; however, similar breakout patterns occur year to year (Falconer and Pyne, 2004).

\section{Sea ice break-up}

During spring, sea surface temperatures are sufficiently low to keep ice solid until around mid-November when surface air temperatures rise to near that of the sea surface temperature $\left(-2^{\circ} \mathrm{C}\right)$, making the fast ice isothermal, which assists its break-up (Falconer and Pyne, 2004; A.R. Pyne, pers. comm., 2012). A time sequence of satellite images showing sea ice break-up in the southwest Ross Sea over the 2010-2011 summer is shown in Figure 1.10, Break-out from McMurdo Sound occurs from south to north, with broken ice accumulating against Drygalski Ice Tongue before rotating out into the sea. Ice from McMurdo Sound and the southwest Ross Sea, is prevented from drifting east by the winds flowing off the Ross Ice Shelf that form the Ross Sea Polynya. Instead, jumbles of large (km-scale) floes travel northwards along the coastline.

Rising air temperatures accelerate sea ice melt through December, with the majority of sea ice gone by January, and all but perennial sea ice gone by February (A.R. Pyne, pers. comm., 2012). Low salinity meltwater floats on top of higher density sea water forming a relatively stable surface layer. Unless strong winds disturb the stratification, phytoplankton blooms will occur within the layer adjacent to the retreating sea ice edge, as shown in Figure 1.10 g. Interannual variability in annual biogenic production is strongly linked to changes in sea ice cover (Arrigo et al., 2008). 


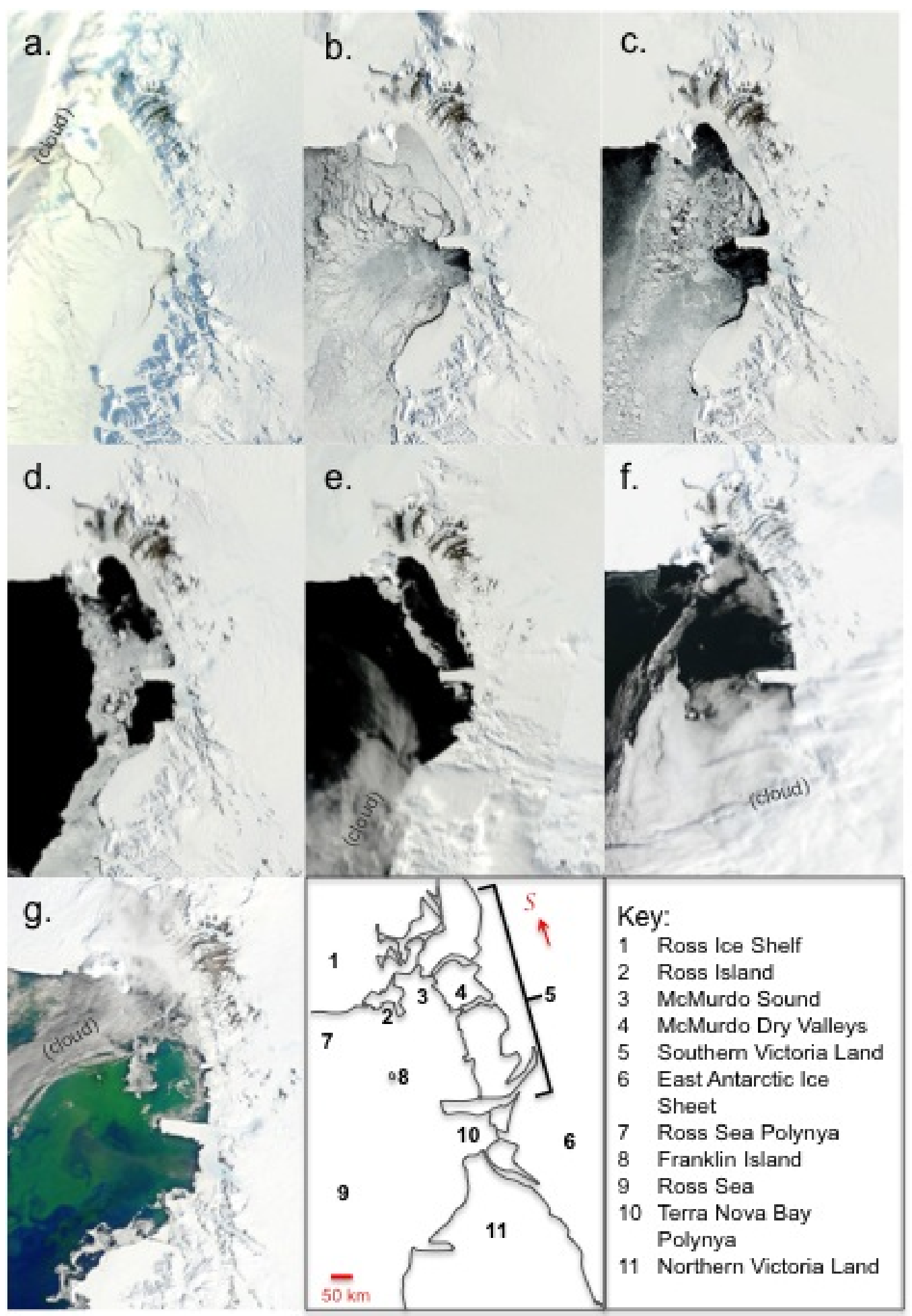

Figure 1.10: Satellite images showing the seasonal break-up of sea ice, and a large phytoplankton bloom, in the southwest Ross Sea over the 2010-2011 summer. a) September 15, 2010, winter ice extent still locked in and thick, b) October 31, 2010, break up of pack ice, polynya formation, c) November 12, 2010, pack ice floes blown northwards, d,) December 11, 2010, fast ice break up begins, e) January 15, 2011, pack ice gone, fast ice remains, f) February 25, 2011, fast ice gone, and g) January 22, 2011, true-colour image of phytoplankton blooming in the absence of sea ice. Images obtained from NASA-EO MODIS database, http://modis.gsfc.nasa.gov/. 


\section{Part I}

\section{Physical processes and observations}





\section{Chapter 2 \\ Aeolian sediment entrainment and transport}

\subsection{Physical requirements for aeolian processes}

Aeolian processes vary spatially and temporally and have contributed to the development of Earth's surface over both geological and human timescales. Almost all depositional environments have a component of material that has been blown there by the wind (Nickling, 1994; Nichols, 2009). Many physical factors influence wind's ability to move sediment, the most important being sediment supply and a strong, frequent wind regime (Greeley and Iversen, 1985; Pye, 1987; Nickling, 1994). Vegetation reduces surface wind speeds at ground level, so it is generally unvegetated land where aeolian processes have the greatest effect, in particular arid drylands, beaches, river outwash plains and agricultural landscapes (Warren, 1979; Greeley and Iversen, 1985).

The Physics of Blown Sand and Desert Dunes (Bagnold, 1941) was the first text to outline the fundamental physics of aeolian transport processes, through wind-tunnel tests and physical observations in arid desert dune fields. Decades of subsequent research by numerous workers to understand the complexity of aeolian sediment transport has shown these first principles to be essentially correct. Indeed, most subsequent treatments are refinements of the semi-empirical relationships between boundary-layer theory and the mechanics of particle transport (Greeley and Iversen, 1985; Sherman and Li, 2012). The following sections outline the physical aspects of aeolian sediment transport of most relevance to this study, largely drawing on the work of Bagnold.

\subsubsection{Sediment transporting wind systems}

Winds are air masses travelling between areas of atmospheric high and low pressure generated by variations in solar heating. The turbulent, near-surface layer of the atmosphere, the atmospheric boundary layer, interacts directly with surface features of the Earth on varying scales. Significant exchanges of atmospheric momentum, heat 
and mass occur between the surface and the boundary layer. It is close to the surface interface that the majority of aeolian sediment transport occurs (Greeley and Iversen, 1985; Dover, 1993; Dong et al., 2011).

The highest persistent surface wind speeds on Earth $\left(\sim 20 \mathrm{~m} \mathrm{~s}^{-1}\right.$, as mentioned in Subsection 1.5.3) are found in Antarctica where katabatic drainage (Figure 1.6) creates localised confluences of wind moving at sustained high speeds, generating extremely high annual mean surface winds speeds at sea level (Parish and Bromwich, 1987; Bromwich, 1989; McKenna-Neuman, 1993; Parish and Bromwich, 2007). Such intensity of wind velocities, particularly during winter months, provides considerable power for erosion of exposed land surfaces and for transport of unconsolidated sediment.

\subsubsection{Aeolian sediment}

Aeolian sediment needs to be freely available at the surface, and small enough (typically $<2,000 \mu \mathrm{m}$ ) for wind to transport it. Greeley and Iversen (1985) observe that of all windblown particles, sand $(63-2,000 \mu \mathrm{m})$ is the most susceptible to aeolian action, typically transported along the land surface, often forming dunes. However, given high enough velocities, even pebble-sized material can be moved by the air, albeit over relatively short distances, occasionally forming aeolian structures such as the gravel ripples found in the MDV (Lindsay, 1973).

Particles smaller than sand ( $<63 \mu$ m, i.e. silt and clay) in the aeolian context can be separated into coarse dust $(\sim 20-63 \mu \mathrm{m})$ usually transported within localised storms, and fine dust $(\sim 2-20 \mu \mathrm{m})$ which can be globally dispersed in the troposphere. Fine-grained material is generated by physical and chemical weathering of rock material (Pye, 1987; Middleton, 1989) and, in the absence of fluvial processes, aeolian abrasion becomes an important mechanism for producing particles $<63 \mu \mathrm{m}$ (Bullard and Livingstone, 2009). Figure 2.1 illustrates typical grain size distributions of aeolian sediment samples and their characteristic transport patterns, showing that long-transport (atmospheric) aeolian deposits generally consist of dust-sized particles, though some sand can also be present. The bulk of sand and silt grains in the majority of settings are quartz, as it is more resistant to sub-aerial breakdown than other key rock-forming minerals (Greeley and Iversen, 1985; Middleton, 1989). In the case of Antarctic source rocks, chemical weathering is limited due to the hyper-arid climate, so the majority of weathering action is from physical processes, particularly aeolian abrasion (Kelly and Zumberge, 1961; Malin, 1992). 


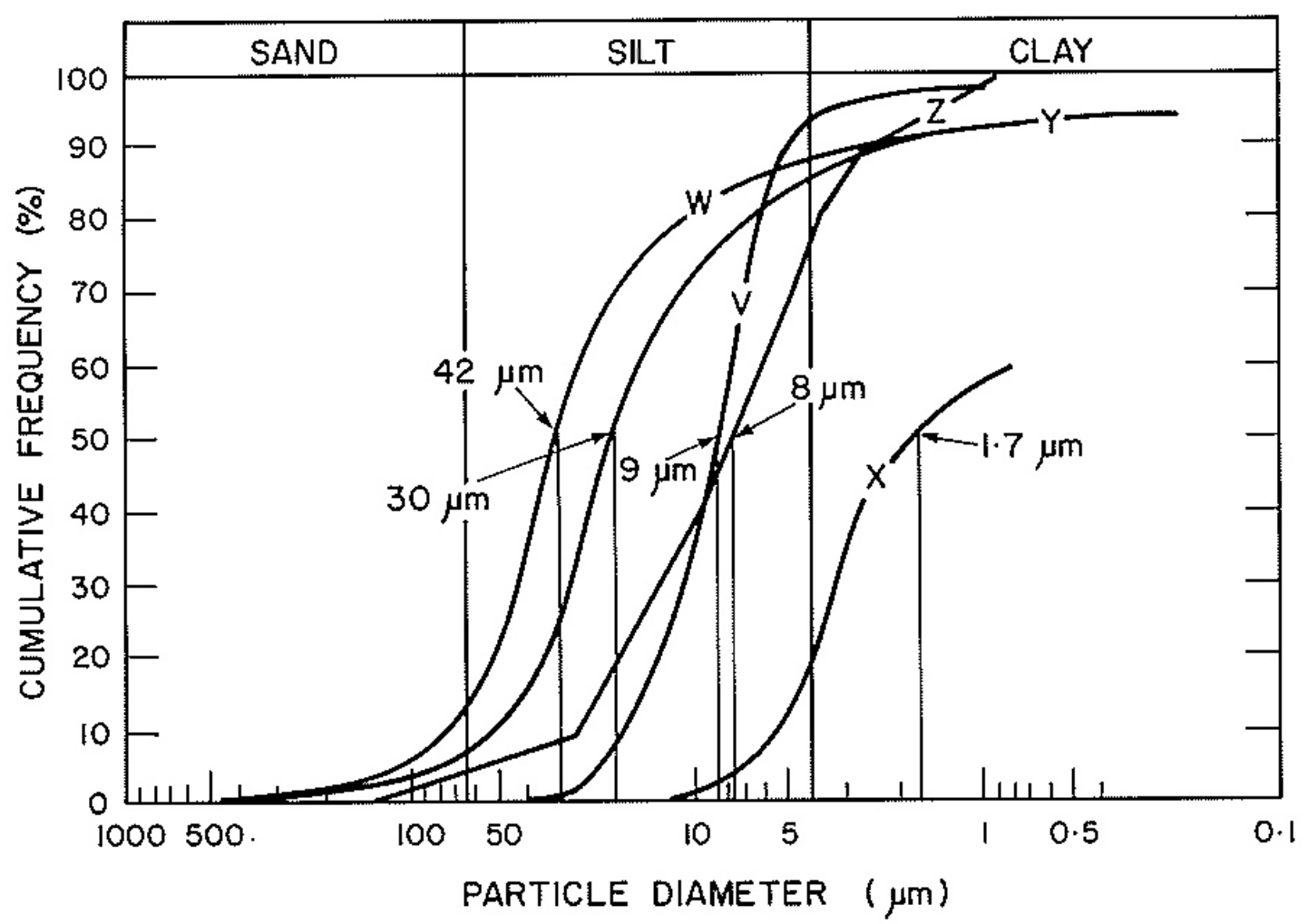

Figure 2.1: Cumulative grain size frequency curves of some atmospheric dust samples from different parts of the world: V=Saharan dust deposited in eastern England, $\mathrm{W}=$ local Kansas dust, $\mathrm{X}=$ Saharan dust collected in Barbados, $\mathrm{Y}=$ local Arizona dust, $\mathrm{Z}=$ Mongolian dust deposited in Beijing. After Pye, 1987 .

\subsubsection{The wind profile}

Air is a fluid, and though threshold values differ, the physical principles for water can be translated and used to explain the entrainment and movement of sediment by wind (Bagnold, 1941; Boggs, 2006). Turbulence is a major feature of airflow within the atmospheric boundary layer (Greeley and Iversen, 1985). Wind passing over a stationary bed is retarded by surface friction. This creates turbulent eddies which move in streamwise, corkscrew vortices at variable velocities and scales (Pye, 1987; Allen, 1994; Nickling, 1994). Typical velocity profiles for the boundary layer under differing flow conditions are shown in Figure 2.2. A turbulent velocity profile (e.g. wind) increases rapidly with distance above the bed surface, whereas increases for a laminar profile (e.g. ice) are more gradual. For air perturbing a bed composed of very small particles (i.e.silt), a very thin laminar sub-layer $(<1 \mathrm{~mm})$ can exist adjacent to the bed, even when the majority of the wind flow is turbulent. For turbulence to occur in the boundary layer, relatively high wind velocities are required. However, the aerodynamics of the bed (Nickling, 1994) and the motion of grains, once entrained into the air 
Figure 2.2: A comparison of (non-dimensional) velocity profiles in a) turbulent, and b) laminar, boundary layers. After (Allen, 1994).

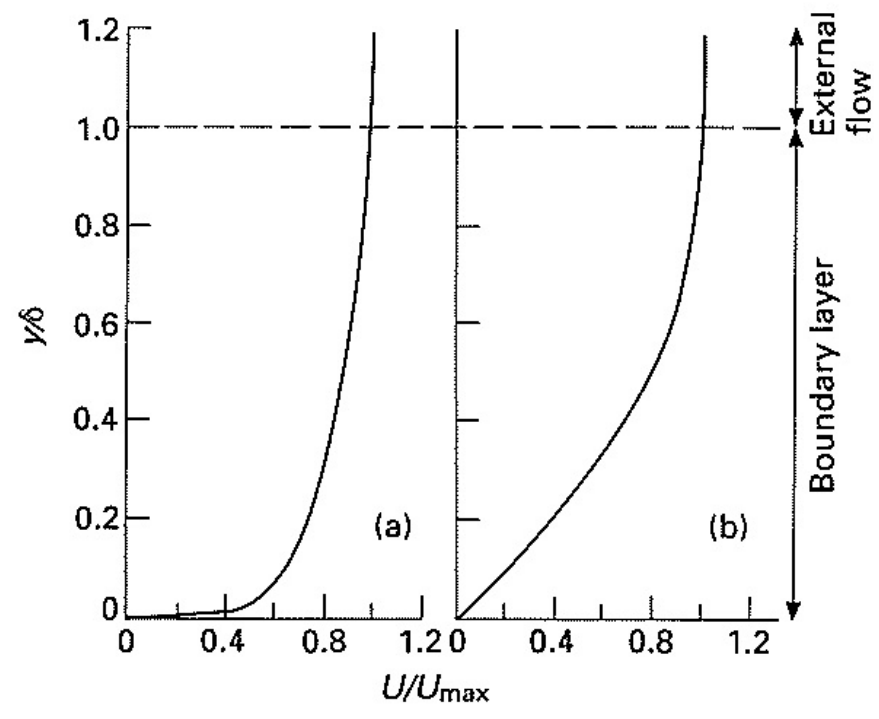

stream (Li and McKenna-Neuman, 2012), can also affect the intensity of turbulent flow.

Surface roughness elements, i.e. obstacles protruding into the boundary layer at all scales, determine how aerodynamic a bed surface is and how easily grains can be entrained. The presence of non-erodible elements transfers some of the wind's momentum onto the larger obstacles affecting turbulence by creating eddies, but conversely also reducing wind stress on erodible surfaces by altering the wind velocity profile (Nickling and McKenna-Neuman, 2009; Turpin et al., 2010) (Figure 2.3).

The aerodynamic smoothness or roughness of a bed can be calculated by using Reynold's formula, a dimensionless ratio describing the relative importance of inertial forces (i.e. fluid density $(\rho)$, multiplied by a characteristic fluid velocity $(U)$ and a characteristic length $(L)$ ) to viscous forces (i.e. absolute viscosity $\mu$, a function of fluid composition and temperature) (Carson, 1971; Greeley and Iversen, 1985). When the resulting Reynold's number (Re) is small, viscous forces are dominant and flow is laminar, when large, inertial forces are dominant and flow is turbulent.

For aeolian processes, a particle friction Reynold's number $\left(R e_{p}\right)$ determines the importance of inertial forces of surface roughness elements relative to the viscous forces of the air. $R e_{p}$ is described by multiplying shear velocity $\left(u_{*}\right)$ by the fractional difference of the mean grain diameter $(D)$ of the bed material to the kinematic viscosity of the air $(v)$, as follows:

$$
\operatorname{Re}_{p}=u_{*} \frac{D}{v}
$$


A flow with small $R e_{p}$, i.e. $\leq 5$, and small particles $(<80 \mu \mathrm{m})$ on the bed, can be considered aerodynamically smooth. For beds with $R e_{p} \leq 70$, a thin laminar sub-layer persists directly at the boundary surface and velocity within this layer increases linearly from zero with height (z) (Nickling, 1994), as shown in Figure 2.3, A bed with $R e_{p} \geq 70$, corresponds to large surface elements that are aerodynamically rough. For $R e_{p} \geq 70$, the sub-layer becomes viscous, for which the velocity profile is not well defined (Nickling and McKenna-Neuman, 2009). In this instance, inertial flow characterises layer motion, producing turbulence above the sub-layer. The elevation above the sub-layer, also termed the roughness height $\left(z_{0}\right)$, is considered to be $1 / 30$ of the average height of roughness elements on the ground (Nickling, 1994; Raupach, 1994), as shown in Table 2.1. Provided the bed is very smooth, surface roughness elements protruding below $z_{0}$ will not be sheared off (Warren, 1979).

The thickness of the sub-layer, which is generally 0.5-1 mm (Warren, 1979; Nickling, 1994), is important in determining the erosive force of wind on the boundary surface (Carson, 1971). Above the height of the laminar sub-layer, wind velocity $(U)$ in a neutral atmosphere turbulent boundary layer increases approximately logarithmically with height (Pye, 1987). The slope of the logarithmic wind profile, as shown in Figure 2.3, is determined by the Prandtl-von Kármán equation:

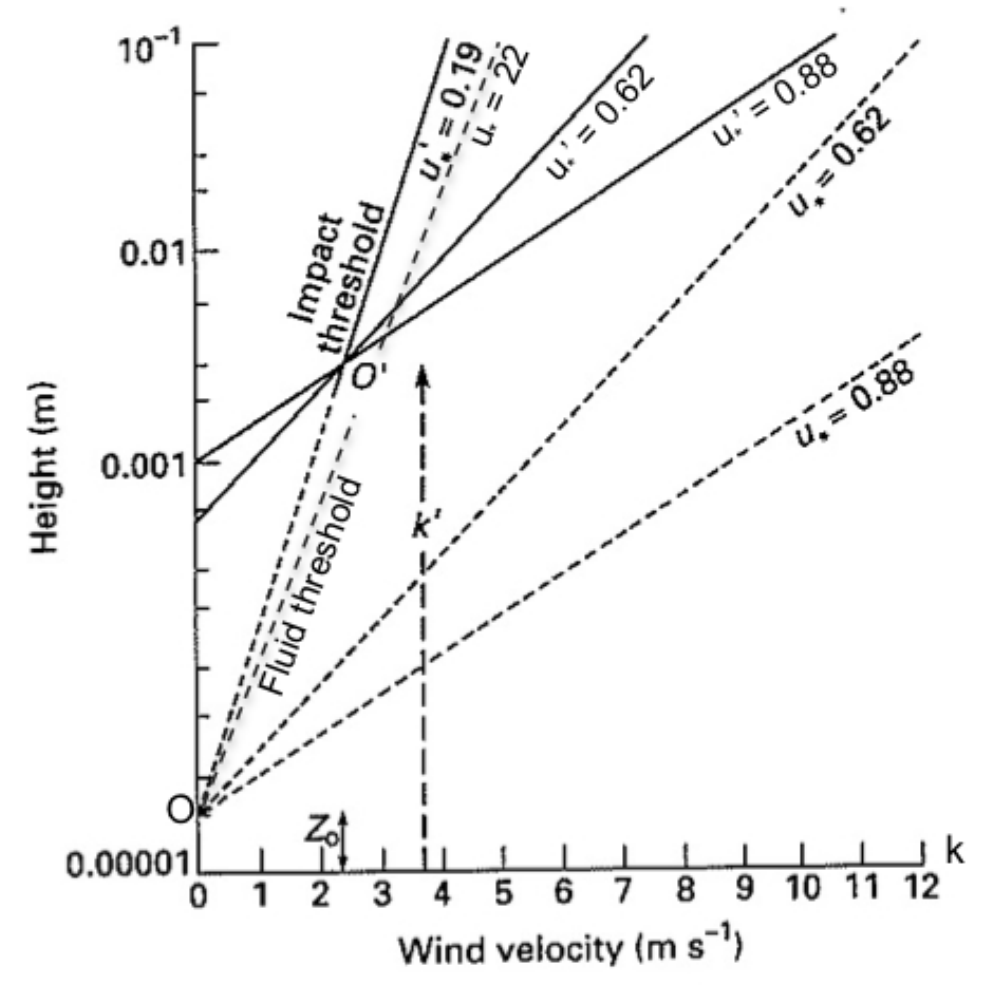

Figure 2.3: Wind velocity profiles over both a stationary and a mobile sand bed showing the relative shear velocities (as defined in Equation 2.1.3.2 below). $u_{*}=$ shear velocity in absence of sand movement, $u_{*}^{\prime}=$ shear velocity when sand is in motion, $O^{\prime}=$ focus to which wind velocity profiles converge during sand motion, $k^{\prime}=$ focus height, $z_{0}=$ roughness height. Modified from Nickling (1994), after Bagnold (1941) and Watson (1989). 
Table 2.1: Aerodynamic properties of natural surfaces. After Nickling (1994), modified from Oke (1978).

\begin{tabular}{|c|c|c|c|}
\hline Surface & $\begin{array}{l}\text { Remarks, } \\
\text { length }\end{array}$ & $\begin{array}{l}z_{0} \\
\text { Roughness } \\
\text { displacement } \\
\text { (m) }\end{array}$ & $\begin{array}{l}d \\
\text { Zero plane } \\
(\mathrm{m})\end{array}$ \\
\hline Water* & Still-open sea & $0.1-10.0 \times 10^{-5}$ & - \\
\hline Ice & Smooth & $0.1 \times 10^{-4}$ & - \\
\hline Snow & & $0.5-10.0 \times 10^{-4}$ & - \\
\hline Sand, desert & & 0.0003 & - \\
\hline \multirow[t]{2}{*}{ Grass* } & $0.02-0.1 \mathrm{~m}$ & $0.003-0.01$ & $\leq 0.07$ \\
\hline & $0.25-1.0 \mathrm{~m}$ & $0.04-0.20$ & $\leq 0.66$ \\
\hline Agricultural crops* & & $0.04-0.20$ & $\leq 3.0$ \\
\hline Orchards* & & $0.5-1.0$ & $\leq 4.0$ \\
\hline \multirow[t]{2}{*}{ Forests* } & Deciduous & $1.0-6.0$ & $\leq 20.0$ \\
\hline & Coniferous & $1.0-6.0$ & $\leq 30.0$ \\
\hline
\end{tabular}

$* z_{0}$ depends on wind speed.

$$
\frac{U}{u_{*}}=\frac{1}{K} \ln \frac{z}{z_{0}}
$$

where: $K$ is the von Kármán constant (0.4) which varies with temperature gradient, $U$ is the wind velocity measured at height $(z)$ above the ground, and $u_{*}$ is the shear velocity (Pye, 1987; Nickling, 1994). This equation describes the wind profile in both eroding and non-eroding conditions (Scott et al., 1995). During sand motion, provided that $U$ at any $z=5.75$, this equation can be re-written for $u_{*}$ :

$$
u_{*}=\left(\frac{U}{\log _{10} z-\log _{10} k^{\prime}}\right) \cdot \frac{1}{5.75}
$$

where: $k^{\prime}$ is focus height at which velocity profiles diverge, as illustrated in Figure 2.3. The spacing and size of the roughness elements is important in dictating whether lag elements will protect from, or enhance, entrainment of finer particles (Nickling and McKenna-Neuman, 2009). With high densities of roughness elements, such as rough terrain or vegetation, the wind velocity profile is elevated to a new plane of reference, the zero plane displacement height (d) (Nickling, 1994), as described by:

$$
\frac{U}{u_{*}}=\frac{1}{k}\left(\frac{z-d}{z_{0}}\right)
$$


where: $u_{*}$ can be related to shear stress $\left(\tau_{0}\right)$ and air density $\left(\rho_{a}\right)$ as follows:

$$
u_{*}=\sqrt{\frac{\tau_{0}}{\rho_{a}}}
$$

Typical values of $d$ are shown in Table 2.1. Both $u_{*}$ and $\tau_{0}$ increase as $U$ increases. At some critical point, termed the fluid threshold (Figure 2.3), grains on the bed start to move due to momentum losses from the air to the sediment (Pye, 1987; Nickling, 1994).

\subsection{Aeolian sediment transport thresholds}

\subsubsection{Particle forces}

Shear stress on the bed is the major driving force of transport by wind. Upstream and downstream pressure differences help to de-stabilise erodible particles and initiate motion (Warren, 1979). At the moment of entrainment, retarding forces (weight and interparticle cohesion; properties of particles on a bed) are overcome by promotional forces (shear, lift and moment; a result of the aerodynamic flow over a particle) via the Bernouilli effect, where decreased fluid static pressure on top of a grain, and the steep pressure gradient surrounding the grain, effectively cause lift; the same forces that lift an aeroplane wing (Warren, 1979; Pye, 1987; Nickling, 1994).

\subsubsection{The threshold of particle motion}

The critical point at which drag forces overcome the inertia of an erodible grain, termed the entrainment or fluid threshold velocity $\left(u_{* t}\right)$, the velocity at which motion of a grain will occur, can be derived from Shield's criterion (Miller et al., 1977). This fluid mechanics formula relates the effective weight of a sinking grain to a dimensionless coefficient which summarises threshold conditions immediately prior to entrainment (Bagnold, 1941; Hsü, 1989), as per:

$$
u_{* t}=A \sqrt{\frac{\rho_{p}-\rho_{a}}{\rho_{a}} g D}
$$

where: $A$ is an empirical coefficient dependent on the surface grain characteristics, roughly equivalent to 0.1 for $R e_{p}>3.5$ (see Equation 2.1.3.1), $\rho_{p}$ is particle density 
(2.65 $\mathrm{g} \mathrm{cm}^{-3}$ for quartz), $\rho_{a}$ is air density $\left(1.22 \times 10^{-3} \mathrm{~g} \mathrm{~cm}^{-3}\right)$, and $\mathrm{g}$ is acceleration due to gravity $\left(980 \mathrm{~cm} \mathrm{~s}^{-2}\right.$ ). In the instance of aeolian entrainment, a grain is under the influence of a moving flow of air; therefore, $A$ determines the threshold conditions of the respective particle forces (outlined above) acting on the grain at rest (Carson, 1971; Hsü, 1989). Provided $A$ is constant, $u_{* t}$ should vary as the square root of grain diameter (Bagnold, 1941). However, $A$ is only constant within a small range of $R e_{p}$ and its stability is subject to grain size characteristics, i.e. surface roughness.

The relationship of $u_{* t}$ to grain size is illustrated in Figure 2.4. Larger grains protrude into the airstream and carry a greater proportion of drag force than the general surface. For grains $>80 \mu \mathrm{m}, u_{* t}$ increases linearly with the square root of $D$ (Nickling, 1994). A minimum value for $u_{* t}$ is reached when mean grain size is $\sim 80 \mu \mathrm{m}$, i.e. aerodynamically smooth, and surface drag is spread more evenly over the bed. At this point $u_{* t}$ is no longer proportional to $\sqrt{D}$ and becomes dependent on the characteristics of the bed material (Pye, 1987; Nickling, 1994).

Figure 2.4: The relation between particle size and the threshold velocity for movement. For particles finer than $0.06 \mathrm{~mm}$ in diameter, the threshold velocity for movement increases as size decreases. From (Pye, 1987) after (Bagnold, 1941).

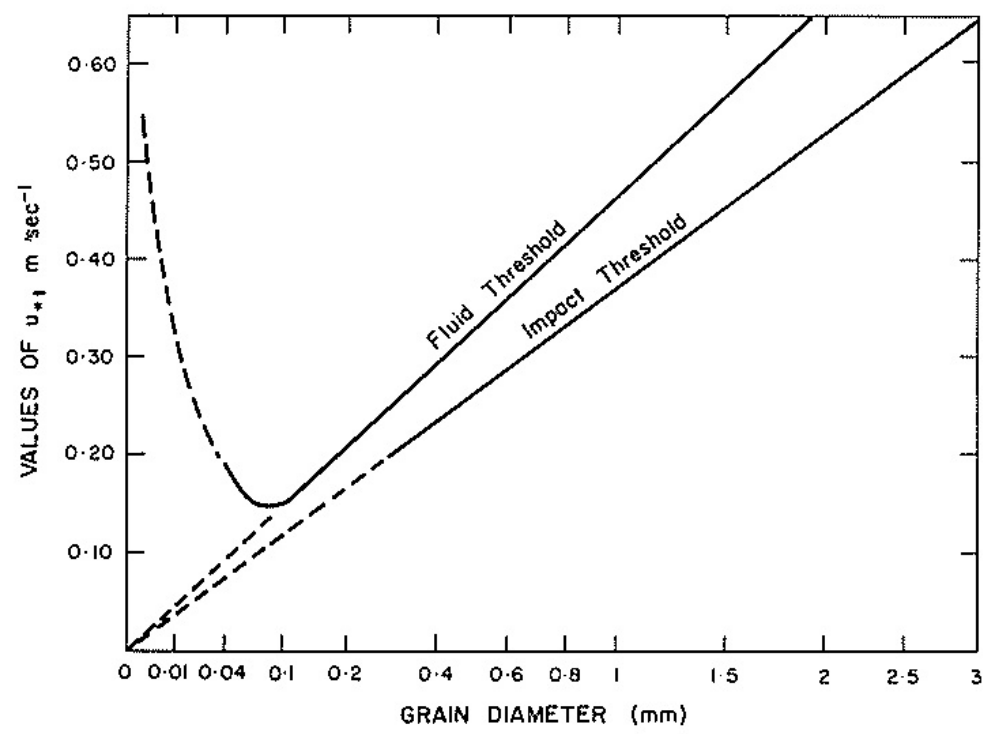

As shown in Figure 2.3 and Figure 2.4, the velocity required to initiate initial entrainment of a grain is greater than that of an impacting grain. Therefore, the velocity required to keep grains in motion is notably lower than for $u_{* t}$. Once grain motion is initiated, subsequent entrainment of material from impacting grains (discussed further in Section 2.3) exerts extra drag on the airstream and a small decrease in $u_{*}$ occurs. Even though the velocity drops below $u_{* t}$ reducing lift force, transport continues until the impact threshold is reached, i.e. limit below which impact entrainment cannot occur (Carson, 1971; Warren, 1979). 


\subsubsection{Settling of a particle}

By experimenting with grains of uniform shape Bagnold (1941) found that grain size dictated the velocity of an entrained grain or particle for a given wind speed. Considering wind velocity in two-dimensions, at any instant there are components both parallel and perpendicular to flow (Tsoar and Pye, 1987). Once in the air, a grain is subject to the downward force of gravity (drift), the resistive force of air itself (drag), which acts opposite to the direction of motion, and to particle inertia. When drift and drag forces are equivalent, terminal or settling velocity $\left(u_{f}\right)$ is acquired (Tsoar and Pye, 1987; Raupach and Lu, 2004).

Suspended particles (refer to Section 2.3 for detail on modes of transport) caught in turbulent eddies, remain aloft until the wind velocity is reduced sufficiently for them to settle out. The duration that a particle remains in suspension is dictated by $u_{f}$, plus the velocity and turbulence of the air flow. Turbulent flow is transferred between atmospheric layers due to fluctuations in velocity $U$ (Bagnold, 1941; Tsoar and Pye, 1987). Diffusion effects by turbulence allow the smallest grains (typically $<63 \mu \mathrm{m}$ ) to reach greater heights and travel larger distances within the air stream than larger grains (Raupach and Lu, 2004; Bullard and Livingstone, 2009).

As summarised by Pye (1987) and Raupach and Lu (2004), reduction of grain velocity is primarily due to drag. Therefore, the larger the grain size, or the more angular the grain, the larger the drag force. The larger the particle, the greater its ability to cut through turbulence due to greater drift forces acting at $u_{f}$ and particle inertia. The more spherical a particle, the greater its $u_{f}$, regardless of mass.

For suspended particles in a turbulent airflow, long residence times can occur when $u_{f}$ is much smaller than $u_{*}$, so transport closely follows the velocity of the wind into which the particle is entrained, as shown in Figure 2.5. The ratio of upward motion to downward motion $\left(u_{f} / u_{*}\right)$ can be used to calculate the degree of suspension of a particle (Pye, 1987). The larger the $u_{f} / u_{*}$, the shorter the particle residence time in the atmosphere; therefore, only the smallest particles (i.e. $<20 \mu \mathrm{m}$, where $u_{f} / u_{*}<0.1$ ), enter long-term suspension (Tsoar and Pye, 1987; Nickling and McKenna-Neuman, 2009). 


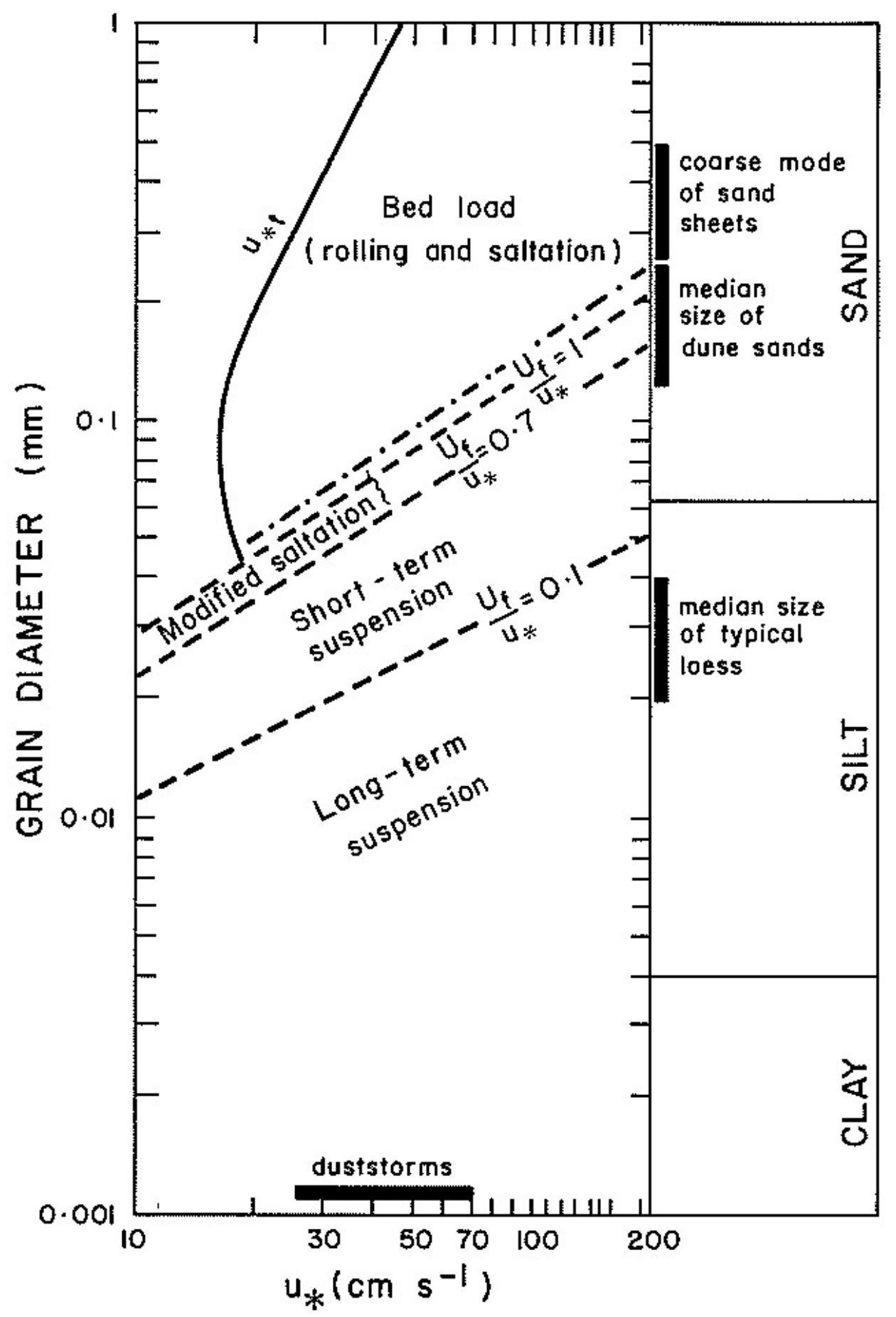

Figure 2.5: Modes of transport of quartz spheres of different diameters at different wind shear velocities. From Pye (1987), after Tsoar and Pye (1987). 


\subsubsection{Complicating effects for application of entrainment equations}

Idealised conditions for entrainment of aeolian sediment are seldom found in the natural world, due to multiple complicating effects. The most important of these is cohesion. Cohesive forces of an erodible bed are primarily influenced by ambient temperature and humidity (discussed further in Subsection 2.4.2), as well as soil moisture and surface crusting (Nickling, 1994; Raupach and Lu, 2004). Presence of moisture on surface sediments can reduce transport rates by several orders of magnitude for a given wind speed by greatly increasing inter-granular cohesion (Nickling and McKenna-Neuman, 2009). Surface condition (moisture content, crusts, bonding agents) and temporal and spatial fluctuations in wind speed and direction (intermittency) can limit sediment supply, decrease $u_{* t}$, and create substantial variability in transport rates (Nickling, 1994; Ellis et al., 2012). Other factors influencing sediment supply, entrainment and transport rates, include textural and geomorphic variability, granular electrification, and anthropogenic effects.

\subsection{Modes of aeolian transport}

\subsubsection{Saltation, suspension and creep}

Individual grains behave differently in the air because of varying grain size, shape and specific gravity. First documented by Bagnold (1941), three modes of aeolian transport are now widely accepted, as illustrated schematically in Figure 2.6, Each transport mechanism propels sediment from entrainment either through the air or along the surface, depending on grain characteristics.

Suspension occurs when entrained grains are too small, typically $<70 \mu \mathrm{m}$, to fall through the air-column back to the surface. Collision of suspended particles into each other or into air molecules can maintain their suspension in the wind system for long periods of time (Pye, 1987). Alternately, precipitation can wash fine dust from the troposphere, or aggregates of multiple dust particles can settle out, once large enough (Greeley and Iversen, 1985). The lightest grains $(<20 \mu \mathrm{m})$, can have residence times in the atmosphere of several days, sometimes travelling thousands of kilometres from source (Nickling and McKenna-Neuman, 2009); however, the coarse dust fraction travels mainly in short-term suspension (Figure 2.6) at low-levels in the airstream, enabling particles to be trapped by surface elements (e.g. vegetation) or water bodies, unless deposited by rain (Tsoar and Pye, 1987). 


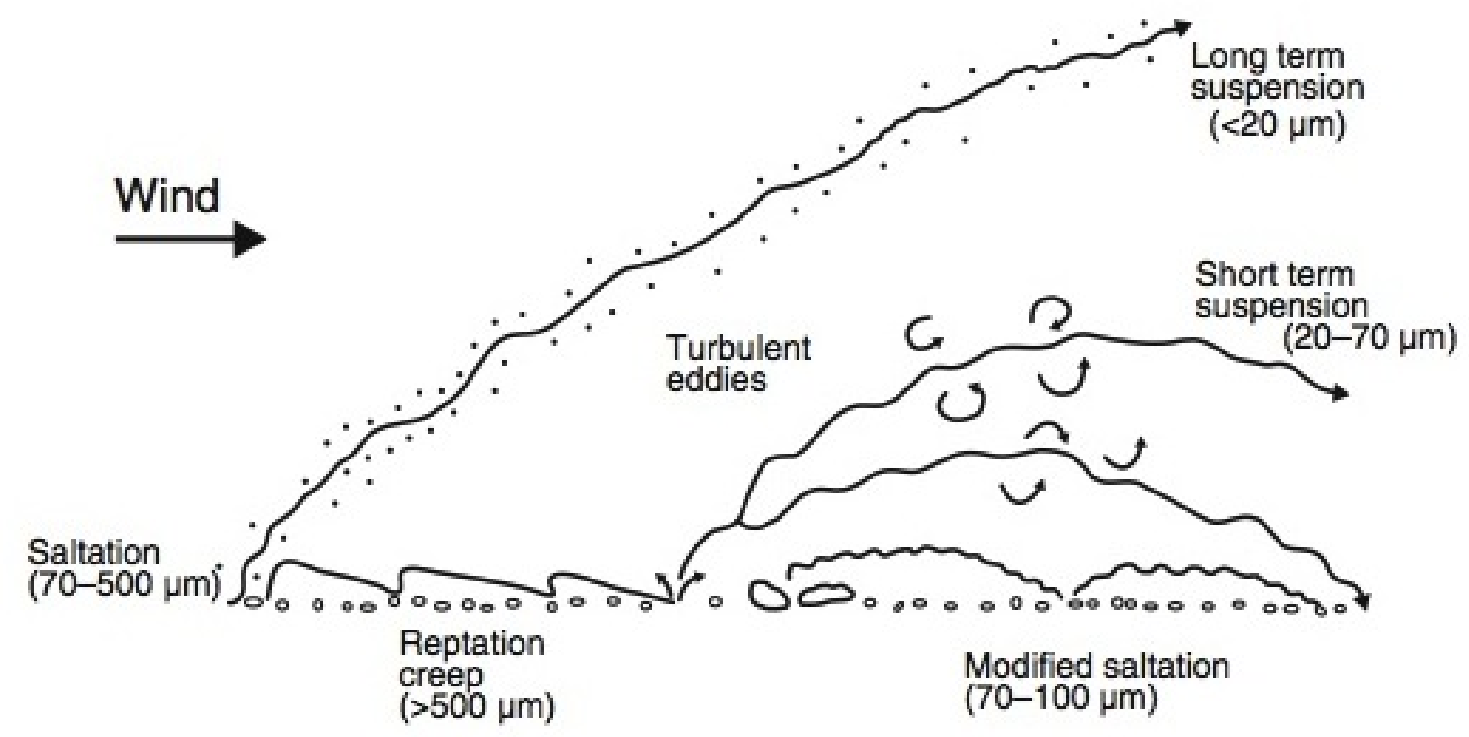

Figure 2.6: Modes of aeolian transport: saltation, suspension and creep. From Nickling and McKenna-Neuman (2009), after Pye (1987).

Particles $>70 \mu \mathrm{m}$ bound or saltate along the surface of the ground following long, arc-like projectile paths (Figure 2.6), the process of saltation. Assuming no bed roughness, the saltating grain will either 'bounce' back into the airstream, or the impact will dislodge grains or fine particles into suspension, i.e. saltation splash (Raupach and Lu, 2004), as schematically illustrated in Figure 2.7. The majority of dust-sized particles are entrained by impact of saltating grains (Nickling and McKenna-Neuman, 2009).

Unless the saltating grain becomes buried at some point along the transport path, this pattern of uplift, trajectory and impact is repeated until $U$ and $u_{*}$ are diminished enough to cease continued entrainment of the grain (Greeley and Iversen, 1985) (refer to Section 2.2). Bagnold (1941) observed that saltating grains have different heights of trajectory and different distance of travel under the same wind conditions (Figure 2.8). Thus, Bagnold determined a characteristic (mean) path of trajectory for modelling purposes (Figure 2.9).

The specific gravity of individual grains varies according to composition; therefore, saltation trajectories are dependent on both grain size and composition (Warren 1979). A transitional state between pure suspension and pure saltation, called modified saltation, is characterised by semi-random particle trajectories that are influenced by inertia and settling velocity (Pye, 1987; Nickling and McKenna-Neuman, 2009) (see Figure 2.5 and Figure 2.6). The largest grains $(>2,000 \mu \mathrm{m}$ ) require greater wind energy to move them, so instead of saltating they slide or roll while keeping contact 


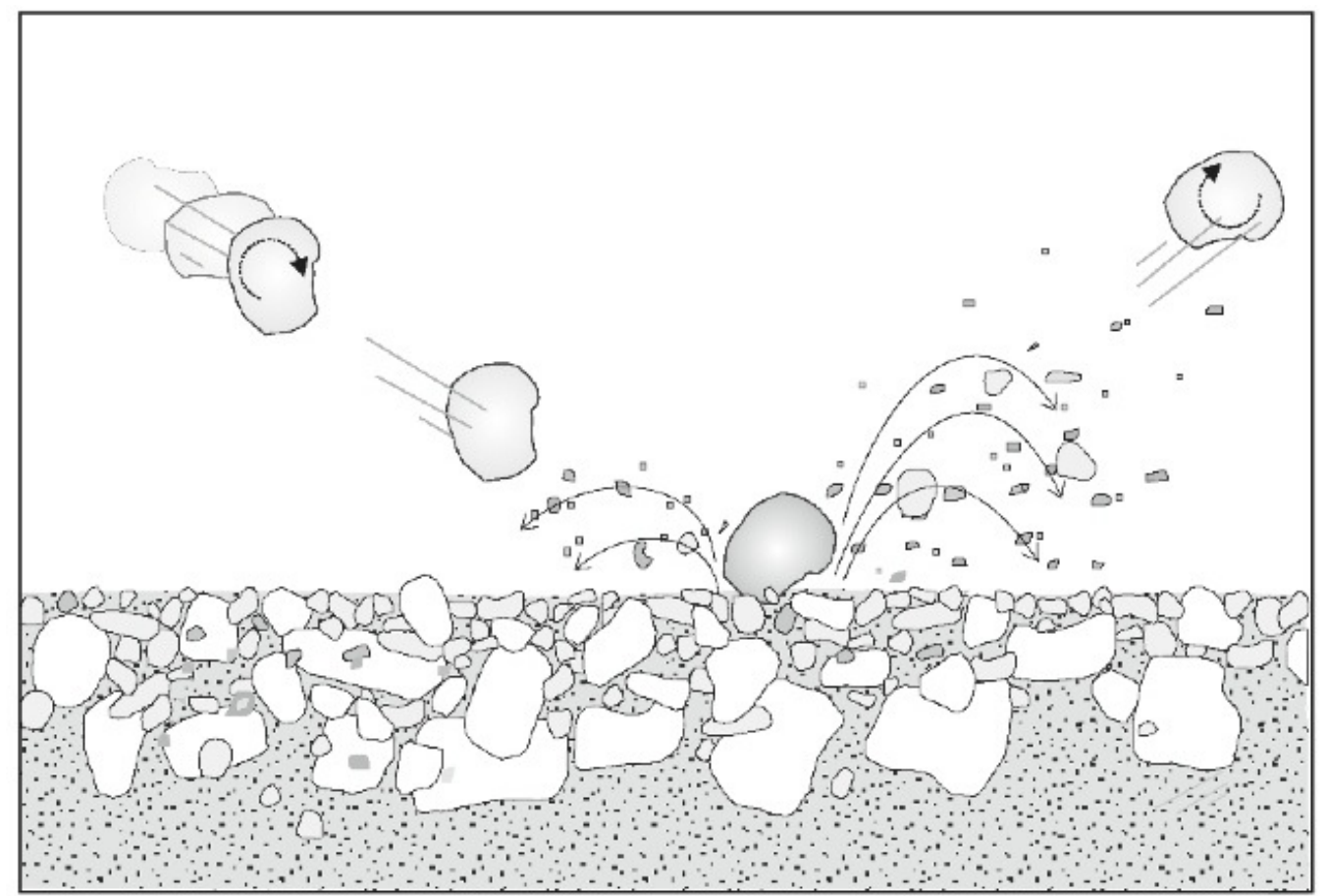

Figure 2.7: Schematic diagram showing the impact of a relatively large saltating grain splashing up numerous low-energy ejecta of varying size moving short distances, and a few high-energy ejecta moving in saltation or modified saltation. Saltation splash is recognized as a major contributor to saltation transport. From Nickling and McKenna-Neuman (2009).

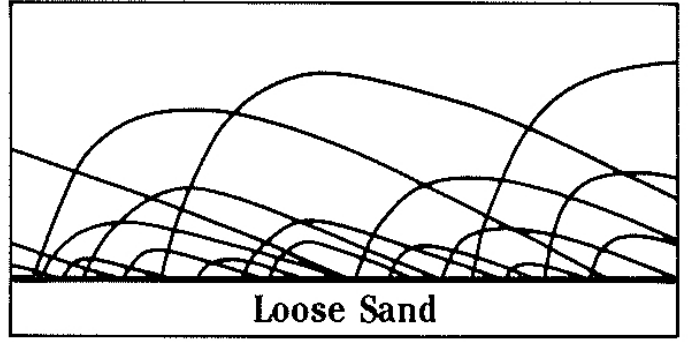

(a)

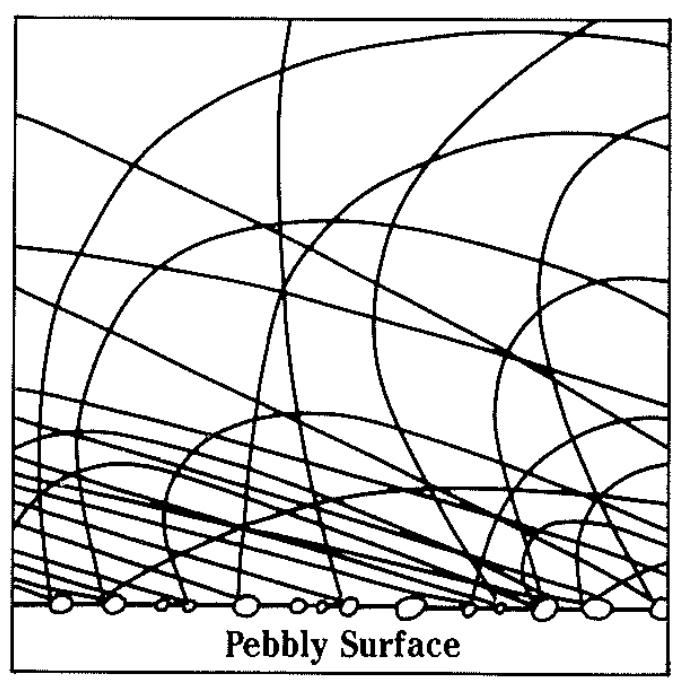

(b)

Figure 2.8: Saltation of a) sand grains over a surface of unconsolidated sand, and b) sand grains over a pebbly surface. Wind flow is from left to right. From Watson (1989), after Bagnold (1941). 
Figure 2.9: The characteristic saltation path showing vertical and horizontal components of grain velocity relative to the ground at take-off and before landing.

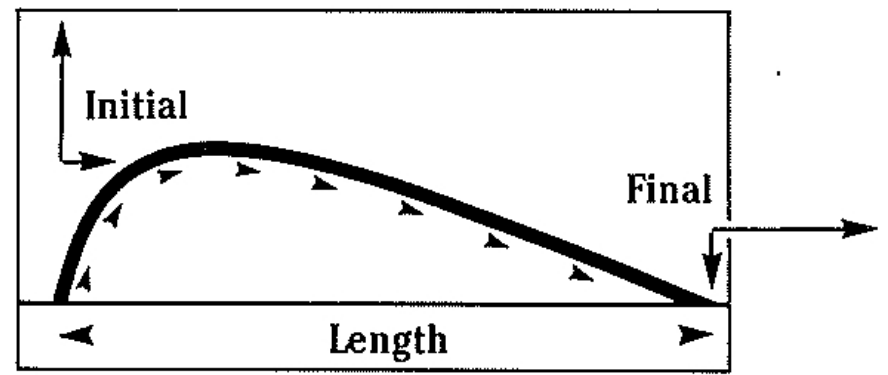

From Watson (1989) after Bagnold (1941).

with the surface, either pushed directly by the wind or triggered by a saltating grain. This is termed surface creep (Greeley and Iversen, 1985).

In his field observations of desert sand storms, Bagnold (1941) noted for sand between 0.08-0.75 mm diameter, entrainment occurred at a wind speed of $\sim 5 \mathrm{~m} \mathrm{~s}^{-1}$. All sand grains were suspended $<1 \mathrm{~m}$ above the ground surface, with an average suspended height of $\sim 10 \mathrm{~cm}$. From field studies in China, Dong et al. (2011) observed that natural windblown sediments of a range of sizes are mainly transported within $50 \mathrm{~m}$ of the surface, with $\sim 90 \%$ of the mass flux transported below $15 \mathrm{~m}$ above surface, 80\% below $5 \mathrm{~m}$, and 70\% below $1 \mathrm{~m}$. Furthermore, Šabacká et al. (2012) note in a study of aeolian sediment transport in the Taylor Valley, Antarctica that 3 to 5 times more sediment transport was observable close to the ground $(<20 \mathrm{~cm})$ than seen at $1 \mathrm{~m}$ above the ground. This suggests the majority of windblown material is saltated very close to the the suface.

\subsubsection{Sediment transport rates}

The flux of sediment being moved in saltation $\left(q_{s l t}\right)$ is dependent on mean grain diameter, degree of uniformity of grain size, and the gradient of $u_{*}$ (Bagnold, 1941). Where $u_{*}>u_{* t}, q_{s l t}$ can be calculated by describing the flux as proportional to the third power of $u_{*}$, as follows:

$$
q_{s l t}=\delta \sqrt{\frac{D}{d}} \cdot u_{*}^{3} \cdot \frac{\rho_{a}}{g}
$$

where: $\delta$ is an empirical coefficient relating to the degree of sorting of the source material (e.g. 0.15 for well sorted material and 0.28 for poorly sorted material), $d$ is the mean grain size of the source material, and $D$ is the diameter of a standard grain (250 $\mu \mathrm{m})$ (Bagnold, 1941; Anderson and Hallet, 1986). Sorting of source material 
affects grain trajectories (as illustrated in Figure 2.8), and can alter the turbulence of flow and therefore $u_{* t}$ (also discussed in Section 2.2).

Furthermore, provided the condition of $u_{*}>u_{* t}$ is met, where $d<100 \mu \mathrm{m}$, sediment flux from modified saltation and suspension $\left(q_{\text {sus }}\right)$ can also be estimated. $q_{\text {sus }}$ varies approximately proportionally to the third power of $u_{*}$, and varies inversely to $d$ (Bagnold, 1941), by the following expression:

$$
q_{\text {sus }}=\left(\frac{{\frac{d^{2}}{2}}^{2} \pi u_{*}^{3}}{d}\right) \cdot U
$$

\subsection{Aeolian processes in cold environments}

\subsubsection{Niveo-aeolian processes}

Aeolian processes in cold, hyper-arid regions inevitably coincide with blown snow, affecting entrainment, transport and deposition of sediment. Sea ice prevents direct deposition of aeolian sediment into seawater for the majority of the year, with sediment accumulation on sea ice strongly controlled by the trapping mechanism of snowdrifts. Niveo-aeolian processes ('niveo'; from the Latin niv meaning snow) involve coincident snow and sediment transport by wind. Niveo-aeolian deposits are formed in two ways: 1) falling or blown snow is mixed, or redistributed, with wind-drifted sediments, or 2) drifted aeolian sediment is deposited on top of a snow deposit without simultaneous snowfall (Seppälä, 2004).

As summarised by McKenna-Neuman (1993), transported snow saltates like sand grains. However, particle trajectory heights are greater for snow than sand, increasing in height with lowering of temperature. Most drifting snow occurs within 1-2 m of the surface; therefore, sediment may be transported in the lowest few $\mathrm{cm}$ of mobilised niveo-aeolian material. Following deposition snow bonds strongly to the snow pack, producing cohesive forces at least an order of magnitude greater than inherent inertial forces from particle mass, in turn affecting entrainment thresholds, and therefore limiting mobilisation of niveo-aeolian material.

Reported entrainment threshold velocities for loose blown snow in Antarctica range from $7 \mathrm{~m} \mathrm{~s}^{-1}$ in winter and $13 \mathrm{~m} \mathrm{~s}^{-1}$ in summer ('wetter' summer surface conditions enhance cohesion of snow drifts and thereby increase the threshold velocity required for entrainment) (Holmes et al., 2000; Knuth et al., 2010). But for entrainment of 
dense, bonded snow pack, extremely strong winds $\left(>30 \mathrm{~m} \mathrm{~s}^{-1}\right)$ are required for entrainment to occur (Seppälä, 2004). Wind-packed snow surfaces also provide a firmer surface for saltating material to traverse in comparison to dry, fresh snow. Therefore, seasonal changes in snowfall and snow surface conditions may impact on flux rates of niveo-aeolian transport. Snow entrainment and drifting is also affected by snowfall intensity in combination with wind shear velocity. With a saturation of snow in the airstream, suspension becomes dominant over saltation as a transport mode (McKenna-Neuman, 1993).

\subsubsection{Temperature and humidity effects}

Aeolian processes operating in cold climates are essentially the same as those in warm climates, except for temperature, which reduces air density and viscosity (Table 2.2), ice, snow and permafrost cover affecting sediment supply, and increases the rate of chemical breakdown of minerals (Kohfeld and Tegen, 2007; Brookfield, 2011). Cold air can entrain particles $40-50 \%$ larger in diameter than warm air due to aerodynamic drag being up to $30 \%$ greater in cold or high latitude settings, as compared to hot deserts, due to greater air density and viscosity at lower temperatures (McKenna-Neuman, 2003). Notably, entrainment threshold velocities are up to $2 \mathrm{~m}$ $\mathrm{s}^{-1}$ lower in Antarctica compared to temperate climates (Ayling and McGowan, 2006).

Table 2.2: Density and kinematic viscosity of air in terms of temperature at a pressure of $0.099 \mathrm{MPa}$. Density calculated using the ideal gas law: $P=\rho R_{d} T$, where $P$ is air pressure in $\mathrm{hPa}, \rho$ is the density of dry air in $\mathrm{kg} \mathrm{m}^{-3}, T$ is temperature in ${ }^{\circ} \mathrm{K}$, and $R_{d}=0.287053 \mathrm{kPa} \mathrm{K}^{-1} \mathrm{~m}^{3} \mathrm{~kg}^{-1}$ Modified from Seppälä (2004), after Schlichting (1979).

\begin{tabular}{ccc}
\hline Temperature ${ }^{\circ} \mathrm{C}$ & $\begin{array}{c}\text { Density } \rho \\
\mathrm{kg} \mathrm{m}^{-3}\end{array}$ & $\begin{array}{c}\text { Kinematic viscosity } \\
v \times 10^{6} \mathrm{~m}^{2} \mathrm{~s}^{-1}\end{array}$ \\
\hline-100 & 1.98 & 5.95 \\
-50 & 1.53 & 9.55 \\
-20 & 1.39 & 11.2 \\
-10 & 1.34 & 12.1 \\
0 & 1.29 & 13.0 \\
+10 & 1.25 & 13.9 \\
+20 & 1.21 & 14.8 \\
\hline
\end{tabular}


Air density is inversely proportional to air temperature, which in turn lowers entrainment threshold velocities (McKenna-Neuman, 2003; Seppälä, 2004; Ayling and McGowan, 2006) and can increase transport rates in cold environments (Lancaster, 2002). A major effect of low temperature is to reduce both the amount of water vapour in the air and the matric potential at which this water adsorbed onto particle surfaces, affecting interparticle cohesion. In polar regions the low humidity reduces interparticle cohesion of surface sediments and, therefore, particle entrainment velocities (McKenna-Neuman, 2003; Seppälä, 2004).

\subsection{Aeolian processes in McMurdo Sound}

\subsubsection{Aeolian sediment supply}

Local dust sources were not thought significant in ice cores until advances in geochemistry enabled provenance determination of dust (e.g. Basile et al., 1997; Delmonte et al., 2004b a; Grousset and Biscaye, 2005; Gaiero, 2007 and Delmonte et al., 2008). It is now proposed that dust from the MDV could potentially reach the Atlantic coastal region of Antarctica (Bory et al., 2010). It has also been inferred that dust found in Holocene ice cores from East Antarctic locations such as EPICA-Dome C $\left(75^{\circ} 06^{\prime}\right.$ S, $123^{\circ} 21^{\prime} \mathrm{E} ; 3,233 \mathrm{~m}$ above sea level) and Talos Dome (72 $49^{\prime} \mathrm{S}, 159^{\circ} 11^{\prime} \mathrm{E} ; 2,315$ $\mathrm{m}$ above sea level) may have come from MVG and Victoria Land sources (Delmonte et al., 2010b; Vallelonga et al., 2010; Delmonte et al., 2013). New sediment in the MDV has been generated primarily by aeolian processes since ice retreat in the mid-Miocene (Cuffey et al., 2000; Atkins and Dickinson, 2007; Marchant and Head, 2007); however, despite very slow weathering rates (Brook et al., 1995; Sugden et al., 1999; Summerfield et al., 1999) deglaciation of the MDV has afforded the time for lag surfaces of non-erodible material to form, protecting the erodible material below and restricting sediment supply.

\subsubsection{Aeolian transport}

Ayling and McGowan (2006) and Speirs et al. (2008) observed entrainment threshold velocities for loose sands, of $5.5 \mathrm{~m} \mathrm{~s}^{-1}$ and $5.3 \mathrm{~m} \mathrm{~s}^{-1}$ respectively, and Lancaster et al. (2010) measured 6.5-7.2 $\mathrm{m} \mathrm{s}^{-1}$ for intermittent sand transport in the MDV. In addition, Lancaster et al. (2010) calculated that wind speeds exceeding $12.2 \mathrm{~m}$ $\mathrm{s}^{-1}$ (at $6 \mathrm{~m}$ height) would be required for spatially continuous sand transport to occur at the site. Winds of this strength in the MDV are entirely possible, with high peak wind speeds of up to $41 \mathrm{~m} \mathrm{~s}^{-1}$ (Keys, 1980; Fountain et al., 2010) recorded. 
Anecdotal evidence suggests the calculation by Lancaster et al. (2010) fits observed sand transport at Mt Discovery, on the southern margin of the McMurdo debris bands, where medium to coarse sand was observed in spatially continuous transport at $\sim 28$ knots ( 14.4 $\mathrm{m} \mathrm{s}^{-1}$ ) (N.R. Golledge, pers.comm., 2012).

Similarly, observations of a katabatic wind event at Cape Roberts on 31 October, 2010 showed that $>65$ knot ( $>33 \mathrm{~m} \mathrm{~s}-1$ ) winds have the capacity to move pebble-sized sediment into trajectories reaching vertical heights of at least $1 \mathrm{~m}$ (this study). Observations from US field workers in Explorer Cove, at the mouth of Taylor Valley, reported significant sand transport onto the sea ice during this katabatic event suggesting this is the primary transporting mechanism for the sand sized material found on the sea ice in New Harbour (Murray et al., 2012). Figure 2.10 shows blown snow over sea ice in the early stages of this storm event at Granite Harbour and mid-storm event snow/sediment transport at Cape Roberts.

\subsubsection{Aeolian sediment deposition}

Studies by Bentley (1979); Barrett and Treves (1981); Barrett et al. (1983); MacpherSon (1987); Atkins and Dunbar (2009) and Murray et al. (2012) show that volumes of sand and dust blown from peripheral sources to McMurdo Sound are observable on sea ice year on year. Inheritance of transport-generated sorting creates a distinctive signature for aeolian material found on the sea ice and also the sea floor (Barrett et al., 1983). This is demonstrated in the bimodal texture of samples collected in southern McMurdo Sound by Atkins and Dunbar (2009), from which they conclude that both suspension and saltation processes are important in moving sediment from the McMurdo Ice Shelf debris bands to sea ice. Great variability in rates of material reaching the seafloor is evident. Atkins and Dunbar (2009) surmise that the final distribution pattern of aeolian sediment on the seafloor is influenced by the pattern of sea ice drift and melting rate during summer break-out, and by ocean currents. 


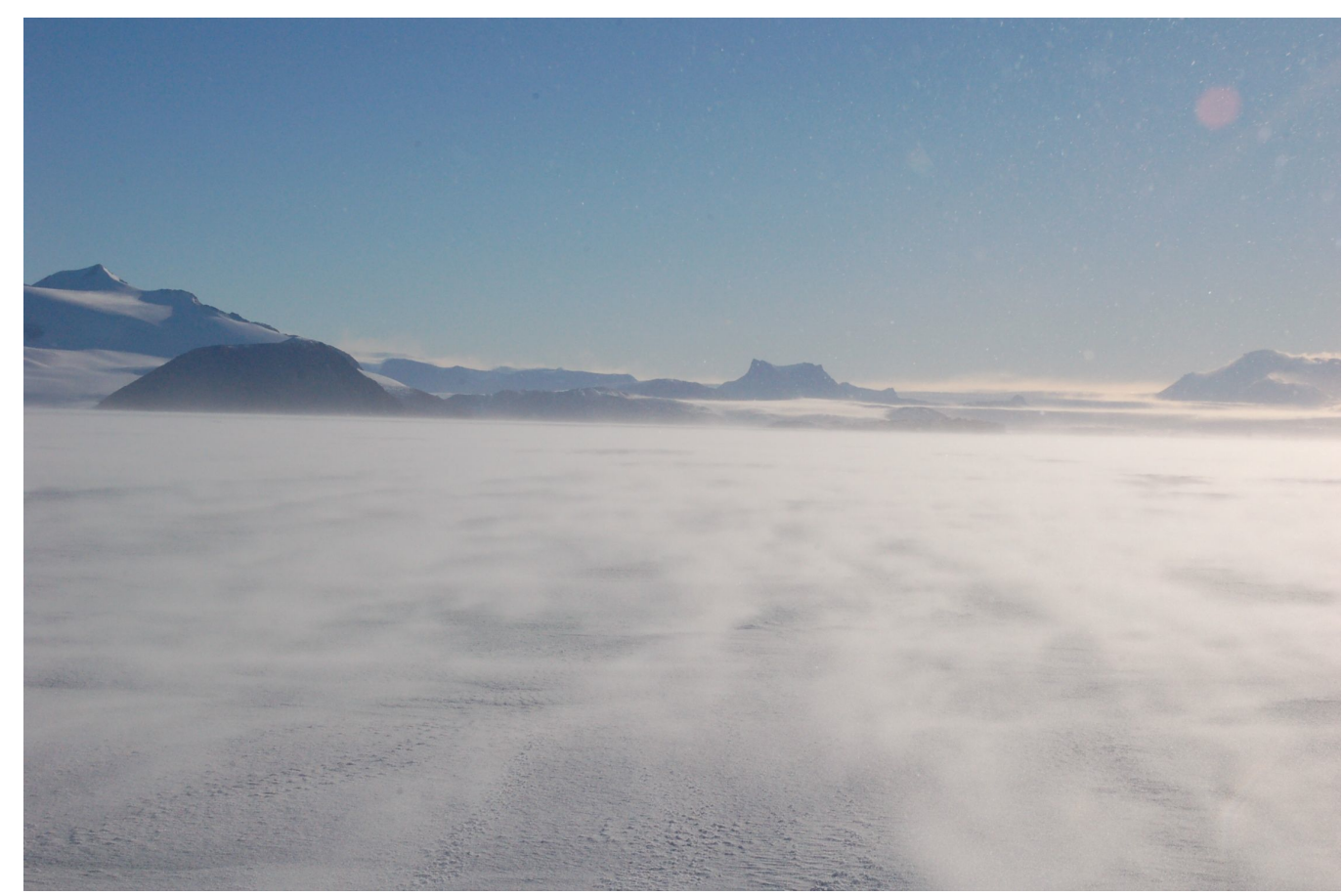

(a)

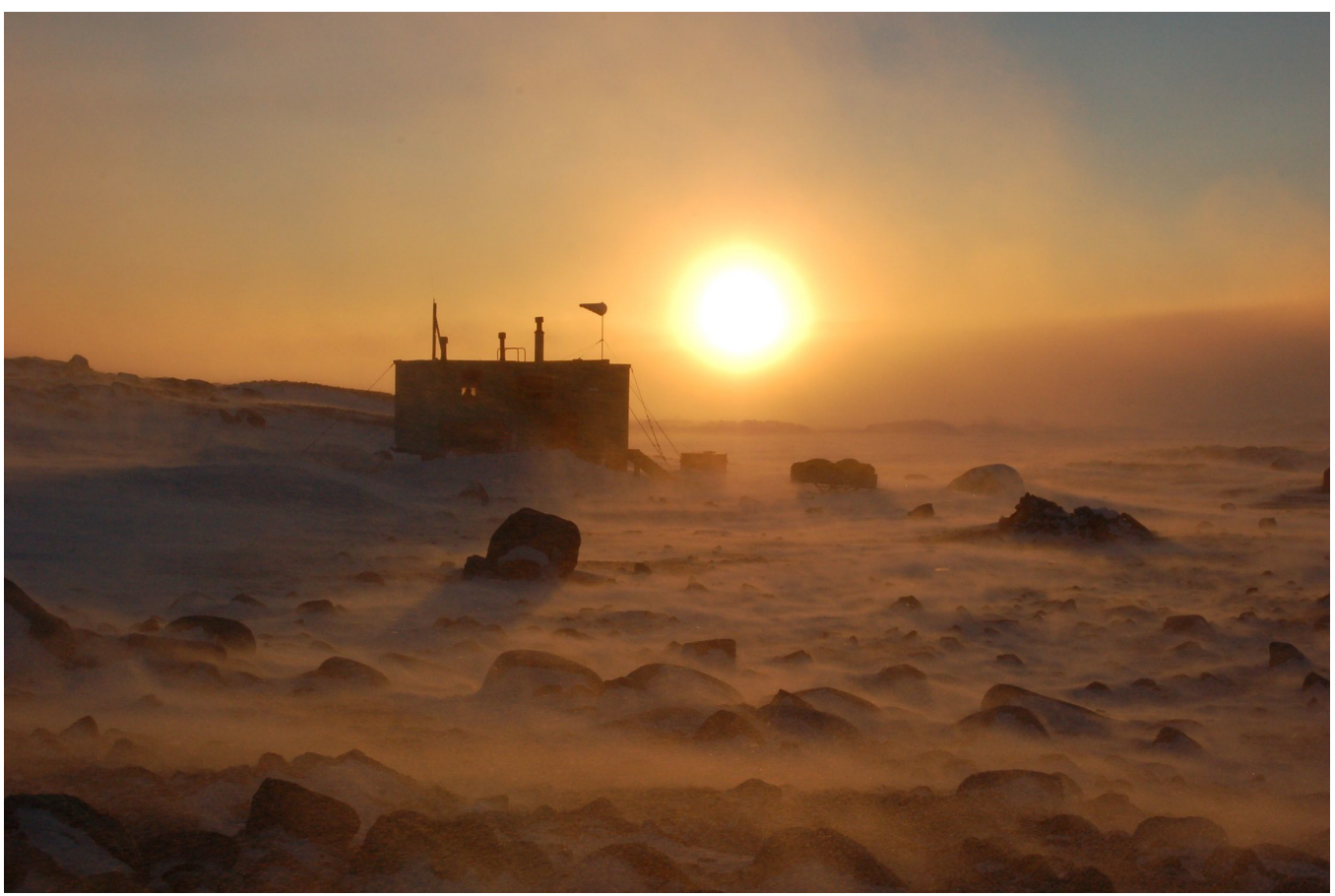

(b)

Figure 2.10: Windblown snow streamers, 31 October 2010, over a) sea ice - Granite Harbour, looking west, and b) gravelly till with coincident sediment transport - Cape Roberts, looking south. Spindrift from the plateau was first observed over the western horizon approximately 3-hours before the wind reached the sea ice. Further spindrift eddies were observed as the air flow decended over the mountain range to the coast. Peak wind velocities exceeded 65 knots. Photos courtesy of B.V. Alloway, 2010. 


\subsection{Summary of aeolian sediment entrainment and transport}

Aeolian processes operate at a variety of scales. Abundant supply of erodible sediment and wind, plus a lack of vegetation, are essential requirements for significant aeolian sediment transport. Aeolian sediment transport occurs mainly within $50 \mathrm{~m}$ of Earth's surface in the atmospheric boundary layer; however, much of this occurs within $1 \mathrm{~m}$ of the surface. Aeolian sediment is typically $<2,000 \mu \mathrm{m}$ diameter and can be separated into sand (63-2,000 $\mu \mathrm{m})$, coarse dust $(\sim 20-63 \mu \mathrm{m})$, and fine dust $(\sim 2-20 \mu \mathrm{m})$.

Turbulence, controlled by roughness height $\left(z_{0}\right)$ and shear velocity $\left(u_{*}\right)$, are major controls on the wind velocity profile and its capacity to erode a bed. The susceptibility of a grain to entrainment is primarily a function of grain size $(d)$, which determines the magnitude of particle forces acting on the grain. A critical threshold velocity $\left(u_{* t}\right)$ must be met for entrainment to be initiated. A greater velocity is needed to initiate particle motion than that required to maintain transport.

Cohesion, temperature and humidity, surface moisture, surface crusts, textural conditions, spatial and temporal intermittency, granular electification and anthropogenic effects provide additional complexity to aeolian entrainment. Saltation, suspension and surface creep are the three primary modes of aeolian sediment transport. Sphericity and grain size determine the settling velocity $\left(u_{f}\right)$ of a particle and its residence time in the atmosphere. Sediment transport rates are dependent on the mean grain diameter $(d)$, degree of uniformity of grain size and gradient of $u_{*}$, with sediment flux ( $q$ ) being approximately proportional to the third power of $u_{*}$, and for $d<100 \mu \mathrm{m}$ varying inversely to grain diameter.

Niveo-aeolian processes, temperature and humidity, frozen surfaces and snow cover are additional considerations for aeolian processes in high latitude, cool desert environments. Though noted as being a probable source of dust to adjacent regions, not a lot is known about aeolian sediment dispersal from the MDV and McMurdo Sound sources. Frequent strong wind events easily exceed sediment entrainment thresholds. However, great variability is seen in aeolian processes active in the McMurdo Sound area, with bimodal transport processes and deposition evident in localised deposits on sea ice. Final deposition into the ocean with sea ice melt is poorly constrained with sea ice drift and melt rates, as well as ocean currents, affecting ultimate dispersal of aeolian material. 


\section{Chapter 3 \\ Sea ice sedimentology methods}

\subsection{Sampling locations and rationale}

Field work was carried out during the 2010/11 Antarctic field season, between 20 October and 28 November by a three-person field team from Victoria University of Wellington, comprising: Dr. Cliff Atkins, Dr. Brent Alloway and the author. Field logistics support was supplied by Antarctica New Zealand through Scott Base. The field area encompassed $600 \mathrm{~km}^{2}$ of coastal sea ice fringing the Scott Coast, Victoria Land, situated from southern McMurdo Sound (5-10 km north of the Dailey Islands) to Cape Archer on the northern side of Granite Harbour (Figure 1.1). Two base camps were established, 1) Cape Roberts huts, and 2) a sea ice field camp at Marble Point.

This region was selected for its proximity to previously identified point sources of aeolian sediment in McMurdo Sound (Atkins and Dunbar, 2009), i.e. the McMurdo Ice Shelf debris bands and MDV coastal exposures (refer Figure 1.2). The field area also overlaps with past major geological drilling project sites: DVDP-15: Dry Valley Drilling Project, 1972-1974 (Barrett and Treves, 1981); MSSTS-1: McMurdo Sound Sediment and Tectonic Study, 1979 (Barrett, 1986); CIROS-1 and -2: Cenozoic Investigations of the Ross Sea project, 1986 (Barrett, 1989); CRP-1, -2 and -3: Cape Roberts Project, 1995-2000 (Barrett, 2007); and AND-1B and -2a: ANtarctic geological DRILLing project (ANDRILL), 2006-2012 (Naish et al., 2009) (http://www.arf.fsu.edu) (Figure 1.1). Lastly, this region is readily accessible from Scott Base.

The objective of the field work was to sample for aeolian dust trapped in snow on the sea ice surface over as broad an area of sea ice in McMurdo Sound as possible, given constraints of available time, available fuel and physical accessibility, in order to quantify the sediment mass, grain size, provenance and distribution of aeolian sediment trapped on sea ice. This greatly expands the spatial coverage as compared to previous aeolian sediment studies in the region (Bentley, 1979; Atkins and Dunbar, 2009; Winton, 2011). 


\subsection{Field methods}

\subsubsection{Sampling methodology}

Travelling from base-camp each day, 22 west-east sampling transects were systematically sampled at both $2.5 \mathrm{~km}$ and $5 \mathrm{~km}$ intervals in a grid pattern. In a small number of cases the actual sampling point is 1-2 km off the true grid position due to the local occurrence of large re-frozen sea ice cracks, stranded ice-bergs, sastrugi (rough and broken ice), tide-cracks and heavily broken areas at the fast ice edge.

The transect routes and 248 sampling sites were plotted onto a topographic map of the region (USGS, 1970) and geographic positioning system (GPS) coordinates were used to find them. Transects ran west to east, with 'A' the northern-most transect and ' $\mathrm{V}$ ' the southern-most transect. Sampling positions along the transects corresponded geographically along lines running north to south, with number ' 1 ' the western-most site and number ' 18 ' the eastern-most site. Together these transects and lines formed a $600 \mathrm{~km}^{2}$ sampling grid (Figure 3.1). Sample names were prefixed by base camp name (Cape Roberts-CR; Marble Point-MP). A summary of sample collection data, including sample site latitude and longitude and sample dimensions is supplied in Appendix A.

Two types of sample were collected in the field area: a) 271 trace element clean samples (including 22 duplicates) in bottles, and b) 154 bulk snow samples in plastic bags (as indicated in Figure 3.1). All samples were collected upwind from people and vehicles. A Tyvek "clean-suit" and clean laboratory gloves were worn to prevent contamination of samples by clothing fibres and skin. A summary of types of sample collected and sampling methods is given in Table 3.1. 


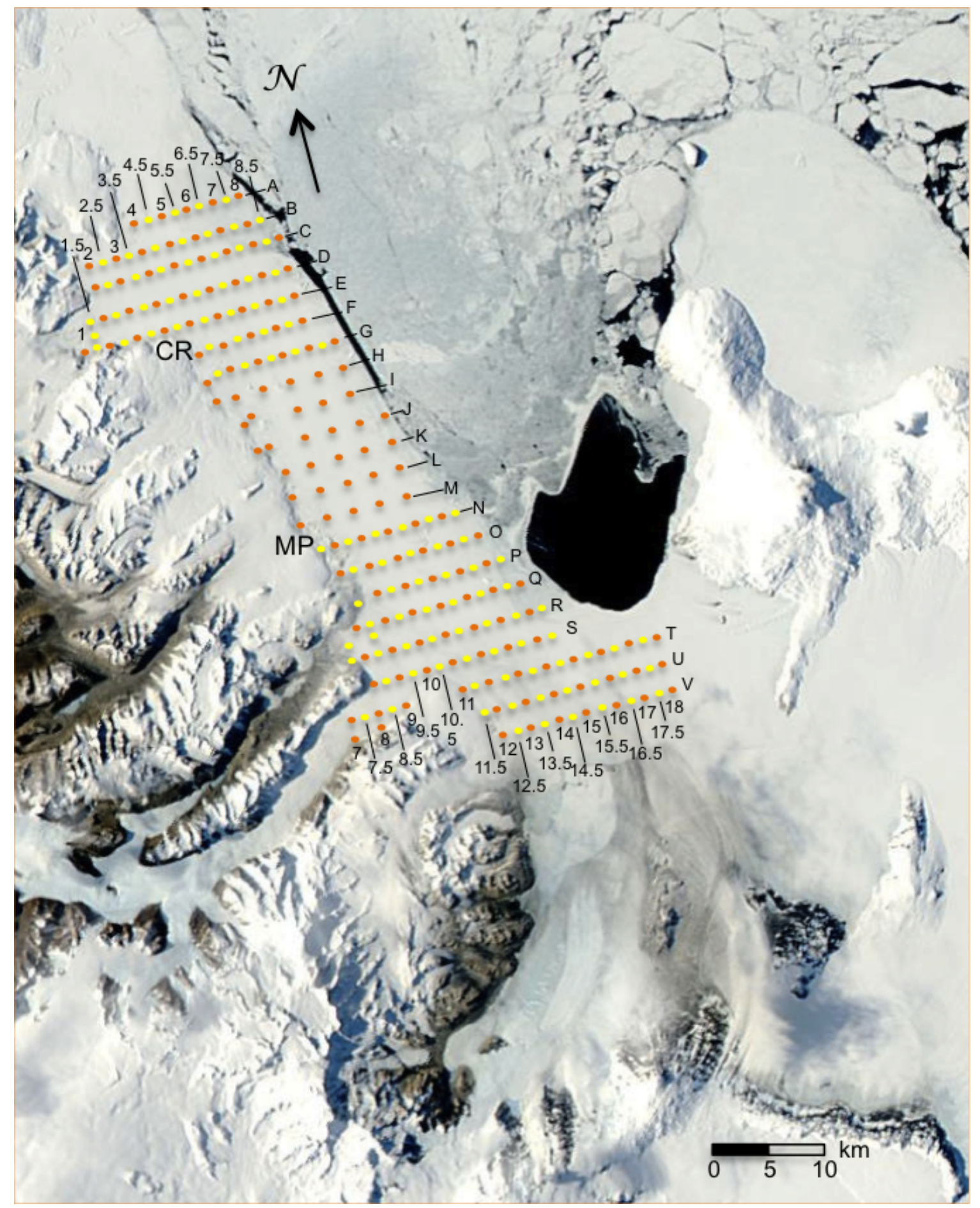

Figure 3.1: Event K001-D sampling sites, 2010 field season, western McMurdo Sound. Orange dots=sites where both bulk snow and trace element clean samples were taken (5 km intervals); yellow dots=sites where only trace element clean samples were taken ( $2.5 \mathrm{~km}$ intervals). Base camps are indicated by $\mathrm{CR}=$ Cape Roberts, and MP $=$ Marble Point. Numbers indicate line number south-north. Letters indicated transect line west-east. 
Table 3.1: Summary of types of sample collected and methods used in collection:

Event K001-D - 2010 field season.

\begin{tabular}{|c|c|c|}
\hline Sample type & Method & Details \\
\hline \multirow[t]{3}{*}{ Trace element clean } & $500 \mathrm{ml}$ Nalgene bottles & $\begin{array}{l}\text { Pre-cleaned in triplicate with Milli-Q ultra-clean } \\
(18 \mathrm{~m} \Omega) \text { water }\end{array}$ \\
\hline & Plastic sampling tools & $\begin{array}{l}\text { Scoop, pan, ruler, funnel; pre-cleaned in acid } \\
\text { wash; kept clean in field in pre-cleaned plastic } \\
\text { container }\end{array}$ \\
\hline & Snow profile & $\begin{array}{l}\text { 1. Localised pit dug into snow drift upwind } \\
\text { from vehicles and people using (non-trace ele- } \\
\text { ment clean) metal spade } \\
\text { 2. Upwind snow-pit wall scraped clean using } \\
\text { clean tools(to remove any spade contaminants } \\
\text { 3. Profile sampled } 10 \text { mm above sea ice to snow } \\
\text { drift surface, placed into pre-cleaned bottle } \\
\text { 4. Bottle labelled using permanent marker and } \\
\text { placed into snap-lock, "sandwich" bags } \\
\text { 5. Bottled sample stored in insulated container } \\
\text { for transport }\end{array}$ \\
\hline \multirow[t]{3}{*}{ Bulk snow } & Plastic bags & $\begin{array}{l}\text { Thick, clear, open-ended bags were chosen for } \\
\text { durability in cold climate conditions, and their } \\
\text { capacity (i.e. room for sample and sealing off) }\end{array}$ \\
\hline & Sampling tools & Metal spade; sharp, carving-style knife \\
\hline & Snow profile & $\begin{array}{l}\text { 1. Block of snow cut out of snow-pit wall by } \\
\text { spade and reduced to } \sim 0.001 \mathrm{~m}^{3} \text { volume using } \\
\text { knife, retaining profile depth dimension } \\
\text { 2. Sample placed into plastic bag, labelled using } \\
\text { a permanent marker, and sealed by expelling air, } \\
\text { folding opening onto itself three times with en- } \\
\text { closed plastic cable tie, which was then fastened } \\
\text { 3. Bagged sample stored in insulated container } \\
\text { for transport }\end{array}$ \\
\hline
\end{tabular}

At each site, the sampling area was chosen as representative of the local $\left(10 \mathrm{~m}^{2}\right)$ situation. Some sites had very low snow relief and poor snow-drift coverage, while others were blanketed by thick snow that fully covered the sea ice surface to up to dm-scale depth. Therefore, it is clear there is m-scale variability in snow (and presumably aeolian sediment) cover that is within the km-scale grid resolution used here.

Trace element clean samples were collected using acid washed plastic tools, to $2.5 \mathrm{~km}$ grid resolution, sampling from snow surface to $10 \mathrm{~mm}$ above the sea-ice surface into 
$500 \mathrm{ml}$, pre-cleaned Nalgene bottles. This $10 \mathrm{~mm}$ margin was instigated to prevent incorporation of material not likely to have been aeolian in origin (e.g. sea salts, marine diatoms). Trace element clean procedures were implemented to ensure sample suitability for geochemical analyses. Some samples from this suite have been studied for iron content by Winton (2011). As the trace element clean suite of samples falls outside the scope of this thesis, they will not be further discussed in the text.

For bulk snow samples, a block of snow was collected at $5 \mathrm{~km}$ grid resolution, using a spade and sharp carving style knife cleaned prior to use in the local snow. Samples were bagged in heavy-weight plastic bags, sealed using plastic cable ties and labelled using a permanent marker. Each sample represents the full thickness of the profile of the sampled snow-drift. The dimensions of each block were chosen to be approximately equivalent to a $0.001 \mathrm{~m}^{3}$ volume, a practicable size for storage in the field and for ease of transportation to Scott Base.

\subsubsection{Sample storage and transport}

In the field, samples were kept frozen in portable insulated containers placed into a snow pit. Most samples were then transported from the field to Scott Base via helicopter, while the final samples were taken by skidoo traverse on our return to Scott Base. From Scott Base to New Zealand the samples were kept at $-20^{\circ} \mathrm{C}$ in a refrigerated container, which was shipped from McMurdo Station to Port Lyttleton.

At Lyttleton the container temperature log showed that temperatures reached $-1^{\circ} \mathrm{C}$ following a power failure; however, it is not thought to have compromised the samples for the purpose of this study because the snow samples showed no sign of melt, which would have increased the risk of sample contamination or loss. Once on New Zealand shores, samples were transferred to the New Zealand Ice Core Research Facility, GNS Science, Gracefield, Lower Hutt (cold store temperature $-35^{\circ} \mathrm{C}$ ), by refrigerated truck.

\subsubsection{General weather observations}

Anemometer readings and basic meteorological observations were taken each day in the field to assess the local weather conditions. In late October (departure from Scott Base was on 26 October, 2010) maximum daily temperatures, as recorded at Scott Base, ranged from $-19.1^{\circ} \mathrm{C}$ to $-15.2^{\circ} \mathrm{C}$, warming dramatically on 31 October to $-7.2^{\circ} \mathrm{C}$. November maximum temperatures were noticeably warmer, ranging between $-13.6^{\circ} \mathrm{C}$ to $+1.7^{\circ} \mathrm{C}$. The minimum temperature, as recorded at Scott Base, during the 
field season was $-30.3^{\circ} \mathrm{C}$ on 29 October. The warmest minimum temperature was on 10 November, with a minimum temperature of $-9.8^{\circ} \mathrm{C}$.

Weather in the southern sector (south of transect ' $K$ ') was slightly more overcast on average than the northern sector (north of transect 'K'), but still generally fair. One or two warm days provided snowfall in New Harbour. Though generally windspeeds were light $\left(<15 \mathrm{~m} \mathrm{~s}^{-1}\right)$, a notable katabatic wind event occurred along the Scott Coast vicinity in the late afternoon of 31 October, 2010 (as noted in Subsection 2.5.2). Wind velocities during this storm exceeded $33 \mathrm{~m} \mathrm{~s}^{-1}$ and mobilised snow and sediment across the field area, affecting all samples collected after this date (transects CR-F to -J, MP-K to -V) (Figure 3.1). The storm, as observed from Cape Roberts base camp, came from the southwest with local variation due to topography.

The Granite Harbour transects (CR-A to $-\mathrm{E}$ ) had all been completed prior to the katabatic event. On return to the Granite Harbour following the storm, it was noted that the snow-drift cover previously sampled had been significantly dispersed, leaving greater areas of smooth blue sea ice. The neighbouring Wilson Piedmont Glacier had a visible layer of aeolian sediment on its surface, potentially sourced from the Dry Valleys inland from the Piedmont. Anecdotal evidence suggests significant sediment movement from coast to sea ice occurred at Explorer Cove, Taylor Valley mouth, during this event (M.F. Miller, pers. comm., 2010).

\subsection{Sediment mass determination}

Bulk snow samples were filtered for sediment mass using a Millipore vacuum filtration system. This system uses running water to create a vacuum via a hose attached to a "frit" filter head, made of porous glass. The suction created by the vacuum draws sample in fluid suspension from a feeder bowl, onto a filter paper placed over the porous frit surface, with the material smaller than the filter gauge and liquid passing through into a catching vessel, as shown in Figure 3.2.

Snow samples were weighed in triplicate on a balance, then were allowed to melt at room temperature. Once melted they were filtered individually through pre-weighed $0.4 \mu \mathrm{m}$ polycarbonate filters. Once filtered the meltwater was discarded. Sample bags were rinsed three times using Milli-Q ultra-clean $(18 \mathrm{~m} \Omega$ ) water, then were cut into pieces and each piece rinsed to ensure sediment did not remain in seams of the plastic. Filters were placed in open petri dishes and dried in a dessicator for at least 24 hours prior to weighing. Filter weights were taken in conjunction with petri dish weights. 


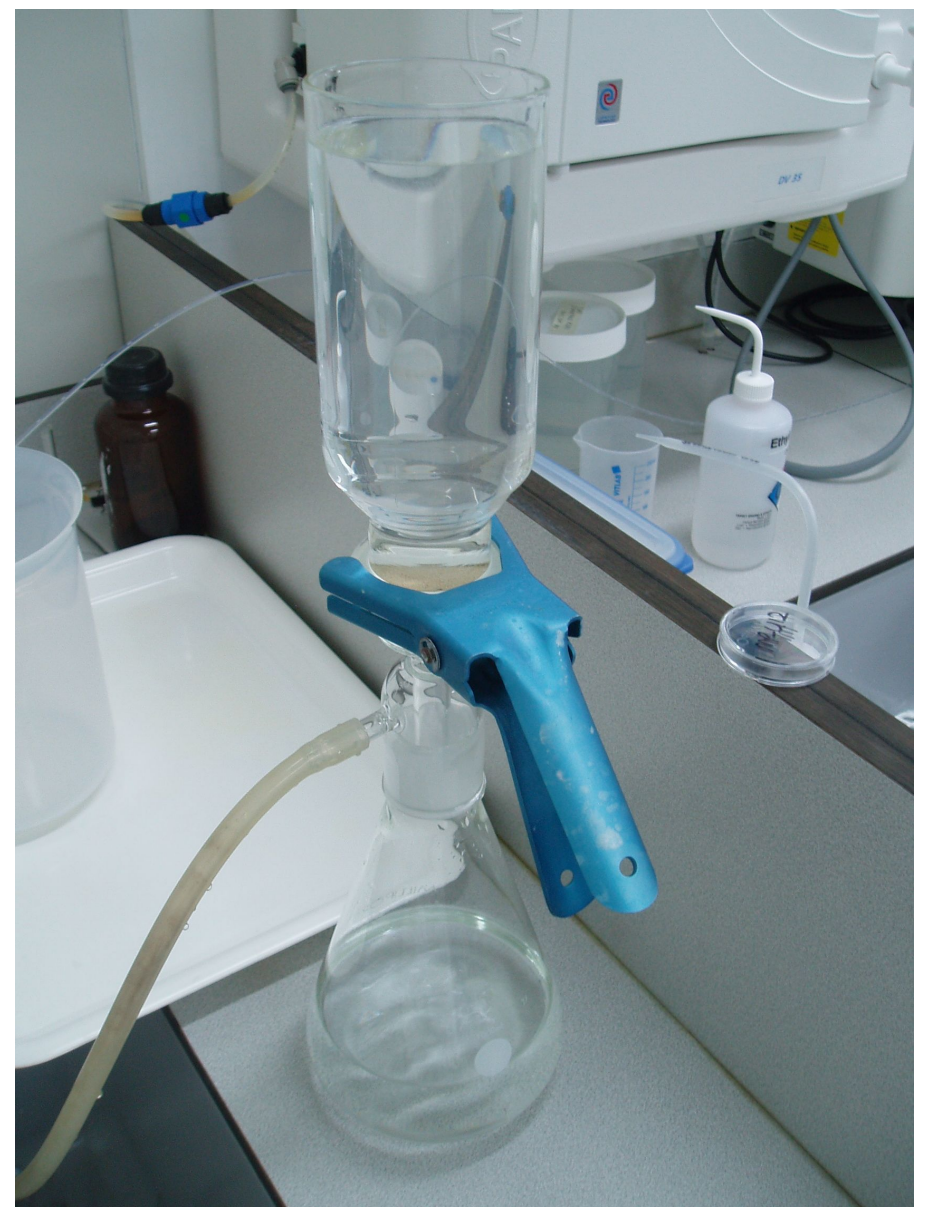

Figure 3.2: Millipore vacuum filtration system showing filtered sediment (tan colour) on filter in centre of unit.

Triplicate weights were measured on a micro-balance and the average recorded to four decimal places for each measure. The weight of the sediment was then calculated by subtracting the mass of the filter and petri dish from the total mass. Snow weights were calculated by subtracting bag and tie weights from measured weight.

Although due care was taken in handling samples, some (minor) sample loss occurred during filtration, 1) where sample meltwater splashed outside of the feeder bowl, 2) where sample meltwater leaked out between the bowl and frit during filtration, or 3) during the removal of the filter paper from the frit where sediment had washed off the paper. Any water leaked during melt from holes in sample bags was caught within a plastic container. These events are noted in Appendix B.

Visible lint, or other obvious non-sample material, was removed with tweasers and in a couple of instances a coarse-grain $(500 \mu \mathrm{m})$ filter was placed over the head of the bowl to extract lint as sample was poured through. Discolouration of three samples occurred where a hole in the respective sample bags meant that meltwater interacted with the permanent marker label on the exterior of the bag. This was deemed irrelevant to mass results. 
Figure 3.3: Potential contaminant of sediment samples appearing as a white residue on glass interior of Millipore vacuum filtration unit feeder bowl.

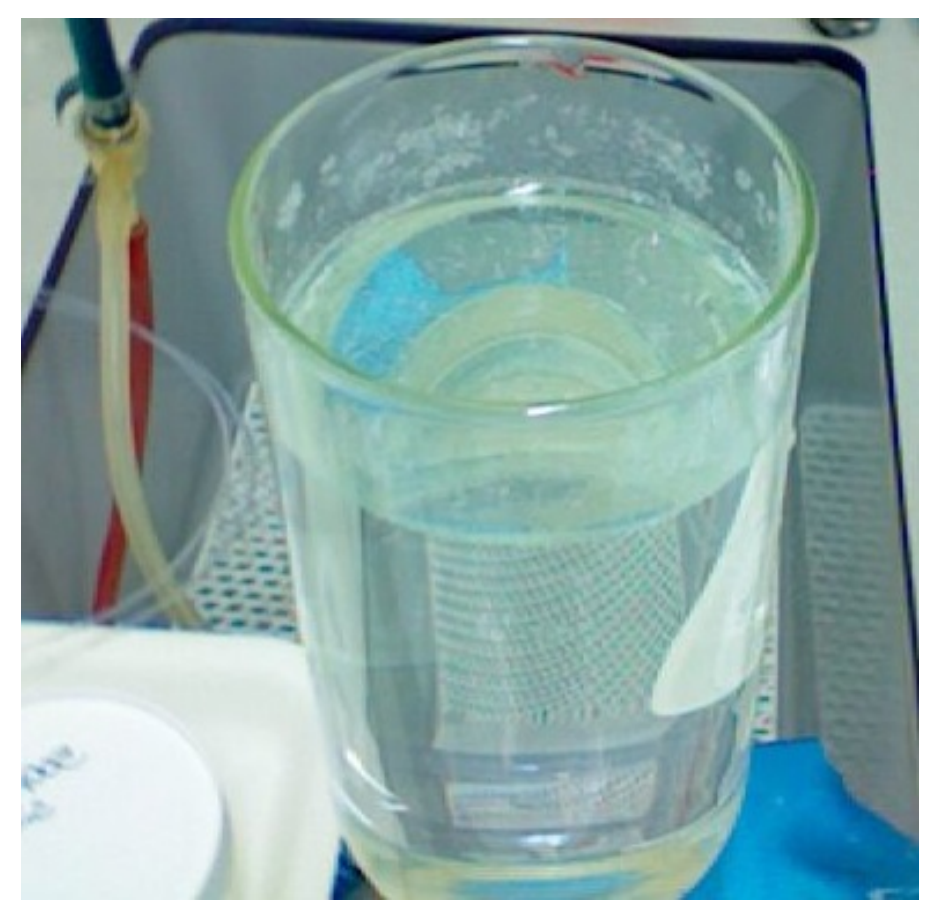

Potential sample contamination may also have occurred from whitish, very fine grained, particulates found in some samples, as shown in Figure 3.3. This material remains unidentified but is thought to be manufacturing residue from the sample bags. It is unlikely to be a naturally occuring mineral (e.g. calcite, some form of precipitate) due to its optical properties and shape, but this also cannot be ruled out. The potential contaminant affected $\sim 25 \%$ of the samples, i.e. these samples contained a portion of white particulates on the filter. One sample contained $\sim 20-30 \%$ residue; however, all other samples had extremely minor residue content (contents visually estimated).

Attempts to float off the residue in water were ineffectual, and given the small sample sizes and that most affected samples had trace amounts of the residue, separation using chemical methods was thought to be too damaging, potentially impairing the integrity of the grains. It was decided to continue with grain-size analysis without removing the material, as the possibility of it naturally occurring could not be ruled out. It is possible that it would appear as a contribution to the clay-size part of the grain size distribution. However, where possible, affected samples were avoided for grain size analysis, as shown in Appendix B.

Mass accumulation rate (MAR) results are reported in $\mathrm{g} \mathrm{m}^{-2} \mathrm{y}^{-1}$. In reality land-fast sea ice is present in McMurdo Sound 8-12 months of every year, but there can be no accumulation onto sea ice when the sea ice is not present. Aeolian transport rates for the summer period when open water conditions are possible are difficult to estimate. 
Therefore, to simplify and to make observed values comparable to published data, only accumulation onto sea ice is considered and any aeolian sediment deposition to the Sound during open water conditions is assumed to be nil. Standard deviation of aeolian sediment weights for each sample range between 0.0-0.00035 g, with an average standard deviation of $\pm 0.00013 \mathrm{~g}$. Area is calculated from the two surface dimensions of sample volume measurements. MAR data was plotted graphically (refer Chapter 4) and also as a contour map to observe spatial distribution of data.

\subsection{Provenance determination by smear slide analysis}

Provenance determination was carried out by smear slide analysis of the particulates captured on polycarbonate filters after weighing. Smear slides were made from toothpick samples smeared onto a glass slide and fixed using a Norland optical adhesive (No. 61) with a refractive index of 1.65 , in order to qualitatively determine the presence of key provenance indicators.

These indicators are: 1) volcanic glass, a unique component of the dominant, fine-grained, locally derived volcanic material of the McMurdo Ice Shelf debris bands (Glasser et al., 2006); the debris bands is the largest accumulation of volcanic sediments in the region, 2) quartz grains, which are more common in the TAM lithologies than in the McMurdo Ice Shelf debris; although, it should be noted that quartz can also be sourced from boulders of TAM lithologies located in the debris bands, and 3) terrestrial diatoms were also investigated as a possible tracer of MDV origin given the presence of endemic freshwater species in meltwater streams. However, upon comparison with the literature, it was found that no terrestrial species are unique to the MDV, with the same species also being found in McMurdo Ice Shelf debris bands meltwater ponds (Kellogg et al., 1980; Kellogg and Kellogg, 1987; Cremer et al., 2004); therefore, this third indicator was not explored further. Other compositional elements, such as silicate minerals, opaques, and biological remains, were noted.

Presence of volcanic glass was qualitatively evaluated as common, rare and absent, based on abundance observed on smear slides. The fine grain size of the material made absolute identification of individual grains problematic, and a similar relative abundance assessment for quartz grains was not possible. Quartz presence instead was noted where positive identification was made. Point counting of minerals to obtain a quantitative analysis of abundance was considered, but due to the variability of sampling volumes used in the smear slide construction method, it was not attempted. Other mineralogical analyses (e.g. thin section, x-ray fluorescence, scanning electron 
microscope) were considered of limited value due to the volume of Transantarctic Mountain material located on the debris bands as erratics meaning presence of minerals is not a reliable indicator of dust origin .

All samples used for smear slide studies were collected during the 2010 field season. Thirty-one of the slides were prepared by the author, and four were prepared by Winton (2011). Relative abundances of volcanic glass were assessed for 31 of the slides as there were differences in volume used in manufacture between the two batches. A contour map of relative abundance of volcanic glass was drafted to observe the spatial distribution of this tracer and is supplied in Chapter 4. Records of analyses are provided in Appendix C.

\subsection{Grain size analysis}

Grain size analysis was carried out to determine the distribution of particle size and to investigate particle transport and the energy within the aeolian system. A multi-component Beckman Coulter LS 13320 Multi-Wavelength Laser Diffraction Particle Size Analyser was used to analyse the samples. This instrument has a relatively narrow optimum range of "obscuration" which is determined by sample surface area, and thus sample concentration and size distribution (Beckman Coulter, 2011). Due to the range in mass (0.0041-0.273 g) and grain size of the samples (clay - coarse sand), two LS 13320 sample modules were required to obtain the optimum obscuration the aqueous liquid module (ALM) and the micro liquid module (MLM). Ideally the obscuration should be $8-12 \%$, but practical experience suggest acceptable results are obtained for obscuration values between 3 and 20\%. In each case the samples were suspended in distilled water (MLM) or Milli-Q ultra clean (18 $\mathrm{m} \Omega$ ) water (ALM).

Prior to analysis, sediment was recovered from the polycarbonate filters by diluting in 50-60 $\mathrm{ml}$ distilled water, with dry sediment being carefully washed from the filter and petri dish. The sample solution was then sonicated for a minimum of 10 minutes to disperse aggregates. Reproducibility checks were achieved by running standard glass beads, and performing replicate analyses on individual samples, as shown in Figure 3.4. All samples were processed using the QuartzNatural.rf780d optical model, which assumes all material has a refractive index of quartz suspended in water. For the ALM, samples were stirred by hand to keep particulates in suspension immediately after sonication and prior to analysis. The pump speed operated at 70\%. For the MLM, a magnetic stirrer (set at $\sim 60 \%$ ) was used to keep the sample in suspension while 1-2.5 ml aliquots were syringed off. The inbuilt electronic stirrer was used during 


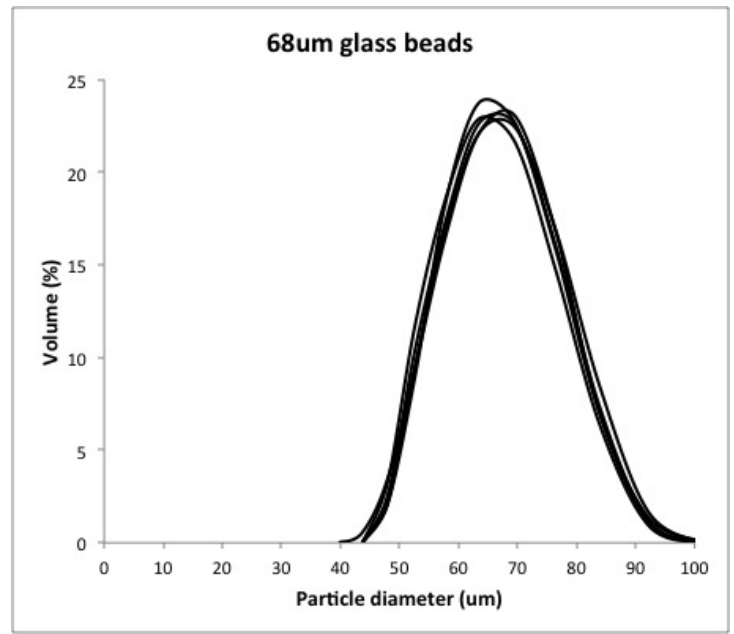

(a)

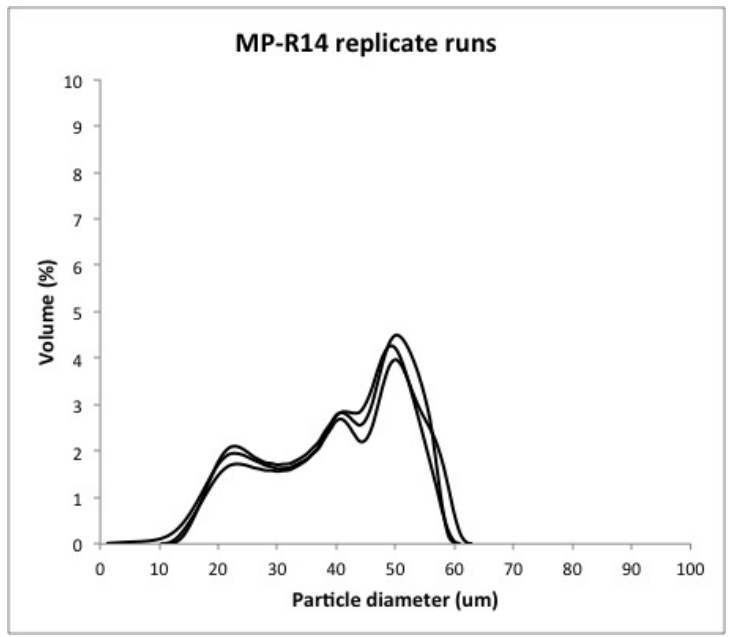

(c)

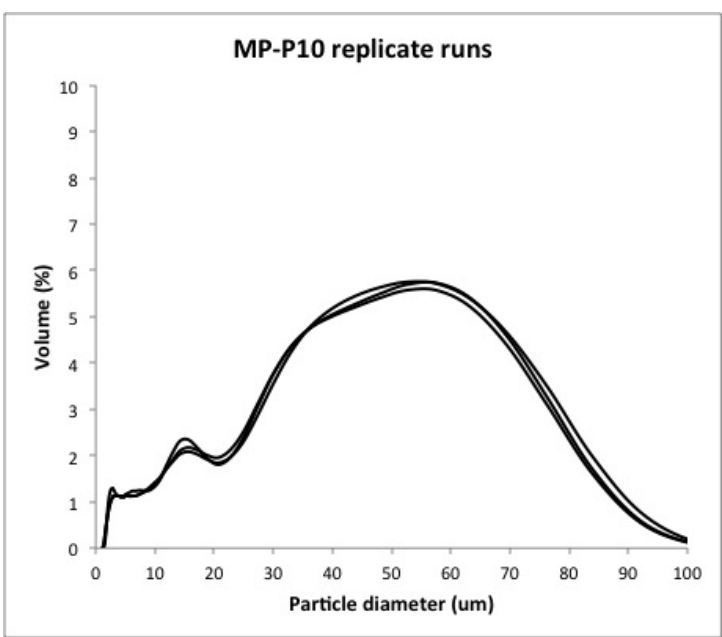

(b)

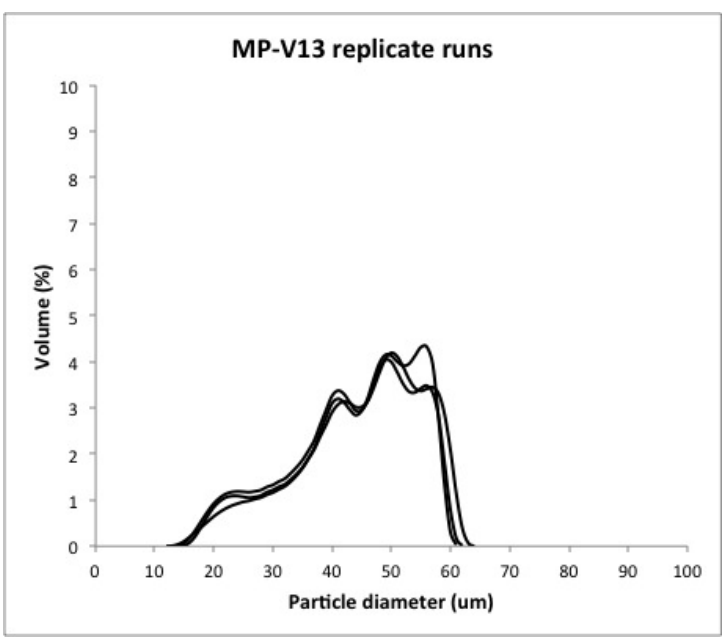

(d)

Figure 3.4: Replicate runs to show accuracy of Beckman Coulter LS 13320 laser sizer for both a) $68 \mu \mathrm{m}$ spherical glass beads, and McMurdo Sound dust samples b) sample MP-P10, c) sample MP-R14, and d) sample MP-V13.

analysis with the MLM. Where obscuration of the solution was high, the sample was further diluted and new aliquots taken. The duration of each background and sample measurement was 60 seconds.

The Beckman Coulter laser sizer produces frequency curves and summary statistics that can be used to compare individual grain size distributions. Spatial relationships of grain size distributions were analysed to observe if transport pathways from source areas (e.g. McMurdo Ice Shelf debris bands, TAM coastal exposures) are reflected in distributions, and if so, to what extent are source influences seen throughout the field area. Raw data are provided in Appendix C. 


\section{Chapter 4 Results of sea ice sedimentology}

\subsection{Spatial patterns of aeolian sediment mass accumulation rates}

Aeolian sediment MAR of samples collected in western McMurdo Sound show high variability and a complex distribution; however, some general trends are apparent. Table 4.1 summarises sample collection and laboratory data. MAR and corresponding data are supplied in full in Appendix B.

Table 4.1: K001-D 2010-2011 field season sample collection* and lab analysis statistics.

\begin{tabular}{lc}
\hline Statistic & Value \\
\hline \hline Field area (coastal fast ice platform and multi-year ice) & $\sim 600 \mathrm{~km}^{2}$ \\
Min-Max distance coastline to fast ice edge & $\sim 22-\sim 40 \mathrm{~km}$ \\
Sampling area latitudinal boundaries & $7746.00^{\circ} \mathrm{S}-7649.00^{\circ} \mathrm{S}$ \\
Sampling area longitudinal boundaries & $16224.00^{\circ} \mathrm{E}-16554.05^{\circ} \mathrm{E}$ \\
Sampling resolution & $5 \mathrm{~km}$ \\
\hline Number samples collected & 154 \\
Number samples used for mass analysis & 141 \\
Number samples used for grain size analysis & 32 \\
Number samples used for smear slide analysis & 35 \\
\hline Mass analysis samples processed by author & 136 \\
Mass analysis samples processed by Winton $(2011)$ & 5 \\
\hline Average sample volume (snow) & $0.00073 \mathrm{~m}^{3}$ \\
Average sample weight (snow) & $611.3 \mathrm{~g}$ \\
Average sample surface area (snow) & $0.0098 \mathrm{~m}^{2}$ \\
Average sample depth (snow) & $15 \mathrm{~cm}$ \\
Average weight of sediment recovered from samples & $0.0261 \mathrm{~g}$ \\
Weight range of sediment recovered from samples & $0.0015-0.2730 \mathrm{~g}$ \\
Average weight of 0.4 $\mu \mathrm{m}$ polycarbonate filter & $0.0151 \mathrm{~g}$ \\
\hline \hline
\end{tabular}

*only samples pertinent to this study are included 
Figure 4.1 and Figure 4.2 graphically summarise sample MARs. Sediment MARs are largest close to the coast and near the McMurdo Ice Shelf. Localised plumes, which rapidly decrease in MAR with distance from the coast, are observable in the data to the north of the McMurdo Ice Shelf debris bands in southern McMurdo Sound (Figure 4.1, top left corner), and to the north-northeast of outcropping rock exposures between New Harbour to Granite Harbour (Figure 4.1, centre). MAR values generally decrease with distance away from the coast. An area of low accumulation occurs in a band running west-east from the centre of Granite Harbour (Figure 4.1, lower right). Greatest spatial variability of values is found in southern McMurdo Sound.

The largest sediment MARs (i.e. $54.6 \mathrm{~g} \mathrm{~m}^{-2} \mathrm{y}^{-1}, 30.1 \mathrm{~g} \mathrm{~m}^{-2} \mathrm{y}^{-1}$ and $24.4 \mathrm{~g} \mathrm{~m}^{-2} \mathrm{y}^{-1}$ ) are found near Gneiss and Marble Points, as shown on Figure 4.1 and Figure 4.2. These values reflect the greater quantity of medium-coarse sand found in these samples (see Section 4.3). The other large sediment MARs (i.e. $15.7 \mathrm{~g} \mathrm{~m}^{-2} \mathrm{y}^{-1}$ and $15.2 \mathrm{~g} \mathrm{~m}^{-2} \mathrm{y}^{-1}$ ) were found close to the McMurdo Ice Shelf. These values fall within the top $10 \%$ of MARs. The smallest MARs (i.e. $0.15 \mathrm{~g} \mathrm{~m}^{-2} \mathrm{y}^{-1}, 0.2 \mathrm{~g} \mathrm{~m}^{-2} \mathrm{y}^{-1}$ and 0.27 $\mathrm{g} \mathrm{m}^{-2} \mathrm{y}^{-1}$ ) were found in the Granite Harbour area, within a belt of low accumulation, as mentioned above. MARs average $3.2 \mathrm{~g} \mathrm{~m}^{-2} \mathrm{y}^{-1}$ for the entire study area.

Many sampling sites contained obvious variability in snow and dust at m-scale. Figure 4.3 illustrates the extremes of variability seen within the field area. The highest MAR values were found near Marble Point where visibly discoloured snow and sea ice were common. The lowest MARs were found on the south side of Granite Harbour and beyond Cape Roberts where clean sea ice and clean, low-lying snow drifts were common. Sastrugi, multi-year pitting, sea ice cracks, stranded icebergs, refrozen uneven ice, snowdrifts, sea-ice blisters, and other features of the fast-ice made the surface and accumulating material highly variable. 


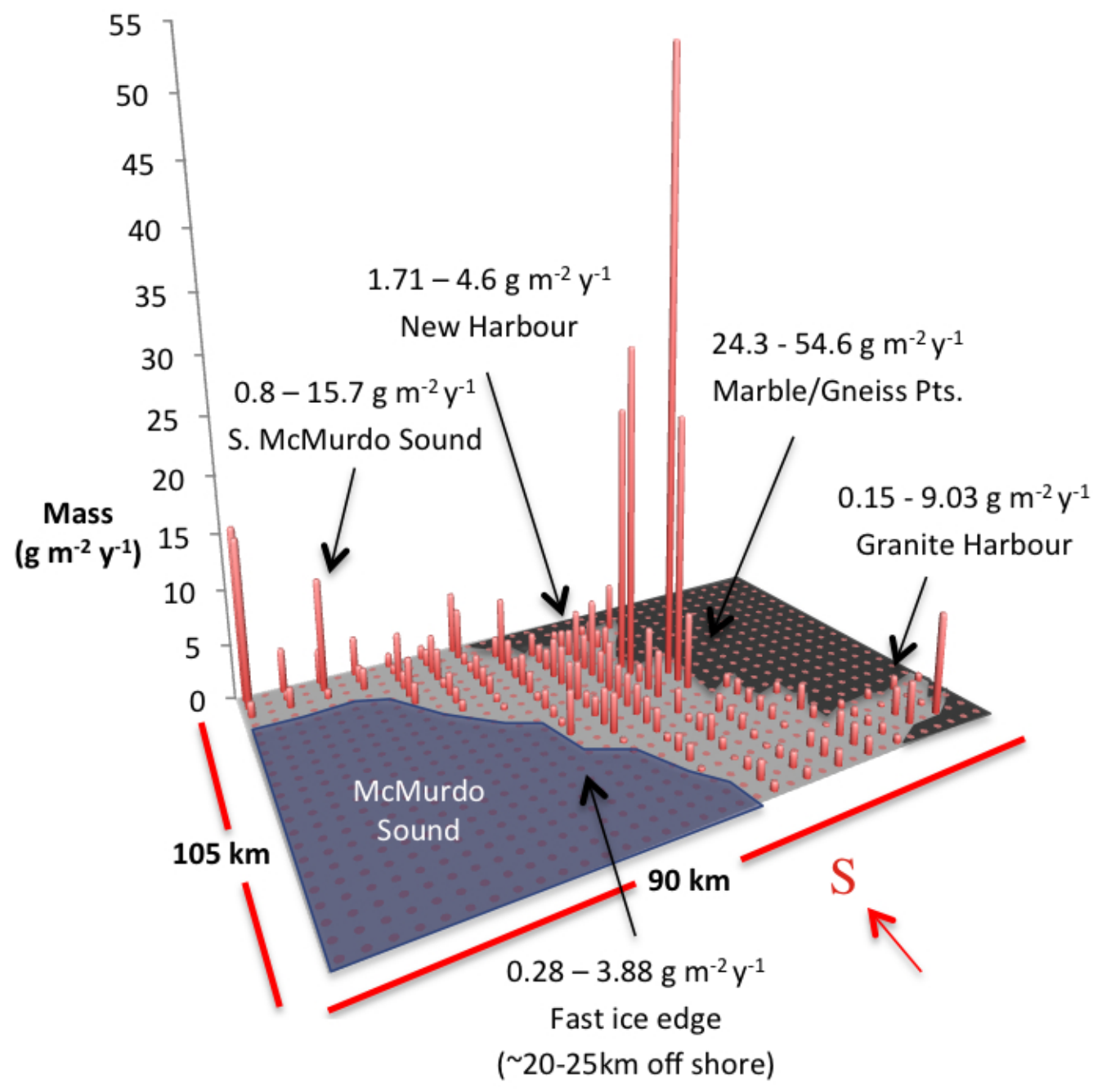

Figure 4.1: Sediment mass accumulation rates (red bars) found in western McMurdo Sound snow samples. Dark grey area=continent, light grey area=land-fast sea ice, blue area $=$ McMurdo Sound beyond fast-ice edge. Intersection of light grey and blue areas indicates fast-ice edge for November, 2010. 


\begin{tabular}{|c|c|c|c|c|c|c|c|c|c|c|c|c|c|c|c|c|c|c|c|}
\hline \multicolumn{2}{|c|}{ Transect/Line } & 1 & 2 & 3 & 4 & 5 & 6 & 7 & 8 & 9 & 10 & 11 & 12 & 13 & 14 & 15 & 16 & 17 & 18 \\
\hline \multicolumn{2}{|c|}{ (values $\mathrm{g} / \mathrm{m} 2$ ) } & & & & $\sim 163^{\circ}$ & & & & & $\sim 164^{\circ}$ & & & & & $\sim 165^{\circ}$ & & & & \\
\hline A & & \multicolumn{3}{|c|}{ Cape Archer } & 0.7 & 1.5 & 1.4 & 0.9 & 0.8 & I & & & & & I & & & & \\
\hline B & \multicolumn{2}{|c|}{ Lion Is } & 9.0 & 3.8 & 0.9 & 1.8 & 1.5 & 1.3 & 1.6 & I & & & & & I & & & & \\
\hline C & \multicolumn{2}{|c|}{ Kar Plateau } & 0.4 & 2.5 & 0.8 & 2.1 & 0.0 & 1.0 & 1.0 & I & & & & & 1 & & & & \\
\hline D & \multicolumn{2}{|c|}{ McKay Gl. } & 0.2 & 0.3 & 0.8 & 0.2 & & 0.3 & 0.1 & 0.3 & & & & & I & & & & \\
\hline $\mathbf{E}$ & $\sim 77.00^{\circ}$ & 0.7 & 1.3 & 0.8 & 0.7 & 1.0 & 0.5 & 0.7 & 1.0 & 1.4 & - & - & - & - & + & - & - & - & - \\
\hline $\mathbf{F}$ & \multicolumn{2}{|c|}{ The Flatiron } & \multicolumn{3}{|c|}{ Cape Roberts } & 2.3 & 1.2 & 1.3 & 2.2 & 1.4 & & & & & 1 & & & & \\
\hline G & & & & & I & 0.4 & 1.3 & 1.2 & 1.5 & 0.6 & 0.4 & & & & 1 & & & & \\
\hline H & & & & & I & 1.0 & 1.3 & 1.6 & 0.6 & 2.1 & 0.3 & & & & I & & & & \\
\hline I & & & & & I & & 1.4 & 0.5 & 2.2 & 2.3 & 3.5 & & & & 1 & & & & \\
\hline $\mathbf{J}$ & & & & & \multicolumn{2}{|c|}{ Dunlop Is. } & 1.2 & 5.5 & & 2.7 & 3.2 & 3.9 & & & 1 & & & & \\
\hline $\mathbf{K}$ & & & & & I & & & 7.0 & 4.3 & 2.9 & 1.7 & 0.6 & & & I & & & & \\
\hline $\mathbf{L}$ & & & & & I & \multicolumn{2}{|c|}{ Spike Cape } & 24.3 & 5.7 & 3.1 & 1.4 & 1.0 & & & I & & & & \\
\hline M & & & & & I & & & 54.6 & 1.6 & 4.5 & 3.4 & 1.7 & & & 1 & & & & \\
\hline $\mathbf{N}$ & & & & & I & & \multicolumn{2}{|c|}{ Gneiss Pt. } & 30.1 & 3.0 & 2.8 & 0.7 & 0.5 & & I & & & & \\
\hline 0 & & & & & I & & \multicolumn{2}{|c|}{ Marble Pt. } & 24.4 & 7.2 & 3.5 & 1.9 & 0.7 & 1.0 & I & & & & \\
\hline $\mathbf{P}$ & $\sim 77.30^{\circ}$ & - & - & - & + & - & \multicolumn{3}{|c|}{ C. Bernacchi } & 3.3 & 3.6 & 2.9 & 1.6 & 1.4 & + & - & - & - & - \\
\hline $\mathbf{Q}$ & & & & & I & & & & 2.7 & 4.9 & 1.9 & 1.8 & 1.8 & 2.1 & 1.9 & & & & \\
\hline $\mathbf{R}$ & & & & & I & \multicolumn{3}{|c|}{ Taylor Valley } & 1.7 & 2.4 & 1.7 & 2.9 & 2.2 & 0.8 & 3.6 & & & & \\
\hline $\mathbf{s}$ & & & & & I & \multicolumn{3}{|c|}{ Mt. Barnes } & 2.0 & 1.7 & 2.2 & 6.3 & 0.9 & 2.9 & 1.6 & & & & \\
\hline $\mathbf{T}$ & & & & & I & \multicolumn{2}{|c|}{ Ferrar Gl. } & 4.6 & 0.9 & 1.0 & & 1.9 & 1.1 & 3.6 & 4.6 & 2.0 & 0.8 & 1.8 & 1.4 \\
\hline $\mathbf{u}$ & & & & & I & & & & & \multicolumn{3}{|c|}{ Bowers Piedmont } & 4.8 & 1.5 & 0.8 & 1.5 & 10.4 & 0.8 & 15.2 \\
\hline v & & & & & I & & & & & \multicolumn{3}{|c|}{ Strand Moraines } & 5.8 & 1.2 & 1.2 & 3.6 & 3.2 & 4.0 & 15.7 \\
\hline & & & & & I & & & & & I & & \multicolumn{3}{|c|}{ (rough ice) } & 1 & & & & \\
\hline & & & & & I & & & & & I & & \multicolumn{3}{|c|}{ Dailey Islands } & I & & \multicolumn{3}{|c|}{ McMurdo Ice Shelf } \\
\hline & & & & & I & & & & & I & & & & & 1 & & & & \\
\hline & & & & & & & & & & I & Cap & Choc & olate & & $\ll$ De & ris & and $\gg>$ & & \\
\hline
\end{tabular}

Figure 4.2: Spatial distribution of aeolian sediment mass accumulation rate data, highlighting areas of high accumulation on sea ice in McMurdo Sound. Dark red=highest accumulation (lower boundary is 84th percentile; $3.75 \mathrm{~g} \mathrm{~m}^{-2} \mathrm{y}^{-1}$ ), orange=high to mid-range accumulation; (lower boundary is 50th percentile; $1.65 \mathrm{~g}$ $\left.\mathrm{m}^{-2} \mathrm{y}^{-1}\right)$ and yellow= low accumulation $\left(<1.65 \mathrm{~g} \mathrm{~m}^{-2} \mathrm{y}^{-1}\right)$. n.b. 16th percentile is $0.7 \mathrm{~g} \mathrm{~m}^{-1} \mathrm{y}^{-1}$. Grey area=continent, light grey=ice shelf, and white area=Ross Sea. 


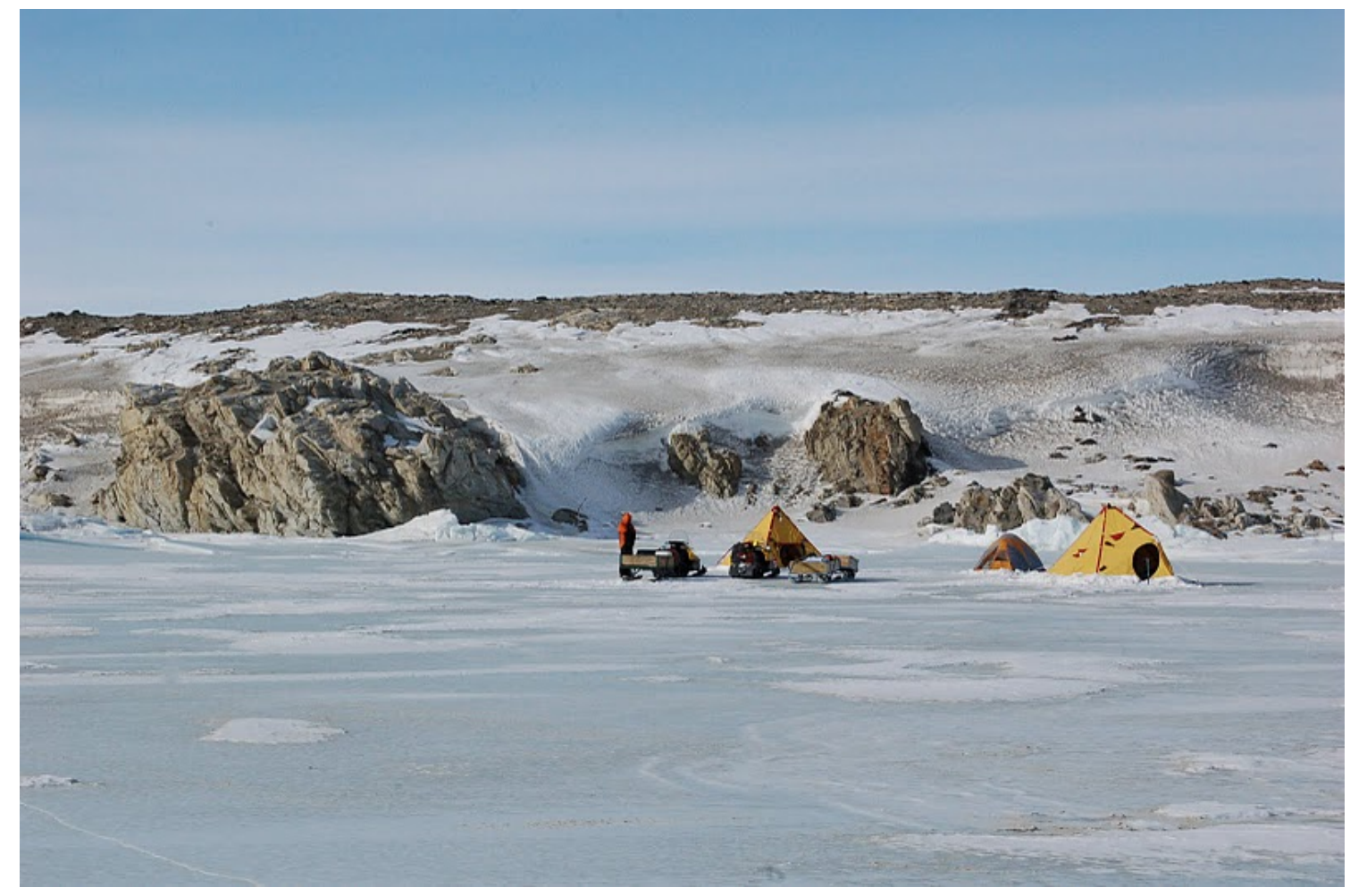

(a)

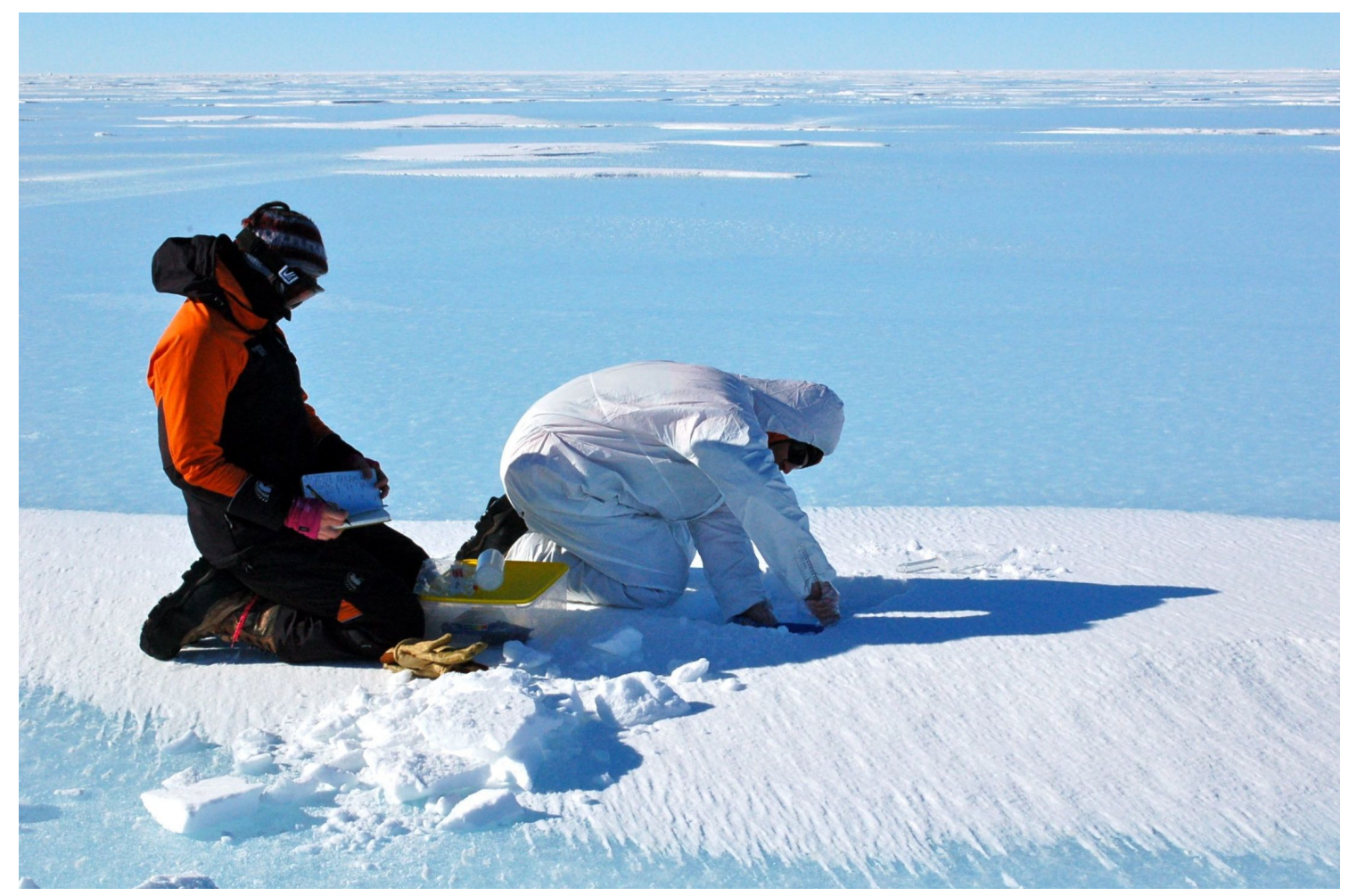

(b)

Figure 4.3: a) Area of highest sediment mass accumulation, Marble Point base camp and beach, looking south; visible aeolian sediment on snow and sea ice, and b) area of lowest sediment mass accumulation, Granite Harbour, looking southeast; low relief snow drifts on blue sea ice, $\sim 10 \mathrm{~km}$ off shore, no visible sediment. Photos courtesy of B. V. Alloway, 2010. 
Due to observed variability within the data, some consideration is given to what represents local deposition relative to $\mathrm{km}$-scale. Although the $5-\mathrm{km}$ resolution of the sampling grid is coarser than observed metre-scale variability, it nevertheless detected the localised plumes of high MAR, suggesting the resolution is adequate for the aims of this study.

Plumes typically contain the highest values, but also have the greatest degree of variability. For example, at Gneiss Point, calculating a mean MAR by taking a prescribed radius from the source (e.g $\sim 5 \mathrm{~km}, \sim 10 \mathrm{~km}$ ) generates standard deviations that actually exceed the calculated value. (i.e. $28 \pm 22 \mathrm{~g} \mathrm{~m}^{-2} \mathrm{y}^{-1}$ for $\mathrm{a} \sim 5 \mathrm{~km}$ radius, and $16 \pm 17 \mathrm{~g} \mathrm{~m}^{-2} \mathrm{y}^{-1}$ for a $\sim 10 \mathrm{~km}$ radius). Finer resolution sampling may help to refine localised plume extent, but whether this would provide any better insight to aeolian processes and dispersal for the region is questionable.

Around $38 \%$ of sampling sites fall within plumes oriented downwind from source areas, which represent $\sim 37 \%$ of the field area, and are considered localised accumulation. To find a MAR value representative of the wider field area (and potentially beyond) such localised features are ignored. Beyond plume areas MARs have a much lower variance. The frequncy distribution of MARs in Figure 4.4 shows the greatest frequency of MARs are $<2.0 \mathrm{~g} \mathrm{~m}^{-2} \mathrm{y}^{-1}$. By excluding MARs from localised plumes (i.e. MAR values $>2.0 \mathrm{~g} \mathrm{~m}^{-2} \mathrm{y}^{-1}$; shown within the red and orange distributions in Figure 4.2), a background aeolian sediment accumulation rate for the region, of 1.14 $\pm 0.57 \mathrm{~g} \mathrm{~m}^{-2} \mathrm{y}^{-1}$ is calculated.

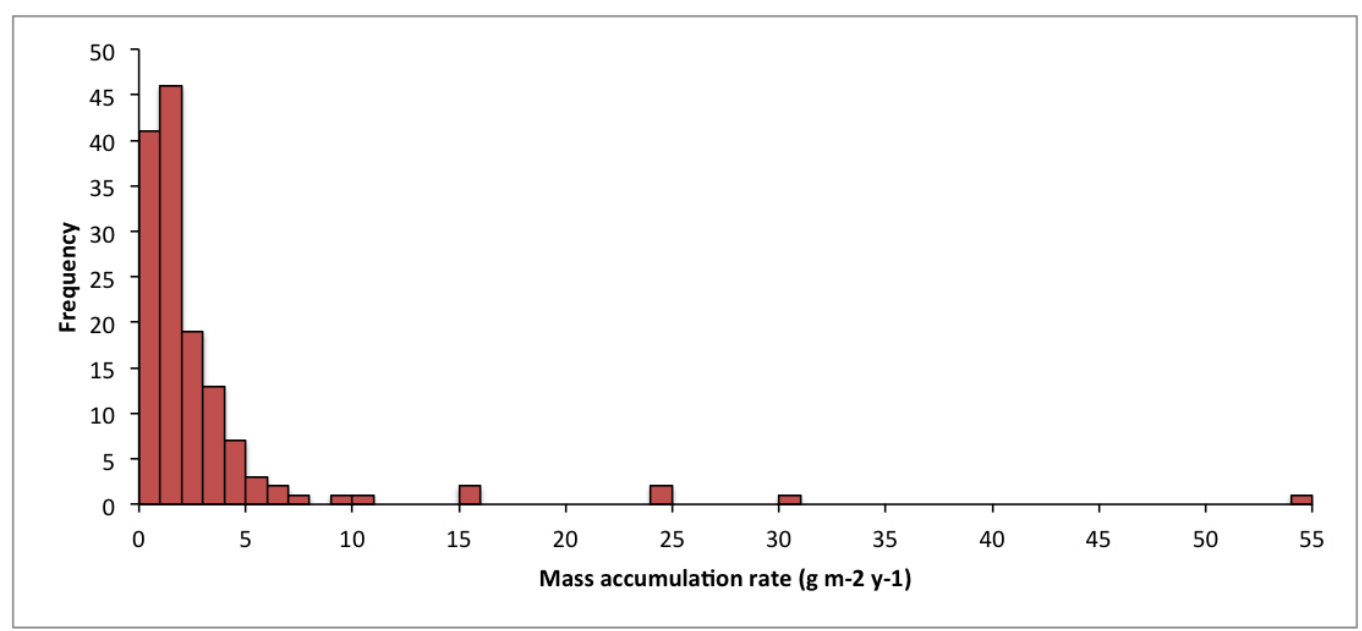

Figure 4.4: Graph showing frequency distribution of mass accumulation rates of aeolian sediment trapped on sea ice in McMurdo Sound, as sampled during OctoberNovember 2010. 


\subsection{Aeolian sediment provenance}

Polarised light microscope analysis of 35 smear slides from aeolian sediment samples, representative of the full field area, show a relatively homogenous aeolian sediment composition. Figure 4.5 shows the typical composition and texture seen on the smear slides. Table 4.2 provides a summary of the composition of the smear slides. The most pervasive grains were volcanic glass, which appeared to be common in 18 of the slides, rare in nine of the slides, and either present in trace quantities or absent in four of the slides.

By plotting the geographic distribution of volcanic glass abundance and extrapolating the data to the rest of the field area (Figure 4.6) a marked decrease in abundance appears to occur in samples north of Cape Roberts and into Granite Harbour, where volcanic glass is rare or absent. A few locations on the sea ice edge and in New Harbour also had volcanic glass present in trace amounts.

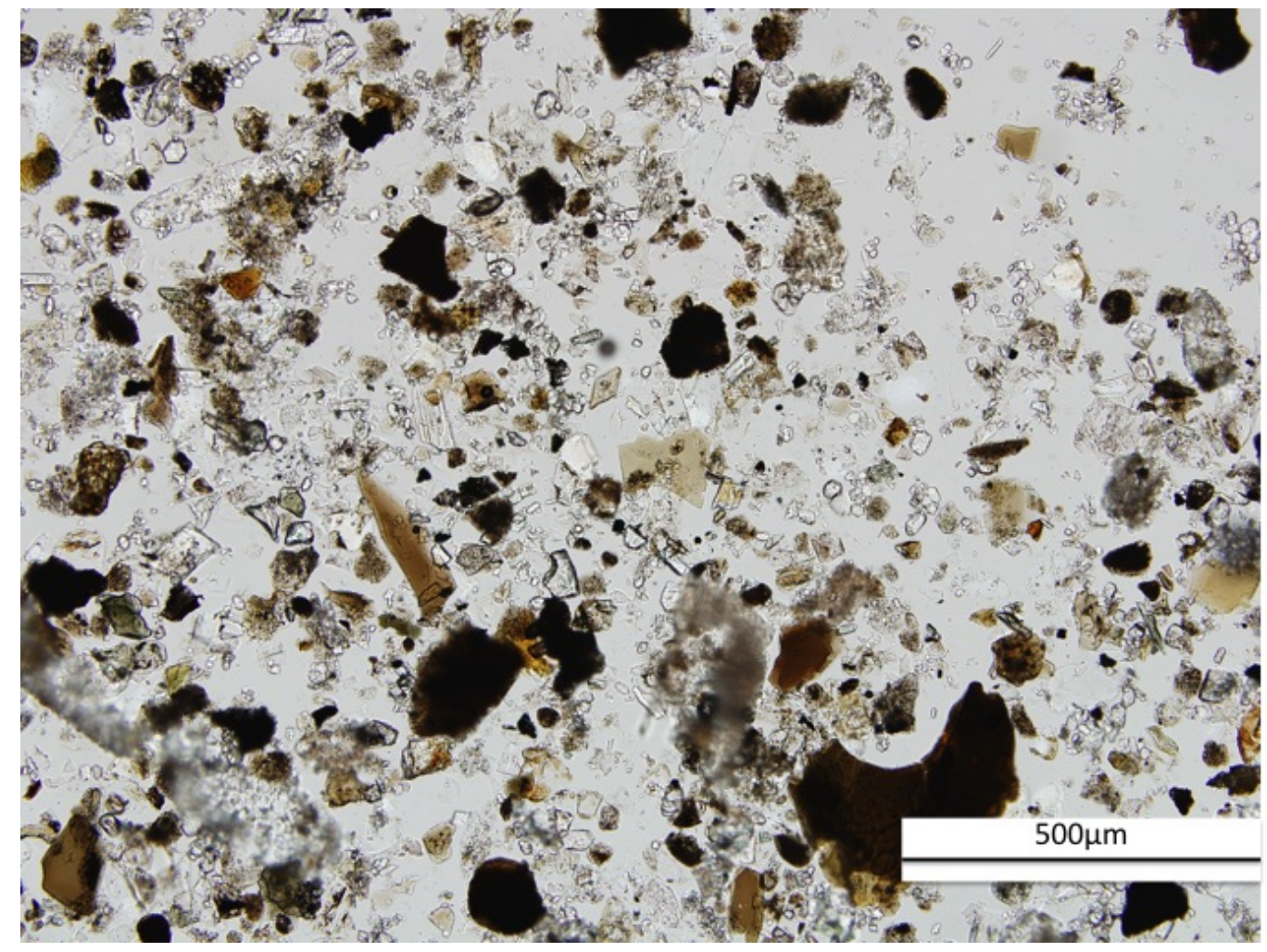

Figure 4.5: Photograph of sample CR-J11, taken using a microscope camera, showing composition and texture of aeolian sediment as seen in smear slides. Large crescent shaped particle (bottom right) is a volcanic glass shard, $\sim 300 \mu \mathrm{m}$ across. 
Table 4.2: Compositional features of aeolian sediment samples from analysis of 35 smear slides and visual description of individual bulk samples. Counts indicate how many slides had a component present out of 35 slides (minerals) and only 31 slides (volcanic glass). *NB. The four slides prepared by V. Winton were excluded from volcanic glass abundance analysis due to significant differences in slide sample volume.

\begin{tabular}{|c|c|c|}
\hline $\begin{array}{l}\text { Component } \\
\text { (smear slide) }\end{array}$ & $\begin{array}{l}\text { Mineral } \\
\text { incl. (no.) }\end{array}$ & Notes \\
\hline Volcanic Glass & 34 & brown \\
\hline Feldspar & 33 & sodic plagioclase, K-feldspar \\
\hline Quartz & 31 & occasional yellowed grains \\
\hline Opaques & 31 & haematite, basalt, ?heavy minerals, ?oxides \\
\hline Sponge Spicule & 29 & whole and fragmented \\
\hline Hornblende & 27 & occasional whole crystals \\
\hline Mica & 26 & $\begin{array}{l}\text { abundant biotite; common muscovite; occasional } \\
\text { chlorite }\end{array}$ \\
\hline Calcite & 18 & $\begin{array}{l}\text { abundant within sample; common snowflake habit, } \\
\text { occasional rhombohedral crystals }\end{array}$ \\
\hline Diatom & 18 & $\begin{array}{l}\text { whole and fragmented; sea ice, marine, and } \\
\text { terrestrial species }\end{array}$ \\
\hline Alteration & 15 & mineral oxidation \\
\hline Organic matter & 3 & probable algae from meltwater ponds \\
\hline \multicolumn{2}{|c|}{ Other minerals present } & amphibole, olivine, ?garnet, ?spinel \\
\hline \multicolumn{2}{|c|}{ Other biogenic grains present } & $\begin{array}{l}\text { silica flagellate dityocha, ?echinoderm appendage, } \\
\text { ?larval remains, ?worm tube, ?plastid }\end{array}$ \\
\hline $\begin{array}{l}\text { Volcanic glass } \\
\text { abundance* }\end{array}$ & $\begin{array}{c}\text { Glass } \\
\text { incl.(no.) }\end{array}$ & Notes \\
\hline Common & 18 & \\
\hline Rare & 9 & \\
\hline Very rare & 3 & contained negligible glass \\
\hline Absent & 1 & (nb. $3 \%=1$ smear slide) \\
\hline $\begin{array}{l}\text { Component } \\
\text { (sample) }\end{array}$ & & Notes \\
\hline Bryophyte moss & rare & found in one sample, $5 \mathrm{~km}$ off Cape Bernacchi \\
\hline Calcite (coarse) & rare & $\begin{array}{l}\text { found mostly in samples at sea ice edge; } \\
\text { relatively large, degraded rhombohedral crystals, } \\
\text { some spheroidal holes, rounded corners }\end{array}$ \\
\hline
\end{tabular}




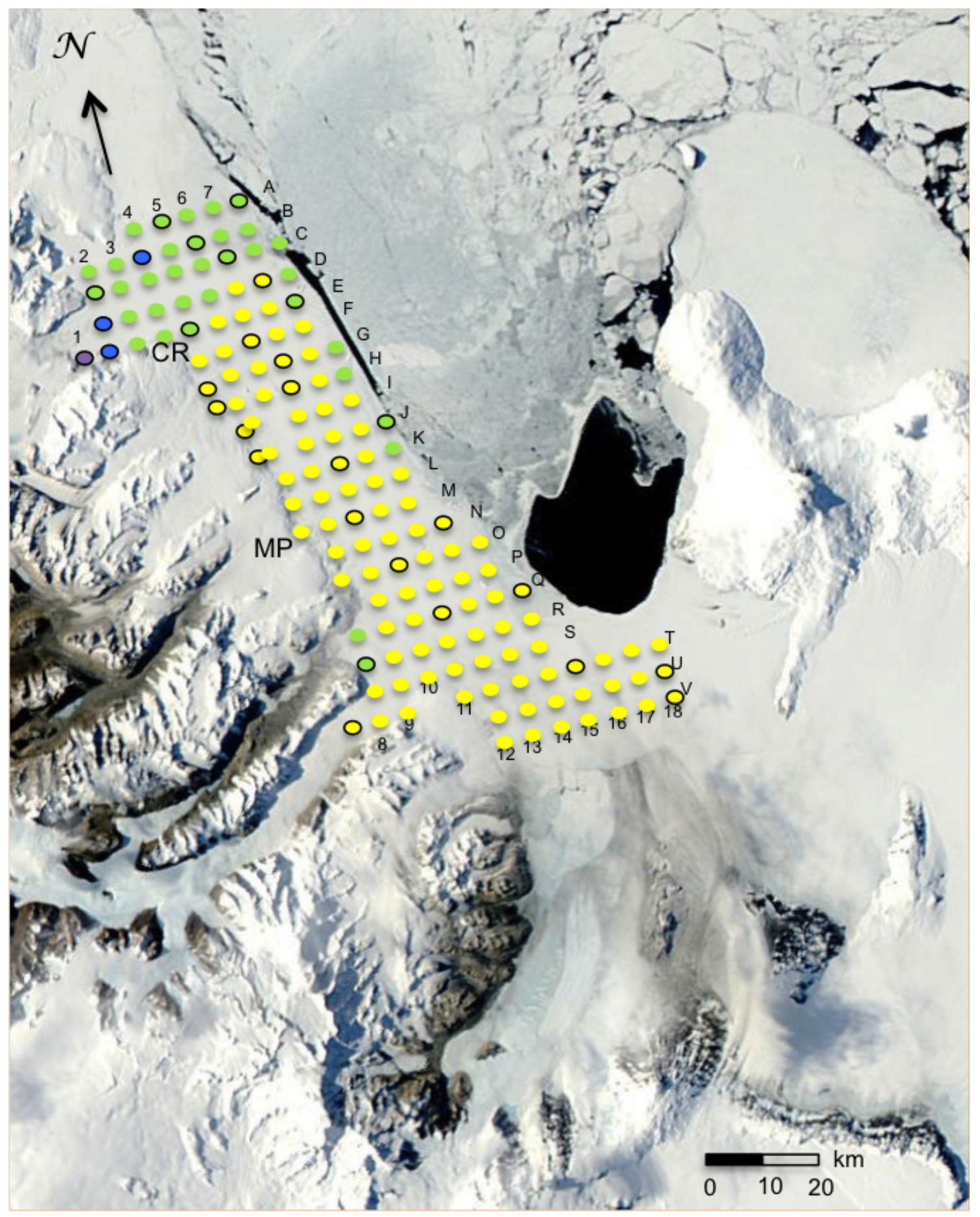

Figure 4.6: Plot of volcanic glass as qualitatively assessed from abundance found in smear slides of aeolian sediment samples. Points with black outline indicates sample point data from which extrapolation to full field area was derived. Points without black outline are inferred from analysed data points. Dot colour key: yellow $=$ common, green $=$ rare, blue $=$ present, and, purple $=$ absent . 
Quartz was common throughout the field area. There appeared to be a slight increase in abundance of quartz for samples from Granite Harbour; however, no spatial trend is apparent in those few places where quartz was absent. All mineral grains were typically angular to sub angular, with occasional sub rounded grains, particularly biotite. Well-rounded sand grains (mostly quartz) occur in the coarsest samples from locations within $5 \mathrm{~km}$ of the Scott Coast (Cape Bernacchi to Spike Cape), suggesting inheritance from the Beacon Sandstone. Similar rounded sand grains were also seen in samples adjacent to the McMurdo Ice Shelf, suggesting a contribution from Beacon sandstone erratics on the debris bands.

A selection of biogenic components found on the smear slides is shown in Figure 4.7. The most abundant were siliceous sponge spicules ( $83 \%$ of slides contained sponge spicules) and diatom frustules (51\% of slides contained diatoms), as well as trace amounts of other biogenic material. Sponge spicules were often broken, with larger and more intact examples found near the McMurdo Ice Shelf or near the coast. Samples containing diatoms, both whole and broken, were most common at locations to the north and northeast of the Scott Coast, and to the north of the McMurdo Ice Shelf debris bands. Notable amongst the other non-mineral grains that could be identified with any certainty was microscopic plant material found in one sample off the Cape Bernacchi coast. This was identified as probable bryophytic moss remains (Figure 4.7-p), which are commonly distributed by the wind on land (I. Hawes, pers. comm., 2012).

Two samples contained particularly abundant diatoms: 1) sample CR-E5, located near a seal colony near Cape Roberts contained almost exclusively sea ice and marine species, the exception being one testate amoebae which had an extensive covering of freshwater diatoms; and 2) sample MP-U13, situated in southern McMurdo Sound near the McMurdo Ice Shelf, contained marine, sea ice and freshwater species. Identification of all diatoms was attempted, but poor preservation, the thickness of mounts, and the refractive index of the mounting medium meant identification beyond general form was not possible in many instances. Of the diatoms found, the forms listed in Table 4.3 were identified to species level (by Dr. M.A. Harper, pers. comm., 2012). More detail on diatoms is given in Appendix D, including frequency of appearance and primary dimension. 


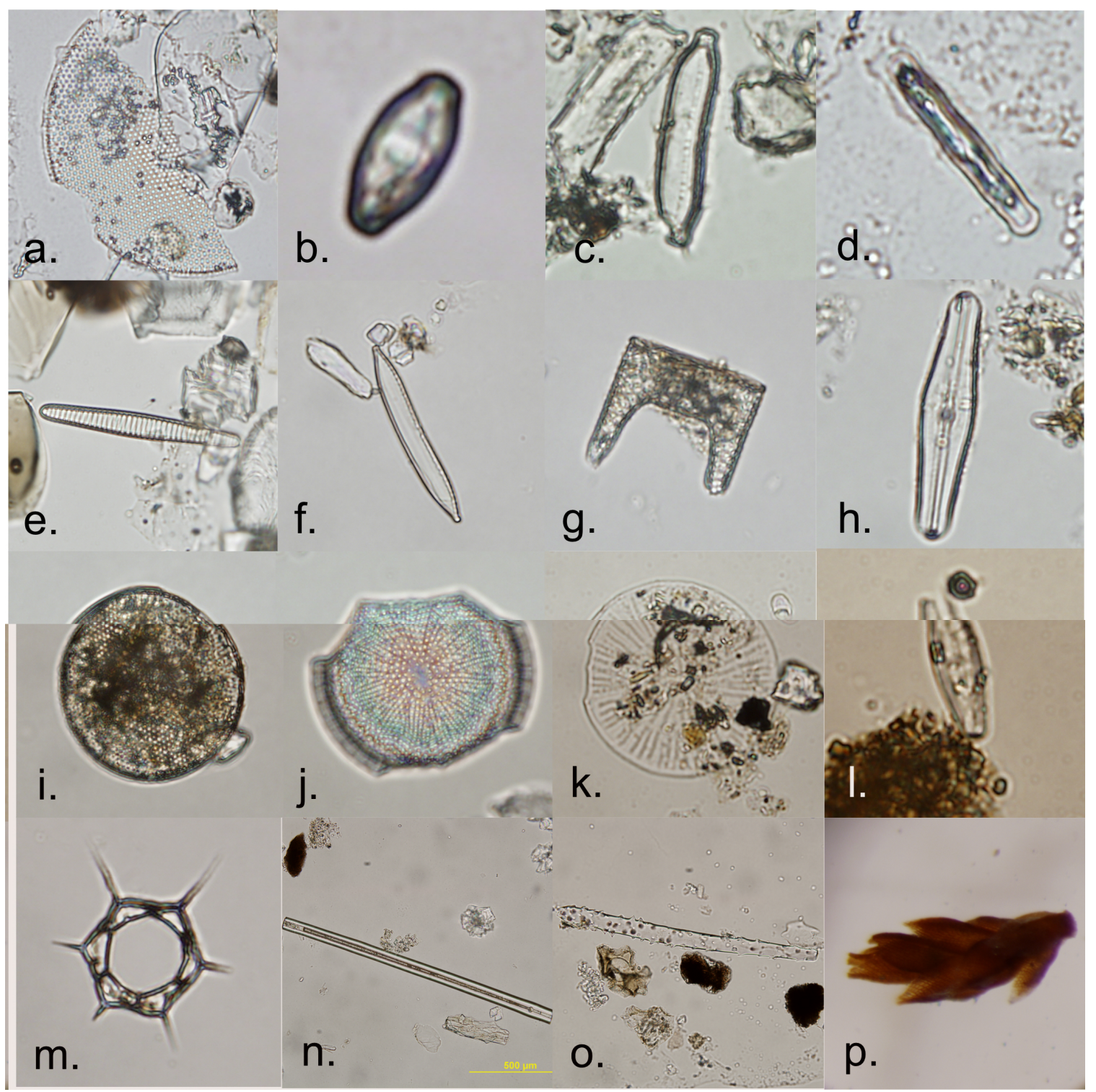

Figure 4.7: Photographs of non-mineral composition elements of aeolian sediment samples: a.) CR-E5: diatom fragment Coscinodiscus sp.?, $\sim 100 \mu \mathrm{m}$ diameter; b.) CRC2: diatom Luticola cf.cohnii var. 1, $\sim 14 \mu \mathrm{m}$ length; c.) CR-C2: diatom cf. Hantzschia amphioxys $c f$. f. muelleri, $\sim 50 \mu \mathrm{m}$ length; d.) CR-D8: diatom $c f$. Chamaepinnularia cymatapleura, $\sim 34 \mu \mathrm{m}$ length; e.) CR-E5: diatom $c f$. Fragilariopsis obliquecostata, $\sim 70 \mu \mathrm{m}$ length; f.) CR-E9: diatom $c f$. Nitzschia westii, $\sim 70 \mu \mathrm{m}$ length; g.) CRH5: diatom Eucampia antarctica, $\sim 36 \mu \mathrm{m}$ width; h.) CR-H8: diatom $c f$. Muelleria peraustralis, $\sim 55 \mu \mathrm{m}$ length; i.) MP-K8: diatom cf. Thalossiosira cf. tumida, $\sim 64$ $\mu \mathrm{m}$ diameter; j.) MPK8: diatom fragment Actinocyclus, $\sim 53 \mu \mathrm{m}$ diameter; k.) MPU13: diatom $c f$. Actinocyclus, $\sim 70 \mu \mathrm{m}$ diameter; 1.) MP-U13: diatom Luticola $c f$. muticopsis/mutica, $\sim 27 \mu \mathrm{m}$ length; m.) MP-K8: Silicoflagellate Dictyocha, $\sim 54 \mu \mathrm{m}$ body width excluding spines; $n$.) CR-E5: sponge spicule, $\sim 1,375 \mu$ m length; o.) CRA8: cf. Echinoderm appendage, $\sim 1,110 \mu$ m length; and, p.) MP-O8: Bryophytic moss particle, $\sim 2,400 \mu \mathrm{m}$ length. (References provided in text.) 
Table 4.3: Diatoms found in aeolian sediment samples, as identified from 31 smear slides representing the full field area. Habitat and endemism are also indicated. At least one whole specimen found within slides, unless indicated.

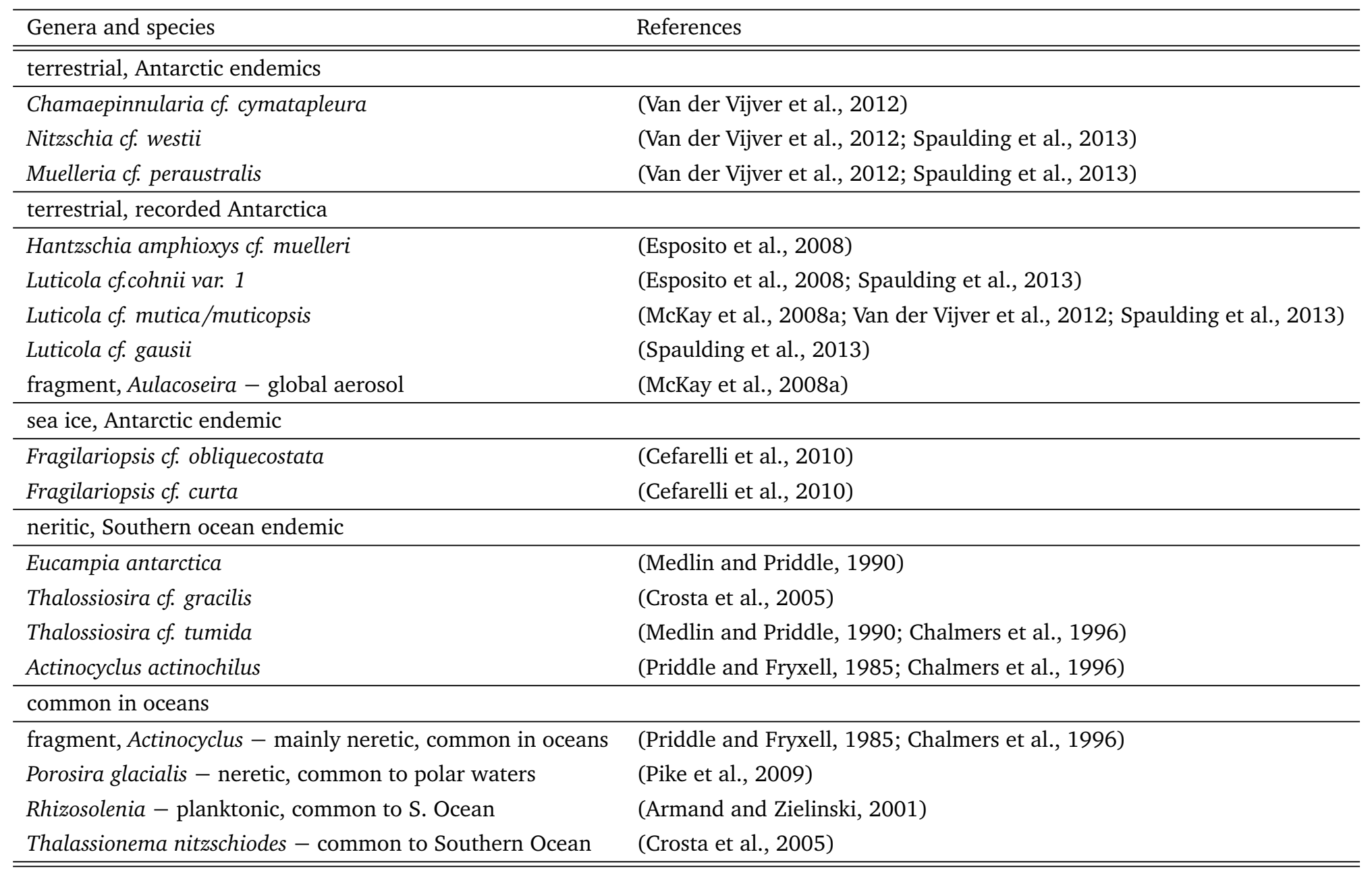




\subsection{Patterns in aeolian sediment grain size}

\subsubsection{General features of grain size distribution}

Laser diffraction grain size analysis of 32 aeolian sediment samples distributed across the field area show most samples are fine sand to silt (Figure 4.8). The grain size distributions of all samples show a common distinctive shape with a marked modal peak in the very-fine sand to coarse silt range, and a broad fine to medium silt component. Particles $>250 \mu \mathrm{m}$ are rare, equating to $\sim 2 \%$ of total samples analysed. The finest grains were clay particles coarser than $>0.87 \mu \mathrm{m}$. One sample (MP-P11) contained material as small as $0.45 \mu \mathrm{m}$; however, this sample included $\sim 10 \%$ white particulates, as described in Section 3.5, so it has been ignored.

\subsubsection{Spatial patterns in grain size data}

Plotting the grain size distribution over the field area reveals there are several "coarse" plumes of sediment. These may reflect potential aeolian transport pathways. Figure 4.9 shows four transects extending offshore from sediment source areas. The coarsest material (sand) is found close to source, with the distribution becoming finer with distance away from the coast. Generally accumulation of sand does not extend more than $\sim 5 \mathrm{~km}$ beyond source areas and plumes quickly fine to silt. Once a predominance of silt is achieved, less variability is evident.

The one anomolous offshore trend appears in the northern-most transect (Figure 4.9 A) where the centre sampling point (CR-C5) is coarser than the site closest to the coast (CR-E3). As other sites (not shown on the figure) directly south of CR-C5, do not show the same trend, but sites to the west of CR-C5 contain a similarly "coarse" distribution, the sand may have originated from Granite Harbour sources (possibly the Kar Plateau, $\sim 20 \mathrm{~km}$ directly west of CR-C5, or sources near the Mackay Glacier tongue, $\sim 20 \mathrm{~km}$ southwest of CR-C5).

A contour map of relative abundances of material coarser than $63 \mu \mathrm{m}$ (the grain size boundary between silt and sand) was drafted to observe spatial distributions of different grain size populations (Figure 4.10). This method was used to determine if modal populations relate to spatial distribution of MAR data and wind field patterns, and also to deduce if modal populations can suggest a transport/ energy threshold within the system. When the data are plotted for modal populations coarser than 63 $\mu \mathrm{m}$, as shown in Figure 4.10, three distinct concentrations of relatively coarse material are evident: 1) northeast of the McMurdo Ice Shelf, 2) off the Cape Bernacchi to Spike 
Cape coastline, and 3) a band extending northwest from Granite Harbour to Cape Archer. Graphically representing the data in this way also indicates a general fining seaward, with the finest values found along the sea ice edge. Two areas of relatively fine material are also indicated near to the coast: 1) off Bowers Piedmont extending southeast to the Dailey Islands in southwest McMurdo Sound, and 2) in northwest Granite Harbour between Kar Plateau and Cape Archer. 


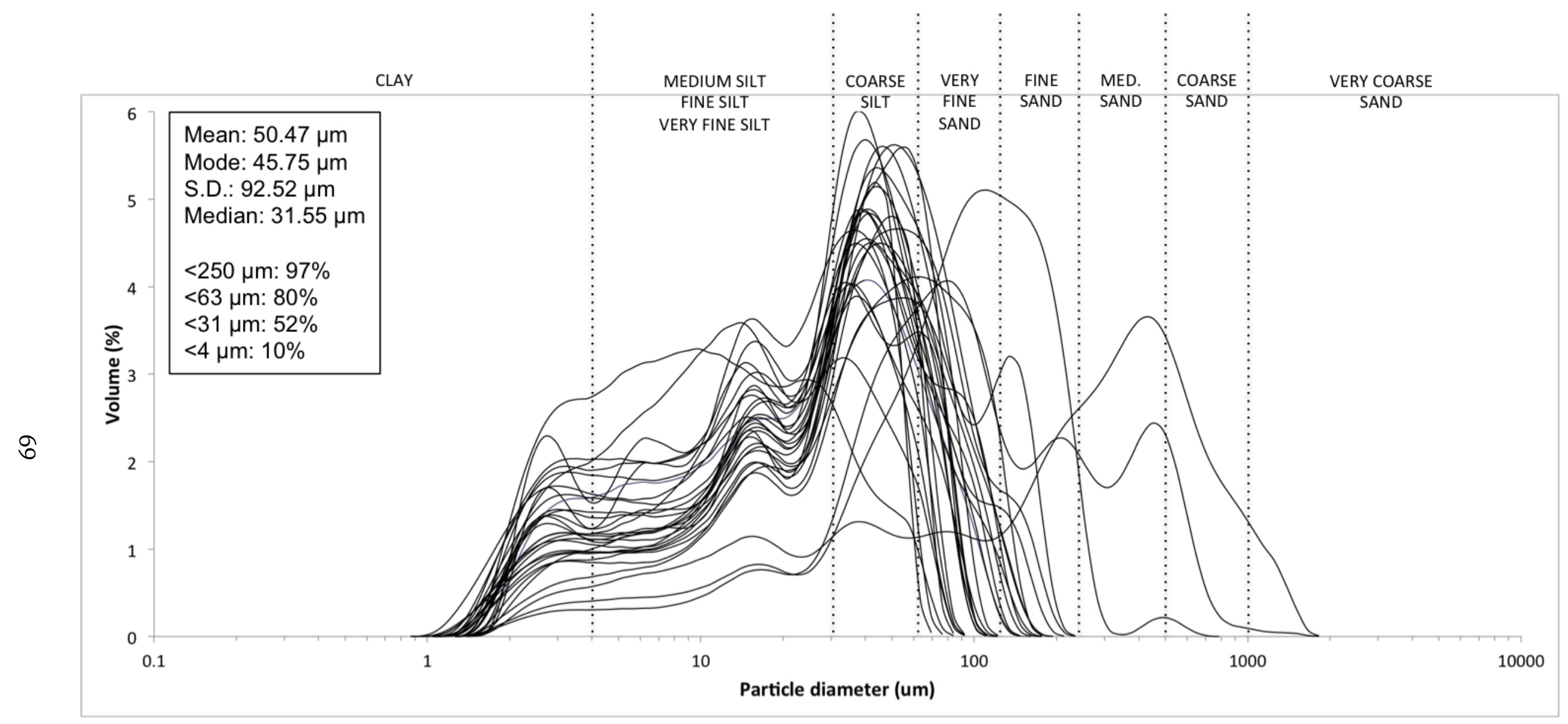

Figure 4.8: Histogram of 31 aeolian sediment sample grain size data from western McMurdo Sound. Grain size data from Beckman-Coulter LS13 320 laser diffraction particle size analysis. Samples included are: CR-A7, CR-B2, CR-C3, CR-C5, CR-D7, CR-E3, CR-F5, CR-F8, CR-G6, CR-H9, CR-J6.5, CR-J10, MP-K9, MP-L8, MP-L9, MP-L11, MP-M7, MP-N8, MP-N10, MP-O12, MP-P10, MP-Q8, MP-R12, MP-R14, MP-29, MP-T11, MP-T13, MP-T16, MP-U18, MP-V13, and MP-V16. (MP-P11-excluded due to suspected contamination by white particulates.) Grain size data is presented in Appendix C. 


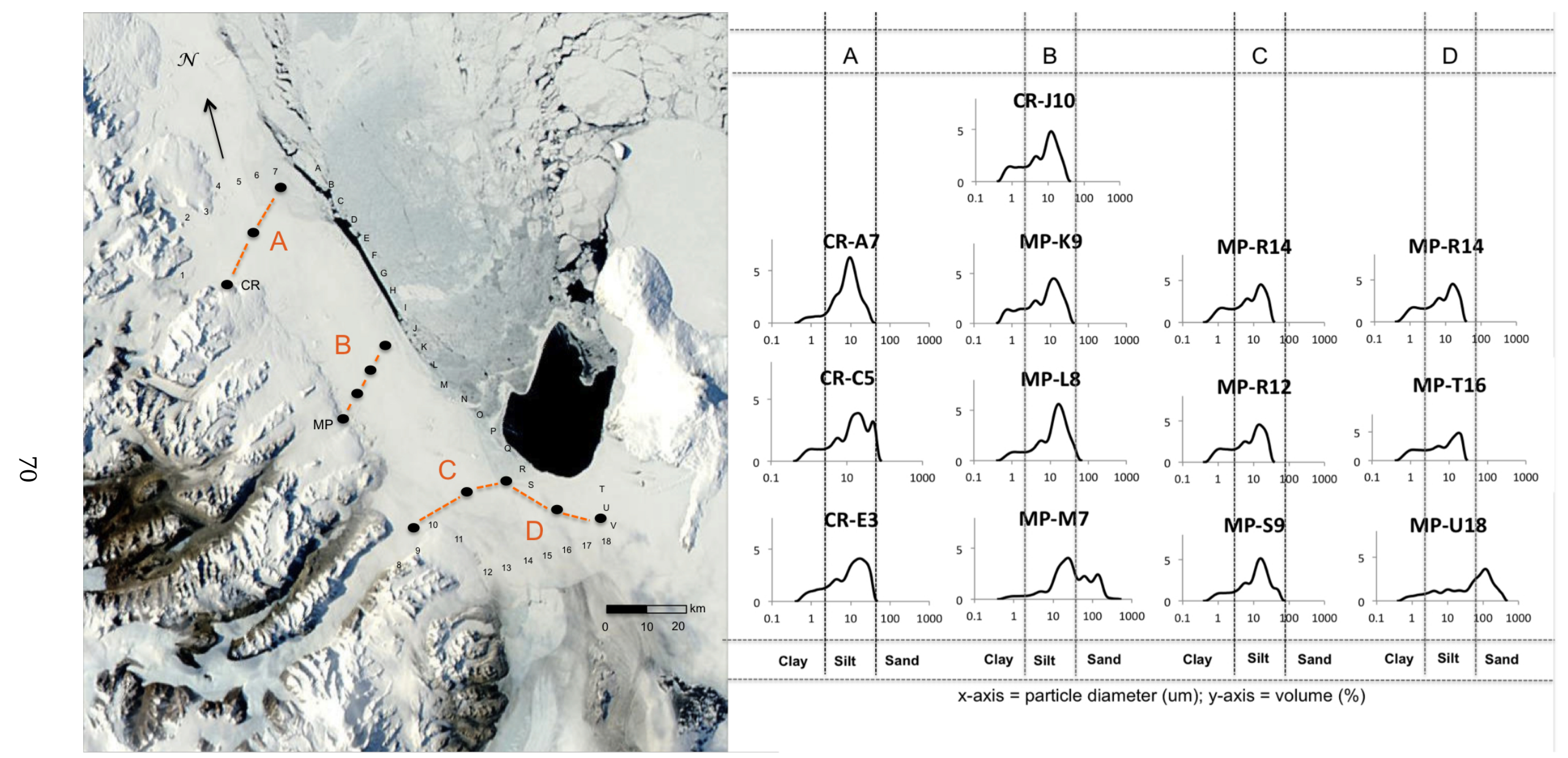

Figure 4.9: Four transects illustrating aeolian sediment fining with distance away from the coast. Transects positioned from observed sources at $\mathrm{A}=$ Cape Roberts, $\mathrm{B}=$ Gneiss/Marble Points, $\mathrm{C}=\mathrm{New}$ Harbour, and $\mathrm{D}=$ McMurdo Ice Shelf, with corresponding histograms of grain size frequency. Black dots=sample sites relating to the histograms shown at right. Sample IDs are written CR or MP for base camp, A to V for west-east transect, and 1-18 for south-north line. 


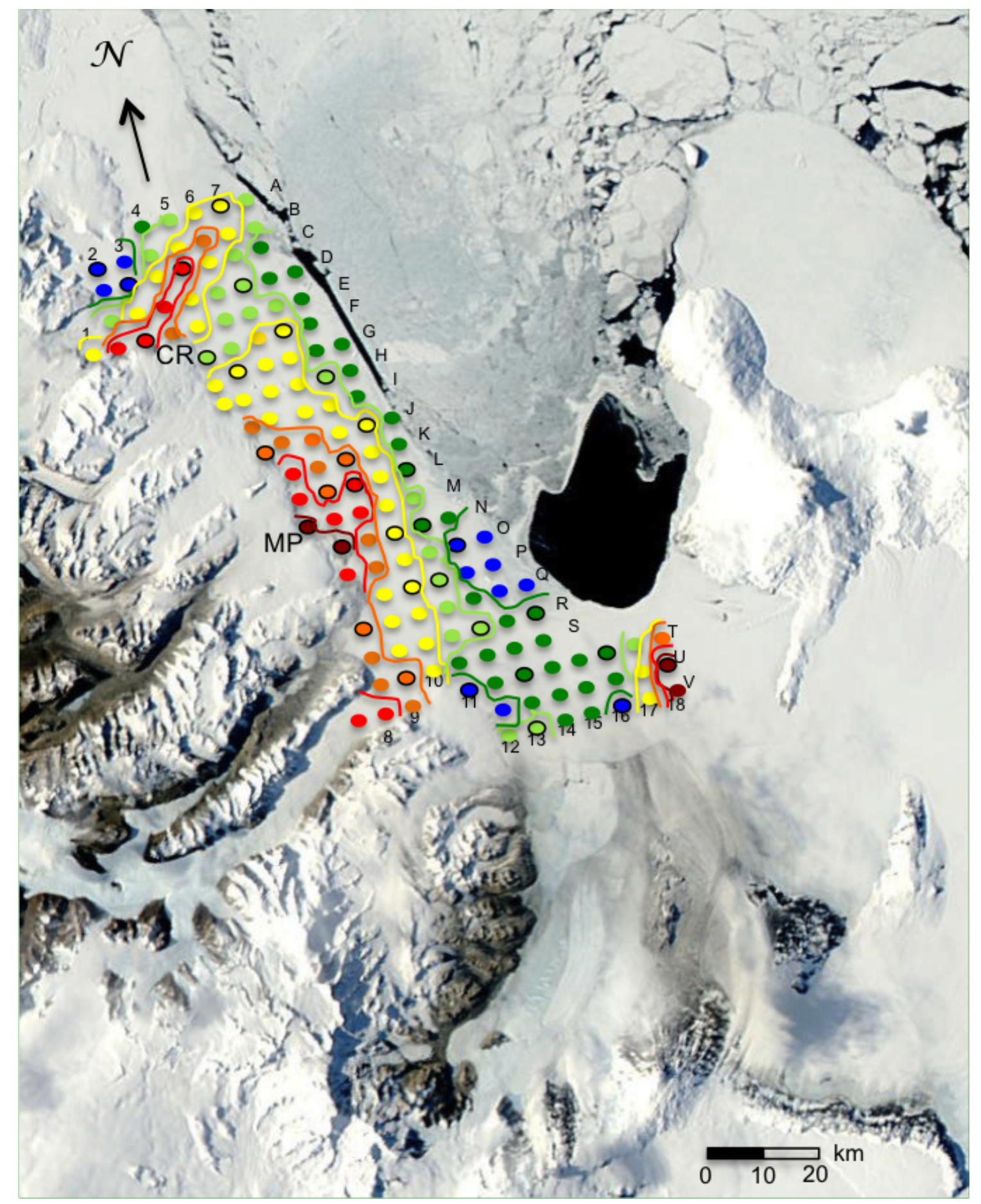

Figure 4.10: Contour map showing percent sand in each sample. Black outline indicates sample point data from which extrapolation was derived. Contour lines are interpolated from point data. Value for points without black outline are inferred. Dot colour key: dark red $=>50 \%$, red $=30-49 \%$, orange $=20-29 \%$, yellow $=10-19 \%$, light green $=5-9 \%$, green $=2-4 \%$, and, blue $=0-4 \%$. Values are the sample percentage of sediment $>63 \mu \mathrm{m}$. 


\subsection{Summary of empirical results}

Aeolian sediment MAR data show high km-scale variability. The highest MARs are found along the coastal margins, with the largest MAR $\left(54.6 \mathrm{~g} \mathrm{~m}^{-2} \mathrm{y}^{-1}\right)$ found near Gneiss Point. Thirty eight percent of samples, including the highest MARs, define plumes extending seawards from the Scott Coast between Cape Bernacchi and Spike Cape, and north of the McMurdo Ice Shelf debris bands. A band of low accumulation, including the lowest MAR $\left(0.15 \mathrm{~g} \mathrm{~m}^{-2} \mathrm{y}^{-1}\right)$ is seen in central Granite Harbour extending east into the Ross Sea. A background aeolian sediment MAR of $1.14 \pm$ $0.57 \mathrm{~g} \mathrm{~m}^{-2} \mathrm{y}^{-1}$ is calculated for the entire field area excluding elevated values from localised accumulation.

Analysis of smear slides of aeolian sediment samples shows a relatively homogenous aeolian sediment composition for the field area, with volcanic grains being the most extensively distributed material but not the most common component in each sample. Quartz and feldspar were similarly widespread, with hornblende, micas and opaques being subordinate. Calcite was present in approximately half of the slides, with the marble of Marble Point being a potential source for this mineral. Spatial patterns were not obvious, except for, 1) volcanic glass which is common for southern and central McMurdo Sound, but rare north of Cape Roberts and into Granite Harbour, and 2) calcite was seen in greatest abundance along the sea ice edge.

Grains were typically angular to sub-angular, with sub-rounded grains seen occasionally. Some well-rounded quartz sand grains were found in samples along the coastal margin. Biogenic components included freshwater diatoms, including species endemic to southern Victoria Land, found within the MDV and on the McMurdo Ice Shelf. Bryophitic moss remains were also found in one sample, most probably sourced from the Cape Bernacchi coastal area where it is known to grow.

The grain size distributions of aeolian sediment samples show distinctive fine sand to coarse silt modal peaks, with subordinate, broad very -fine to medium silt tail. Of the total sample mass analysed, only $\sim 2 \%$ was coarser than $>250 \mu \mathrm{m}$, with rare grains as large as $2,000 \mu \mathrm{m}$. The finest particles were clay $>0.87 \mu \mathrm{m}$. Spatial patterns within the grain size data show plumes of sand extending seawards from the Scott Coast between Cape Bernacchi and Spike Cape, and less clearly northwest of the McMurdo Ice Shelf debris bands, and from southwest Granite Harbour to Cape Archer. A general fining seawards was also apparent, with the finest values found at the sea ice edge. Pockets of relatively fine material were also evident in two areas northwest Granite Harbour, and in southwest McMurdo Sound near Bowers Piedmont. 


\section{Part II}

\section{Physical process modelling}





\section{Chapter 5 Numerical modelling of aeolian sediment dis- persal}

\subsection{Numerical dust transport modelling in Antarctica}

Numerical modelling is an important tool for understanding physical sedimentation in the extreme environment of Antarctica because it provides an opportunity to, 1) isolate specific environmental parameters (e.g. wind speed, source sediment characteristics) and systematically assess the sensitivity of each within the overall sedimentary system, and 2) assist with projecting sedimentation patterns into regions where year-round in situ observations have not been possible. However, to date there have been few modelling studies specifically interested in the role of aeolian sediment distribution from sources in Antarctica.

The few Antarctic aeolian sediment dispersal models that exist have concentrated on qualifying origin, variability and magnitude of global atmospheric dust and aerosol deposition, at a relatively coarse-resolution (Genthon, 1992; Mahowald et al., 1999; Lunt and Valdes, 2001; Li et al., 2008). Most of these models have been developed to understand temporal fluxes over glacial-interglacial timescales of dust deposition to the Antarctic ice sheets from global sources (e.g. Genthon 1992; Lunt and Valdes 2001; Bauer and Ganopolski 2010; Li et al. 2010; Albani et al. 2012) and to better understand dust deposition to the southern high latitude oceans (e.g. Gassó and Stein 2007; Johnson et al. 2010). Figure 5.1 illustrates the current understanding of atmospheric dust distribution to Antarctica and the Southern Ocean from present day Southern Hemisphere sources.

Air-mass back trajectories and global atmospheric circulation models modified to simulate wind erosion and suspended dust transport, are the most common modelling methods, though conceptual models have also been proposed (e.g. Iriondo 2000; Ayling 2001; Fischer et al. 2007). As only sediment smaller than $12 \mu \mathrm{m}$ is typically found at sites $>500 \mathrm{~km}$ from source, global-scale dust transport models generally 

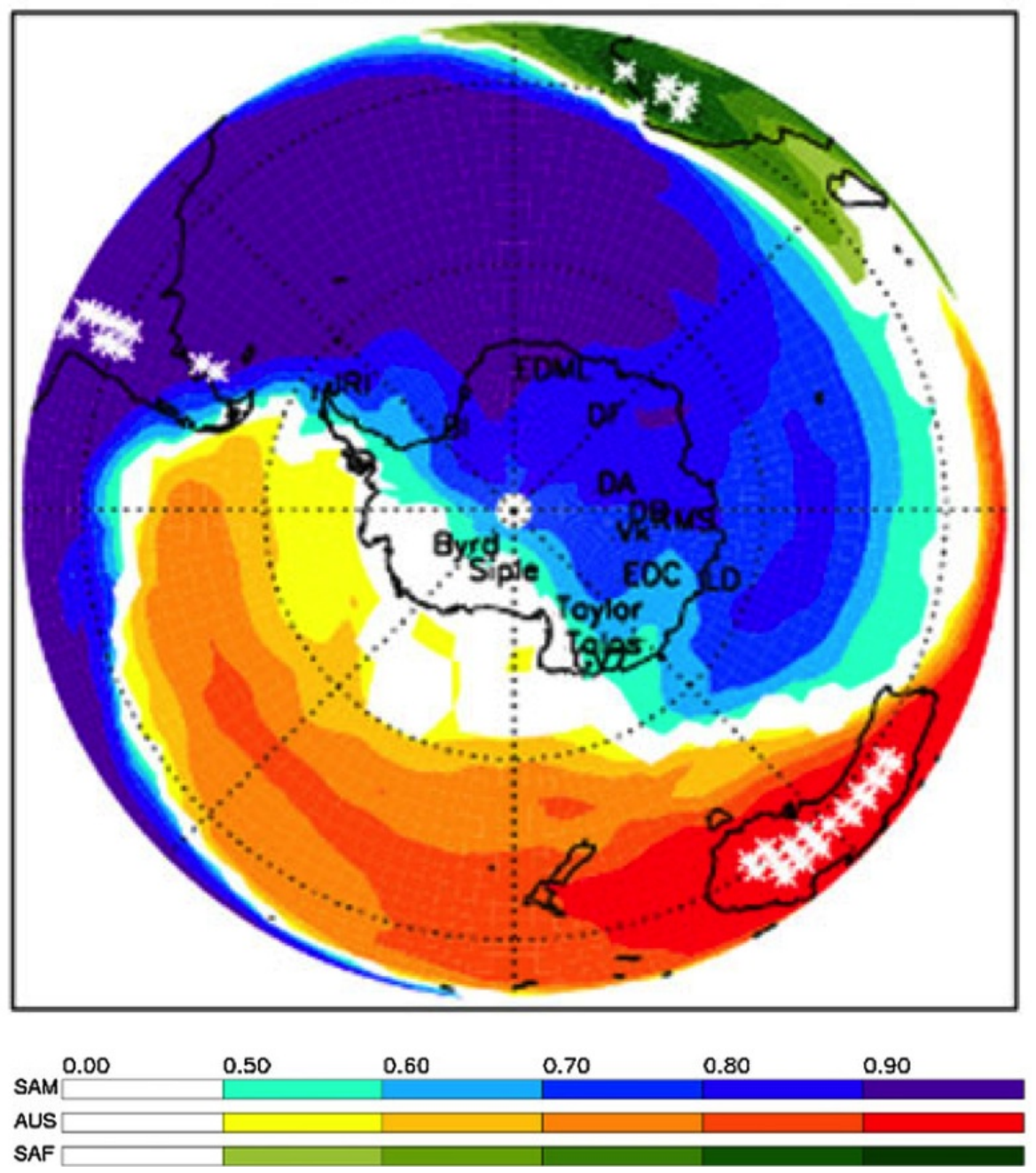

Figure 5.1: Map for relative contribution of three Southern Hemisphere sources to dust deposition in the Southern Hemisphere (present climate), represented by the relative fractions to the total deposition flux, of dust sourced from South America (blue colour scale), Australia (red colour scale) and South Africa (green colour scale). Coloured areas indicate that at least half of the deposited dust originated from the corresponding source area. White stars represent active sources for dust mobilization. From Albani et al. (2012).

ignore coarser material (Nickling, 1994; Mahowald et al., 2009).

\subsection{Model development for this thesis}

A two-dimensional aeolian sediment transport model, Numerical Model for Aeolian Sediment Transport and Evolution (NaMASTE), was written by Dr. Nicholas Golledge (Golledge, 2012) specifically to numerically predict sediment transport within the 
McMurdo Sound and southwest Ross Sea region over a $\sim 100,000 \mathrm{~km}^{2}$ area. This study is the first application of the model. Additional detail on NaMASTE not included in this chapter is given in Appendix $\mathrm{J}$.

By using NaMASTE to explore local and regional wind systems in terms of their ability to move sediment from local sources to the sea ice, and validating the model with empirical field data, a better understanding of aeolian sediment transport processes and dispersal from sources in McMurdo Sound is obtained. Modelling results are provided in Chapter 6 .

\subsubsection{Context and aims}

This study differs to modelling found in the literature (outlined above) in that it attempts to numerically model transport of relatively coarse-grained aeolian material from local sources within Antarctica to sea ice using localised wind fields. Model parameters are constrained by empirical data and focus solely on aeolian sediment dispersal to the southwest Ross Sea sector of the Southern Ocean.

Mechanisms of aeolian sediment dispersal in McMurdo Sound are not well-known. In order to most clearly isolate the effects of each component of the system, initial model experiments employed a number of simplifications (Subsection 5.4.2). Modelling aims for this study were two-fold. Firstly, NaMASTE's capability to simulate aeolian processes required evaluation. This was achieved through a series of sensitivity tests simulating sediment movement by wind within the local physical system. Secondly, the model was used to predict aeolian sediment dispersal within and beyond the field-sampling area from discrete point sources under both 'normal' (annual mean) and 'perturbed' (storm event) conditions. This involved producing modelled sediment distributions that could be compared to, though not expressly to replicate, the empirical dataset and thereby provide validation of model performance.

\subsection{Aeolian sediment transport modelling}

\subsubsection{Seminal empirical studies of aeolian sediment transport}

NaMASTE is based on the semi-empirical physical equations of sand and dust transport developed by Bagnold (1941) from boundary-layer theory and observations of wind-tunnel tests and natural sand transport in desert dune fields, as described in detail in Chapter 2, The NaMASTE spatial model of aeolian sediment dispersal uses 
differences between sediment and air densities to calculate a theoretical entrainment velocity for each modelled ("grouped") grain size category. Wind shear velocity at the air-land/ice interface is computed as a log-function of height (after Bagnold, 1941) using Antarctic Mesoscale Predictive System (AMPS) data (Monaghan et al., 2005).

Where shear velocity exceeds entrainment velocity, transport by saltation is assumed, yielding saltation fluxes proportional to the cube of shear velocity. Where saltation parameters are met, but grain size is $<100 \mu \mathrm{m}$, fluxes from suspension are also calculated. By limiting the total flux to not exceed that sediment available for transport, the sum of these two fluxes provides a net flux for each cell within the domain. Retention in the model environment is a user-defined variable, where the default behaviour produces accumulation as a result of the balance of fluxes. A portion of the net sediment flux is retained within each cell over time; therefore, removing this sediment from further transport and adding it to the total accumulation for a given cell.

It should be noted, a complete understanding of the fundamentals of aeolian sediment transport has yet to be achieved (Ellis et al., 2012). Though important advancements have been made in describing the complex interactions between sediment and wind, how additional land surface processes (e.g. cohesion) affect aeolian entrainment and the wind velocity profile have yet to be generally resolved (e.g. Greeley and Iversen 1985; Anderson and Hallet 1986; Shao and Lu 2000; Raupach and Lu 2004; Sherman and Li 2012).

Because of the high degree of variability of complicating land surface factors, and the problem of scaling-up numerical models from grain-scale to broader applications, particularly over large distances (Li et al., 2008; Ellis et al., 2012), the semi-empirical relationships outlined by Bagnold (1941) continue to provide the closest approximation to real-world processes of available models, albeit under idealised conditions (Sherman and Li, 2012). Accordingly, when investigating aeolian processes at an area-regional scale, the well-tested physical theory of Bagnold (1941) continues to be the logical foundation from which a model can be developed.

\subsection{Model description}

\subsubsection{Model domain and input data}

NaMASTE operates using input AMPS archived real-time numerical weather prediction forecasts (e.g. air temperature, wind velocities and direction) based on local observations, other parameters are user-defined (e.g. sediment supply locations and rates, 
grain sizes, multipliers; as detailed in Subsection 5.4.3). NaMASTE calculates aeolian sediment transport in two horizontal dimensions using a finite difference numerical scheme. Finite differences can be used as a means to solve differential equations. Such equations are concerned with finding rates of change and are dependent on changes to independent variables. Finite differences are found by approximating partial derivitives (incremental rates of change) to different degrees. The finite difference approach, therefore, allows evolving rates-of-change of model parameters to be calculated over discrete distances, such as between nodes on a regularly spaced grid (Abbott and Wardle, 1970; Smith, 2010).

NaMASTE uses local wind field data, normalised to a height of $10 \mathrm{~m}$ above ground, from the AMPS 2002-2006 archive of numerical weather model forecasts (Monaghan et al., 2005) and sediment transport physics as mentioned above. The AMPS domain used in the model is shown in Figure 5.2. The 3.3-km grid resolution used in NaMASTE is shown in Figure 5.2-d. This resolution is comparable to the $5 \mathrm{~km}$ resolution of the empirical sample set collected in western McMurdo Sound for this study and is sufficient to gain insight into regional aeolian sediment transport patterns. Figure 5.3 shows the NaMASTE model domain containing the 85(i) x 115(j) grid cells as denoted by axis tick marks. Geographical features are labelled and a colour scale titled 'dust concentration' relating to sediment accumulation is shown. The domain includes local topography, shown by elevation contours, of Ross Island, MVG provinces and the southern MDV. It assumes a flat, planar surface at sea level, to replicate winter sea ice conditions. 
a) AMPS domains

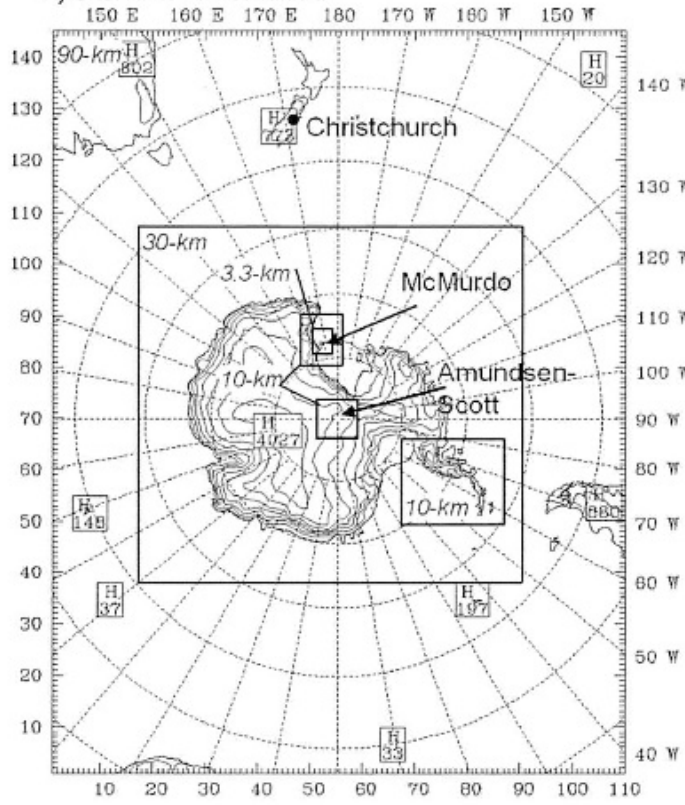

c) AMPS 30-km model topography

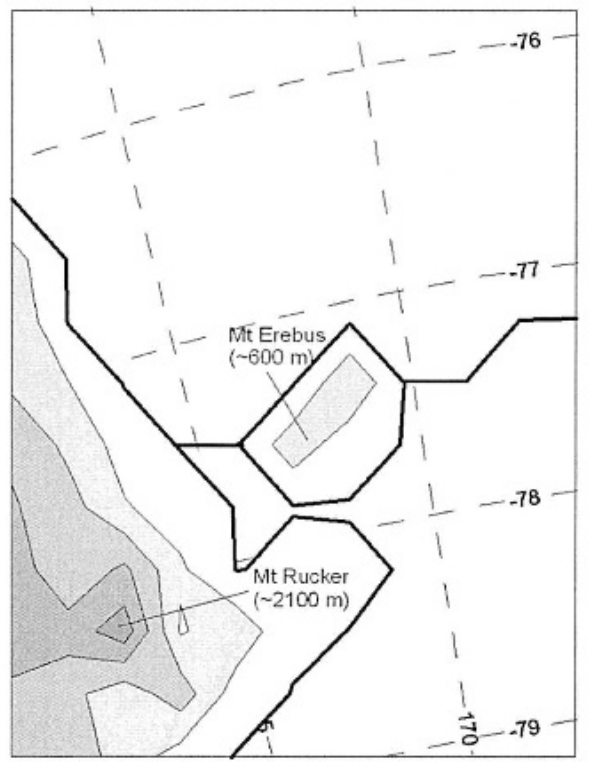

b) RAMP DEM ("observed") topography

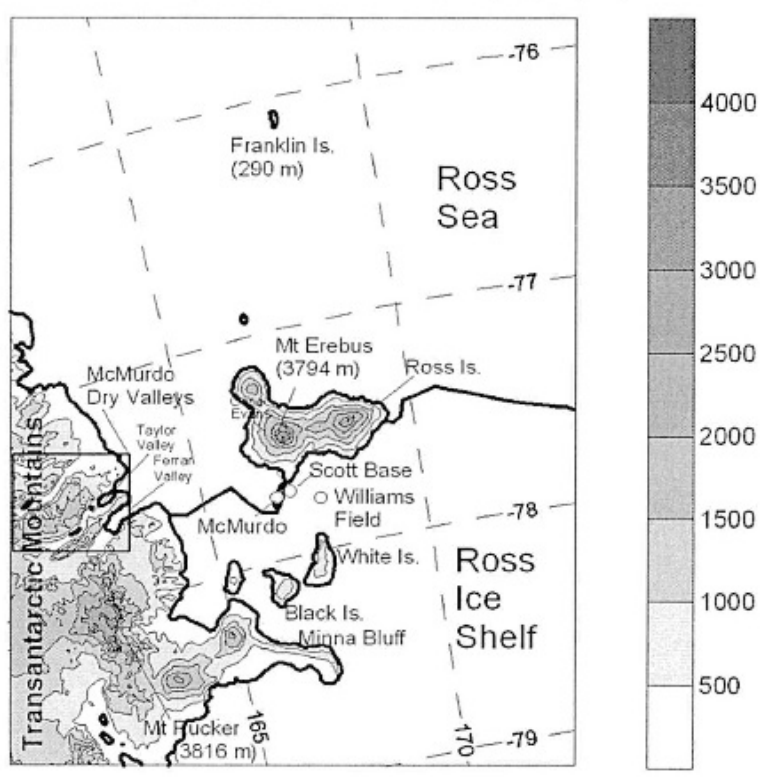

d) AMPS 3.3-km model topography

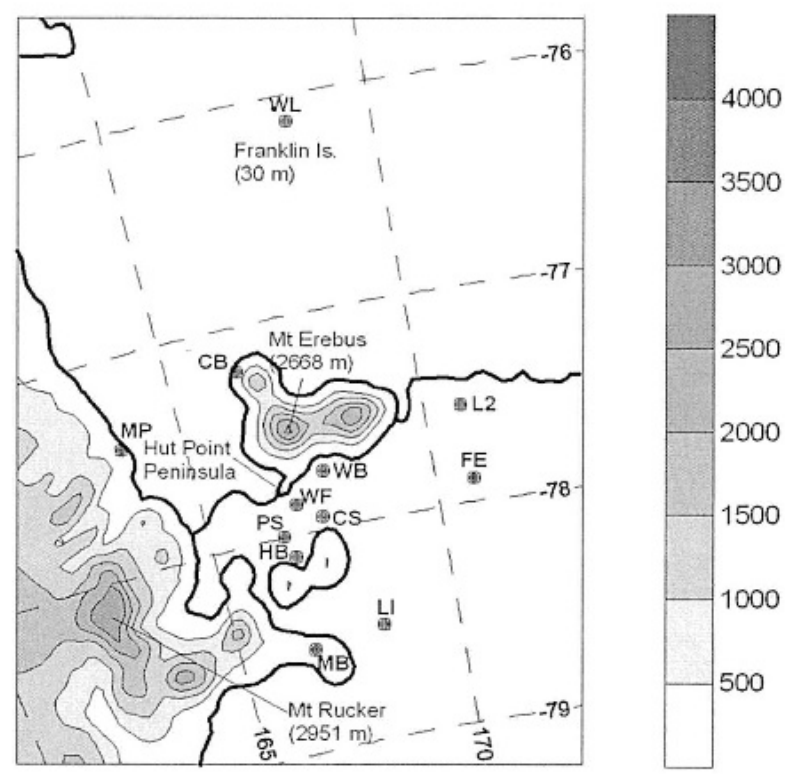

Figure 5.2: Antarctic Mesoscale Prediction System (AMPS) domains: a) the six AMPS domains, b) USGS GTOPO30 ("observed") topography (m above sea level (asl)) in the McMurdo region, c) AMPS 30-km domain topography (m asl), and d) AMPS 3.3$\mathrm{km}$ domain topography (m asl). Locations of the automatic weather stations (AWS) used to evaluate the AMPS model performance are indicated by dots with the following abbreviations: $\mathrm{WL}=$ Whitlock, $\mathrm{CB}=$ Cape Bird, $\mathrm{MP}=$ Marble Point, $\mathrm{WB}=$ Windless Bight, $\mathrm{WF}=$ Williams Field, $\mathrm{CS}=$ Cape Spencer, PS=Pegasus South, HB=Herbie Alley, $\mathrm{LI}=$ Linda, $\mathrm{MB}=$ Minna Bluff, L2=Lauri II, and FE=Ferrell. From Monaghan et al. (2005). 


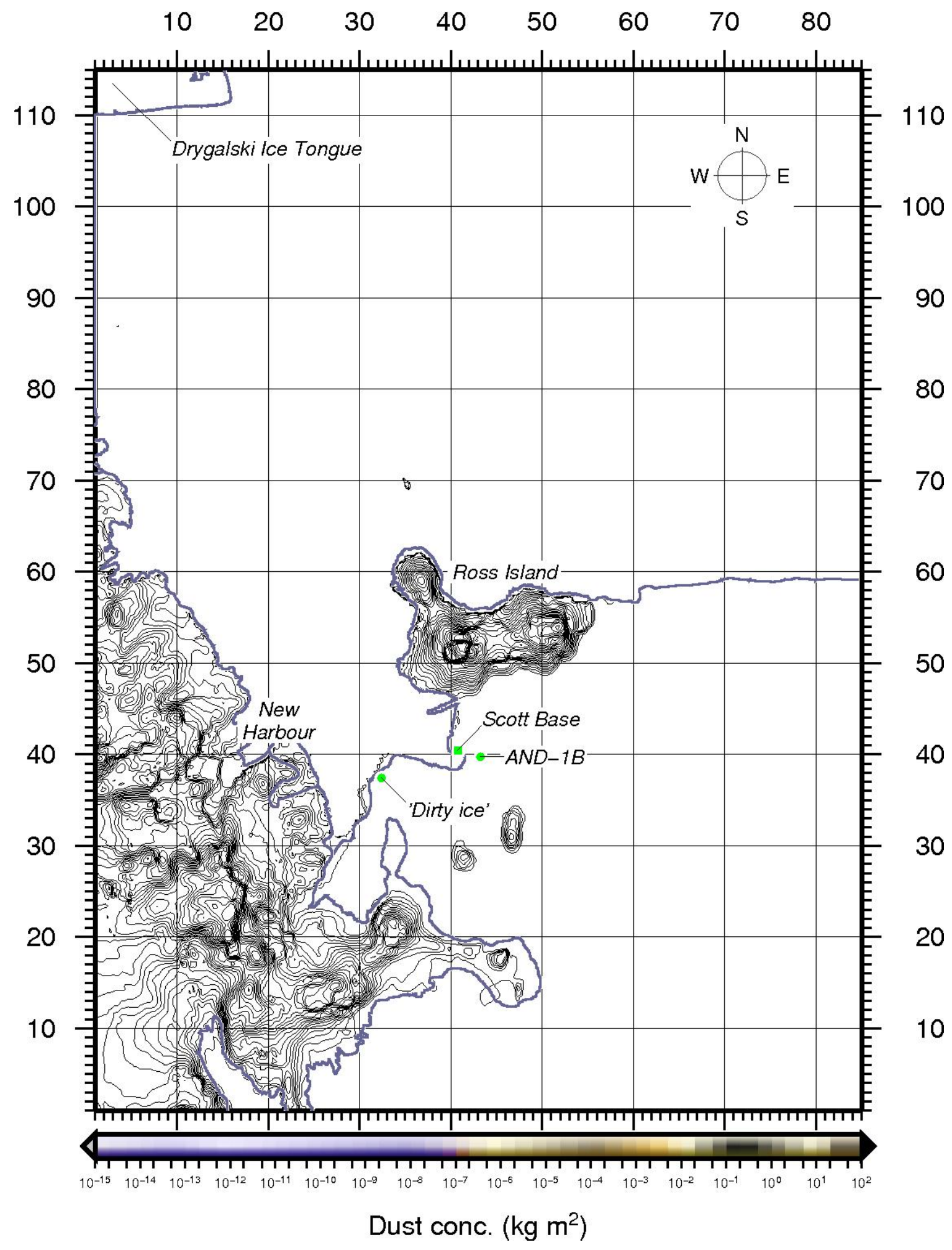

Figure 5.3: Blank NaMASTE model domain containing no wind data, but showing the following features: $85(i) \times 115(j)$ grid cells at $3.3 \mathrm{~km}$ resolution, labelled geographic features, topography, and sediment accumulation (dust concentration) colour scale in $\mathrm{kg} \mathrm{m}^{2}$. With wind perturbation (not shown) the compass in the top right corner will display a mean wind direction vector for the source cell. 
A summary of the NaMASTE model environment is shown in Table 5.1. The AMPS data provides a successive sequence of static wind fields from real-time mesoscale meteorological model forecasts at 6-hr increments. Input into NaMASTE are AMPS forecasts from the start of 2002 to the end of 2005, allowing a selection of more than 5,000 static 6-hr wind fields to generate sediment flux. A multiplication factor ("scalar") is provided to allow scaling-up or down of wind velocities within a fixed wind field.

Figure 5.4, Figure 5.5 and Figure 5.6 show three example wind fields with contoured wind velocities overlying the NaMASTE domain that illustrate the variability within the regional wind system. NaMASTE input data include $2 \mathrm{~m}$ air surface temperature inputs also from AMPS. Figure 5.4 is an averaged 4-year annual mean wind field used in sensitivity testing (Section 5.5). Figure 5.5 is a moderately strong wind field that is influenced by topography, while Figure 5.6 is a peak storm wind field that is over-riding topographic constraints.

Table 5.1: Summary of NaMASTE model environment including model domain, boundary conditions and numerical scheme. Modified after Golledge (2012)

\begin{tabular}{lll}
\hline Component & Description & \\
\hline \hline Domain & AMPS domain 5 & $\left(\sim 76^{\circ}-79^{\circ} \mathrm{S}, \sim 160^{\circ}-173^{\circ} \mathrm{E}\right)$ \\
& $3.3 \mathrm{~km}$ grid & $85(i) \times 115(j)$ cells \\
& & $\approx 280 \times 380 \mathrm{~km}$ \\
\hline Boundary conditions & $U_{v e l(i, j)} ; V_{v e l(i, j)}$ & $10 \mathrm{~m}$ wind velocity fields \\
(input data) & $T_{(i, j)}$ & 2 m surface air temperature \\
& $M_{(i, j)}$ & source sediment supply rate \\
\hline Numerical & $2 \mathrm{D}(x, y)$ centred finite difference scheme \\
scheme & temporal integration & \\
& & 6 -hour static wind fields \\
& sediment fluxes calulated by loop \\
& through 5 grain sizes \\
& particle tracking & peak velocity controlled time-step \\
& (iteration outputs) & 5 grain sizes \\
& particle transport paths \\
\hline \hline
\end{tabular}




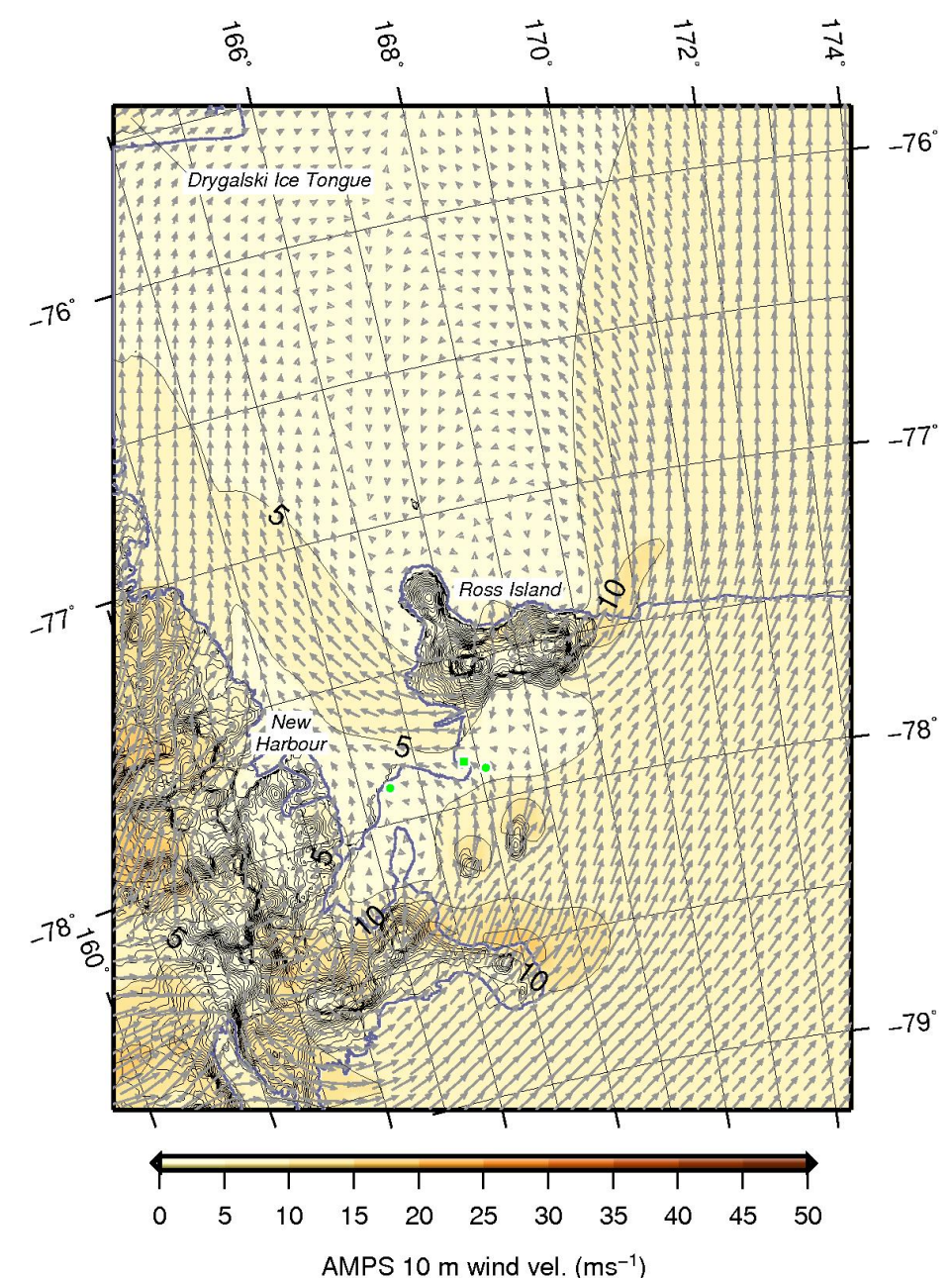

Mean dir: 6.23780123789

Std dir: \pm 57.0599924652

Max dir: 179.709564209

Min dir: -179.829727173

Mean vel: 6.2100113281

9999

Std vel: \pm 3.43041305793

Max vel: 17.5064353943

-- at :00 hrs
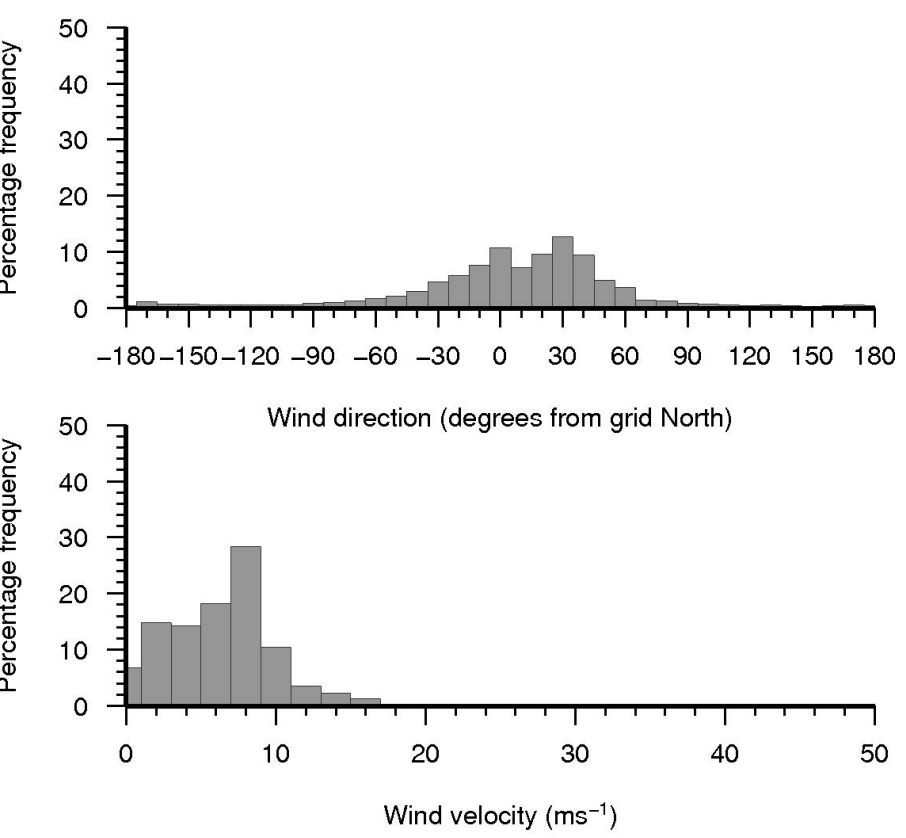

Figure 5.4: NaMASTE model four year annual mean wind field for McMurdo Sound from calculated annual means for AMPS 2002, 2003, 2004 and 2005 annual data sets. Wind velocities $\left(\mathrm{m} \mathrm{s}^{-1}\right)$ are contoured and shown as vectors on the map plot. Summary statistics are supplied to the right. Four digit number and hour increment relate to the input codes for the $6 \mathrm{hr}$ wind field snapshot. 


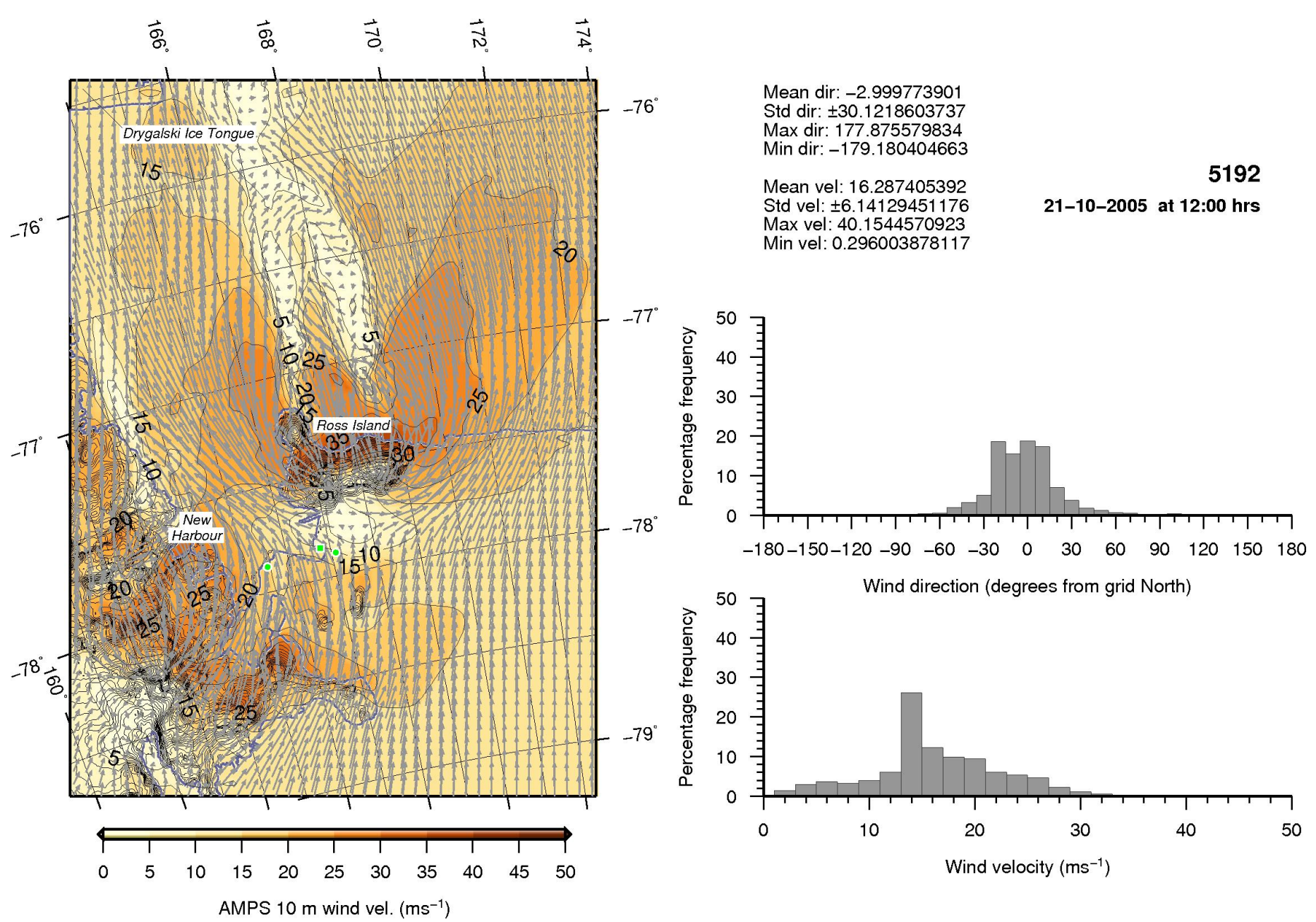

Figure 5.5: NaMASTE model example moderate strength wind field for McMurdo Sound from AMPS 2005 data set. Wind velocities (m s ${ }^{-1}$ ) are contoured and shown as vectors on the map plot. Summary statistics are supplied to the right. Four digit number and hour increment relate to the input codes for the $6 \mathrm{hr}$ wind field snapshot. 


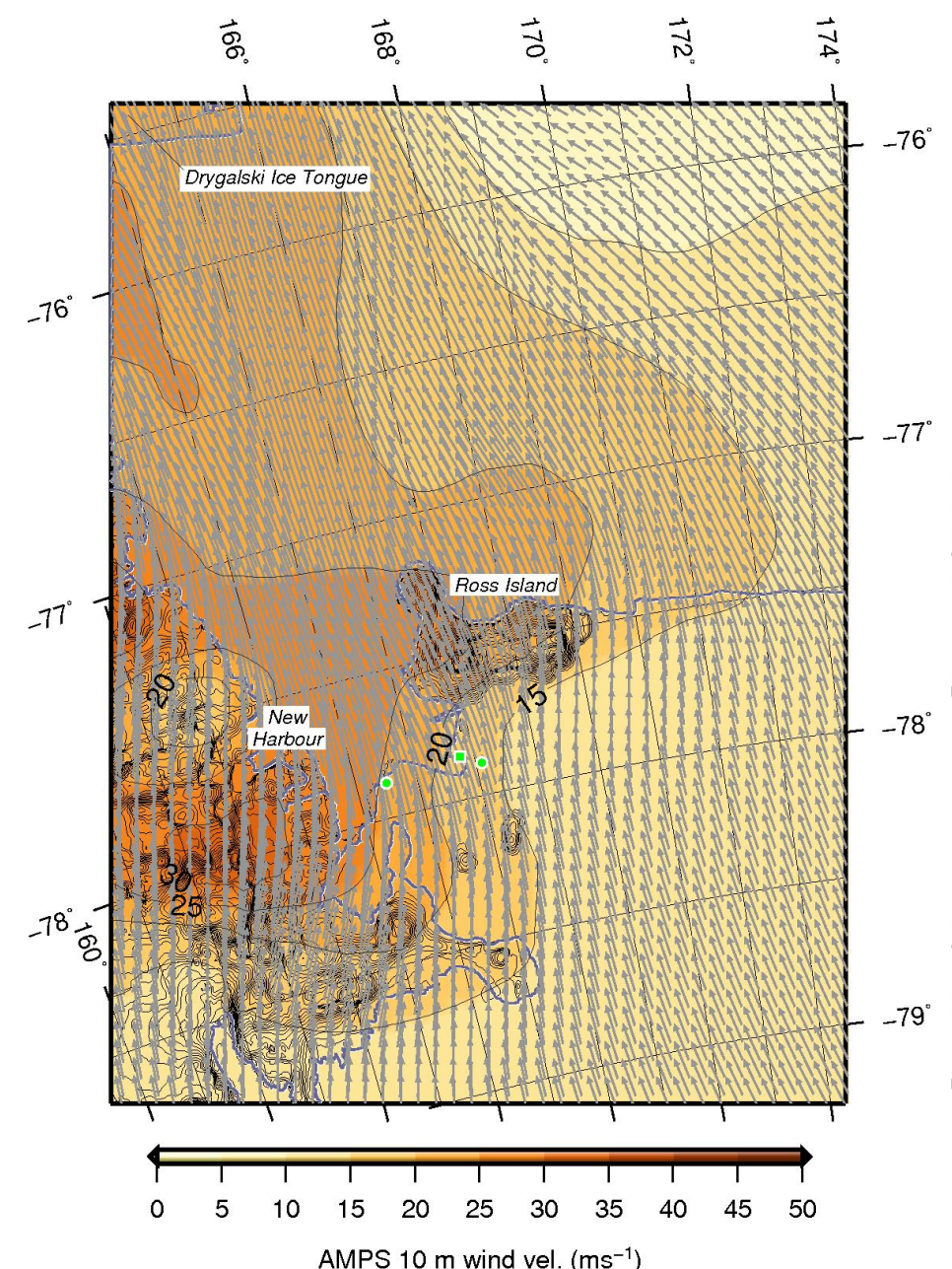

Mean dir: -18.8479164714

Std dir: \pm 14.2484744999

Max dir: 13.8667802811

in dir: -60.2930030823

Mean vel: 17.5807586823

Std vel: \pm 5.8903934583

3211

Max vel: 32.3608322144

16-05-2004 at 06:00 hrs
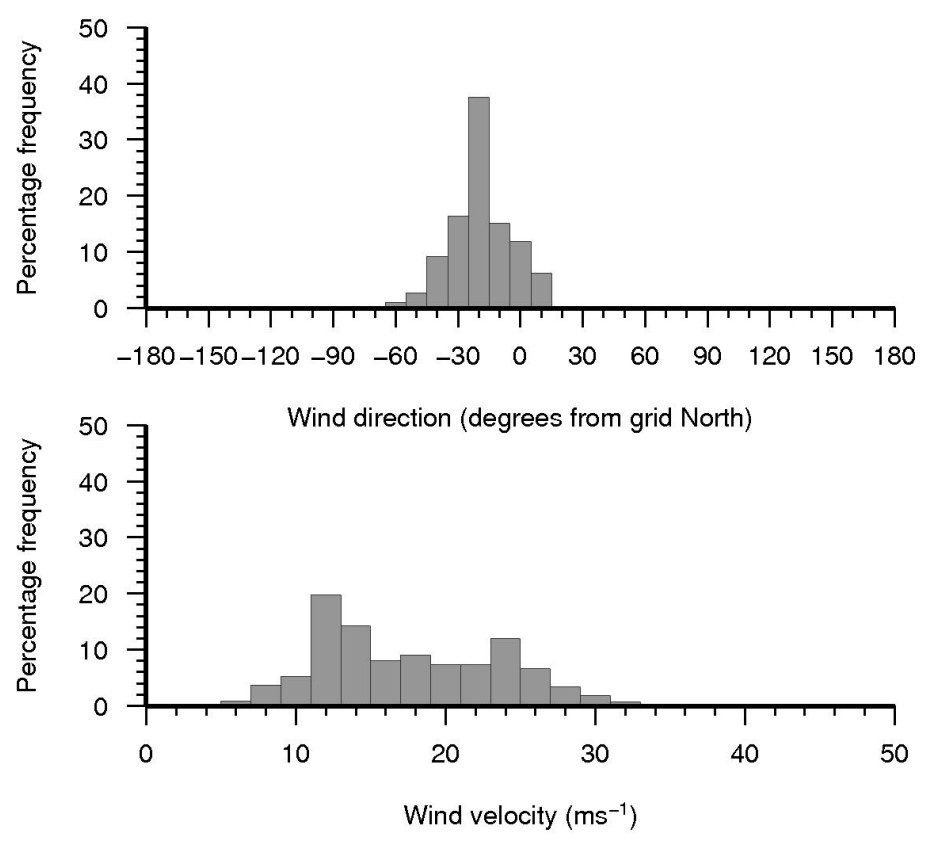

Figure 5.6: NaMASTE model 16 May 2004 katabatic storm event wind field for McMurdo Sound from AMPS 2004 data set. Wind velocities $\left(\mathrm{m} \mathrm{s}^{-1}\right)$ are contoured and shown as vectors on the map plot. Summary statistics are supplied to the right. Four digit number and hour increment relate to the input codes for the $6 \mathrm{hr}$ wind field snapshot. 


\subsubsection{Considerations for modelling physical processes}

The model was specifically written to simulate aeolian processes with some simplifications to the experimental setup in order to more clearly explore the aeolian transport system. Wind fields were made invariant by locking a singular 6-hr wind field increment to run continuously for any chosen duration, intermittency ignored, i.e. no transport limitations (except those inherent in the wind field vectors). Wind moves within two horizontal dimensions at velocities dictated by the chosen 6-hr wind field increment, a vertical wind profile is calculated within the model physics; however, vertical sediment flux is not supplied as an output. The static model wind field increment assumes turbulent flow.

Continuous sediment supply, i.e. no supply limitation, is also assumed, and the area of sediment supply is computed as a source cell (or cells) rather than an exact geographical distribution of source material. Aeolian sediment supply from other regions (e.g. global) is not considered, only sediment supplied from the defined sources. Outputs only calculate material deposited onto the sea ice within the model domain; therefore, sediment transported beyond the domain is not included. The model assumes flat, planar sea ice conditions. Potential traps for sediment such as sastrugi, stranded icebergs, polynyas, etc., are not factored into the model. Sediment was assumed to be transported with, and trapped by, blown snow on the sea ice surface. The model does not include any parameter or calculation for snow flux, instead a retention factor accounts for snow trapping.

\subsubsection{Constants and model variables}

The model calculates sediment transport from a source cell (or cells) onto sea ice from a variety of physical variables and constants (Table 5.2 and Table 5.3). Standard values for well established constants were used (e.g. acceleration due to gravity, air pressure, pi), while the diameter of a standard grain is an experimental constant calculated by Bagnold (1941). 
Table 5.2: Physical constants used in NaMASTE. From Golledge (2012).

\begin{tabular}{llcl}
\hline & Constant & Value & Units \\
\hline$\sigma$ & grain density & 2.65 & $\mathrm{~g} \mathrm{~cm}^{-3}$ \\
$g$ & gravity & 9.81 & $\mathrm{~m} \mathrm{~s}^{-2}$ \\
$p$ & absolute air pressure (SL) & 101.325 & $\mathrm{kPa}$ \\
$\Psi$ & specific gas constant & 287.058 & $\mathrm{~kg} \mathrm{~K}^{-1}$ \\
$z$ & height of vel. measurement & 10 & $\mathrm{~m}$ \\
$D$ & diameter of standard grain & 250 & $\mu \mathrm{m}$ \\
$\pi$ & pi & 3.141593 & - \\
\hline
\end{tabular}

Table 5.3: NaMASTE model variables. Modified after Golledge (2012).

\begin{tabular}{clcl}
\hline & Variable & Value & Units \\
\hline & & & \\
$\rho$ & air density & - & $\mathrm{g} \mathrm{cm}^{-3}$ \\
$v t$ & entrainment velocity & - & $\mathrm{m} \mathrm{s}^{-1}$ \\
$V^{*}$ & shear velocity & - & $\mathrm{m} \mathrm{s}^{-1}$ \\
$q_{s l t}$ & saltation flux & - & $\mathrm{kg} \mathrm{m}^{-2} \mathrm{~s}^{-1}$ \\
$g_{\text {sus }}$ & suspension flux & - & $\mathrm{kg} \mathrm{m}^{-2} \mathrm{~s}^{-1}$ \\
$Q$ & net flux & - & $\mathrm{kg} \mathrm{m}^{-2} \mathrm{~s}^{-1}$ \\
$d$ & grain size & $250 / 150 / 90 / 20 / 10$ & $\mu \mathrm{m}^{-2}$ \\
$H$ & sediment conc. in transit layer & - & $\mathrm{kg} \mathrm{m}^{-2}$ \\
$h$ & accumulated sed. conc. & - & $\mathrm{kg} \mathrm{m}^{-2}$ \\
$T$ & temperature & - & $\mathrm{K}$ \\
$v$ & wind velocity & - & $\mathrm{m} \mathrm{s}^{-1}$ \\
$k$ & focus height & $\frac{1}{30} \lambda$ & $\mathrm{m}$ \\
& & & \\
& Variable & Range & $\mathrm{Units}$ \\
\hline$A$ & entrainment coeff. & $0.01-1$ & - \\
$\lambda$ & ampl. of surface roughness & $0.0001-0.1$ & $\mathrm{~m}$ \\
$\delta$ & sorting coefficient & $0.15-0.35$ & - \\
$R$ & retention factor & $0.01-1$ & - \\
$M$ & sed. supply rate at source & $0.01-1$ & $\mathrm{~kg} \mathrm{~m} \mathrm{~m}^{-2} \mathrm{~s}^{-1}$ \\
$t$ & time & - & $\mathrm{s}$ \\
& & & \\
\hline
\end{tabular}


The validity of model outputs relies on the accuracy of the input wind fields (e.g. wind velocity), model physics (e.g. entrainment and shear velocities, flux estimates), and experimental values (e.g. Bagnold's entrainment and sorting coefficients, surface roughness amplitude, retention). Other variables rely on geological reasoning, such as grain size of source material. Certain model variables relating to the nature of the sediment source and the capacity of the wind field to entrain and transport sediment were the focus of the sensitivity tests. These variables were: entrainment and sorting coefficients, surface roughness, retention, sediment supply rate at source, volume of model grain sizes at source, wind velocity (via scaling), and time.

\subsubsection{Model physics}

NaMASTE simulates sediment movement by wind through time and space from sources fringing McMurdo Sound to the SW Ross Sea. Table 5.4 lists the key physical equations employed. Saltation is assumed as the primary mode of transport, with some flux in suspension (refer to Section 2.3 regarding modes of aeolian transport). Sediment supply is restricted to discrete sediment "seeding" cells dictated by grid coordinates.

Particle transport is in two horizontal dimensions $(x, y)$ with net sediment flux calculated for each cell and constrained by sediment availability. Variables controlling entrainment and retention are used to further constrain sediment movement and trapping. Sediment source ("seed") cells can be positioned anywhere within the domain from which transport and dispersal are calculated in an iterative manner according to the model physics and numerical scheme described above. 
Table 5.4: Summary of NaMASTE model physics. Modified after Golledge (2012)

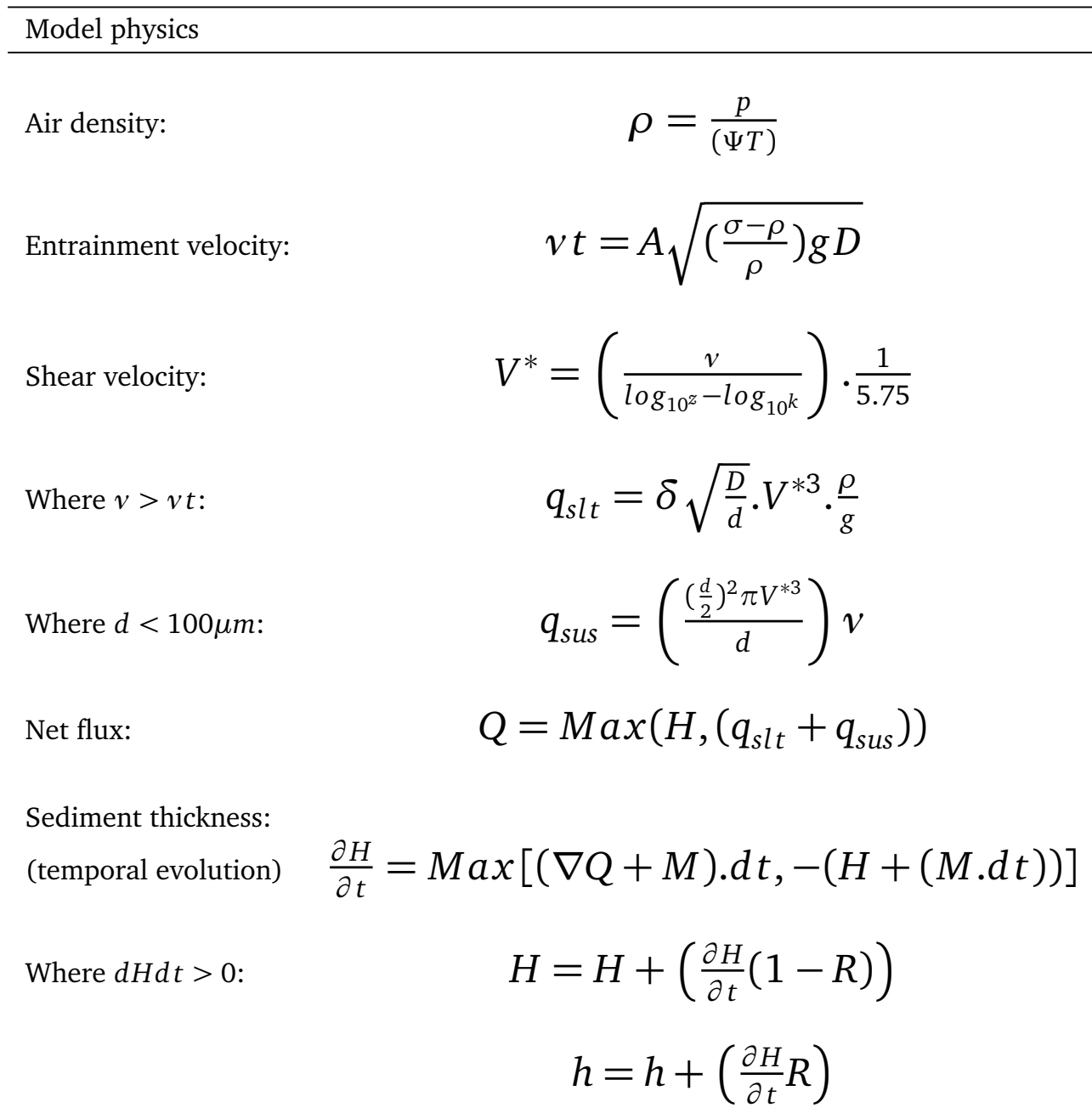

\subsubsection{Sources of error and uncertainty}

The primary modelling objective for this study is to understand the physical system and to see if manipulation of a few simple parameters can produce a simulation that resembles the empirical data. By selecting a "typical" invariant wind field for modelling, the full range of the real wind system is reduced to one scenario, which may or may not represent the real environment. Time and wind field invariance also means realistic particle trajectories cannot be re-created for a given time increment. Particle trajectories can only be considered in terms of the capacity of the wind to move a particle in a fixed direction over a given time increment.

Errors can be produced by unrealistic values; therefore, care is needed with selecting value ranges for model parameters. Consistency of values for each test must be 
maintained to reduce error. The simulations are restricted to five grain sizes, which do not replicate the full range of grain sizes transportable by wind as typically found in source material (clay to pebbles). The grouped grain sizes are, therefore, used as "typical" transportable aeolian sediment under the modes assumed by the model and thereby contain inherent inconsistencies with real source material.

Snow retention on sea ice intermittently changes through time and space. Therefore, estimating a realistic retention of aeolian sediment within the snow matrix is highly uncertain for a fixed wind field scenario. The retention factor used as a proxy for snow capture in NaMASTE is a simplification of the complexity of the real environment, so comparison of outputs to the empirical dataset becomes crucial to refine this parameter.

Though comparable to the resolution $(5 \mathrm{~km}$ ) of the field observation, as mentioned previously, the resolution used in the model $(3.3 \mathrm{~km})$ is reasonably coarse given the high degree of variability seen in the empirical data. $\mathrm{T}$ therefore, the scale of interpretation needs to be appropriate to avoid increasing uncertainty. Furthermore, field observations are limited to a discrete area. Subsequently, modelled distributions extending beyond the field area (as replicated in the model domain) contain uncertainty.

\subsubsection{Runtime outputs}

The model produces model-state variables which are written to ascii log files at each increment. This allows data to be extracted from individual points within the domain ( $x, y$ coordinates) and plots of scaled sediment accumulation to be generated from each individual run. Due to the use of static wind fields, the durations of runs potentially determine unrealistic accumulation outputs for the chosen wind field over time. For sensitivity testing this effect is not important. But for predictive simulations, realistic run durations need to be considered.

\subsection{Experimental approach for this study}

\subsubsection{Sensitivity testing}

The experimental approach to sensitivity testing and reasons for choosing test parameters are summarised in Table 5.5 and Figure 5.7. Model variables were explored by fixing all variables but one test variable and running values within a realistic range for the test variable. Test value ranges were, where possible, guided by published 
studies of aeolian processes, or were chosen by geological reasoning. Though any wind field containing velocities above the minimum entrainment threshold velocity (see Section 2.2 and Section 2.4) could be chosen, a static wind field was used for all sensitivity runs. Fixing the wind field provides a control on wind strength and direction and eliminates additional variability arising from fluctuating wind velocity or direction.

Wind velocities were scaled by a multiplication factor (scalar) across all grid cells as follows: normal (1), moderately strong (5), and storm strength (9), to explore the effect of wind strength on distribution. A duration of 744 hours (31 days; representing one month) was selected to be a practicable run length for the tests, though any timeframe could have been used. Consistency of run duration was maintained for all tests.

Table 5.5: NaMASTE model variables used in sensitivity testing.

\begin{tabular}{|c|c|c|c|c|}
\hline $\begin{array}{l}\text { Variable } \\
\text { (symbol) }\end{array}$ & $\begin{array}{l}\text { Experimental } \\
\text { values }\end{array}$ & $\begin{array}{l}\text { Test values } \\
\text { (range) }\end{array}$ & Units & $\begin{array}{l}\text { Scientific reasoning } \\
\text { for test }\end{array}$ \\
\hline $\begin{array}{l}\text { Entrainment } \\
\text { coefficient }(A)\end{array}$ & $\begin{array}{l}0.08-1.0 \\
(\text { Bagnold, } \\
1941)\end{array}$ & $0.01-1.0$ & & Cold environment \\
\hline $\begin{array}{l}\text { Sorting } \\
\text { coefficient }(\delta)\end{array}$ & $\begin{array}{l}0.15-0.28 \\
\text { (Bagnold, } \\
1941)\end{array}$ & $0.15-3.0$ & & $\begin{array}{l}\text { Source material sorting, } \\
\text { effect on entrainment }\end{array}$ \\
\hline $\begin{array}{l}\text { Surface } \\
\text { roughness }(\lambda)\end{array}$ & $\begin{array}{l}0.0000-6.0 \\
\text { (refer } \\
\text { Table 2.1) }\end{array}$ & $0.0002-0.03$ & $\mathrm{~m}$ & $\begin{array}{l}\text { Variability in source } \\
\text { material, snow cover and } \\
\text { sea ice surface }\end{array}$ \\
\hline Retention $(R)$ & & $0.1-1$ & $\%$ & $\begin{array}{l}\text { Variable accumulation } \\
\text { of sampled area }\end{array}$ \\
\hline $\begin{array}{l}\text { Sediment } \\
\text { supply rate } \\
\text { (source) }(M)\end{array}$ & & $0.1-0.3$ & $\mathrm{~kg} \mathrm{~m}^{-2} \mathrm{~s}^{-1}$ & $\begin{array}{l}\text { Seasonal and geologic/ } \\
\text { geomorphic variability } \\
\text { of source material }\end{array}$ \\
\hline Grain size $(d)$ & $\begin{array}{l}0.45-2000 \\
\text { (this study) }\end{array}$ & $\begin{array}{l}250 / 150 / 90 \\
/ 20 / 10\end{array}$ & $\mu \mathrm{m}$ & $\begin{array}{l}\text { Lagged source surfaces, } \\
\text { different transport modes }\end{array}$ \\
\hline $\begin{array}{l}\text { Wind velocity } \\
\text { (scaling) }(v)\end{array}$ & $\begin{array}{l}\text { 5.3-71.5 } \\
\begin{array}{lll}\text { Speirs } & \text { et } & \text { al. } \\
2008) & \text { (Stein- } \\
\text { hoff } & \text { et } & \text { al. } \\
2008) & & \end{array}\end{array}$ & $\sim 2-50$ & $\mathrm{~m} \mathrm{~s}^{-1}$ & $\begin{array}{l}\text { Variable sediment trans- } \\
\text { porting wind regime }\end{array}$ \\
\hline Time $(t)$ & & 744 & hours & Temporal variability \\
\hline
\end{tabular}




\section{NaMASTE Sensitivity Tests Methodology Diagram}

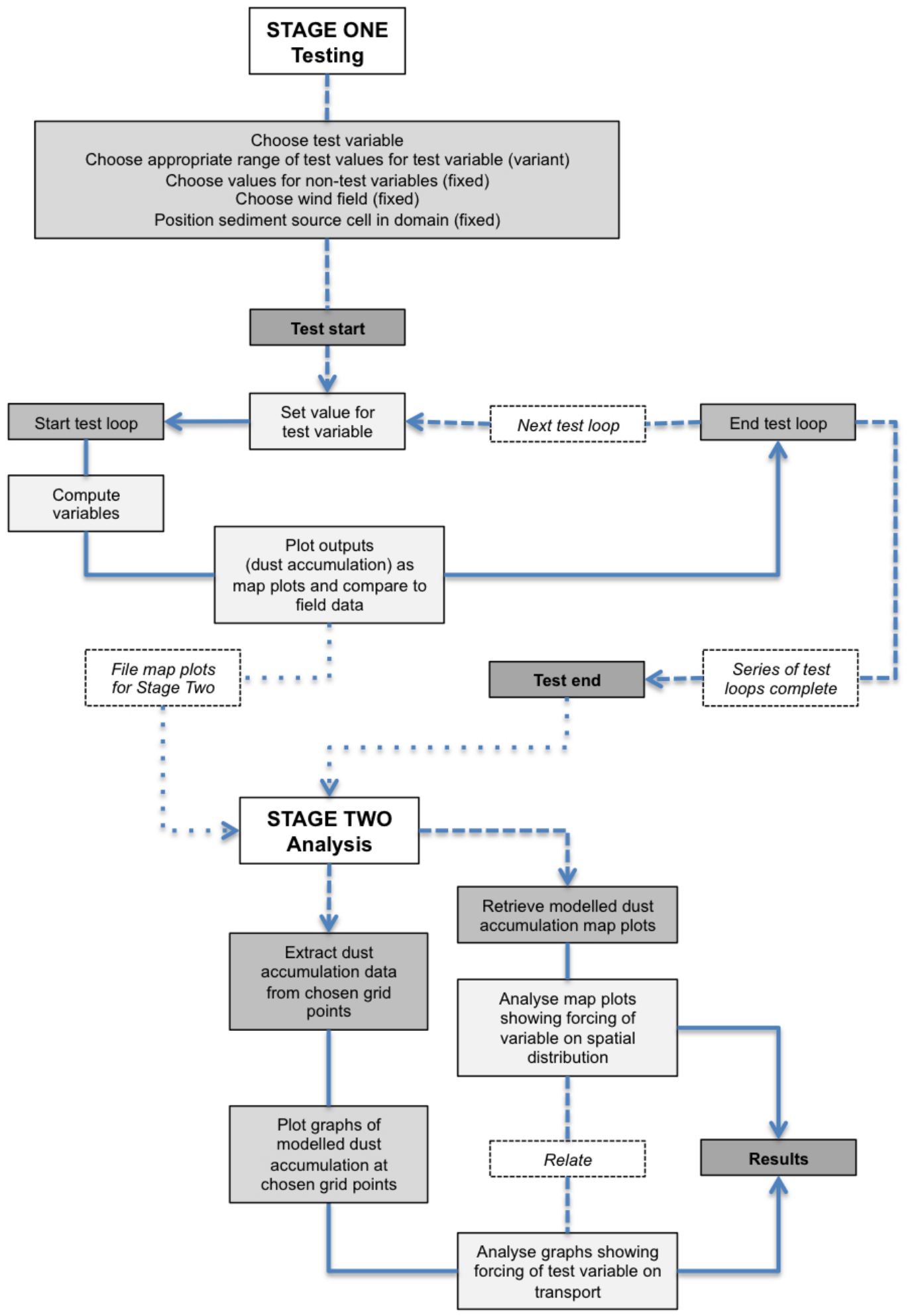

Figure 5.7: Flow diagram showing methodology used for sensitivity testing of NaMASTE model variables. 
The wind regime in McMurdo Sound has a relatively low velocity $\left(<10 \mathrm{~m} \mathrm{~s}^{-1}\right.$ ) background circulation that is punctuated by intense high velocity wind events. By averaging the annual means, a common wind field was found that provided some certainty that the transport pathways being generated by the model were typical of the local wind field. Wind velocities within the 4-yr mean annual wind field ranged from 0 to $17 \mathrm{~m} \mathrm{~s}^{-1}$, but the majority of wind speeds were $<10 \mathrm{~m} \mathrm{~s}^{-1}$. Wind directions varied between 180 degrees either side of grid north; however, most winds are from the southwest to southeast quadrant.

To assist interpretation, the five grain sizes were placed into three grain size groupings - medium sand $(250 \mu \mathrm{m})$, fine sand (150 $\mu \mathrm{m}$ and $90 \mu \mathrm{m})$, and silt $(20 \mu \mathrm{m}$ and $10 \mu \mathrm{m})$ - and each grain size grouping was "seeded" with equivalent values per simulation. It should be noted that the five grain sizes used in the tests are the default values set by the model developer, they are not specifically tuned to match the observed dataset. For this first application of the NaMASTE model the default grain size values provide a simplified grain size range that coarsely approximates the wind blown material likely to be found on sea ice in McMurdo Sound; however, all grain sizes used in the tests are found within the observed distribution. Test values are provided in Appendix $G$.

All runs had a single, fixed sediment source cell positioned on the McMurdo Ice Shelf to simplify the interpretation of the resulting sediment distribution pattern. Comparitive accumulation data was extracted from three "extraction" grid points (proximal: $\sim 30 \mathrm{~km}$, medial: $\sim 96 \mathrm{~km}$, and distal: $\sim 198 \mathrm{~km}$ ) relative to the source cell, and situated within the main sediment transport path generated by the 4-year annual mean wind field. Three points were selected in order to assess variability in accumulation downstream from a single point source. The three grain size categories were compared at each extraction point.

\subsubsection{Predictive modelling}

A second suite of modelling experiments was undertaken to predict for a "best fit" to the MAR distribution of the empirical data, reported in Chapter 4, Experimental set-up involved consideration of realistic values for model variables. Duration, source location, source material and surface roughness can be compared to local observations. Values published in the literature and results from sensitivity testing assisted choice of coefficients. As no direct observations of sediment flux retention within snowdrifts on sea ice are available, the test value for retention was estimated. Test values used for predictive experiments are supplied in Appendix I. 
Sensitivity test results suggest the majority of aeolian transport is generated by the strongest wind velocities. To test this assumption, the top $1 \%$ of wind speeds for 2010 was chosen as a test quantity (Figure 5.8). The frequency of wind events recorded at Pegasus North automatic weather station (AWS) $\left(77^{\circ} 94^{\prime} \mathrm{S}, 166^{\circ} 51^{\prime} \mathrm{E}\right.$; http://amrc.ssec.wisc.edu/) between 1 January and 31 December 2010 was analysed to obtain the top $1 \%$ of winds, which equates to wind speeds $>20 \mathrm{~m} \mathrm{~s}^{-1}$ (i.e. Beaufort scale $>8)$. Pegasus North AWS was chosen because of the station's location in the southern sector of the NaMASTE domain, its proximity to the McMurdo debris bands, that its geographical position would experience the majority of high wind speed events, and that its record includes 2010, the year in which the empirical data was collected.

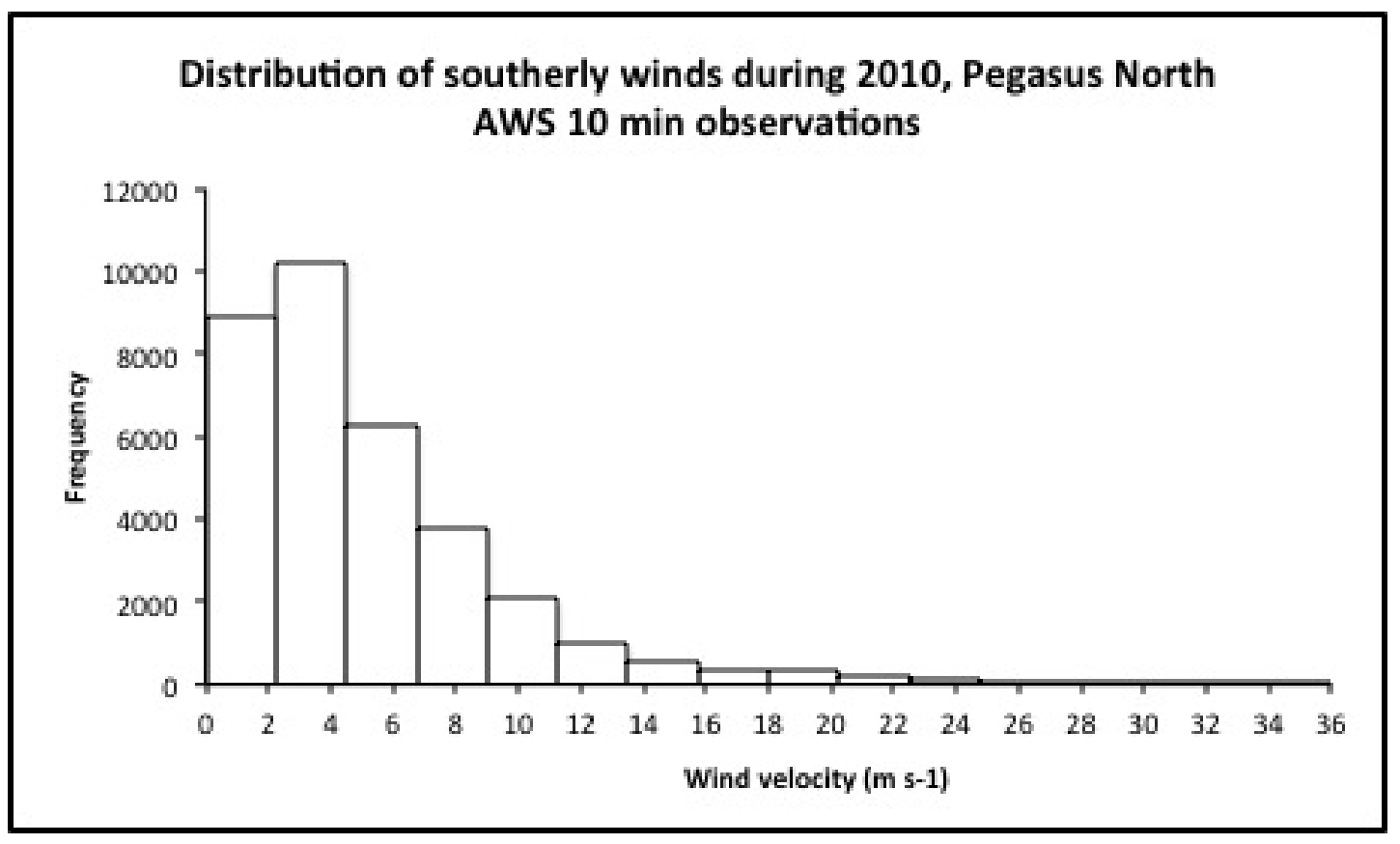

Figure 5.8: Distribution of southerly winds at Pegasus North AWS during 2010. 
Sea ice is present in McMurdo Sound during April to November, a period of 8 months, or 244 days. Taking $1 \%$ of 244 days, a duration in which winds exceeded $20 \mathrm{~m} \mathrm{~s}^{-1}$ is calculated as 58.56 hours. The assumption that the top $1 \%$ of wind speeds occur during the austral winter months is supported by the findings of Chenoli et al. (2012) (see Figure 1.5), which show the winter months (March to October) have the highest frequency of strong wind events greater than a Beaufort scale 6 and, assuming a similar distribution, winds $>20 \mathrm{~m} \mathrm{~s}^{-1}$. From this reasoning, a duration of 59 hours was adopted as the test duration.

Given the high wind speeds considered above, the choice of static wind field from those available (i.e. 2002-2006 AMPS archive data) needed to include appropriate wind speeds. Scanning the Pegasus North data for wind events exceeding the desired $20 \mathrm{~m} \mathrm{~s}^{-1}$ threshold, a storm sequence in late-October 2005 was selected, based on its duration and variability. From this sequence a number of differing wind fields were considered, based on wind velocity range across the domain, the pattern of wind direction (i.e. vectors of air flow), and how similar or different the windfields were to the 4-year annual mean used in sensitivity testing. From this process, a number of wind fields were tested. Wind field eliminations were based on output match to the empirical MAR distribution.

The geographic spread of source material surrounding McMurdo Sound suggested three source cells were needed to represent the source areas indicated by the MAR distribution: 1) on the McMurdo Ice Shelf, 2) at Gneiss/Marble Points, and 3) on the southeast Granite Harbour coast (refer to Figure 1.1 for geographic locations). Source material grain size and sorting were considered for each of these locations, based on grain size data at these sites or similar sites published in Barrett and Treves (1981); Barrett et al. (1983); Macpherson (1987); Atkins and Dunbar (2009) and Murray et al. (2012). As the full range of grain sizes shown at these sites is not replicable in NaMASTE, a relative coarseness of grain size and a relative abundance of material between sources, were coarsely approximated using the input values for modelled grain sizes.

Surface roughness was assumed to be equivalent to a smooth snow surface $\left(\mathrm{z}_{0}=\right.$ $0.0005 \mathrm{~m}$ ). The MAR data was investigated for longitudinal patterns of accumulation running downwind from source points that could be used to approximate degree of snow trapping. However, due to the high variability of the data and the lack of observations relating to the temporal variability of sediment transport and accumulation, this was discarded. No scalar of wind velocities was used in these experiments. 


\section{Chapter 6 Modelling results}

\subsection{Sensitivity testing}

Sediment accumulation (i.e. dust concentration, $\mathrm{kg} \mathrm{m}^{-2}$ per run length) is used as a measure of entrained material, under three different wind scenarios, for three different grain size groupings, for each test. Net accumulation is calculated per grid cell as outlined in Chapter 5, but can effectively be considered as sediment transported in saltation or settled out of suspension for a given run duration.

\subsubsection{Entrainment coefficient $(A)$}

The entrainment coefficient variable $(A)$ was tested to determine whether semiempirical values for $A$ from the literature are valid within the context of the McMurdo Sound climatic regime. Bagnold (1941) derived values for $A$ of 0.1 for the fluid (entrainment) threshold velocity, and 0.08 for the impact threshold velocity and these have been confirmed by many subsequent workers. For example, Greeley and Iversen (1985) report experiments investigating the effect of particle size and packing of grains on entrainment thresholds. Experimental values of $A$ ranging between 0.01 to 0.1 were used to explore what would occur if cohesion forces didn't exist, and values ranging between 0.1 and 0.5 were used to investigate the ratio of lift to drag force. Values as small as 0.01 were considered, but found to be only valid for large particles. However, all of these studies were conducted in non-polar conditions and no experimental estimates of $A$ are available for windblown sand and dust travelling across sea ice. Also, most aeolian experiments do not consider aeolian material larger than sand, whereas in polar environments it is possible for material $>2,000 \mu \mathrm{m}$ to be moved by the wind.

The model sensitivity of this parameter over a wide range of values (0.01-1.0), encompassing the range reported in the literature and centered on the widely used "Bagnold" values, was assessed and the results are shown in Figure 6.1. Accumulation 


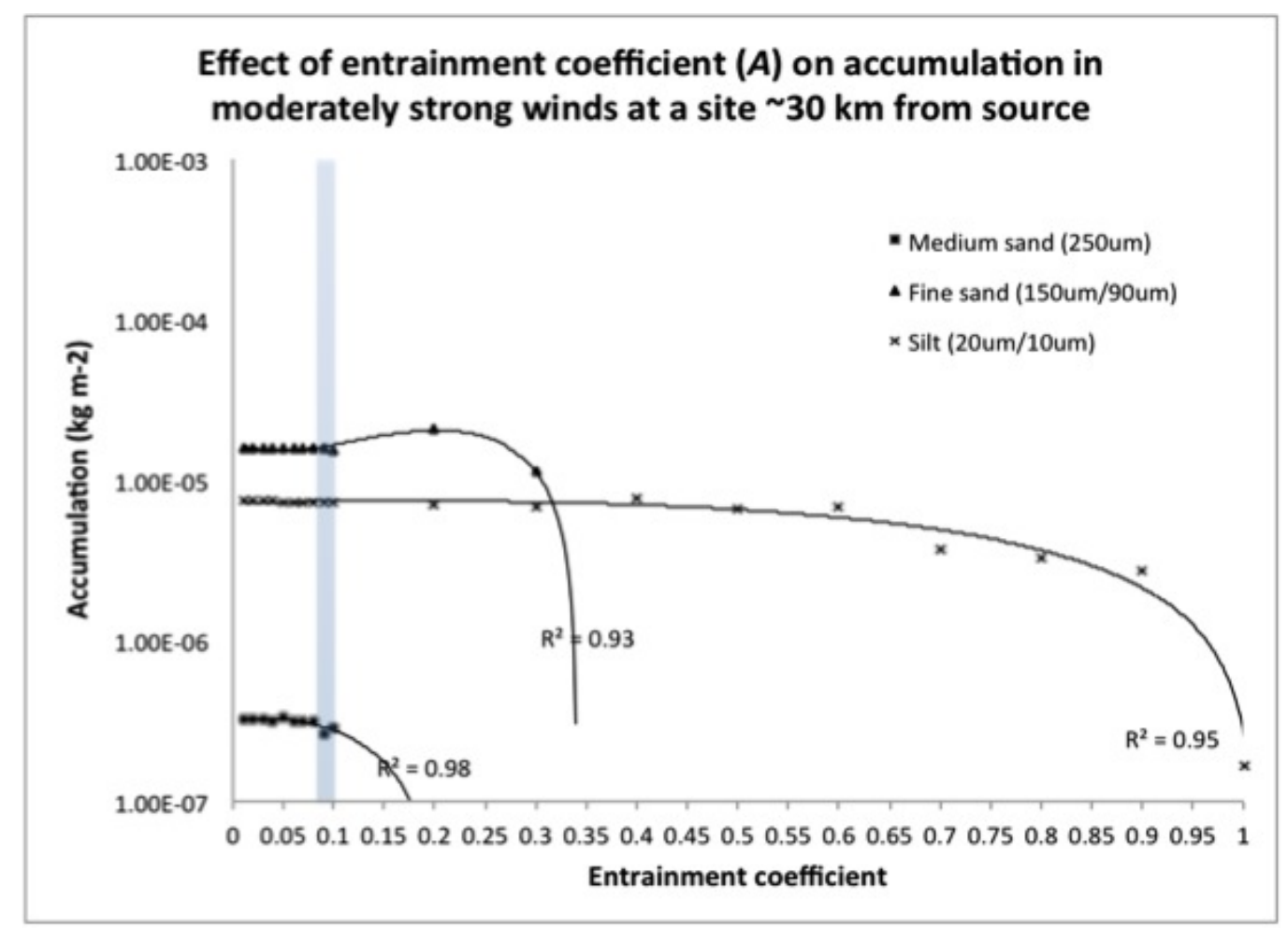

Figure 6.1: Effect of entrainment coefficient on accumulation from NaMASTE sensitivity tests. Accumulation data is for a location $\sim 30 \mathrm{~km}$ downstream from a source positioned on the McMurdo Ice Shelf debris bands. Blue bar indicates position of semi-empirical coefficients relating to entrainment threshold (0.1) and impact threshold (0.08) as determined by (Bagnold, 1941).

in this instance is used as a measure of entrainment. Three grain sizes are shown, silt $(20 / 10 \mu \mathrm{m})$, fine sand $(90 / 150 \mu \mathrm{m})$, and medium sand $(250 \mu \mathrm{m})$, under moderately strong wind speeds. Trendlines are strongly second- to third-order polynomial for medium sand and silt, and strongly third-order polynomial for fine sand; however, the values between 0.01-0.1 for all three grain sizes show a strongly linear relationship. 
Halving $A$ from that of Bagnold's entrainment coefficient (0.1) does not appear to have any effect on accumulation. In contrast, doubling it provides varied results: medium sand registers zero accumulation, silt registers no change in accumulation, and fine sand registers a slight increase in accumulation. Medium sand is not entrained beyond $A=0.1$. Fine sand ceases to accumulate at $A=0.35$, while silt is entrained for all test values, continuing linearly until $A=0.65$ when its accumulation begins to decrease.

\subsubsection{Sorting coefficient $(\delta)$}

The grain size sorting coefficient variable $(\delta)$, as described by semi-empirical values from the literature, was tested to see what effect the sorting of source sediments has on sediment accumulation rates. In sedimentology, sorting is the ratio estimating the spread of grain size. Field observations suggest that source sediments in McMurdo Sound are generally very-poorly sorted, containing material ranging in size from fine silt to boulder. The default values are those of Bagnold (1941), more recently reworked by Anderson and Hallet (1986). These values are: 0.15 for very well sorted sand, 0.18 for moderately sorted 'dune' sand, 0.28 for poorly sorted sand, and 0.35 for essentially immobile sediment, such as pebbles. It should be noted that sedimentologists have standardised sediment sorting values since Bagnold's time (e.g. Boggs, 2006); however, numerical aeolian transport models still utilise Bagnold's values.

The sorting coefficient is of main importance in the calculation of saltation flux and characteristic trajectory paths of saltating grains in relation to the source material because it determines the supply rate of various size particles. It should be noted that this variable is subject to which grain sizes are included in a given experiment, therefore, limiting the capacity of the model to reflect the realistic environment.

$\delta$ was tested in the range $0.15-0.30$ to observe differences in accumulation from source material is from well sorted. As illustrated in Figure 6.2, $\delta$ exerts only a subtle change in accumulation. Higher accumulation corresponds to an increase in $\delta$, which relates to a decrease in source sediment sorting. Medium sand has the least accumulation of the three grain sizes modelled, but shows the greatest response, a very strong linear relationship, to changes in $\delta$. This holds true for all wind speeds tested, as can be seen in the additional graphical plots supplied in Appendix F, but differs from the other two grain sizes in which third-order polynomial relationships are a best fit, though much weaker for fine sand than for silt. Therefore, this parameter is of most importance to the largest particles. 


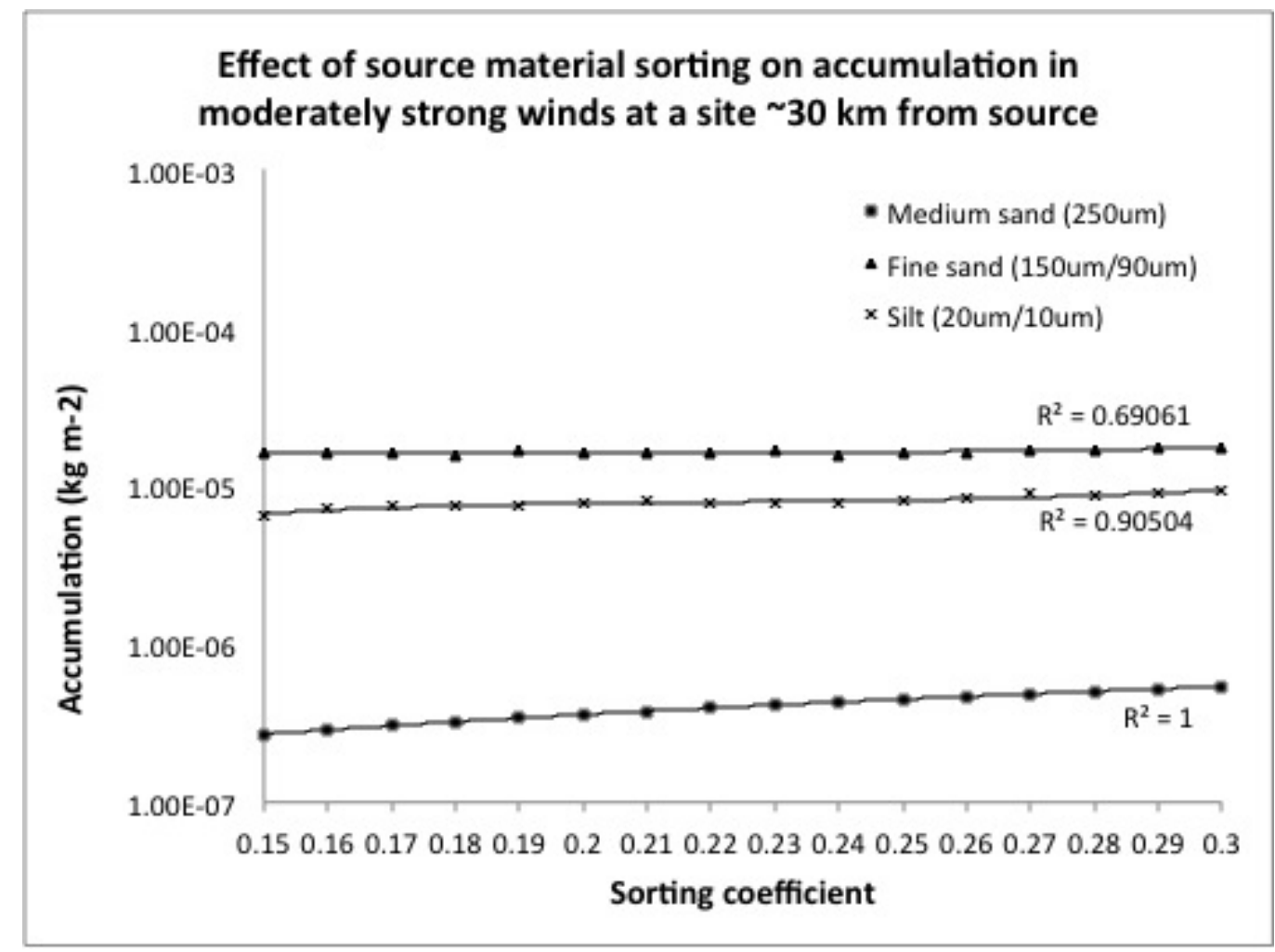

Figure 6.2: Effect of source material sorting on accumulation. Accumulation data is for a location $\sim 30 \mathrm{~km}$ downstream from a source positioned on the McMurdo Ice Shelf debris bands. Medium sand shows a strongly linear relationship, while a 3rdorder polynomial provides the best trend to the fine sand and silt data.

\subsubsection{Roughness amplitude $(\lambda)$}

A surface roughness (i.e. $\mathrm{z}_{0}$ ) parameter, roughness amplitude $(\lambda)$, accounts for the effect of relatively non-erodible surface roughness elements within an erodible bed on a boundary layer airflow and partially determines shear velocity $\left(V^{*}\right)$. Values are calculated as $1 / 30$ the average dimension of roughness elements, as previously discussed in Subsection 2.1.3. The greater the roughness, the greater the turbulence of the eroding and transporting wind flow.

In NaMASTE the magnitude of surface roughness is expressed as $\lambda$, the average grain diameter found on a flat bed, and focus height $k$ is $1 / 30 \lambda$. Boundary layer shear velocity $\left(V^{*}\right)$ is computed as a $\log$ function of height $(z)$, and $k$ is subtracted from $z$ to account for displacement of surface airflow due to interaction with roughness elements.

Degree of scale is important, as roughness can be measured at grain-scale (e.g. 250 $\mu \mathrm{m}$ grains pose a greater degree of roughness to the boundary flow, than $20 \mu \mathrm{m}$ or 
$10 \mu \mathrm{m}$ grains) or at much larger-scales. NaMASTE assumes a flat, planar surface for both source material and the sea ice surface with surface roughness only considered at grain-scale; however, in reality there is greater variability to both these surfaces. Larger surface roughness elements applicable to the field area can include, in the case of sea ice, sastrugi, snow drifts and stranded ice bergs, or in the case of sediment sources, gravel and boulders.

$\lambda$ was tested in the range $0.0002-0.03 \mathrm{~m}$ to explore the effect on accumulation of surface roughness elements at grain-scale. Significantly larger features, although clearly obstacles to flow, were not considered in testing due to their sporadic concentration within the field area. Figure 6.3 illustrates the low magnitude increase in accumulation with increasing $\lambda$ (and by definition, increasing $V^{*}$ ) for three grain size classes under moderately strong winds. This is consistent for all grain sizes and at all wind speeds, as illustrated in further graphical plots supplied in Appendix G.

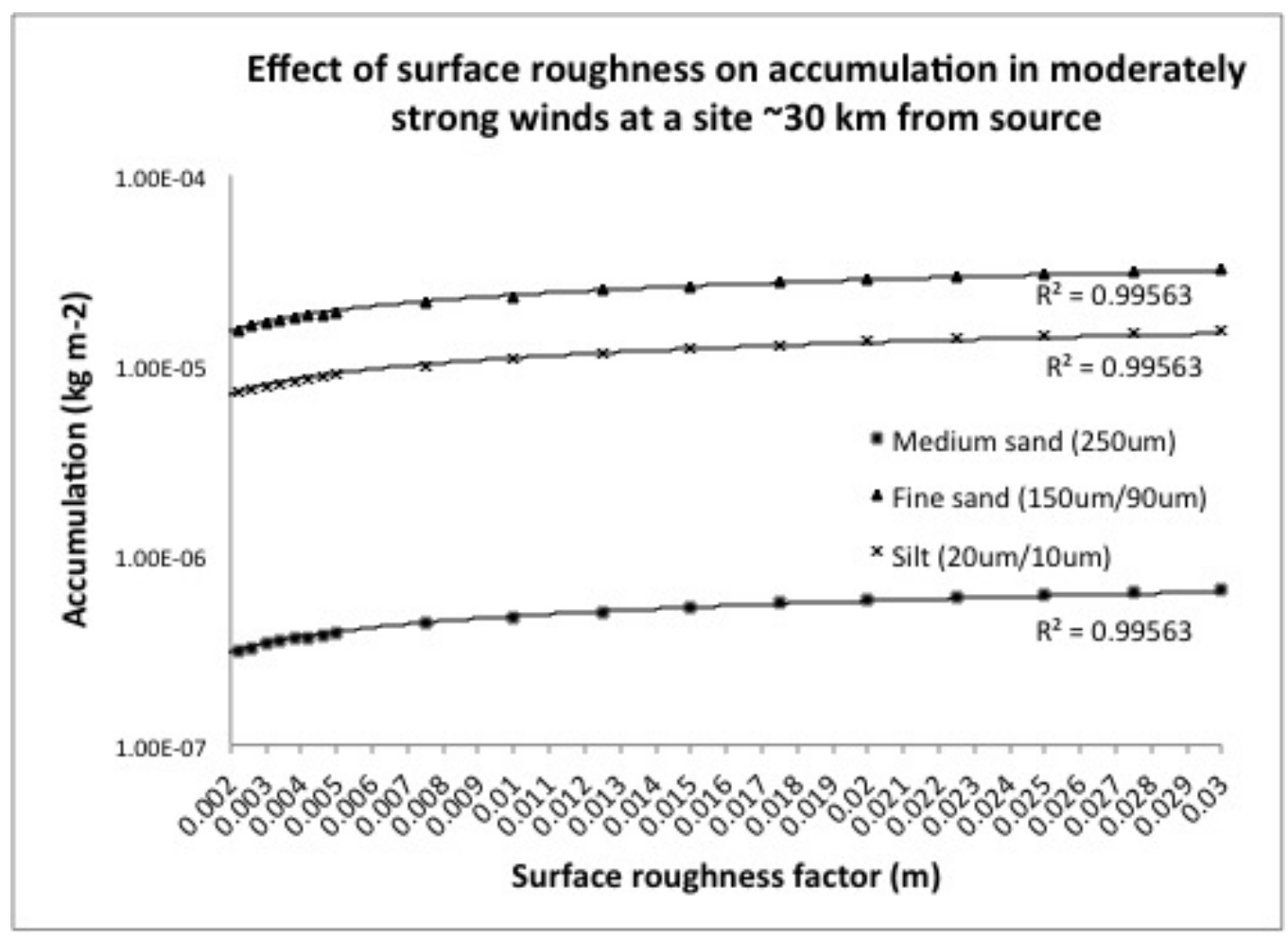

Figure 6.3: Effect of surface roughness $(\lambda)$ on accumulation at grain-scale. Accumulation data is for a location $\sim 30 \mathrm{~km}$ downstream from a source positioned on the McMurdo Ice Shelf debris bands. 
The strongest relationship to the data for each grain size is found by using a power law. The rate of change of $\lambda$ is greatest between 0.0002 and $0.0006 \mathrm{~m}$, (equivalent to a bed covered with fine to coarse sand), while between 0.005 to $0.03 \mathrm{~m}$ (equivalent to gravel or, at the upper end, low amplitude snow drifts) this rate decreases.

\subsubsection{Retention factor $(R)$}

Field observations suggest that the thin $(\mathrm{cm}-\mathrm{dm})$ snow covering on the sea ice in McMurdo Sound acts as a natural sediment trap and that this effect would need to be accounted for in the NaMASTE model environment. Accordingly, NaMASTE assumes snow capture to be the sole trapping mechanism for transitory aeolian sediment. This is achieved by incorporating a retention factor $(R)$ into the model; however, few empirical contraints for this value are available.

Here $R$ is calculated as a percentage of transitory sediment retained at a given point, within a given cell, at a given time (n.b. the model assumes sediment flux to be coincident with snow flux). $R$ was tested in the range $0.01-1.0$ (i.e. from $1 \%-100 \%$ sediment retention), to assess the effect on accumulation downstream from source. Figure 6.4 shows that no accumulation occurs beyond $R=0.9$ for each of the chosen sites. The greatest increase in accumulation occurs between $R=0.01$ and $R=0.1$, where it increases by an order of magnitude.

With greater increments of $R$, accumulation continues to increase but the rate of change decreases. The total accumulation is distributed closer and closer to source with each increase in $R$, hence the increase in accumulation, until all the sediment is kept at source $(R=100 \%)$. Accumulation increase is fairly consistent between $r=0.2$ to 0.8 suggesting the model is relatively insensitive to this parameter. The best relationships to the data are given by power law for silt and fine sand, and a third-order polynomial for medium sand. 


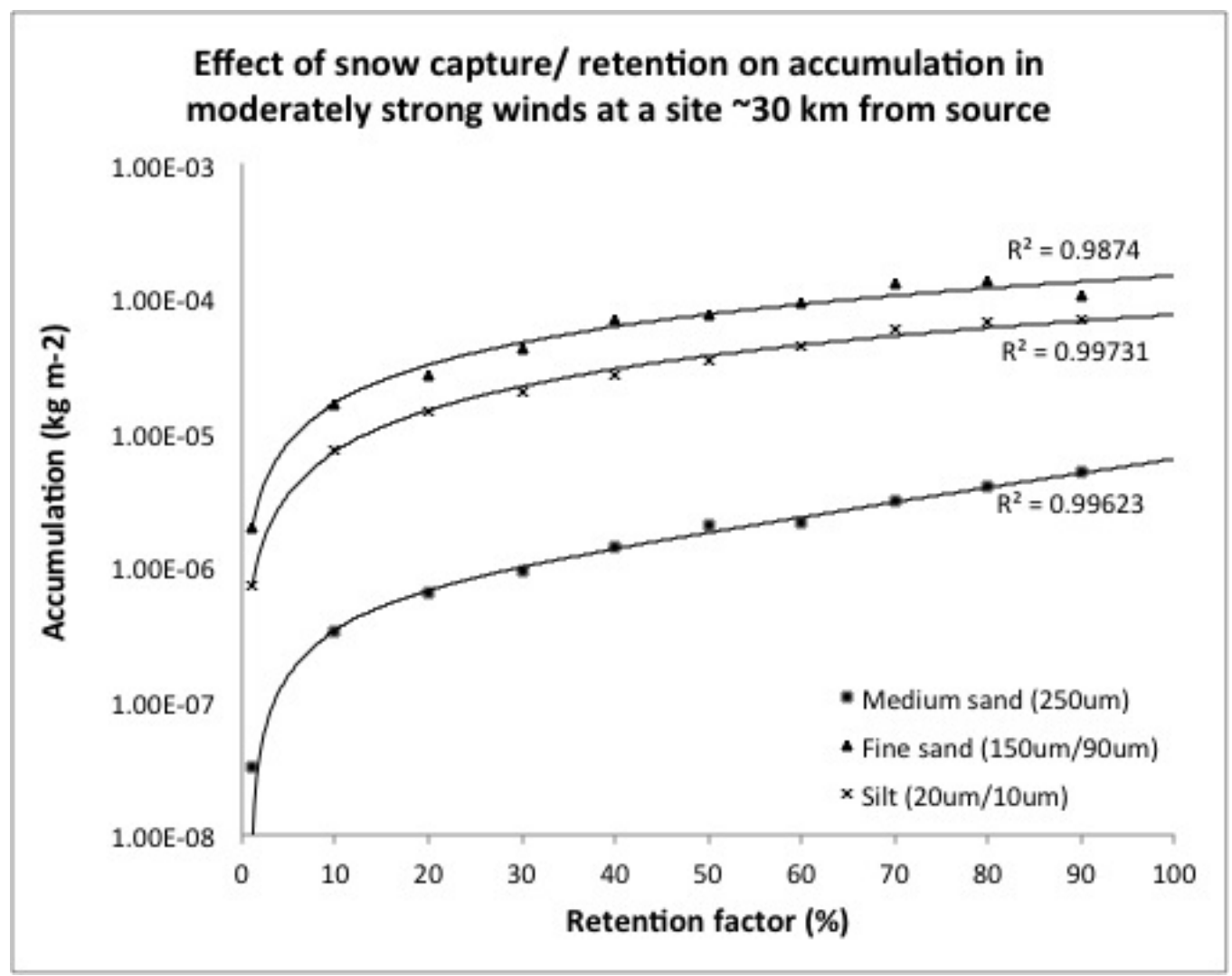

Figure 6.4: Effect of snow capture/ retention on accumulation. Accumulation data are for a location $\sim 30 \mathrm{~km}$ downstream from a source positioned on the McMurdo Ice Shelf debris bands (as illustrated in Figure 1.2). Trendlines are given by a 3rd order polynomial for medium sand and a power law for both fine sand and silt.

\subsubsection{Sediment supply rate $(M)$}

Field observations from the McMurdo Ice Shelf debris bands indicate there is more sediment present than the wind can move. In the NaMASTE model the sediment supply rate $(M)$ sets the rate at which new material is supplied at locations specified as "seed cells", or sediment point sources. Calculated outward flux (i.e. erosion) cannot exceed the amount of sediment that actually exists at any given cell, including in these seed cell(s).

For the purpose of sensitivity testing each seed cell was assumed to contain an equivalent mass of each of the three grain size groupings used in this study (i.e. medium sand, fine sand, and silt). $M$ was tested in the range $0.1-1.0 \mathrm{~kg} \mathrm{~m}^{-2} \mathrm{~s}^{-1}$ to assess how variations in the availability of source sediment affects accumulation downstream. The three grain size groupings show no change in sediment accumulation with change 
in $M$ (Figure 6.5). The only variance in sediment accumulation is due to grain size and wind strength which, as mentioned above, is a consistent trend throughout all tests. This suggests the erosion rate is lower than the lowest values tested.

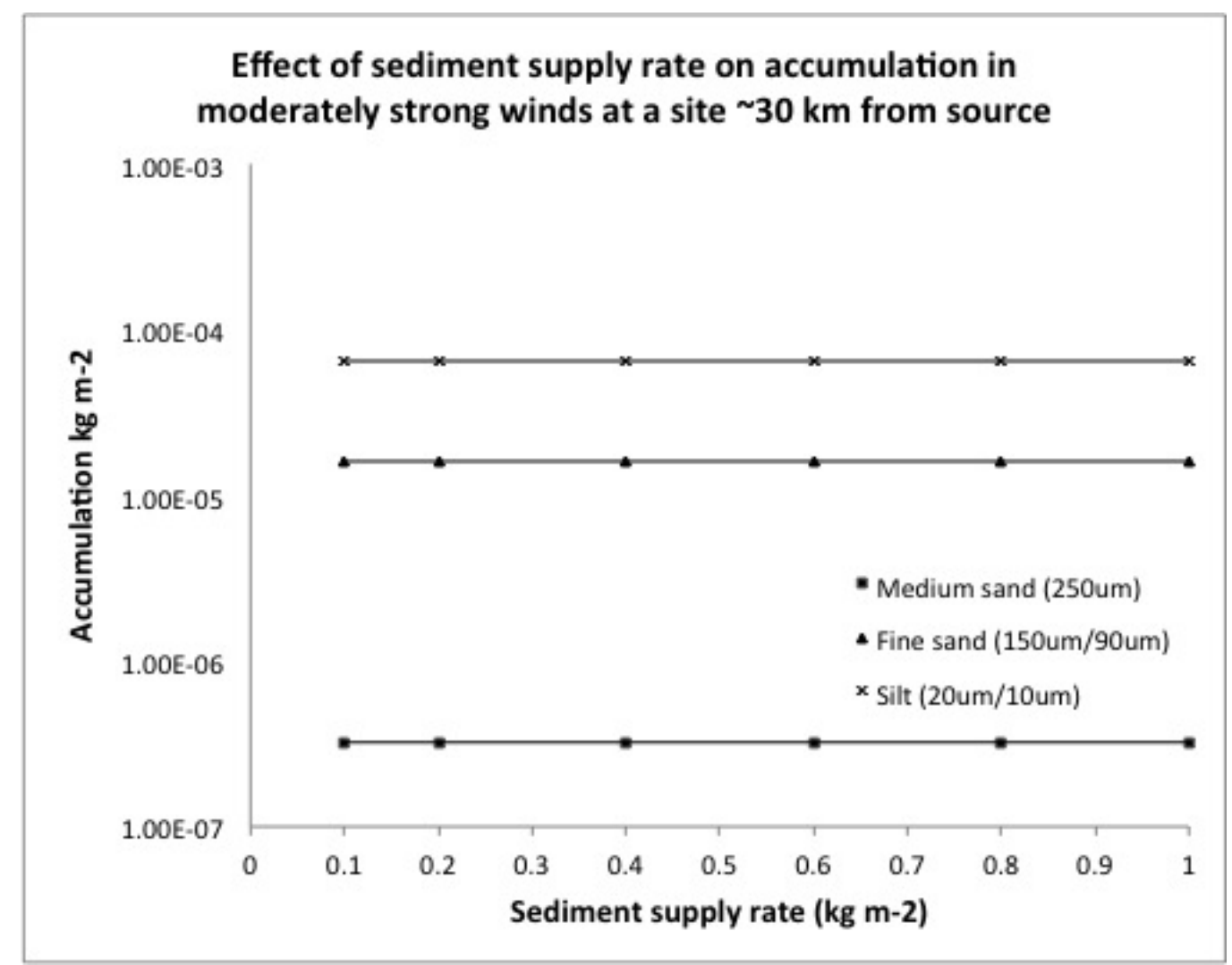

Figure 6.5: Effect of sediment supply rate on accumulation in light winds. Accumulation data is for a location $\sim 30 \mathrm{~km}$ downstream from a source positioned on the McMurdo Ice Shelf debris bands. 


\subsubsection{Wind velocity $(v)$}

Wind speed $(v)$ was prescribed by a simple multiplier (scalar) of the fixed wind field velocities. The four-year annual mean wind field used in all tests has velocities ranging between $0-17 \mathrm{~m} \mathrm{~s}^{-1}$ depending on geographic location. It was scaled up by 5 and 9 to obtain wind speeds on the sea ice (and McMurdo Ice Shelf debris bands) as per the values given in Table 6.1. These wind speeds provided outputs pertaining to winds that are 1) just strong enough to entrain and transport material (light), 2) those events thought to be most-likely to transport significant amounts of sediment (moderately strong), and 3) for the case of an extreme wind event (e.g. 16 May, 2005 katabatic storm; Steinhoff et al., 2008). Note that the scalar does not alter wind direction.

Of the parameters investigated, increasing the wind speed over a realistic range of values for the sea ice platform causes the largest variance in sediment accumulation of all variables tested. In all instances, with increased velocity, entrainment and thereby accumulation are exponentially enhanced (see Section 2.1 and Section 2.2) for each of the grain size groupings, resulting in higher accumulation, as clearly shown in Figure 6.6.

Table 6.1: Range of velocities within static wind fields (from AMPS input data), including those scaled up by a simple multiplier (scalar). Beaufort scale equivalent relates to the range of velocities over the sea ice. Wind direction tends to be more directional from the south with increased wind speeds.

\begin{tabular}{|c|c|c|c|c|c|c|c|}
\hline Field & Wind & Scalar & Min-Max & Mean & $\begin{array}{l}\text { Sea ice } \\
\text { range }\end{array}$ & $\begin{array}{c}\text { Beaufort } \\
\text { Scale }\end{array}$ & $\begin{array}{l}\text { Mean wind } \\
\text { direction }\end{array}$ \\
\hline & & & $\mathrm{m} \mathrm{s}^{-1}$ & $\mathrm{~m} \mathrm{~s}^{-1}$ & $\mathrm{~m} \mathrm{~s}^{-1}$ & (equiv.) & $\begin{array}{c}\text { (degrees from } \\
\text { grid North) }\end{array}$ \\
\hline \multirow[t]{3}{*}{9999} & Light & 1 & $0-17$ & $6 \pm 3$ & $1-5$ & $1-3$ & $+6 \pm 57$ \\
\hline & Moderately strong & 5 & $5-85$ & $31 \pm 17$ & $5-25$ & $3-9$ & \\
\hline & Hurricane force & 9 & $9-153$ & $56 \pm 31$ & $9-45$ & $8-12$ & \\
\hline 5208 & Fresh (variable) & 1 & $0-28$ & $12 \pm 5$ & $0-15$ & $0-7$ & $+29 \pm 57$ \\
\hline 5192 & Moderately strong & 1 & $0-40$ & $16 \pm 6$ & $5-25$ & $3-9$ & $-3 \pm 30$ \\
\hline 5207 & Strong & 1 & $8-28$ & $15 \pm 4$ & $10-20$ & $5-8$ & $+5 \pm 23$ \\
\hline $3211^{*}$ & Gale force & 1 & $6-32$ & $17 \pm 6$ & $15-30$ & $7-11$ & $-18 \pm 14$ \\
\hline
\end{tabular}

*16 May, 2004 storm peak, true peak velocity under-represented by AMPS 


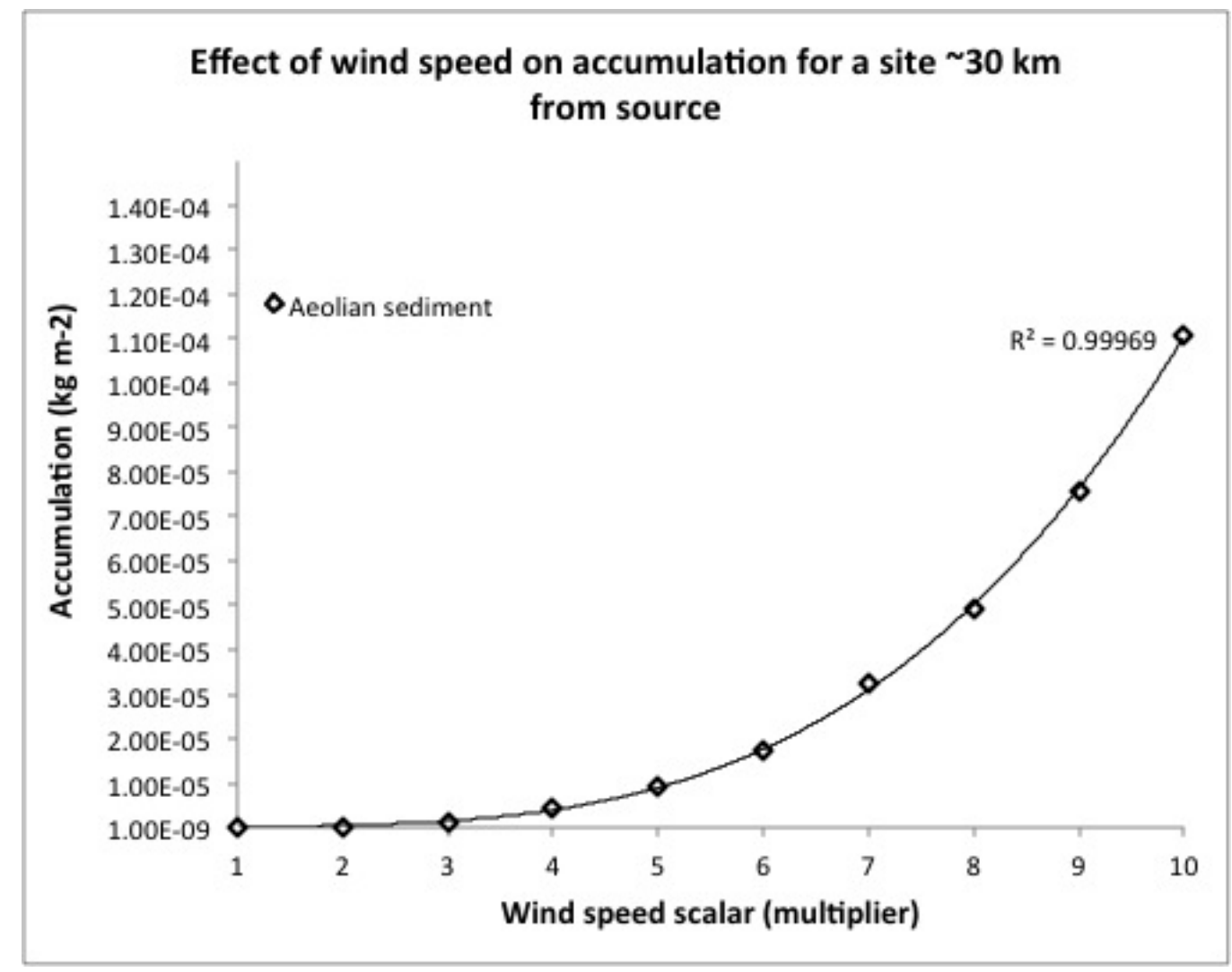

Figure 6.6: Effect of wind strength on accumulation using a multiplication factor to scale wind strength in a fixed wind field. Accumulation data is for a location $\sim 5 \mathrm{~km}$ downstream from a source positioned on the McMurdo Ice Shelf debris bands.

\subsubsection{Time $(t)$}

Time $(t)$ exerts a significant effect on accumulation as illustrated in Figure 6.7. The relationship between sediment accumulation and time is strongly linear for locations nearest to source, while locations further afield exhibit a strong power law relationship, as evinced by an $\mathrm{R}^{2}$ value of 0.96 . Using a storm-state wind field (refer Figure 5.6 and a source located on the McMurdo Ice Shelf for progressively increasing increments of time (hours) this simulation reaches an almost steady state after 72 hours.

A steady-state arises when the system is 'saturated' and fluxes are balanced, i.e. the flux out of a cell is equal to the flux entering the cell. The distribution suggests, 1) the material least easily moved (i.e. that with greater mass) reaches saturation close to the source, while material more readily moved takes a longer time to reach the same state, or 2) that it takes a longer time to move coarser sediment to a more distant location to thereby achieve the balance of fluxes at a given point. 


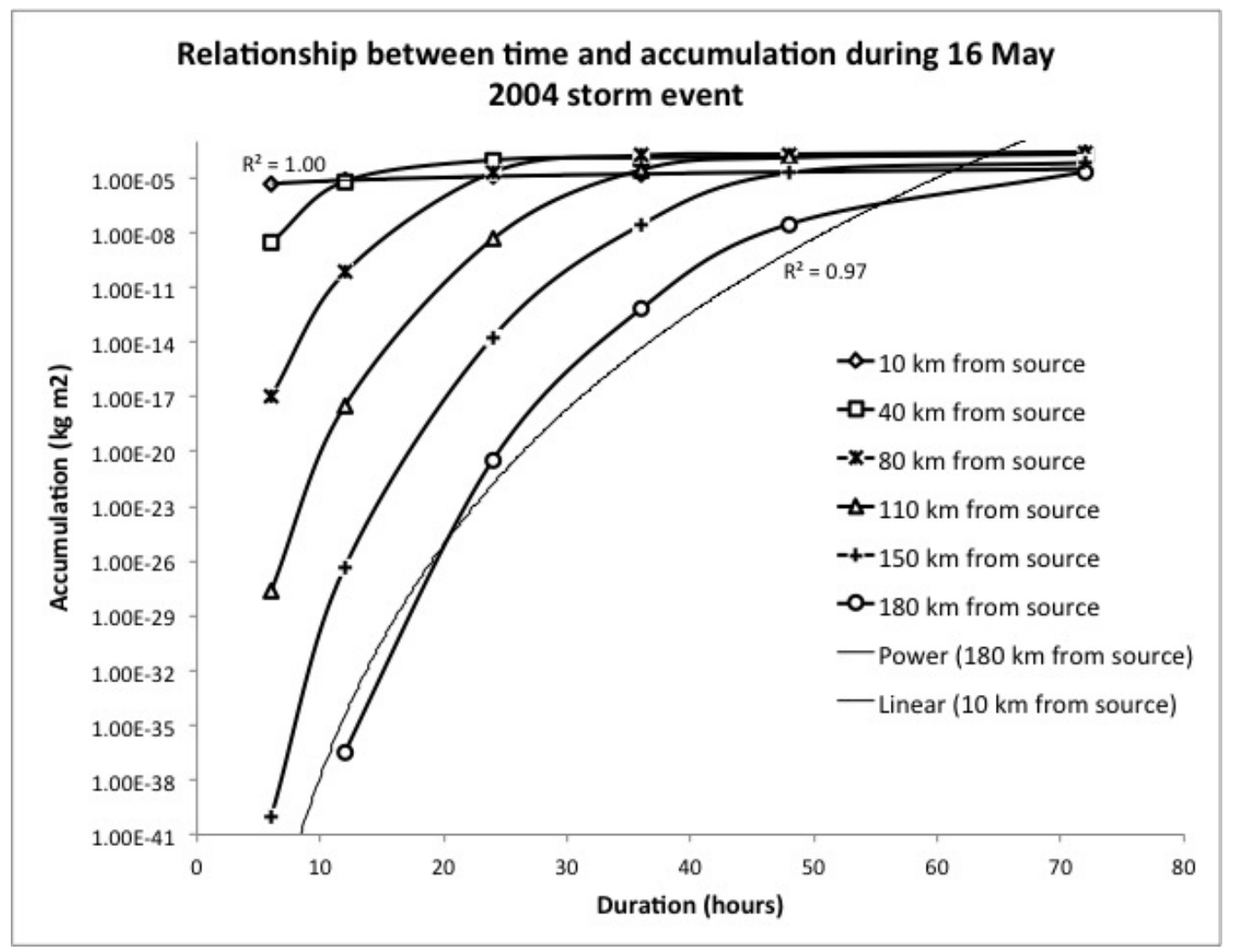

Figure 6.7: Effect of time on accumulation in a fixed wind field. Accumulation data is for a locations situated along a transect running $\sim 10-180 \mathrm{~km}$ downstream from a source positioned on the McMurdo Ice Shelf debris bands.

\subsection{Predictive modelling}

For this first application of NaMASTE, the primary goal for predictive modelling was to see if the spatial distribution pattern provided by the empirical data in McMurdo Sound could be broadly replicated by the model. Parameter values used to predict for the observed distribution are shown in Table 6.2. Once a "best fit" distribution was produced (Figure 6.8), a selection of sample site locations within the domain (shown as dots) were chosen as points of comparison. Aeolian sediment is found at all of these points within the modelled distribution though in greatly varying quantities (as discussed below). 
Table 6.2: Test variables used to predict a "best fit" distribution of modelled accumulation to the MAR distribution found in the empirical data. Three source cells were included, these were: a.) McMurdo Ice Shelf debris bands; b.) Gneiss/Marble Points; and, c.) Discovery Bluff, Granite Harbour. Outputs are shown as map plots in Figure 6.8 and Figure 6.9.

\begin{tabular}{lccc}
\hline \multicolumn{3}{c}{ Test parameters for wind fields: 5192, 5207, and 5208 } \\
\hline Variable & Symbol & Units & Value \\
\hline \hline Runtime & $t$ & hours & 59 \\
Scalar & & & 1.0 \\
\hline Entrainment coefficient & $A$ & & 0.1 \\
Retention factor & $R$ & & 0.2 \\
Sorting coefficient & $\delta$ & & 0.2 \\
Roughness factor & $\lambda$ & $\mathrm{m}^{-2}$ & 0.0005 \\
\hline Seed1a $(250 \mu \mathrm{m})$ & $M$ & $\mathrm{~kg} \mathrm{~m}^{-2}$ & 1.00 \\
Seed1b $(150 \mu \mathrm{m})$ & $M$ & $\mathrm{~kg} \mathrm{~m}^{-2}$ & 0.50 \\
Seed1c $(90 \mu \mathrm{m})$ & $M$ & $\mathrm{~kg} \mathrm{~m}^{-2}$ & 0.50 \\
Seed1d $(20 \mu \mathrm{m})$ & $M$ & $\mathrm{~kg} \mathrm{~m}^{-2}$ & 0.01 \\
Seed1e $(10 \mu \mathrm{m})$ & $M$ & $\mathrm{~kg} \mathrm{~m}^{-2}$ & 0.01 \\
\hline Seed2a $(250 \mu \mathrm{m})$ & $M$ & $\mathrm{~kg} \mathrm{~m}^{-2}$ & 1.00 \\
Seed2b $(150 \mu \mathrm{m})$ & $M$ & $\mathrm{~kg} \mathrm{~m}^{-2}$ & 0.01 \\
Seed2c $(90 \mu \mathrm{m})$ & $M$ & $\mathrm{~kg} \mathrm{~m}^{-2}$ & 0.50 \\
Seed2d $(20 \mu \mathrm{m})$ & $M$ & $\mathrm{~kg} \mathrm{~m}^{-2}$ & 0.50 \\
Seed2e $(10 \mu \mathrm{m})$ & $M$ & $\mathrm{~kg} \mathrm{~m}^{-2}$ & 0.10 \\
\hline Seed3a $(250 \mu \mathrm{m})$ & $M$ & $\mathrm{~kg} \mathrm{~m}^{-2}$ & 0.01 \\
Seed3b $(150 \mu \mathrm{m})$ & $M$ & $\mathrm{~kg} \mathrm{~m}^{-2}$ & 0.02 \\
Seed3c $(90 \mu \mathrm{m})$ & $M$ & $\mathrm{~kg} \mathrm{~m}^{-2}$ & 0.02 \\
Seed3d $(20 \mu \mathrm{m})$ & $M$ & $\mathrm{~kg} \mathrm{~m}^{-2}$ & 0.01 \\
Seed3e $(10 \mu \mathrm{m})$ & $M$ & $\mathrm{~kg} \mathrm{~m}^{-2}$ & 0.01 \\
\hline Source $(\mathrm{a})$ grid coordinates & & $(\mathrm{x}, \mathrm{y})$ & $(33,35)$ \\
Source $(\mathrm{b})$ grid coordinates & & $(\mathrm{x}, \mathrm{y})$ & $(16,46)$ \\
Source $(\mathrm{c})$ grid coordinates & & $(\mathrm{x}, \mathrm{y})$ & $(01,58)$ \\
\hline \hline
\end{tabular}




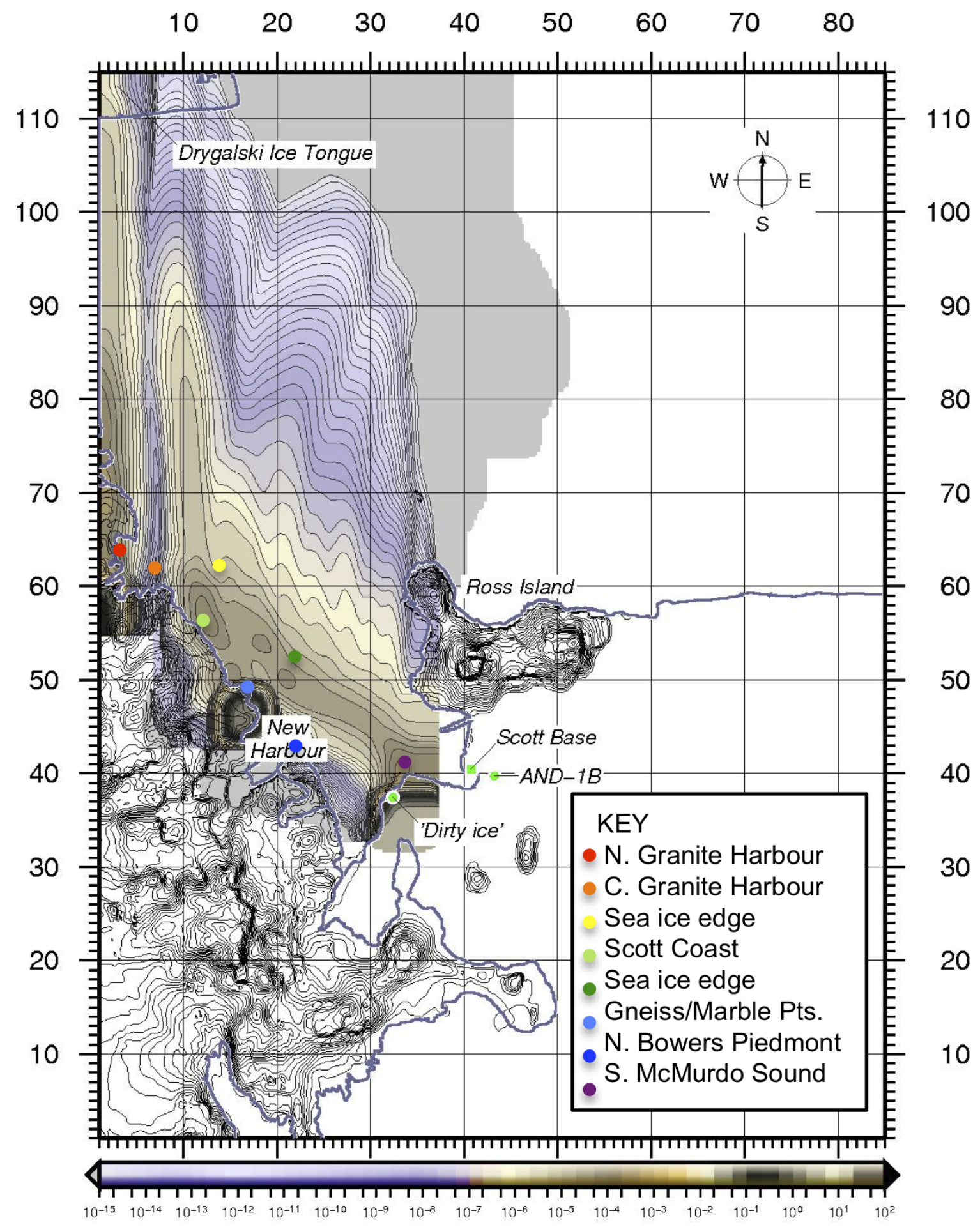

Dust conc. $\left(\mathrm{kg} \mathrm{m}^{2}\right)$

Figure 6.8: NaMASTE predictive plot of aeolian sediment dispersal for McMurdo Sound and the southwest Ross Sea providing a strong resemblance to the distribution observed in the empirical aeolian sediment dataset collected in 2010 for this study. Dots=locations used for comparison between modelled accumulation and observed values. Model run duration is 59 hours, as calculated from Pegasus North AWS 2001-2012, 10 min data. Dominant wind direction at source indicated by compass arrow (top right corner). Model wind field velocity range is shown in Figure 5.5. 


\section{Spatial distribution}

The general pattern of the modelled scenario provides a good match to observed distribution features, for example, the areas of relatively high accumulation north of the McMurdo Ice Shelf and Marble Point, and an area of low accumulation in Granite Harbour, though the fit is not as good for southwest McMurdo Sound. In some depositional areas the sediment plumes generated from the three user-defined point sources merge downstream from source. Because of this complexity, attributing the relative contribution of accumulation to individual sediment sources is difficult once merging has occurred; however, before sediment pathways merge, attribution to specific sources is possible.

Sediment plume margins also show dispersal onto the coastal topography, indicating dispersal is possible onto piedmont glaciers (as previously suggested by Ayling, 2001 and Schuck, 2009), and onto Ross Island. Dust accumulation decreases east with distance from the Victoria Land Coast, which is also the case for observed data. It is also worth noting that the northern extremities of the modelled distribution also reach as far as the Drygalski Ice Tongue and areas east of Ross Island, though in amounts much lower $\left(10^{-5}-10^{-12} \mathrm{~g} \mathrm{~m}^{-2} \mathrm{y}^{-1}\right)$ than would be expected from global fallout rates.

\section{Sediment accumulation}

Replicating observed sediment accumulation values is problematic because the static wind field cannot reproduce a year's variability of strong wind events. To account for this, a cumulative estimate for strong wind event duration was used in conjunction with a typically strong wind field (explained in Subsection 5.5.2). Modelled accumulation values do not reliably replicate observed values, as illustrated in Table 6.3, and are highly variable.

To illustrate peturbation by the same variables under different wind fields, two alternative plots are provided in Figure 6.9. Comparative values for the selected matching points in Figure 6.8 are also shown in Table 6.3. In all three scenarios, modelled values are generally several orders of magnitude lower than observed MAR values, which were all within $10^{-1}$ to $10 \mathrm{~g} \mathrm{~m}^{-2} \mathrm{y}^{-1}$ ). Trace quantities to the degree suggested by the model may of course be present in the real system; however, they are not seen in the MAR values or are not detectable at the resolution to which samples were analysed.

Static wind fields are used for simplicity, but they are not a good representation of reality. Aeolian processes are threshold dependent, but there is more than one 
Table 6.3: Observed accumulation and modelled accumulation for corresponding locations both within the domain and field area. Values in italics are below the observed minimum MAR.

\begin{tabular}{lcccccc}
\hline $\begin{array}{l}\text { Location } \\
\text { (geographic) }\end{array}$ & $\begin{array}{c}\text { Sample site } \\
\text { (ID) }\end{array}$ & $\begin{array}{c}\text { MAR } \\
\mathrm{g} \mathrm{m}^{-2} \mathrm{y}^{-1}\end{array}$ & $\begin{array}{c}\text { Domain } \\
\text { grid ref. } \\
(\mathrm{x}, \mathrm{y})\end{array}$ & $\begin{array}{c}\text { Modelled accumulation } \\
\mathrm{g} \mathrm{m}^{-2} \mathrm{y}^{-1} \\
(5192)\end{array}$ & $(5207)$ & $(5208)$ \\
\hline \hline N. Granite Harbour & CR-C3 & 2.52 & $(03,64)$ & 0.05 & 0.47 & 0.03 \\
C. Granite Harbour & CR-D5 & 0.20 & $(07,62)$ & $3.37 E-09$ & 0.01 & $1.70 E-07$ \\
Sea ice edge & CR-F9 & 1.42 & $(14,62)$ & 0.01 & $1.46 E-09$ & $1.33 \mathrm{E}-04$ \\
Scott Coast & CR-J6.5 & 5.54 & $(12,56)$ & 2.01 & 0 & $4.45 E-06$ \\
Sea ice edge & MP-M11 & 1.66 & $(22,53)$ & 0.01 & $8.48 E-07$ & $7.78 E-10$ \\
Gneiss/Marble Points & MP-N8 & 30.1 & $(17,49)$ & 0.05 & 1.01 & 0.46 \\
N. Bowers Piedmont & MP-S10 & 6.31 & $(22,43)$ & $2.13 E-08$ & NaN & $1.66 \mathrm{E}-04$ \\
S. McMurdo Sound & MP-V17 & 4.03 & $(34,41)$ & 0.24 & 0.25 & $8.60 \mathrm{E}-04$ \\
\hline \hline
\end{tabular}

threshold to consider (e.g. entrainment velocity, sediment availablity, grain size); therefore, variability between output distributions should be expected. However, if a single windfield can produce a good match to the observed data, it could suggest the sediment is moving only in short-term 'blasts', during intermittent strong wind events. 


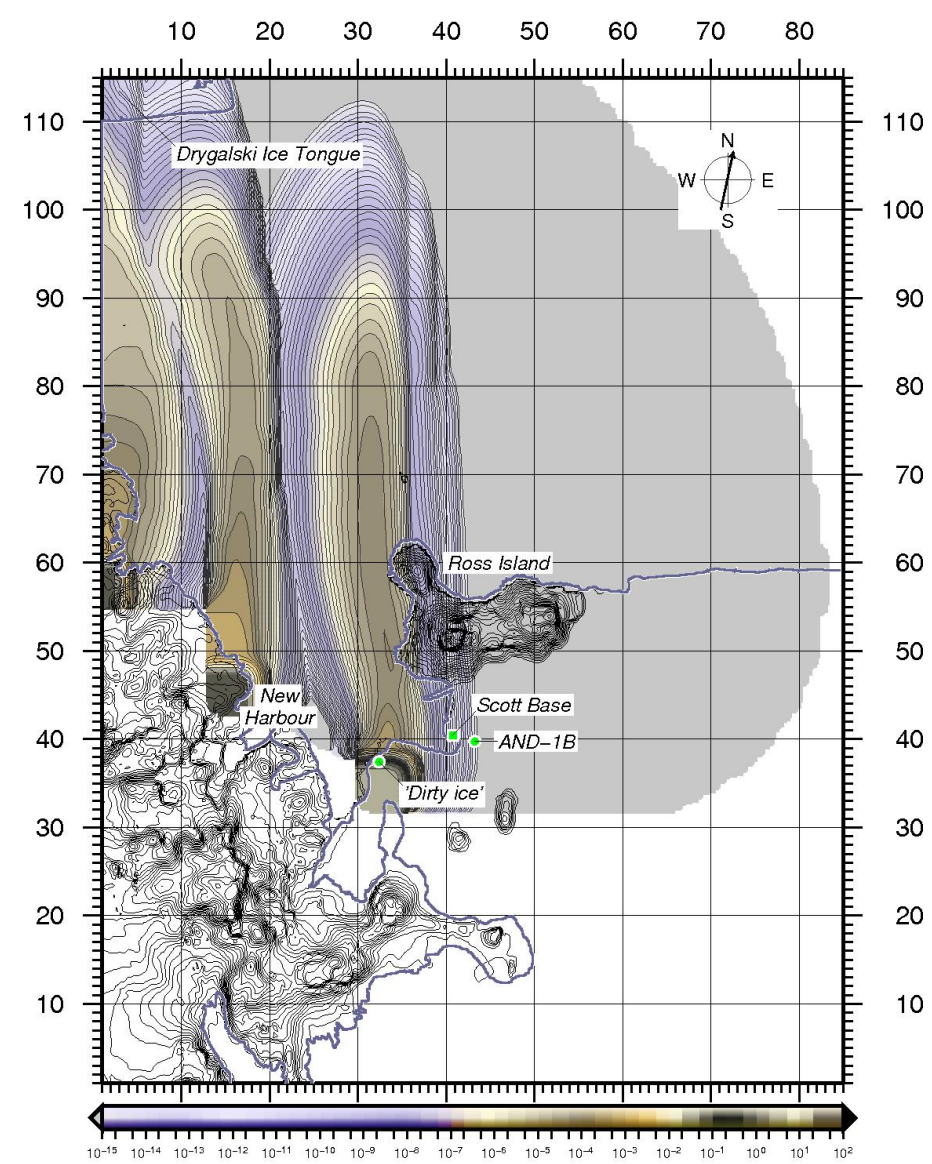

Dust conc. $\left(\mathrm{kg} \mathrm{m}^{2}\right)$

(a)

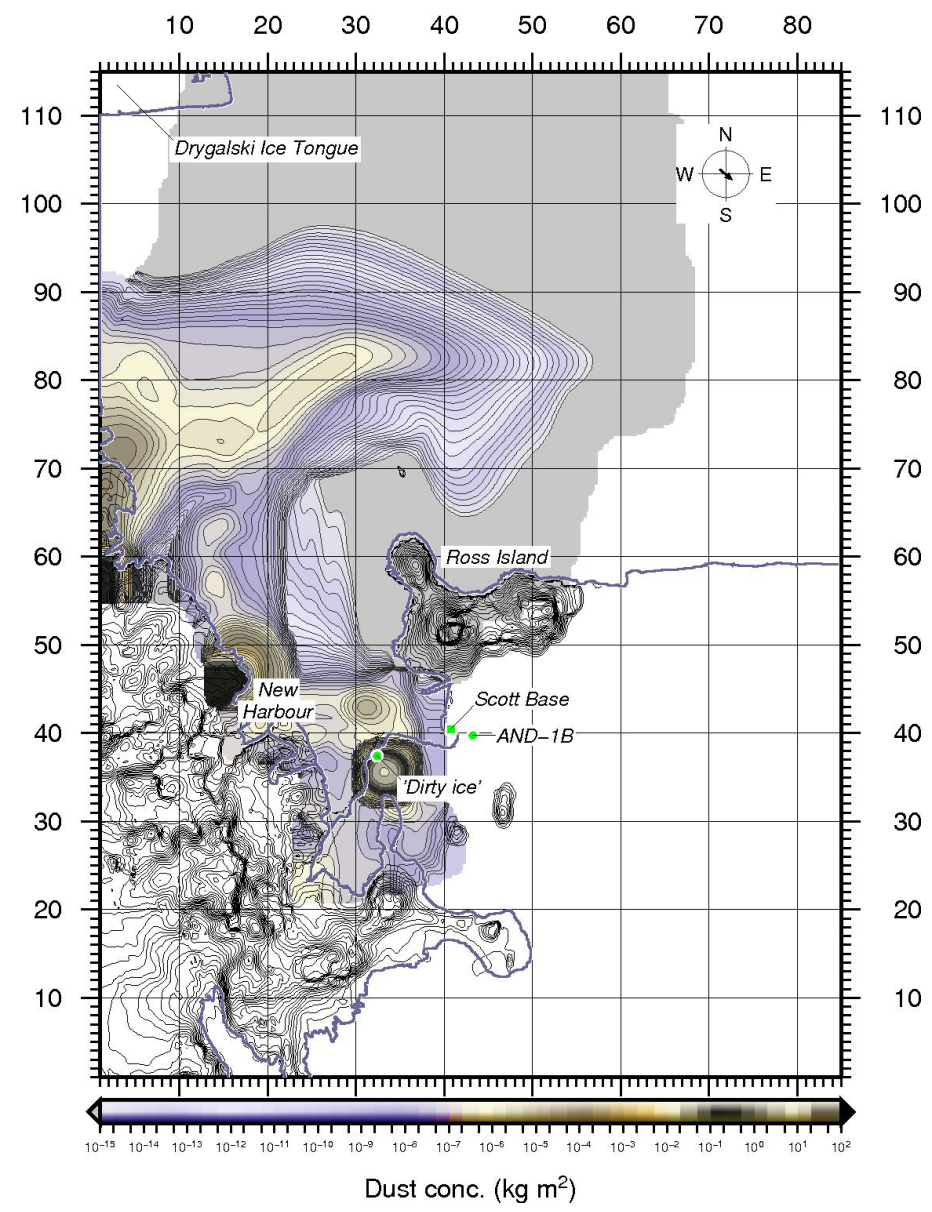

(b)

Figure 6.9: NaMASTE alternative predictive plots of aeolian sediment dispersal for McMurdo Sound and the southwest Ross Sea for comparison to best fit plot, using: a) a strong katabatic storm event wind field, and b) a strong, but more variable wind field. Model run duration is 59 hours, as for best fit plot shown in Figure 6.8, as calculated from Pegasus North AWS 2001-2012, 10 min data. Model wind fields used (5207 and 5208, respectively) are provided in Appendix E. Dominant wind direction at source indicated by compass arrow (top right corner). 


\subsection{Summary of modelling results}

Sensitivity tests were run to explore appropriate value ranges for the user-defined independent variables. Values for the entrainment coefficient $(A)$ published in the literature, 0.1 for initial entrainment and 0.08 for continued entrainment, were tested for their applicability to the environment of the study area. A range of values greater and less than these values was also tested. Sand was not as easily entrained for values $>0.1$. Values lower than 0.08 showed no change in accumulation; therefore, the published values were found to be appropriate for the conditions, as entrainment occurred for all grain sizes at these values.

The sorting coefficient $(\delta)$ exerted only subtle changes on accumulation, with medium sand being the most responsive to changes in this parameter (though it should be noted that the range of sorting values used in modelling is narrower than the observed data). With a decrease in sorting, a slight increase in accumulation occurs, suggesting that though this parameter does not strongly influence accumulation, the poorer the sorting of source material, the more sediment available for transport. Surface roughness $(\lambda)$ was also investigated at grain-scale, to observe its effect on entrainment. Results show that the relationship follows a power law with accumulation increasing with increase in $\lambda$ value. This increase is most pronounced for the lowest values tested.

A retention factor $(R)$ is provided to simulate snow capture of sediment on the sea ice. The model was found to be relatively insensitive to this parameter, therefore, an estimate of $R$ was used for predictive modelling runs. The rate of sediment supply $(M)$ was also investigated. No change in sediment accumulation with change in $M$ was seen, suggesting the erosion rate is less than the lowest value tested.

Wind speed $(v)$ was found to be the most significant influence on accumulation. With increased velocity, accumulation increases by a power law. The effect of time $(t)$ on accumulation was explored by comparing accumulation at distances along a transect running downstream from source during a storm event. It showed that given enough time an equilibrium state would be reached, as could be expected.

Application of the model to replicate the dispersal pattern seen in observed data found the model simulates the observed spatial distribution convincingly, but reproducing accumulation was not as successful. That the spatial distribution can be broadly matched within a single wind field suggests that strong wind events are the dominant mechanism for dispersal in the region. 


\section{Part III}

\section{Synthesis of empirical and modelling findings}





\section{Chapter 7 McMurdo Sound aeolian sediment dispersal}

\subsection{What are the sources of aeolian sediment in McMurdo Sound?}

Local sources of aeolian sediment have yet to be included in dust distribution models for Antarctica in general and the Ross Sea in particular, in part through lack of constraining data (e.g. Li et al., 2010; Albani et al., 2012). Aeolian sediment accumulation rates for locations in Antarctica are highly variable, as shown in Table 7.1, with values for ice cores from the continental interior being much lower than those found in coastal regions. The distribution of aeolian sediment MARs, grain size, petrography, and numerical modelling of transport pathways under the local wind regime show that a number of local sources contribute to aeolian sediment found on the sea ice in McMurdo Sound. Furthermore, results from this study show "global" dust models underestimate aeolian sediment inputs for the southwest Ross Sea by 3-5 orders of magnitude.

Attributing relative importance of these local sources is difficult; however, the primary source of aeolian sediment in McMurdo Sound is considered to be the McMurdo Ice Shelf debris bands, (described in Subsection 1.5.2). There are three reasons for making this statement, 1 ) both MARs and the percentage of coarse sediment in sea ice samples decrease with distance downwind from the debris bands, forming a sediment "plume" trailing north from the McMurdo Ice Shelf, which is visible in satellite imagery (Figure 7.1), 2) the McMurdo Ice Shelf debris bands represents the largest area of exposed, unconsolidated sediment $\left(\sim 750 \mathrm{~km}^{2}\right)$ in the region; the high ablation rate (43-411 $\mathrm{mm} \mathrm{y}^{-1}$; Glasser et al., 2006) combined with basal freezing, means there is a constantly renewed source of fine sediment to the surface of the ice shelf, and 3) petrographic analysis of sea ice samples shows that volcanic glass, sourced from MVG-derived sediment in the debris bands, is widespread throughout the study area. Volcanic glass is present in $99 \%$ of the samples studied, and is common in $71 \%$ of the samples (Section 4.2). The large surface area of meltwater ponds means the debris 
bands produces a large component of silt-sized biogenic material (e.g. Hawes and Howard-Williams, 2003) also present in sediment on the sea ice, most commonly in the form of siliceous sponge spicules (of seafloor origin) and freshwater diatoms which were both widespread.

Table 7.1: Aeolian sediment accumulation rates at various locations on the Antarctic continent from observations and modelled data.

\begin{tabular}{|c|c|c|c|}
\hline Site & $\begin{array}{c}\text { Equiv. aeolian } \\
\text { sed. accum. rate } \\
\left(\mathrm{g} \mathrm{m}^{-2} \mathrm{y}^{-1}\right)\end{array}$ & $\begin{array}{l}\text { Modal } \\
\text { size } \\
(\mu \mathrm{m})\end{array}$ & Reference \\
\hline \multirow[t]{3}{*}{ Byrd Station } & 0.001 & $<20$ & Windom (1969) \\
\hline & 0.005 & $0.1-10$ & Mahowald et al. (1999) \\
\hline & 0.001 & & Li et al. $(2010)$ \\
\hline \multirow[t]{4}{*}{ Dome C } & $\sim 0.0001$ & $0.1-10$ & Lambert et al. (2008) \\
\hline & (modelled) 0.001 & & Li et al. (2010) \\
\hline & Holocene 0.0045 & & Delmonte et al. (2004b) \\
\hline & Holocene 0.004 & $0.1-10$ & Lambert et al. (2008) \\
\hline \multirow[t]{3}{*}{ MDV - exposures } & $0.43-3.73$ & silt/clay & Lancaster (2002) \\
\hline & $0.86-441.8$ & sand & Lancaster (2002) \\
\hline & $0.83-2,447.3$ & & Šabacká et al. (2012) \\
\hline \multirow[t]{2}{*}{ MDV - Victoria L. Gl. } & 24.9 & $63-200$ & Schuck (2009) \\
\hline & summer 6.48 & & Ayling and McGowan (2006) \\
\hline Talos Dome & Holocene 0.013 & $<5$ & Delmonte et al. (2010a) \\
\hline Taylor Dome & Holocene 0.0009 & & Hinkley and Matsumoto (2001) \\
\hline \multirow[t]{4}{*}{ Vostok } & $\sim 0.0005$ & $0.1-10$ & Petit and etal (1999) \\
\hline & 0.0004 & 1 & Delmonte et al. $(2004 \mathrm{~b})$ \\
\hline & $\sim 0.0005$ & $1-1.25$ & Lambert et al. (2008) \\
\hline & (modelled) 0.0012 & & Li et al. (2010) \\
\hline
\end{tabular}

*MDV: McMurdo Dry Valleys

In addition to the McMurdo Ice Shelf debris bands, several other sources of aeolian sediment are apparent. A source of secondary importance, as suggested by very high MARs and a high concentration of sand-sized material forming a large plume $\left(\sim 150 \mathrm{~km}^{2}\right)$ on the sea ice, is unconsolidated Ross Sea Drift and beach deposits along the Scott Coast (Figure 7.2). This stretch of coastline is isolated from potential inland MDV sediment sources by Wilson Piedmont Glacier. Numerical modelling of aeolian transport by local winds undertaken in this study suggests some material from sources further south may merge with local sediment at this site, making it difficult to attribute relative contributions; however, the high quantities of fine sand and a lower abundance of volcanic glass close to the coast suggest a significant amount of, at least the sand-sized sediment, originates here. 


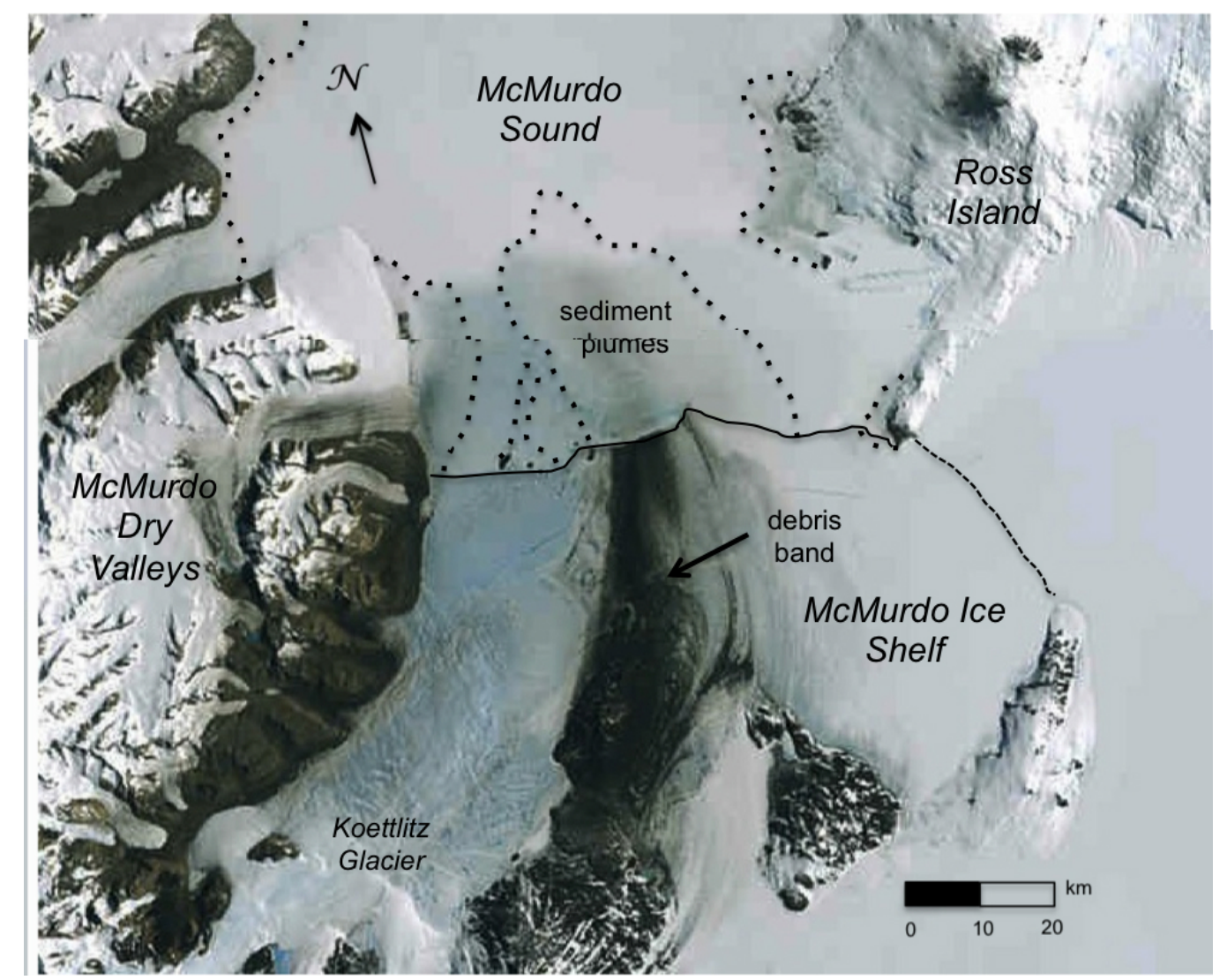

Figure 7.1: Satellite image of the McMurdo Ice Shelf debris bands, with aeolian sediment plume extending northwards onto sea ice in McMurdo Sound. Image: NASA.

Taylor Valley, in contrast to the glacier-dammed valleys to the north, is open to the sea at New Harbour. Significant amounts of aeolian sediment are seen on the sea ice within New Harbour, suggesting that sediments derived from the lower Taylor Valley and coastal deposits around New Harbour are the source of this sediment. MARs and sand content values from this study are highest close to the coastline, which is consistent with studies by Bentley (1979) and Murray et al. (2012) that documented significant aeolian sediment deposits on the sea ice in this area. It is unclear how far this sediment extends into McMurdo Sound as it merges with sediment from other sources along the coast and the McMurdo Ice Shelf debris bands.

North of Cape Roberts and within Granite Harbour volcanic glass becomes rare, while quartz appears to be slightly more abundant (also observed by Winton, 2011), suggesting material from the McMurdo Ice Shelf is diluted by a greater input from quartz-rich TAM sources to the west. This is also consistent with neodymium and strontium isotopic analyses that suggested a greater contribution from TAM lithologies in dust samples from sea ice in southeast Granite Harbour compared to samples from southern McMurdo Sound (Winton, 2011). 


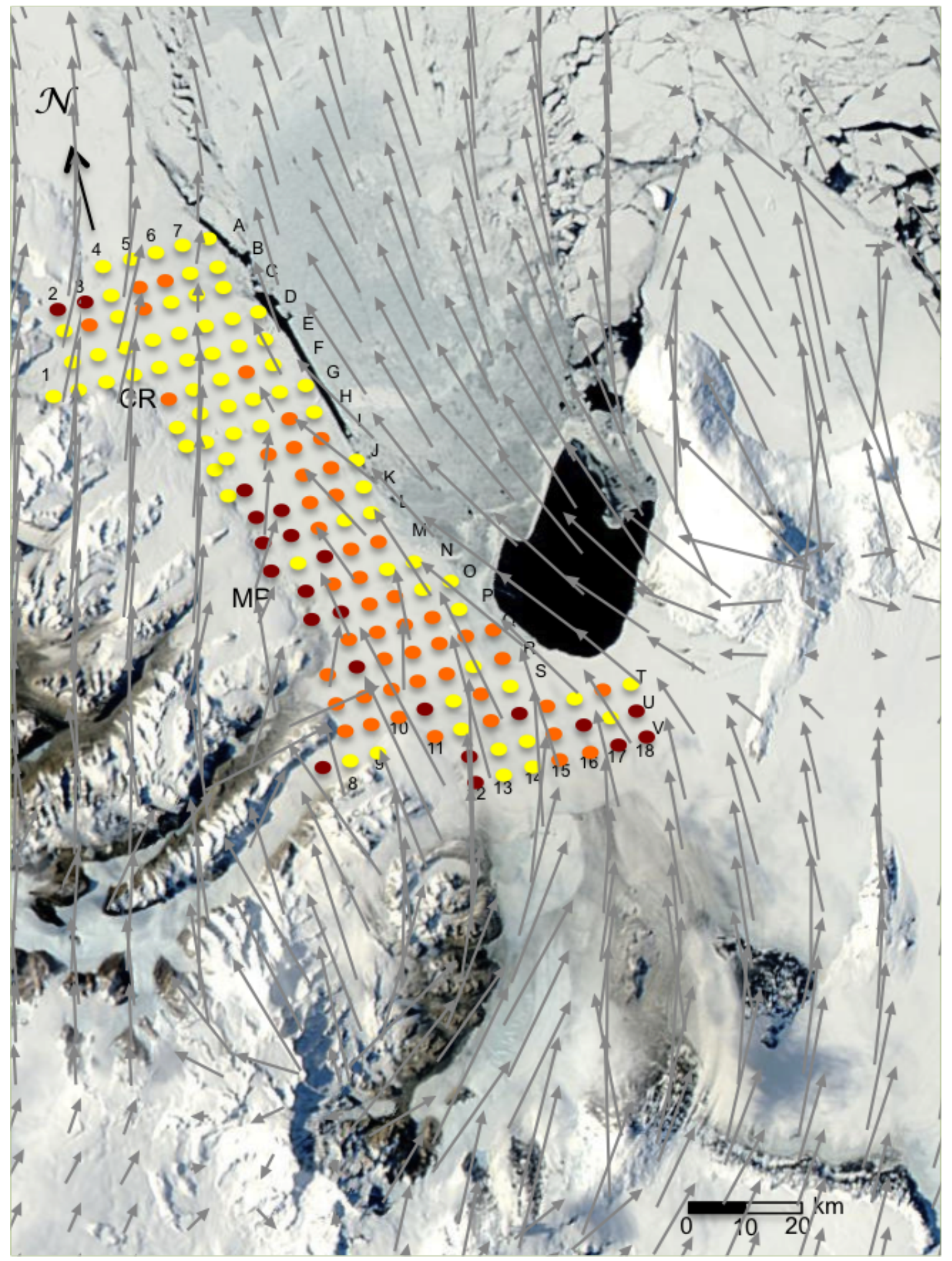

Figure 7.2: Mass accumulation rates and storm-dominated wind flow. Accumulation rate plotted as: brown=high accumulation (lower boundary $3.75 \mathrm{~g} \mathrm{~m}^{-2} \mathrm{y}^{-1}, 84$ th percentile), red=mid-range accumulation (lower boundary $1.65 \mathrm{~g} \mathrm{~m}^{-2} \mathrm{y}^{-1}$, 50th percentile) and yellow=low accumulation $\left(<1.65 \mathrm{~g} \mathrm{~m}^{-2} \mathrm{y}^{-1}, 16\right.$ th percentile $)$. 
Whether material from the MDV could be carried over the Wilson Piedmont to the sea ice has yet to be determined. Certainly, no clear evidence was found in this study to suggest that this occurs. Within this Victoria Lower Glacier system on the western side of Wilson Piedmont, a predominance of sediment $<100 \mu$ ) is found in glacier ice and reasonably high sediment accumulation rates have been observed (Table 7.1), plus sand recycling within the glacier has been suggested (Ayling and McGowan, 2006; Schuck, 2009). Such information implies only fine material $(<100 \mu \mathrm{m})$ is transported to the upper piedmont from the valley floors and walls. As no significant accumulation attributable to inland sources was observed on the sea ice along the piedmont coastal margin, this suggests any material moving seawards from valley sources is deposited onto the glacier surface and returned to the MDV, therefore making little offshore contribution. Moreover, any MDV sediment would presumably be overprinted by the greater abundance of material generated from Ross Sea Drifts along the Wilson Piedmont coastline.

Comparing MAR and grain size data to the distribution of high velocity winds, as shown in Figure 7.2 and Figure 7.3, highlights transport pathways and source areas. The contribution of individual sediment sources to aeolian deposition is likely to vary year on year, depending on storm frequency, wind direction and strength, as well as sea ice surface characteristics (e.g. multi-year sea ice retains more sediment than smooth first year ice due to surface melt creating pitted surfaces; Murray et al., 2012), but the general pattern probably remains consistent, as demonstrated by sediment plumes appearing on sea ice in similar locations each year (e.g Barrett et al. 1983, Fig. 2; Denton and Marchant 2000, Figs. 10-a, and 10-1; Dunbar and Barrett 2004, Fig.4; Atkins and Dunbar 2009, Fig. 1; Winton 2011, Fig. 2.3).

Notably, the highest MAR values in Figure 7.2 correspond to direct wind flow over unconsolidated deposits onto sea ice, and values decrease with distance downwind. In Figure 7.3, the areas of high sand content also correspond to direct wind flow from sediment sources to sea ice, as would be expected for saltating material. In addition, sand values decrease with distance from source, reinforcing the idea that the sandy sediment plumes can be used to refine the location of source areas and help to constrain source input parameters for future modelling. 


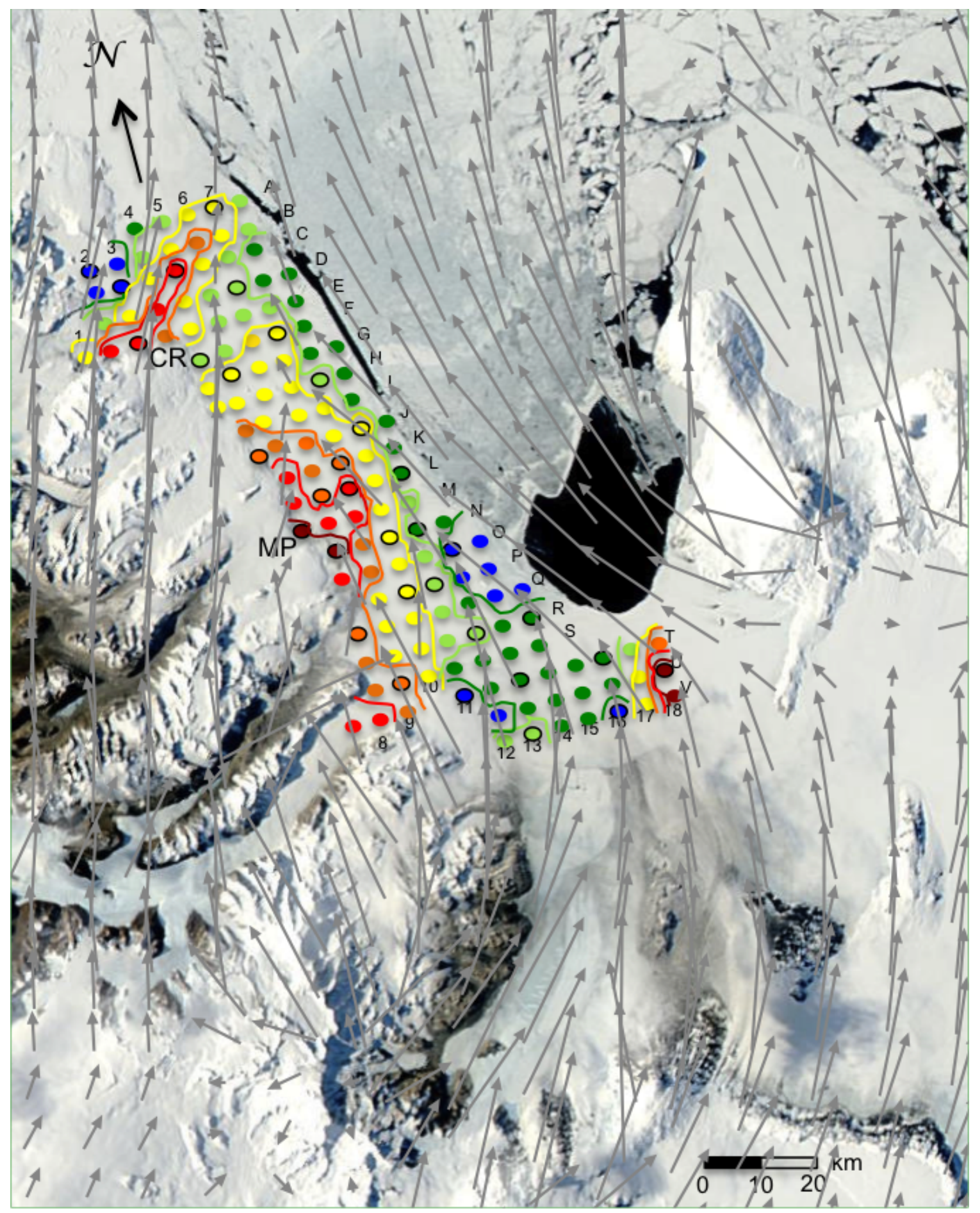

Figure 7.3: Percentage sand and storm dominated wind flow. Percentage sand plotted as: dark red $=>50 \%$, red $=30-49 \%$, orange $=20-29 \%$, yellow $=10-19 \%$, light green $=5-9 \%$, green $=2-4 \%$, and, blue $=0-4 \%$. Values are the sample percentage of sediment $>63 \mu \mathrm{m}$. 
In addition to the broad patterns of sediment dispersal outlined above, spatially minor concentrations of silt-sized material also occur. These potentially indicate localised sediment sources, or zones of low or fluctuating wind velocity and eddies. Two such concentrations are observable within the field area, 1) in northwest Granite Harbour, and 2) along the eastern edge of Bowers Piedmont, as shown by locally high MARs and very low sand contents (Figure 7.2 and Figure 7.3). Vaguaries of the wind field are the best explanation for the high variability of distribution seen within the data.

The results from this study suggest the McMurdo Ice Shelf debris bands is the main source of aeolian sediment in McMurdo Sound based on the relative prevalence of volcanic glass; a unique constituent to the debris bands. Additional sediment sources are exposures of unconsolidated deposits proximal to the coast, as shown by very high MARs and sand content falling in plumes extending directly offshore from these sites. A significant contribution of sediment to the sea ice from MDV sources beyond Wilson Piedmont is unlikely.

\subsection{How extensive is aeolian sediment dispersal from McMurdo Sound in the southwest Ross Sea?}

Predictions by global dust distribution models widely vary in their estimates for the high southern latitudes and few measurements are available to constrain them (e.g. Jickells et al., 2005; Li et al., 2008; Bowie et al., 2009; Albani et al., 2012). Furthermore, no global dust model incorporates dispersal from Victoria Land sources. Therefore, it remains an open question as to how far dust from McMurdo Sound is distributed across the Ross Sea and into the TAM. In part, the contribution of local sediment sources to windblown dust in the Ross Sea region can be estimated from MARs, grain size and provenance indicators.

Modelling by Albani et al. (2012) (Figure 7.4), suggests that global background aeolian dust fall-out to the Ross Sea is extremely low $\left(<0.001 \mathrm{~g} \mathrm{~m}^{-2} \mathrm{y}^{-1}\right)$ and fine grained $(<10 \mu \mathrm{m})$, as it receives minor input from sources such as Patagonia and Australia. Therefore, sediment found on sea ice accumulating at rates substantially above this value and comprising coarser material are considered to be derived from local sources. Although the NaMASTE model as it is currently configured significantly underestimates (by up to several orders of magnitude) MARs compared to observed values, it is still qualitatively useful for estimating dispersal pathways and extent.

Evidence for sediment from the McMurdo Ice Shelf being transported onto the eastern 


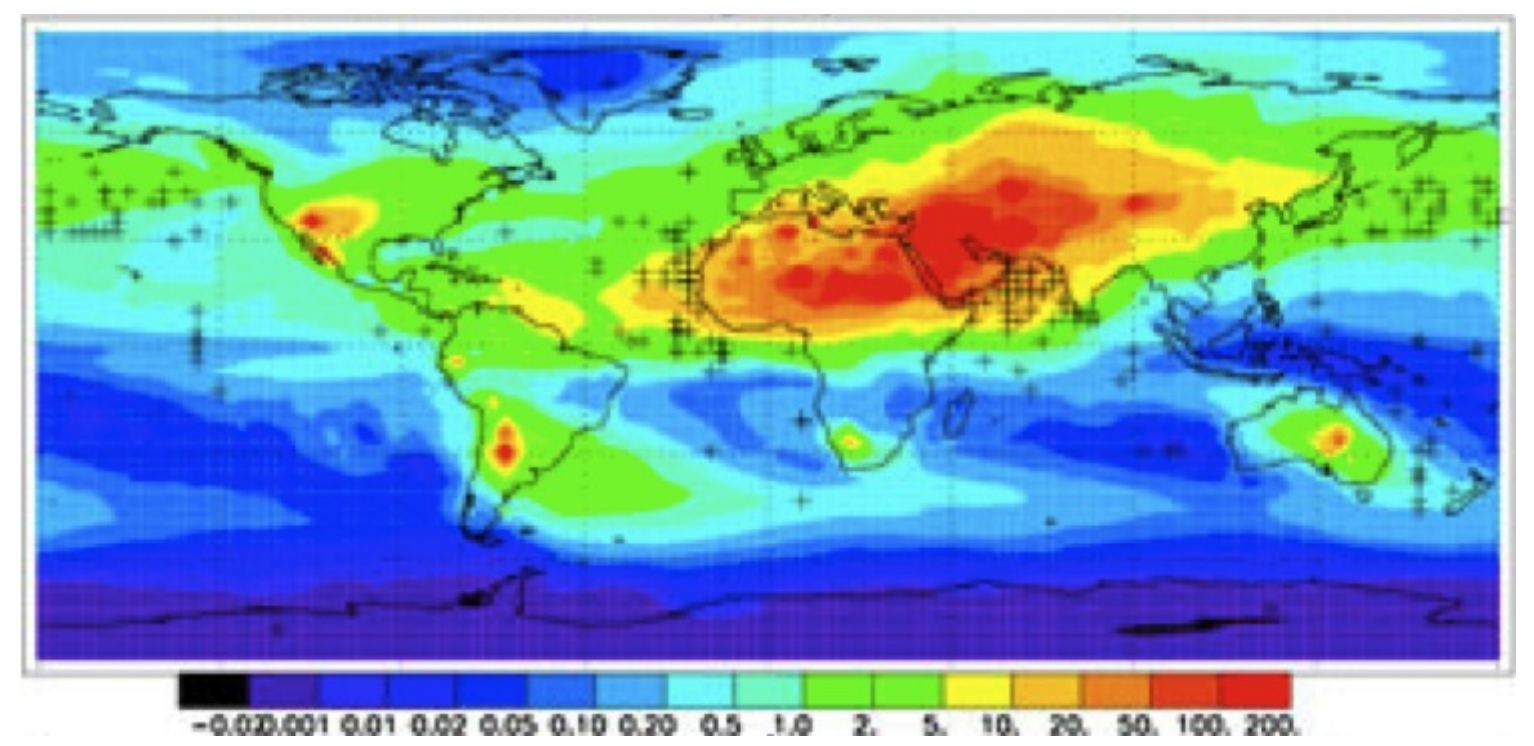

Figure 7.4: Modelled dust deposition in $\mathrm{g} \mathrm{m}^{-2} \mathrm{y}^{-1}$ for the globe, including Antarctica and the Southern Ocean. From Albani et al. (2012).

flanks of the TAM to the west comes from both elevated MARs and provenance indicators. Delmonte et al. (2013) report that higher dust accumulation rates and distinct isotopic compositions are found in coastal ice cores (e.g. Talos Dome) compared to those from the Antarctic interior (e.g. Dome C and Vostok), suggesting a contribution from local dust sources in coastal locations. Studies of sediment accumulation in ice from Wilson and Evans Piedmont Glaciers (Ayling, 2001; Bull, 2009) also noted the presence of volcanic glass, sponge spicules and freshwater diatoms, confirming at least some material accumulating there is sourced from the McMurdo Ice Shelf. Modelling by NaMASTE infers it is possible for aeolian sediment to be transported from the debris bands onto glaciers and other elevated coastal features surrounding McMurdo Sound, but topography tends to limit extent of dispersal. The pattern of dispersal is strongly controlled by wind strength and direction, suggesting high velocity winds are needed for debris bands material to enter the TAM.

Spatial variability is characteristic of sediment deposition on sea ice, with the local wind regime being a dominant influence on dispersal. Predictive modelling suggests that during the 8-month period in which sea ice is present in the southwest Ross Sea, sequential wind events exceeding $20 \mathrm{~m} \mathrm{~s}^{-1}$ can potentially transport aeolian sediment considerable distances over the sea ice. Despite the uncertainty surrounding the accumulation values derived in modelled outputs, which are much lower than those found in the empirical data, modelled distributions suggest dust can reach as far as the Drygalski Ice Tongue, $\sim 250 \mathrm{~km}$ north of the McMurdo Ice Shelf (Figure 6.8), though potentially not in volumes greater than the global dust background for the Ross Sea. 
A simple relationship between observed MAR and distance from the dominant source of aeolian sediment (the McMurdo Ice Shelf debris bands) can also be used as a guide to the distance at which sediment from the ice shelf accumulates at rates above that of the global background. Transport of windblown material from the ice shelf is mostly south-north. In terms of eastward transport into the Ross Sea, the model suggests sediment is not transported more than $30-40 \mathrm{~km}$ east of the northern tip of Ross Island. The average MAR close to the northern margin of the McMurdo Ice Shelf is $\sim 5$ $\mathrm{g} \mathrm{m}^{-2} \mathrm{y}^{-1}$; this drops to $2.2 \mathrm{~g} \mathrm{~m}^{-2} \mathrm{y}^{-1}$ off Marble Point and to $0.8 \mathrm{~g} \mathrm{~m}^{-2} \mathrm{y}^{-1}$ off Cape Archer, as shown in Figure 7.5.

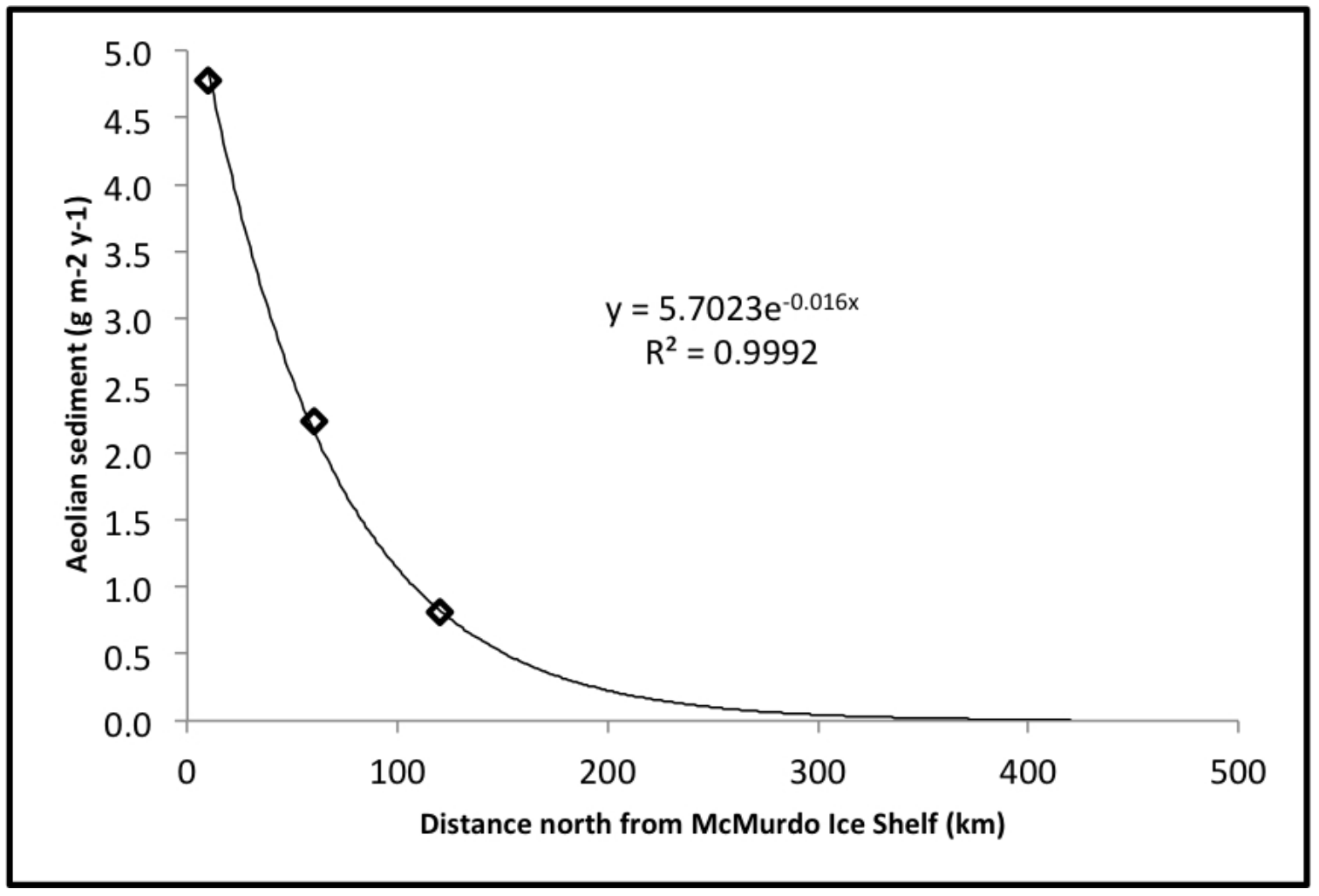

Figure 7.5: Relationship between observed mass accumulation rates with distance from the dominant aeolian sediment source, the McMurdo Ice Shelf debris bands. $\mathrm{R}^{2}$ value shows an exponential relationship to the data.

Fitting an exponential function to these data indicates that sediment can be dispersed up to $\sim 540 \mathrm{~km}$ from the McMurdo Ice Shelf before the input of locally derived sediment drops below the estimated global background level of $\sim 0.001 \mathrm{~g} \mathrm{~m}^{-2} \mathrm{y}^{-1}$, which is well north of the Drygalski Ice Tongue. However, if a linear fit is used $\left(R^{2}=0.9543\right)$, this location moves to $\sim 140 \mathrm{~km}$ distance from the debris bands source, or not much 
beyond Cape Archer. Though accumulation values from modelling outputs contain a high degree of uncertainty, modelling distributions suggest that the real value may lie somewhere in between these two estimates.

Regardless, the predictions of aeolian sediment transport from the McMurdo Ice Shelf to the Drygalski Ice Tongue, and possibly beyond, should be relatively easy to test by sampling surface snow accumulating on sea ice there. Furthermore, additional tuning of the NaMASTE model may improve its predictive capabilities. In particular, the modelled accumulation values are potentially limited by the following considerations, 1) the point sources used in the model under-represent the scale of sediment sources in the real environment, 2) the true variability of the local wind system (directional shifts, velocity shifts, eddies) is not replicated by the static wind field, affecting whether given points within the domain are eroding or accumulating, and 3) the trapping mechanism of snow on the sea ice surface is approximated by a simple retention parameter, whereas niveo-aeolian processes are highly complex, with a high degree of spatial variability. These factors suggest that a greater entrainment and distribution of material is possible in the real system than could be replicated by the model. Also, it is worth noting that NaMASTE was primarily designed to examine transport of sand and silt sized material and does not calculate how much sediment is likely to be entrained into long-term suspension.

NaMASTE model distributions tend to replicate the observed spatial pattern of distribution in McMurdo Sound well, particularly sediment plumes observed near to sources. Observations show modal volumes of very-fine sand to silt are found throughout the field area, while coarser sand-sized material is restricted to near-shore plumes. Model sensitivity testing during this study suggests fine sand (150 $\mu \mathrm{m}$ and 90 $\mu \mathrm{m}$ ) and silt (20 $\mu \mathrm{m}$ and $10 \mu \mathrm{m})$ are distributed similar distances, whereas medium sand $(250 \mu \mathrm{m})$ is more restricted. However, the choice of model constants such as retention factor may disproportionally affect output distributions. MAR and grain size distributions tend to suggest transport is particularly limited for sand, either by supply or by the low frequency of strong wind events $(\sim 1 \%$ of winds during a year are $>20 \mathrm{~m} \mathrm{~s}^{-1}$ ). Alternatively, snow trapping effects may be enhanced for sand-sized material due to sand being transported close to the ground in saltation; therefore, sand distributions may be affected to a greater degree than finer sediment by blown snow processes and thresholds.

Localised deposition appears to be the most notable aspect of aeolian processes in McMurdo Sound, with the bulk of aeolian sediment, in particular sand, being constrained within highly localised plumes. This points to there being a limit to the 
distance sediment larger than fine sand can be moved by the local wind regime over snow-covered sea ice. Modelling also suggests that there are limits to the capacity of wind to move silt-sized material beyond the model domain. Finer material may be transported farther in long-range suspension. From this, it appears that windblown sediment from sources in McMurdo Sound is largely confined to the southwest Ross Sea.

\subsection{What is the flux of dust from McMurdo Sound sources to the seafloor?}

It is clear that aeolian sediment is being mobilised and deposited in McMurdo Sound in greater volumes than for other locations in the Ross Sea; however, in comparison to other sources of sediment to the oceans (schematically illustrated in Figure 7.6), the contribution of aeolian sediment to marine sedimentation is poorly quantified.

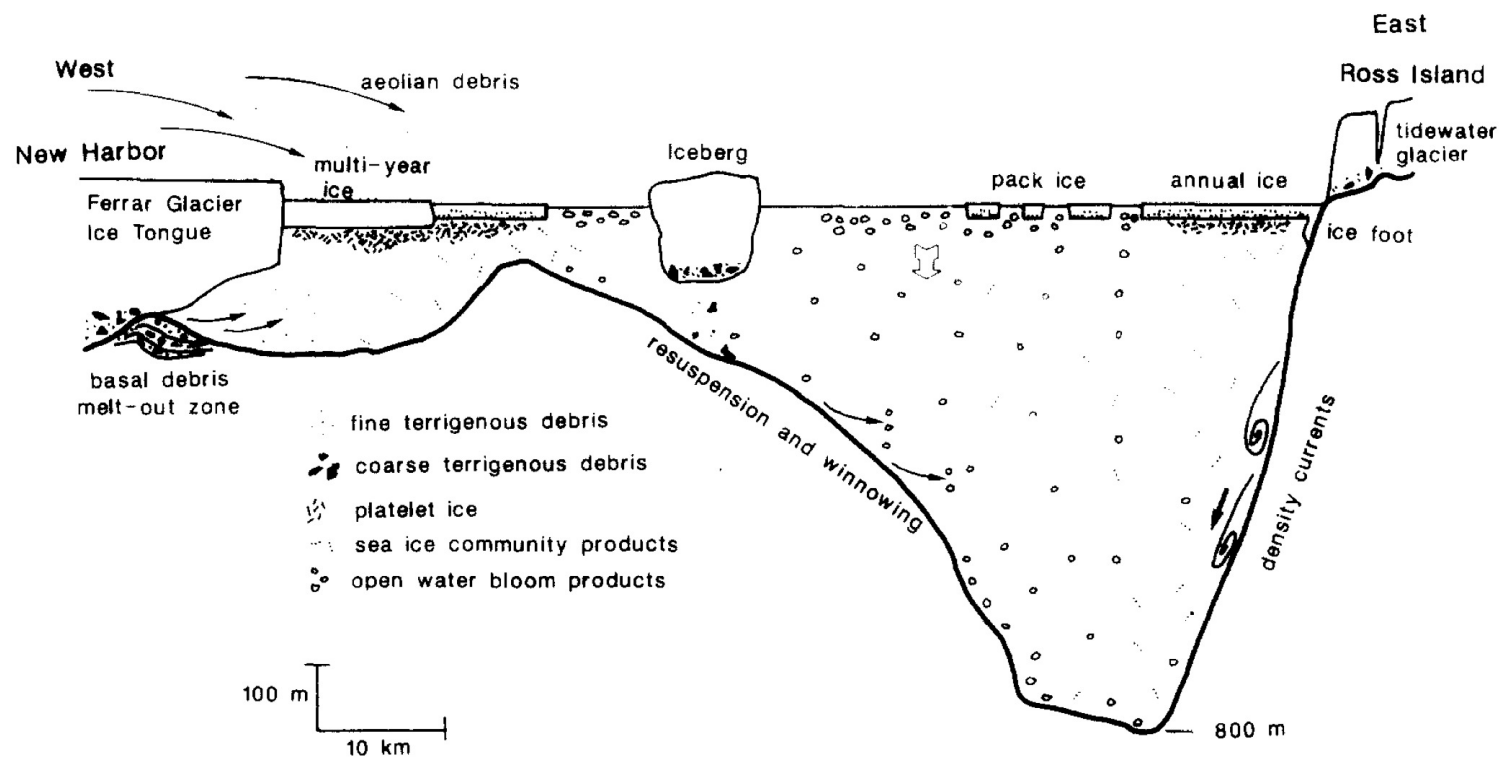

Figure 7.6: Schematic cross section of McMurdo Sound illustrating sediment inputs including aeolian sediment. From Dunbar et al. (1989).

By taking the calculated background MAR for McMurdo Sound $\left(1.14 \pm 0.57 \mathrm{~g} \mathrm{~m}^{-2}\right.$ $\left.\mathrm{y}^{-1}\right)$ and applying it to the entire field area $\left(600 \mathrm{~km}^{2}\right)$, a minimum of $\sim 0.68 \mathrm{Gg} \mathrm{y}^{-1}$ of aeolian sediment is estimated to enter McMurdo Sound during summer sea ice melt in the modern environment (n.b. direct deposition when no sea ice is present is not considered). An estimate of atmospheric dust (i.e. $<5 \mu \mathrm{m}$ ) deposition in the Southern Ocean of $6 \mathrm{Tg} \mathrm{y}^{-1}$ (Raiswell et al., 2008)) far exceeds the value for McMurdo 
Sound; however, when compared to model estimates of global dust deposition for the Ross Sea region (Table 7.2), locally it is important. For example, extrapolating the modelled values for dust deposition to the Ross Sea from Mahowald et al. (2006) $\left(<0.01 \mathrm{~g} \mathrm{~m}^{-2} \mathrm{y}^{-1}\right)$ and Albani et al. (2012) $\left(<0.001 \mathrm{~g} \mathrm{~m}^{-2} \mathrm{y}^{-1}\right)$ to the field area, the global atmospheric dust contribution for McMurdo Sound is $6,000 \mathrm{~kg} \mathrm{y}^{-1}$ or $600 \mathrm{~kg}$ $\mathrm{y}^{-1}$, respectively. However, the generalised approach and extremely specific grain size ranges used in global dust deposition simulations, makes comparison with observed distibutions problematic.

Atkins and Dunbar (2009) calculate a linear seafloor sedimentation rate (LSR) in McMurdo Sound by assuming, 1) the mass of aeolian sediment accumulating on the sea ice is transferred directly to the seafloor underneath, and 2) that this sediment accumulates on the seafloor with a wet bulk density of $1.64 \mathrm{~g} \mathrm{~cm}^{-3}$. Following the methodology and rationale of Atkins and Dunbar (2009), this study calculates a LSR of $0.009-3.3 \mathrm{~cm} \mathrm{ky}^{-1}$ depending on location, averaging $0.2 \mathrm{~cm} \mathrm{ky}^{-1}$ for the McMurdo Sound area. However, the highest values are extremely localised. If only those samples found within source-oriented plumes are considered, the average value increases to $0.4 \mathrm{~cm} \mathrm{ky}^{-1}$.

Holocene sedimentation rates associated with sediment derived from other sources in the Ross Sea are summarised in Table 7.3. This table shows the high degree of variability found between different processes, ranging from very localised biogenic deposition that is orders of magnitude greater than dust deposition, to sub-ice shelf deposition of terrigenous sediment, which is lower than the estimated contribution from dust. Additionally in nearshore areas such as Granite Harbour, terminating glaciers can contribute large volumes of basal debris to sedimentation (e.g. Macpherson, 1987).

In general, areas subject to seasonally open water (e.g. polynyas and seasonal sea ice zones such as the SW Ross Sea) are dominated by biogenic sedimentation, but LSR vary widely due to variability in phytoplankton production (Hughes and Krissek, 1985; Reddy and Arrigo, 2006; Arrigo et al., 2012). The aeolian sediment LSR determined by this study is comparable, though averaged over a larger surface area, to that determined by other studies that have measured aeolian sediment input to the ocean from plumes on the sea ice (e.g. 0.5-1.5 $\mathrm{cm} \mathrm{ky}^{-1}$, Atkins and Dunbar, 2009; and 0.4-5.2 $\mathrm{cm} \mathrm{ky}^{-1}$, Winton, 2011). At a regional-scale, the contribution by aeolian sediment is minor compared to that by biogenic sediment, but locally (within 5 to 10 $\mathrm{km}$ from source areas) it can be considered important.

Atkins and Dunbar (2009) noted there is a strong correlation between the sand 
content found on sea ice in southern McMurdo Sound and that found directly below on the seafloor. Results from this study also suggest that sand deposition is important to local direct sedimentation, with a calculated LSR for sand-sized ( $>63 \mu \mathrm{m}$ ) sediment of $0.0002-2.2 \mathrm{~cm} \mathrm{ky}^{-1}$. Interestingly, the prominent silt mode evident in sea ice samples (Section 4.3) is a very minor component in sea floor sediments and it remains uncertain where this material ends up once in the water column. Atkins and Dunbar (2009) speculate that relatively fast northward flowing $\left(0.35 \mathrm{~m} \mathrm{~s}^{-1}\right.$; Atkins and Dunbar, 2009) currents may advect much of this material out of the study area, however, there are presently limited observation data available to test this hypothesis (e.g. Robinson et al., 2010). Therefore, aeolian sediment is only likely to make a significant direct contribution to the seafloor sedimentation in McMurdo Sound in areas immediately downwind and proximal to sources such as the McMurdo Ice Shelf debris bands or coastal outcrops, as previously suggested by Atkins and Dunbar (2009). 
Table 7.2: Aeolian sediment a) accumulation rates and b) total deposition estimates for the Southern Ocean and the southwest Ross Sea area, from observations and modelled data.

\begin{tabular}{|c|c|c|c|}
\hline \multicolumn{4}{|l|}{ (a) } \\
\hline Site & $\begin{array}{l}\text { Equiv. aeolian } \\
\text { sed. accum. rate } \\
\left(\mathrm{g} \mathrm{m}^{-2} \mathrm{y}^{-1}\right)\end{array}$ & $\begin{array}{l}\text { Modal } \\
\text { size } \\
(\mu \mathrm{m})\end{array}$ & Reference \\
\hline \multirow[t]{6}{*}{ S. Ocean } & $0.01-0.1$ & dust & Duce et al. (1991) \\
\hline & (modelled) $<0.2$ & & Jickells et al. (2005) \\
\hline & (modelled) $0.1 \pm 0.02$ & dust & Mahowald et al. (2005) \\
\hline & $0.01 \pm 0.005$ & $<5$ & Wagener et al. (2008) \\
\hline & $0.13 \pm 0.07$ & & Bowie et al. (2009) \\
\hline & (modelled) $<0.02$ & $1.0-5.0$ & Albani et al. (2012) \\
\hline \multirow[t]{2}{*}{ Ross Sea } & (modelled) $<0.01$ & aerosol & Mahowald et al. (2006) \\
\hline & (modelled) $<0.001$ & $<10$ & Albani et al. (2012) \\
\hline C. McMurdo Sound & $0.32-54.6$ & $40-110$ & (this study) \\
\hline \multirow[t]{3}{*}{ Granite Harbour } & $3.0-17.4$ & v.f.sand & Macpherson (1987) \\
\hline & 0.7 & & Winton (2011) \\
\hline & $0.15-9.03$ & $36-63$ & (this study) \\
\hline \multirow[t]{2}{*}{ New Harbour } & 265 & & Bentley (1979) \\
\hline & $0.9-4.9$ & $40-43$ & (this study) \\
\hline \multirow[t]{3}{*}{ S. McMurdo Sound } & $7.8-24.0$ & $76.3-129.3$ & Atkins and Dunbar (2009) \\
\hline & $26.0-83.2$ & $69-130$ & Winton (2011) \\
\hline & $0.77-15.7$ & $7.4-450$ & (this study) \\
\hline \multirow[t]{3}{*}{ Windless Bight } & average 0.8 & & Dunbar et al. (2009) \\
\hline & summer $0.33 \pm 0.3$ & & Dunbar et al. (2009) \\
\hline & winter $0.48 \pm 0.46$ & & Dunbar et al. (2009) \\
\hline \multicolumn{4}{|l|}{ b) } \\
\hline \multirow[t]{2}{*}{ Site } & Sediment & Source & Reference \\
\hline & $\begin{array}{c}\text { deposition } \\
\left(\operatorname{Tg~}^{-1}\right)\end{array}$ & & \\
\hline \multirow[t]{5}{*}{ S. Ocean } & (modelled) 27 & atmospheric dust & Jickells et al. (2005) \\
\hline & (modelled) 11 & atmospheric dust & Li et al. (2008) \\
\hline & (modelled) 6 & dust on sea ice & Raiswell et al. (2008) \\
\hline & (modelled) 1,250 & iceberg/glacial sed. & Raiswell et al. (2008) \\
\hline & (modelled) 33 & aeolian & Raiswell et al. (2008) \\
\hline McMurdo Sound & $0.00068 *$ & sea ice aeolian sed. & (this study) \\
\hline \multicolumn{4}{|c|}{ *does not include deposition during summer months with no sea ice present } \\
\hline \multicolumn{4}{|c|}{$\begin{array}{l}{ }^{1} \text { Overestimation of modelled values when predicting for dust deposition over oceanic regions of } \\
\text { the Southern Hemisphere, has been attributed to model parameterisation for Northern Hemi- } \\
\text { sphere conditions (Wagener et al., 2008; Bowie et al. 2009)). }\end{array}$} \\
\hline
\end{tabular}


Table 7.3: Sedimentation rates for aeolian and other sources of sediment from localities within a) McMurdo Sound and b) the Ross Sea.

\begin{tabular}{|c|c|c|c|c|}
\hline \multicolumn{5}{|l|}{ a) } \\
\hline Location & $\begin{array}{c}\text { LSR } \\
\mathrm{cm} \mathrm{ky}^{-1}\end{array}$ & $\begin{array}{c}\mathrm{LSR}>63 \mu \mathrm{m} \\
\mathrm{cm} \mathrm{ky}^{-1}\end{array}$ & $\begin{array}{l}\text { Sediment } \\
\text { type }\end{array}$ & Reference \\
\hline S. McMurdo Sd. ${ }^{* \star}$ & $0.485-1.53$ & $0.2-0.84$ & aeolian & Atkins and Dunbar (2009) \\
\hline S. McMurdo Sd. (SMS) ${ }^{* \star}$ & $0.4-5.20$ & $0.17-3.0$ & aeolian & Winton (2011) \\
\hline $20 \mathrm{~km}$ west of SMS site ${ }^{\star}$ & 0.16 & 0.08 & aeolian & Winton (2011) \\
\hline $15 \mathrm{~km}$ east of SMS site ${ }^{\star}$ & 0.14 & 0.005 & aeolian & Winton (2011) \\
\hline McMurdo Sd. ${ }^{* \star}$ & $0.009-3.3$ & $0.0002-2.2$ & aeolian & (this study) \\
\hline \multicolumn{5}{|l|}{ b) } \\
\hline Location & $\begin{array}{l}\text { Sed. rate. } \\
\mathrm{cm} \mathrm{ky}^{-1}\end{array}$ & Method & $\begin{array}{l}\text { Sediment } \\
\text { type }\end{array}$ & Reference \\
\hline N. Ross Sea & 1.7 & box-core & all & Frignani et al. (2003) \\
\hline Drygalski Trough & $\sim 9$ & sed. core & diatom ooze & Domack et al. (1999) \\
\hline Terra Nova Bay Polynya & 1.73 & sed. trap & all & Frignani et al. (2003) \\
\hline S. Ross Sea & $60-250$ & box-core & biogenic silica & Ledford-Hoffman et al. (1986) \\
\hline S. Ross Sea & 0.85 & box-core & all & Frignani et al. (2003) \\
\hline Granite Harbour & 248 & gravity-core & sandy mud & Macpherson (1987) \\
\hline Lewis Basin & 80 & piston core & all & Macpherson (1987) \\
\hline Lewis Basin & 20 & sed. core & diatom ooze & McKay et al. (2008b) \\
\hline Windless Bight & 1 & sed. core & sandy mud & McKay et al. (2008b) \\
\hline
\end{tabular}

$\mathrm{LSR}=$ Linear sedimentation rate

* "lobe" of aeolian sediment in close proximity to McMurdo Ice Shelf debris bands.

${ }^{\star}$ Rate assumes a wet bulk density of $\approx 1.64 \mathrm{~cm}^{3}$.

SMS $=$ ANDRILL Southern McMurdo Sound drillsite 


\section{Chapter 8 Conclusions and future work}

\subsection{Conclusions}

Mapping the distribution of aeolian sediment over sea ice in McMurdo Sound shows the most significant source of windblown sediment in the study area is the McMurdo Ice Shelf debris bands in southern McMurdo Sound. This is determined by: 1) the wide distribution of volcanic glass sourced from the McMurdo Volcanics Group provinces surrounding the ice shelf, which occurs in the majority of samples, 2) a decrease in modal grain size away from this area, and 3) a decrease in mass accumulation rates away from this source area. Secondary sources are localised exposures of Ross Sea Drifts and beach deposits along the Scott Coast between Cape Bernacchi and Spike Cape and surrounding New Harbour. Additionally, material from Transantarctic Mountains lithologies is inferred as a localised source to Granite Harbour, based on a slight increase in quartz content and a localised area of higher sand content.

Overall the aeolian sediment distribution is defined by an exponential decrease in mass accumulation rates from the McMurdo Ice Shelf debris bands to sea ice seaward of Cape Roberts, $\sim 120 \mathrm{~km}$ to the north. However, very close to the shoreline mass accumulation rates are extremely variable and localised plumes, characterised by high mass accumulation rates and high sand content that disperse from secondary source areas, are present. Mass accumulation rates of aeolian sediment on seasonal fast-ice in McMurdo Sound range from $0.15 \mathrm{~g} \mathrm{~m}^{-2} \mathrm{y}^{-1}$ to $54.6 \mathrm{~g} \mathrm{~m}^{-2} \mathrm{y}^{-1}$, averaging $3.2 \mathrm{~g}$ $\mathrm{m}^{-2} \mathrm{y}^{-1}$. The highest MAR's occur within $5 \mathrm{~km}$ of Gneiss and Marble Points on the Scott Coast and the lowest were found in outer Granite Harbour. If localised plumes are ignored, a minimum average mass accumulation rate of $1.14 \pm 0.57 \mathrm{~g} \mathrm{~m}^{-2} \mathrm{y}^{-1}$ is calculated for the entire McMurdo Sound area, which is 3-5 orders of magnitude greater than estimated global atmospheric dust inputs.

The NaMASTE model allows good simulation of aeolian sediment dispersal in McMurdo Sound, but has less certainty around modelled accumulation rate values. 
Modelling suggests wind velocity is the dominant control on aeolian sediment dispersal in this polar environment, with the majority of transport from source area to sea ice occurring intermittently during strong wind events, where wind velocities often exceed $30 \mathrm{~m} \mathrm{~s}^{-1}$ from the south. Additionally a transport threshold within the system is suggested, controlled by frequency, strength and duration of strong wind events, with medium sand showing a more limited range of dispersal than fine sand and silt. This corresponds well to the observed distributions seen within the mass accumulation rate and grain size data. Simulated dust transport beyond McMurdo Sound, using NaMASTE, suggests windblown sediment can be distributed $\sim 250 \mathrm{~km}$ north of the McMurdo Ice Shelf and $\sim 100 \mathrm{~km}$ east from the Scott Coast, but only in very low quantities.

In the modern context, a calculated volume $\sim 0.7 \mathrm{Gg} \mathrm{y}^{-1}$ of aeolian sediment enters the McMurdo Sound sector of the southwest Ross Sea from fast ice alone, which is 6-7 orders of magnitude greater than deposition volumes suggested by published global background dust values for the area. The calculated seafloor linear sedimentation rate for this material ranges from $0.009-3.3 \mathrm{~cm} \mathrm{ky}^{-1}$, averaging $0.2 \mathrm{~cm} \mathrm{ky}^{-1}$. This average rate is much less than is observed for biogenic-dominated sediment that occurs over most of the modern Ross Sea $\left(9-250 \mathrm{~cm} \mathrm{ky}^{-1}\right)$. Therefore, only at sites directly proximal to these major source areas (within 5-10 km, under extant conditions) is aeolian sediment a significant contributor to seafloor sedimentation.

\subsection{Future work}

Findings of this study may have direct relevance for geological drilling projects, for calculating dissolved Fe budgets for biological production, and for sea ice albedo studies within the region. Further research would help to clarify the source-to-sink process of aeolian sediment deposition in McMurdo Sound and the southwest Ross Sea.

More extensive sampling to the north and east could validate the model dispersal findings, and determine if any other important sediment sources exist along the Victoria Land coast. Collecting shallow sediment cores, combined with modelling sea ice break up patterns and oceanic currents, would provide insight into the limits of dispersal of aeolian sediment, for both direct sedimentation and advection of the silt fraction. Additional sampling, or long term, in situ sediment trapping on the piedmont glaciers may help to define the potential influence of material exiting the glacier-dammed McMurdo Dry Valleys. 
The NaMASTE model would benefit from vertical wind velocity profile measurements specific to this polar environment, including both wind flow characteristics and sediment flux (concurrent with snow flux), as it would help to better constrain model parameters. Investigating ways to better replicate the influence of blown and drifting snow, and snow trapping, on sediment dispersal would also help to improve the model physics. Increasing the resolution of source cells to better replicate the spatial-scale of sediment source areas and using higher-resolution wind field inputs would improve on the model's ability to represent sediment supply, and in replicating spatial dispersal characteristics.

Time-dependent model experiments could be used to explore sediment dispersal by individual strong wind events. Lastly, modelling of future environments to explore factors that may influence future aeolian sediment inputs to the ocean, such as sea ice extent, a warming ocean, deglaciation, changes to atmospheric circulation and precipitation, sediment source area, cohesion of surfaces, and vegetation, would help to predict for potential future changes in aeolian sedimentation in the Ross Sea region. 


\section{Part IV}

\section{Appendices}





\section{Appendix A Sample collection data}


K001-D McMurdo Sound FIELD DATA, SAMPLING LOCATIONS \& NOTES = Oct/Nov 2010

\begin{tabular}{l} 
CAPE ROBERTS \\
\hline GPS Coordinates: \\
\\
S76 49.000 E163 00.000 \\
S76 $49.000 \mathrm{E} 16306.000$ \\
S76 $49.000 \mathrm{E} 16312.000$ \\
S76 $49.000 \mathrm{E} 16318.000$ \\
S76 $49.000 \mathrm{E} 16324.000$ \\
\\
S76 $49.000 \mathrm{E} 16330.000$ \\
S76 $49.000 \mathrm{E} 16336.000$ \\
S76 $49.000 \mathrm{E} 16342.000$ \\
S76 $49.000 \mathrm{E} 16348.000$
\end{tabular}

$\begin{array}{cc}\begin{array}{c}\text { Area ID } \\ \text { (prefix) }\end{array} & \begin{array}{c}\text { Transect } \\ \text { (E-W) }\end{array} \\ \text { CR } & \text { A } \\ \text { CR } & \text { A } \\ \text { CR } & \text { A } \\ \text { CR } & \text { A } \\ \text { CR } & \text { A } \\ & \\ \text { CR } & \text { A } \\ \text { CR } & \text { A } \\ \text { CR } & \text { A } \\ \text { CR } & \text { A } \\ \text { CR } & \text { A }\end{array}$

$\begin{array}{cccccccc}\begin{array}{c}\text { Line } \\ (\mathrm{N}-\mathrm{S})\end{array} & \begin{array}{c}\text { Bottle } \\ \#\end{array} & \begin{array}{c}\text { Bag } \\ \#\end{array} & \begin{array}{c}\text { Depth } \\ (\mathrm{cm})\end{array} & \begin{array}{c}\text { Bagged sample dimension: } \\ (\mathrm{cm})\end{array} & \begin{array}{c}\text { Volume } \\ (\mathrm{cm})\end{array} & \begin{array}{c}(\mathrm{cm}) \\ (\mathrm{cm} 3)\end{array} \\ 4.5 & 1 & 1 & 7 & 10 & 10 & 7.5 & 750 \\ 5 & 1 & 0 & 14 & & & & \\ 5.5 & 2 & 1 & 11.5 & 10 & 10 & 11 & 1100 \\ 6 & 1 & 0 & 12.5 & & & & \\ & 1 & 1 & 15 & 10 & 10 & 13 & 1300 \\ 6.5 & 1 & 0 & 25 & & & & \\ 7 & 1 & 1 & 8.5 & 10 & 10 & 7 & 700 \\ 7.5 & 1 & 0 & 11.5 & & & & \\ 8 & 1 & 1 & 13 & 9 & 10 & 11 & 990 \\ 8.5 & 1 & 0 & 13.5 & & & & \end{array}$

Bagged sample dimension:

0.10

$\begin{array}{ll}0.00 & 0.00 \\ 0.10 & 0.10\end{array}$

$\begin{array}{ll}0.10 & 0.10 \\ 0.00 & 0.00 \\ 0.00 & 0.00\end{array}$

0.10

0.10

0.00

0.10
0.00
0.09

S76 $51.800 \mathrm{E} 16236.000$

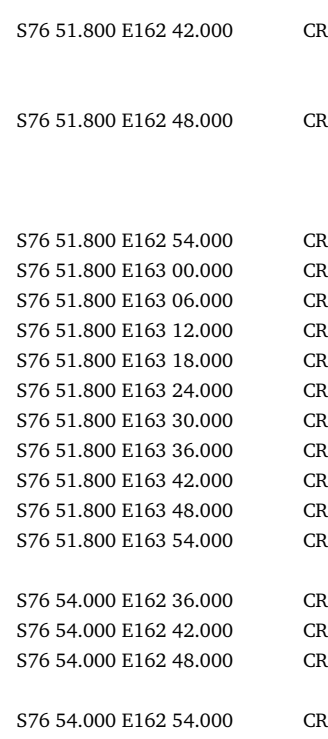

0.0008

0.32

is
on multi-year ice $200 \mathrm{~m}$ off Lion Island; snow is deep but with visible dust layer; "stratigraphy of pit: base $=$ sea ice, $+15 \mathrm{~cm}$ coarse refrozen ice-last yean, +23 m stratifed snow; them danker dust layer, t5m snow to surface (photos taken)

also in deep snow on multi-year ice; recrystallised ice layer $14 \mathrm{~cm}$, stratified snow, take above refreeze layer

back onto first year ice btw CR-B-2.5 \& CR-B. 3 ; snow drifts up to $20 \mathrm{~cm} \times 30 \mathrm{~cm} \times 5 \mathrm{~m}$ oriented offshore $\mathrm{S}-\mathrm{N}$, smooth blue sea ice in between $30 \%$ snow drifts

blue ice

blue ice

blue ice

blue ice

0.0000 blue ice

0.0009 blue ice
0.0000 blue ice, low lying snow drifts, $80 \%$ coverage

0.0010 snow very icy and firmly packed

0.0000

0.0010

adjacent to large icebergs (probably from McKay Glacier)

blue ice, $40 \%$ snow coverage, some new(? drifts from last night's katabatic 
S76 54.000 E16300.000 S76 54.000 E163 06.000 $\$ 7654.000 \mathrm{E163} 12.000$ S76 54.000 E163 18.000 S76 54.000 E163 24.000 S76 54.000 E163 30.000 S76 54.000 E163 36.000 S76 54.000 E163 42.000 S76 54.000 E163 48.000 S76 54.000 E163 54.000

S76 $58.600 \mathrm{E} 16230.000$ S76 57.200 E162 24.000 S76 57.200 E162 30.000

S76 57.200 E162 36.000 S76 57.200 E162 42.000 S76 57.200 E162 48.000 S76 57.200 E162 54.000 S76 57.200 E163 00.000

S76 57.200 E163 06.000 S76 57.200 E163 12.000 S76 57.200 E163 18.000 S76 57.200 E163 24.000 S76 57.200 E163 30.000

S76 57.200 E163 36.000 S76 57.200 E163 42.000 S76 57.200 E163 48.000 S76 57.200 E163 54.000 S76 57.200 E164 00.000

CR

$\begin{array}{cccccc}6.5 & 5 & 13 & 13 & 845 & 0.05 \\ 6 & & & & & 0.00 \\ 21 & 10 & 10 & 10 & 1000 & 0.10 \\ 7.5 & & & & & 0.00 \\ 20 & 10 & 10 & 10 & 1000 & 0.10 \\ 18 & & & & & 0.00 \\ 12 & 9 & 10 & 12 & 1080 & 0.09 \\ 8 & & & & & 0.00 \\ 13 & 10 & 10 & 13 & 1300 & 0.10 \\ 14 & & & & & 0.00 \\ & & & & & 0.00\end{array}$

0.13
0.00
0.10
0.00
0.10
0.00
0.10
0.00
0.10
0.00
0.00

0.0008

0.0000

0.0010
0.0000

0.0010

0.0000

0.0011

0.0000

0.0013
0.0000
0.000

0.0000

0.0007

0.0007
0.0000

0.0012

0.0007

0.0012

0.0009

0.0000

0.0007

0.0000

0.0011

0.0000

0.0009

0.0000

0.0012

0.0000

0.0015

$$
\begin{aligned}
& \text { rel young sea ice, broken ice terrain, adjacent } \\
& \text { to large bergs, wind drift direction N-S; CR-E- } \\
& 9 \text { on smooth, extensive, flat sea ice extending } \\
& \text { north from berg cluster }
\end{aligned}
$$

Btw Cuff Cape \& Finger Point, 150m from $r x$ old multi-year ice with scaly blistered surface; sampled new snow in centre of wide refrozen crack; many seals \& seal crap \& salts on suface; sampled snow appears clean. 


\begin{tabular}{|c|c|c|c|c|c|c|c|c|c|c|c|c|c|c|c|}
\hline S77 00.000 E162 48.000 & $\mathrm{CR}$ & E & 3 & 1 & 1 & 9 & 10 & 10 & 9 & 900 & 0.10 & 0.10 & 0.09 & 0.0009 & \\
\hline S77 00.000 E162 54.000 & $\mathrm{CR}$ & $\mathrm{E}$ & 3.5 & 1 & 1 & 13 & ? & $?$ & ? & & \#VALUE! & \#VALUE! & \#VALUE! & \#VALUE! & "bagged sample dimensions missing \\
\hline S77 00.000 E163 00.000 & $\mathrm{CR}$ & $\mathrm{E}$ & 4 & 1 & 1 & 15 & 10 & 11 & 15 & 1650 & 0.10 & 0.11 & 0.15 & 0.0017 & \\
\hline S77 00.000 E163 06.000 & $\mathrm{CR}$ & $\mathrm{E}$ & 4.5 & 1 & 1 & 11 & 10 & 10 & 10 & 1000 & 0.10 & 0.10 & 0.10 & 0.0010 & \\
\hline S77 00.000 E163 12.000 & $\mathrm{CR}$ & $\mathrm{E}$ & 5 & 1 & 1 & 17 & 10 & 10 & 16 & 1600 & 0.10 & 0.10 & 0.16 & 0.0016 & lots of bergs \& seals pupping \\
\hline$S 7700.000$ E163 18.000 & $\mathrm{CR}$ & $\mathrm{E}$ & 5.5 & 1 & 0 & 10 & & & & & 0.00 & 0.00 & 0.00 & 0.0000 & \\
\hline S77 00.000 E163 24.000 & $\mathrm{CR}$ & $\mathrm{E}$ & 6 & 1 & 1 & 14 & 10 & 10 & 14 & 1400 & 0.10 & 0.10 & 0.14 & 0.0014 & $\begin{array}{l}\text { elongate snow drifts up to } 50 \mathrm{~cm} \text { depth ori- } \\
\text { ented S-N }\end{array}$ \\
\hline S77 00.000 E163 30.000 & $\mathrm{CR}$ & $\mathrm{E}$ & 6.5 & 1 & 0 & 14 & & & & & 0.00 & 0.00 & 0.00 & 0.0000 & $\begin{array}{l}\text { some moderately rough ice between CR-E- } 5.5 \\
\text { and CR-E- } 6.5\end{array}$ \\
\hline S77 00.000 E163 36.000 & $\mathrm{CR}$ & $\mathrm{E}$ & 7 & 1 & 1 & 13 & 10 & 10 & 12 & 1200 & 0.10 & 0.10 & 0.12 & 0.0012 & \\
\hline S77 00.000 E163 42.000 & $\mathrm{CR}$ & $\mathrm{E}$ & 7.5 & 1 & 0 & 12 & & & & & 0.00 & 0.00 & 0.00 & 0.0000 & $\begin{array}{l}\text { mix of smooth snow-covered ice \& jumbled } \\
\text { broken ice } 1 \mathrm{~m} \text { depth btw CR-E- } \& \text { CR-E-7.5; } \\
\text { drifts oriented S-N }\end{array}$ \\
\hline S77 00.000 E163 48.000 & $\mathrm{CR}$ & $\mathrm{E}$ & 8 & 1 & 1 & 11 & 10 & 10 & 10 & 1000 & 0.10 & 0.10 & 0.10 & 0.0010 & more broken ice \& smooth plates (as before) \\
\hline S77 00.000 E163 54.000 & $\mathrm{CR}$ & $\mathrm{E}$ & 8.5 & 1 & 0 & 9 & & & & & 0.00 & 0.00 & 0.00 & 0.0000 & drilled ice more than $1 \mathrm{~m}$ \\
\hline S77 00.000 E164 00.000 & $\mathrm{CR}$ & $\mathrm{E}$ & 9 & 1 & 1 & 8 & 10 & 10 & 10 & 1000 & 0.10 & 0.10 & 0.10 & 0.0010 & $\begin{array}{l}\text { beside large berg; extremely rough ice sea- } \\
\text { ward of CR-E-9, also rough north towards } \text { - }- \\
\text { D-9; "bagged sample dimensions missing }\end{array}$ \\
\hline S77 03.061 E163 12.044 & $\mathrm{CR}$ & $\mathrm{F}$ & 5 & 1 & 1 & 10 & 10 & 10 & 10 & 1000 & 0.10 & 0.10 & 0.10 & 0.0010 & $200 \mathrm{~m}$ offshore from piedmont \\
\hline S77 02.720 E163 18.000 & $\mathrm{CR}$ & $\mathrm{F}$ & 5.5 & 1 & 0 & 12.5 & & & & & 0.00 & 0.00 & 0.00 & 0.0000 & $\begin{array}{l}\text { small sastrugi, snow drifts up to } 30 \mathrm{~cm} \text {, very } \\
\text { irregular, } 80 \% \text { snow cover }\end{array}$ \\
\hline S77 03.005 E163 23.007 & $\mathrm{CR}$ & $\mathrm{F}$ & 6 & 1 & 1 & 12 & 10 & 10 & 12 & 1200 & 0.10 & 0.10 & 0.12 & 0.0012 & \\
\hline S77 02.720 E163 29.880 & $\mathrm{CR}$ & $\mathrm{F}$ & 6.5 & 1 & 0 & 12.5 & & & & & 0.00 & 0.00 & 0.00 & 0.0000 & $\begin{array}{l}\text { mod rough ice btw CR-F-6 \& CR-F-6.5, } \\
\text { changed to smooth } 500 \mathrm{~m} \mathrm{~W} \text { of CR-F-6.5; } \\
\text { snow drifts up to } 30 \mathrm{~cm} \text { oriented S-N, } 70 \% \\
\text { drift cover }\end{array}$ \\
\hline S77 02.720 E163 35.900 & $\mathrm{CR}$ & $\mathrm{F}$ & 7 & 1 & 1 & 15 & 10 & 10 & 15 & 1500 & 0.10 & 0.10 & 0.15 & 0.0015 & \\
\hline S77 02.720 E163 41.930 & $\mathrm{CR}$ & $\mathrm{F}$ & 7.5 & 1 & 0 & 19 & & & & & 0.00 & 0.00 & 0.00 & 0.0000 & \\
\hline S77 02.720 E163 47.950 & $\mathrm{CR}$ & $\mathrm{F}$ & 8 & 1 & 1 & 24 & 10 & 10 & 24 & 2400 & 0.10 & 0.10 & 0.24 & 0.0024 & \\
\hline S77 02.720 E163 53.970 & $\mathrm{CR}$ & $\mathrm{F}$ & 8.5 & 1 & 0 & 16 & & & & & 0.00 & 0.00 & 0.00 & 0.0000 & \\
\hline S77 02.720 E164 00.000 & $\mathrm{CR}$ & $\mathrm{F}$ & 9 & 2 & 1 & 17 & 10 & 10 & 22 & 2200 & 0.10 & 0.10 & 0.22 & 0.0022 & \\
\hline S77 06.000 E163 11.997 & $\mathrm{CR}$ & G & 5 & 1 & 1 & 11 & 10 & 10 & 11 & 1100 & 0.10 & 0.10 & 0.11 & 0.0011 & $200 \mathrm{~m}$ north of piedmont ice tongues \\
\hline S77 05.440 E163 18.000 & $\mathrm{CR}$ & G & 5.5 & 1 & 0 & 7 & & & & & 0.00 & 0.00 & 0.00 & 0.0000 & $\begin{array}{l}\text { under huge berg, sample taken } 150 \mathrm{~m} \text { north } \\
\text { of site; small } 20 \mathrm{~cm} \text { drifts on sea ice, } 10 \% \text { cov- } \\
\text { erage }\end{array}$ \\
\hline S77 05.440 E163 23.700 & $\mathrm{CR}$ & G & 6 & 1 & 1 & 14 & 10 & 10 & 14 & 1400 & 0.10 & 0.10 & 0.14 & 0.0014 & $\begin{array}{l}\text { back over our traverse tracks btw CR-G \& CR- } \\
\text { F and offshore another } 500 \mathrm{~m} \text { (date: } 29-10- \\
10 \text { ) }\end{array}$ \\
\hline double up & $\mathrm{CR}$ & G & 6 & 1 & 1 & 14.5 & 10 & 10 & 10 & 1000 & 0.10 & 0.10 & 0.10 & 0.0010 & $\begin{array}{l}100 \% \text { snow coverage in low drifts oriented } \mathrm{N} \text { - } \\
\text { S (date: } 7-11-10 \text { ) }\end{array}$ \\
\hline S77 05.440 E163 29.760 & $\mathrm{CR}$ & G & 6.5 & 1 & 0 & 13 & & & & & 0.00 & 0.00 & 0.00 & 0.0000 & \\
\hline S77 05.440 E163 35.810 & $\mathrm{CR}$ & G & 7 & 1 & 1 & 14 & 10 & 10 & 14 & 1400 & 0.10 & 0.10 & 0.14 & 0.0014 & \\
\hline S77 05.440 E163 41.860 & $\mathrm{CR}$ & G & 7.5 & 1 & 0 & 14.5 & & & & & 0.00 & 0.00 & 0.00 & 0.0000 & $\begin{array}{l}\text { mod rough sasstrugi btw CR-G- } \& \text { CR-G-7.5; } \\
100 \% \text { snow coverage with drifts up to } 40 \mathrm{~cm} \\
\text { N-S }\end{array}$ \\
\hline S77 05.440 E163 47.900 & $\mathrm{CR}$ & G & 8 & 1 & 1 & 13 & 10 & 10 & 13 & 1300 & 0.10 & 0.10 & 0.13 & 0.0013 & more sasstrugi btw CR-G-7.5 \& CR-G-8 \\
\hline
\end{tabular}




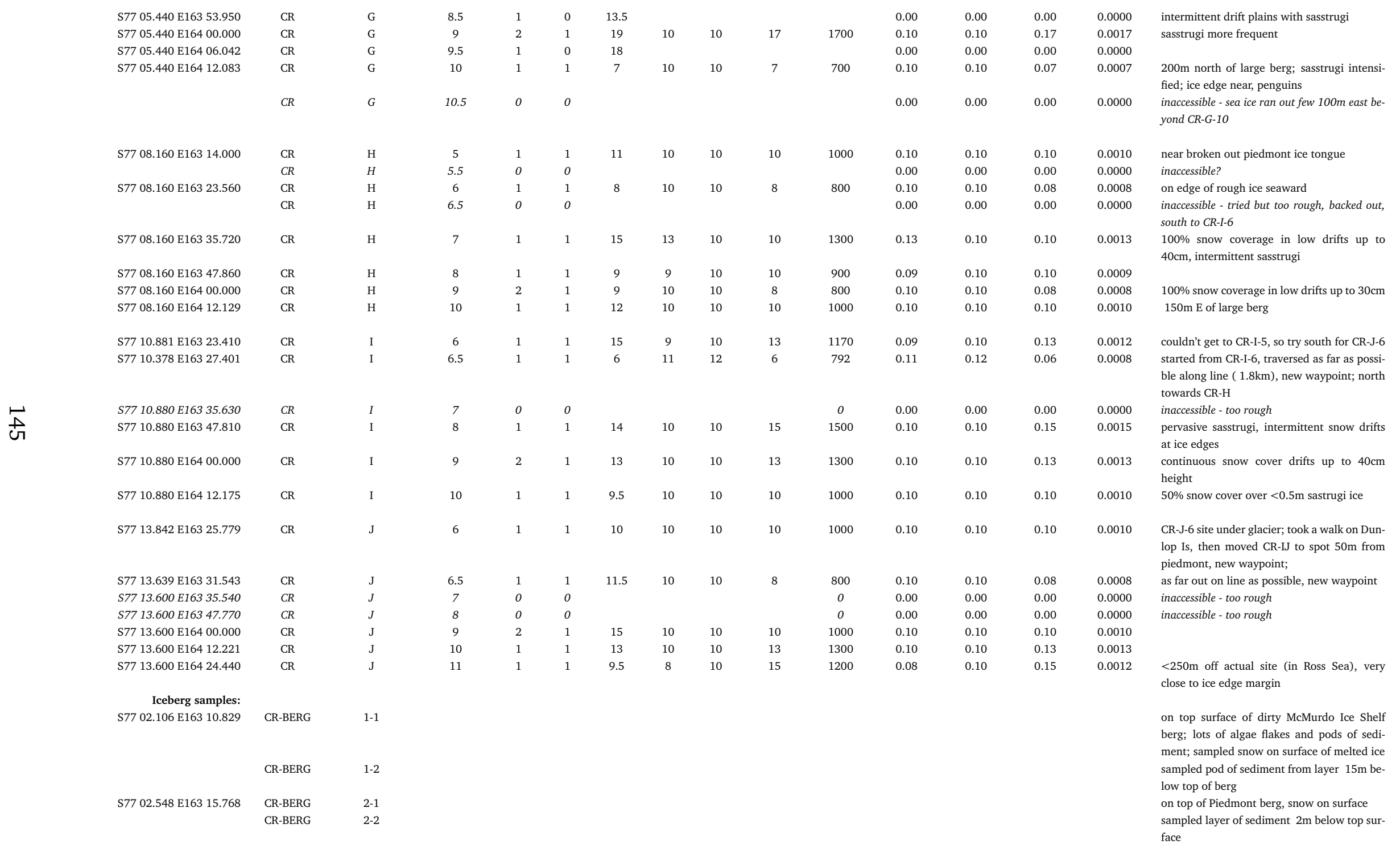


S77 02.408 E163 $15.915 \quad$ CR-BERG

Additional samples:

Kar Plateau, Point Retreat

Dunlop Island

loose sediment

rock sampled top $25 \mathrm{~cm}$ of dirty snow on top of Ross Ice Shelf berg (tilted block)

$20 \mathrm{~m}$ above sea level

$<20 \mathrm{~m}$ above sea level 


\begin{tabular}{|c|c|c|c|c|c|c|c|c|c|c|c|c|c|c|c|}
\hline \multirow{3}{*}{$\begin{array}{l}\text { MARBLE POINT } \\
\text { GPS Coordinates: }\end{array}$} & \multirow{3}{*}{$\begin{array}{l}\text { Area ID } \\
\text { (prefix) }\end{array}$} & \multirow{3}{*}{$\begin{array}{c}\text { Transect } \\
\text { (E-W) }\end{array}$} & \multirow{3}{*}{$\begin{array}{l}\text { Line } \\
(\mathrm{N}-\mathrm{S})\end{array}$} & \multirow{3}{*}{$\begin{array}{c}\text { Bottle } \\
\#\end{array}$} & \multirow{3}{*}{$\begin{array}{c}\text { Bag } \\
\#\end{array}$} & \multirow{3}{*}{$\begin{array}{l}\text { Depth } \\
(\mathrm{cm})\end{array}$} & \multirow{2}{*}{\multicolumn{3}{|c|}{ Bagged sample dimension: }} & \multirow{3}{*}{$\begin{array}{l}\text { Volume } \\
(\mathrm{cm} 3)\end{array}$} & \multirow{2}{*}{\multicolumn{3}{|c|}{ Bagged sample dimension: }} & \multirow{3}{*}{$\begin{array}{l}\text { Volume } \\
(\mathrm{m} 3)\end{array}$} & \multirow{3}{*}{ Notes } \\
\hline & & & & & & & & & & & & & & & \\
\hline & & & & & & & $(\mathrm{cm})$ & (cm) & $(\mathrm{cm})$ & & $(\mathrm{m})$ & (m) & (m) & & \\
\hline S77 16.360 E163 35.450 & MP & $\mathrm{K}$ & 7 & 1 & 1 & & 10 & 10 & 14 & 1400 & 0.10 & 0.10 & 0.14 & 0.0014 & $\begin{array}{l}\text { on smooth coastal 1st year ice } 1 \mathrm{~km} \text { wide; ran } \\
\text { out of bottles so filled one back at camp from } \\
\text { a block of snow collected for this purpose - } \\
\text { trimmed down with clean ruler prior to place- } \\
\text { ment in bottle }\end{array}$ \\
\hline S77 16.360 E163 47.720 & MP & $\mathrm{K}$ & 8 & 1 & 1 & 8 & 10 & 10 & 8 & 800 & 0.10 & 0.10 & 0.08 & 0.0008 & $\begin{array}{l}\text { very rough ice between MP-K7 \& MP-K8; MP- } \\
\text { K8 taken on very rough ice }\end{array}$ \\
\hline S77 16.360 E164 00.000 & MP & $\mathrm{K}$ & 9 & 2 & 1 & 19 & 10 & 12 & 17 & 2040 & 0.10 & 0.12 & 0.17 & 0.0020 & \\
\hline S77 16.360 E164 12.260 & MP & $\mathrm{K}$ & 10 & 1 & 1 & 22 & 10 & 9 & 22 & 1980 & 0.10 & 0.09 & 0.22 & 0.0020 & $\begin{array}{l}\text { patches of smooth snow covered ice with } \\
\text { some rough }\end{array}$ \\
\hline S77 16.360 E164 24.530 & MP & K & 11 & 1 & 1 & 6 & 10 & 10 & 5 & 500 & 0.10 & 0.10 & 0.05 & 0.0005 & Rough beyond MP-K11 \\
\hline S77 19.080 E163 35.360 & MP & $\mathrm{L}$ & 7 & 1 & 1 & 38 & 10 & 10 & 33 & 3300 & 0.10 & 0.10 & 0.33 & 0.0033 & $\begin{array}{l}300 \mathrm{~m} \text { off coast; smooth } 1 \text { st yr ice with small } \\
<30 \mathrm{~cm} \text { sastrugi; snow drifts over } 60 \% \text { up to } \\
30 \mathrm{~cm} \text { deep; brown discolouration of snow }\end{array}$ \\
\hline S77 19.080 E163 47.680 & MP & $\mathrm{L}$ & 8 & 1 & 1 & 14 & 10 & 10 & 15 & 1500 & 0.10 & 0.10 & 0.15 & 0.0015 & \\
\hline S77 19.080 E164 00.000 & MP & $\mathrm{L}$ & 9 & 2 & 1 & 18 & 18 & 10 & 10 & 1800 & 0.18 & 0.10 & 0.10 & 0.0018 & some very rough ice between MP-L8 \& MP-L9 \\
\hline S77 19.080 E164 12.310 & MP & $\mathrm{L}$ & 10 & 1 & 1 & 9 & 9 & 11 & 8 & 792 & 0.09 & 0.11 & 0.08 & 0.0008 & \\
\hline S77 19.080 E164 24.620 & MP & $\mathrm{L}$ & 11 & 1 & 1 & 10 & 10 & 10 & 10 & 1000 & 0.10 & 0.10 & 0.10 & 0.0010 & lunch at ice edge just beyond MP-L11 \\
\hline S77 21.800 E163 35.270 & MP & M & 7 & 1 & 1 & 19 & 10 & 19 & 5 & 950 & 0.10 & 0.19 & 0.05 & 0.0010 & $\begin{array}{l}\text { conspicuous sediment in drift; } 30 \% \text { drift cov- } \\
\text { erage }<40 \mathrm{~cm} \text { high }\end{array}$ \\
\hline S77 21.800 E163 47.630 & MP & M & 8 & 1 & 1 & 24 & 9 & 8 & 22 & 1584 & 0.09 & 0.08 & 0.22 & 0.0016 & $\begin{array}{l}100 \% \text { snow drift cover; dunes } 30 \mathrm{~cm} \text { ampli- } \\
\text { tude }\end{array}$ \\
\hline S77 21.800 E164 00.000 & MP & M & 9 & 2 & 1 & 23 & 6 & 10 & 18 & 1080 & 0.06 & 0.10 & 0.18 & 0.0011 & $\begin{array}{l}\text { snow drifts }<30 \mathrm{~cm} ; \text { many ice blocks } 40 \% \\
<60 \mathrm{~cm} \text { high }\end{array}$ \\
\hline S77 21.800 E164 12.360 & MP & M & 10 & 1 & 1 & 19 & 10 & 8 & 17 & 1360 & 0.10 & 0.08 & 0.17 & 0.0014 & $\begin{array}{l}\text { continuous drift cover } 100 \% \text {; small drift } \\
\text { mound }<20 \mathrm{~cm}\end{array}$ \\
\hline S77 21.800 E164 24.720 & MP & M & 11 & 1 & 1 & 13 & 10 & 10 & 12 & 1200 & 0.10 & 0.10 & 0.12 & 0.0012 & $\begin{array}{l}\text { continuous drift cover } 100 \% \text {; small drift } \\
\text { mound }<20 \mathrm{~cm}\end{array}$ \\
\hline S77 24.520 E163 41.380 & MP & $\mathrm{N}$ & 7.5 & 1 & 0 & & & & & & 0.00 & 0.00 & 0.00 & 0.0000 & \\
\hline S77 24.520 E163 47.590 & MP & $\mathrm{N}$ & 8 & 1 & 1 & 22 & 5 & 10 & 20 & 1000 & 0.05 & 0.10 & 0.20 & 0.0010 & $\begin{array}{l}80 \% \text { snow coverage; ice ridges }<1 \mathrm{~m} \text { height; } \\
\text { multi year }\end{array}$ \\
\hline S77 24.520 E163 53.800 & MP & $\mathrm{N}$ & 8.5 & 1 & 0 & 13 & & & & & 0.00 & 0.00 & 0.00 & 0.0000 & snow drift 100\% coverage \\
\hline S77 24.520 E164 00.000 & MP & $\mathrm{N}$ & 9 & 2 & 1 & 10 & 10 & 10 & 10 & 1000 & 0.10 & 0.10 & 0.10 & 0.0010 & \\
\hline S77 24.520 E164 06.200 & MP & $\mathrm{N}$ & 9.5 & 1 & 0 & 19 & & & & & 0.00 & 0.00 & 0.00 & 0.0000 & $80 \%$ drift cover; dunes $<60 \mathrm{~cm}$ height \\
\hline S77 24.520 E164 12.400 & MP & $\mathrm{N}$ & 10 & 1 & 1 & 14 & 10 & 10 & 12 & 1200 & 0.10 & 0.10 & 0.12 & 0.0012 & $60 \%$ drift snow coverage $<30 \mathrm{~cm}$ high \\
\hline S77 24.520 E164 18.600 & MP & $\mathrm{N}$ & 10.5 & 1 & 0 & 8 & & & & & 0.00 & 0.00 & 0.00 & 0.0000 & \\
\hline S77 24.520 E164 24.810 & MP & $\mathrm{N}$ & 11 & 1 & 1 & 10 & 10 & 10 & 9 & 900 & 0.10 & 0.10 & 0.09 & 0.0009 & discontinuous snow drift cover $20 \%$ \\
\hline S77 24.520 E164 31.000 & MP & $\mathrm{N}$ & 11.5 & 1 & 0 & 15 & & & & & 0.00 & 0.00 & 0.00 & 0.0000 & $\begin{array}{l}\text { semi-continuous snow drift coverage } 70 \% \text {; } \\
\text { drifts }<60 \mathrm{~cm}\end{array}$ \\
\hline S77 24.520 E164 37.220 & MP & $\mathrm{N}$ & 12 & 1 & 1 & 7 & 10 & 15 & 6 & 900 & 0.10 & 0.15 & 0.06 & 0.0009 & high patchy snow drifts $<20 \%$ coverage \\
\hline S77 24.520 E164 43.400 & MP & $\mathrm{N}$ & 12.5 & 1 & 0 & $>100$ & & & & & 0.00 & 0.00 & 0.00 & 0.0000 & sampled top $20 \mathrm{~cm}$ \\
\hline
\end{tabular}




\begin{tabular}{|c|c|c|c|c|c|c|c|c|c|c|c|c|c|c|c|}
\hline S77 27.240 E163 47.540 & MP & $\mathrm{o}$ & 8 & 1 & 1 & 10 & 10 & 10 & 12 & 1200 & 0.10 & 0.10 & 0.12 & 0.0012 & \\
\hline S77 27.240 E163 53.770 & MP & $\mathrm{o}$ & 8.5 & 1 & 0 & 26 & & & & & 0.00 & 0.00 & 0.00 & 0.0000 & \\
\hline S77 27.240 E164 00.000 & MP & $\mathrm{o}$ & 9 & 2 & 1 & 12 & 10 & 10 & 13 & 1300 & 0.10 & 0.10 & 0.13 & 0.0013 & \\
\hline S77 27.240 E164 06.220 & MP & $\mathrm{o}$ & 9.5 & 1 & 0 & 14 & & & & & 0.00 & 0.00 & 0.00 & 0.0000 & $\begin{array}{l}\text { sampled top } 11 \mathrm{~cm} \text {; low snow drifts to } 20 \mathrm{~cm} \\
50 \% \text {; ice covered in latest snow }\end{array}$ \\
\hline S77 27.240 E164 12.450 & MP & $\mathrm{o}$ & 10 & 1 & 1 & 8.5 & 10 & 10 & 10 & 1000 & 0.10 & 0.10 & 0.10 & 0.0010 & $100 \%$ snow cover in low drifts to $30 \mathrm{~cm}$ \\
\hline S77 27.240 E164 18.610 & MP & $\mathrm{o}$ & 10.5 & 1 & 0 & 13.5 & & & & & 0.00 & 0.00 & 0.00 & 0.0000 & sampled top $10.5 \mathrm{~cm}$ \\
\hline S77 27.240 E164 24.900 & MP & $\mathrm{o}$ & 11 & 1 & 1 & 10.5 & 10 & 10 & 10 & 1000 & 0.10 & 0.10 & 0.10 & 0.0010 & sampled top $8.5 \mathrm{~cm}$ \\
\hline S77 27.240 E164 31.120 & MP & $\mathrm{o}$ & 11.5 & 1 & 0 & 13.5 & & & & & 0.00 & 0.00 & 0.00 & 0.0000 & $\begin{array}{l}\text { sampled top } 11 \mathrm{~cm} \text {; common low-lying sas- } \\
\text { trugi }\end{array}$ \\
\hline S77 27.240 E164 37.360 & MP & $\mathrm{o}$ & 12 & 1 & 1 & 6 & 8 & 10 & 15 & 1200 & 0.08 & 0.10 & 0.15 & 0.0012 & $100 \%$ snow cover; low drifts to $40 \mathrm{~cm}$ \\
\hline S77 27.240 E164 43.570 & MP & $\mathrm{o}$ & 12.5 & 1 & 0 & 15 & & & & & 0.00 & 0.00 & 0.00 & 0.0000 & $\begin{array}{l}\text { low sastrugi; } 100 \% \text { snow cover; drfits to } \\
20 \mathrm{~cm}\end{array}$ \\
\hline S77 27.240 E164 49.810 & MP & $\mathrm{o}$ & 13 & 1 & 1 & 12 & 10 & 10 & 13 & 1300 & 0.10 & 0.10 & 0.13 & 0.0013 & $\begin{array}{l}\text { sampled top } 10 \mathrm{~cm} \text {; taken at ice edge; pen- } \\
\text { guins; significant sastrugi between MP-O13 \& } \\
\text { MP-P13, very broken \& jumbled with large } \\
\text { drifts to } 2 \mathrm{~m}\end{array}$ \\
\hline S77 30.539 E163 51.281 & MP & $\mathrm{P}$ & $8.5 \mathrm{NEW}$ & 1 & 0 & 5 & & & & & 0.00 & 0.00 & 0.00 & 0.0000 & $\begin{array}{l}\text { off Cape Bernacchi; multi year ice; broken } \\
\text { plates; intermittent frozen snow drifts }<10 \mathrm{~cm}\end{array}$ \\
\hline S77 30.000 E164 00.000 & MP & $\mathrm{P}$ & 9 & 2 & 1 & 13 & 10 & 10 & 16 & 1600 & 0.10 & 0.10 & 0.16 & 0.0016 & \\
\hline S77 30.000 E164 06.250 & MP & $\mathrm{P}$ & 9.5 & 1 & 0 & 11 & & & & & 0.00 & 0.00 & 0.00 & 0.0000 & $\begin{array}{l}50 \% \text { snow drift coverage }<20 \mathrm{~cm} \text {; latest snow } \\
\text { fall crystallised on ice; }\end{array}$ \\
\hline S77 30.000 E164 12.500 & MP & $\mathrm{P}$ & 10 & 1 & 1 & 17 & 10 & 10 & 17 & 1700 & 0.10 & 0.10 & 0.17 & 0.0017 & drifts $100 \%<40 \mathrm{~cm}$ \\
\hline S77 30.000 E164 18.750 & MP & $\mathrm{P}$ & 10.5 & 1 & 0 & 20 & & & & & 0.00 & 0.00 & 0.00 & 0.0000 & sampled top $18 \mathrm{~cm}$ \\
\hline S77 30.000 E164 25.000 & MP & $\mathrm{P}$ & 11 & 1 & 1 & 19 & 10 & 10 & 20 & 2000 & 0.10 & 0.10 & 0.20 & 0.0020 & $\begin{array}{l}\text { sampled top } 17 \mathrm{~cm} \text {; some low sastrugi; } 100 \% \\
\text { snow cover; drifts }<60 \mathrm{~cm}\end{array}$ \\
\hline S77 30.000 E164 31.250 & MP & $\mathrm{P}$ & 11.5 & 1 & 0 & 17.5 & & & & & 0.00 & 0.00 & 0.00 & 0.0000 & sampled top $15.5 \mathrm{~cm}$ \\
\hline S77 30.000 E164 37.500 & MP & $\mathrm{P}$ & 12 & 1 & 1 & 15 & 10 & 10 & 13 & 1300 & 0.10 & 0.10 & 0.13 & 0.0013 & \\
\hline S77 30.000 E164 43.750 & MP & $\mathrm{P}$ & 12.5 & 1 & 0 & 14.5 & & & & & 0.00 & 0.00 & 0.00 & 0.0000 & sampled top $12.5 \mathrm{~cm}$ \\
\hline S77 30.000 E164 50.000 & MP & $\mathrm{P}$ & 13 & 1 & 1 & 9 & 8 & 10 & 15 & 1200 & 0.08 & 0.10 & 0.15 & 0.0012 & sampled top $7 \mathrm{~cm}$ \\
\hline S77 30.000 E164 56.250 & MP & $\mathrm{P}$ & 13.5 & 1 & 0 & 16 & & & & & 0.00 & 0.00 & 0.00 & 0.0000 & $\begin{array}{l}\text { moderate sastrugi between MP-P13 \& MP- } \\
\text { P13.5; sastrugi amplitude up to } 1-1.5 \mathrm{~m} \text {; sam- } \\
\text { ple taken amongst moderate sastrugi }\end{array}$ \\
\hline S77 32.720 E163 47.470 & MP & $\mathrm{Q}$ & 8 & 1 & 1 & 30 & 10 & 10 & 30 & 3000 & 0.10 & 0.10 & 0.30 & 0.0030 & $\begin{array}{l}\text { off Taylor Valley; sampled top } 20 \mathrm{~cm} \text {; bottom } \\
10 \mathrm{~cm} \text { coarse recrystallised ice; multi year ice; } \\
\text { thick snow cover }>30 \mathrm{~cm} \text {; undulating surface; } \\
\text { occasional ice blisters; drifts oriented E-W; } \\
\text { visible dust }\end{array}$ \\
\hline S77 32.720 E163 53.730 & MP & Q & 8.5 & 1 & 0 & 20 & & & & & 0.00 & 0.00 & 0.00 & 0.0000 & \\
\hline S77 32.720 E164 00.000 & MP & $\mathrm{Q}$ & 9 & 2 & 1 & 28 & 5 & 10 & 25 & 1250 & 0.05 & 0.10 & 0.25 & 0.0013 & icy snow \\
\hline S77 32.720 E164 06.260 & MP & $\mathrm{Q}$ & 9.5 & 1 & 0 & 22 & & & & & 0.00 & 0.00 & 0.00 & 0.0000 & icy snow \\
\hline S77 32.720 E164 12.520 & MP & $\mathrm{Q}$ & 10 & 1 & 1 & 14 & 10 & 10 & 10 & 1000 & 0.10 & 0.10 & 0.10 & 0.0010 & \\
\hline S77 32.720 E164 18.790 & MP & $\mathrm{Q}$ & 10.5 & 1 & 0 & 16 & & & & & 0.00 & 0.00 & 0.00 & 0.0000 & \\
\hline S77 32.720 E164 25.040 & MP & Q & 11 & 1 & 1 & 10.5 & 10 & 10 & 10 & 1000 & 0.10 & 0.10 & 0.10 & 0.0010 & \\
\hline S77 32.720 E164 31.310 & MP & $\mathrm{Q}$ & 11.5 & 1 & 0 & 18 & & & & & 0.00 & 0.00 & 0.00 & 0.0000 & \\
\hline S77 32.720 E164 37.570 & MP & $\mathrm{Q}$ & 12 & 1 & 1 & 13 & 10 & 10 & 13 & 1300 & 0.10 & 0.10 & 0.13 & 0.0013 & \\
\hline
\end{tabular}




\begin{tabular}{|c|c|c|c|c|c|c|c|c|c|c|c|c|c|c|c|c|}
\hline & S77 32.720 E164 43.830 & MP & $\mathrm{Q}$ & 12.5 & 1 & 0 & 7 & & & & & 0.00 & 0.00 & 0.00 & 0.0000 & \\
\hline & S77 32.720 E164 50.090 & MP & $\mathrm{Q}$ & 13 & 1 & 0 & 17 & 10 & 10 & 17 & 1700 & 0.10 & 0.10 & 0.17 & 0.0017 & no bag taken \\
\hline & S77 32.720 E164 56.350 & MP & $\mathrm{Q}$ & 13.5 & 1 & 0 & 10 & & & & & 0.00 & 0.00 & 0.00 & 0.0000 & $\begin{array}{l}\text { wind blew away } 1 \mathrm{x} \text { empty sample bottle in } \\
\text { bag }\end{array}$ \\
\hline & S77 32.720 E165 02.610 & MP & $\mathrm{Q}$ & 14 & 1 & 1 & 25 & 7 & 10 & 23 & 1610 & 0.07 & 0.10 & 0.23 & 0.0016 & ice edge in sight $1 \mathrm{~km}$ away \\
\hline & S77 34.095 E163 41.794 & MP & $\mathrm{QR}$ & 7.5 & 1 & 1 & 11 & 10 & 10 & 9 & 900 & 0.10 & 0.10 & 0.09 & 0.0009 & continuous snow coverage $100 \%$ \\
\hline & S77 33.791 E163 54.254 & MP & $\mathrm{QR}$ & 8.5 & 1 & 1 & 17 & 10 & 8 & 15 & 1200 & 0.10 & 0.08 & 0.15 & 0.0012 & continuous snow coverage $100 \%$ \\
\hline & S77 35.440 E163 41.170 & MP & $\mathrm{R}$ & $7.5 \mathrm{~A}$ & 1 & 0 & 13 & & & & & 0.00 & 0.00 & 0.00 & 0.0000 & $\begin{array}{l}\text { (unsure if MP-7.5B was bottled or still in the } \\
\text { bag) }\end{array}$ \\
\hline & S77 35.440 E163 41.170 & MP & $\mathrm{R}$ & $7.5 \mathrm{~B}$ & 0 & 1 & 21 & & & & & 0.00 & 0.00 & 0.00 & 0.0000 & $\begin{array}{l}\text { labelled duplicate, but not true duplicate; bag } \\
\text { sampled taken to fill bottle at camp }\end{array}$ \\
\hline & S77 35.440 E163 47.450 & MP & $\mathrm{R}$ & 8 & 1 & 1 & 26 & 5 & 10 & 20 & 1000 & 0.05 & 0.10 & 0.20 & 0.0010 & sampled top $25 \mathrm{~cm} ; 100 \%$ snow coverage \\
\hline & S77 35.440 E163 53.720 & MP & $\mathrm{R}$ & 8.5 & 1 & 0 & 28.5 & & & & & 0.00 & 0.00 & 0.00 & 0.0000 & sampled top $27.5 \mathrm{~cm}$ \\
\hline & S77 $35.440 \mathrm{E} 16400.000$ & MP & $\mathrm{R}$ & 9 & 2 & 1 & 22 & 10 & 8 & 17 & 1360 & 0.10 & 0.08 & 0.17 & 0.0014 & $\begin{array}{l}\text { sampled top } 18 \mathrm{~cm} \text {; extensive planar snow } \\
\text { drift; amplitude }<20 \mathrm{~cm}\end{array}$ \\
\hline & S77 35.440 E164 06.270 & MP & $\mathrm{R}$ & 9.5 & 1 & 0 & 23 & & & & & 0.00 & 0.00 & 0.00 & 0.0000 & deep snow, smooth surface on multi year ice \\
\hline & S77 35.440 E164 12.540 & MP & $\mathrm{R}$ & 10 & 1 & 1 & 11 & 10 & 10 & 11 & 1100 & 0.10 & 0.10 & 0.11 & 0.0011 & $\begin{array}{l}\text { on 1st year ice; smooth snow-covered sur- } \\
\text { face; some low sastrugi }<50 \mathrm{~cm} \text { surrounding } \\
\text { area }\end{array}$ \\
\hline & S77 35.440 E164 18.810 & MP & $\mathrm{R}$ & 10.5 & 1 & 0 & 7 & & & & & 0.00 & 0.00 & 0.00 & 0.0000 & 1 st year ice; smooth $10 \mathrm{~cm}$ drifts \\
\hline & S77 35.440 E164 25.090 & MP & $\mathrm{R}$ & 11 & 1 & 1 & 18 & 10 & 10 & 15 & 1500 & 0.10 & 0.10 & 0.15 & 0.0015 & \\
\hline & S77 35.440 E164 31.360 & MP & $\mathrm{R}$ & 11.5 & 1 & 0 & 17 & & & & & 0.00 & 0.00 & 0.00 & 0.0000 & \\
\hline$f$ & S77 35.440 E164 37.640 & MP & $\mathrm{R}$ & 12 & 1 & 1 & 23 & 10 & 10 & 23 & 2300 & 0.10 & 0.10 & 0.23 & 0.0023 & \\
\hline & S77 35.440 E164 43.900 & MP & $\mathrm{R}$ & 12.5 & 1 & 0 & 22 & & & & & 0.00 & 0.00 & 0.00 & 0.0000 & \\
\hline & S77 35.440 E164 50.180 & MP & $\mathrm{R}$ & 13 & 1 & 1 & 10 & 10 & 10 & 9 & 900 & 0.10 & 0.10 & 0.09 & 0.0009 & \\
\hline & S77 35.440 E164 56.450 & MP & $\mathrm{R}$ & 13.5 & 1 & 0 & 21 & & & & & 0.00 & 0.00 & 0.00 & 0.0000 & \\
\hline & S77 35.440 E165 02.730 & MP & $\mathrm{R}$ & 14 & 1 & 1 & 26 & 10 & 10 & 24 & 2400 & 0.10 & 0.10 & 0.24 & 0.0024 & \\
\hline & S77 35.440 E165 09.000 & MP & $\mathrm{R}$ & 14.5 & 1 & 0 & 21 & & & & & 0.00 & 0.00 & 0.00 & 0.0000 & \\
\hline & S77 38.160 E163 47.420 & MP & $\mathrm{s}$ & 8 & 1 & 1 & 18 & 8 & 10 & 16 & 1280 & 0.08 & 0.10 & 0.16 & 0.0013 & $\begin{array}{l}\text { sampled top } 14 \mathrm{~cm} ; 100 \% \text { snow coverage; no } \\
\text { seasonal ice protrusions }\end{array}$ \\
\hline & S77 38.160 E163 53.710 & MP & $\mathrm{s}$ & 8.5 & 1 & 0 & 19 & & & & & 0.00 & 0.00 & 0.00 & 0.0000 & $\begin{array}{l}\text { sampled top } 14 \mathrm{~cm} \text {; conditions good; } 100 \% \\
\text { snow coverage }\end{array}$ \\
\hline & S77 38.160 E164 00.000 & MP & $\mathrm{s}$ & 9 & 2 & 1 & 21 & 10 & 9 & 15 & 1350 & 0.10 & 0.09 & 0.15 & 0.0014 & $\begin{array}{l}\text { sampled top } 15 \mathrm{~cm} \text {; extensive planar snow } \\
\text { drift; amplitude }<20 \mathrm{~cm}\end{array}$ \\
\hline & S77 38.160 E164 06.290 & MP & $\mathrm{s}$ & 9.5 & 1 & 0 & 21 & & & & & 0.00 & 0.00 & 0.00 & 0.0000 & sampled top $16 \mathrm{~cm}$; bottom $5 \mathrm{~cm}$ refreeze zone \\
\hline & S77 38.160 E164 12.570 & MP & $\mathrm{s}$ & 10 & 1 & 1 & 21 & 10 & 10 & 25 & 2500 & 0.10 & 0.10 & 0.25 & 0.0025 & $\begin{array}{l}\text { sampled top } 15 \mathrm{~cm} \text {; bottom } 6 \mathrm{~cm} \text { refreeze } \\
\text { zone; bag sampled to base }\end{array}$ \\
\hline & S77 38.160 E164 18.870 & MP & $\mathrm{s}$ & 10.5 & 1 & 0 & 18 & & & & & 0.00 & 0.00 & 0.00 & 0.0000 & \\
\hline & S77 38.160 E164 25.140 & MP & $\mathrm{s}$ & 11 & 1 & 1 & 20 & 10 & 10 & 19 & 1900 & 0.10 & 0.10 & 0.19 & 0.0019 & \\
\hline & S77 38.160 E164 31.450 & MP & $\mathrm{s}$ & 11.5 & 1 & 0 & 15 & & & & & 0.00 & 0.00 & 0.00 & 0.0000 & $100 \%$ snow cover; eroded drifts to $30 \mathrm{~cm}$ \\
\hline & S77 38.160 E164 37.710 & MP & $\mathrm{s}$ & 12 & 1 & 1 & 17 & 5 & 15 & 20 & 1500 & 0.05 & 0.15 & 0.20 & 0.0015 & \\
\hline & S77 38.160 E164 43.990 & MP & $\mathrm{s}$ & 12.5 & 1 & 0 & 13 & & & & & 0.00 & 0.00 & 0.00 & 0.0000 & \\
\hline & S77 38.160 E164 50.280 & MP & $\mathrm{s}$ & 13 & 1 & 1 & 14 & 10 & 10 & 15 & 1500 & 0.10 & 0.10 & 0.15 & 0.0015 & \\
\hline & S77 38.160 E164 56.580 & MP & $\mathrm{s}$ & 13.5 & 1 & 0 & 22 & & & & & 0.00 & 0.00 & 0.00 & 0.0000 & \\
\hline & S77 38.160 E165 02.850 & MP & $\mathrm{s}$ & 14 & 1 & 1 & 14 & 10 & 10 & 14 & 1400 & 0.10 & 0.10 & 0.14 & 0.0014 & \\
\hline & S77 38.160 E165 09.130 & MP & $s$ & 14.5 & 1 & 0 & 30 & & & & & 0.00 & 0.00 & 0.00 & 0.0000 & snow covered; drift relief to $20 \mathrm{~cm}$ \\
\hline
\end{tabular}




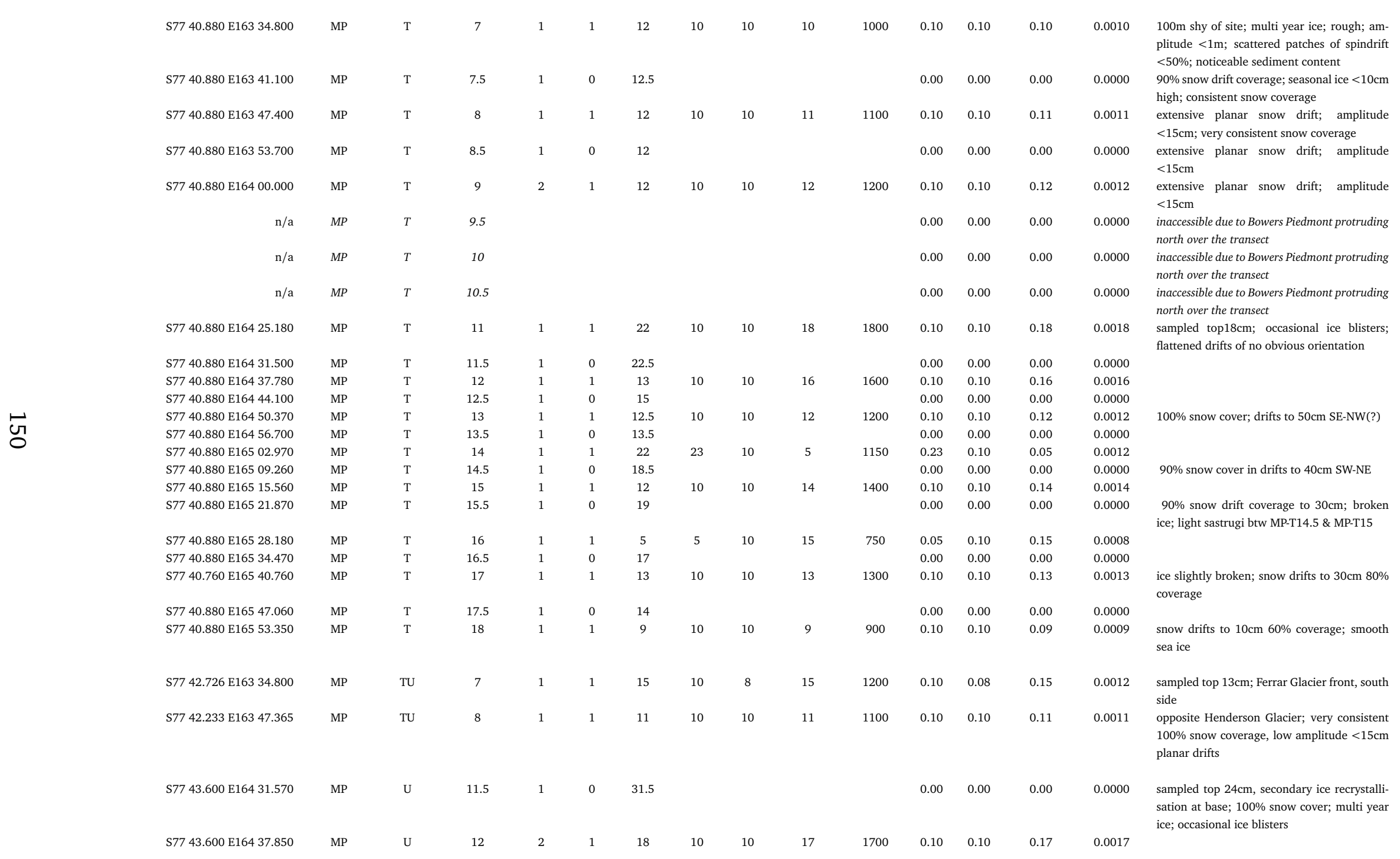




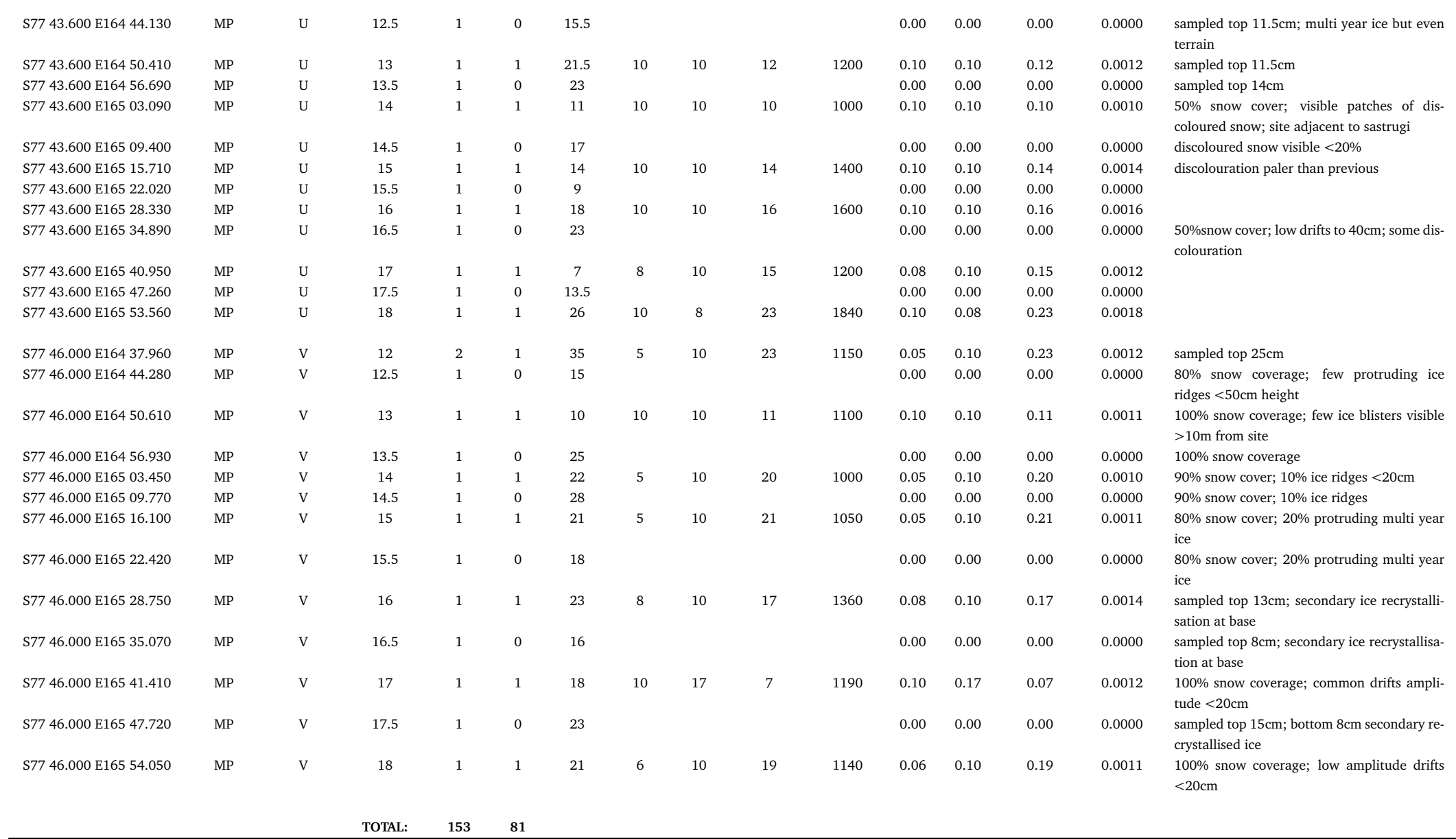




\section{Appendix B}

Mass accumulation data 


\begin{tabular}{|c|c|c|c|c|c|c|c|c|c|c|c|c|c|c|c|c|c|c|}
\hline \multicolumn{19}{|c|}{$\begin{array}{l}\text { K001-D Dust Recovery-MASS WEIGHTS, FILTRATION NOTES: Snow and petri dish weights } \\
\end{array}$} \\
\hline \multicolumn{19}{|c|}{ Abbreviations: bt=bag and tie; Calc.=calculated; $\mathrm{d}=\mathrm{dust} ; \mathrm{f}=$ filter; $\mathrm{pb}=$ petri-base; res=residue; $s=$ snow, vis.app=visual appearance } \\
\hline Sample & $s+b t(A)$ & $s+b t(B)$ & $s+b t(C)$ & $s+b t(\bar{x})$ & bt (A) & bt (B) & bt (C) & bt $(\bar{x})$ & Calc. $s$ & $\mathrm{pb}(\mathrm{A})$ & $\mathrm{pb}(\mathrm{B})$ & $\mathrm{pb}(\mathrm{C})$ & $\mathrm{pb}(\bar{x})$ & $\mathrm{pb}+\mathrm{f}(\mathrm{A})$ & $\mathrm{pb}+\mathrm{f}(\mathrm{B})$ & $\mathrm{pb}+\mathrm{f}(\mathrm{C})$ & $\mathrm{pb}+\mathrm{f}(\bar{x})$ & 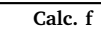 \\
\hline \# & (g) & (g) & (g) & (g) & (g) & (g) & (g) & (g) & (g) & (g) & (g) & (g) & (g) & (g) & (g) & (g) & (g) & (g) \\
\hline CR-A4 & 385 & 385 & 385 & 385 & 44.61 & 44.6 & 44.59 & 44.6 & 340.4 & 4.1503 & 4.1504 & 4.1505 & 4.1504 & 4.1663 & 4.1664 & 4.1661 & 4.166267 & 0.015867 \\
\hline CR-A5 & 691.8 & 691.7 & 691.8 & 691.7667 & 44.98 & 44.98 & 44.98 & 44.98 & 646.7867 & 4.1861 & 4.186 & 4.1859 & 4.186 & 4.2012 & 4.2013 & 4.2013 & 4.201267 & 0.015267 \\
\hline CR-A6 & 705 & 705 & 705 & 705 & 44.7 & 44.7 & 44.7 & 44.7 & 660.3 & 4.1255 & 4.1255 & 4.1257 & 4.125567 & 4.1403 & 4.1402 & 4.1401 & 4.1402 & 0.014633 \\
\hline CR-A7 & 443 & 443.1 & 443.1 & 443.0667 & 44.62 & 44.62 & 44.62 & 44.62 & 398.4467 & 4.1108 & 4.111 & 4.1111 & 4.110967 & 4.1267 & 4.1267 & 4.1265 & 4.126633 & 0.015667 \\
\hline CR-A8 & 570 & 570 & 570 & 570 & 44.77 & 44.78 & 44.78 & 44.77667 & 525.2233 & 4.1296 & 4.1294 & 4.1294 & 4.129467 & 4.1426 & 4.1425 & 4.1428 & 4.142633 & 0.013167 \\
\hline CR-B2 & 593.9 & 594 & 594 & 593.9667 & 43.99 & 43.99 & 43.99 & 43.99 & 549.9767 & 4.191 & 4.191 & 4.1908 & 4.190933 & 4.2062 & 4.2065 & 4.2065 & 4.2064 & 0.015467 \\
\hline CR-B3 & 833 & 833.1 & 833.1 & 833.0667 & 43.63 & 43.63 & 43.63 & 43.63 & 789.4367 & 4.1907 & 4.1908 & 4.1906 & 4.1907 & 4.2065 & 4.2068 & 4.2068 & 4.2067 & 0.016 \\
\hline CR-B4 & 445 & 445 & 445 & 445 & 43.58 & 43.58 & 43.57 & 43.57667 & 401.4233 & 4.1537 & 4.1541 & 4.1541 & 4.153967 & 4.1705 & 4.1705 & 4.1706 & 4.170533 & 0.016567 \\
\hline CR-B5 & 720 & 720 & 720 & 720 & 44.51 & 44.51 & 44.51 & 44.51 & 675.49 & 4.1505 & 4.1508 & 4.1507 & 4.150667 & 4.1663 & 4.1662 & 4.1661 & 4.1662 & 0.015533 \\
\hline CR-B6 & 750 & 750 & 750 & 750 & 45.05 & 45.04 & 45.03 & 45.04 & 704.96 & 4.1268 & 4.1269 & 4.1268 & 4.126833 & 4.1416 & 4.1418 & 4.1419 & 4.141767 & 0.014933 \\
\hline CR-B7 & 881.6 & 881.6 & 881.6 & 881.6 & 44.84 & 44.85 & 44.84 & 44.84333 & 836.7567 & 4.1897 & 4.1896 & 4.1895 & 4.1896 & 4.2061 & 4.2061 & 4.2059 & 4.206033 & 0.016433 \\
\hline CR-B8 & 580 & 580 & 580 & 580 & 44.27 & 44.28 & 44.28 & 44.27667 & 535.7233 & 4.1261 & 4.1264 & 4.1263 & 4.126267 & 4.1426 & 4.1427 & 4.1425 & 4.1426 & 0.016333 \\
\hline CR-C2 & 617.9 & 617.8 & 617.8 & 617.8333 & 44.14 & 44.14 & 44.14 & 44.14 & 573.6933 & 4.1159 & 4.1164 & 4.1162 & 4.116167 & 4.1305 & 4.1305 & 4.1303 & 4.130433 & 0.014267 \\
\hline CR-C3 & 474.2 & 474.2 & 474.2 & 474.2 & 44.83 & 44.82 & 44.83 & 44.82667 & 429.3733 & 4.1906 & 4.1901 & 4.1903 & 4.190333 & 4.2059 & 4.2058 & 4.206 & 4.2059 & 0.015567 \\
\hline CR-C4 & 450 & 450 & 450 & 450 & 43.55 & 43.55 & 43.54 & 43.54667 & 406.4533 & 4.1508 & 4.1508 & 4.1505 & 4.1507 & 4.1683 & 4.1681 & 4.1676 & 4.168 & 0.0173 \\
\hline CR-C5 & 770 & 770.1 & 770 & 770.0333 & 43.31 & 43.31 & 43.31 & 43.31 & 726.7233 & 4.1908 & 4.1906 & 4.1907 & 4.1907 & 4.2071 & 4.2071 & 4.2072 & 4.207133 & 0.016433 \\
\hline CR-C6 & 555 & 555 & 555 & 555 & 44.87 & 44.88 & 44.88 & 44.87667 & 510.1233 & 4.1253 & 4.1255 & 4.1256 & 4.125467 & 4.14 & 4.1404 & 4.1404 & 4.140267 & 0.0148 \\
\hline CR-C7 & 578.7 & 578.5 & 578.5 & 578.5667 & 44.05 & 44.05 & 44.05 & 44.05 & 534.5167 & 4.1176 & 4.1175 & 4.1174 & 4.1175 & 4.1328 & 4.1332 & 4.1329 & 4.132967 & 0.015467 \\
\hline CR-C8 & 720 & 720 & 720 & 720 & 44.1 & 44.1 & 44.1 & 44.1 & 675.9 & 4.1337 & 4.1337 & 4.1335 & 4.133633 & 4.1486 & 4.1486 & 4.1484 & 4.148533 & 0.0149 \\
\hline CR-D2 & 309.8 & 309.8 & 309.8 & 309.8 & 43.79 & 43.78 & 43.78 & 43.78333 & 266.0167 & 3.4625 & 3.4626 & 3.4625 & 3.462533 & 3.4781 & 3.478 & 3.4779 & 3.478 & 0.015467 \\
\hline CR-D3 & 356 & 356 & 356 & 356 & 43.65 & 43.65 & 43.65 & 43.65 & 312.35 & 3.4623 & 3.4622 & 3.4621 & 3.4622 & 3.4779 & 3.478 & 3.478 & 3.477967 & 0.015767 \\
\hline CR-D4* & 557.5 & 557.5 & 557.5 & 557.5 & 43.73 & 43.73 & 43.73 & 43.73 & 513.77 & 3.464 & 3.4643 & 3.4644 & 3.464233 & 3.48 & 3.4799 & 3.4799 & 3.479933 & 0.0157 \\
\hline CR-D5 & 350.3 & 350.3 & 350.3 & 350.3 & 43.93 & 44.02 & 43.95 & 43.96667 & 306.3333 & 3.4698 & 3.4697 & 3.4696 & 3.4697 & 3.4849 & 3.4847 & 3.4847 & 3.484767 & 0.015067 \\
\hline CR-D6 & 499 & 499 & 499 & 499 & 43.68 & 43.69 & 43.69 & 43.68667 & 455.3133 & 3.4626 & 3.4626 & 3.4622 & 3.462467 & 3.4783 & 3.4782 & 3.4783 & 3.478267 & 0.0158 \\
\hline CR-D7 & 474.2 & 474.2 & 474.2 & 474.2 & 43.94 & 43.93 & 43.94 & 43.93667 & 430.2633 & 3.4649 & 3.4649 & 3.4651 & 3.464967 & 3.4809 & 3.4806 & 3.4806 & 3.4807 & 0.015733 \\
\hline CR-D8 & 503.7 & 503.7 & 503.7 & 503.7 & 43.9 & 43.91 & 43.9 & 43.90333 & 459.7967 & 3.4662 & 3.466 & 3.4661 & 3.4661 & 3.481 & 3.4808 & 3.4809 & 3.4809 & 0.0148 \\
\hline CR-D9 & 438.9 & 438.9 & 438.9 & 438.9 & 43.47 & 43.48 & 43.47 & 43.47333 & 395.4267 & 3.461 & 3.4611 & 3.4609 & 3.461 & 3.4777 & 3.4779 & 3.4775 & 3.4777 & 0.0167 \\
\hline CR-E1 & 514 & 514 & 513.9 & 513.9667 & 43.84 & 43.85 & 43.84 & 43.84333 & 470.1233 & 3.4568 & 3.457 & 3.4568 & 3.456867 & 3.4722 & 3.4721 & 3.4722 & 3.472167 & 0.0153 \\
\hline CR-E2 & 322.1 & 322.1 & 322.1 & 322.1 & 43.51 & 43.51 & 43.51 & 43.51 & 278.59 & 3.4551 & 3.4553 & 3.455 & 3.455133 & 3.4705 & 3.4704 & 3.4704 & 3.470433 & 0.0153 \\
\hline CR-E3 & 441.4 & 441.4 & 441.4 & 441.4 & 43.31 & 43.31 & 43.31 & 43.31 & 398.09 & 3.4532 & 3.4529 & 3.4528 & 3.452967 & 3.4689 & 3.469 & 3.4689 & 3.468933 & 0.015967 \\
\hline CR-E4 & 599.5 & 600.4 & 599.5 & 599.8 & 43.67 & 43.67 & 43.67 & 43.67 & 556.13 & 3.4525 & 3.4526 & 3.4523 & 3.452467 & 3.4682 & 3.4682 & 3.4681 & 3.468167 & 0.0157 \\
\hline CR-E5 & 581.4 & 581.4 & 581.4 & 581.4 & 44.1 & 44.09 & 44.1 & 44.09667 & 537.3033 & 3.4628 & 3.4628 & 3.4627 & 3.462767 & 3.4783 & 3.4785 & 3.4786 & 3.478467 & 0.0157 \\
\hline CR-E7 & 559.1 & 559.1 & 559.1 & 559.1 & 44.45 & 44.45 & 44.45 & 44.45 & 514.65 & 4.1919 & 4.1917 & 4.1919 & 4.191833 & 4.2075 & 4.2075 & 4.2074 & 4.207467 & 0.015633 \\
\hline CR-E8 & 781.3 & 781.3 & 781.2 & 781.2667 & 43.69 & 43.69 & 43.69 & 43.69 & 737.5767 & 4.1835 & 4.1834 & 4.1833 & 4.1834 & 4.2001 & 4.1999 & 4.2 & 4.2 & 0.0166 \\
\hline CR-E9 & 433.5 & 433.6 & 433.6 & 433.5667 & 43.23 & 43.22 & 43.22 & 43.22333 & 390.3433 & 4.1925 & 4.1926 & 4.1926 & 4.192567 & 4.2074 & 4.2073 & 4.2073 & 4.207333 & 0.014767 \\
\hline CR-F5 & 1055.6 & 1055.6 & 1055.6 & 1055.6 & 43.92 & 43.91 & 43.91 & 43.91333 & 1011.687 & 4.1901 & 4.1901 & 4.1901 & 4.1901 & 4.206 & 4.206 & 4.2059 & 4.205967 & 0.015867 \\
\hline CR-F6 & 635.5 & 635.4 & 635.4 & 635.4333 & 43.89 & 43.89 & 43.89 & 43.89 & 591.5433 & 4.1902 & 4.19 & 4.1899 & 4.190033 & 4.2055 & 4.2055 & 4.2056 & 4.205533 & 0.0155 \\
\hline CR-F7 & 909.8 & 909.8 & 909.9 & 909.8333 & 44.41 & 44.41 & 44.41 & 44.41 & 865.4233 & 4.1906 & 4.1905 & 4.1909 & 4.190667 & 4.2067 & 4.2066 & 4.2066 & 4.206633 & 0.015967 \\
\hline CR-F8 & 1080 & 1080 & 1080 & 1080 & 43.88 & 43.87 & 43.87 & 43.87333 & 1036.127 & 4.133 & 4.1329 & 4.1329 & 4.132933 & 4.147 & 4.1467 & 4.1467 & 4.1468 & 0.013867 \\
\hline CR-F9 & 1380.5 & 1380.4 & 1380.8 & 1380.567 & 44 & 44.01 & 44 & 44.00333 & 1336.563 & 4.1847 & 4.1843 & 4.1843 & 4.184433 & 4.2001 & 4.1998 & 4.2001 & 4.2 & 0.015567 \\
\hline CR-G10 & 330 & 330 & 330 & 330 & 44.88 & 44.87 & 44.87 & 44.87333 & 285.1267 & 4.1247 & 4.1248 & 4.1248 & 4.124767 & 4.1377 & 4.1378 & 4.1376 & 4.1377 & 0.012933 \\
\hline CR-G5* & 508 & 508 & 507.9 & 507.9667 & 44.37 & 44.36 & 44.36 & 44.36333 & 463.6033 & 4.1878 & 4.188 & 4.1876 & 4.1878 & 4.203 & 4.2032 & 4.2036 & 4.203267 & 0.015467 \\
\hline CR-G6 & 570 & 570 & 570 & 570 & 44.4 & 44.4 & 44.39 & 44.39667 & 525.6033 & 4.1328 & 4.1332 & 4.133 & 4.133 & 4.1473 & 4.1474 & 4.1479 & 4.147533 & 0.014533 \\
\hline CR-G7 & 628.1 & 628 & 628.1 & 628.0667 & 44.1 & 44.1 & 44.1 & 44.1 & 583.9667 & 4.1128 & 4.1127 & 4.1126 & 4.1127 & 4.1286 & 4.128 & 4.1283 & 4.1283 & 0.0156 \\
\hline
\end{tabular}




\begin{tabular}{|c|c|c|c|c|c|c|c|c|c|c|c|c|c|c|c|c|c|c|}
\hline CR-G9 & 810 & 810 & 810.1 & 810.0333 & 44.54 & 44.54 & 44.54 & 44.54 & 765.4933 & 4.192 & 4.1919 & 4.192 & 4.191967 & 4.2083 & 4.2082 & 4.2082 & 4.208233 & 0.016267 \\
\hline CR-H10 & 470 & 470 & 470 & 470 & 44.58 & 44.58 & 44.59 & 44.58333 & 425.4167 & 4.1326 & 4.1328 & 4.1328 & 4.132733 & 4.1485 & 4.1486 & 4.1484 & 4.1485 & 0.015767 \\
\hline CR-H5 & 403.5 & 403.6 & 403.5 & 403.5333 & 44.81 & 44.81 & 44.81 & 44.81 & 358.7233 & 4.1826 & 4.1825 & 4.1825 & 4.182533 & 4.1984 & 4.1983 & 4.1982 & 4.1983 & 0.015767 \\
\hline CR-H6 & 545 & 545 & 545 & 545 & 44.06 & 44.05 & 44.06 & 44.05667 & 500.9433 & 4.133 & 4.1333 & 4.1331 & 4.133133 & 4.1493 & 4.1493 & 4.1494 & 4.149333 & 0.0162 \\
\hline CR-H7 & 726.8 & 726.7 & 726.6 & 726.7 & 44.54 & 44.54 & 44.54 & 44.54 & 682.16 & 4.1811 & 4.1812 & 4.1811 & 4.181133 & 4.197 & 4.1964 & 4.1965 & 4.196633 & 0.0155 \\
\hline CR-H8 & 425 & 425 & 425 & 425 & 44.36 & 44.36 & 44.36 & 44.36 & 380.64 & 4.1248 & 4.1249 & 4.1248 & 4.124833 & 4.1395 & 4.1393 & 4.1392 & 4.139333 & 0.0145 \\
\hline CR-H9 & 481 & 481.1 & 481.1 & 481.0667 & 45.17 & 45.17 & 45.17 & 45.17 & 435.8967 & 4.1912 & 4.1911 & 4.1911 & 4.191133 & 4.2071 & 4.2069 & 4.2068 & 4.206933 & 0.0158 \\
\hline CR-I10 & 485 & 485 & 485 & 485 & 44.64 & 44.63 & 44.63 & 44.63333 & 440.3667 & 4.1246 & 4.1248 & 4.1246 & 4.124667 & 4.1387 & 4.1388 & 4.1387 & 4.138733 & 0.014067 \\
\hline CR-I6 & 568.6 & 568.6 & 568.6 & 568.6 & 44.57 & 44.61 & 44.59 & 44.59 & 524.01 & 4.1129 & 4.1129 & 4.1131 & 4.112967 & 4.1296 & 4.1295 & 4.1296 & 4.129567 & 0.0166 \\
\hline CR-I6.5 & 495 & 495 & 495 & 495 & 45.2 & 45.19 & 45.19 & 45.19333 & 449.8067 & 4.1267 & 4.1267 & 4.1268 & 4.126733 & 4.1419 & 4.1418 & 4.1418 & 4.141833 & 0.0151 \\
\hline CR-I8 & 465 & 465 & 465 & 465 & 44.73 & 44.73 & 44.73 & 44.73 & 420.27 & 4.1245 & 4.1242 & 4.1243 & 4.124333 & 4.1396 & 4.1395 & 4.1395 & 4.139533 & 0.0152 \\
\hline CR-19 & 727.3 & 727.3 & 727.3 & 727.3 & 44.74 & 44.75 & 44.75 & 44.74667 & 682.5533 & 4.1819 & 4.1819 & 4.1818 & 4.181867 & 4.1974 & 4.1977 & 4.1977 & 4.1976 & 0.015733 \\
\hline CR-J10 & 745 & 745 & 745 & 745 & 44.72 & 44.71 & 44.7 & 44.71 & 700.29 & 4.132 & 4.1325 & 4.1322 & 4.132233 & 4.1458 & 4.1457 & 4.1456 & 4.1457 & 0.013467 \\
\hline CR-J11 & 470 & 470 & 470 & 470 & 44.94 & 44.97 & 44.96 & 44.95667 & 425.0433 & 4.1537 & 4.154 & 4.1543 & 4.154 & 4.1703 & 4.1705 & 4.1705 & 4.170433 & 0.016433 \\
\hline CR-J6 & 467.9 & 467.9 & 467.8 & 467.8667 & 44.23 & 44.23 & 44.23 & 44.23 & 423.6367 & 4.1186 & 4.1182 & 4.1181 & 4.1183 & 4.1344 & 4.1344 & 4.1344 & 4.1344 & 0.0161 \\
\hline CR-J6.5 & 494 & 493.9 & 493.9 & 493.9333 & 45.02 & 45.02 & 45.02 & 45.02 & 448.9133 & 4.1129 & 4.1128 & 4.1133 & 4.113 & 4.1296 & 4.1297 & 4.1295 & 4.1296 & 0.0166 \\
\hline CR-J9 & 740.3 & 740.3 & 740.3 & 740.3 & 44.85 & 44.85 & 44.85 & 44.85 & 695.45 & 4.1125 & 4.1125 & 4.1125 & 4.1125 & 4.1287 & 4.1287 & 4.1288 & 4.128733 & 0.016233 \\
\hline MP-K11 & 510 & 510 & 510 & 510 & 44.62 & 44.61 & 44.62 & 44.61667 & 465.3833 & 4.1504 & 4.1502 & 4.1502 & 4.150267 & 4.1665 & 4.1669 & 4.1668 & 4.166733 & 0.016467 \\
\hline MP-K7 & 811.8 & 811.7 & 811.7 & 811.7333 & 45.21 & 45.22 & 45.2 & 45.21 & 766.5233 & 4.116 & 4.116 & 4.1161 & 4.116033 & 4.1308 & 4.1308 & 4.1304 & 4.130667 & 0.014633 \\
\hline MP-K8 & 530 & 535 & 535 & 533.3333 & 45.07 & 45.06 & 45.06 & 45.06333 & 488.27 & 4.1308 & 4.1306 & 4.1309 & 4.130767 & 4.1454 & 4.1452 & 4.1451 & 4.145233 & 0.014467 \\
\hline MP-K9 & 996.3 & 996.3 & 996.3 & 996.3 & 40.19 & 40.19 & 40.19 & 40.19 & 956.11 & 4.1816 & 4.1812 & 4.1815 & 4.181433 & 4.1969 & 4.197 & 4.1968 & 4.1969 & 0.015467 \\
\hline MP-L10 & 425 & 425 & 425 & 425 & 45.43 & 45.42 & 45.43 & 45.42667 & 379.5733 & 4.0955 & 4.096 & 4.0956 & 4.0957 & 4.111 & 4.1107 & 4.1111 & 4.110933 & 0.015233 \\
\hline MP-L11 & 575 & 575 & 575 & 575 & 45.25 & 45.23 & 45.22 & 45.23333 & 529.7667 & 4.1562 & 4.1559 & 4.1559 & 4.156 & 4.172 & 4.1723 & 4.1722 & 4.172167 & 0.016167 \\
\hline MP-L7 & 1772.3 & 1772.6 & 1772.3 & 1772.4 & 77.04 & 77.04 & 77.05 & 77.04333 & 1695.357 & 4.1188 & 4.1186 & 4.1187 & 4.1187 & 4.135 & 4.135 & 4.1351 & 4.135033 & 0.016333 \\
\hline MP-L8 & 1005 & 1005 & 1005 & 1005 & 45.27 & 45.27 & 45.27 & 45.27 & 959.73 & 4.1242 & 4.1243 & 4.1243 & 4.124267 & 4.1384 & 4.1383 & 4.1385 & 4.1384 & 0.014133 \\
\hline MP-L9 & 1143.9 & 1143.9 & 1143.8 & 1143.867 & 44.61 & 44.61 & 44.61 & 44.61 & 1099.257 & 4.1169 & 4.1162 & 4.1163 & 4.116467 & 4.1313 & 4.1308 & 4.1313 & 4.131133 & 0.014667 \\
\hline MP-M10 & 780 & 780 & 780 & 780 & 39.77 & 39.77 & 39.77 & 39.77 & 740.23 & 4.1274 & 4.1273 & 4.1273 & 4.127333 & 4.1425 & 4.1424 & 4.1423 & 4.1424 & 0.015067 \\
\hline MP-M11 & 645 & 645 & 645 & 645 & 44.78 & 44.78 & 44.76 & 44.77333 & 600.2267 & 4.1522 & 4.1521 & 4.152 & 4.1521 & 4.1679 & 4.1676 & 4.1681 & 4.167867 & 0.015767 \\
\hline MP-M7 & 579.8 & 579.7 & 579.7 & 579.7333 & 40.11 & 40.07 & 40.08 & 40.08667 & 539.6467 & 4.1169 & 4.117 & 4.1172 & 4.117033 & 4.1336 & 4.1336 & 4.1333 & 4.1335 & 0.016467 \\
\hline MP-M8 & 600 & 600 & 600 & 600 & 39.68 & 39.68 & 39.68 & 39.68 & 560.32 & 4.1333 & 4.1332 & 4.133 & 4.133167 & 4.1474 & 4.1473 & 4.1473 & 4.147333 & 0.014167 \\
\hline MP-M9 & 663.9 & 663.9 & 663.9 & 663.9 & 44.8 & 44.81 & 44.81 & 44.80667 & 619.0933 & 4.1918 & 4.1919 & 4.1916 & 4.191767 & 4.2057 & 4.2056 & 4.2055 & 4.2056 & 0.013833 \\
\hline MP-N10 & 700 & 700 & 700 & 700 & 77.7 & 77.68 & 77.68 & 77.68667 & 622.3133 & 4.134 & 4.1344 & 4.1343 & 4.134233 & 4.1483 & 4.1482 & 4.1484 & 4.1483 & 0.014067 \\
\hline MP-N12 & 395 & 395 & 395 & 395 & 45.23 & 45.23 & 45.24 & 45.23333 & 349.7667 & 4.1417 & 4.1419 & 4.142 & 4.141867 & 4.1546 & 4.1546 & 4.1548 & 4.154667 & 0.0128 \\
\hline MP-N8 & 729.4 & 729.4 & 729.4 & 729.4 & 39.74 & 39.75 & 39.75 & 39.74667 & 689.6533 & 4.1126 & 4.1121 & 4.1121 & 4.112267 & 4.1265 & 4.1266 & 4.1266 & 4.126567 & 0.0143 \\
\hline MP-N9 & 520 & 520 & 520 & 520 & 45 & 44.99 & 44.99 & 44.99333 & 475.0067 & 4.133 & 4.1333 & 4.1331 & 4.133133 & 4.1456 & 4.1461 & 4.1461 & 4.145933 & 0.0128 \\
\hline MP-010 & 540 & 540 & 540 & 540 & 40.2 & 40.19 & 40.2 & 40.19667 & 499.8033 & 4.1243 & 4.1245 & 4.1249 & 4.124567 & 4.1388 & 4.1389 & 4.1388 & 4.138833 & 0.014267 \\
\hline MP-O11 & 610 & 610 & 610 & 610 & 40.07 & 40.07 & 40.08 & 40.07333 & 569.9267 & 4.1583 & 4.1581 & 4.1587 & 4.158367 & 4.1741 & 4.1739 & 4.1742 & 4.174067 & 0.0157 \\
\hline MP-O12 & 520 & 520 & 520 & 520 & 39.93 & 39.94 & 39.94 & 39.93667 & 480.0633 & 4.1416 & 4.1416 & 4.1415 & 4.141567 & 4.1565 & 4.1564 & 4.1564 & 4.156433 & 0.014867 \\
\hline MP-013 & 540 & 540 & 540 & 540 & 39.59 & 39.59 & 39.58 & 39.58667 & 500.4133 & 4.1252 & 4.1254 & 4.1252 & 4.125267 & 4.1388 & 4.1386 & 4.1388 & 4.138733 & 0.013467 \\
\hline MP-08 & 684.1 & 683.7 & 684.1 & 683.9667 & 39.9 & 39.89 & 39.91 & 39.9 & 644.0667 & 4.1196 & 4.1193 & 4.1194 & 4.119433 & 4.1318 & 4.1321 & 4.1325 & 4.132133 & 0.0127 \\
\hline MP-09 & 734.9 & 734.9 & 735 & 734.9333 & 40.12 & 40.12 & 40.12 & 40.12 & 694.8133 & 4.1814 & 4.1815 & 4.1812 & 4.181367 & 4.197 & 4.1968 & 4.1969 & 4.1969 & 0.015533 \\
\hline MP-P10 & 805 & 805 & 805 & 805 & 39.78 & 39.78 & 39.78 & 39.78 & 765.22 & 4.1417 & 4.1417 & 4.1419 & 4.141767 & 4.155 & 4.1551 & 4.1549 & 4.155 & 0.013233 \\
\hline MP-P11 & 1080 & 1080 & 1080 & 1080 & 39.96 & 39.97 & 39.95 & 39.96 & 1040.04 & 4.1588 & 4.1588 & 4.1583 & 4.158633 & 4.174 & 4.1739 & 4.1742 & 4.174033 & 0.0154 \\
\hline MP-P12 & 705 & 700 & 700 & 701.6667 & 39.82 & 39.8 & 39.81 & 39.81 & 661.8567 & 4.1465 & 4.147 & 4.147 & 4.146833 & 4.1596 & 4.1594 & 4.1598 & 4.1596 & 0.012767 \\
\hline MP-P13 & 645 & 645 & 645 & 645 & 39.98 & 39.97 & 39.97 & 39.97333 & 605.0267 & 4.1537 & 4.1537 & 4.1541 & 4.153833 & 4.1686 & 4.1686 & 4.1685 & 4.168567 & 0.014733 \\
\hline MP-P9 & 726 & 725.9 & 725.9 & 725.9333 & 39.7 & 39.71 & 39.7 & 39.70333 & 686.23 & 4.1116 & 4.1114 & 4.1112 & 4.1114 & 4.1262 & 4.1257 & 4.1257 & 4.125867 & 0.014467 \\
\hline MP-Q10 & 590 & 590 & 585 & 588.3333 & 44.28 & 44.26 & 44.26 & 44.26667 & 544.0667 & 4.141 & 4.1407 & 4.141 & 4.1409 & 4.1549 & 4.155 & 4.155 & 4.154967 & 0.014067 \\
\hline MP-Q11 & 625 & 625 & 625 & 625 & 44.44 & 44.44 & 44.45 & 44.44333 & 580.5567 & 4.1505 & 4.1508 & 4.1512 & 4.150833 & 4.1666 & 4.1665 & 4.167 & 4.1667 & 0.015867 \\
\hline MP-Q12 & 840 & 840 & 840 & 840 & 45.41 & 45.41 & 45.4 & 45.40667 & 794.5933 & 4.1475 & 4.1481 & 4.1479 & 4.147833 & 4.1631 & 4.163 & 4.1632 & 4.1631 & 0.015267 \\
\hline
\end{tabular}




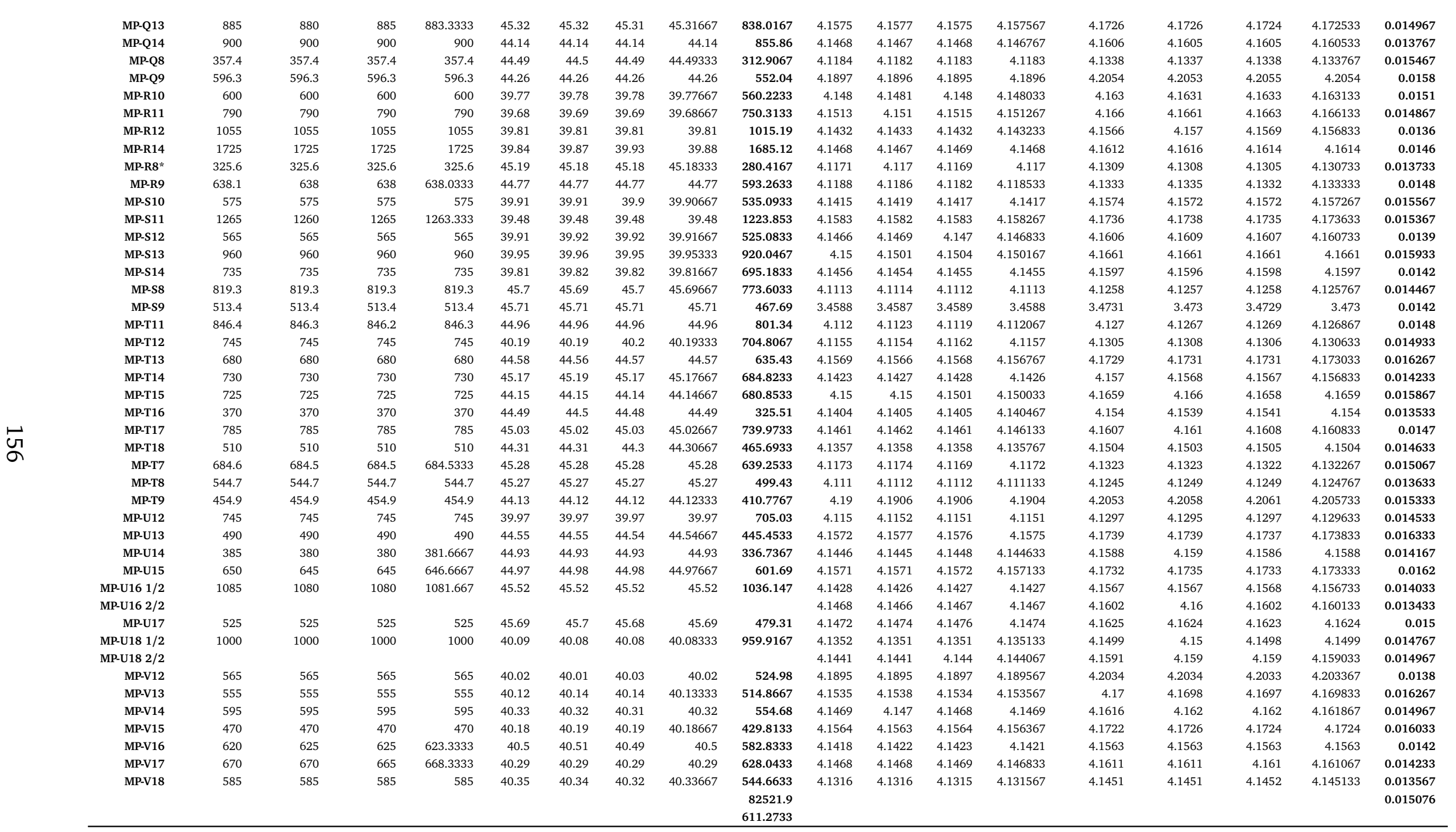




\begin{tabular}{|c|c|c|c|c|c|c|c|c|c|}
\hline \multicolumn{10}{|c|}{ K001-D Dust Recovery-MASS WEIGHTS, FILTRATION NOTES: Dust weights } \\
\hline \multicolumn{10}{|c|}{ reviations: bt=bag and tie; $\mathrm{d}=$ dust; $\mathrm{f}=$ filter; $\mathrm{pb}=$ =etri-base; res=residue; $s=$ snow, vis.app=visual appeara } \\
\hline Sample & $p b+f+d(A)$ & $p b+f+d(B)$ & $p b+f+d(C)$ & $\mathrm{pb}+\mathrm{f}+\mathrm{d}(\bar{x})$ & $\mathrm{d}$ & $1 \sigma \mathrm{d}$ & $\mathrm{d} / \mathrm{s}$ & residue & vis. App. \\
\hline & (g) & (g) & (g) & $(\mathrm{g})$ & (g) & (g) & (per mil) & (presence) & \\
\hline CR-A4 & 4.1732 & 4.1731 & 4.173 & 4.1731 & 0.006833 & $1 \mathrm{E}-04$ & 0.020074 & & very fine \\
\hline CR-A5 & 4.216 & 4.216 & 4.216 & 4.216 & 0.014733 & 0 & 0.022779 & & very fine \\
\hline CR-A6 & 4.1539 & 4.1538 & 4.1537 & 4.1538 & 0.0136 & 0.0001 & 0.020597 & & very fine \\
\hline CR-A7 & 4.1353 & 4.1355 & 4.1354 & 4.1354 & 0.008767 & 0.0001 & 0.022002 & & very fine \\
\hline CR-A8 & 4.1494 & 4.1494 & 4.1496 & 4.149467 & 0.006833 & 0.000115 & 0.01301 & & very fine \\
\hline CR-B2 & 4.2289 & 4.2291 & 4.2289 & 4.228967 & 0.022567 & 0.000115 & 0.041032 & & very fine \\
\hline CR-B3 & 4.225 & 4.2251 & 4.2253 & 4.225133 & 0.018433 & 0.000153 & 0.02335 & & very fine \\
\hline CR-B4 & 4.1797 & 4.1798 & 4.18 & 4.179833 & 0.0093 & 0.000153 & 0.023168 & & very fine \\
\hline CR-B5 & 4.1811 & 4.1812 & 4.1811 & 4.181133 & 0.014933 & $5.77 \mathrm{E}-05$ & 0.022107 & & very fine $>$ fine \\
\hline CR-B6 & 4.1566 & 4.1565 & 4.1567 & 4.1566 & 0.014833 & $1 \mathrm{E}-04$ & 0.021041 & & very fine $>$ fine \\
\hline CR-B7 & 4.2191 & 4.2193 & 4.2193 & 4.219233 & 0.0132 & 0.000115 & 0.015775 & & very fine \\
\hline CR-B8 & 4.1506 & 4.151 & 4.1508 & 4.1508 & 0.0082 & 0.0002 & 0.015306 & & very fine \\
\hline CR-C2 & 4.1349 & 4.1348 & 4.1348 & 4.134833 & 0.0044 & $5.77 \mathrm{E}-05$ & 0.00767 & & very fine \\
\hline CR-C3 & 4.2312 & 4.231 & 4.231 & 4.231067 & 0.025167 & 0.000115 & 0.058613 & & very fine \\
\hline CR-C4 & 4.181 & 4.1807 & 4.181 & 4.1809 & 0.0129 & 0.000173 & 0.031738 & & very fine \\
\hline CR-C5 & 4.2285 & 4.2285 & 4.2287 & 4.228567 & 0.021433 & 0.000115 & 0.029493 & & very fine $>$ fine \\
\hline CR-C6 & 4.1525 & 4.1526 & 4.1525 & 4.152533 & 0.012267 & $5.77 \mathrm{E}-05$ & 0.024046 & & very fine \\
\hline CR-C7 & 4.1417 & 4.1417 & 4.1418 & 4.141733 & 0.008767 & $5.77 \mathrm{E}-05$ & 0.016401 & & very fine \\
\hline CR-C8 & 4.1585 & 4.1587 & 4.1584 & 4.158533 & 0.01 & 0.000153 & 0.014795 & & very fine \\
\hline CR-D2 & 3.4824 & 3.4821 & 3.4822 & 3.482233 & 0.004233 & 0.000153 & 0.015914 & & very fine \\
\hline CR-D3 & 3.4812 & 3.4813 & 3.4809 & 3.481133 & 0.003167 & 0.000208 & 0.010138 & & very fine \\
\hline CR-D4* & 3.488 & 3.4879 & 3.488 & 3.487967 & 0.008033 & $5.77 \mathrm{E}-05$ & 0.015636 & & very fine \\
\hline CR-D5 & 3.4876 & 3.4876 & 3.4875 & 3.487567 & 0.0028 & $5.77 \mathrm{E}-05$ & 0.00914 & & very fine \\
\hline CR-D6 & 3.4773 & 3.4774 & 3.4773 & 3.477333 & -0.00093 & $5.77 \mathrm{E}-05$ & -0.00205 & & very fine \\
\hline CR-D7 & 3.4847 & 3.4848 & 3.4848 & 3.484767 & 0.004067 & $5.77 \mathrm{E}-05$ & 0.009452 & & very fine \\
\hline CR-D8 & 3.4823 & 3.4823 & 3.4825 & 3.482367 & 0.001467 & 0.000115 & 0.00319 & & very fine \\
\hline CR-D9 & 3.4819 & 3.4819 & 3.4821 & 3.481967 & 0.004267 & 0.000115 & 0.01079 & & very fine \\
\hline CR-E1 & 3.4793 & 3.4794 & 3.4792 & 3.4793 & 0.007133 & $1 \mathrm{E}-04$ & 0.015173 & & very fine \\
\hline CR-E2 & 3.4832 & 3.4833 & 3.4829 & 3.483133 & 0.0127 & 0.000208 & 0.045587 & & very fine \\
\hline CR-E3 & 3.4771 & 3.4772 & 3.477 & 3.4771 & 0.008167 & $1 \mathrm{E}-04$ & 0.020515 & & very fine \\
\hline CR-E4 & 3.4754 & 3.4753 & 3.4753 & 3.475333 & 0.007167 & $5.77 \mathrm{E}-05$ & 0.012887 & & very fine \\
\hline CR-E5 & 3.4887 & 3.4889 & 3.4889 & 3.488833 & 0.010367 & 0.000115 & 0.019294 & & very fine \\
\hline CR-E7 & 4.214 & 4.2142 & 4.214 & 4.214067 & 0.0066 & 0.000115 & 0.012824 & & very fine \\
\hline CR-E8 & 4.2095 & 4.2096 & 4.2095 & 4.209533 & 0.009533 & $5.77 \mathrm{E}-05$ & 0.012925 & & very fine \\
\hline CR-E9 & 4.2213 & 4.2212 & 4.2212 & 4.221233 & 0.0139 & 5.77E- 05 & 0.03561 & & very fine \\
\hline CR-F5 & 4.2288 & 4.2285 & 4.2288 & 4.2287 & 0.022733 & 0.000173 & 0.022471 & & very fine \\
\hline CR-F6 & 4.2184 & 4.2185 & 4.2184 & 4.218433 & 0.0129 & $5.77 \mathrm{E}-05$ & 0.021807 & & very fine \\
\hline CR-F7 & 4.2182 & 4.218 & 4.2181 & 4.2181 & 0.011467 & 0.0001 & 0.01325 & & very fine \\
\hline CR-F8 & 4.1684 & 4.1683 & 4.1684 & 4.168367 & 0.021567 & $5.77 \mathrm{E}-05$ & 0.020815 & & very fine $>$ fine \\
\hline CR-F9 & 4.2142 & 4.2139 & 4.2146 & 4.214233 & 0.014233 & 0.000351 & 0.010649 & & very fine $>$ fine \\
\hline CR-G10 & 4.1412 & 4.1413 & 4.1411 & 4.1412 & 0.0035 & 0.0001 & 0.012275 & & very fine \\
\hline CR-G5* & 4.2077 & 4.2077 & 4.2075 & 4.207633 & 0.004367 & 0.000115 & 0.009419 & & very fine \\
\hline CR-G6 & 4.1602 & 4.1604 & 4.1605 & 4.160367 & 0.012833 & 0.000153 & 0.024416 & & very fine \\
\hline CR-G7 & 4.1405 & 4.1407 & 4.1409 & 4.1407 & 0.0124 & 0.0002 & 0.021234 & & very fine $>$ fine \\
\hline
\end{tabular}




\begin{tabular}{|c|c|c|c|c|c|c|c|c|c|}
\hline CR-G9 & 4.215 & 4.2141 & 4.2139 & 4.214333 & 0.0061 & 0.000586 & 0.007969 & & very fine \\
\hline CR-H10 & 4.1516 & 4.1517 & 4.1518 & 4.1517 & 0.0032 & $1 \mathrm{E}-04$ & 0.007522 & & very fine \\
\hline CR-H5 & 4.2076 & 4.2085 & 4.2083 & 4.208133 & 0.009833 & 0.000473 & 0.027412 & & very fine \\
\hline CR-H6 & 4.1618 & 4.162 & 4.1618 & 4.161867 & 0.012533 & 0.000115 & 0.025019 & & very fine $>$ fine \\
\hline CR-H7 & 4.2124 & 4.2124 & 4.2124 & 4.2124 & 0.015767 & 0 & 0.023113 & & very fine \\
\hline CR-H8 & 4.1456 & 4.1453 & 4.1454 & 4.145433 & 0.0061 & 0.000153 & 0.016026 & & very fine \\
\hline CR-H9 & 4.2277 & 4.2273 & 4.2275 & 4.2275 & 0.020567 & 0.0002 & 0.047182 & & very fine $>$ fine \\
\hline CR-I10 & 4.1741 & 4.1738 & 4.1739 & 4.173933 & 0.0352 & 0.000153 & 0.079933 & & very fine $>$ fine \\
\hline CR-16 & 4.1426 & 4.1424 & 4.1424 & 4.142467 & 0.0129 & 0.000115 & 0.024618 & & very fine \\
\hline CR-16.5 & 4.1483 & 4.1485 & 4.1488 & 4.148533 & 0.0067 & 0.000252 & 0.014895 & & very fine \\
\hline CR-I8 & 4.1614 & 4.1613 & 4.1614 & 4.161367 & 0.021833 & $5.77 \mathrm{E}-05$ & 0.051951 & & very fine $>$ fine \\
\hline CR-19 & 4.2207 & 4.2204 & 4.2204 & 4.2205 & 0.0229 & 0.000173 & 0.03355 & & fine \\
\hline CR-J10 & 4.1777 & 4.1777 & 4.1777 & 4.1777 & 0.032 & 0 & 0.045695 & & very fine $>$ fine \\
\hline CR-J11 & 4.2286 & 4.2287 & 4.2287 & 4.228667 & 0.058233 & $5.77 \mathrm{E}-05$ & 0.137006 & & fine \\
\hline CR-J6 & 4.1461 & 4.1462 & 4.1459 & 4.146067 & 0.011667 & 0.000153 & 0.027539 & & very fine \\
\hline CR-J6.5 & 4.185 & 4.185 & 4.1851 & 4.185033 & 0.055433 & $5.77 \mathrm{E}-05$ & 0.123483 & & very fine $>$ fine \\
\hline CR-J9 & 4.1554 & 4.1559 & 4.1557 & 4.155667 & 0.026933 & 0.000252 & 0.038728 & & very fine $>$ fine \\
\hline MP-K11 & 4.1729 & 4.1726 & 4.1726 & 4.1727 & 0.005967 & 0.000173 & 0.012821 & & very fine \\
\hline MP-K7 & 4.2003 & 4.2005 & 4.2009 & 4.200567 & 0.0699 & 0.000306 & 0.091191 & & very fine $>$ fine \\
\hline MP-K8 & 4.1879 & 4.188 & 4.1881 & 4.188 & 0.042767 & 0.0001 & 0.087588 & & very fine $>$ fine \\
\hline MP-K9 & 4.2319 & 4.232 & 4.2322 & 4.232033 & 0.035133 & 0.000153 & 0.036746 & 1 & fine \\
\hline MP-L10 & 4.1234 & 4.1232 & 4.1233 & 4.1233 & 0.012367 & 0.0001 & 0.03258 & & very fine $>$ fine \\
\hline MP-L11 & 4.1818 & 4.1816 & 4.1819 & 4.181767 & 0.0096 & 0.000153 & 0.018121 & & very fine $>$ fine \\
\hline MP-L7 & 4.378 & 4.3782 & 4.3781 & 4.3781 & 0.243067 & $1 \mathrm{E}-04$ & 0.143372 & & very fine $>$ coarse \\
\hline MP-L8 & 4.1955 & 4.1955 & 4.1958 & 4.1956 & 0.0572 & 0.000173 & 0.0596 & & fine \\
\hline MP-L9 & 4.1619 & 4.1617 & 4.1615 & 4.1617 & 0.030567 & 0.0002 & 0.027807 & & very fine $>$ fine \\
\hline MP-M10 & 4.1698 & 4.1698 & 4.17 & 4.169867 & 0.027467 & 0.000115 & 0.037106 & 1 & fine \\
\hline MP-M11 & 4.1844 & 4.1846 & 4.1845 & 4.1845 & 0.016633 & $1 \mathrm{E}-04$ & 0.027712 & & very fine $>$ fine \\
\hline MP-M7 & 4.4064 & 4.4063 & 4.4069 & 4.406533 & 0.273033 & 0.000321 & 0.505948 & 1 & fine $>$ coarse \\
\hline MP-M8 & 4.1593 & 4.159 & 4.1592 & 4.159167 & 0.011833 & 0.000153 & 0.021119 & 1 & very fine $>$ fine \\
\hline MP-M9 & 4.2325 & 4.2325 & 4.2324 & 4.232467 & 0.026867 & 5.77E-05 & 0.043397 & & fine \\
\hline MP-N10 & 4.1757 & 4.1759 & 4.1757 & 4.175767 & 0.027467 & 0.000115 & 0.044136 & 1 & fine \\
\hline MP-N12 & 4.1617 & 4.1618 & 4.1618 & 4.161767 & 0.0071 & $5.77 \mathrm{E}-05$ & 0.020299 & & very fine \\
\hline MP-N8 & 4.2768 & 4.277 & 4.2773 & 4.277033 & 0.150467 & 0.000252 & 0.218177 & 1 & fine \\
\hline MP-N9 & 4.1756 & 4.1758 & 4.1759 & 4.175767 & 0.029833 & 0.000153 & 0.062806 & & fine \\
\hline MP-010 & 4.1743 & 4.1742 & 4.1743 & 4.174267 & 0.035433 & $5.77 \mathrm{E}-05$ & 0.070895 & 1 & fine \\
\hline MP-O11 & 4.1932 & 4.1931 & 4.1931 & 4.193133 & 0.019067 & 5.77E-05 & 0.033455 & 1 & very fine $>$ fine \\
\hline MP-O12 & 4.1667 & 4.1667 & 4.1667 & 4.1667 & 0.010267 & 0 & 0.021386 & 1 & very fine \\
\hline MP-O13 & 4.1483 & 4.1483 & 4.1482 & 4.148267 & 0.009533 & $5.77 \mathrm{E}-05$ & 0.019051 & 1 & very fine $>$ fine \\
\hline MP-O8 & 4.3757 & 4.3758 & 4.3759 & 4.3758 & 0.243667 & $1 \mathrm{E}-04$ & 0.378325 & 1 & fine $>$ coarse \\
\hline MP-09 & 4.2686 & 4.2685 & 4.2683 & 4.268467 & 0.071567 & 0.000153 & 0.103001 & 1 & fine $>$ coarse \\
\hline MP-P10 & 4.1908 & 4.191 & 4.1911 & 4.190967 & 0.035967 & 0.000153 & 0.047002 & 1 & fine \\
\hline MP-P11 & 4.2027 & 4.2027 & 4.2026 & 4.202667 & 0.028633 & $5.77 \mathrm{E}-05$ & 0.027531 & 1 & fine \\
\hline MP-P12 & 4.176 & 4.1762 & 4.1759 & 4.176033 & 0.016433 & 0.000153 & 0.024829 & 1 & very fine $>$ fine \\
\hline MP-P13 & 4.1894 & 4.1891 & 4.1892 & 4.189233 & 0.020667 & 0.000153 & 0.034158 & 1 & very fine $>$ fine \\
\hline MP-P9 & 4.1584 & 4.1584 & 4.1588 & 4.158533 & 0.032667 & 0.000231 & 0.047603 & 1 & very fine $>$ fine \\
\hline MP-Q10 & 4.1745 & 4.1743 & 4.1743 & 4.174367 & 0.0194 & 0.000115 & 0.035657 & & very fine $>$ fine \\
\hline MP-Q11 & 4.185 & 4.1848 & 4.1846 & 4.1848 & 0.0181 & 0.0002 & 0.031177 & & very fine $>$ fine \\
\hline MP-Q12 & 4.1807 & 4.1805 & 4.1806 & 4.1806 & 0.0175 & $1 \mathrm{E}-04$ & 0.022024 & & very fine $>$ fine \\
\hline
\end{tabular}




\begin{tabular}{|c|c|c|c|c|c|c|c|c|c|}
\hline MP-Q13 & 4.1932 & 4.1929 & 4.193 & 4.193033 & 0.0205 & 0.000153 & 0.024463 & & very fine $>$ fine \\
\hline MP-Q14 & 4.1741 & 4.1741 & 4.174 & 4.174067 & 0.013533 & $5.77 \mathrm{E}-05$ & 0.015813 & & very fine \\
\hline MP-Q8 & 4.1603 & 4.1605 & 4.1607 & 4.1605 & 0.026733 & 0.0002 & 0.085435 & & very fine $>$ fine \\
\hline MP-Q9 & 4.2298 & 4.2303 & 4.2302 & 4.2301 & 0.0247 & 0.000265 & 0.044743 & & very fine \\
\hline MP-R10 & 4.1803 & 4.1805 & 4.1803 & 4.180367 & 0.017233 & 0.000115 & 0.030762 & 1 & fine \\
\hline MP-R11 & 4.1959 & 4.1959 & 4.1955 & 4.195767 & 0.029633 & 0.000231 & 0.039495 & & fine \\
\hline MP-R12 & 4.1789 & 4.1793 & 4.179 & 4.179067 & 0.022233 & 0.000208 & 0.021901 & 1 & fine \\
\hline MP-R14 & 4.1971 & 4.1971 & 4.1971 & 4.1971 & 0.0357 & 0 & 0.021185 & 1 & fine \\
\hline MP-R8* & 4.1391 & 4.1394 & 4.1393 & 4.139267 & 0.008533 & 0.000153 & 0.030431 & & very fine \\
\hline MP-R9 & 4.1527 & 4.1527 & 4.1527 & 4.1527 & 0.019367 & 0 & 0.032644 & & very fine $>$ fine \\
\hline MP-S10 & 4.1791 & 4.1792 & 4.1794 & 4.179233 & 0.021967 & 0.000153 & 0.041052 & 1 & very fine $>$ fine \\
\hline MP-S11 & 4.2367 & 4.2369 & 4.2367 & 4.236767 & 0.063133 & 0.000115 & 0.051586 & & fine \\
\hline MP-S12 & 4.167 & 4.1671 & 4.1673 & 4.167133 & 0.0064 & 0.000153 & 0.012189 & 1 & very fine $>$ fine \\
\hline MP-S13 & 4.1952 & 4.195 & 4.1949 & 4.195033 & 0.028933 & 0.000153 & 0.031448 & 1 & very fine $>$ fine \\
\hline MP-S14 & 4.1753 & 4.1753 & 4.1753 & 4.1753 & 0.0156 & 0 & 0.02244 & 1 & very fine $>$ fine \\
\hline MP-S8 & 4.1419 & 4.1416 & 4.1418 & 4.141767 & 0.016 & 0.000153 & 0.020682 & & very fine \\
\hline MP-S9 & 3.4886 & 3.4886 & 3.4884 & 3.488533 & 0.015533 & 0.000115 & 0.033213 & 1 & fine \\
\hline MP-T11 & 4.1461 & 4.146 & 4.1463 & 4.146133 & 0.019267 & 0.000153 & 0.024043 & & very fine \\
\hline MP-T12 & 4.1411 & 4.1414 & 4.1414 & 4.1413 & 0.010667 & 0.000173 & 0.015134 & 1 & fine \\
\hline MP-T13 & 4.2088 & 4.2087 & 4.2089 & 4.2088 & 0.035767 & $1 \mathrm{E}-04$ & 0.056287 & & fine \\
\hline MP-T14 & 4.1796 & 4.1795 & 4.1796 & 4.179567 & 0.022733 & $5.77 \mathrm{E}-05$ & 0.033196 & & very fine $>$ fine \\
\hline MP-T15 & 4.1856 & 4.1855 & 4.1852 & 4.185433 & 0.019533 & 0.000208 & 0.028689 & & very fine $>$ fine \\
\hline MP-T16 & 4.1662 & 4.1661 & 4.1661 & 4.166133 & 0.012133 & $5.77 \mathrm{E}-05$ & 0.037275 & 1 & very fine $>$ fine \\
\hline MP-T17 & 4.1791 & 4.1791 & 4.1789 & 4.179033 & 0.0182 & 0.000115 & 0.024595 & & very fine \\
\hline MP-T18 & 4.1644 & 4.1641 & 4.1642 & 4.164233 & 0.013833 & 0.000153 & 0.029705 & & very fine \\
\hline MP-T7 & 4.1782 & 4.1784 & 4.1783 & 4.1783 & 0.046033 & $1 \mathrm{E}-04$ & 0.072011 & & very fine $>$ fine \\
\hline MP-T8 & 4.1332 & 4.1335 & 4.1333 & 4.133333 & 0.008567 & 0.000153 & 0.017153 & & very fine \\
\hline MP-T9 & 4.2157 & 4.2157 & 4.2156 & 4.215667 & 0.009933 & $5.77 \mathrm{E}-05$ & 0.024182 & & very fine \\
\hline MP-U12 & 4.1774 & 4.1772 & 4.1775 & 4.177367 & 0.047733 & 0.000153 & 0.067704 & 1 & fine \\
\hline MP-U13 & 4.1886 & 4.189 & 4.1892 & 4.188933 & 0.0151 & 0.000306 & 0.033898 & & very fine $>$ fine \\
\hline MP-U14 & 4.1668 & 4.1667 & 4.1667 & 4.166733 & 0.007933 & $5.77 \mathrm{E}-05$ & 0.023559 & & very fine $>$ fine \\
\hline MP-U15 & 4.1887 & 4.1887 & 4.1884 & 4.1886 & 0.015267 & 0.000173 & 0.025373 & & very fine $>$ fine \\
\hline MP-U16 1/2 & 4.2461 & 4.2463 & 4.2465 & 4.2463 & 0.089567 & 0.0002 & 0.086442 & & very fine $>$ fine \\
\hline MP-U16 2/2 & 4.1744 & 4.1746 & 4.1745 & 4.1745 & 0.014367 & $1 \mathrm{E}-04$ & & & very fine $>$ fine \\
\hline MP-U17 & 4.174 & 4.1739 & 4.174 & 4.173967 & 0.011567 & $5.77 \mathrm{E}-05$ & 0.024132 & & very fine $>$ fine \\
\hline MP-U18 1/2 & 4.199 & 4.1991 & 4.1991 & 4.199067 & 0.049167 & $5.77 \mathrm{E}-05$ & 0.05122 & 1 & fine $>$ coarse \\
\hline MP-U18 2/2 & 4.2315 & 4.2315 & 4.2316 & 4.231533 & 0.0725 & $5.77 \mathrm{E}-05$ & & & very fine $>$ coarse \\
\hline MP-V12 & 4.2323 & 4.2325 & 4.2324 & 4.2324 & 0.029033 & $1 \mathrm{E}-04$ & 0.055304 & 1 & fine \\
\hline MP-V13 & 4.1822 & 4.1823 & 4.1823 & 4.182267 & 0.012433 & $5.77 \mathrm{E}-05$ & 0.024149 & 1 & very fine $>$ fine \\
\hline MP-V14 & 4.1681 & 4.168 & 4.1681 & 4.168067 & 0.0062 & $5.77 \mathrm{E}-05$ & 0.011178 & 1 & very fine $>$ fine \\
\hline MP-V15 & 4.1907 & 4.1905 & 4.1903 & 4.1905 & 0.0181 & 0.0002 & 0.042111 & 1 & very fine $>$ fine \\
\hline MP-V16 & 4.182 & 4.182 & 4.182 & 4.182 & 0.0257 & 0 & 0.044095 & 1 & very fine $>$ fine \\
\hline MP-V17 & 4.1894 & 4.1893 & 4.1892 & 4.1893 & 0.028233 & 0.0001 & 0.044954 & 1 & very fine $>$ fine \\
\hline \multirow[t]{2}{*}{ MP-V18 } & 4.2393 & 4.2394 & 4.2396 & 4.239433 & 0.0943 & 0.000153 & 0.173134 & 1 & fine $>$ coarse \\
\hline & & & & & & & 0.041434 & 36 & \\
\hline
\end{tabular}




\begin{tabular}{|c|c|c|c|c|c|c|c|c|c|c|c|c|c|c|c|}
\hline \multicolumn{16}{|l|}{ K001-D Dust Distribution- } \\
\hline & (prefix) & (E-W) & (N-S) & \# & $\#$ & \# & (cm) & (m) & (m) & (m) & (m3) & (m2) & (g) & (x by) & $(\mathrm{g} / \mathrm{m} 2)$ \\
\hline S76 49.000 E163 00.000 & $\mathrm{CR}$ & A & 4 & 1 & 1 & 1 & 7 & 0.1 & 0.1 & 0.075 & 0.00075 & 0.01 & 0.0068 & 100 & 0.6833 \\
\hline S76 49.000 E163 06.000 & CR & A & 4.5 & 1 & 0 & 0 & 14 & 0 & 0 & 0 & 0 & & & & \\
\hline S76 49.000 E163 12.000 & CR & A & 5 & 2 & 1 & 1 & 11.5 & 0.1 & 0.1 & 0.11 & 0.0011 & 0.01 & 0.0147 & 100 & 1.4733 \\
\hline S76 49.000 E163 18.000 & CR & A & 5.5 & 1 & 0 & 0 & 12.5 & 0 & 0 & 0 & 0 & & & & \\
\hline S76 49.000 E163 24.000 & CR & A & 6 & 1 & 1 & 1 & 15 & 0.1 & 0.1 & 0.13 & 0.0013 & 0.01 & 0.0136 & 100 & 1.3600 \\
\hline S76 49.000 E163 30.000 & CR & A & 6.5 & 1 & 0 & 0 & 25 & 0 & 0 & 0 & 0 & & & & \\
\hline S76 49.000 E163 36.000 & CR & $\mathrm{A}$ & 7 & 1 & 1 & 1 & 8.5 & 0.1 & 0.1 & 0.07 & 0.0007 & 0.01 & 0.0088 & 100 & 0.8767 \\
\hline S76 49.000 E163 42.000 & $\mathrm{CR}$ & A & 7.5 & 1 & 0 & 0 & 11.5 & 0 & 0 & 0 & 0 & & & & \\
\hline \multirow[t]{2}{*}{ S76 49.000 E163 48.000} & CR & A & 8 & 1 & 1 & 1 & 13 & 0.09 & 0.1 & 0.11 & 0.00099 & 0.009 & 0.0068 & 111 & 0.7593 \\
\hline & CR & A & 8.5 & 1 & 0 & 0 & 13.5 & 0 & 0 & 0 & 0 & & & & \\
\hline S76 51.800 E162 36.000 & CR & в & 2 & 1 & 1 & 1 & 32 & 0.05 & 0.05 & 0.32 & 0.0008 & 0.0025 & 0.0226 & 400 & 9.0267 \\
\hline S76 51.800 E162 42.000 & $\mathrm{CR}$ & в & 2.5 & 1 & 0 & 0 & 50.5 & 0 & 0 & 0 & 0 & & & & \\
\hline S76 51.800 E162 48.000 & $\mathrm{CR}$ & в & 3 & 1 & 1 & 1 & 28 & 0.07 & 0.07 & 0.28 & 0.001372 & 0.0049 & 0.0184 & 204 & 3.7619 \\
\hline S76 51.800 E162 54.000 & CR & в & 3.5 & 1 & 0 & 0 & 11 & 0 & 0 & 0 & 0 & & & & \\
\hline S76 51.800 E163 00.000 & $\mathrm{CR}$ & в & 4 & 1 & 1 & 1 & 10 & 0.1 & 0.1 & 0.1 & 0.001 & 0.01 & 0.0093 & 100 & 0.9300 \\
\hline S76 51.800 E163 06.000 & CR & в & 4.5 & 1 & 0 & 0 & 14 & 0 & 0 & 0 & 0 & & & & \\
\hline S76 51.800 E163 12.000 & CR & в & 5 & 2 & 1 & 1 & 12.5 & 0.09 & 0.09 & 0.12 & 0.000972 & 0.0081 & 0.0149 & 123 & 1.8436 \\
\hline S76 51.800 E163 18.000 & $\mathrm{CR}$ & в & 5.5 & 1 & 0 & 0 & 14 & 0 & 0 & 0 & 0 & & & & \\
\hline S76 51.800 E163 24.000 & $\mathrm{CR}$ & в & 6 & 1 & 1 & 1 & 15 & 0.1 & 0.1 & 0.15 & 0.0015 & 0.01 & 0.0148 & 100 & 1.4833 \\
\hline S76 51.800 E163 30.000 & $\mathrm{CR}$ & в & 6.5 & 1 & 0 & 0 & 15.5 & 0 & 0 & 0 & 0 & & & & \\
\hline S76 51.800 E163 36.000 & CR & в & 7 & 1 & 1 & 1 & 18 & 0.1 & 0.1 & 0.13 & 0.0013 & 0.01 & 0.0132 & 100 & 1.3200 \\
\hline S76 51.800 E163 42.000 & CR & B & 7.5 & 1 & 0 & 0 & 9.5 & 0 & 0 & 0 & 0 & & & & \\
\hline S76 51.800 E163 48.000 & CR & в & 8 & 1 & 1 & 1 & 20 & 0.05 & 0.1 & 0.18 & 0.0009 & 0.005 & 0.0082 & 200 & 1.6400 \\
\hline S76 51.800 E163 54.000 & $\mathrm{CR}$ & в & 8.5 & 1 & 0 & 0 & 11.5 & 0 & 0 & 0 & 0 & & & & \\
\hline S76 54.000 E162 36.000 & CR & C & 2 & 1 & 1 & 1 & 12 & 0.1 & 0.1 & 0.1 & 0.001 & 0.01 & 0.0044 & 100 & 0.4400 \\
\hline S76 54.000 E162 42.000 & $\mathrm{CR}$ & C & 2.5 & 1 & 0 & 0 & 7 & 0 & 0 & 0 & 0 & & & & \\
\hline S76 54.000 E162 48.000 & CR & c & 3 & 1 & 1 & 1 & 10 & 0.1 & 0.1 & 0.1 & 0.001 & 0.01 & 0.0252 & 100 & 2.5167 \\
\hline S76 54.000 E162 54.000 & CR & c & 3.5 & 1 & 0 & 0 & 4 & 0 & 0 & 0 & 0 & & & & \\
\hline S76 54.000 E163 00.000 & $\mathrm{CR}$ & C & 4 & 1 & 1 & 1 & 6.5 & 0.13 & 0.13 & 0.05 & 0.000845 & 0.0169 & 0.0129 & 59 & 0.7633 \\
\hline S76 54.000 E163 06.000 & $\mathrm{CR}$ & c & 4.5 & 1 & 0 & 0 & 6 & 0 & 0 & 0 & 0 & & & & \\
\hline S76 54.000 E163 12.000 & $\mathrm{CR}$ & c & 5 & 2 & 1 & 1 & 21 & 0.1 & 0.1 & 0.1 & 0.001 & 0.01 & 0.0214 & 100 & 2.1433 \\
\hline S76 54.000 E163 18.000 & $\mathrm{CR}$ & C & 5.5 & 1 & 0 & 0 & 7.5 & 0 & 0 & 0 & 0 & & & & \\
\hline S76 54.000 E163 24.000 & CR & C & 6 & 1 & 1 & 1 & 20 & 0.1 & 0.1 & 0.1 & 0.001 & 0.01 & 0.0123 & 100 & 1.2267 \\
\hline S76 54.000 E163 30.000 & CR & c & 6.5 & 1 & 0 & 0 & 18 & 0 & 0 & 0 & 0 & & & & \\
\hline S76 54.000 E163 36.000 & $\mathrm{CR}$ & C & 7 & 1 & 1 & 1 & 12 & 0.09 & 0.1 & 0.12 & 0.00108 & 0.009 & 0.0088 & 111 & 0.9741 \\
\hline S76 54.000 E163 42.000 & CR & $\mathrm{C}$ & 7.5 & 1 & 0 & 0 & 8 & 0 & 0 & 0 & 0 & & & & \\
\hline S76 54.000 E163 48.000 & $\mathrm{CR}$ & c & 8 & 1 & 1 & 1 & 13 & 0.1 & 0.1 & 0.13 & 0.0013 & 0.01 & 0.0100 & 100 & 1.0000 \\
\hline \multirow[t]{2}{*}{ S76 54.000 E163 54.000} & $\mathrm{CR}$ & c & 8.5 & 1 & 0 & 0 & 14 & 0 & 0 & 0 & 0 & & & & \\
\hline & $C R$ & c & 9 & 0 & 0 & 0 & & 0 & 0 & 0 & 0 & & & & \\
\hline S76 58.600 E162 30.000 & CR & D & MGT & 1 & 1 & 0 & 4 & 0.13 & 0.13 & 0.04 & 0.000676 & 0.0169 & & 59 & \\
\hline$S 7657.200 E 16224.000$ & $C R$ & $D$ & 1 & 0 & 0 & 0 & & 0 & $o$ & $o$ & 0 & & & & \\
\hline S76 57.200 E162 30.000 & $\mathrm{CR}$ & D & 1.5 & 1 & 1 & 0 & 10 & 0.12 & 0.12 & 0.08 & 0.001152 & 0.0144 & & 69 & \\
\hline S76 57.200 E162 36.000 & $\mathrm{CR}$ & D & 2 & 1 & 1 & 1 & 3 & 0.15 & 0.15 & 0.03 & 0.000675 & 0.0225 & 0.0042 & 44 & 0.1881 \\
\hline S76 57.200 E162 42.000 & CR & D & 2.5 & 1 & 1 & 0 & 6 & 0.1 & 0.1 & 0.06 & 0.0006 & 0.01 & & 100 & \\
\hline S76 57.200 E162 48.000 & CR & D & 3 & 1 & 1 & 1 & 7 & 0.1 & 0.1 & 0.07 & 0.0007 & 0.01 & 0.0032 & 100 & 0.3167 \\
\hline
\end{tabular}


S76 57.200 E162 54.000 S76 57.200 E163 00.000

S76 57.200 E163 06.000 S76 57.200 E163 18.000 $57657.200 \mathrm{E} 16324.000$ $57657.200 \mathrm{E} 16330.000$ $57657.200 \mathrm{E} 16348.000$

S76 57.200 E163 54.000

S76 57.200 E164 00.000 S77 00.000 E162 24.000

S77 00.000 E162 36.000 S77 00.000 E162 48.000 S77 00.000 E162 54.000 $57700.000 \mathrm{E} 16300.000$ S77 00.000 E163 06.000 $\mathrm{S} 7700.000 \mathrm{E} 16312.000$ $57700.000 \mathrm{E} 16318.000$

\begin{tabular}{|c|c|c|c|c|c|c|c|c|c|c|c|c|c|c|}
\hline $\mathrm{CR}$ & D & 3.5 & 1 & 1 & 0 & 9 & 0.1 & 0.1 & 0.09 & 0.0009 & 0.01 & & 100 & \\
\hline CR & D & 4 & 1 & 1 & 1 & 11.5 & 0.1 & 0.1 & 0.115 & 0.00115 & 0.01 & 0.0080 & 100 & 0.8033 \\
\hline CR & D & 4.5 & 1 & 1 & 0 & 10 & 0.1 & 0.1 & 0.09 & 0.0009 & 0.01 & & 100 & \\
\hline CR & D & 4.5 TRUE & 1 & 0 & 0 & 11 & 0 & 0 & 0 & 0 & & & & \\
\hline CR & D & 5 & 1 & 1 & 1 & 5 & 0.1 & 0.14 & 0.05 & 0.0007 & 0.014 & 0.0028 & 71 & 0.2000 \\
\hline $\mathrm{CR}$ & D & 5.5 & 1 & 0 & 0 & 12 & 0 & 0 & 0 & 0 & & & & \\
\hline CR & D & 6 & 1 & 1 & 1 & 16 & 0.1 & 0.1 & 0.11 & 0.0011 & 0.01 & 0.0000 & 100 & 0.0000 \\
\hline CR & D & 6.5 & 1 & 0 & 0 & 13 & 0 & 0 & 0 & 0 & & & & \\
\hline CR & D & 7 & 1 & 1 & 1 & 7 & 0.1 & 0.15 & 0.06 & 0.0009 & 0.015 & 0.0041 & 67 & 0.2711 \\
\hline CR & D & 7.5 & 1 & 0 & 0 & 11 & 0 & 0 & 0 & 0 & & & & \\
\hline CR & D & 8 & 1 & 1 & 1 & 11 & 0.1 & 0.1 & 0.12 & 0.0012 & 0.01 & 0.0015 & 100 & 0.1467 \\
\hline CR & D & 8.5 & 1 & 0 & 0 & 11 & 0 & 0 & 0 & 0 & & & & \\
\hline CR & D & 9 & 1 & 1 & 1 & 9 & 0.1 & 0.15 & 0.1 & 0.0015 & 0.015 & 0.0043 & 67 & 0.2844 \\
\hline CR & $\mathrm{E}$ & 1 & 1 & 1 & 1 & 13 & 0.1 & 0.1 & 0.13 & 0.0013 & 0.01 & 0.0071 & 100 & 0.7133 \\
\hline CR & $\mathrm{E}$ & 1.5 & 1 & 1 & 0 & 5 & 0.12 & 0.12 & 0.05 & 0.00072 & 0.0144 & & 69 & \\
\hline CR & E & 2 & 1 & 1 & 1 & 6 & 0.1 & 0.1 & 0.065 & 0.00065 & 0.01 & 0.0127 & 100 & 1.2700 \\
\hline CR & E & 2.5 & 1 & 1 & 0 & 6 & 0.15 & 0.1 & 0.06 & 0.0009 & 0.015 & & 67 & \\
\hline CR & $\mathrm{E}$ & 3 & 1 & 1 & 1 & 9 & 0.1 & 0.1 & 0.09 & 0.0009 & 0.01 & 0.0082 & 100 & 0.8167 \\
\hline CR & E & 3.5 & 1 & 1 & 0 & 13 & 0.1 & 0.1 & 0.13 & 0.0013 & 0.01 & & 100 & \\
\hline $\mathrm{CR}$ & $\mathrm{E}$ & 4 & 1 & 1 & 1 & 15 & 0.1 & 0.11 & 0.15 & 0.00165 & 0.011 & 0.0072 & 91 & 0.6515 \\
\hline $\mathrm{CR}$ & E & 4.5 & 1 & 1 & 0 & 11 & 0.1 & 0.1 & 0.1 & 0.001 & 0.01 & & 100 & \\
\hline CR & $\mathrm{E}$ & 5 & 1 & 1 & 1 & 17 & 0.1 & 0.1 & 0.16 & 0.0016 & 0.01 & 0.0104 & 100 & 1.0367 \\
\hline $\mathrm{CR}$ & $\mathrm{E}$ & 5.5 & 1 & 0 & 0 & 10 & 0 & 0 & 0 & 0 & & & & \\
\hline $\mathrm{CR}$ & E & 6 & 1 & 1 & 1 & 14 & 0.1 & 0.1 & 0.14 & 0.0014 & 0.01 & 0.0045 & 100 & 0.4500 \\
\hline $\mathrm{CR}$ & $\mathrm{E}$ & 6.5 & 1 & 0 & 0 & 14 & 0 & 0 & 0 & 0 & & & & \\
\hline CR & E & 7 & 1 & 1 & 1 & 13 & 0.1 & 0.1 & 0.12 & 0.0012 & 0.01 & 0.0066 & 100 & 0.6600 \\
\hline CR & E & 7.5 & 1 & 0 & 0 & 12 & 0 & 0 & 0 & 0 & & & & \\
\hline CR & $\mathrm{E}$ & 8 & 1 & 1 & 1 & 11 & 0.1 & 0.1 & 0.1 & 0.001 & 0.01 & 0.0095 & 100 & 0.9533 \\
\hline $\mathrm{CR}$ & $\mathrm{E}$ & 8.5 & 1 & 0 & 0 & 9 & 0 & 0 & 0 & 0 & & & & \\
\hline $\mathrm{CR}$ & $\mathrm{E}$ & 9 & 1 & 1 & 1 & 8 & 0.1 & 0.1 & 0.1 & 0.001 & 0.01 & 0.0139 & 100 & 1.3900 \\
\hline CR & F & 5 & 1 & 1 & 1 & 10 & 0.1 & 0.1 & 0.1 & 0.001 & 0.01 & 0.0227 & 100 & 2.2733 \\
\hline $\mathrm{CR}$ & F & 5.5 & 1 & 0 & 0 & 12.5 & 0 & 0 & 0 & 0 & & & & \\
\hline CR & F & 6 & 1 & 1 & 1 & 12 & 0.1 & 0.1 & 0.12 & 0.0012 & 0.01 & 0.0115 & 100 & 1.1467 \\
\hline $\mathrm{CR}$ & F & 6.5 & 1 & 0 & 0 & 12.5 & 0 & 0 & 0 & 0 & & & & \\
\hline CR & F & 7 & 1 & 1 & 1 & 15 & 0.1 & 0.1 & 0.15 & 0.0015 & 0.01 & 0.0129 & 100 & 1.2900 \\
\hline CR & F & 7.5 & 1 & 0 & 0 & 19 & 0 & 0 & 0 & 0 & & & & \\
\hline $\mathrm{CR}$ & $\mathrm{F}$ & 8 & 1 & 1 & 1 & 24 & 0.1 & 0.1 & 0.24 & 0.0024 & 0.01 & 0.0216 & 100 & 2.1567 \\
\hline $\mathrm{CR}$ & F & 8.5 & 1 & 0 & 0 & 16 & 0 & 0 & 0 & 0 & & & & \\
\hline $\mathrm{CR}$ & F & 9 & 2 & 1 & 1 & 17 & 0.1 & 0.1 & 0.22 & 0.0022 & 0.01 & 0.0142 & 100 & 1.4233 \\
\hline CR & G & 5 & 1 & 1 & 1 & 11 & 0.1 & 0.1 & 0.11 & 0.0011 & 0.01 & 0.0044 & 100 & 0.4367 \\
\hline $\mathrm{CR}$ & G & 5.5 & 1 & 0 & 0 & 7 & 0 & 0 & 0 & 0 & & & & \\
\hline $\mathrm{CR}$ & G & 6 & 1 & 1 & 0 & 14 & 0.1 & 0.1 & 0.14 & 0.0014 & 0.01 & 0.0128 & 100 & 1.2833 \\
\hline $\mathrm{CR}$ & G & 6 & 1 & 1 & 1 & 14.5 & 0.1 & 0.1 & 0.1 & 0.001 & 0.01 & 0.0128 & 100 & 1.2833 \\
\hline $\mathrm{CR}$ & G & 6.5 & 1 & 0 & 0 & 13 & 0 & 0 & 0 & 0 & & & & \\
\hline $\mathrm{CR}$ & G & 7 & 1 & 1 & 1 & 14 & 0.1 & 0.1 & 0.14 & 0.0014 & 0.01 & 0.0124 & 100 & 1.2400 \\
\hline $\mathrm{CR}$ & G & 7.5 & 1 & 0 & 0 & 14.5 & 0 & 0 & 0 & 0 & & & & \\
\hline $\mathrm{CR}$ & G & 8 & 1 & 1 & 1 & 13 & 0.1 & 0.1 & 0.13 & 0.0013 & 0.01 & 0.0152 & 100 & 1.5200 \\
\hline CR & G & 8.5 & 1 & 0 & 0 & 13.5 & 0 & 0 & 0 & 0 & & & & \\
\hline CR & G & 9 & 2 & 1 & 1 & 19 & 0.1 & 0.1 & 0.17 & 0.0017 & 0.01 & 0.0061 & 100 & 0.6100 \\
\hline
\end{tabular}


S77 05.440 E164 06.042

57708.160016314 .000

S77 $08.160 \mathrm{E} 16323.560$

S77 08.160 E163 35.720

S77 08.160 E163 47.860 S77 08.160 E164 00.000

S77 08.160 E164 12.129

S77 10.881 E163 23.410

S77 10.378 E163 27.40

$S 7710.880 E 16335.630$

$S 7710.880$ E163 47.810

S77 10.880 E164 00.000

S77 10.880 E164 12.175

S77 13.842 E163 25.779

S77 13.639 E163 31.543

S77 13.600 E163 35.540

S77 13.600 E163 47.770

S77 13.600 E164 00.000

S77 13.600 E164 24.440

S77 16.360 E163 35.450

S77 16.360 E163 47.720

S77 16.360 E164 12.260

S77 $16.360 \mathrm{E} 16424.530$

S77 19.080 E163 35.360

S77 19.080 E163 47.680

(1)

S77 19.080 E164 12.310

S77 19.080 E164 24.620

$57721.800=16335.620$

$57721.800 \mathrm{E} 16347.630$

$S 7721.800 \mathrm{E} 163$ 47.630

$57721.800 \mathrm{E} 16412.060$

$57721.800 \mathrm{E} 16424.720$

77724.520046341 .380

$77724.520=16347.590$

$57724.520=16353.800$

$57724.520 \mathrm{~B} 16353.800$

(777 $24.520 \mathrm{~B} 16400.000$

$\$ 7724.520$ E164 12.400

S77 24.520 E164 18.600

S77 24.520 E164 24.810

S77 24.520 E164 31.000

S77 24.520 E164 37.220 $\begin{array}{cc}0 & 0.01 \\ 0.001 & 0.01\end{array}$ 
S77 24.520 E164 43.400 S77 27.240 E163 53.770 S77 27.240 E164 12.450 S77 27.240 E164 18.610 S77 27.240 E164 24.900 S77 27.240 E164 31.120 S77 27.240 E164 37.360 S77 27.240 E164 43.570 S77 27.240 E164 49.810 S77 30.539 E163 51.281 S77 30.000 E164 00.000 S77 30.000 E164 06.250 S77 30.000 E164 12.500 S77 30.000 E164 18.750 S77 30.000 E164 25.000 S77 30.000 E164 31.250 S77 30.000 E164 37.500 S77 30.000 E164 43.750 S77 30.000 E164 50.000 S77 30.000 E164 56.250

\begin{tabular}{|c|c|c|c|c|c|c|c|c|}
\hline$>100$ & 0 & 0 & 0 & 0 & & & & \\
\hline 10 & 0.1 & 0.1 & 0.12 & 0.0012 & 0.01 & 0.2437 & 100 & 24.3667 \\
\hline 26 & 0 & 0 & 0 & 0 & & & & \\
\hline 12 & 0.1 & 0.1 & 0.13 & 0.0013 & 0.01 & 0.0716 & 100 & 7.1567 \\
\hline 14 & 0 & 0 & 0 & 0 & & & & \\
\hline 8.5 & 0.1 & 0.1 & 0.1 & 0.001 & 0.01 & 0.0354 & 100 & 3.5433 \\
\hline 13.5 & 0 & 0 & 0 & 0 & & & & \\
\hline 10.5 & 0.1 & 0.1 & 0.1 & 0.001 & 0.01 & 0.0191 & 100 & 1.9067 \\
\hline 13.5 & 0 & 0 & 0 & 0 & & & & \\
\hline 6 & 0.15 & 0.1 & 0.08 & 0.0012 & 0.015 & 0.0103 & 67 & 0.6867 \\
\hline 15 & 0 & 0 & 0 & 0 & 0 & & & \\
\hline 12 & 0.10 & 0.10 & 0.13 & 0.0013 & 0.01 & 0.0095 & 100 & 0.9533 \\
\hline 5 & 0 & 0 & 0 & 0 & & & & \\
\hline 13 & 0.1 & 0.1 & 0.16 & 0.0016 & 0.01 & 0.0327 & 100 & 3.2667 \\
\hline 11 & 0 & 0 & 0 & 0 & & & & \\
\hline 17 & 0.1 & 0.1 & 0.17 & 0.0017 & 0.01 & 0.0360 & 100 & 3.5967 \\
\hline 20 & 0 & 0 & 0 & 0 & & & & \\
\hline 19 & 0.1 & 0.1 & 0.2 & 0.002 & 0.01 & 0.0286 & 100 & 2.8633 \\
\hline 17.5 & 0 & 0 & 0 & 0 & & & & \\
\hline 15 & 0.1 & 0.1 & 0.13 & 0.0013 & 0.01 & 0.0164 & 100 & 1.6433 \\
\hline 14.5 & 0 & 0 & 0 & 0 & & & & \\
\hline 9 & 0.15 & 0.1 & 0.08 & 0.0012 & 0.015 & 0.0207 & 67 & 1.3778 \\
\hline 16 & 0 & 0 & 0 & 0 & & & & \\
\hline 30 & 0.1 & 0.1 & 0.3 & 0.003 & 0.01 & 0.0267 & 100 & 2.6733 \\
\hline 20 & 0 & 0 & 0 & 0 & & & & \\
\hline 28 & 0.05 & 0.1 & 0.25 & 0.00125 & 0.005 & 0.0247 & 200 & 4.9400 \\
\hline 22 & 0 & 0 & 0 & 0 & & & & \\
\hline 14 & 0.1 & 0.1 & 0.1 & 0.001 & 0.01 & 0.0194 & 100 & 1.9400 \\
\hline 16 & 0 & 0 & 0 & 0 & & & & \\
\hline 10.5 & 0.1 & 0.1 & 0.1 & 0.001 & 0.01 & 0.0184 & 100 & 1.8433 \\
\hline 18 & 0 & 0 & 0 & 0 & & & & \\
\hline 13 & 0.1 & 0.1 & 0.13 & 0.0013 & 0.01 & 0.0175 & 100 & 1.7500 \\
\hline 7 & 0 & 0 & 0 & 0 & & & & \\
\hline 17 & 0.1 & 0.1 & 0.17 & 0.0017 & 0.01 & 0.0205 & 100 & 2.0500 \\
\hline 10 & 0 & 0 & 0 & 0 & & & & \\
\hline 25 & 0.07 & 0.1 & 0.23 & 0.00161 & 0.007 & 0.0135 & 143 & 1.9333 \\
\hline 11 & 0.1 & 0.1 & 0.09 & 0.0009 & 0.01 & & 100 & \\
\hline 17 & 0.1 & 0.08 & 0.15 & 0.0012 & 0.008 & & 125 & \\
\hline \multicolumn{9}{|l|}{13} \\
\hline \multicolumn{9}{|l|}{21} \\
\hline 26 & 0.05 & 0.1 & 0.2 & 0.001 & 0.005 & 0.0085 & 200 & 1.7067 \\
\hline 28.5 & 0 & 0 & 0 & 0 & & & & \\
\hline 22 & 0.1 & 0.08 & 0.17 & 0.00136 & 0.008 & 0.0194 & 125 & 2.4208 \\
\hline 23 & 0 & 0 & 0 & 0 & & & & \\
\hline 11 & 0.1 & 0.1 & 0.11 & 0.0011 & 0.01 & 0.0172 & 100 & 1.7233 \\
\hline 7 & 0 & 0 & 0 & 0 & & & & \\
\hline 18 & 0.1 & 0.1 & 0.15 & 0.0015 & 0.01 & 0.0292 & 100 & 2.9200 \\
\hline 17 & 0 & 0 & 0 & 0 & & & & \\
\hline 23 & 0.1 & 0.1 & 0.23 & 0.0023 & 0.01 & 0.0222 & 100 & 2.2233 \\
\hline
\end{tabular}


S77 35.440 E164 43.900 S77 35.440 E164 50.180 57735.40016502730 $57735.440 \mathrm{D} 16509.000$ s77 $38.4160 \mathrm{~B} 16347.420$ 57738.16016347 .420 $57738.160 \mathrm{10} 53.730$ S77 $38.160 \mathrm{~B} 16400.000$ S77 $38.160 \mathrm{104} 06.290$ S77 $38.160 \mathrm{~B} 16412.570$ S77 38.160 E164 18.870 S77 38.160 E164 25.140 S77 38.160 E164 31.450 S77 38.160 E164 37.710 S77 38.160 E164 43.990 S77 38.160 E164 50.280 S77 38.160 E164 56.580 S77 38.160 E165 02.850 S77 38.160 E165 09.130 S77 $40.880 \mathrm{E} 16334.800$ S77 40.880 E163 41.100 $S 7740.880 \mathrm{E} 16347.400$ 


\begin{tabular}{|c|c|c|c|c|c|c|c|c|c|c|c|c|c|c|c|}
\hline S77 43.600 E165 03.090 & MP & $\mathrm{u}$ & 14 & 1 & 1 & 1 & 11 & 0.1 & 0.1 & 0.1 & 0.001 & 0.01 & 0.0079 & 100 & 0.7933 \\
\hline S77 43.600 E165 09.400 & MP & $\mathrm{u}$ & 14.5 & 1 & 0 & 0 & 17 & 0 & 0 & 0 & 0 & & & & \\
\hline S77 43.600 E165 15.710 & MP & $\mathrm{u}$ & 15 & 1 & 1 & 1 & 14 & 0.1 & 0.1 & 0.14 & 0.0014 & 0.01 & 0.0153 & 100 & 1.5267 \\
\hline S77 43.600 E165 22.020 & MP & $\mathrm{u}$ & 15.5 & 1 & 0 & 0 & 9 & 0 & 0 & 0 & 0 & & & & \\
\hline S77 43.600 E165 28.330 & MP & $\mathrm{u}$ & 16 & 1 & 1 & 1 & 18 & 0.1 & 0.1 & 0.16 & 0.0016 & 0.01 & 0.1039 & 100 & 10.3933 \\
\hline S77 43.600 E165 34.890 & MP & $\mathrm{u}$ & 16.5 & 1 & 0 & 0 & 23 & 0 & 0 & 0 & 0 & & & & \\
\hline S77 43.600 E165 40.950 & MP & $\mathrm{U}$ & 17 & 1 & 1 & 1 & 7 & 0.15 & 0.1 & 0.08 & 0.0012 & 0.015 & 0.0116 & 67 & 0.7711 \\
\hline S77 43.600 E165 47.260 & MP & $\mathrm{u}$ & 17.5 & 1 & 0 & 0 & 13.5 & 0 & 0 & 0 & 0 & & & & \\
\hline S77 43.600 E165 53.560 & MP & $\mathrm{u}$ & 18 & 1 & 1 & 1 & 26 & 0.1 & 0.08 & 0.23 & 0.00184 & 0.008 & 0.1217 & 125 & 15.2083 \\
\hline S77 46.000 E164 37.960 & MP & $\mathrm{v}$ & 12 & 2 & 1 & 1 & 35 & 0.05 & 0.1 & 0.23 & 0.00115 & 0.005 & 0.0290 & 200 & 5.8067 \\
\hline S77 46.000 E164 44.280 & MP & $\mathrm{v}$ & 12.5 & 1 & 0 & 0 & 15 & 0 & 0 & 0 & 0 & & & & \\
\hline S77 46.000 E164 50.610 & MP & $\mathrm{v}$ & 13 & 1 & 1 & 1 & 10 & 0.1 & 0.1 & 0.11 & 0.0011 & 0.01 & 0.0124 & 100 & 1.2433 \\
\hline S77 46.000 E164 56.930 & MP & $\mathrm{v}$ & 13.5 & 1 & 0 & 0 & 25 & 0 & 0 & 0 & 0 & & & & \\
\hline S77 46.000 E165 03.450 & MP & $\mathrm{v}$ & 14 & 1 & 1 & 1 & 22 & 0.05 & 0.1 & 0.2 & 0.001 & 0.005 & 0.0062 & 200 & 1.2400 \\
\hline S77 46.000 E165 09.770 & MP & $\mathrm{v}$ & 14.5 & 1 & 0 & 0 & 28 & 0 & 0 & 0 & 0 & & & & \\
\hline S77 46.000 E165 16.100 & MP & $\mathrm{v}$ & 15 & 1 & 1 & 1 & 21 & 0.05 & 0.1 & 0.21 & 0.00105 & 0.005 & 0.0181 & 200 & 3.6200 \\
\hline S77 46.000 E165 22.420 & MP & $\mathrm{v}$ & 15.5 & 1 & 0 & 0 & 18 & 0 & 0 & 0 & 0 & & & & \\
\hline S77 46.000 E165 28.750 & MP & $\mathrm{v}$ & 16 & 1 & 1 & 1 & 23 & 0.08 & 0.1 & 0.17 & 0.00136 & 0.008 & 0.0257 & 125 & 3.2125 \\
\hline S77 46.000 E165 35.070 & MP & $\mathrm{v}$ & 16.5 & 1 & 0 & 0 & 16 & 0 & 0 & 0 & 0 & & & & \\
\hline S77 46.000 E165 41.410 & MP & $\mathrm{v}$ & 17 & 1 & 1 & 1 & 18 & 0.1 & 0.07 & 0.17 & 0.00119 & 0.007 & 0.0282 & 143 & 4.0333 \\
\hline S77 46.000 E165 47.720 & MP & $\mathrm{v}$ & 17.5 & 1 & 0 & 0 & 23 & 0 & 0 & 0 & 0 & & & & \\
\hline S77 46.000 E165 54.050 & MP & $\mathrm{v}$ & 18 & 1 & 1 & 1 & 21 & 0.06 & 0.1 & 0.19 & 0.00114 & 0.006 & & 167 & 15.7167 \\
\hline & & & TOTAL: & 271 & 154 & 141 & & & & Sum: & 0.1901 & 1.5313 & 3.6829 & & \\
\hline & & & & & & & 15 & & & Average: & 0.00073 & 0.0099 & 0.0261 & & \\
\hline
\end{tabular}


Appendix C

Grain size data 
K001-D Grain Size-BECKMAN COULTER LS13320 STATISTICS: samples CR-A7 to MPN10

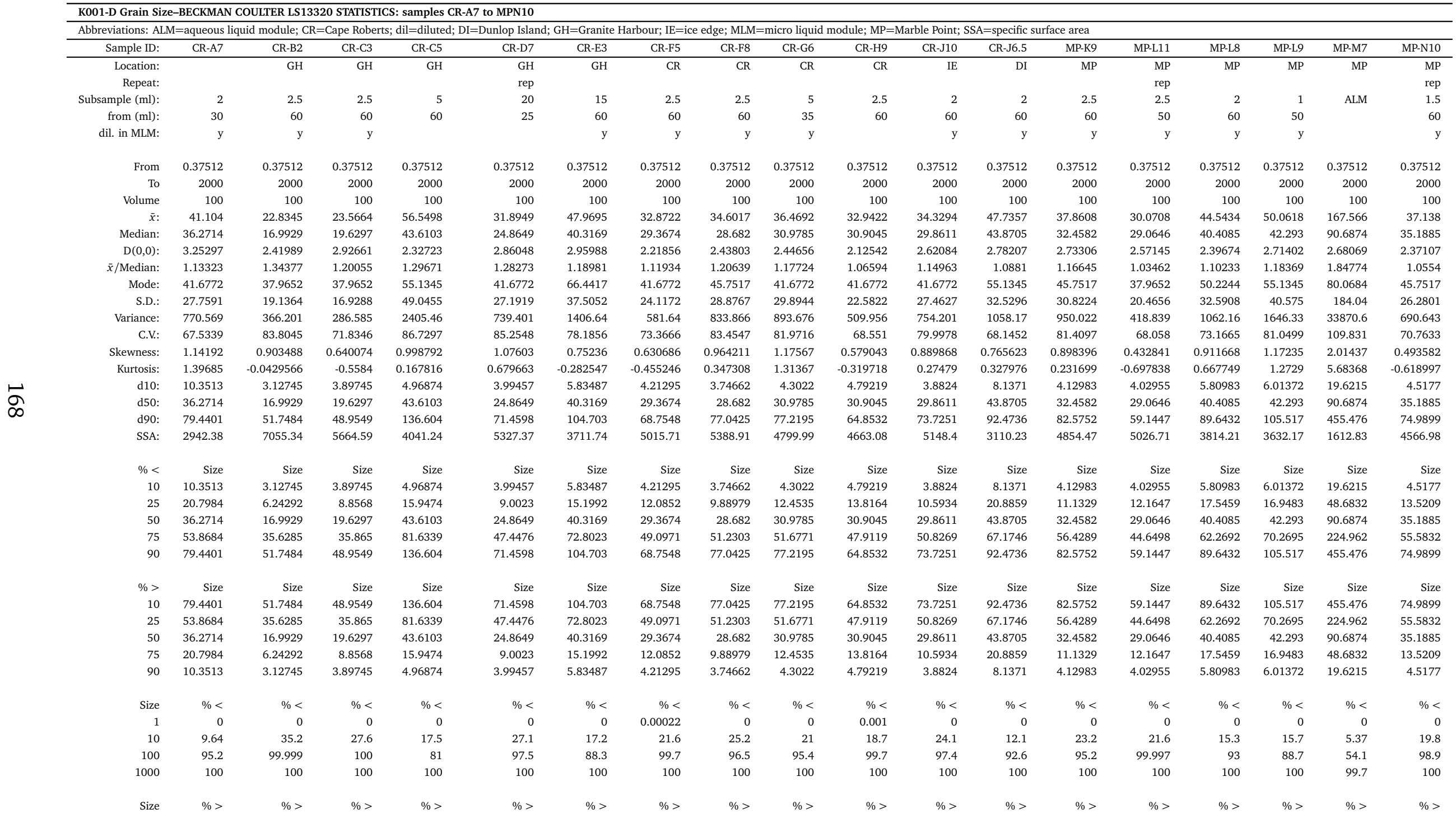




\begin{tabular}{|c|c|c|c|c|c|c|c|c|c|c|c|c|c|c|c|c|c|c|}
\hline 1 & 100 & 100 & 100 & 100 & 100 & 100 & 100 & 100 & 100 & 99.999 & 100 & 100 & 100 & 100 & 100 & 100 & 100 & 100 \\
\hline 10 & 90.4 & 64.8 & 72.4 & 82.5 & 72.9 & 82.8 & 78.4 & 74.8 & 79 & 81.3 & 75.9 & 87.9 & 76.8 & 78.4 & 84.7 & 84.3 & 94.6 & 80.2 \\
\hline 100 & 4.78 & 0.0014 & 0 & 19 & 2.49 & 11.7 & 0.31 & 3.52 & 4.61 & 0.28 & 2.57 & 7.45 & 4.78 & 0.003 & 6.98 & 11.3 & 45.9 & 1.07 \\
\hline 1000 & 0 & 0 & 0 & 0 & 0 & 0 & 0 & 0 & 0 & 0 & 0 & 0 & 0 & 0 & 0 & 0 & 0.32 & 0 \\
\hline
\end{tabular}




\begin{tabular}{|c|c|c|c|c|c|c|c|c|c|c|c|c|c|c|}
\hline \multicolumn{15}{|l|}{ Abbreviations: ALM } \\
\hline Sample ID: & MP-N8 & MP-O12 & MP-P10 & MP-P11 & MP-Q8 & MP-R12 & MP-R14 & MP-S9 & MP-T11 & MP-T13 & MP-T16 & MP-U18 & MP-V13 & MPV16 \\
\hline Location: & MP & MP & MP & MP & $\mathrm{NH}$ & MP & MP & $\mathrm{NH}$ & SMS & SMS & SMS & SMS & SMS & SMS \\
\hline Repeat: & & rep & rep & & rep & & rep & rep & rep & & rep & & & \\
\hline Subsample (ml): & ALM & 1 & 1 & 2 & 5 & 2 & 1.5 & 6 & 2 & 2 & 4 & ALM & 4 & 2 \\
\hline from (ml): & & 60 & 60 & 60 & 60 & 60 & 60 & 50 & 60 & 60 & 60 & & 60 & 60 \\
\hline dil. in MLM: & & $\mathrm{y}$ & $\mathrm{y}$ & $\mathrm{y}$ & $\mathrm{y}$ & $\mathrm{y}$ & $\mathrm{y}$ & $\mathrm{y}$ & $\mathrm{y}$ & $\mathrm{y}$ & y & & $\mathrm{y}$ & $\mathrm{y}$ \\
\hline From & 0.37512 & 0.37512 & 0.37512 & 0.37512 & 0.37512 & 0.37512 & 0.37512 & 0.37512 & 0.37512 & 0.37512 & 0.37512 & 0.37512 & 0.37512 & 0.37512 \\
\hline То & 2000 & 2000 & 2000 & 2000 & 2000 & 2000 & 2000 & 2000 & 2000 & 2000 & 2000 & 2000 & 2000 & 2000 \\
\hline Volume & 100 & 100 & 100 & 100 & 100 & 100 & 100 & 100 & 100 & 100 & 100 & 100 & 100 & 100 \\
\hline $\bar{x}:$ & 105.869 & 22.5225 & 34.9374 & 30.341 & 39.8675 & 29.8917 & 25.2028 & 43.6604 & 20.4828 & 26.5093 & 25.8712 & 306.286 & 30.2244 & 16.1757 \\
\hline Median: & 94.1762 & 17.4211 & 33.5501 & 25.38 & 33.7558 & 25.2743 & 20.0715 & 36.9789 & 14.0623 & 18.4606 & 20.1423 & 216.453 & 23.6898 & 10.5235 \\
\hline $\mathrm{D}(0,0):$ & 2.70959 & 2.85615 & 2.58358 & 1.45408 & 2.18974 & 2.40149 & 2.03243 & 2.43749 & 2.76229 & 2.60829 & 2.32476 & 2.96299 & 2.52056 & 2.71374 \\
\hline $\bar{x} /$ Median: & 1.12416 & 1.29283 & 1.04135 & 1.19547 & 1.18106 & 1.18269 & 1.25565 & 1.18068 & 1.45657 & 1.436 & 1.28442 & 1.41503 & 1.27584 & 1.53711 \\
\hline Mode: & 116.279 & 45.7517 & 55.1345 & 41.6772 & 41.6772 & 41.6772 & 37.9652 & 45.7517 & 14.9377 & 37.9652 & 50.2244 & 471.128 & 34.5839 & 10.2861 \\
\hline S.D.: & 78.378 & 17.2708 & 24.3033 & 25.0243 & 32.2254 & 23.5829 & 20.1996 & 36.1697 & 17.8905 & 23.4986 & 20.7266 & 322.332 & 23.8036 & 15.1196 \\
\hline Variance: & 6143.11 & 298.28 & 590.649 & 626.214 & 1038.48 & 556.153 & 408.023 & 1308.25 & 320.069 & 552.186 & 429.593 & 103898 & 566.61 & 228.602 \\
\hline C.V.: & 74.0329 & 76.6824 & 69.5624 & 82.4767 & 80.8314 & 78.8944 & 80.1481 & 82.8433 & 87.344 & 88.6429 & 80.1147 & 105.239 & 78.7562 & 93.4711 \\
\hline Skewness: & 1.7086 & 0.589411 & 0.373422 & 0.786047 & 0.97486 & 0.68669 & 0.720233 & 1.3334 & 1.23315 & 1.05637 & 0.592133 & 1.39984 & 0.860284 & 1.54733 \\
\hline Kurtosis: & 7.01052 & -0.884765 & -0.869653 & -0.158197 & 0.380967 & -0.443906 & -0.426059 & 1.85573 & 0.8389 & 0.404006 & -0.854961 & 1.86319 & -0.14703 & 2.04716 \\
\hline d10: & 15.2605 & 3.28244 & 4.19613 & 2.9185 & 4.28406 & 3.47403 & 2.99006 & 5.27777 & 3.5162 & 3.30558 & 3.1503 & 9.76864 & 4.33198 & 3.01287 \\
\hline d50: & 94.1762 & 17.4211 & 33.5501 & 25.38 & 33.7558 & 25.2743 & 20.0715 & 36.9789 & 14.0623 & 18.4606 & 20.1423 & 216.453 & 23.6898 & 10.5235 \\
\hline d90: & 203.486 & 48.7934 & 69.2471 & 67.1644 & 89.1937 & 64.8868 & 55.3938 & 91.7647 & 47.9871 & 61.9732 & 57.2162 & 751.243 & 67.6475 & 38.1435 \\
\hline SSA: & 1857.94 & 6490.1 & 4759.24 & 6967.31 & 4737.3 & 5879.87 & 6953.16 & 4092.02 & 6842.49 & 6527.49 & 6714.49 & 2082.9 & 5132.38 & 8395.65 \\
\hline$\%<$ & Size & Size & Size & Size & Size & Size & Size & Size & Size & Size & Size & Size & Size & Size \\
\hline 10 & 15.2605 & 3.28244 & 4.19613 & 2.9185 & 4.28406 & 3.47403 & 2.99006 & 5.27777 & 3.5162 & 3.30558 & 3.1503 & 9.76864 & 4.33198 & 3.01287 \\
\hline 25 & 49.3038 & 6.9363 & 12.6809 & 7.87558 & 13.5068 & 8.53989 & 7.07671 & 15.4323 & 6.64109 & 6.77932 & 6.74967 & 37.5849 & 10.8474 & 5.02648 \\
\hline 50 & 94.1762 & 17.4211 & 33.5501 & 25.38 & 33.7558 & 25.2743 & 20.0715 & 36.9789 & 14.0623 & 18.4606 & 20.1423 & 216.453 & 23.6898 & 10.5235 \\
\hline 75 & 149.768 & 36.8205 & 53.5728 & 46.6741 & 56.6623 & 46.3513 & 39.4713 & 59.4244 & 30.1808 & 40.6892 & 42.4614 & 466.259 & 44.8933 & 22.6562 \\
\hline 90 & 203.486 & 48.7934 & 69.2471 & 67.1644 & 89.1937 & 64.8868 & 55.3938 & 91.7647 & 47.9871 & 61.9732 & 57.2162 & 751.243 & 67.6475 & 38.1435 \\
\hline$\%>$ & Size & Size & Size & Size & Size & Size & Size & Size & Size & Size & Size & Size & Size & Size \\
\hline 10 & 203.486 & 48.7934 & 69.2471 & 67.1644 & 89.1937 & 64.8868 & 55.3938 & 91.7647 & 47.9871 & 61.9732 & 57.2162 & 751.243 & 67.6475 & 38.1435 \\
\hline 25 & 149.768 & 36.8205 & 53.5728 & 46.6741 & 56.6623 & 46.3513 & 39.4713 & 59.4244 & 30.1808 & 40.6892 & 42.4614 & 466.259 & 44.8933 & 22.6562 \\
\hline 50 & 94.1762 & 17.4211 & 33.5501 & 25.38 & 33.7558 & 25.2743 & 20.0715 & 36.9789 & 14.0623 & 18.4606 & 20.1423 & 216.453 & 23.6898 & 10.5235 \\
\hline 75 & 49.3038 & 6.9363 & 12.6809 & 7.87558 & 13.5068 & 8.53989 & 7.07671 & 15.4323 & 6.64109 & 6.77932 & 6.74967 & 37.5849 & 10.8474 & 5.02648 \\
\hline 90 & 15.2605 & 3.28244 & 4.19613 & 2.9185 & 4.28406 & 3.47403 & 2.99006 & 5.27777 & 3.5162 & 3.30558 & 3.1503 & 9.76864 & 4.33198 & 3.01287 \\
\hline Size & $\%<$ & $\%<$ & $\%<$ & $\%<$ & $\%<$ & $\%<$ & $\%<$ & $\%<$ & $\%<$ & $\%<$ & $\%<$ & $\%<$ & $\%<$ & $\%<$ \\
\hline 1 & 0 & 0 & 0 & 0.36 & 0.00019 & 0 & 0.004 & 0 & 0 & 0 & 0 & 0 & 0 & 0 \\
\hline 10 & 7.01 & 33.5 & 21.2 & 28.7 & 19.8 & 27.7 & 31.4 & 17.2 & 37.5 & 33.5 & 32.7 & 10.2 & 23.2 & 48.2 \\
\hline 100 & 53.2 & 100 & 99.8 & 99.3 & 93.4 & 99.8 & 99.998 & 91.7 & 99.999 & 99.5 & 100 & 37.6 & 99.7 & 100 \\
\hline 1000 & 100 & 100 & 100 & 100 & 100 & 100 & 100 & 100 & 100 & 100 & 100 & 95.3 & 100 & 100 \\
\hline Size & $\%>$ & $\%>$ & $\%>$ & $\%>$ & $\%>$ & $\%>$ & $\%>$ & $\%>$ & $\%>$ & $\%>$ & $\%>$ & $\%>$ & $\%>$ & $\%>$ \\
\hline
\end{tabular}




\begin{tabular}{|c|c|c|c|c|c|c|c|c|c|c|c|c|c|c|}
\hline 1 & 100 & 100 & 100 & 99.6 & 100 & 100 & 99.996 & 100 & 100 & 100 & 100 & 100 & 100 & 100 \\
\hline 10 & 93 & 66.5 & 78.8 & 71.3 & 80.2 & 72.3 & 68.6 & 82.8 & 62.5 & 66.5 & 67.3 & 89.8 & 76.8 & 51.8 \\
\hline 100 & 46.8 & 0 & 0.16 & 0.69 & 6.62 & 0.17 & 0.0019 & 8.34 & 0.0013 & 0.47 & 0 & 62.4 & 0.27 & 0 \\
\hline 1000 & 0 & 0 & 0 & 0 & 0 & 0 & 0 & 0 & 0 & 0 & 0 & 4.73 & 0 & 0 \\
\hline
\end{tabular}




\begin{tabular}{|c|c|c|c|c|c|c|c|c|c|c|c|c|c|c|}
\hline \\
\hline File ID: & CR-A7 & $\begin{array}{ll}\text { CR-B2 } \\
\end{array}$ & CR_C3 & CR-C5 & CR-D7 & $\begin{array}{l}\text { CR-E3 } \\
\end{array}$ & CR-F5 & CR-F8 & CR-G6 & CR-H9 & CR-J10 & CR-J6.5 & MP-K9 & MP-L11 \\
\hline $\begin{array}{l}\text { Volume } \\
\end{array}$ & Particle & Particle & Particle & $\begin{array}{l}\text { Particle } \\
\end{array}$ & $\begin{array}{l}\text { Particle } \\
\end{array}$ & $\begin{array}{l}\text { Particle } \\
\end{array}$ & $\begin{array}{l}\text { Particle } \\
\end{array}$ & $\begin{array}{l}\text { Particle } \\
\end{array}$ & $\begin{array}{l}\text { Particle } \\
\end{array}$ & $\begin{array}{l}\text { Particle } \\
\end{array}$ & $\begin{array}{l}\text { Particle } \\
\end{array}$ & $\begin{array}{l}\text { Particle } \\
\end{array}$ & $\begin{array}{l}\text { Particle } \\
\end{array}$ & $\begin{array}{l}\text { Particle } \\
\end{array}$ \\
\hline$\%$ & $\begin{array}{c}\text { diameter } \\
\text { um }<\end{array}$ & $\begin{array}{c}\text { diameter } \\
\text { um < }\end{array}$ & $\begin{array}{c}\text { diameter } \\
\text { um < }\end{array}$ & $\begin{array}{c}\text { diameter } \\
\text { um }<\end{array}$ & $\begin{array}{c}\text { diameter } \\
\text { um < }\end{array}$ & $\begin{array}{c}\text { diameter } \\
\text { um < }\end{array}$ & $\begin{array}{c}\text { diameter } \\
\text { um < }\end{array}$ & $\begin{array}{c}\text { diameter } \\
\text { um }<\end{array}$ & $\begin{array}{c}\text { diameter } \\
\text { um }<\end{array}$ & $\begin{array}{c}\text { diameter } \\
\text { um < }\end{array}$ & $\begin{array}{c}\text { diameter } \\
\text { um }<\end{array}$ & $\begin{array}{c}\text { diameter } \\
\text { um }<\end{array}$ & $\begin{array}{c}\text { diameter } \\
\text { um }<\end{array}$ & $\begin{array}{c}\text { diameter } \\
\text { um < }\end{array}$ \\
\hline 10 & 10.3513 & 3.12745 & 3.89745 & 4.96874 & 3.99457 & 5.83487 & 4.21295 & 3.74662 & 4.3022 & 4.79219 & 3.8824 & 8.1371 & 4.12983 & 4.02955 \\
\hline 25 & 20.7984 & 6.24292 & 8.8568 & 15.9474 & 9.0023 & 15.1992 & 12.0852 & 9.88979 & 12.4535 & 13.8164 & 10.5934 & 20.8859 & 11.1329 & 12.1647 \\
\hline 50 & 36.2714 & 16.9929 & 19.6297 & 43.6103 & 24.8649 & 40.3169 & 29.3674 & 28.682 & 30.9785 & 30.9045 & 29.8611 & 43.8705 & 32.4582 & 29.0646 \\
\hline 75 & 53.8684 & 35.6285 & 35.865 & 81.6339 & 47.4476 & 72.8023 & 49.0971 & 51.2303 & 51.6771 & 47.9119 & 50.8269 & 67.1746 & 56.4289 & 44.6498 \\
\hline 90 & 79.4401 & 51.7484 & 48.9549 & 136.604 & 71.4598 & 104.703 & 68.7548 & 77.0425 & 77.2195 & 64.8532 & 73.7251 & 92.4736 & 82.5752 & 59.1447 \\
\hline Diameter & Diff. & Diff. & Diff. & Diff. & Diff. & Diff. & Diff. & Diff. & Diff. & Diff. & Diff. & Diff. & Diff. & Diff. \\
\hline (Lower) & Volume & Volume & Volume & Volume & Volume & Volume & Volume & Volume & Volume & Volume & Volume & Volume & Volume & Volume \\
\hline um & $\%$ & $\%$ & $\%$ & $\%$ & $\%$ & $\%$ & $\%$ & $\%$ & $\%$ & $\%$ & $\%$ & $\%$ & $\%$ & $\%$ \\
\hline 0.37512 & & & & & & & & & & & & & & \\
\hline 0.4118 & & & & & & & & & & & & & & \\
\hline 0.45206 & & & & & & & & & & & & & & \\
\hline 0.49625 & & & & & & & & & & & & & & \\
\hline 0.54477 & & & & & & & & & & & & & & \\
\hline 0.59803 & & & & & & & & & & & & & & \\
\hline 0.65649 & & & & & & & & & & & & & & \\
\hline 0.72068 & & & & & & & & & & & & & & \\
\hline 0.79113 & & & & & & & & & & & & & & \\
\hline 0.86848 & & & & & & & & & & $5.79 \mathrm{E}-05$ & & & & \\
\hline 0.95338 & & & & & & & 0.000444596 & & & 0.00191461 & & & & \\
\hline 1.0466 & & $8.82 \mathrm{E}-05$ & & 0.000549102 & & & 0.00632161 & & & 0.0144219 & & & & \\
\hline 1.1489 & & 0.00428652 & & 0.00758327 & & & 0.0355812 & 0.00149524 & 0.00120582 & 0.054513 & & & & \\
\hline 1.2612 & & 0.0370961 & & 0.042196 & & & 0.10282 & 0.0186564 & 0.0151962 & 0.125155 & 0.00119832 & 0.000669187 & & 0.001179 \\
\hline 1.3845 & & 0.154471 & & 0.119543 & 0.00215337 & 0.00118831 & 0.206871 & 0.0977353 & 0.0801177 & 0.218568 & 0.0176677 & 0.0082143 & 0.00256298 & 0.0174593 \\
\hline 1.5199 & 0.000958684 & 0.375034 & 0.00443055 & 0.236515 & 0.0276939 & 0.0151483 & 0.331304 & 0.257118 & 0.212203 & 0.322276 & 0.100849 & 0.0429819 & 0.0323877 & 0.100705 \\
\hline 1.6685 & 0.0110502 & 0.663997 & 0.0529828 & 0.368326 & 0.14377 & 0.0777648 & 0.467219 & 0.476181 & 0.394752 & 0.434273 & 0.28971 & 0.111134 & 0.167579 & 0.293765 \\
\hline 1.8316 & 0.0571934 & 0.96336 & 0.267641 & 0.507294 & 0.376787 & 0.20217 & 0.611231 & 0.698758 & 0.581531 & 0.551763 & 0.567175 & 0.205412 & 0.433792 & 0.583456 \\
\hline 2.0107 & 0.14473 & 1.24756 & 0.667403 & 0.640365 & 0.681908 & 0.363263 & 0.750131 & 0.910469 & 0.759144 & 0.663748 & 0.85274 & 0.297664 & 0.772883 & 0.885447 \\
\hline 2.2072 & 0.260746 & 1.50791 & 1.14931 & 0.761735 & 0.970133 & 0.517269 & 0.881665 & 1.10138 & 0.918823 & 0.767777 & 1.10588 & 0.388868 & 1.0654 & 1.14306 \\
\hline 2.423 & 0.360738 & 1.71944 & 1.50413 & 0.857773 & 1.20818 & 0.64948 & 0.988491 & 1.25097 & 1.04133 & 0.846024 & 1.2897 & 0.468537 & 1.26711 & 1.30559 \\
\hline 2.6599 & 0.444154 & 1.88478 & 1.68796 & 0.929367 & 1.39114 & 0.763537 & 1.07216 & 1.36373 & 1.13142 & 0.905969 & 1.40584 & 0.538831 & 1.37365 & 1.37323 \\
\hline 2.92 & 0.501414 & 1.98375 & 1.67604 & 0.968302 & 1.50509 & 0.851221 & 1.12756 & 1.42459 & 1.17626 & 0.941461 & 1.45028 & 0.595321 & 1.38638 & 1.35055 \\
\hline 3.2054 & 0.535688 & 2.02636 & 1.53079 & 0.982694 & 1.5624 & 0.915412 & 1.15853 & 1.44549 & 1.18676 & 0.961207 & 1.44355 & 0.633684 & 1.34588 & 1.27754 \\
\hline 3.5188 & 0.555879 & 2.03369 & 1.34565 & 0.980331 & 1.57918 & 0.958466 & 1.17376 & 1.43961 & 1.17487 & 0.968087 & 1.4046 & 0.660079 & 1.28076 & 1.18085 \\
\hline 3.8628 & 0.565709 & 2.02323 & 1.23895 & 0.969453 & 1.58098 & 0.986492 & 1.17134 & 1.42354 & 1.15501 & 0.963669 & 1.36443 & 0.674554 & 1.23287 & 1.10349 \\
\hline 4.2405 & 0.587553 & 2.02912 & 1.27025 & 0.966783 & 1.61395 & 1.02834 & 1.17607 & 1.42156 & 1.15158 & 0.96812 & 1.35641 & 0.698805 & 1.23789 & 1.07564 \\
\hline 4.6551 & 0.606053 & 2.02322 & 1.42718 & 0.9594 & 1.65895 & 1.06995 & 1.17093 & 1.41436 & 1.14662 & 0.966001 & 1.36182 & 0.718837 & 1.28015 & 1.08182 \\
\hline 5.1102 & 0.638023 & 2.03313 & 1.66807 & 0.965551 & 1.72642 & 1.12642 & 1.18581 & 1.42409 & 1.16287 & 0.98706 & 1.39047 & 0.750757 & 1.3594 & 1.13037 \\
\hline 5.6098 & 0.643237 & 2.00804 & 1.85088 & 0.956387 & 1.75113 & 1.15467 & 1.18374 & 1.40973 & 1.15896 & 0.992638 & 1.38625 & 0.766481 & 1.40694 & 1.15773 \\
\hline 6.1582 & 0.651705 & 2.00007 & 1.97907 & 0.963707 & 1.767 & 1.18199 & 1.19993 & 1.41512 & 1.17647 & 1.02322 & 1.38748 & 0.788837 & 1.44871 & 1.20041 \\
\hline 6.7603 & 0.648077 & 1.98035 & 1.97872 & 0.967896 & 1.75428 & 1.19471 & 1.21317 & 1.41303 & 1.18944 & 1.05176 & 1.36797 & 0.808569 & 1.44641 & 1.21272 \\
\hline 7.4212 & 0.679543 & 1.99689 & 1.96814 & 1.00025 & 1.77072 & 1.23421 & 1.2637 & 1.44467 & 1.2409 & 1.1236 & 1.37975 & 0.85305 & 1.45589 & 1.2505 \\
\hline
\end{tabular}




\begin{tabular}{|c|c|c|c|c|c|c|c|c|c|c|c|c|c|c|}
\hline 8.1467 & 0.735685 & 2.02805 & 1.94321 & 1.04209 & 1.80304 & 1.2915 & 1.33851 & 1.48551 & 1.30727 & 1.21519 & 1.39976 & 0.915865 & 1.45512 & 1.27735 \\
\hline 8.9432 & 0.828492 & 2.07429 & 1.97826 & 1.09567 & 1.85086 & 1.36405 & 1.43759 & 1.53924 & 1.39381 & 1.33221 & 1.43903 & 0.996134 & 1.46562 & 1.32508 \\
\hline 9.8175 & 0.976678 & 2.16732 & 2.14663 & 1.18042 & 1.93121 & 1.46559 & 1.57843 & 1.63215 & 1.525 & 1.49522 & 1.53028 & 1.1087 & 1.52979 & 1.44566 \\
\hline 10.777 & 1.1709 & 2.28045 & 2.41753 & 1.28407 & 2.01188 & 1.57406 & 1.7349 & 1.74368 & 1.68228 & 1.68423 & 1.65903 & 1.23724 & 1.63724 & 1.64667 \\
\hline 11.831 & 1.46514 & 2.48964 & 2.8611 & 1.45587 & 2.15333 & 1.73739 & 1.96536 & 1.93568 & 1.92577 & 1.96113 & 1.89104 & 1.41686 & 1.85396 & 2.01011 \\
\hline 12.988 & 1.78683 & 2.69798 & 3.25039 & 1.62734 & 2.27369 & 1.89075 & 2.19794 & 2.11983 & 2.16347 & 2.2347 & 2.12205 & 1.5932 & 2.06222 & 2.3909 \\
\hline 14.257 & 2.15529 & 2.92021 & 3.56612 & 1.80006 & 2.40941 & 2.04907 & 2.45659 & 2.30846 & 2.40435 & 2.51934 & 2.34961 & 1.77937 & 2.24651 & 2.74773 \\
\hline 15.651 & 2.43982 & 3.01715 & 3.6305 & 1.87143 & 2.47231 & 2.12059 & 2.62283 & 2.38951 & 2.52475 & 2.68205 & 2.43889 & 1.896 & 2.27469 & 2.87004 \\
\hline 17.181 & 2.64421 & 2.98961 & 3.52525 & 1.83693 & 2.49135 & 2.10911 & 2.68854 & 2.37003 & 2.53241 & 2.72788 & 2.39362 & 1.94572 & 2.1645 & 2.75951 \\
\hline 18.861 & 2.77035 & 2.87062 & 3.39071 & 1.73019 & 2.49034 & 2.03458 & 2.66085 & 2.2854 & 2.46387 & 2.68865 & 2.2691 & 1.93006 & 2.00087 & 2.53377 \\
\hline 20.705 & 2.9065 & 2.75336 & 3.31977 & 1.62346 & 2.50964 & 1.95189 & 2.61817 & 2.20707 & 2.40232 & 2.65948 & 2.15898 & 1.89761 & 1.88127 & 2.37053 \\
\hline 22.729 & 3.19295 & 2.78561 & 3.46179 & 1.64151 & 2.63309 & 1.96572 & 2.70568 & 2.26323 & 2.48809 & 2.7987 & 2.21745 & 1.95263 & 1.94893 & 2.50951 \\
\hline 24.951 & 3.67028 & 2.97728 & 3.72393 & 1.81107 & 2.84239 & 2.09204 & 2.96966 & 2.47768 & 2.74834 & 3.14712 & 2.47532 & 2.14322 & 2.20895 & 2.99544 \\
\hline 27.391 & 4.3681 & 3.33306 & 4.07676 & 2.16308 & 3.15407 & 2.36571 & 3.44881 & 2.88269 & 3.21404 & 3.73877 & 2.96084 & 2.54491 & 2.66675 & 3.82654 \\
\hline 30.068 & 5.13107 & 3.7011 & 4.38551 & 2.61125 & 3.4828 & 2.71504 & 4.01503 & 3.38464 & 3.77385 & 4.43566 & 3.56315 & 3.11213 & 3.20666 & 4.77215 \\
\hline 33.008 & 5.80157 & 3.96327 & 4.58003 & 3.0609 & 3.77905 & 3.08088 & 4.52888 & 3.88671 & 4.31371 & 5.08855 & 4.15441 & 3.79024 & 3.72019 & 5.55696 \\
\hline 36.235 & 6.20357 & 4.03024 & 4.64581 & 3.41993 & 3.98724 & 3.39731 & 4.83589 & 4.27569 & 4.70672 & 5.5319 & 4.60025 & 4.45946 & 4.12272 & 5.97349 \\
\hline 39.778 & 6.25505 & 3.89644 & 4.58551 & 3.6459 & 4.07285 & 3.62994 & 4.8797 & 4.47415 & 4.87874 & 5.68056 & 4.81654 & 5.01201 & 4.37223 & 5.96561 \\
\hline 43.667 & 5.9836 & 3.63652 & 4.37664 & 3.77229 & 4.04204 & 3.80208 & 4.72852 & 4.4745 & 4.83246 & 5.55675 & 4.80469 & 5.39949 & 4.48764 & 5.63583 \\
\hline 47.936 & 5.45923 & 3.30875 & 3.98739 & 3.83451 & 3.88946 & 3.92587 & 4.47711 & 4.28424 & 4.58845 & 5.21168 & 4.59085 & 5.59019 & 4.47616 & 5.12653 \\
\hline 52.622 & 4.7974 & 2.9372 & 3.35083 & 3.86761 & 3.64072 & 4.02646 & 4.24188 & 3.95853 & 4.20294 & 4.7365 & 4.2429 & 5.61396 & 4.35361 & 4.56401 \\
\hline 57.767 & 4.09235 & 2.51119 & 2.22494 & 3.86387 & 3.32452 & 4.09593 & 4.06107 & 3.56422 & 3.72432 & 4.18934 & 3.82351 & 5.48688 & 4.12478 & 3.98034 \\
\hline 63.414 & 3.42818 & 1.98855 & 1.04643 & 3.78049 & 2.97241 & 4.11369 & 3.86489 & 3.16575 & 3.20477 & 3.58019 & 3.38448 & 5.22114 & 3.80669 & 3.35695 \\
\hline 69.614 & 2.86337 & 1.25494 & 0.234411 & 3.57373 & 2.61961 & 4.07527 & 3.54185 & 2.82571 & 2.70108 & 2.90914 & 2.96411 & 4.82462 & 3.43084 & 2.26498 \\
\hline 76.42 & 2.42656 & 0.559421 & 0.0229569 & 3.23023 & 2.28014 & 3.98116 & 2.94886 & 2.561 & 2.25849 & 2.16339 & 2.56579 & 4.30143 & 3.04103 & 1.09633 \\
\hline 83.891 & 2.11944 & 0.120692 & & 2.82987 & 1.93941 & 3.85984 & 1.91184 & 2.32747 & 1.9129 & 1.3485 & 2.16696 & 3.69038 & 2.66702 & 0.247806 \\
\hline 92.092 & 1.88776 & 0.0111617 & & 2.51742 & 1.57872 & 3.72005 & 0.859491 & 2.0557 & 1.66043 & 0.627713 & 1.74033 & 3.05225 & 2.29338 & 0.0246812 \\
\hline 101.1 & 1.65479 & & & 2.42401 & 1.17529 & 3.49045 & 0.185369 & 1.65661 & 1.45165 & 0.176682 & 1.26556 & 2.43285 & 1.88367 & \\
\hline 110.98 & 1.34023 & & & 2.60405 & 0.71485 & 3.08883 & 0.0169604 & 1.04664 & 1.22383 & 0.0246444 & 0.72942 & 1.85985 & 1.39863 & \\
\hline 121.83 & 0.914652 & & & 2.94692 & 0.316153 & 2.43491 & & 0.459534 & 0.925513 & 0.000835601 & 0.294437 & 1.33322 & 0.81803 & \\
\hline 133.74 & 0.464359 & & & 3.20281 & 0.0772185 & 1.48816 & & 0.0976508 & 0.543426 & & 0.0589125 & 0.84915 & 0.331731 & \\
\hline 146.81 & 0.14845 & & & 3.06734 & 0.00893166 & 0.629412 & & 0.00880944 & 0.218751 & & 0.00491237 & 0.427795 & 0.0664677 & \\
\hline 161.17 & 0.0235002 & & & 2.41248 & 0.000115085 & 0.129726 & & & 0.04323 & & & 0.146788 & 0.00546003 & \\
\hline 176.92 & 0.00116788 & & & 1.39197 & & 0.0112536 & & & 0.00348558 & & & 0.025721 & & \\
\hline 194.22 & & & & 0.523588 & & & & & & & & 0.00168094 & & \\
\hline 213.21 & & & & 0.0969059 & & & & & & & & & & \\
\hline 234.05 & & & & 0.00676881 & & & & & & & & & & \\
\hline 256.94 & & & & & & & & & & & & & & \\
\hline 282.06 & & & & & & & & & & & & & & \\
\hline 309.63 & & & & & & & & & & & & & & \\
\hline 339.9 & & & & & & & & & & & & & & \\
\hline 373.13 & & & & & & & & & & & & & & \\
\hline 409.61 & & & & & & & & & & & & & & \\
\hline 449.66 & & & & & & & & & & & & & & \\
\hline 493.62 & & & & & & & & & & & & & & \\
\hline 541.88 & & & & & & & & & & & & & & \\
\hline 594.85 & & & & & & & & & & & & & & \\
\hline 653.01 & & & & & & & & & & & & & & \\
\hline 716.85 & & & & & & & & & & & & & & \\
\hline
\end{tabular}


786.93

863.87

948.32

104

1142.8

1254.5

1377.2

1511.8

1659.6
1821.9

2000 


\begin{tabular}{|c|c|c|c|c|c|c|c|c|c|c|c|c|c|c|}
\hline \multicolumn{15}{|c|}{ K001-D Grain Size-BECKMAN COULTER LS13320 VOLUME PERCENT: samples MPL8 to MPT13 } \\
\hline File ID: & MP-L8 & MP-L9 & MPM-7 & MP-N10 & MP-N8 & MP-O12 & MP-P10 & MP-P11 & MP-Q8 & MP-R12 & MP-R14 & MP-S9 & MP-T11r & MP-T13 \\
\hline Volume & Particle & Particle & Particle & Particle & Particle & Particle & Particle & Particle & Particle & Particle & Particle & Particle & Particle & Particle \\
\hline$\%$ & $\begin{array}{r}\text { diameter } \\
\text { um }<\end{array}$ & $\begin{array}{c}\text { diameter } \\
\text { um }<\end{array}$ & $\begin{array}{r}\text { diameter } \\
\text { um }<\end{array}$ & $\begin{array}{r}\text { diameter } \\
\text { um }<\end{array}$ & $\begin{array}{r}\text { diameter } \\
\text { um }<\end{array}$ & $\begin{array}{r}\text { diameter } \\
\text { um }<\end{array}$ & $\begin{array}{r}\text { diameter } \\
\text { um }<\end{array}$ & $\begin{array}{r}\text { diameter } \\
\text { um }<\end{array}$ & $\begin{array}{r}\text { diameter } \\
\text { um }<\end{array}$ & $\begin{array}{r}\text { diameter } \\
\text { um }<\end{array}$ & $\begin{array}{l}\text { diameter } \\
\text { um }<\end{array}$ & $\begin{array}{r}\text { diameter } \\
\text { um }<\end{array}$ & $\begin{array}{r}\text { diameter } \\
\text { um }<\end{array}$ & diameter \\
\hline 10 & 5.80983 & 6.01372 & 19.6215 & 4.5177 & 15.2605 & 3.28244 & 4.19613 & 2.9185 & 4.28406 & 3.47403 & 2.99006 & 5.27777 & 3.5162 & 3.30558 \\
\hline 25 & 17.5459 & 16.9483 & 48.6832 & 13.5209 & 49.3038 & 6.9363 & 12.6809 & 7.87558 & 13.5068 & 8.53989 & 7.07671 & 15.4323 & 6.64109 & 6.77932 \\
\hline 50 & 40.4085 & 42.293 & 90.6874 & 35.1885 & 94.1762 & 17.4211 & 33.5501 & 25.38 & 33.7558 & 25.2743 & 20.0715 & 36.9789 & 14.0623 & 18.4606 \\
\hline 75 & 62.2692 & 70.2695 & 224.962 & 55.5832 & 149.768 & 36.8205 & 53.5728 & 46.6741 & 56.6623 & 46.3513 & 39.4713 & 59.4244 & 30.1808 & 40.6892 \\
\hline 90 & 89.6432 & 105.517 & 455.476 & 74.9899 & 203.486 & 48.7934 & 69.2471 & 67.1644 & 89.1937 & 64.8868 & 55.3938 & 91.7647 & 47.9871 & 61.9732 \\
\hline Diameter & Diff. & Diff. & Diff. & Diff. & Diff. & Diff. & Diff. & Diff. & Diff. & Diff. & Diff. & Diff. & Diff. & Diff. \\
\hline (Lower) & Volume & Volume & Volume & Volume & Volume & Volume & Volume & Volume & Volume & Volume & Volume & Volume & Volume & Volume \\
\hline um & $\%$ & $\%$ & $\%$ & $\%$ & $\%$ & $\%$ & $\%$ & $\%$ & $\%$ & $\%$ & $\%$ & $\%$ & $\%$ & $\%$ \\
\hline \multirow{2}{*}{\multicolumn{15}{|c|}{$\begin{array}{r}0.37512 \\
0.4118\end{array}$}} \\
\hline & & & & & & & & & & & & & & \\
\hline 0.45206 & & & & & & & & $1.38 \mathrm{E}-05$ & & & & & & \\
\hline 0.49625 & & & & & & & & 0.000345719 & & & & & & \\
\hline 0.54477 & & & & & & & & 0.00265338 & & & & & & \\
\hline 0.59803 & & & & & & & & 0.00991227 & & & & & & \\
\hline 0.65649 & & & & & & & & 0.0240901 & & & & & & \\
\hline 0.72068 & & & & & & & & 0.0448804 & & & & & & \\
\hline 0.79113 & & & & & & & & 0.0745463 & & & & & & \\
\hline 0.86848 & & & & & & & & 0.115532 & & & 0.000456834 & & & \\
\hline 0.95338 & & & & & & & & 0.172615 & 0.000378339 & & 0.00718399 & & & \\
\hline 1.0466 & 0.000189359 & & & 0.000434049 & & & & 0.246148 & 0.00561089 & 0.000111079 & 0.0426273 & 0.000101853 & & \\
\hline 1.1489 & 0.00366555 & & & 0.00656727 & & & & 0.339232 & 0.0330165 & 0.00406334 & 0.130171 & 0.00276503 & & \\
\hline 1.2612 & 0.0241979 & 0.0006329 & 0.00039161 & 0.038849 & 0.000484505 & & 0.00112662 & 0.450495 & 0.0992399 & 0.0330457 & 0.272367 & 0.020766 & 0.00139875 & 0.00233865 \\
\hline 1.3845 & 0.0810782 & 0.00939973 & 0.00476831 & 0.116812 & 0.00576348 & & 0.0166004 & 0.579443 & 0.207002 & 0.131307 & 0.449616 & 0.0774294 & 0.0197281 & 0.0300775 \\
\hline 1.5199 & 0.178043 & 0.0538473 & 0.0245155 & 0.241322 & 0.0294061 & 0.00615818 & 0.0954889 & 0.722489 & 0.33863 & 0.312697 & 0.651001 & 0.17967 & 0.111647 & 0.159616 \\
\hline 1.6685 & 0.296934 & 0.154765 & 0.0622622 & 0.386393 & 0.0740129 & 0.0732381 & 0.277361 & 0.871966 & 0.484179 & 0.546915 & 0.866349 & 0.309398 & 0.316278 & 0.422569 \\
\hline 1.8316 & 0.422676 & 0.303699 & 0.11233 & 0.540901 & 0.133196 & 0.368778 & 0.548143 & 1.02446 & 0.634918 & 0.790074 & 1.08684 & 0.446224 & 0.619906 & 0.782011 \\
\hline 2.0107 & 0.542718 & 0.45773 & 0.159146 & 0.689635 & 0.188729 & 0.915998 & 0.82747 & 1.16706 & 0.778134 & 1.02093 & 1.29412 & 0.576946 & 0.93378 & 1.12665 \\
\hline 2.2072 & 0.653651 & 0.599153 & 0.203091 & 0.82899 & 0.242129 & 1.57121 & 1.06466 & 1.29744 & 0.907288 & 1.23251 & 1.47731 & 0.699068 & 1.22788 & 1.43279 \\
\hline 2.423 & 0.742143 & 0.709173 & 0.239596 & 0.943515 & 0.288547 & 2.04804 & 1.21696 & 1.39692 & 1.00356 & 1.40297 & 1.60845 & 0.798355 & 1.46403 & 1.66714 \\
\hline 2.6599 & 0.809819 & 0.792565 & 0.269417 & 1.03307 & 0.328808 & 2.27963 & 1.28701 & 1.46824 & 1.06869 & 1.53179 & 1.69141 & 0.876966 & 1.65349 & 1.83232 \\
\hline 2.92 & 0.847676 & 0.843791 & 0.290237 & 1.08803 & 0.360369 & 2.24203 & 1.28063 & 1.50289 & 1.09552 & 1.60238 & 1.71951 & 0.925012 & 1.78941 & 1.92231 \\
\hline 3.2054 & 0.860963 & 0.869256 & 0.300888 & 1.11315 & 0.380936 & 2.01329 & 1.23281 & 1.50939 & 1.09682 & 1.62305 & 1.71138 & 0.946835 & 1.87802 & 1.94638 \\
\hline 3.5188 & 0.858301 & 0.874802 & 0.304514 & 1.11905 & 0.39408 & 1.73417 & $\begin{array}{l}1.1662 \\
\end{array}$ & 1.49547 & 1.08104 & 1.61332 & 1.68107 & 0.95262 & 1.93548 & 1.92894 \\
\hline 3.8628 & 0.846377 & 0.8737 & 0.303471 & 1.11082 & 0.401438 & 1.55098 & $\begin{array}{l}1.11672 \\
\end{array}$ & 1.46358 & 1.05651 & 1.58853 & 1.63932 & 0.948329 & 1.9803 & 1.90112 \\
\hline 4.2405 & 0.843942 & 0.890193 & 0.307084 & 1.1105 & 0.413444 & 1.54399 & 1.10879 & 1.4347 & 1.0418 & 1.57857 & 1.61233 & 0.955267 & 2.07032 & 1.90973 \\
\hline 4.6551 & 0.8371 & 0.910858 & 0.309745 & 1.10224 & 0.423161 & 1.69696 & 1.12633 & 1.39323 & 1.02295 & 1.56169 & 1.58144 & 0.957233 & 2.17869 & 1.93043 \\
\hline 5.1102 & 0.844864 & 0.948015 & 0.317421 & 1.10922 & 0.43694 & 1.94909 & 1.1743 & 1.37081 & 1.02489 & 1.561 & 1.5792 & 0.974998 & 2.32923 & 1.97604 \\
\hline 5.6098 & 0.837994 & 0.961829 & 0.318051 & 1.09907 & 0.441458 & 2.14531 & 1.19873 & 1.33401 & 1.01311 & 1.53487 & 1.56121 & 0.976215 & 2.4402 & 1.98173 \\
\hline 6.1582 & 0.847078 & 0.982191 & 0.322462 & 1.10496 & 0.448014 & 2.26428 & 1.23242 & 1.32424 & 1.02556 & 1.52453 & 1.57583 & 0.992997 & 2.55632 & 1.99077 \\
\hline 6.7603 & 0.855571 & 0.992557 & 0.326663 & 1.10848 & 0.452133 & 2.24125 & 1.23467 & 1.31676 & 1.03589 & 1.5082 & 1.58916 & 1.00752 & 2.64865 & 1.98127 \\
\hline 7.4212 & 0.895464 & 1.03217 & 0.342999 & 1.14497 & 0.466231 & 2.18859 & 1.24801 & 1.35151 & 1.08434 & 1.52634 & 1.64755 & 1.05322 & 2.77992 & 2.00741 \\
\hline
\end{tabular}




\begin{tabular}{|c|c|c|c|c|c|c|c|c|c|c|c|c|c|c|}
\hline 8.1467 & 0.9516 & 1.08357 & 0.366837 & 1.20151 & 0.486368 & 2.12135 & 1.24066 & 1.40856 & 1.14777 & 1.56209 & 1.72045 & 1.11556 & 2.92712 & 2.04674 \\
\hline 8.9432 & 1.02759 & 1.14852 & 0.398491 & 1.28046 & 0.511836 & 2.10872 & 1.24323 & 1.48898 & 1.23412 & 1.61564 & 1.81013 & 1.19707 & 3.07105 & 2.09367 \\
\hline 9.8175 & 1.14202 & 1.24601 & 0.444745 & 1.39993 & 0.549841 & 2.21754 & 1.31211 & 1.61097 & 1.36548 & 1.7098 & 1.94264 & 1.31622 & 3.22719 & 2.17331 \\
\hline 10.777 & 1.28095 & 1.36295 & 0.499497 & 1.53673 & 0.593176 & 2.40634 & 1.45996 & 1.74664 & 1.52527 & 1.82074 & 2.09357 & 1.45489 & 3.34074 & 2.25638 \\
\hline 11.831 & 1.48661 & 1.55103 & 0.577023 & 1.73621 & 0.659114 & 2.72207 & 1.75564 & 1.9513 & 1.76861 & 2.00957 & 2.33337 & 1.65771 & 3.48747 & 2.41934 \\
\hline 12.988 & 1.68724 & 1.7365 & 0.649731 & 1.92447 & 0.722396 & 2.96442 & 2.06013 & 2.14034 & 2.00508 & 2.19703 & 2.55428 & 1.85244 & 3.55763 & 2.56906 \\
\hline 14.257 & 1.88508 & 1.9206 & 0.721319 & 2.11452 & 0.788984 & 3.12494 & 2.3158 & 2.32832 & 2.23881 & 2.39858 & 2.76266 & 2.04972 & 3.58412 & 2.72309 \\
\hline 15.651 & 1.97968 & 1.9937 & 0.757278 & 2.20326 & 0.82153 & 3.0843 & 2.34228 & 2.4023 & 2.34535 & 2.49616 & 2.82279 & 2.15129 & 3.46247 & 2.7561 \\
\hline 17.181 & 1.97387 & 1.95078 & 0.761265 & 2.18817 & 0.818149 & 2.91965 & 2.16706 & 2.36467 & 2.32715 & 2.48786 & 2.75648 & 2.16605 & 3.23148 & 2.66608 \\
\hline 18.861 & 1.89595 & 1.8288 & 0.738937 & 2.08942 & 0.780185 & 2.74571 & 1.93586 & 2.253 & 2.22818 & 2.40237 & 2.63191 & 2.11761 & 2.96385 & 2.49765 \\
\hline 20.705 & 1.82314 & 1.70667 & 0.708558 & 1.98256 & 0.724973 & 2.62093 & 1.80419 & 2.15266 & 2.14296 & 2.32381 & 2.55528 & 2.0778 & 2.73767 & 2.33579 \\
\hline 22.729 & 1.88844 & 1.72428 & 0.720918 & 2.01626 & 0.705773 & 2.66508 & 1.95809 & 2.21277 & 2.22744 & 2.39633 & 2.67572 & 2.17036 & 2.67531 & 2.33262 \\
\hline 24.951 & 2.14267 & 1.92013 & 0.800085 & 2.24994 & 0.743973 & 2.83139 & 2.38755 & 2.47059 & 2.52288 & 2.65004 & 2.9878 & 2.43243 & 2.74602 & 2.51001 \\
\hline 27.391 & 2.64751 & 2.34063 & 0.996869 & 2.75519 & 0.883394 & 3.16027 & 3.05989 & 2.95884 & 3.06106 & 3.10852 & 3.47461 & 2.91129 & 2.93397 & 2.8833 \\
\hline 30.068 & 3.32889 & 2.90177 & 1.30822 & 3.44666 & 1.11148 & 3.59854 & 3.77136 & 3.55756 & 3.71668 & 3.64442 & 3.96677 & 3.51691 & 3.10866 & 3.32489 \\
\hline 33.008 & 4.08943 & 3.49817 & 1.72218 & 4.1996 & 1.40849 & 4.11109 & 4.35591 & 4.12434 & 4.33302 & 4.12935 & 4.33338 & 4.15151 & 3.18712 & 3.69832 \\
\hline 36.235 & 4.78166 & 4.00835 & 2.18297 & 4.83585 & 1.72832 & 4.62724 & 4.75132 & 4.50813 & 4.74388 & 4.44226 & 4.49103 & 4.68286 & 3.12798 & 3.88281 \\
\hline 39.778 & 5.2879 & 4.35632 & 2.61832 & 5.22629 & 2.02307 & 5.03488 & 4.99623 & 4.63016 & 4.85731 & 4.5473 & 4.44052 & 5.02069 & 2.94993 & 3.83757 \\
\hline 43.667 & 5.5638 & 4.55602 & 2.98747 & 5.36037 & 2.2899 & 5.19276 & 5.19774 & 4.5212 & 4.69423 & 4.49958 & 4.25219 & 5.14575 & 2.71855 & 3.62443 \\
\hline 47.936 & 5.58867 & 4.63909 & 3.26259 & 5.28269 & 2.53448 & 4.97237 & 5.40076 & 4.24893 & 4.32894 & 4.35764 & 3.97118 & 5.05606 & 2.47351 & 3.3281 \\
\hline 52.622 & 5.40067 & 4.66157 & 3.46844 & 5.09587 & 2.7921 & 3.62264 & 5.57252 & 3.90836 & 3.87973 & 4.17738 & 3.61475 & 4.79166 & 2.2297 & 3.03565 \\
\hline 57.767 & 5.03739 & 4.63926 & 3.63745 & 4.86862 & 3.09277 & 1.84419 & 5.56413 & 3.5593 & 3.4505 & 3.94255 & 3.15915 & 4.38206 & 1.96311 & 2.7837 \\
\hline 63.414 & 4.54623 & 4.54758 & 3.7962 & 4.61186 & 3.44391 & 0.426868 & 5.20093 & 3.21871 & 3.12198 & 3.58699 & 2.57338 & 3.86254 & 1.63919 & 2.5528 \\
\hline 69.614 & 3.98727 & 4.33369 & 3.95019 & 4.24948 & 3.84565 & 0.0436987 & 4.363 & 2.84878 & 2.92654 & 3.04145 & 1.65987 & 3.27756 & 1.08574 & 2.27932 \\
\hline 76.42 & 3.41585 & 3.94179 & 4.055 & 3.68166 & 4.25989 & & 3.06925 & 2.39735 & 2.84667 & 2.27523 & 0.758995 & 2.68384 & 0.511241 & 1.89921 \\
\hline 83.891 & 2.89338 & 3.38529 & 4.04278 & 2.84834 & 4.63315 & & 1.61533 & 1.82831 & 2.81675 & 1.31735 & 0.165564 & 2.16665 & 0.113477 & 1.39474 \\
\hline 92.092 & 2.4567 & 2.76402 & 3.85218 & 1.71132 & 4.91782 & & 0.547168 & 1.09557 & 2.71509 & 0.521397 & 0.0156599 & 1.79279 & 0.0110074 & 0.791825 \\
\hline 101.1 & 2.08454 & 2.22046 & 3.4652 & 0.709859 & 5.07104 & & 0.0921758 & 0.457076 & 2.4329 & 0.101697 & & 1.58891 & & 0.307964 \\
\hline 110.98 & 1.73038 & 1.86639 & 2.95433 & 0.143865 & 5.10543 & & 0.00530455 & 0.0932906 & 1.91746 & 0.00797969 & & 1.52014 & & 0.0592704 \\
\hline 121.83 & 1.33742 & 1.6944 & 2.45019 & 0.0120534 & 5.0585 & & & 0.0079045 & 1.21413 & & & 1.4873 & & 0.00460314 \\
\hline 133.74 & 0.892074 & 1.60956 & 2.08307 & & 4.97839 & & & & 0.555037 & & & 1.37829 & & \\
\hline 146.81 & 0.455107 & 1.46338 & 1.9243 & & 4.88654 & & & & 0.149719 & & & 1.11444 & & \\
\hline 161.17 & 0.15251 & 1.14831 & 1.95659 & & 4.74131 & & & & 0.0196344 & & & 0.683452 & & \\
\hline 176.92 & 0.0257821 & 0.675222 & 2.10403 & & 4.45633 & & & & 0.000574815 & & & 0.28533 & & \\
\hline 194.22 & 0.00153837 & 0.261505 & 2.24124 & & 3.94 & & & & & & & 0.0579687 & & \\
\hline 213.21 & & 0.0497359 & 2.26352 & & 3.17084 & & & & & & & 0.00490043 & & \\
\hline 234.05 & & 0.00363486 & 2.14104 & & 2.20429 & & & & & & & & & \\
\hline 256.94 & & & 1.93602 & & 1.1802 & & & & & & & & & \\
\hline 282.06 & & & 1.75971 & & 0.425903 & & & & & & & & & \\
\hline 309.63 & & & 1.70448 & & 0.0877227 & & & & & & & & & \\
\hline 339.9 & & & 1.80836 & & 0.0238031 & & & & & & & & & \\
\hline 373.13 & & & 2.04073 & & 0.0395088 & & & & & & & & & \\
\hline 409.61 & & & 2.29967 & & 0.111906 & & & & & & & & & \\
\hline 449.66 & & & 2.44086 & & 0.18909 & & & & & & & & & \\
\hline 493.62 & & & 2.34297 & & 0.21655 & & & & & & & & & \\
\hline 541.88 & & & 1.98052 & & 0.181107 & & & & & & & & & \\
\hline 594.85 & & & 1.44147 & & 0.104823 & & & & & & & & & \\
\hline 653.01 & & & 0.889453 & & 0.0392565 & & & & & & & & & \\
\hline 716.85 & & & 0.467902 & & 0.0069884 & & & & & & & & & \\
\hline
\end{tabular}




\begin{tabular}{|c|c|c|}
\hline 786.93 & 0.235816 & 0.000493738 \\
\hline 863.87 & 0.138706 & \\
\hline 948.32 & 0.107052 & \\
\hline 1041 & 0.0824813 & \\
\hline 1142.8 & 0.0585561 & \\
\hline 1254.5 & 0.0475142 & \\
\hline 1377.2 & 0.0427531 & \\
\hline 1511.8 & 0.0339874 & \\
\hline 1659.6 & 0.0112104 & \\
\hline 1821.9 & 0.0016674 & \\
\hline 2000 & & \\
\hline
\end{tabular}




\begin{tabular}{|c|c|c|c|c|}
\hline \multicolumn{5}{|c|}{$\begin{array}{l}\text { K001-D Grain Size-BECKMAN COULTER LS13320 VOLUME } \\
\text { PERCENT: samples MPT16 to MPV16 }\end{array}$} \\
\hline File ID: & MP-T16 & MP-U18 & MP-V13 & MP-V16 \\
\hline Volume & $\begin{array}{l}\text { Particle } \\
\end{array}$ & $\begin{array}{l}\text { Particle } \\
\end{array}$ & $\begin{array}{l}\text { Particle } \\
\end{array}$ & Particle \\
\hline$\%$ & $\begin{array}{r}\text { diameter } \\
\text { um }<\end{array}$ & $\begin{array}{r}\text { diameter } \\
\text { um }<\end{array}$ & $\begin{array}{r}\text { diameter } \\
\text { um }<\end{array}$ & $\begin{aligned} \text { diameter } \\
\text { um }<\end{aligned}$ \\
\hline 10 & 3.1503 & 9.76864 & 4.33198 & 3.01287 \\
\hline 25 & 6.74967 & 37.5849 & 10.8474 & 5.02648 \\
\hline 50 & 20.1423 & 216.453 & 23.6898 & 10.5235 \\
\hline 75 & 42.4614 & 466.259 & 44.8933 & 22.6562 \\
\hline 90 & 57.2162 & 751.243 & 67.6475 & 38.1435 \\
\hline Diameter & Diff. & Diff. & Diff. & Diff. \\
\hline (Lower) & Volume & Volume & Volume & Volume \\
\hline um & $\%$ & $\%$ & $\%$ & $\%$ \\
\hline 0.37512 & & & & \\
\hline 0.4118 & & & & \\
\hline 0.45206 & & & & \\
\hline 0.49625 & & & & \\
\hline 0.54477 & & & & \\
\hline 0.59803 & & & & \\
\hline 0.65649 & & & & \\
\hline 0.72068 & & & & \\
\hline 0.79113 & & & & \\
\hline 0.86848 & & & & \\
\hline 0.95338 & & & & \\
\hline 1.0466 & 0.000869682 & & & \\
\hline 1.1489 & 0.0128052 & & 0.000868331 & \\
\hline 1.2612 & 0.0740986 & & 0.0116346 & 0.00167304 \\
\hline 1.3845 & 0.217838 & 0.000583893 & 0.0648517 & 0.0253614 \\
\hline 1.5199 & 0.441477 & 0.00794496 & 0.183054 & 0.148653 \\
\hline 1.6685 & 0.69734 & 0.0423162 & 0.360867 & 0.437299 \\
\hline 1.8316 & 0.965619 & 0.114625 & 0.558154 & 0.8757 \\
\hline 2.0107 & 1.22098 & 0.211653 & 0.750885 & 1.34207 \\
\hline 2.2072 & 1.45361 & 0.306471 & 0.920883 & 1.77987 \\
\hline 2.423 & 1.64051 & 0.385614 & 1.04348 & 2.13574 \\
\hline 2.6599 & 1.77863 & 0.449571 & 1.13051 & 2.4108 \\
\hline 2.92 & 1.85421 & 0.494808 & 1.17255 & 2.5901 \\
\hline 3.2054 & 1.87801 & 0.525445 & 1.18687 & 2.68075 \\
\hline 3.5188 & 1.87097 & 0.545901 & 1.18086 & 2.71218 \\
\hline 3.8628 & 1.84789 & 0.561631 & 1.17192 & 2.72343 \\
\hline 4.2405 & 1.83918 & 0.589587 & 1.19013 & 2.78833 \\
\hline 4.6551 & 1.82259 & 0.621815 & 1.2178 & 2.87732 \\
\hline 5.1102 & 1.82292 & 0.664961 & 1.2838 & 3.00151 \\
\hline 5.6098 & 1.7985 & 0.692468 & 1.3279 & 3.07077 \\
\hline 6.1582 & 1.79363 & 0.718015 & 1.40066 & 3.12762 \\
\hline 6.7603 & 1.78327 & 0.732396 & 1.46307 & 3.14769 \\
\hline
\end{tabular}




$\begin{array}{rrrrr}7.4212 & 1.80682 & 0.758859 & 1.57806 & 3.19245 \\ 8.1467 & 1.84254 & 0.792085 & 1.71126 & 3.24081 \\ 8.9432 & 1.88962 & 0.829614 & 1.86621 & 3.26971 \\ 9.8175 & 1.9739 & 0.87888 & 2.07021 & 3.28931 \\ 10.777 & 2.07126 & 0.925893 & 2.29681 & 3.24511 \\ 11.831 & 2.23801 & 0.99888 & 2.63241 & 3.21673 \\ 12.988 & 2.37878 & 1.06308 & 2.952 & 3.1306 \\ 14.257 & 2.49828 & 1.12746 & 3.25741 & 3.06402 \\ 15.651 & 2.4934 & 1.14419 & 3.37412 & 2.96572 \\ 17.181 & 2.40271 & 1.11041 & 3.30342 & 2.89021 \\ 18.861 & 2.28787 & 1.03715 & 3.11962 & 2.85786 \\ 20.705 & 2.23355 & 0.951532 & 2.94157 & 2.86356 \\ 22.729 & 2.34476 & 0.910829 & 2.95132 & 2.9215 \\ 24.951 & 2.59459 & 0.925684 & 3.14544 & 2.93297 \\ 27.391 & 2.97616 & 1.01088 & 3.50437 & 2.87053 \\ 30.068 & 3.3672 & 1.12953 & 3.85107 & 2.67404 \\ 33.008 & 3.73274 & 1.24149 & 4.03921 & 2.38311 \\ 36.235 & 4.05593 & 1.30644 & 3.9975 & 2.06963 \\ 39.778 & 4.34353 & 1.30555 & 3.77578 & 1.79806 \\ 43.667 & 4.61257 & 1.25788 & 3.52125 & 1.61386 \\ 47.936 & 4.7887 & 1.19213 & 3.3531 & 1.49927 \\ 52.622 & 4.762 & 1.14142 & 3.33465 & 1.40486 \\ 57.767 & 4.4113 & 1.12485 & 3.42488 & 1.27255 \\ 63.414 & 3.13243 & 1.14002 & 3.48202 & 0.898181 \\ 69.614 & 1.55675 & 1.17296 & 3.32612 & 0.446541 \\ 76.42 & 0.354306 & 1.19695 & 2.80412 & 0.101722 \\ 83.891 & 0.0354044 & 1.19225 & 1.80117 & 0.0101769 \\ 92.092 & & 1.1587 & 0.785433 & \\ 101.1 & & 1.11365 & 0.164605 & \\ 110.98 & & 1.09499 & 0.0141376 & \\ 121.83 & & 1.13404 & & \\ 133.74 & & 1.25227 & & \\ 146.81 & & 1.45047 & & \\ 161.17 & & 1.70264 & & \\ 176.92 & & 1.97154 & & \\ 194.22 & & 2.21406 & & \\ 213.21 & & 2.4097 & & \\ 234.05 & & 2.56318 & & \\ 256.94 & & 2.70111 & & \\ 282.06 & & 2.85827 & & \\ 309.63 & & 3.05411 & & \\ 339.9 & & 3.28069 & & \\ 373.13 & & 3.4969 & & \\ 409.61 & & 3.63725 & & \\ 449.66 & & 3.63809 & & \\ 493.62 & & 3.46757 & & \\ 541.88 & & 3.14862 & & \\ 594.85 & & 2.75219 & & \\ 653.01 & & 2.36424 & & \\ & & & & \\ & & & \end{array}$


716.85

786.93

863.87

948.32

1041

1142.8

1254.5

1377.2

1511.8

1659.6
1821.9

2000

2.04375

1.80428

1.61454

1.43169

1.03242

0.00782937 


\section{Appendix D Smear slide analysis data}


K001-D 2010: Provenance-SMEAR SLIDE ANALYSIS

Abbreviations: alt=alteration; ccl=calcite; $\mathrm{dm}=$ diatom;fsp=feldspar; hbl=hornblende; $\mathrm{mca}=$ mica; opq=opaques; org=organics; qtz=quartz; rdg=rounding; ssp=sponge spicule; vg=volcanic glass

\begin{tabular}{|c|c|c|c|c|c|c|c|c|c|c|c|c|c|c|c|}
\hline Smear Slide & vg abund. & $\mathrm{vg}$ & ssp & $\mathrm{dm}$ & qtz & fsp & $\mathrm{hbl}$ & mca & $\mathrm{ccl}$ & opq & org & alt \& rdg & Provenance notes & Key: & \\
\hline Sample \# & (see below) & 0.97 & 0.83 & 0.51 & 0.89 & 0.94 & 0.77 & $\begin{array}{r}0.74 \\
\mathrm{chl}=0.2\end{array}$ & 0.51 & 0.89 & $\begin{array}{r}0.09 \\
\text { ?algae }\end{array}$ & 0.43 & & & \\
\hline CR-A5 & rare & $\mathrm{b}$ & $\mathrm{w}$ & & $\mathrm{x}$ & $\mathrm{x}$ & $\mathrm{x}$ & & $w, p$ & hae & & ox & qtz common & $\mathrm{f}$ & fragments \\
\hline CR-A8 & rare & $\mathrm{b}$ & $\mathrm{f}$ & $\mathrm{w}$ & $\mathrm{x}$ & $\mathrm{x}$ & & $\mathrm{x}$ & & & & & spiky spicule & $\mathrm{w}$ & whole \\
\hline CR-B4 & very rare & $\mathrm{b}, \mathrm{B}$ & & & & $\mathrm{x}$ & $\mathrm{x}$ & & & hae, oxides & & & fdsp common; black oxides ?basalt & ox & oxidisation of grains \\
\hline CR-B6 & rare & $\mathrm{b}, \mathrm{v}$ & $\mathrm{f}$ & & $\mathrm{x}$ & $\mathrm{x}$ & $\mathrm{x}$ & $\mathrm{x}, \mathrm{chl}$ & & hae, B-oxides & & ox & many unknown objects; orthoclase? & sr & sub-rounded grains \\
\hline CR-C2 & rare & $\mathrm{b}, \mathrm{c}, \mathrm{v}$ & $\mathrm{f}, \mathrm{w}$ & $\mathrm{f}, \mathrm{w}$ ? & $\mathrm{x}$ & $\mathrm{x}$ & $\mathrm{x}$ & $\mathrm{x}, \mathrm{chl}$ & $\mathrm{p}$ & hae, B\&r-oxides & & ox & $\begin{array}{l}\text { occasional ccl p; some noticably yellow qtz } \\
\text { (ppl); vg rare }\end{array}$ & $\mathrm{v}$ & vesicular \\
\hline CR-C7 & rare & $\mathrm{b}, \mathrm{v}$ & $\mathrm{f}$ & f? & $\mathrm{x}$ & $\mathrm{x}$ & $\mathrm{x}$ & $\mathrm{x}, \mathrm{chl}$ & & hae, B-oxides & & ox & seems coarser than other GH slides & $\mathrm{p}$ & precipitate \\
\hline CR-D2 & very rare & $\mathrm{v}$ & $\mathrm{f}$ & & $\mathrm{x}$ & $\mathrm{x}$ & $\mathrm{x}$ & & & hae, B-oxides & ? & & qtz common; rare vg \& sp & $\mathrm{b}$ & brown \\
\hline CR-D8 & common & $b, o$ & $\mathrm{f}$ & $\mathrm{w}$ & $\mathrm{x}$ & $\mathrm{x}$ & $\mathrm{x}$ & $\mathrm{x}$ & & & & $\mathrm{sr}$ & twinned mineral; vg very rare & B & black \\
\hline CR-E1 & absent & & $\mathrm{f}$ & & $\mathrm{x}$ & $\mathrm{x}$ & $\mathrm{x}$ & $\mathrm{x}$ & & $\begin{array}{l}\text { hae, B-oxides, } \\
\text { ?spinel }\end{array}$ & & ox, sr & sp frags $(45,98)$; rare sub-rounded grains & $\mathrm{g}$ & green \\
\hline CR-E2 & very rare & $\mathrm{b}$ & $f ?$ & & $\mathrm{x}$ & $\mathrm{x}$ & $\mathrm{x}$ & $\mathrm{x}$ & $\mathrm{w}$ & $\begin{array}{l}\text { hae, B\&r-oxides, } \\
\text { ?spinel/olv }\end{array}$ & & & seastar appendage?; single shard v.g & c & clear \\
\hline CR-E5 & rare & $b, v$ & $\mathrm{f}, \mathrm{w}$ & $f, w$ & $\mathrm{x}$ & $\mathrm{x}$ & $\mathrm{x}$ & $\mathrm{x}, \mathrm{chl}$ & $\mathrm{w}, \mathrm{p}$ & hae, B\&r-oxides & & & $\begin{array}{l}\text { ccl abundant; dm common; silica flagellate } \\
\text { occasional; vg rare }\end{array}$ & $\mathrm{r}$ & red \\
\hline CR-E6 & & $b, B, v, g, o$ & $\mathrm{w}$ & & $\mathrm{x}$ & $\mathrm{x}$ & & $\mathrm{x}, \mathrm{chl}$ & $\mathrm{w}$ & B-oxides & & ox & $o$ and $g \operatorname{vg}(?)$ very rare and unvesiculated & & \\
\hline CR-E9 & rare & $\mathrm{b}, \mathrm{o}$ & & & $\mathrm{x}$ & $\mathrm{x}$ & $\mathrm{x} ?$ & $\mathrm{x}$ & $\mathrm{w}, \mathrm{p}$ & B-oxides & & & ccl abundant & o & orange \\
\hline CR-F7 & common & $\mathrm{b}$ & $\mathrm{f}$ & $f, w$ & $\mathrm{x}$ & $\mathrm{x}$ & $\mathrm{x}$ & & & hae; B-oxides & & $\mathrm{ox}, \mathrm{sr}$ & & hae & haematite \\
\hline CR-G5 & common & $b, v$ & $\mathrm{f}$ & $\mathrm{w} ?$ & $\mathrm{x}$ & $\mathrm{x}$ & $\mathrm{x}$ & $\mathrm{x}$ & $\mathrm{p}$ & hae, B-oxides & & & rare ccl & & \\
\hline CR-G8 & & $\mathrm{b}, \mathrm{v}$ & $\mathrm{f}$ & & $\mathrm{x}$ & $\mathrm{x}$ & $\mathrm{x}$ & $\mathrm{x}$ & $w, p$ & B\&r-oxides & ? & & ccl common; vg occasional; ?fibre & & \\
\hline CR-H10 & common & b & $\mathrm{f}$ & & $\mathrm{x}$ & $\mathrm{x}$ & & $\mathrm{x}$ & & hae & & ox & ccl absent & & \\
\hline CR-H5 & common & $b, c, v$ & $\mathrm{w}$ & $\mathrm{w}$ & $\mathrm{x}$ & $\mathrm{x}$ & $\mathrm{x}$ & $\mathrm{x}, \mathrm{chl}$ & $\mathrm{x}$ & hae, B-oxides & & ox & vg occasional; ccl with lamellae; sea ice dm & & \\
\hline CR-H8 & common & $\mathrm{b}, \mathrm{v}$ & $\mathrm{f}, \mathrm{w}$ & $\mathrm{f}$ & $\mathrm{x}$ & $\mathrm{x}$ & $\mathrm{x}$ & $\mathrm{x}$ & $\mathrm{w}$ & hae, B-oxides & & & ?amphibole xtl & & \\
\hline CR-I6 +J6 & common & $\mathrm{b}, \mathrm{v}$ & $\mathrm{w}$ & $\mathrm{w}$ & $\mathrm{x}$ & $\mathrm{x}$ & $\mathrm{x}$ & $\mathrm{x}$ & $w, p$ & hae, B-oxides & & $\mathrm{ox}, \mathrm{sr}$ & $\begin{array}{l}\text { ccl abundant - some degraded, some whole } \\
\text { xtls; rare sub-rounded grains }\end{array}$ & & \\
\hline CR-J11 & rare & $b, v$ & $\mathrm{f}$ & & $\mathrm{x}$ & $\mathrm{x}$ & $\mathrm{x}$ & $\mathrm{x}, \mathrm{chl}$ & $w, p$ & hae, B-oxides & & & ccl abundant; vg rare & & \\
\hline CR-J6 & common & $\mathrm{b}$ & $\mathrm{f}, \mathrm{w}$ & $f, w$ & $\mathrm{x}$ & $\mathrm{x}$ & $\mathrm{x}$ & & $\mathrm{w}$ & oxides & & ox & fdsp common & & \\
\hline MP-K10 & & $\mathrm{b}, \mathrm{v}$ & $\mathrm{f}, \mathrm{w}$ & & $\mathrm{x}$ & $\mathrm{x}$ & $\mathrm{x}$ & $\mathrm{x}$ & $w, p$ & B-oxides & & & $\begin{array}{l}\text { vg \& ccl occasional; yellow fdsp rare; ?clear } \\
\text { garnets; some ccl with lamellae }\end{array}$ & & \\
\hline МР-K8 & common & $b, c, v$ & & $f, w$ & $\mathrm{x}$ & $\mathrm{x}$ & $\mathrm{x}$ & $\mathrm{x}$ & $\mathrm{w}, \mathrm{p}$ & hae, B\&r-oxides & & & $\begin{array}{l}\text { rare dm; thalossiosira; silica flagellate dicty- } \\
\text { ocha; relatively common hbl; rare oxidation }\end{array}$ & & \\
\hline MP-M9 & common & $\mathrm{b}$ & $\mathrm{f}$ & & $\mathrm{x}$ & & & $\mathrm{x}$ & $\mathrm{x}$ & & & & & & \\
\hline MP-N12 & common & $b, v$ & & & $\mathrm{x}$ & & & & $\mathrm{w}, \mathrm{p}$ & hae, B-oxides & & & $\begin{array}{l}\text { ccl abundant - snowflake habit; no obvious } \\
\text { silicates }\end{array}$ & & \\
\hline MP-O10 & common & b & $\mathrm{f}$ & & & $\mathrm{x}$ & & $\mathrm{x}$ & & & & & $\begin{array}{l}\text { small amoutn of sample lost when petri base } \\
\text { dropped from shallow height ; }\end{array}$ & & \\
\hline MP-O13 & & & & & & & & & $\mathrm{p}$ & & & & $\begin{array}{l}\text { large, severely degraded rhombhedral xtls, } \\
\text { some with spheroidal holes, rounded corners }\end{array}$ & & \\
\hline MP-Q11 & common & $b, v$ & & $\mathrm{w}$ ? & $\mathrm{x}$ & $\mathrm{x}$ & $\mathrm{x}$ & $\mathrm{x}$ & $\mathrm{w}, \mathrm{p}$ & hae, ?spinel & & ox & ?spinel - isotropic, green?? & & \\
\hline MP-Q14 & common & $\mathrm{b}$ & $\mathrm{f}$ & $f, w$ & $\mathrm{x}$ & $\mathrm{x}$ & $\mathrm{x}$ & $\mathrm{x}$ & & hae, B-oxides & & ox & & & \\
\hline MP-R13 & & $b, v$ & & & $\mathrm{x}$ & $\mathrm{x}$ & & & & B-oxides & & & very sparse sample on slide & & \\
\hline MP-R8 & rare & $b, v$ & $\mathrm{f}, \mathrm{w}$ & $f, w$ & $\mathrm{x}$ & $\mathrm{x}$ & & & & B-oxides & & $\mathrm{ox}, \mathrm{sr}$ & some fdsp well-rounded & & \\
\hline MP-T15 & common & $\mathrm{b}$ & $\mathrm{f}$ & $\mathrm{w}$ & $\mathrm{x}$ & $\mathrm{x}$ & $\mathrm{x}$ & $\mathrm{x}$ & & olv? & $\mathrm{x} ?$ & & $\begin{array}{l}\text { nitzschia or fragiolariopsis; single large ?or- } \\
\text { ganic flake }\end{array}$ & & \\
\hline
\end{tabular}




\begin{tabular}{|c|c|c|c|c|c|c|c|c|c|c|c|c|c|}
\hline MP-T7 & common & b, g & $f, w$ & & & $\mathrm{x}$ & $\mathrm{x}$ & $\mathrm{x}$ & & $\begin{array}{l}\text { B-oxides, grt?, } \\
\text { ?spinel }\end{array}$ & & & $\begin{array}{l}\text { ?plastid, ?algae, large mineral grains (fdsp), } \\
\text { ?clear garnet }\end{array}$ \\
\hline MP-U13 & common & $b, v$ & $f, w$ & $\mathrm{w}$ & & $\mathrm{x}$ & $\mathrm{x}$ & $\mathrm{x}$ & & oxides & & & $\begin{array}{l}\text { thalossiosira; actinocyclus; nitzschia; fragio- } \\
\text { lariopsis; navicula; common v.g }\end{array}$ \\
\hline MP-V18 & common & b, $g$ & $f, w$ & $\mathrm{f}$ & $\mathrm{x}$ & $\mathrm{x}$ & $\mathrm{x}$ & & & B-oxides & & ox, sr & $\begin{array}{l}\text { sp } 4 \mathrm{~mm} \text { long; sea star appendage?; black ox- } \\
\text { ides large and common }\end{array}$ \\
\hline & & 34 & 29 & 18 & 31 & 33 & 27 & 26 & 18 & 31 & 3 & 15 & ox \\
\hline Other & vg abund. & $\mathrm{vg}$ & ssp & $\mathrm{dm}$ & qtz & fsp & hbl & mca & ccl & opq & org & alt \& rdg & Provenance notes \\
\hline $\begin{array}{r}\text { MP-08 } \\
\text { MP-013 }\end{array}$ & & & & & & & & & $\mathrm{x}$ & & $\mathrm{x}$ & & $\begin{array}{l}\text { ?bryophyte frag } \\
\text { large, severely degraded rhombhedral xtls, } \\
\text { some with spheroidal holes, rounded corners }\end{array}$ \\
\hline
\end{tabular}




\begin{tabular}{|c|c|c|c|c|}
\hline \multicolumn{5}{|c|}{ Genera, species, and authorities of SILICEOUS MICRO-ORGANISMS found in McMurdo Sound aeolian sediment samples } \\
\hline \multicolumn{5}{|c|}{ Siliceous micro-organisms (Phylum Ochrophyta } \\
\hline \multicolumn{5}{|l|}{ Diatoms (Class Bacillariophyceae) } \\
\hline Genera and species & Authorities & $\begin{array}{l}\text { †Max. dim. } \\
\mu \mathrm{m}\end{array}$ & $\begin{array}{c}\text { Count } \\
\text { (all slides) }\end{array}$ & $\begin{array}{l}\text { Figure } 4.7 \\
\text { image ref. }\end{array}$ \\
\hline "Actinocyclus & C.G. Ehrenberg & 53 & 1 & j j \\
\hline Actinocyclus actinochilus & (Ehrenberg) Simonsen & 70 & 1 & $\mathrm{k}$ \\
\hline *Aulacoseira & G.H.K. Thwaites & 6 & 1 & \\
\hline Chamaepinnularia cymatopleura & (W. West and G.S. West) Cavacini & 34 & 7 & $\mathrm{~d}$ \\
\hline *Coscinodiscus & C.G. Ehrenberg & 100 & 1 & a \\
\hline Eucampia antarctica & (Grunow) Jorgensen & 36 & 1 & $\mathrm{~g}$ \\
\hline Fragilariopsis curta & (Van Heurck) Hustedt & 23 & $>10$ & \\
\hline Fragilariopsis obliquecostata & (Van Heurck) Heiden & 70 & $>5$ & e \\
\hline Hantzschia amphioxys & fo. muelleri Ko-Bayashi & 50 & 2 & c \\
\hline Luticola cohnii & (Hilse) D.G. Mann & 14 & 1 & $\mathrm{~b}$ \\
\hline Luticola gaussi & (Heiden) D.G.Mann & 15 & 3 & \\
\hline Luticola mutica & (Kuetzing) D.G. Mann & 27 & 2 & 1 \\
\hline Or Luticola muticopsis & (Van Heurck) D.G. Mann & & & \\
\hline Muelleria peraustralis & (W. West and G.S. West) Spaulding and Stoermer & 55 & 1 & $\mathrm{~h}$ \\
\hline Nitzschia westii & Kellogg, Stuiver, et al. & 70 & 3 & $\mathrm{f}$ \\
\hline *Pleurosigma & W.Smith (uncertain identification) & 250 & 1 & \\
\hline Porosira glacialis & (Grunow) E. Jorgensen & 237 & 1 & \\
\hline *Rhizosolenia & T. Brightwell & 15 & 2 & \\
\hline Thalassionema nitzschioides & (Grunow) Mereschkowsky & 70 & 5 & \\
\hline Thalassiosira gracilis & (Karsten) Hustedt & 12 & 3 & \\
\hline Thalassiosira tumida & (Janisch) Hasle & 64 & 3 & $\mathrm{i}$ \\
\hline \multicolumn{5}{|l|}{ Silicoflagellate (Dictyochophyceae) } \\
\hline Dictyocha speculum & Ehrenberg & 54 & $>5$ & $\mathrm{~m}$ \\
\hline
\end{tabular}

*Identification only to genus level

$\dagger$ maximum dimension 


\section{Appendix E Additional NaMASTE wind field plots}




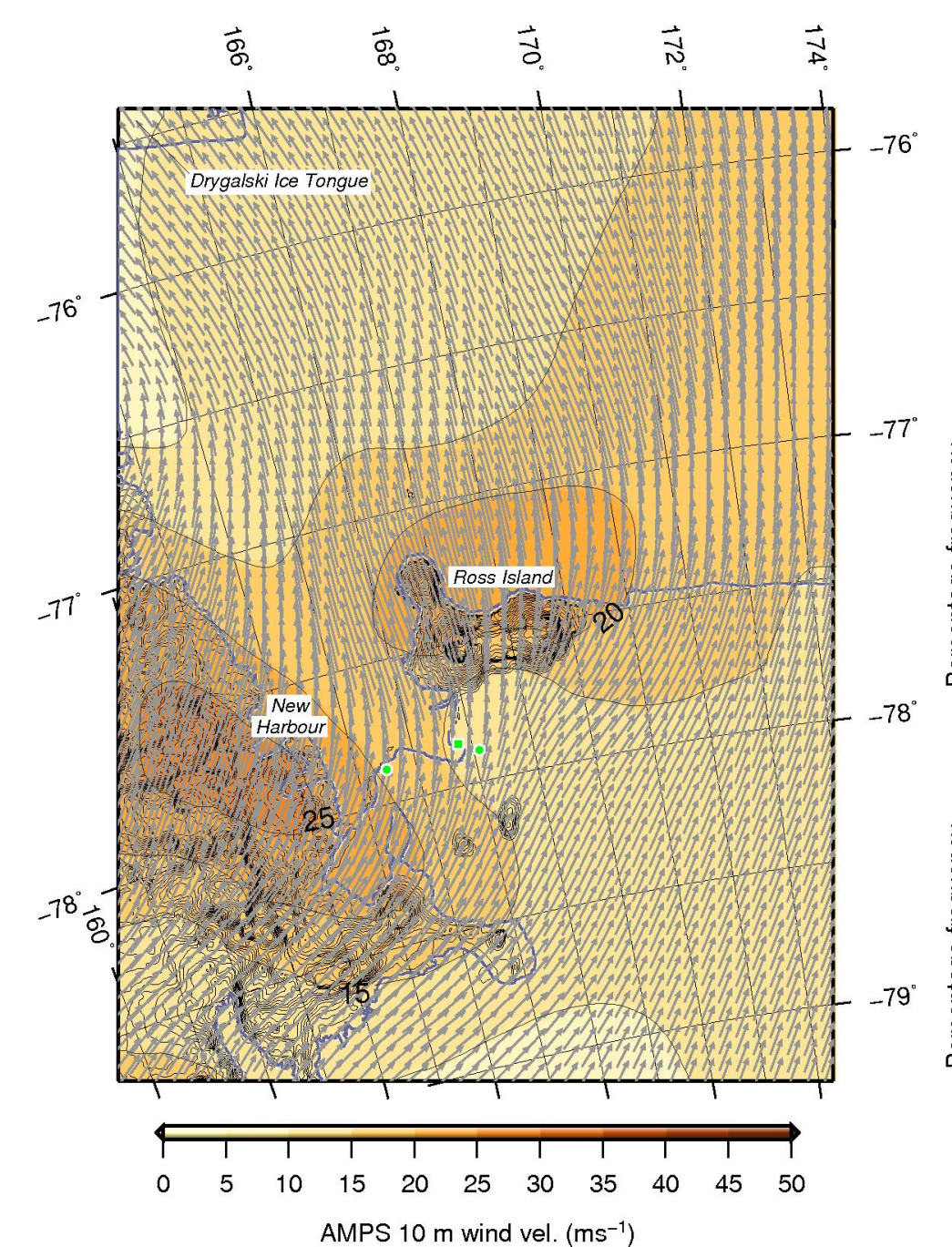

Mean dir: 4.7663613805

Std dir: \pm 23.5059490962

Max dir: 52.6727218628

Min dir: -37.8624572754

Mean vel: 15.4706987144

Std vel: \pm 3.94288180542

Min vel: 7.5635766983

5207

25-10-2005 at 06:00 hrs
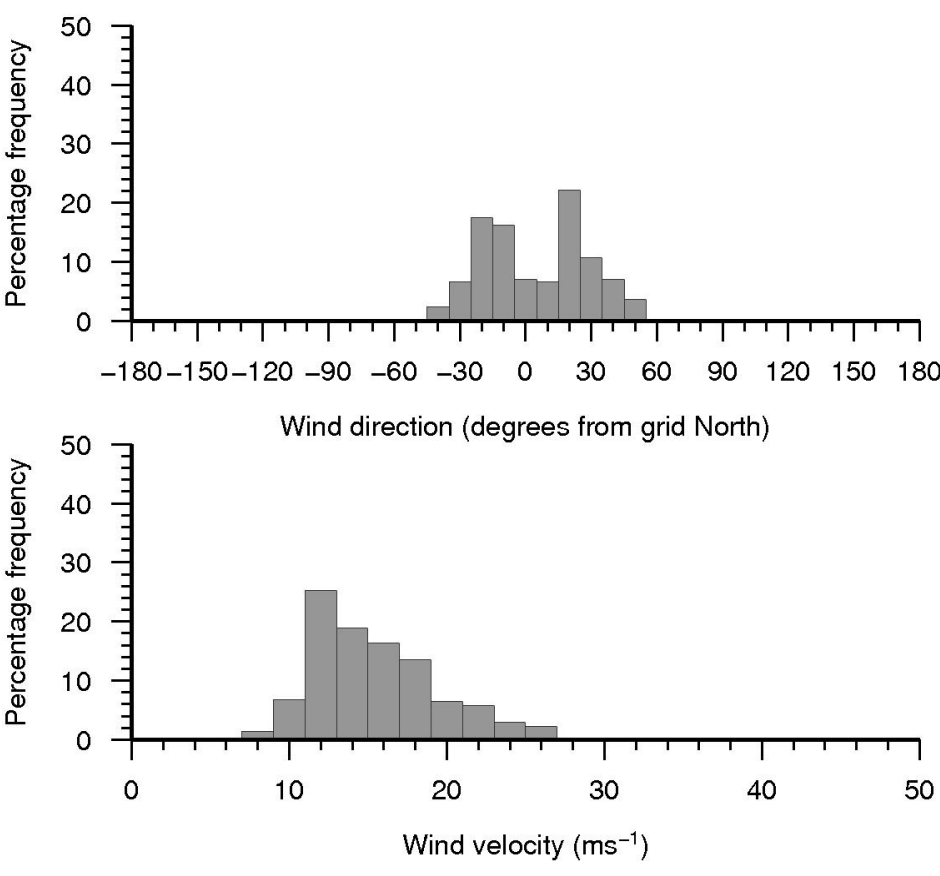

Figure E.1: NaMASTE wind field 5207, including wind direction and velocity statistics. Date and hours reference the AMPS 2005 archive 6 hourly forecast increment. 


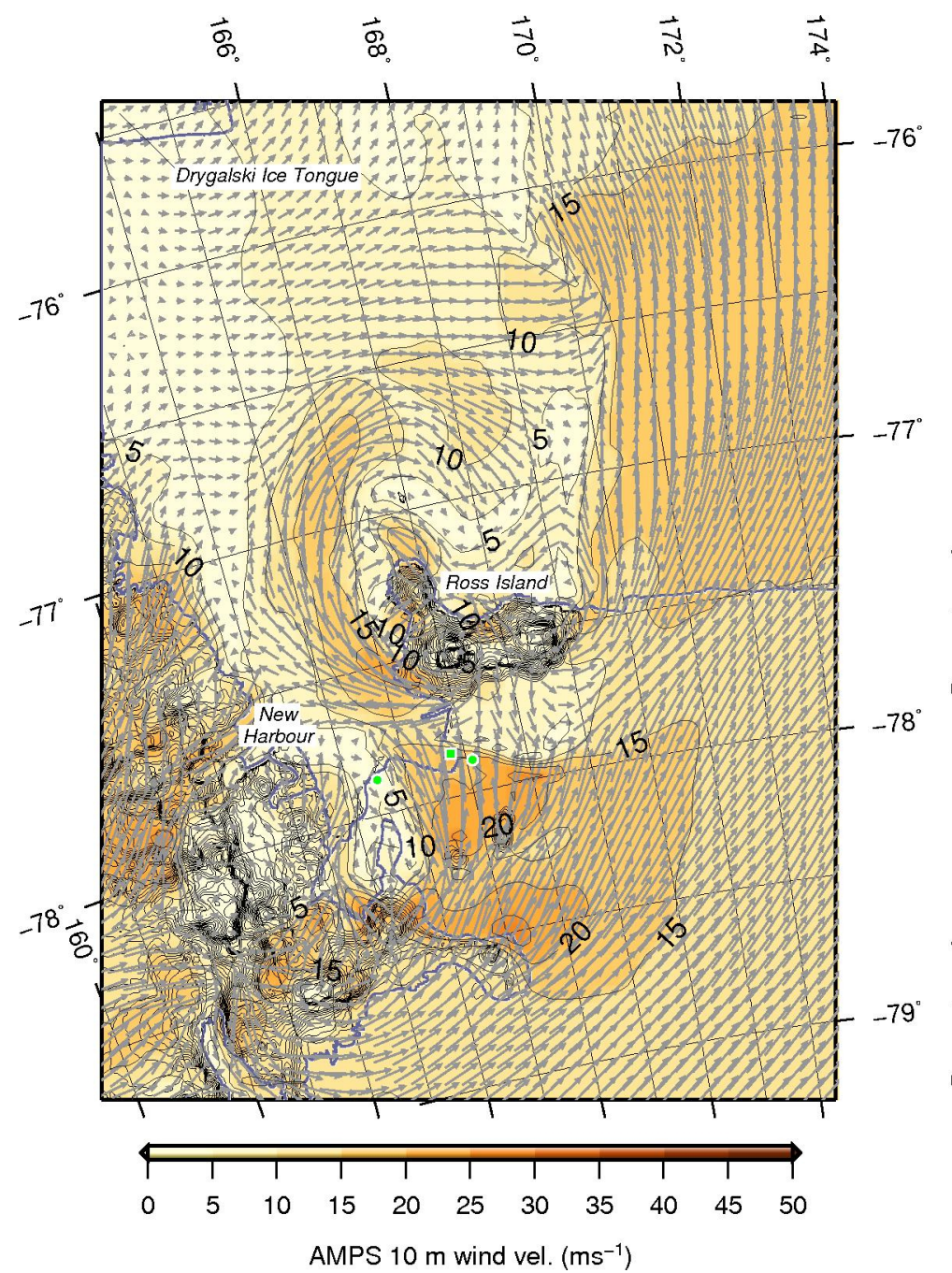

Mean dir: 29.1805866675

Std dir: \pm 57.1034890654

Max dir: 179.774246216

Mean vel: 11.7050045035

Std vel: \pm 5.38923123946

Max vel: 28.7778530121

5208

25-10-2005 at 12:00 hrs
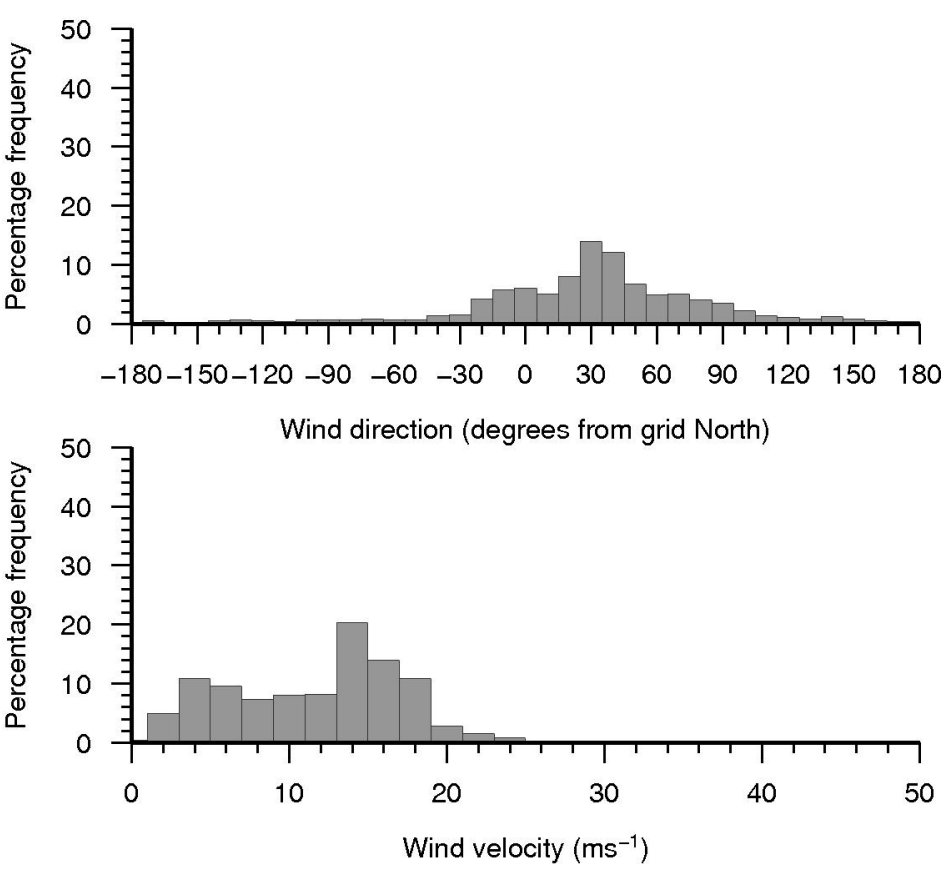

Figure E.2: NaMASTE wind field 5208, including wind direction and velocity statistics. Date and hours reference the AMPS 2005 archive 6 hourly forecast increment. 


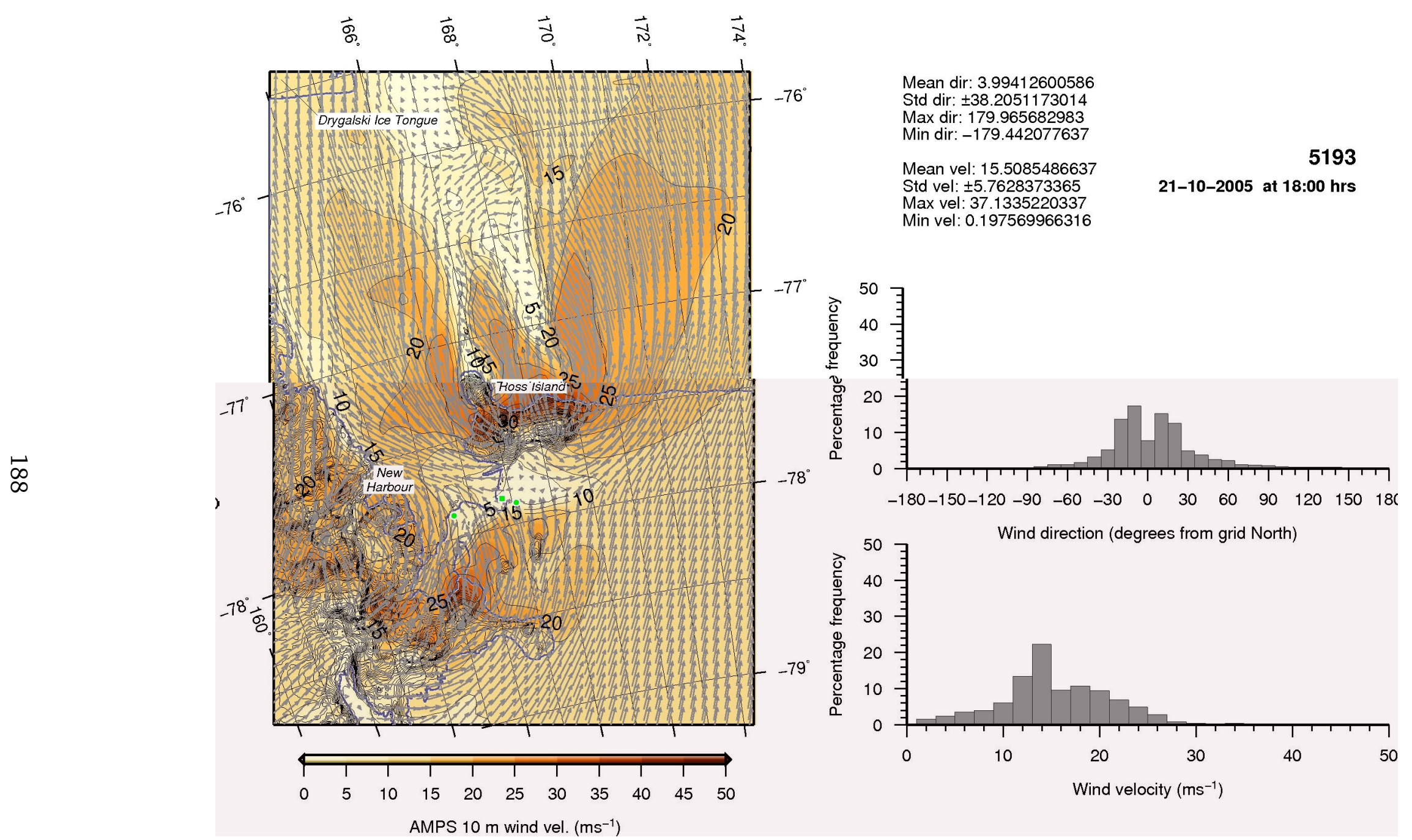

Figure E.3: NaMASTE wind field 5193, including wind direction and velocity statistics. Date and hours reference the AMPS 2005 archive 6 hourly forecast increment. 


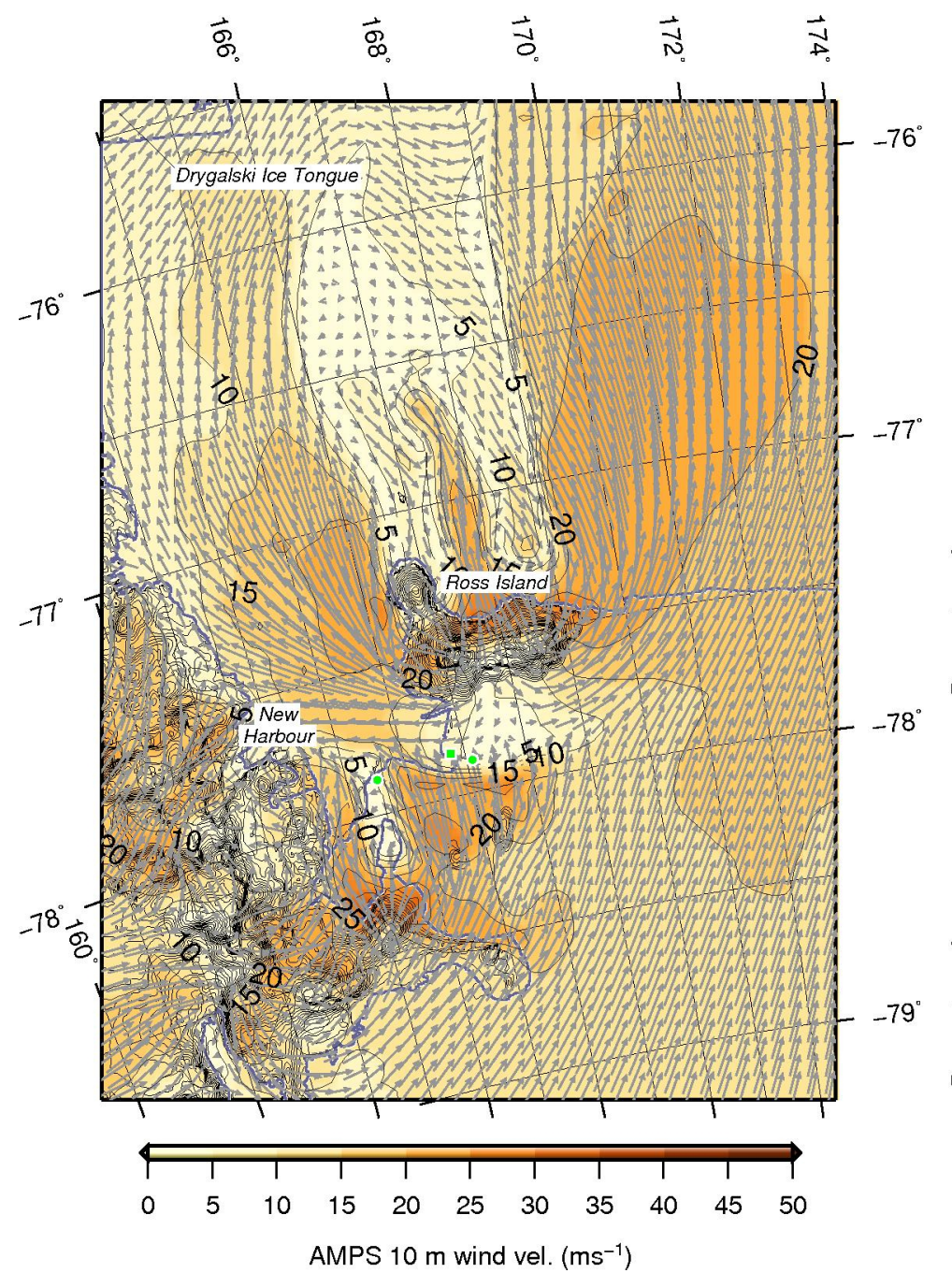

Mean dir: 14.6383515368

Std dir: \pm 52.7209577548

Max dir: 179.83732605

Mean vel: 13.9573571651

Std vel: \pm 5.80446829228

Max vel: 33.4895782471

5194

22-10-2005 at 00:00 hrs
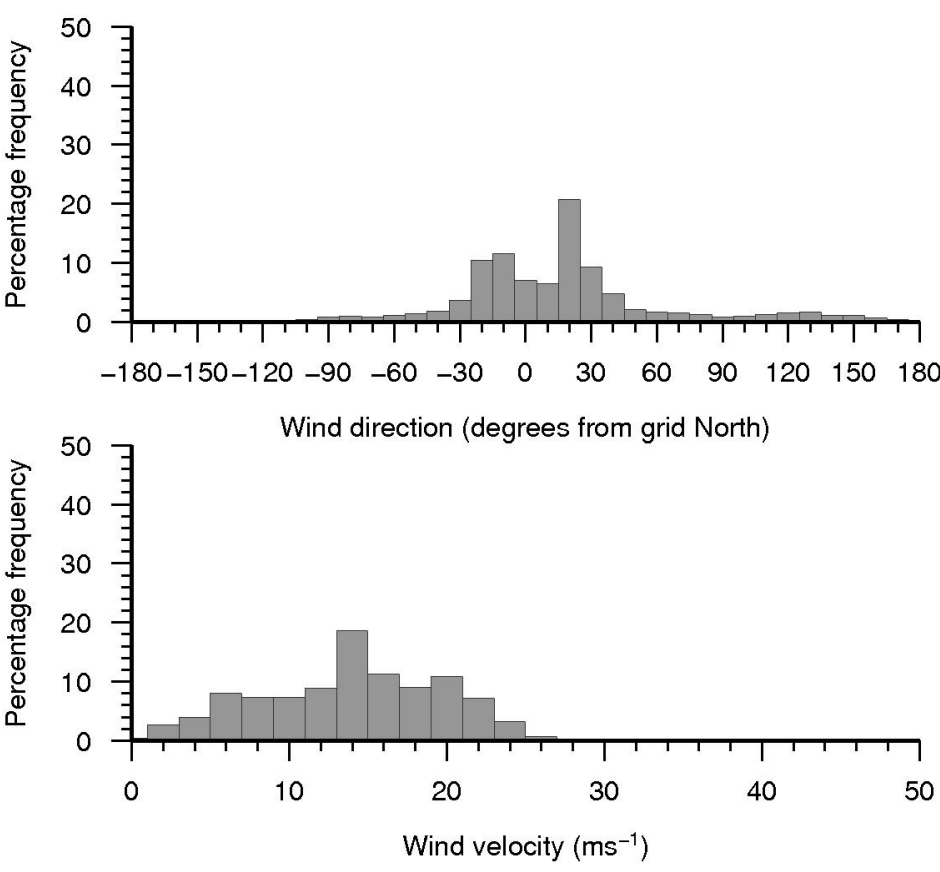

Figure E.4: NaMASTE wind field 5194, including wind direction and velocity statistics. Date and hours reference the AMPS 2005 archive 6 hourly forecast increment. 


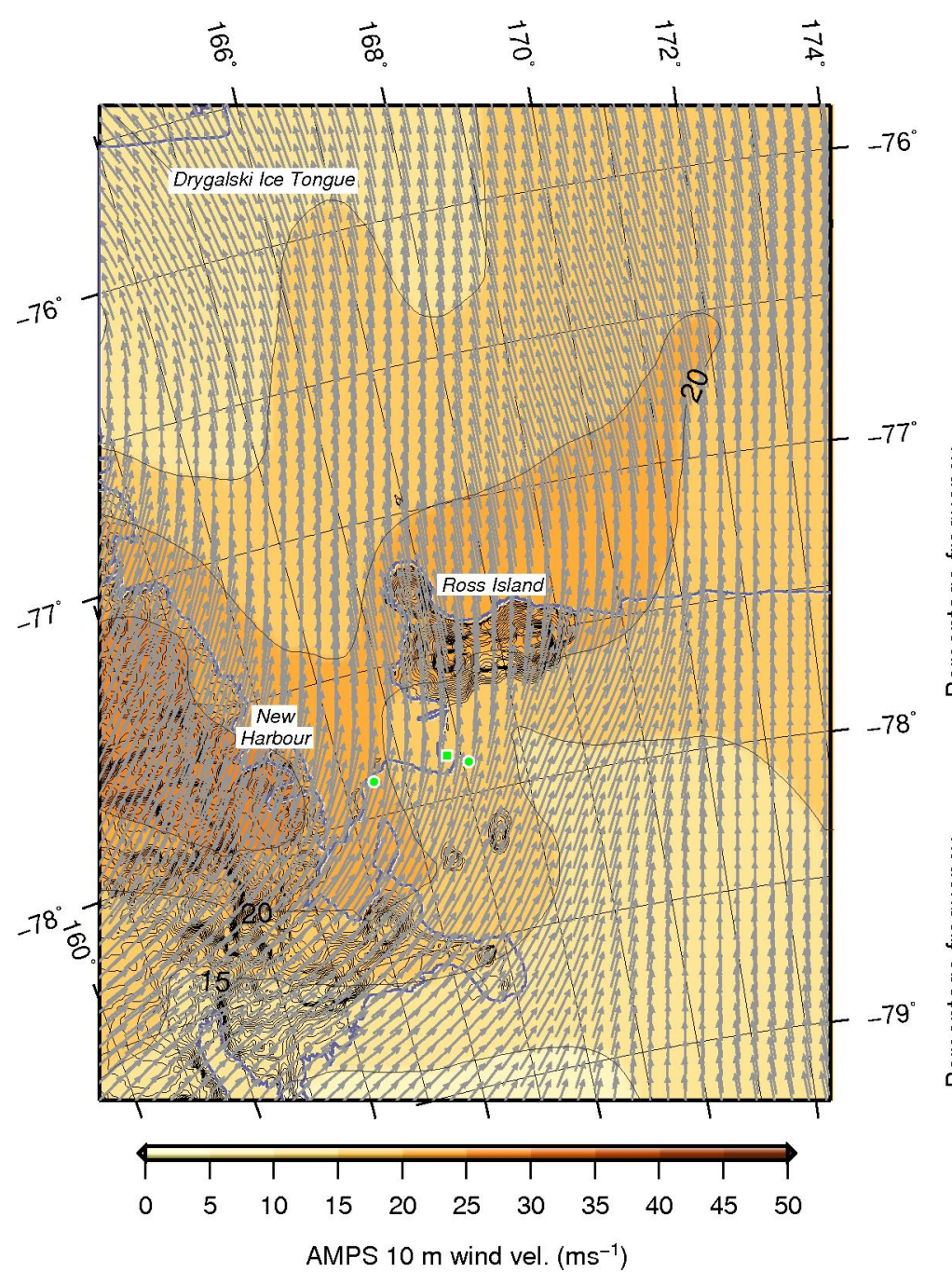

Mean dir: 4.88693558777

Std dir: \pm 20.5275335034

Max dir: 56.9004745483

Min dir: -42.4173088074

Mean vel: 17.0315336453

Std vel: \pm 3.84168687657

Min vel: 8.32192325592

5195

22-10-2005 at 06:00 hrs
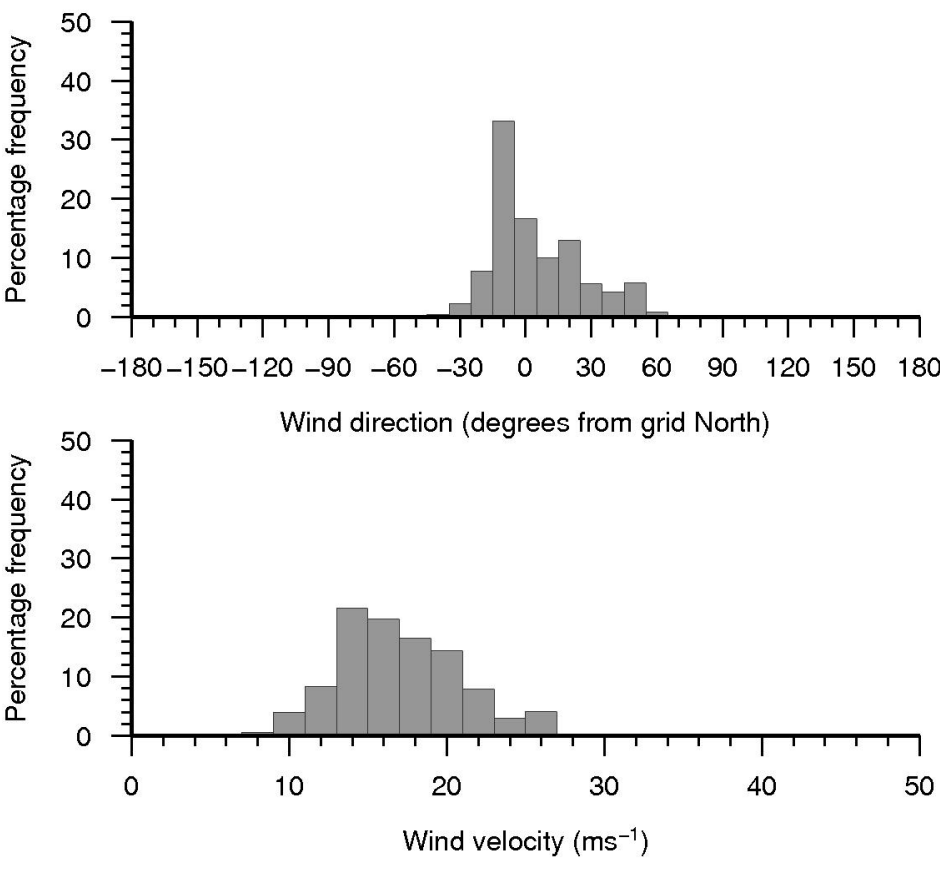

Figure E.5: NaMASTE wind field 5195, including wind direction and velocity statistics. Date and hours reference the AMPS 2005 archive 6 hourly forecast increment. 


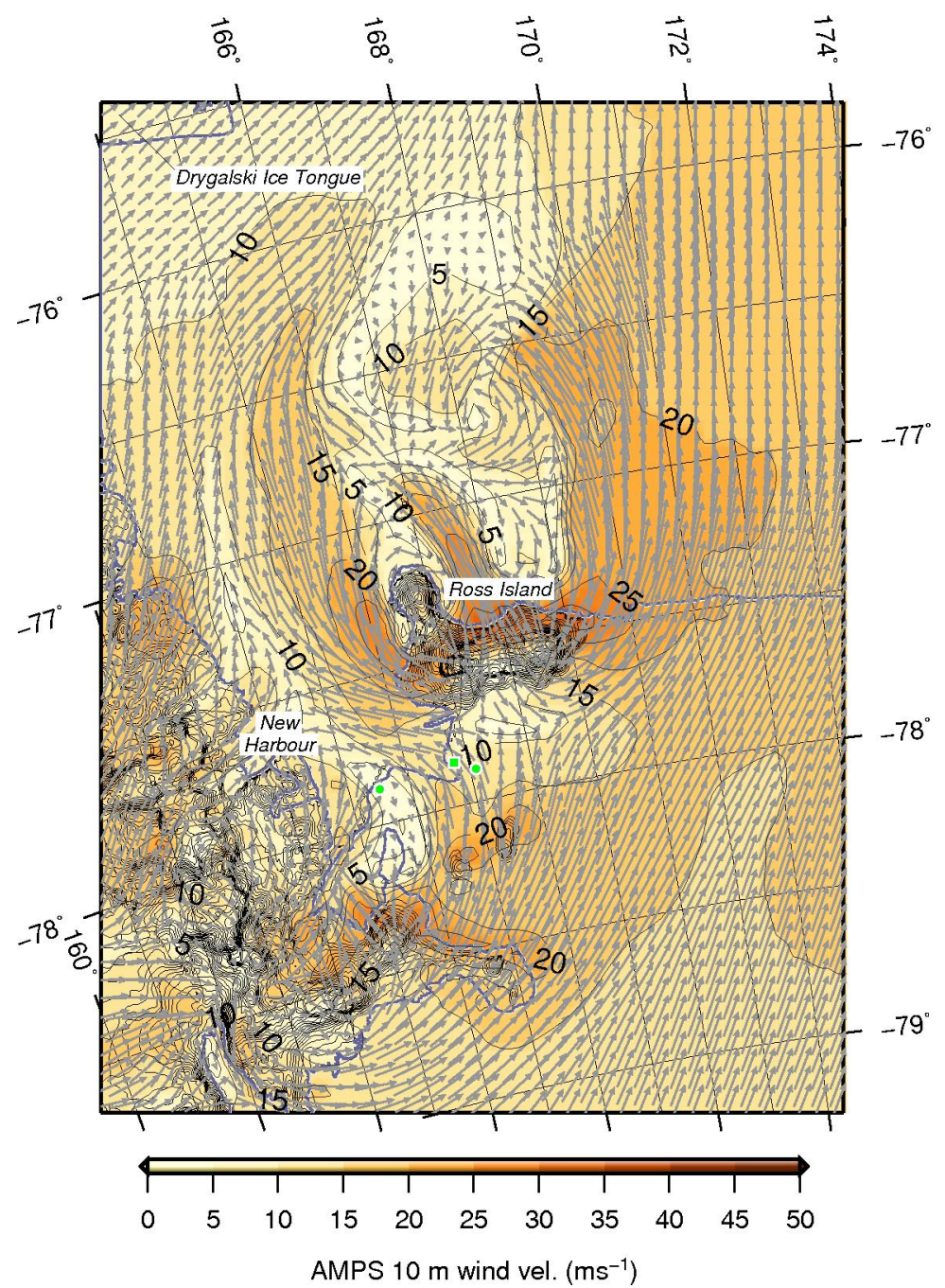

Mean dir: 13.5046093061

Std dir: \pm 49.567645126

Min dir: -179.974838257

Mean vel: 14.0758529645

Std vel: \pm 5.3115350284

Max vel: 34.003463745

5196

Min vel: 0.268997132778

22-10-2005 at 12:00 hrs
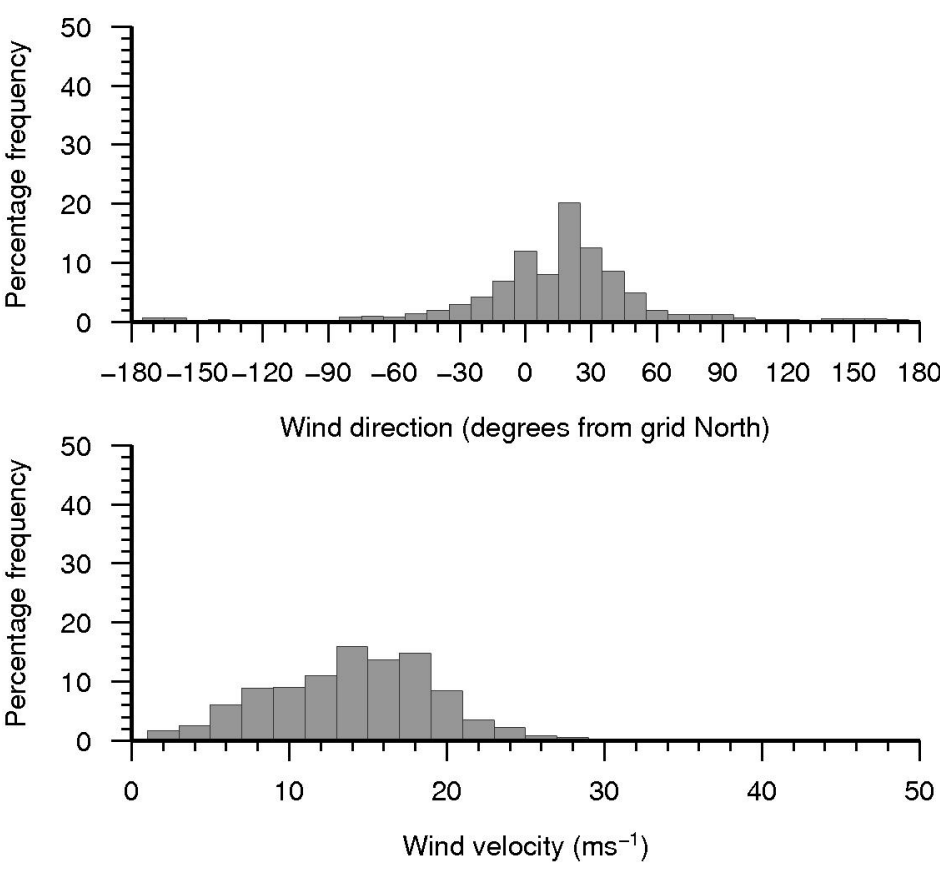

Figure E.6: NaMASTE wind field 5196, including wind direction and velocity statistics. Date and hours reference the AMPS 2005 archive 6 hourly forecast increment. 
Appendix F

NaMASTE test output data 


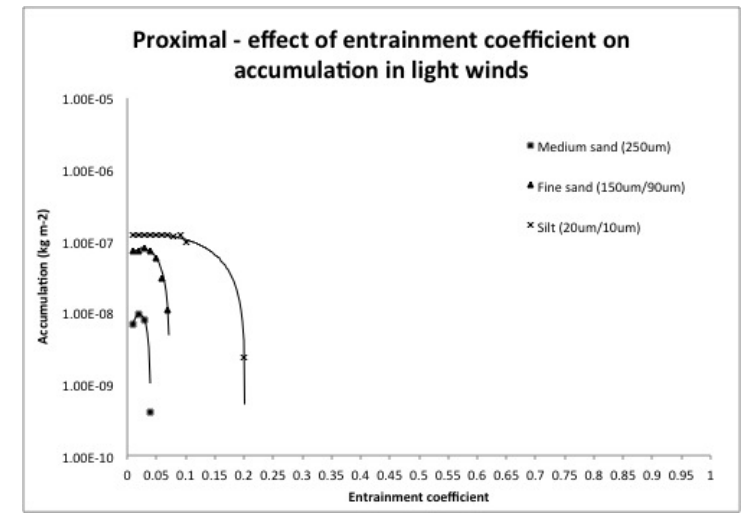

(a)

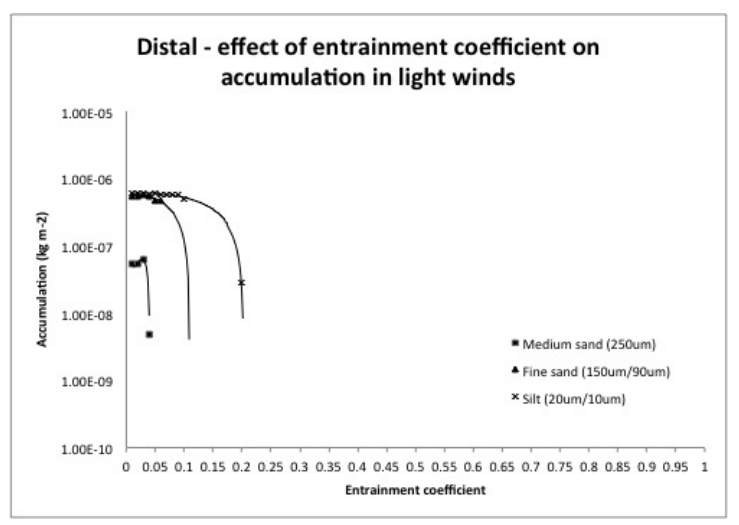

(c)

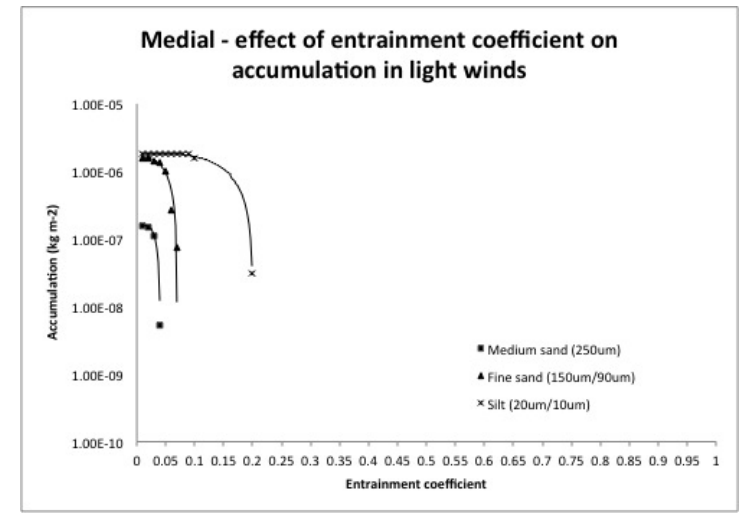

(b)

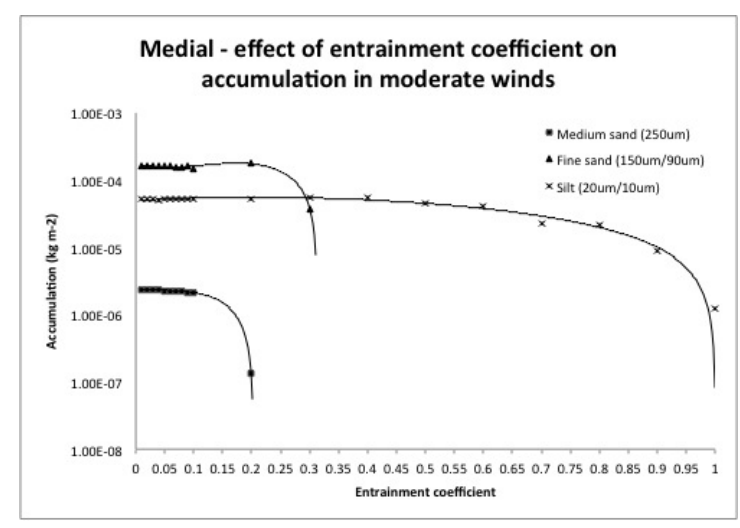

(d)

Figure F.1: Graphical illustration of results of NaMASTE sensitivity tests for entrainment coefficient $(A)$ for three locations (proximal $\sim 30 \mathrm{~km}$, medial $\sim 100 \mathrm{~km}$, distal $\sim 200 \mathrm{~km}$ ) downwind from a source situated on the McMurdo Ice Shelf debris band, under three different wind strengths ('light', 'moderate', i.e. moderately strong, 'strong' i.e. hurricane force, refer Table 6.1). Note: the results for the proximal location with moderate strength winds is dispayed in modelling results (Chapter 6). 


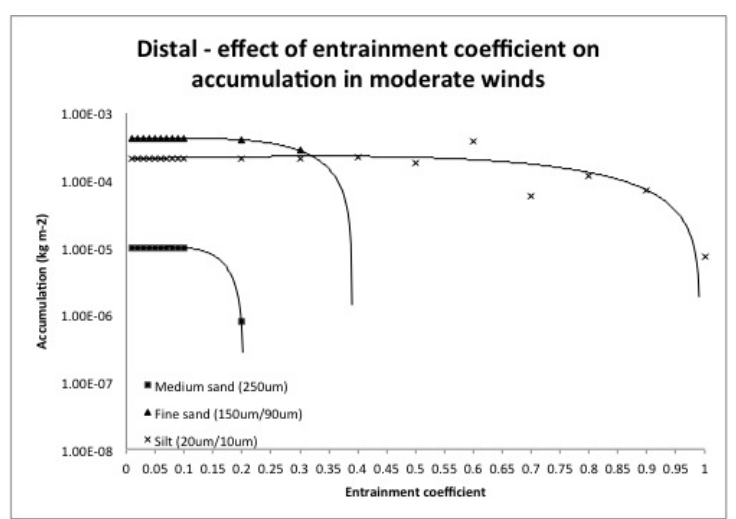

(a)

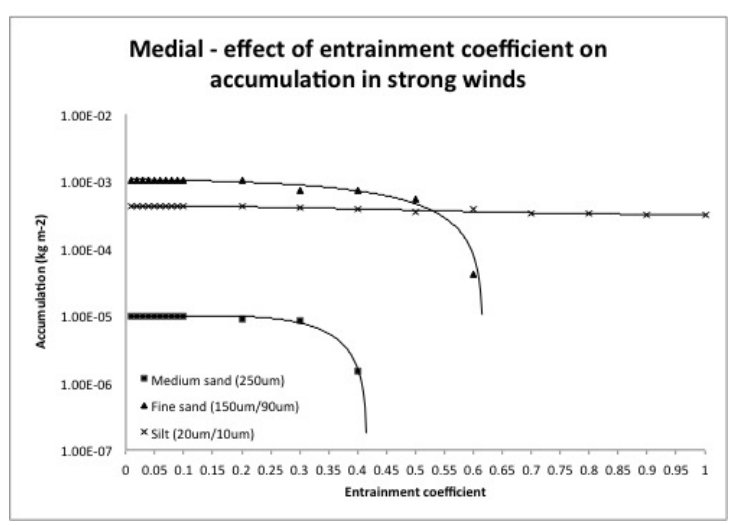

(c)

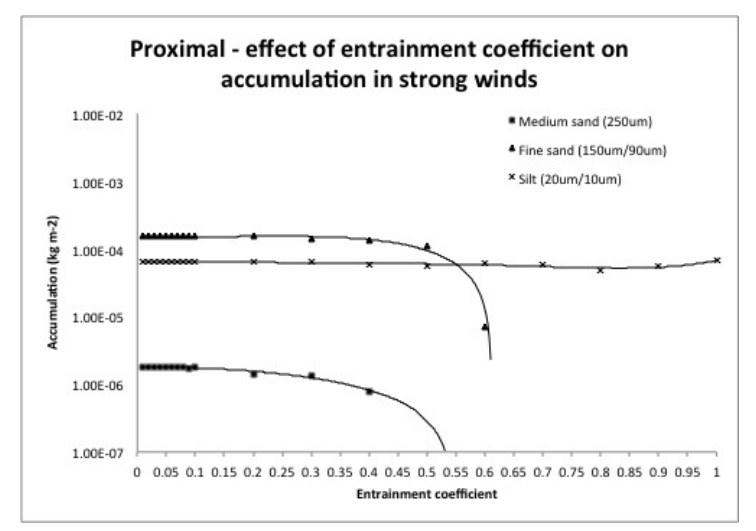

(b)

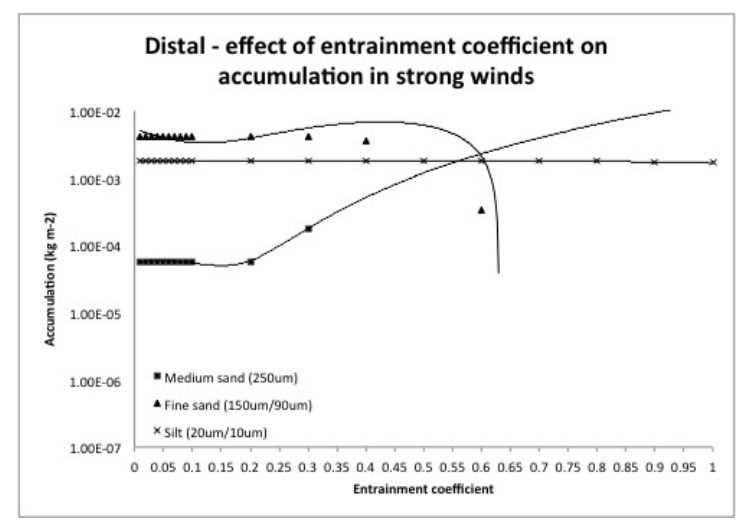

(d)

Figure F.2: Continued from Figure F.1 


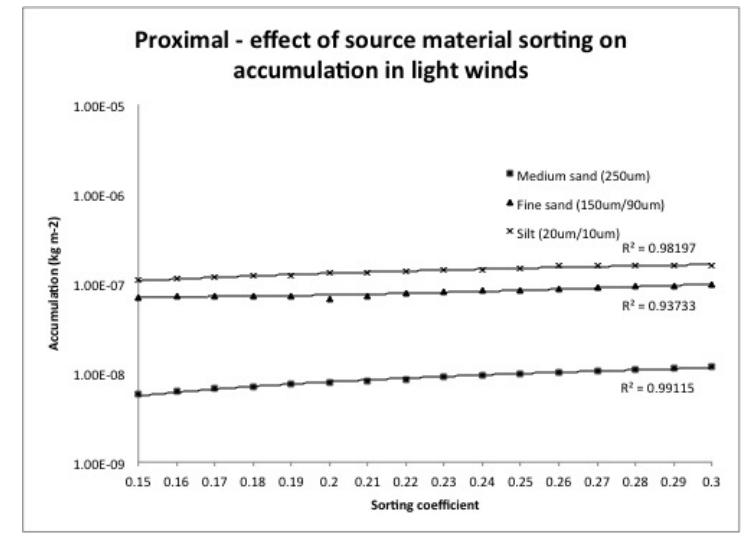

(a)

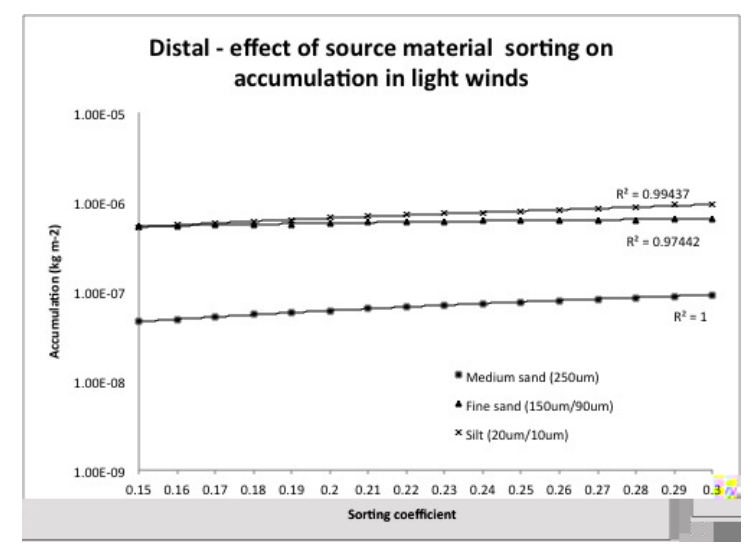

(c)

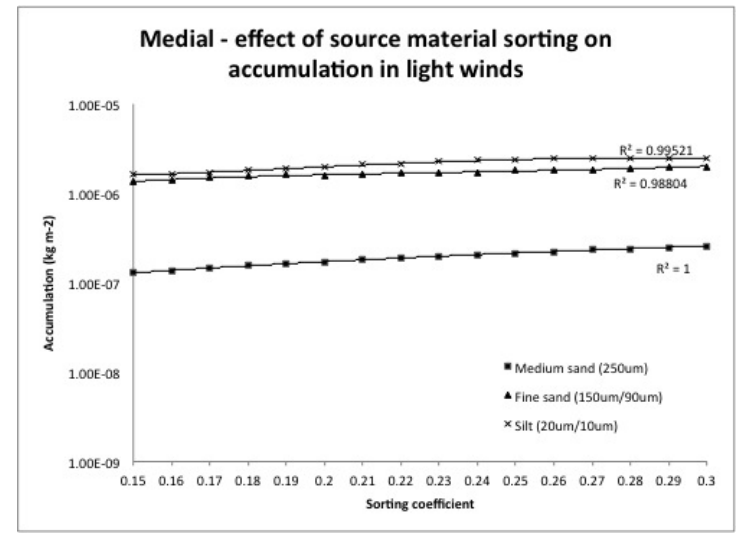

(b)

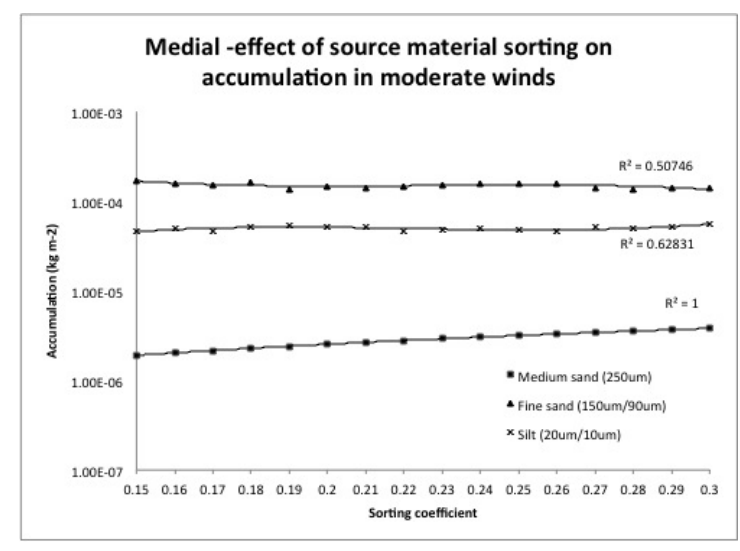

(d)

Figure F.3: Graphical illustration of results of NaMASTE sensitivity tests for sorting coefficient $(\delta)$ for three locations (proximal $\sim 30 \mathrm{~km}$, medial $\sim 100 \mathrm{~km}$, distal $\sim 200$ $\mathrm{km}$ ) downwind from a source situated on the McMurdo Ice Shelf debris band, under three different wind strengths ('light', 'moderate', i.e. moderately strong, 'strong' i.e. hurricane force, refer Table 6.1). Note: the results for the proximal location with moderate strength winds is dispayed in modelling results (Chapter 6). 


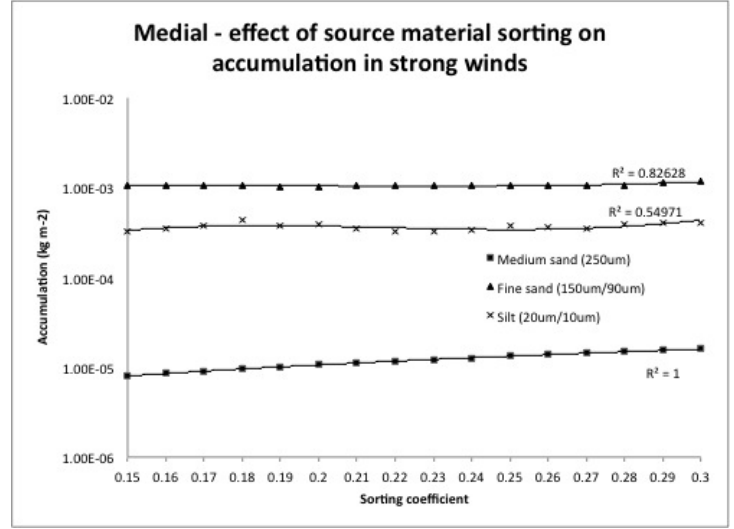

(a)

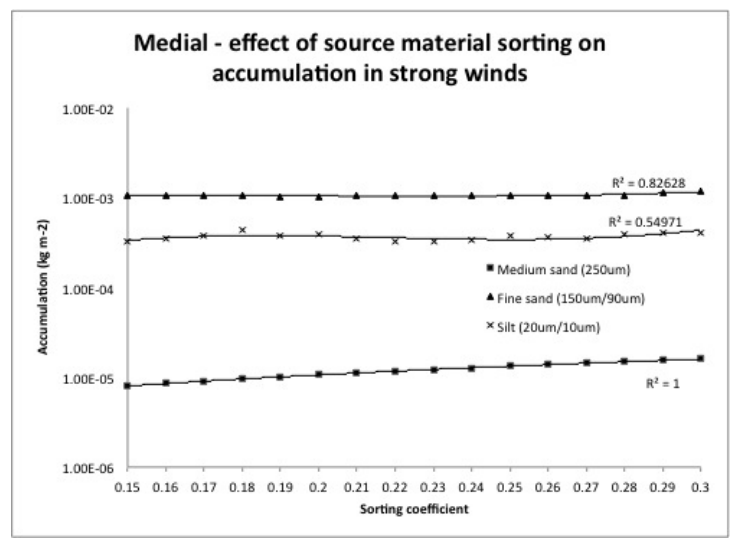

(c)

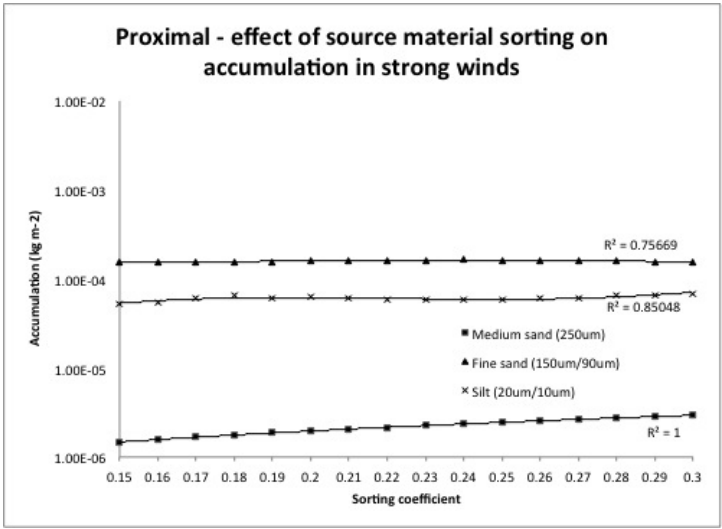

(b)

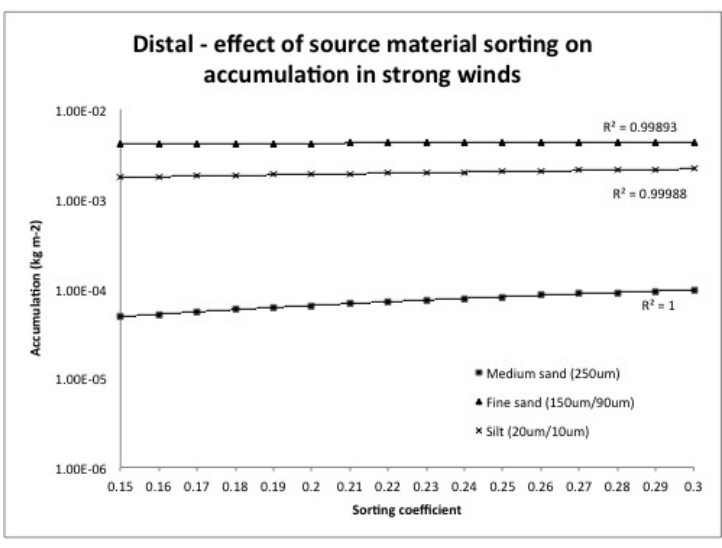

(d)

Figure F.4: Continued from Figure F.3 


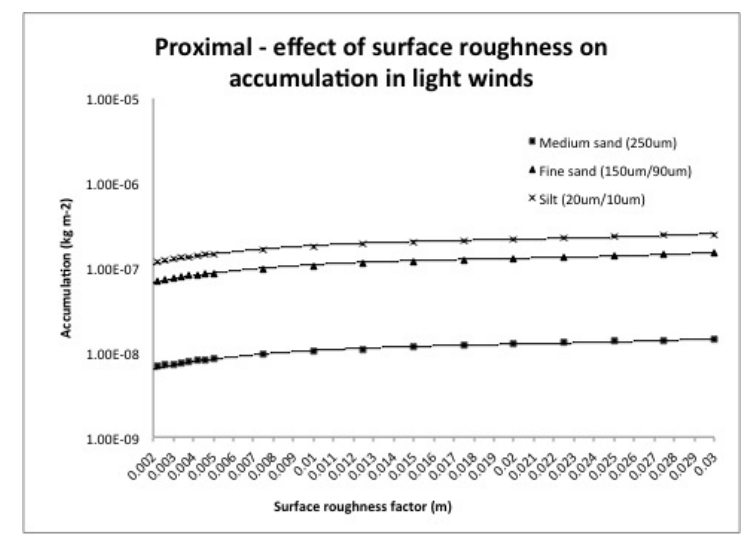

(a)

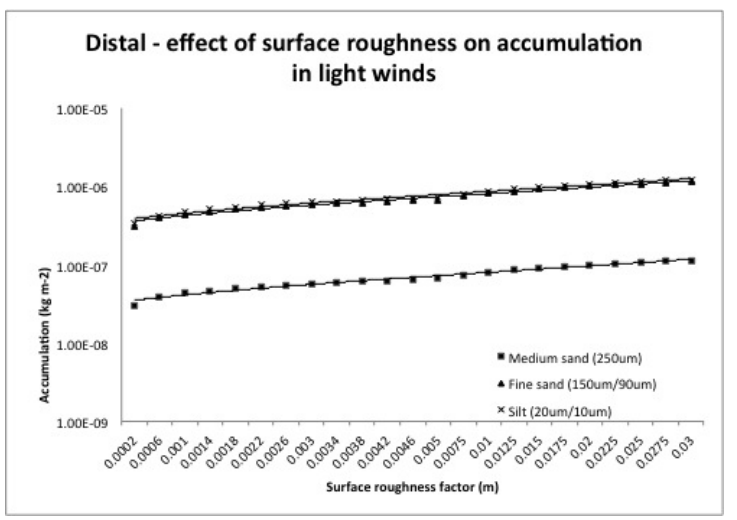

(c)

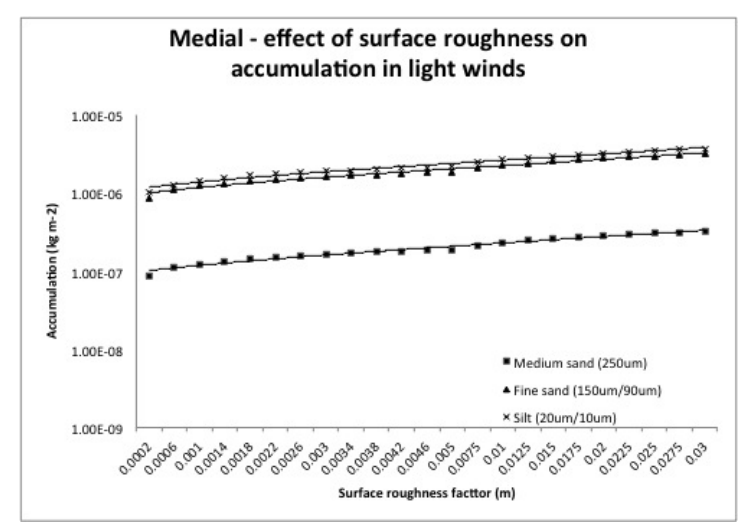

(b)

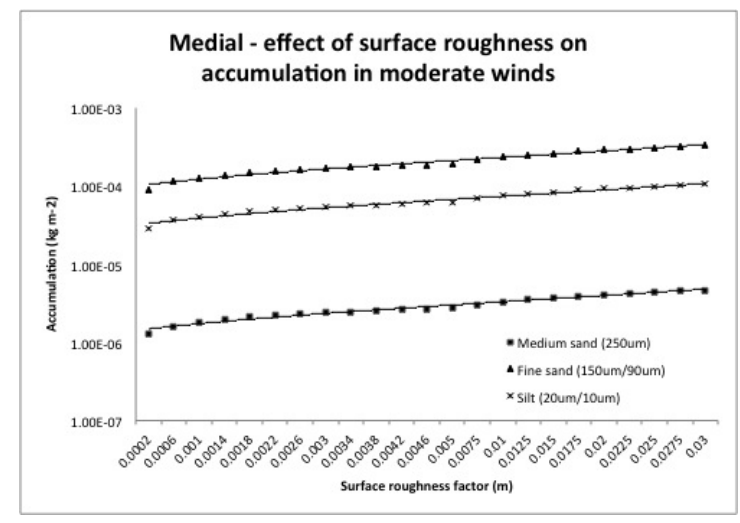

(d)

Figure F.5: Graphical illustration of results of NaMASTE sensitivity tests for surface roughness factor $(\lambda)$ for three locations (proximal $\sim 30 \mathrm{~km}$, medial $\sim 100 \mathrm{~km}$, distal $\sim 200 \mathrm{~km}$ ) downwind from a source situated on the McMurdo Ice Shelf debris band, under three different wind strengths ('light', 'moderate', i.e. moderately strong, 'strong' i.e. hurricane force, refer Table 6.1). Note: the results for the proximal location with moderate strength winds is dispayed in modelling results (Chapter 6). 


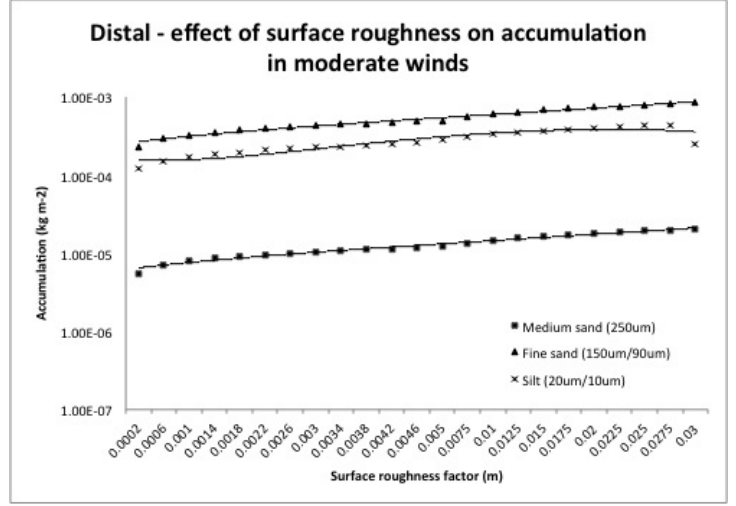

(a)

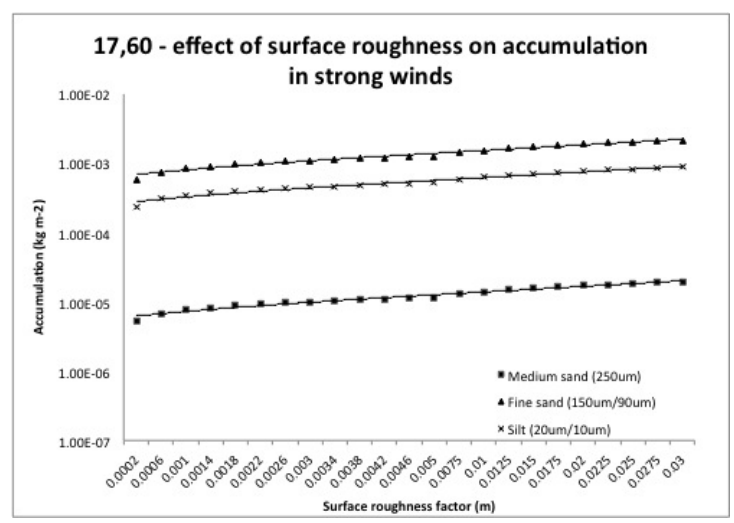

(c)

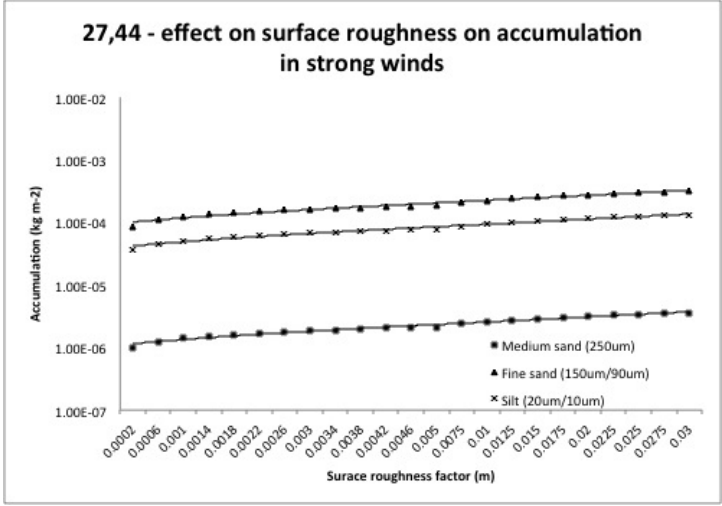

(b)

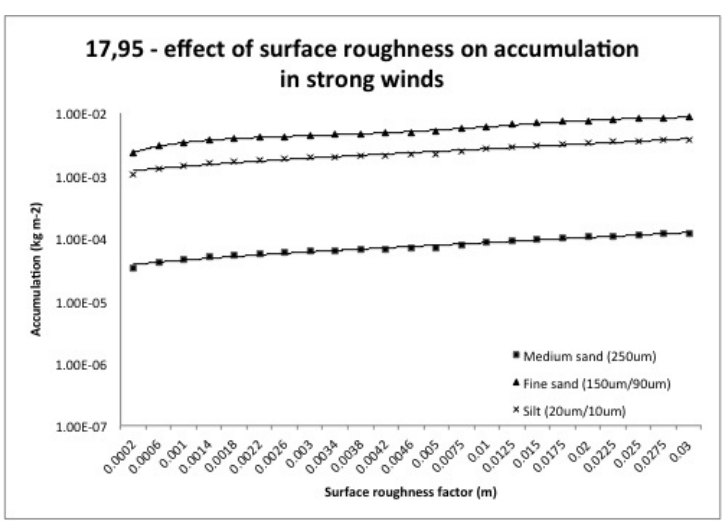

(d)

Figure F.6: Continued from Figure F.5 


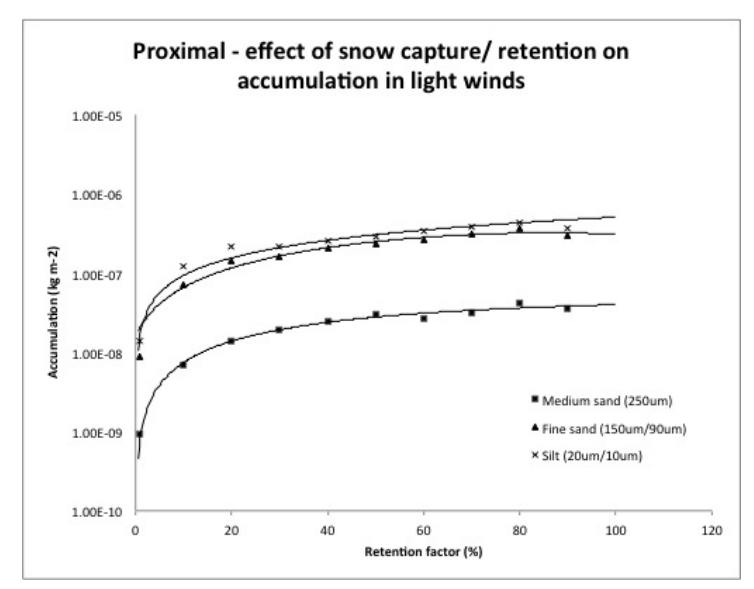

(a)

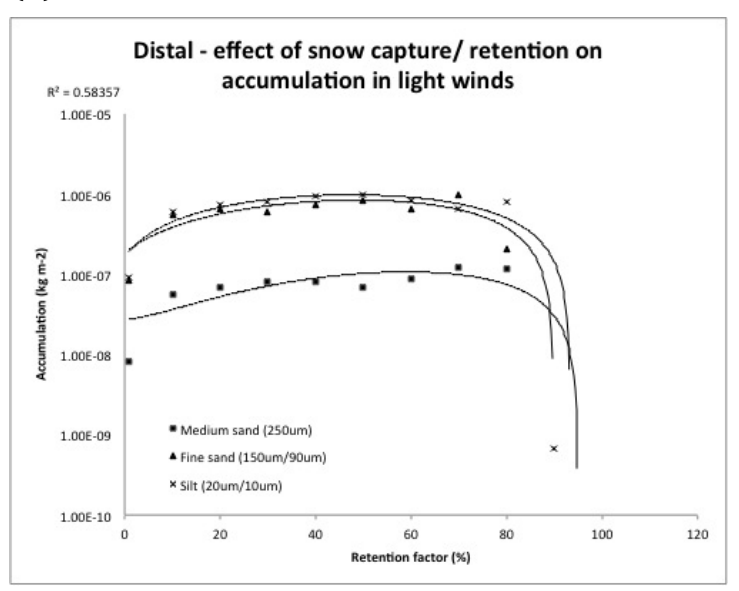

(c)

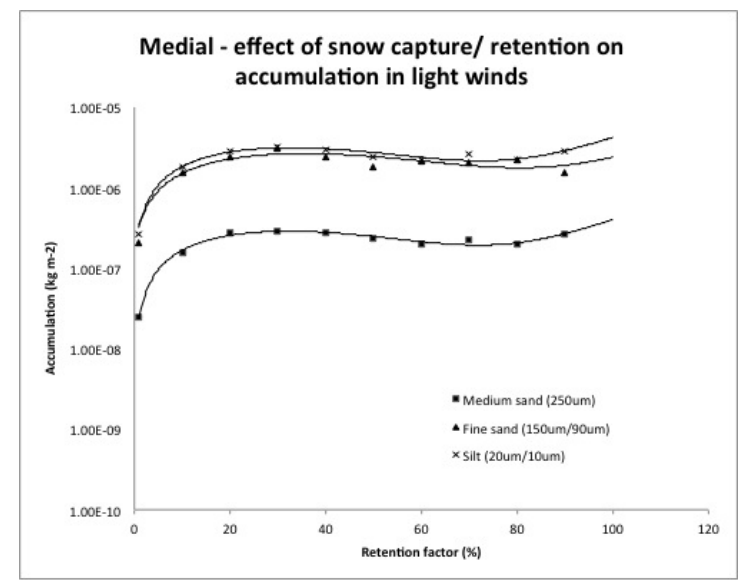

(b)

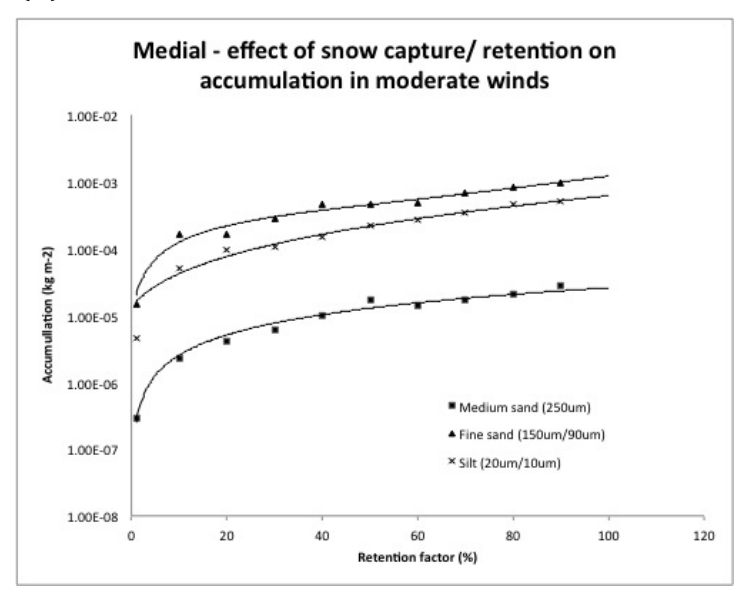

(d)

Figure F.7: Graphical illustration of results of NaMASTE sensitivity tests for retention factor $(R)$ for three locations (proximal $\sim 30 \mathrm{~km}$, medial $\sim 100 \mathrm{~km}$, distal $\sim 200 \mathrm{~km}$ ) downwind from a source situated on the McMurdo Ice Shelf debris band, under three different wind strengths ('light', 'moderate', i.e. moderately strong, 'strong' i.e. hurricane force, refer Table 6.1). Note: the results for the proximal location with moderate strength winds is dispayed in modelling results (Chapter 6). 


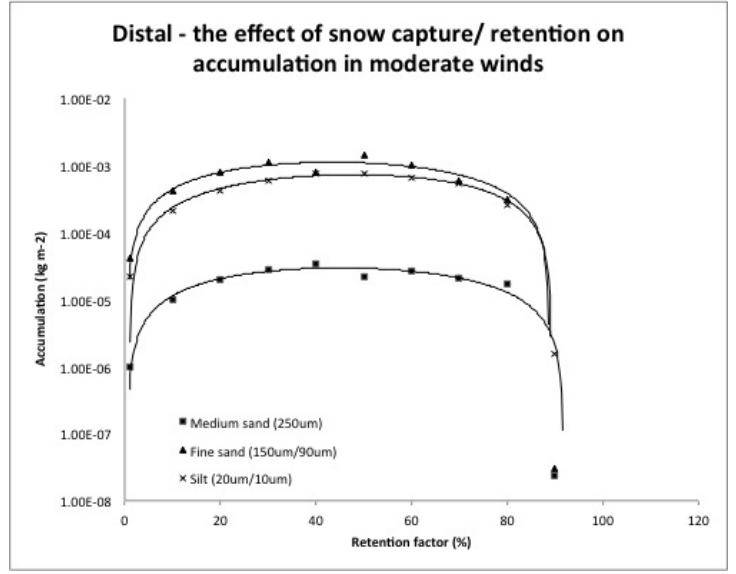

(a)

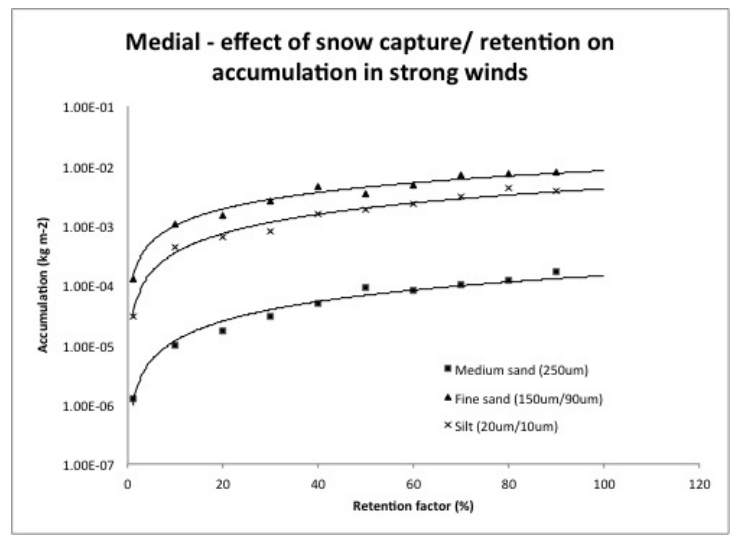

(c)

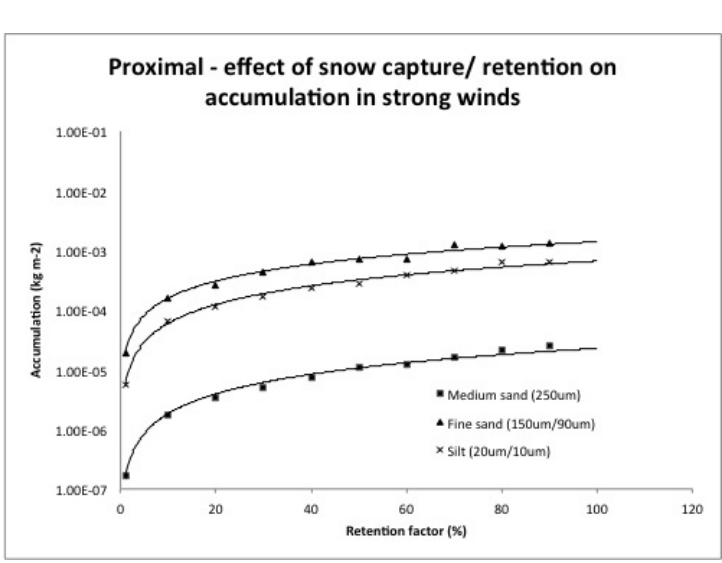

(b)

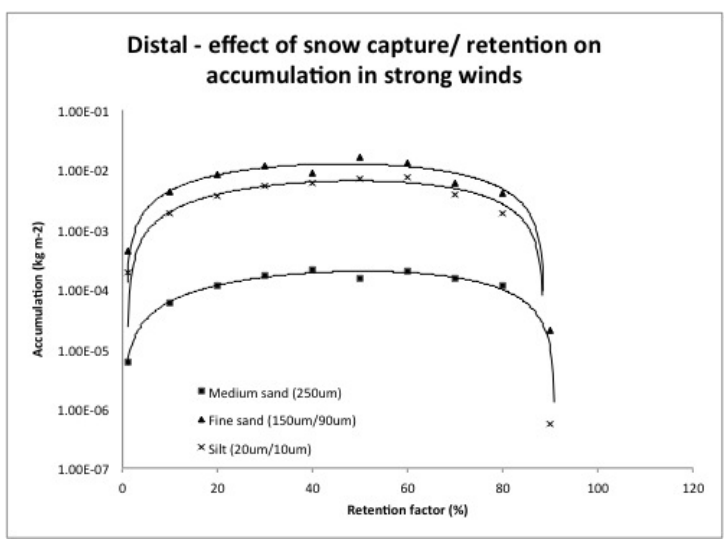

(d)

Figure F.8: Continued from Figure F.7 


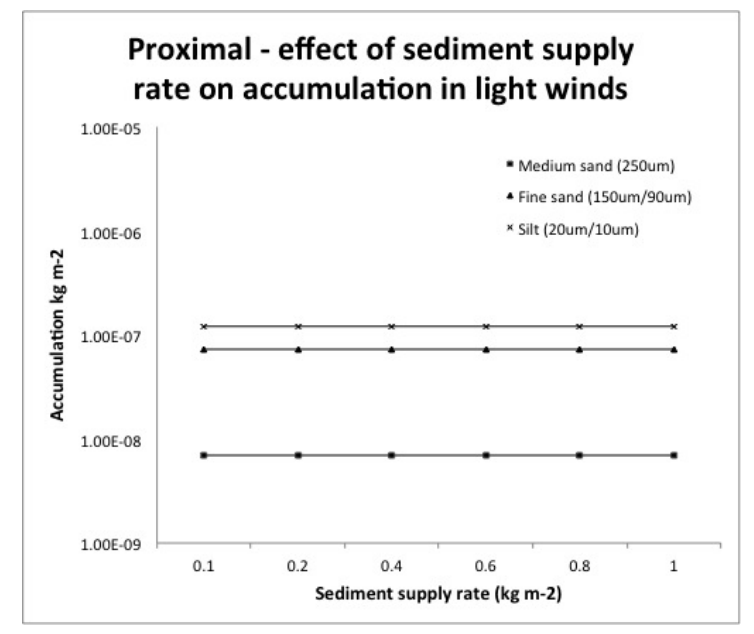

(a)

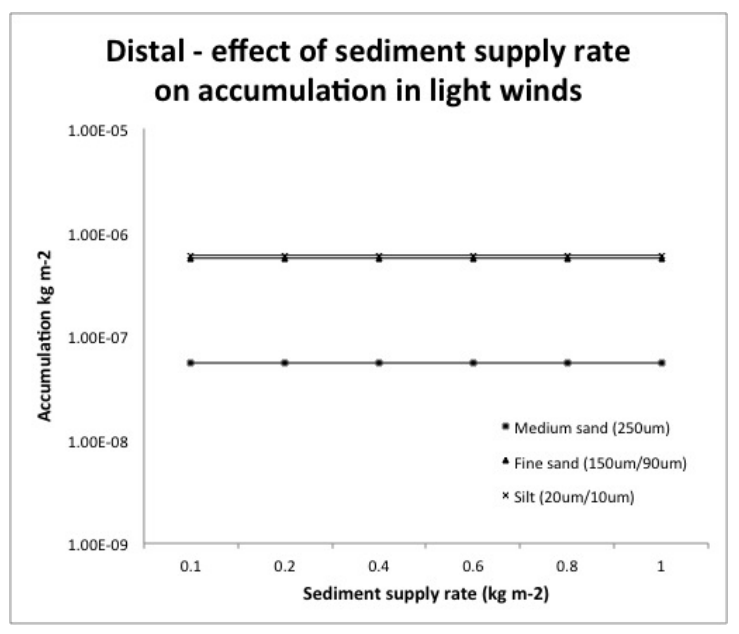

(c)

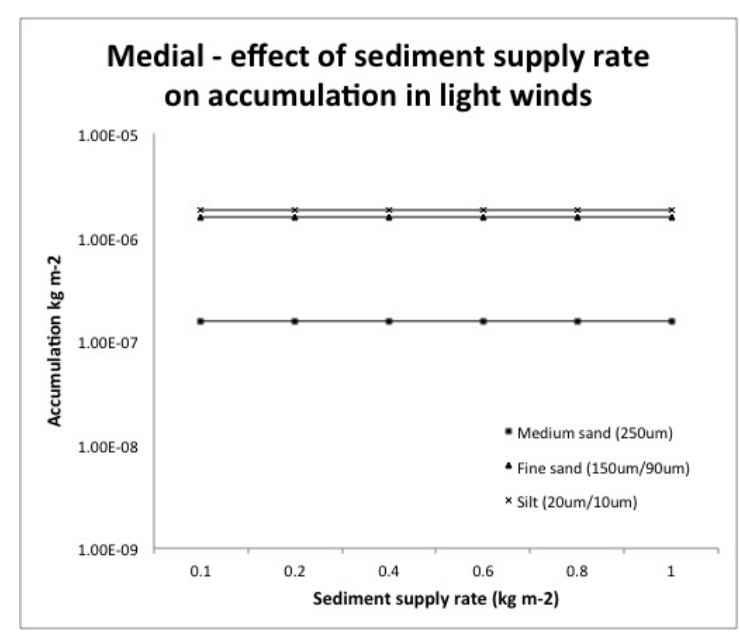

(b)

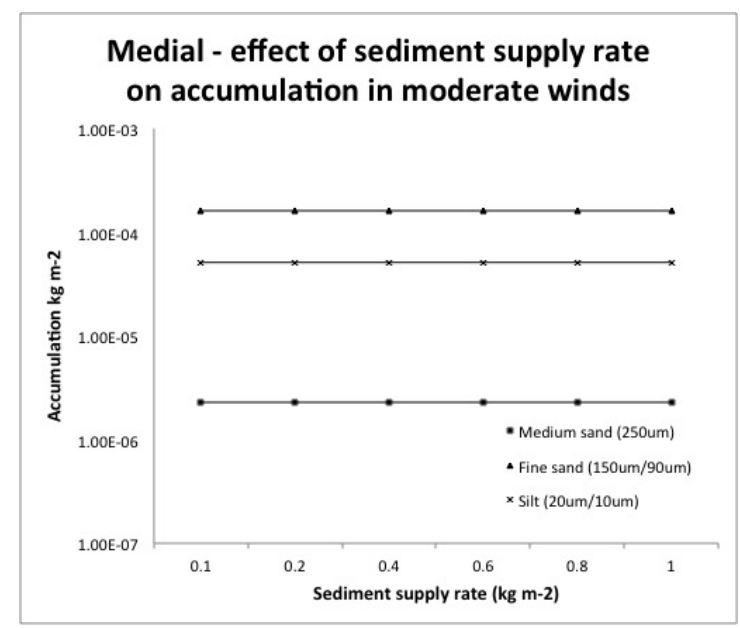

(d)

Figure F.9: Graphical illustration of results of NaMASTE sensitivity tests for sediment supply rate $(M)$ for three locations (proximal $\sim 30 \mathrm{~km}$, medial $\sim 100 \mathrm{~km}$, distal $\sim 200$ $\mathrm{km}$ ) downwind from a source situated on the McMurdo Ice Shelf debris band, under three different wind strengths ('light', 'moderate', i.e. moderately strong, 'strong' i.e. hurricane force, refer Table 6.1). Note: the results for the proximal location with moderate strength winds is dispayed in modelling results (Chapter 6). 

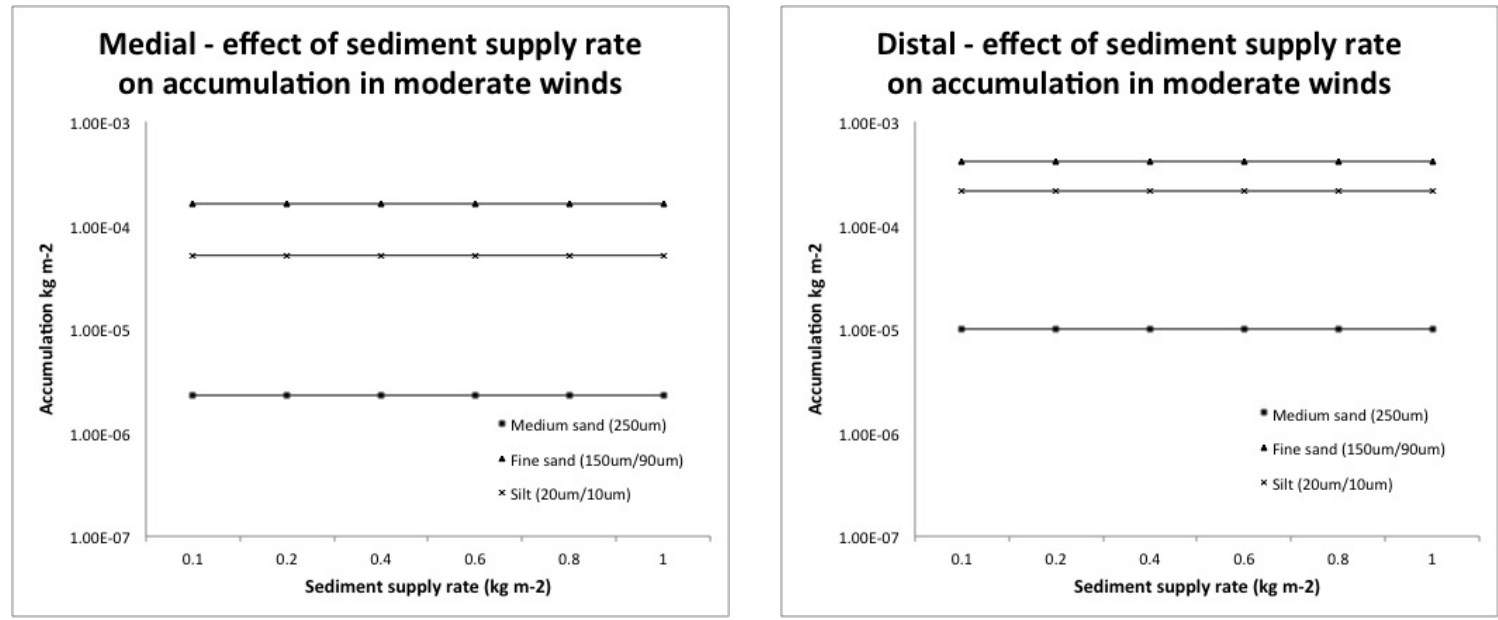

(a)

(b)
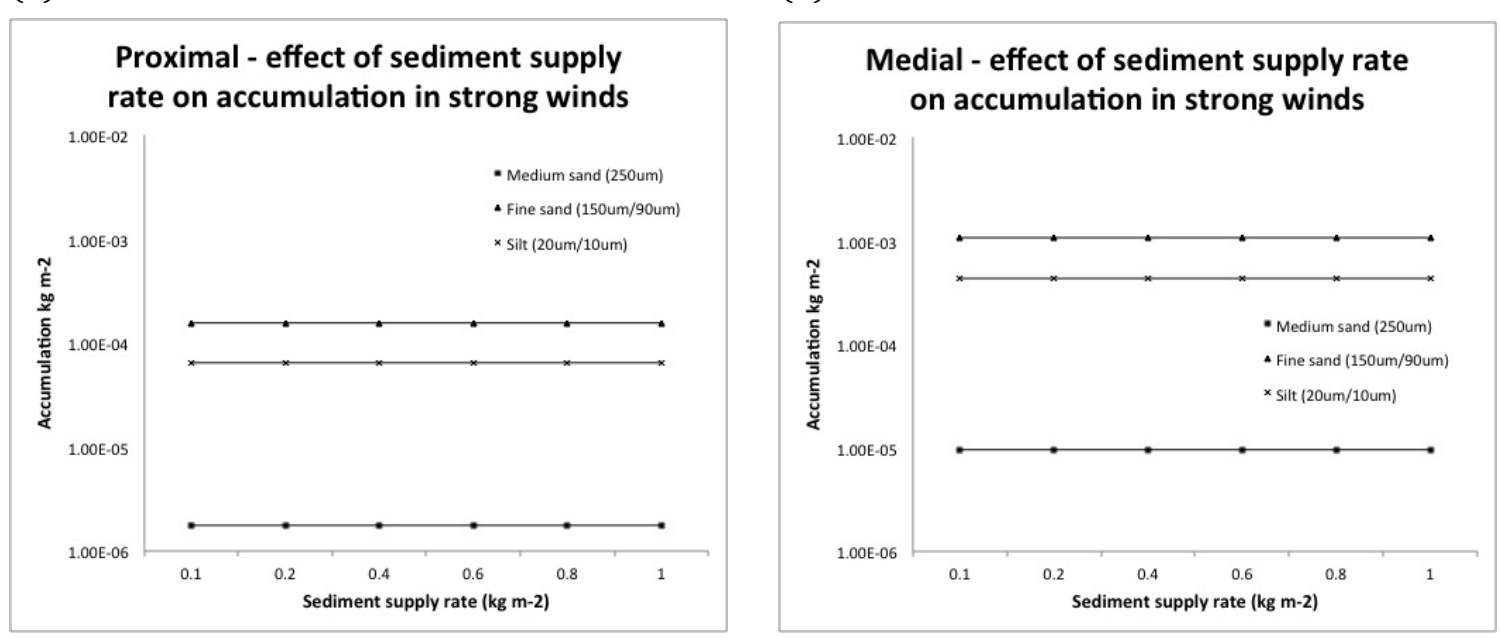

(c)

(d)

Continued from Figure F.9 


\section{Appendix G NaMASTE sensitivity test variable values}

Supplied as accessory tables in supplementary disc (inside cover). Folder containing corresponding map plots of model run outputs also included. 


\section{Appendix $\mathbf{H}$}

NaMASTE predictive test output data (selected) 

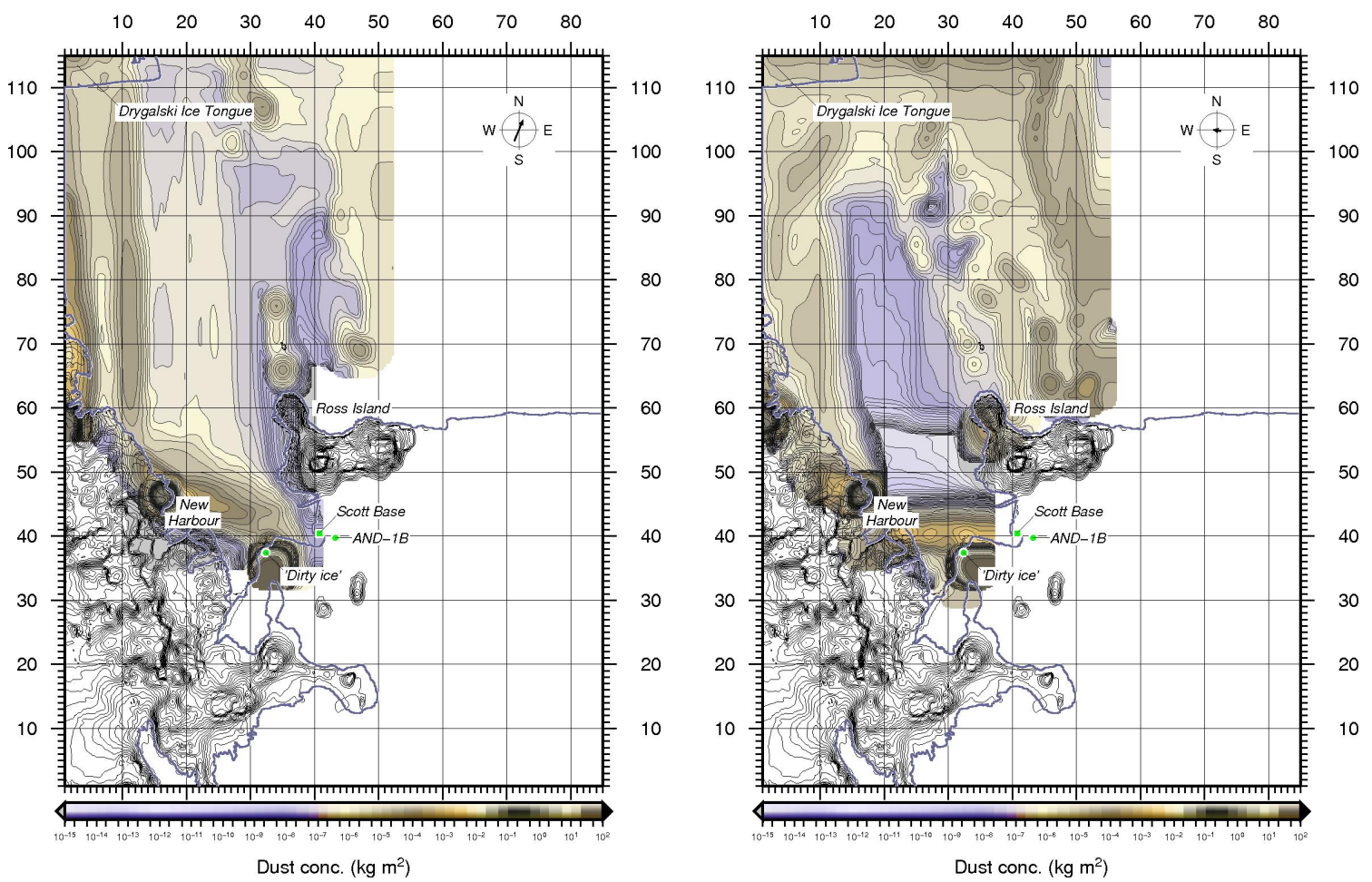

(a)

(b)
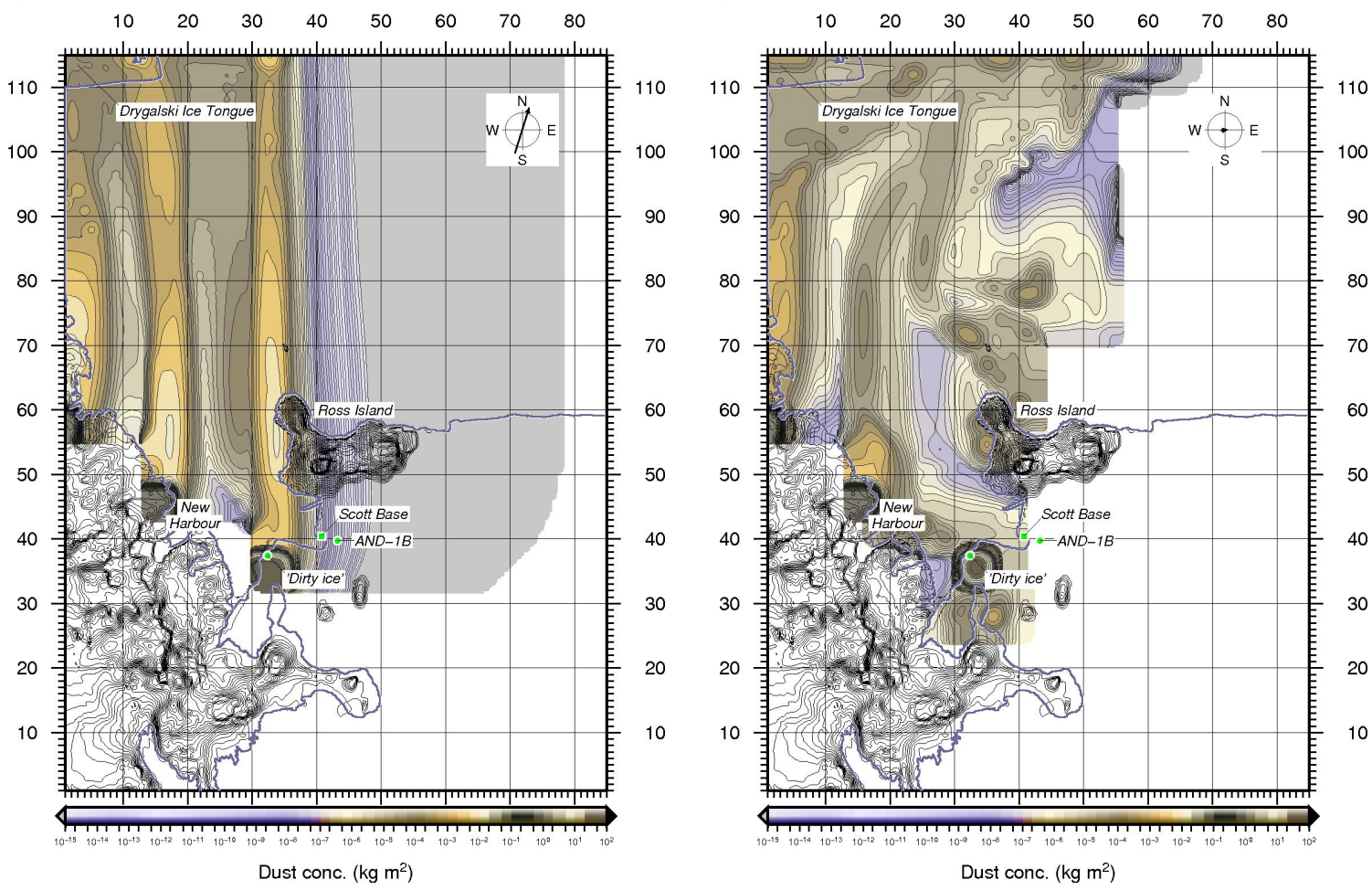

(c)

(d)

Figure H.1: Selected graphical illustrations of NaMASTE predictive test outputs. Examples from testing of the influence of static wind field shape on dispersal. Nb. Run time far exceeds realistic cumulative duration of strong wind events exceeding $20 \mathrm{~m} \mathrm{~s}^{-1}$, therefore accumulation values are unrealistic. a) Wind field 5193; b) wind field 5194; c) wind field 5195; and wind field 5196. (Refer Appendix Efor additional wind fields.) 


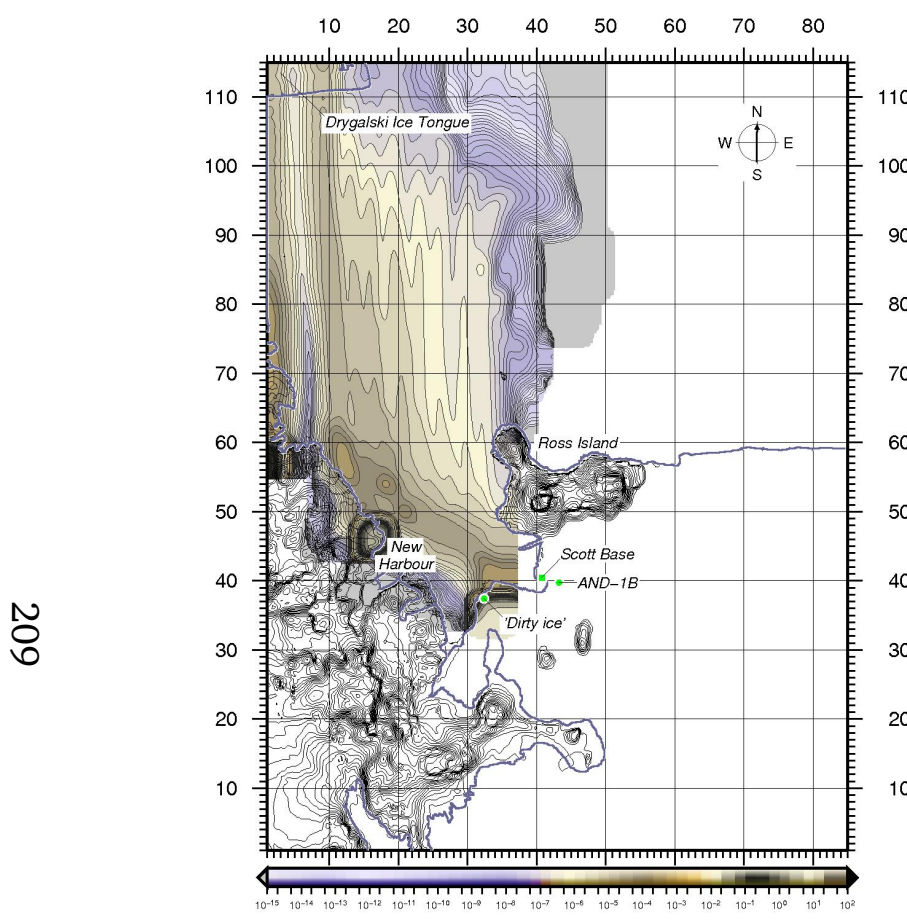

Dust conc. (kg m²)

(a)

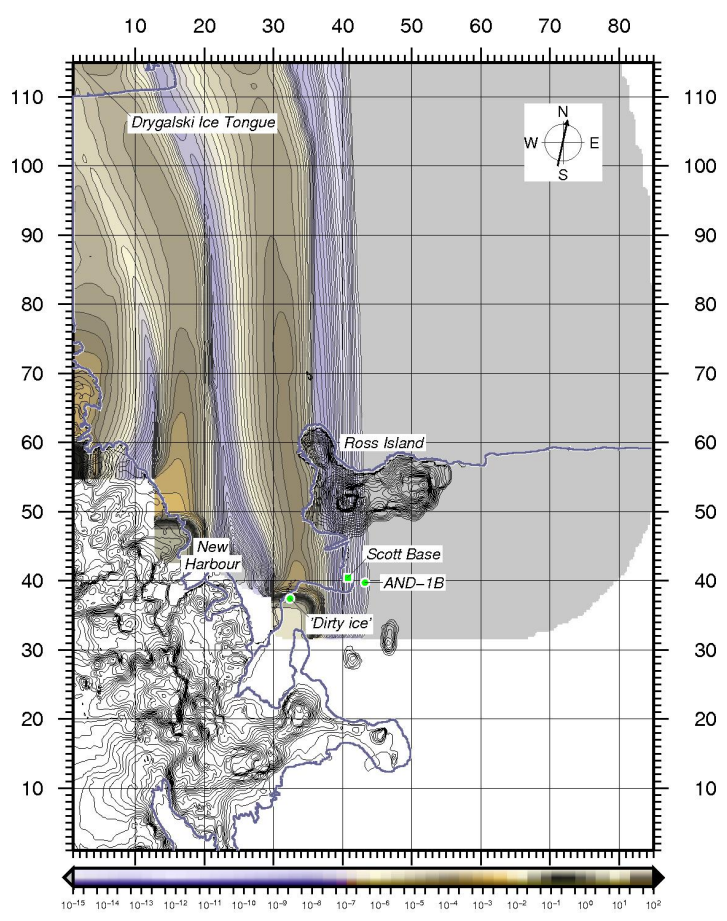

Dust conc. (kg m²)

(b)

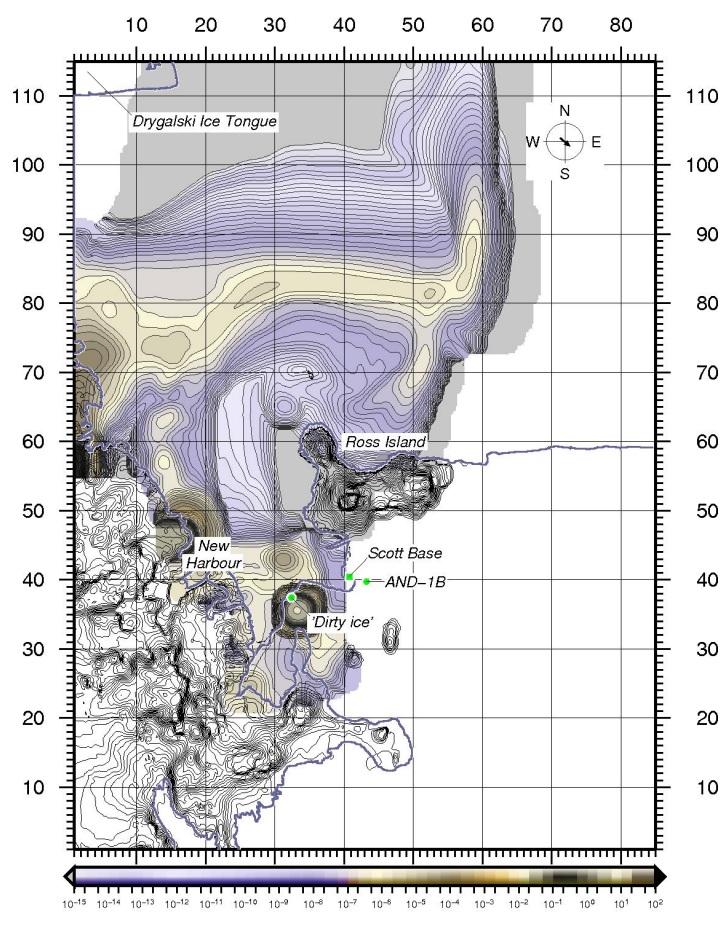

Dust conc. (kg m²)

(c)

Figure H.2: Selected graphical illustrations of NaMASTE predictive test outputs. Examples from run duration testing, for time required to increase accumulation to that seen in observed data. Run time: 103 hours. a) Wind field 5192; b) wind field 5207; and c) wind field 5208 (as supplied in Appendix E). 


\section{Appendix I NaMASTE predictive test variable values}




\begin{tabular}{|c|c|c|c|c|c|c|c|c|c|c|c|c|c|}
\hline \multicolumn{14}{|c|}{ NaMASTE Predictive Tests-VARIIABLE VALUES: 1 of 4} \\
\hline Filename: & $5200 \_1132 \mathrm{~h}$ & $5200 \_2 \_1132 \mathrm{~h}$ & 5200_3_1132 & $5200 \_411132$ & $5200 \_5$ 11132 & $5192 \_1132 \mathrm{~h}$ & $5192 \_2 \_1132 \mathrm{~h}$ & $5192 \_3 \_1132 \mathrm{~h}$ & $5192 \_4 \_1132 \mathrm{~h}$ & $5192 \_5 \_1132 \mathrm{~h}$ & $5192 \_6 \_1132 \mathrm{~h}$ & 5192_7_1132h & $5192 \_8 \_1132 \mathrm{~h}$ \\
\hline \multicolumn{14}{|l|}{ Run variable: } \\
\hline A & 0.08 & 0.08 & 0.08 & 0.08 & 0.08 & 0.08 & 0.08 & 0.08 & 0.08 & 0.08 & 0.08 & 0.08 & 0.08 \\
\hline ret & 0.3 & 0.3 & 0.2 & 0.1 & 0.5 & 0.2 & 0.2 & 0.2 & 0.2 & 0.2 & 0.2 & 0.2 & 0.2 \\
\hline seed 1a & 0.10 & 0.50 & 0.50 & 0.50 & 0.50 & 0.50 & 0.50 & 0.50 & 0.50 & 0.50 & 0.50 & 0.70 & 0.50 \\
\hline seed $2 a$ & 0.10 & 0.50 & 0.50 & 0.50 & 0.50 & 0.50 & 0.50 & 0.50 & 0.50 & 0.50 & 0.50 & 0.70 & 0.50 \\
\hline seed $3 a$ & 0.10 & 0.50 & 0.50 & 0.50 & 0.50 & 0.50 & 0.50 & 0.50 & 0.50 & 0.50 & 0.50 & 0.70 & 0.50 \\
\hline seed $4 a$ & 0.10 & 0.50 & 0.50 & 0.50 & 0.50 & 0.50 & 0.50 & 0.50 & 0.50 & 0.50 & 0.50 & 0.70 & 0.50 \\
\hline seed $5 a$ & 0.10 & 0.50 & 0.50 & 0.50 & 0.50 & 0.50 & 0.50 & 0.50 & 0.50 & 0.50 & 0.50 & 0.70 & 0.50 \\
\hline seed $1 \mathrm{~b}$ & 0.01 & 0.10 & 0.10 & 0.10 & 0.10 & 0.10 & 0.10 & 0.08 & 0.08 & 0.05 & 0.01 & 0.01 & 0.01 \\
\hline seed $2 b$ & 0.01 & 0.10 & 0.10 & 0.10 & 0.10 & 0.10 & 0.10 & 0.08 & 0.08 & 0.05 & 0.01 & 0.01 & 0.01 \\
\hline seed 3b & 0.01 & 0.10 & 0.10 & 0.10 & 0.10 & 0.10 & 0.10 & 0.08 & 0.08 & 0.05 & 0.01 & 0.01 & 0.01 \\
\hline seed $4 \mathrm{~b}$ & 0.01 & 0.10 & 0.10 & 0.10 & 0.10 & 0.10 & 0.10 & 0.08 & 0.08 & 0.05 & 0.01 & 0.01 & 0.01 \\
\hline seed $5 b$ & 0.01 & 0.10 & 0.10 & 0.10 & 0.10 & 0.10 & 0.10 & 0.08 & 0.08 & 0.05 & 0.01 & 0.01 & 0.01 \\
\hline seed 1c & 0.01 & 0.01 & 0.01 & 0.01 & 0.01 & 0.01 & 0.01 & 0.01 & 0.01 & 0.01 & 0.01 & 0.01 & 0.01 \\
\hline seed $2 c$ & 0.01 & 0.01 & 0.01 & 0.01 & 0.01 & 0.01 & 0.01 & 0.01 & 0.01 & 0.01 & 0.01 & 0.01 & 0.01 \\
\hline seed $3 c$ & 0.01 & 0.01 & 0.01 & 0.01 & 0.01 & 0.01 & 0.01 & 0.01 & 0.01 & 0.01 & 0.01 & 0.01 & 0.01 \\
\hline seed $4 c$ & 0.01 & 0.01 & 0.01 & 0.01 & 0.01 & 0.01 & 0.01 & 0.01 & 0.01 & 0.01 & 0.01 & 0.01 & 0.01 \\
\hline seed $5 c$ & 0.01 & 0.01 & 0.01 & 0.01 & 0.01 & 0.01 & 0.01 & 0.01 & 0.01 & 0.01 & 0.01 & 0.01 & 0.01 \\
\hline sort & 0.28 & 0.28 & 0.28 & 0.28 & 0.28 & 0.28 & 0.25 & 0.28 & 0.28 & 0.28 & 0.28 & 0.28 & 0.28 \\
\hline rough & 0.0005 & 0.0005 & 0.0005 & 0.0005 & 0.0005 & 0.0005 & 0.0005 & 0.0005 & 0.0005 & 0.0005 & 0.0005 & 0.0005 & 0.0005 \\
\hline snap & 5200 & 5200 & 5200 & 5200 & 5200 & 5192 & 5192 & 5192 & 5192 & 5192 & 5192 & 5192 & 5192 \\
\hline scalar & 1.0 & 1.0 & 1.0 & 1.0 & 1.0 & 1.0 & 1.0 & 1.0 & 1.0 & 1.0 & 1.0 & 1.0 & 1.0 \\
\hline thresh & 0.0 & 0.0 & 0.0 & 0.0 & 0.0 & 0.0 & 0.0 & 0.0 & 0.0 & 0.0 & 0.0 & 0.0 & 0.0 \\
\hline source xa & 32 & 32 & 32 & 32 & 32 & 32 & 32 & 32 & 32 & 32 & 32 & 32 & 35 \\
\hline source ya & 37 & 37 & 37 & 37 & 37 & 37 & 37 & 37 & 37 & 37 & 37 & 37 & 39 \\
\hline source $\mathrm{xb}$ & 16 & 16 & 16 & 16 & 16 & 16 & 16 & 16 & 14 & 16 & 16 & 16 & 16 \\
\hline source yb & 47 & 47 & 47 & 47 & 47 & 47 & 47 & 47 & 42 & 47 & 47 & 47 & 47 \\
\hline source xc & 3 & 3 & 3 & 3 & 3 & 3 & 3 & 3 & 3 & 3 & 1 & 1 & 1 \\
\hline source $x c$ & 58 & 58 & 58 & 58 & 58 & 58 & 58 & 58 & 58 & 58 & 58 & 58 & 58 \\
\hline stthk a & 0.0 & 0.0 & 0.0 & 0.0 & 0.0 & 0.0 & 0.0 & 0.0 & 0.0 & 0.0 & 0.0 & 0.0 & 0.0 \\
\hline stthk b & 0.0 & 0.0 & 0.0 & 0.0 & 0.0 & 0.0 & 0.0 & 0.0 & 0.0 & 0.0 & 0.0 & 0.0 & 0.0 \\
\hline stthk c & 0.0 & 0.0 & 0.0 & 0.0 & 0.0 & 0.0 & 0.0 & 0.0 & 0.0 & 0.0 & 0.0 & 0.0 & 0.0 \\
\hline Runtime (hrs) & 1132 & 1132 & 1132 & 1132 & 1132 & 1132 & 1132 & 1132 & 1132 & 1132 & 1132 & 1132 & 1132 \\
\hline
\end{tabular}




\begin{tabular}{|c|c|c|c|c|c|c|c|c|c|c|c|c|c|}
\hline \multicolumn{14}{|c|}{ NaMASTE Predictive Tests-VARIABLE VALUES: 2 of 4} \\
\hline Filename: & 5192_9_1132h & 5193_1132h & 5194_1132h & 5195_1132h & 5196_1132h & 5213_1132h & $5192 \_2264 \mathrm{~h}$ & $5192 \_562 \mathrm{~h}$ & 5192 59h & $5192 \_588 \mathrm{~h}$ & $5207 \_59 \mathrm{~h}$ & $5208 \_59 \mathrm{~h}$ & $5208 \_2 \_59 \mathrm{~h}$ \\
\hline Run variable: & Good fit & & & & & & & & Based on 2010 calc & Based on 2010 calc & Based on 2010 calc & Based on 2010 calc & Based on 2010 calc \\
\hline A & 0.08 & 0.08 & 0.08 & 0.08 & 0.08 & 0.08 & 0.08 & 0.08 & 0.08 & 0.08 & 0.08 & 0.08 & 0.08 \\
\hline ret & 0.2 & 0.2 & 0.2 & 0.2 & 0.2 & 0.2 & 0.2 & 0.2 & 0.2 & 0.2 & 0.2 & 0.2 & 0.2 \\
\hline seed 1a & 0.50 & 0.50 & 0.50 & 0.50 & 0.50 & 0.50 & 0.50 & 0.50 & 0.50 & 0.50 & 0.50 & 0.50 & 0.50 \\
\hline seed 2a & 0.50 & 0.50 & 0.50 & 0.50 & 0.50 & 0.50 & 0.50 & 0.50 & 0.50 & 0.50 & 0.50 & 0.50 & 0.50 \\
\hline seed 3a & 0.50 & 0.50 & 0.50 & 0.50 & 0.50 & 0.50 & 0.50 & 0.50 & 0.50 & 0.50 & 0.50 & 0.50 & 0.50 \\
\hline seed 4a & 0.50 & 0.50 & 0.50 & 0.50 & 0.50 & 0.50 & 0.50 & 0.50 & 0.50 & 0.50 & 0.50 & 0.50 & 0.50 \\
\hline seed $5 a$ & 0.50 & 0.50 & 0.50 & 0.50 & 0.50 & 0.50 & 0.50 & 0.50 & 0.50 & 0.50 & 0.50 & 0.50 & 0.50 \\
\hline seed $1 \mathrm{~b}$ & 0.01 & 0.01 & 0.01 & 0.01 & 0.01 & 0.01 & 0.01 & 0.01 & 0.01 & 0.01 & 0.01 & 0.01 & 0.01 \\
\hline seed $2 \mathrm{~b}$ & 0.01 & 0.01 & 0.01 & 0.01 & 0.01 & 0.01 & 0.01 & 0.01 & 0.01 & 0.01 & 0.01 & 0.01 & 0.01 \\
\hline seed $3 b$ & 0.01 & 0.01 & 0.01 & 0.01 & 0.01 & 0.01 & 0.01 & 0.01 & 0.01 & 0.01 & 0.01 & 0.01 & 0.01 \\
\hline seed 4b & 0.01 & 0.01 & 0.01 & 0.01 & 0.01 & 0.01 & 0.01 & 0.01 & 0.01 & 0.01 & 0.01 & 0.01 & 0.01 \\
\hline seed $5 b$ & 0.01 & 0.01 & 0.01 & 0.01 & 0.01 & 0.01 & 0.01 & 0.01 & 0.01 & 0.01 & 0.01 & 0.01 & 0.01 \\
\hline seed 1c & 0.01 & 0.01 & 0.01 & 0.01 & 0.01 & 0.01 & 0.01 & 0.01 & 0.01 & 0.01 & 0.01 & 0.01 & 0.01 \\
\hline seed $2 c$ & 0.01 & 0.01 & 0.01 & 0.01 & 0.01 & 0.01 & 0.01 & 0.01 & 0.01 & 0.01 & 0.01 & 0.01 & 0.01 \\
\hline seed 3c & 0.01 & 0.01 & 0.01 & 0.01 & 0.01 & 0.01 & 0.01 & 0.01 & 0.01 & 0.01 & 0.01 & 0.01 & 0.01 \\
\hline seed $4 c$ & 0.01 & 0.01 & 0.01 & 0.01 & 0.01 & 0.01 & 0.01 & 0.01 & 0.01 & 0.01 & 0.01 & 0.01 & 0.01 \\
\hline seed $5 c$ & 0.01 & 0.01 & 0.01 & 0.01 & 0.01 & 0.01 & 0.01 & 0.01 & 0.01 & 0.01 & 0.01 & 0.01 & 0.01 \\
\hline sort & 0.28 & 0.28 & 0.28 & 0.28 & 0.28 & 0.28 & 0.28 & 0.28 & 0.28 & 0.28 & 0.28 & 0.28 & 0.28 \\
\hline rough & 0.0005 & 0.0005 & 0.0005 & 0.0005 & 0.0005 & 0.0005 & 0.0005 & 0.0005 & 0.0005 & 0.0005 & 0.0005 & 0.0005 & 0.0005 \\
\hline snap & 5192 & 5193 & 5194 & 5195 & 5196 & 5213 & 5192 & 5192 & 5192 & 5192 & 5207 & 5208 & 5208 \\
\hline scalar & 1.0 & 1.0 & 1.0 & 1.0 & 1.0 & 1.0 & 1.0 & 1.0 & 1.0 & 1.0 & 1.0 & 1.0 & 1.0 \\
\hline thresh & 0.0 & 0.0 & 0.0 & 0.0 & 0.0 & 0.0 & 0.0 & 0.0 & 0.0 & 0.0 & 0.0 & 0.0 & 0.0 \\
\hline source xa & 33 & 33 & 33 & 33 & 33 & 33 & 33 & 33 & 33 & 33 & 33 & 33 & 32 \\
\hline source ya & 35 & 35 & 35 & 35 & 35 & 35 & 35 & 35 & 35 & 35 & 35 & 35 & 37 \\
\hline source $\mathrm{xb}$ & 16 & 16 & 16 & 16 & 16 & 16 & 16 & 16 & 16 & 16 & 16 & 16 & 16 \\
\hline source yb & 46 & 46 & 46 & 46 & 46 & 46 & 46 & 46 & 46 & 46 & 46 & 46 & 46 \\
\hline source xc & 1 & 1 & 1 & 1 & 1 & 1 & 1 & 1 & 1 & 1 & 1 & 1 & 1 \\
\hline source $\mathrm{xc}$ & 58 & 58 & 58 & 58 & 58 & 58 & 58 & 58 & 58 & 58 & 58 & 58 & 58 \\
\hline stthk a & 0.0 & 0.0 & 0.0 & 0.0 & 0.0 & 0.0 & 0.0 & 0.0 & 0.0 & 0.0 & 0.0 & 0.0 & 0.0 \\
\hline stthk b & 0.0 & 0.0 & 0.0 & 0.0 & 0.0 & 0.0 & 0.0 & 0.0 & 0.0 & 0.0 & 0.0 & 0.0 & 0.0 \\
\hline stthk c & 0.0 & 0.0 & 0.0 & 0.0 & 0.0 & 0.0 & 0.0 & 0.0 & 0.0 & 0.0 & 0.0 & 0.0 & 0.0 \\
\hline \multirow[t]{3}{*}{ Runtime (hrs) } & 1132 & 1132 & 1132 & 1132 & 1132 & 1132 & 2264 & 562 & 59 & 588 & 59 & 59 & 59 \\
\hline & & & & & & & & & $1 \%$ & $10 \%$ & $1 \%$ & $1 \%$ & $1 \%$ \\
\hline & & & & & & & & & 8 months & 8 months & 8 months & 8 months & 8 months \\
\hline
\end{tabular}




\begin{tabular}{|c|c|c|c|c|c|c|c|c|c|c|c|c|c|}
\hline \multicolumn{14}{|c|}{ NaMASTE Predictive Tes } \\
\hline Filename: & 5208_fs_59h & 5208 fss_588h & 5192_fs_59h & 5192 fs__588h & 5192_gs_588h & 5192_gs_118h & 5192_gs_59h & 5192_gs_103h & 5192_gs_206h & 5208_gs_59h & 5208_gs_103h & 5208_gs_103h & 5208_gs_103h \\
\hline Run variable: & Based on 2010 calc & Based on 2010 calc & Based on 2010 calc & & & & & From PN calc & From PN calc & & & & \\
\hline A & 0.08 & 0.08 & 0.08 & 0.08 & 0.08 & 0.08 & 0.08 & 0.08 & 0.08 & 0.08 & 0.08 & 0.08 & 0.08 \\
\hline ret & 0.2 & 0.2 & 0.2 & 0.2 & 0.2 & 0.2 & 0.2 & 0.2 & 0.2 & 0.2 & 0.2 & 0.2 & 0.2 \\
\hline seed 1a & 0.50 & 0.50 & 0.50 & 0.50 & 1.00 & 1.00 & 1.00 & 1.00 & 1.00 & 1.00 & 1.00 & 1.00 & 1.00 \\
\hline seed $2 \mathrm{a}$ & 1.00 & 1.00 & 1.00 & 1.00 & 0.50 & 0.50 & 0.50 & 0.50 & 0.50 & 0.50 & 0.50 & 0.50 & 0.50 \\
\hline seed $3 a$ & 1.00 & 1.00 & 1.00 & 1.00 & 0.50 & 0.50 & 0.50 & 0.50 & 0.50 & 0.50 & 0.50 & 0.50 & 0.50 \\
\hline seed $4 a$ & 0.50 & 0.50 & 0.50 & 0.50 & 0.01 & 0.01 & 0.01 & 0.01 & 0.01 & 0.01 & 0.01 & 0.01 & 0.01 \\
\hline seed $5 a$ & 0.50 & 0.50 & 0.50 & 0.50 & 0.01 & 0.01 & 0.01 & 0.01 & 0.01 & 0.01 & 0.01 & 0.01 & 0.01 \\
\hline seed $1 \mathrm{~b}$ & 0.01 & 0.01 & 0.01 & 0.01 & 0.01 & 0.01 & 0.01 & 0.01 & 0.01 & 0.01 & 0.01 & 0.01 & 0.01 \\
\hline seed $2 \mathrm{~b}$ & 0.05 & 0.05 & 0.05 & 0.05 & 0.50 & 0.50 & 0.50 & 0.50 & 0.50 & 0.50 & 0.50 & 0.50 & 0.50 \\
\hline seed $3 b$ & 0.05 & 0.05 & 0.05 & 0.05 & 0.50 & 0.50 & 0.50 & 0.50 & 0.50 & 0.50 & 0.50 & 0.50 & 0.50 \\
\hline seed $4 b$ & 0.01 & 0.01 & 0.01 & 0.01 & 0.10 & 0.10 & 0.10 & 0.10 & 0.10 & 0.10 & 0.10 & 0.10 & 0.10 \\
\hline seed $5 b$ & 0.01 & 0.01 & 0.01 & 0.01 & 0.10 & 0.10 & 0.10 & 0.10 & 0.10 & 0.10 & 0.10 & 0.10 & 0.10 \\
\hline seed 1c & 0.01 & 0.01 & 0.01 & 0.01 & 0.01 & 0.01 & 0.01 & 0.01 & 0.01 & 0.01 & 0.01 & 0.01 & 0.01 \\
\hline seed $2 c$ & 0.05 & 0.05 & 0.05 & 0.05 & 0.02 & 0.02 & 0.02 & 0.02 & 0.02 & 0.02 & 0.02 & 0.02 & 0.02 \\
\hline seed $3 c$ & 0.05 & 0.05 & 0.05 & 0.05 & 0.02 & 0.02 & 0.02 & 0.02 & 0.02 & 0.02 & 0.02 & 0.02 & 0.02 \\
\hline seed $4 c$ & 0.01 & 0.01 & 0.01 & 0.01 & 0.01 & 0.01 & 0.01 & 0.01 & 0.01 & 0.01 & 0.01 & 0.01 & 0.01 \\
\hline seed $5 c$ & 0.01 & 0.01 & 0.01 & 0.01 & 0.01 & 0.01 & 0.01 & 0.01 & 0.01 & 0.01 & 0.01 & 0.01 & 0.01 \\
\hline sort & 0.28 & 0.28 & 0.28 & 0.28 & 0.2 & 0.2 & 0.2 & 0.2 & 0.2 & 0.2 & 0.2 & 0.2 & 0.2 \\
\hline rough & 0.0005 & 0.0005 & 0.0005 & 0.0005 & 0.0005 & 0.0005 & 0.0005 & 0.0005 & 0.0005 & 0.0005 & 0.0005 & 0.0005 & 0.0005 \\
\hline snap & 5208 & 5208 & 5192 & 5192 & 5192 & 5192 & 5192 & 5192 & 5192 & 5208 & 5208 & 5208 & 5208 \\
\hline scalar & 1.0 & 1.0 & 1.0 & 1.0 & 1.0 & 1.0 & 1.0 & 1.0 & 1.0 & 1.0 & 1.0 & 1.0 & 1.0 \\
\hline thresh & 0.0 & 0.0 & 0.0 & 0.0 & 0.0 & 0.0 & 0.0 & 0.0 & 0.0 & 0.0 & 0.0 & 0.0 & 0.0 \\
\hline source xa & 33 & 33 & 33 & 33 & 33 & 33 & 33 & 33 & 33 & 33 & 33 & 33 & 33 \\
\hline source ya & 35 & 35 & 35 & 35 & 35 & 35 & 35 & 35 & 35 & 35 & 35 & 35 & 35 \\
\hline source $x b$ & 16 & 16 & 16 & 16 & 16 & 16 & 16 & 16 & 16 & 16 & 16 & 16 & 16 \\
\hline source yb & 46 & 46 & 46 & 46 & 46 & 46 & 46 & 46 & 46 & 46 & 46 & 46 & 46 \\
\hline source $x c$ & 1 & 1 & 1 & 1 & 1 & 1 & 1 & 1 & 1 & 1 & 1 & 1 & 1 \\
\hline source xc & 58 & 58 & 58 & 58 & 58 & 58 & 58 & 58 & 58 & 58 & 58 & 58 & 58 \\
\hline stthk a & 0.0 & 0.0 & 0.0 & 0.0 & 0.0 & 0.0 & 0.0 & 0.0 & 0.0 & 0.0 & 0.0 & 0.0 & 0.0 \\
\hline stthk b & 0.0 & 0.0 & 0.0 & 0.0 & 0.0 & 0.0 & 0.0 & 0.0 & 0.0 & 0.0 & 0.0 & 0.0 & 0.0 \\
\hline stthk c & 0.0 & 0.0 & 0.0 & 0.0 & 0.0 & 0.0 & 0.0 & 0.0 & 0.0 & 0.0 & 0.0 & 0.0 & 0.0 \\
\hline \multirow{3}{*}{ Runtime (hrs) } & 59 & 588 & 59 & 588 & 588 & 59 & 118 & 103 & 206 & 59 & 103 & 118 & 206 \\
\hline & $1 \%$ & $10 \%$ & $1 \%$ & $10 \%$ & $10 \%$ & $1 \%$ & $2 \%$ & $1 \% / 11 \mathrm{yrs}$ & $2 \% / 11 \mathrm{yrs}$ & $1 \%$ & $1 \% / 11 \mathrm{yrs}$ & $2 \%$ & $2 \% / 11 \mathrm{yrs}$ \\
\hline & 8 months & 8 months & 8 months & 8 months & 8 months & 8 months & 8 months & 12 months & 12 months & 8 months & 12 months & 8 months & 12 months \\
\hline
\end{tabular}




\begin{tabular}{|c|c|c|c|}
\hline \multicolumn{4}{|c|}{ NaMASTE Predictive Tests-VARIABLE VALUES: 4 of 4} \\
\hline Filename: & $5207 \_$gs_59h & 5207_gs_103h & \multirow{2}{*}{$\frac{\text { 5192_gs_1132h }}{\text { For comparison of grain size }}$} \\
\hline Run variable: & & & \\
\hline A & 0.08 & 0.08 & 0.08 \\
\hline ret & 0.2 & 0.2 & 0.2 \\
\hline seed 1a & 1.00 & 1.00 & 1.00 \\
\hline seed 2a & 0.50 & 0.50 & 0.50 \\
\hline seed 3a & 0.50 & 0.50 & 0.50 \\
\hline seed $4 \mathrm{a}$ & 0.01 & 0.01 & 0.01 \\
\hline seed $5 \mathrm{a}$ & 0.01 & 0.01 & 0.01 \\
\hline seed $1 \mathrm{~b}$ & 0.01 & 0.01 & 0.01 \\
\hline seed $2 b$ & 0.50 & 0.50 & 0.50 \\
\hline seed $3 b$ & 0.50 & 0.50 & 0.50 \\
\hline seed $4 \mathrm{~b}$ & 0.10 & 0.10 & 0.10 \\
\hline seed $5 b$ & 0.10 & 0.10 & 0.10 \\
\hline seed 1c & 0.01 & 0.01 & 0.01 \\
\hline seed $2 c$ & 0.02 & 0.02 & 0.02 \\
\hline seed $3 c$ & 0.02 & 0.02 & 0.02 \\
\hline seed $4 c$ & 0.01 & 0.01 & 0.01 \\
\hline seed $5 c$ & 0.01 & 0.01 & 0.01 \\
\hline sort & 0.2 & 0.2 & 0.2 \\
\hline rough & 0.0005 & 0.0005 & 0.0005 \\
\hline snap & 5207 & 5207 & 5192 \\
\hline scalar & 1.0 & 1.0 & 1.0 \\
\hline thresh & 0.0 & 0.0 & 0.0 \\
\hline source xa & 33 & 33 & 33 \\
\hline source ya & 35 & 35 & 35 \\
\hline source $x b$ & 16 & 16 & 16 \\
\hline source yb & 46 & 46 & 46 \\
\hline source $\mathrm{xc}$ & 1 & 1 & 1 \\
\hline source xc & 58 & 58 & 58 \\
\hline stthk a & 0.0 & 0.0 & 0.0 \\
\hline stthk b & 0.0 & 0.0 & 0.0 \\
\hline stthk c & 0.0 & 0.0 & 0.0 \\
\hline \multirow[t]{3}{*}{ Runtime (hrs) } & 59 & 103 & 1132 \\
\hline & $1 \%$ & $1 \% / 11 y r s$ & $1 \%$ \\
\hline & 8 months & 12 months & \\
\hline
\end{tabular}




\section{Appendix $\mathrm{J}$ \\ NaMASTE user manual: Golledge, 2012}




\title{
Numerical Model for Aeolian Sediment Transport and Evolution (NaMASTE) - User Manual
}

\author{
Nick Golledge ${ }^{1,2}$ \\ July 17, 2012
}

${ }^{1}$ Antarctic Research Centre, Victoria University of Wellington, P.O. Box 600, Wellington 6140, New Zealand

${ }^{2}$ GNS Science, P.O. Box 30-368, Lower Hutt 5040, New Zealand 


\section{Contents}

1 Aims and context 3

2 Previous research 3

3 Overview 3

4 Requirements $\quad 4$

5 Running simulations $\quad 5$

5.1 The input.nml file . . . . . . . . . . . . . . 7

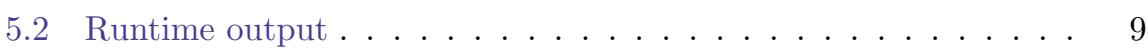

6 Plotting outputs and extracting data 9

6.1 Plotting outputs ..................... 9

6.2 Extracting data . . . . . . . . . . . . . . 10

7 Experimentation \& future development $\quad 12$

8 Appendix I: Model physics $\quad 14$

9 Appendix II: model constants and variables $\quad 16$

\section{List of Figures}

1 Vertical velocity profile and entrainment . . . . . . . . . . 4

2 AMPS data coverage . . . . . . . . . . . . . . 5

3 Typical model outputs . . . . . . . . . . . . . . . . . . 11

\section{List of Tables}

1 Source files for NaMASTE . . . . . . . . . . . . . . 6

2 Physical constants used in the model . . . . . . . . . . . . . . 16

3 Model variables . . . . . . . . . . . . . . . . . . 16 


\section{Aims and context}

Aeolian sediment is thought to contribute bioavailable Fe to the Ross Sea, and the variability in the supply of Fe to the ocean is consequently thought to affect primary productivity. Floating ice in the McMurdo Sound region is a wellstudied and accessible natural aeolian sediment trap, yet so far a process-based predictive scheme simulating aeolian sediment transport (and the presumed flux of Fe to the ocean) in this region is lacking. The principal aim of the numerical model presented here is to simulate aeolian sediment transport in the McMurdo Sound region, using empirically-derived relationships to calculate fluxes and field observations to constrain model parameterisation. Ultimately, the goal is to use the model to predict changes in sediment flux to the ocean under 'normal' (i.e. present) and perturbed environmental conditions.

\section{Previous research}

Considerable research on this topic over the last century has included the now seminal empirical studies by Bagnold (1941) and Inman (1949), as well as more recent studies of the nature of grain transport and sorting (Middleton, 1976; McLaren, 1981; Goosens \& Gross, 2002), process reviews (McKenna-Neuman, 1993; McEwan \& Willetts, 1993) and numerical modelling studies (Gillette, 1981; Foda et al., 1985; Anderson \& Hallet, 1986; Turpin et al., 2010). In many of these studies, the emphasis is on calculating either individual grain trajectories or the dynamics of suspended sediment. By contrast, our requirement is for a simple estimation of aeolian sediment flux in two horizontal dimensions, in which we assume that 1) transport occurs primarily by saltation (possibly in snow clusters) with some proportion advected horizontally in suspension, 2) that a proportion of transported sediment is captured in the snow matrix, and 3) that sediment accumulated on seasonal sea ice is instantaneously released into the ocean when the sea ice breaks up.

\section{Overview}

This manual describes the use of a two-dimensional (2D) numerical model designed to simulate the dispersal of wind-blown (aeolian) sediment. The model is coded in Fortran and is implemented on a 85 x $115 \mathrm{~km}$ domain encompassing the Ross Island and McMurdo Sound region of Antarctica, using Antarctic Mesoscale Prediction System (AMPS) $3.3 \mathrm{~km}$ resolution climate data for the period 2002-2006. Sediment grain sizes $(10,20,90,150,250 \mu \mathrm{m})$ are hardcoded, and their transport is calculated from the balance between entrainment 

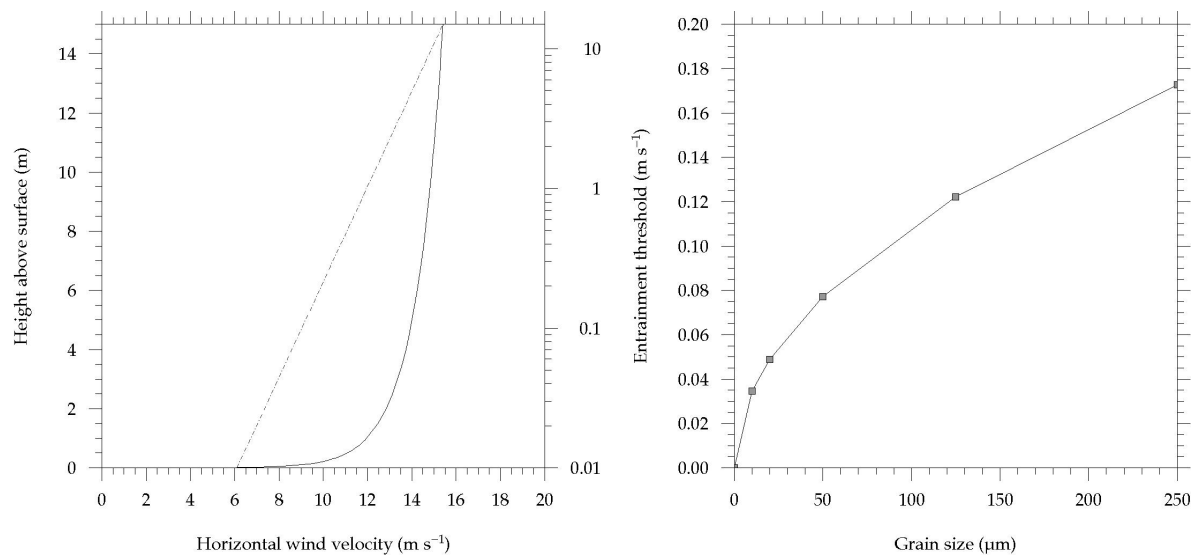

Figure 1: Left: Calculated vertical velocity profile used to translate $10 \mathrm{~m}$ wind velocities into surface shear velocities; Right: shear velocity entrainment thresholds for a range of grain sizes.

velocity and wind shear at the surface, according to empirically-based relationships defined by Bagnold (1941) and Anderson \& Hallet (1986). Vertical wind velocity profiles and entrainment thresholds calculated using these relationships are shown in Fig. 1. The model uses a 2D $(\mathrm{x}, \mathrm{y})$ centred finite difference scheme with a fully explicit numerical solution to translate sediment fluxes between cells into a rate-of-mass-change at each point in the domain. Temporal integration through the model run is controlled by peak domain velocities in order to avoid numerical errors:

$$
d t=\operatorname{int}\left(\frac{d x}{\operatorname{Max}\left(U_{\max }, V_{\max }\right)}\right)
$$

Full details of model physics and numerics are presented in Appendices I \& II. Input windfields for the AMPS period 2002-2006 are (mostly) 6-hourly (Fig. 2). For each 6-hour period, a particle-tracking scheme records particle positions at 15-minute intervals for sediment originating at a specified source. For model initialisation, user input is requested via an input parameter file (input.nml) and on-screen at runtime through a series of prompts. Scrolling screen output displays a number of key parameters during the run, following which the final model state is written to an output file in plain text format. To enable the user to keep track of model runs and parameter choices, a log file is maintained in which key values are recorded, together with run date and time.

\section{Requirements}

A UNIX-type environment (OS X, Linux etc) will make use of the model easiest. It may be possible to compile under MS but I haven't tried it. There 

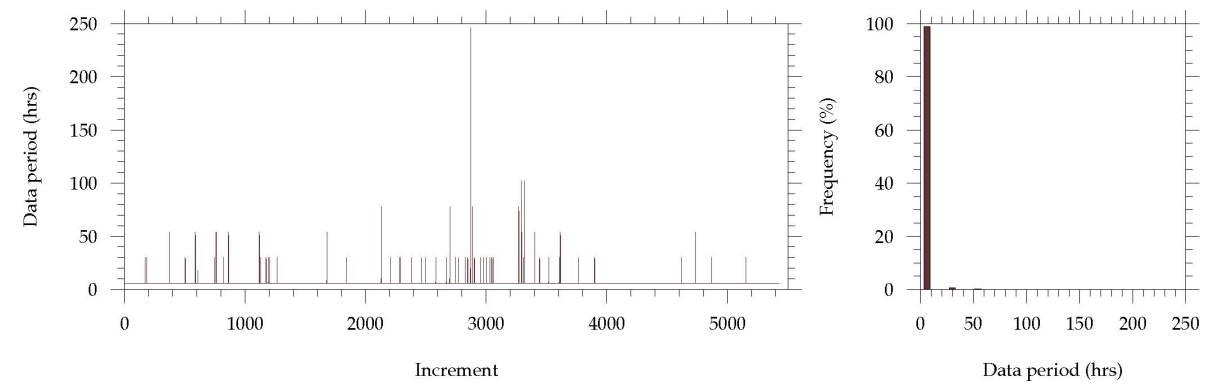

Figure 2: Left: Time periods covered by individual files from the 2002-2006 AMPS Domain 5 climate simulation. Right: same data shown as frequency distribution of time periods.

is no GUI with this code, so some familiarity with command-line operations using basic UNIX commands would make use of the model a lot easier, particularly tools for navigating directories, viewing and editing files etc. At the very least I would recommend becoming familiar with $\mathrm{cd}$, $\mathrm{ls}, \mathrm{cp}, \mathrm{mv}, \mathrm{rm}$, mkdir, less, cat and their various options, as well as ways to deal with their output, such as the use of pipes (i.e.: |) and filtering with regular expressions using grep. Command-line editing tools such as vi, vim, emacs will make remote interaction a lot quicker and easier, but require a little more time to learn. It is possible to run the model without any prior experience of UNIX, but the more comfortable you are with the computing environment as a whole, the more you will get out of the experience.

The model takes as its input wind velocity fields ( $x$ and $y$ components $10 \mathrm{~m}$ above surface), as well as air temperature (surface or $2 \mathrm{~m}$ ), parameter settings from input.nml and additional values from user-input at runtime. Recompilation of the source code is not necessary; however, gfortran was used in the initial compilation of the binary (executable). All the required source files (Table 1) must be present in the correct locations before running the model, otherwise the model will exit with an error.

\section{$5 \quad$ Running simulations}

Before you get too excited about running the model it is important to first plan what it is you are going to do. Good modelling is like good lab work, it is about having a good strategy, and being methodical about how you go about your experiments. Keep records of what you did, which parameters you changed and why. Try and think critically about what your last model output shows before you move on to the next experiment. Once you've had some 
Table 1: Source files required for running NaMASTE and plotting output

\begin{tabular}{lll} 
Name & Type & Location \\
\hline NaMASTE.run & executable &.$/$ \\
input.nml & parameter file &.$/$ \\
runlog.log & log file & $\cdot /$ \\
latlon.txt & coordinates file &.$/$ \\
plot.sh & plotting script &.$/$ \\
dataXtractor.sh & data extraction script &.$/$ \\
archive & directory &.$/$ \\
topo & directory &.$/$ \\
dem1km_LL_MMS.nc & topo grid file &.$/$ topo \\
cpt & directory &.$/$ \\
Brushed_Aluminium.cpt & colour palette file &.$/ \mathrm{cpt}$ \\
Golden_Night.cpt & colour palette file &.$/ \mathrm{cpt}$ \\
gr41_hult.cpt & colour palette file &.$/ \mathrm{cpt}$ \\
redbrown.cpt & colour palette file &.$/ \mathrm{cpt}$ \\
seadreams.cpt & colour palette file &.$/ \mathrm{cpt}$ \\
outputs & directory &.$/$ \\
\hline
\end{tabular}

time playing around with the model, try and devise a plan for exploring 'parameter space', that is, you can't realistically try every combination of every variable against all others, so you need to decide what range of values you're going to choose for your experiments, and which combinations you might carry out. You will probably find that after a little while you have a good idea of what the big controls are, and it might be that you then 'fine-tune' your experiments to concentrate on a particular set of parameters, or combinations thereof.

To run a simulation and plot the results all you need are two commands, typed exactly as shown below:

\section{. NaMASTE.run}

and then

.$/$ plot.sh

To then extract data from the output grids at a given location, run:

\section{./dataXtractor.sh}

When you first run the model it will initialise using parameters stored in the inputs.nml file. This file must exist in the same directory as the NaMASTE. run executable, and it must contain all the variables that are currently in it. This 
file is the only one that you will need to edit, and some care is needed to ensure that no errors are introduced.

\subsection{The input.nml file}

At the command line, type less input.nml. On the screen you'll see the contents of that file. This is a useful way to check your parameters before you run the model. To return to the command line, hit Q. You could also type cat input.nml; this simply prints the contents of the file to the screen, and is good for short files like this one. To edit the values, you need to open the file in a text editor - on Linux, one of the most common is gedit. So to edit the file, type gedit input.nml (making sure you are in the directory where the file exists!). This should open up the file in the text editor, and now you can change anything in it as you would in any other GUI package.

The input.nml file contains 15 variables for you to edit.

- A: entrainment coefficient. Bagnold (1941) uses 0.1, but reduces this to 0.08 for poorly-sorted sediments. Experiment with any values you think interesting, but bear in mind that values greater than 1 imply more entrainment than physically realistic! This variable allows only 1 or 2 decimal places.

- ret: this is a retention coefficient. Again, values greater than unity are not realistic, and at the moment I've envisaged this parameter as needing only $2 \mathrm{dp}$, so you can increase in hundredths from zero; you can try finer increments if you think necessary, but the screen print-out of the value may not show correctly (although it will be correct in the calculations).

- seed1 - 5: from 1 to 5 these correspond to each of five grain sizes prescribed in the model $(250,150,90,20,10 \mu m$ respectively). The values you supply here are the sediment supply rates for each grain size at the source cell, and they take the units $\mathrm{kg} \mathrm{m}^{-2} \mathrm{~s}^{-1}$. It is a continuously supplied source through the duration of the model run. You can choose whatever value you like really, though I would stay in the bounds 0.01-1.00. If you want to carry out runs in which you want to compare transport of one grain size against another, just set to zero all except the one you're interested in, then repeat for a different one and compare the outputs (remember to keep the amounts constant though, and don't change any other variables).

- sort: Bagnold (1941) specifies a sorting coefficient (see p. 106, but divide by 10 as in Anderson \& Hallet, 1986) depending on the overall sorting of 
the sediments being moved. His values are useful guidelines, but feel free to experiment with other values to see how sensitive the results are to this choice.

- rough: a roughness parameter, specified in metres. Bagnold (1941) uses $0.0025 \mathrm{~m}$, based on the diameter of a 'standard' sand grain. Experiment, but bear in mind that this roughness is at the grain-scale, not overall surface roughness.

- snap: simply the number of the 6-hr windfield ('snapshot') you wish to use. Not easy to explain the number scheme, but it comes from the way I set up the model to run the full 4-year period of the AMPS data, which has a total of 5430 timeslices. Numbers 3210-12 span the May 2004 storm I think. The first line of model output at runtime prints the time and date that the file corresponds to in the format (year month day end_hour). If you plot the model output with wind vectors (see below) you'll be able to see how the windfields vary.

- scalar: I've added in this simple multiplier to give you easy control over wind velocities, rather than changing input windfields. So scalar $=1$ gives you the full (original) velocity, whilst scalar $=0.1$ would give you $10 \%$ of the velocity. You can flip the wind direction by specifying a negative value (e.g. scalar $=-1$ ); at the moment this treats both vectors equally, I haven't implemented a way of flipping e.g. the $x$ or $y$ components individually.

- thresh: this threshold acts as a simple filter to remove low-amplitude 'noise'. Units are $\mathrm{m} \mathrm{s}^{-1}$. This should enable you to 'isolate' the effect of high-magnitude events, for example by setting the threshold to 15 or above. Values lower than the threshold are simply reset to zero, which will give unrealistic effects where adjacent cells are either side of the value. I might refine this in future.

- sourcex: this is the grid cell ' $\mathrm{x}$ ' coordinate of the cell you wish to use as a 'seed' area (i.e. the one for which the 'seed' values above apply). By default we expand the seed area by one additional grid cell east from this point.

- sourcey: as above, but corresponding to the ' $y$ ' coordinate of the seed cell. The easiest way to find values for these coordinates is to make a plot in which you choose ' $R$ ' (for rectangular grid) when prompted (see Section 6 , below). 
- stthk: this is simply the starting 'thickness' (actually mass) at the source cell, in $\mathrm{kg} \mathrm{m}^{-2}$.

\subsection{Runtime output}

Once you have got your new set of parameter values, save the file and close it, and go back to your terminal window. Now when you run the model it should read in the updated values. As a check on this, I've coded the model to print some initialisation info before running. Check that what is there corresponds with what you thought you had set in the input file. If you're happy with it, hit enter and the model will run. If you're not happy with it, do $<\operatorname{ctrl}>\mathrm{C}$ to kill the run, and then go and edit your input file again.

Once running, the model will display 6 columns of data. These aren't really very useful for you, since your version of the model is using a single windfield. They were originally intended so that I could keep an eye on things as the model iterated through the 5430 input files spanning 2002-2006. Anyway, the columns, from left to right, are: run time (in seconds), timestep (seconds), maximum velocity value in the domain, sum of the total sediment accumulation in the domain, and the $x$ and $y$ grid cell coordinates of where the maximum velocity occurs. Reading in only one windfield, columns 1 and 4 will be the only ones to change during a run, but if you run the model with different windfields, you should see differences in the other columns too, between runs.

At the end of the run you get a statement telling you where your final model output has been saved, e.g.:

output written at $12 \mathrm{hrs}$ to ./outputs/run1.txt

\section{$6 \quad$ Plotting outputs and extracting data}

\subsection{Plotting outputs}

Assuming the above has all been successful, you are now able to plot the result as a 'map' of sediment accumulation. The model output is written to a multicolumn text file (you can look at it with e.g. less ./outputs/run1.txt). It isn't much use in this format until we plot it, for which we use a script (plot.sh) that first processes the data, then uses Generic Mapping Tools (GMT) to convert it into netCDF (.nc) format and then plot it. You do not need to know 
how to write GMT scripts to plot the data, but if you want to look at the code you can once again use tools such as less or gedit to view the file. As with the other files, only run this script from the directory it is in, if you move it around things might not work! So in your top-level directory, type:

$$
. / \text { plot.sh }
$$

When you run this script you are prompted for some information. Firstly, it will ask which file you wish to plot. Just give it the file name you specified as your output file when running the model (you don't need the .txt extension). Then you have a couple of options - whether you want to include wind vectors on the plot (useful, but may obscure the data), whether you want a Lat / Lon overlay or a rectangular grid showing domain coordinates, and whether you want to plot extra fields ('Plot extra's?') such as air temperature, wind shear strength, air density, entrainment velocity etc. You probably won't want to plot these every time, so by default I have turned them off. Once those options are out of the way, plotting will proceed. Some of the procedures involve numerous stages, so don't expect an instant result, but once the plotting is finished it should give you the message, 'Done: model run run1 plotted to your/file/path...jpg. To view e.g. file ./outputs/run1 map.jpg, type:

$$
\text { gnome-open ./outputs/run1 map.jpg }
$$

Figure 3 illustrates typical plots.

\subsection{Extracting data}

You will have noticed that at the end of the plotting messages there are a couple of extra lines:

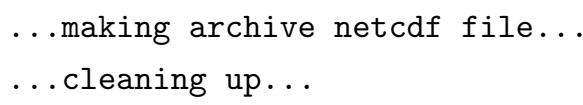

Although we have only plotted total accumulation, the plotting process included creation of grids of all the model parameters in the output text file (./outputs/your-run.txt). At the end of plotting we simply combine all these separate grids into a single netCDF file and move it to the ./archive/ directory, with the filename your-run_all.nc. After doing that we delete all the extra files that were generated during plotting, to avoid clutter and keep things tidy. 

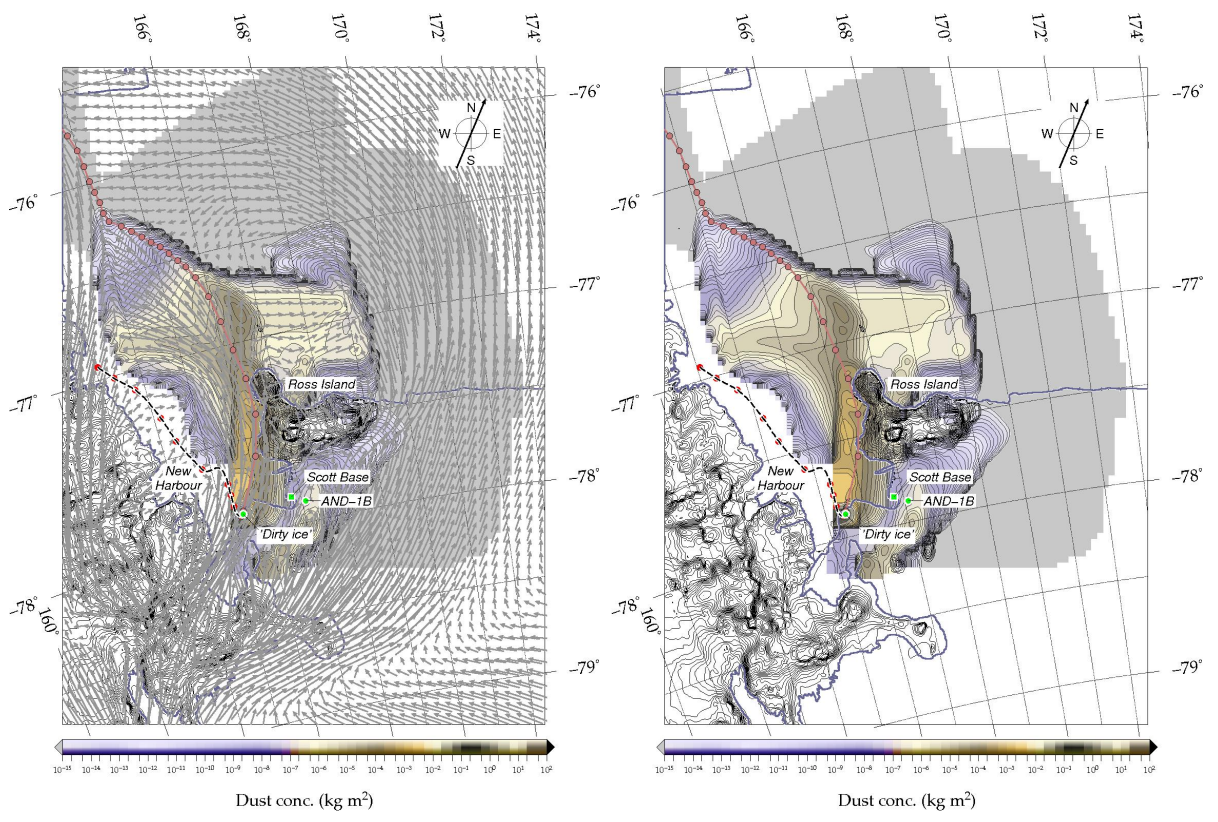

Figure 3: Left: model output showing wind vectors; Right: same output without vectors

Once you have run a few simulations, and have accumulated a few of these 'archive' datasets, you can run the third script to compare them:

\section{./dataXtractor.sh}

On doing so you will be prompted for filenames for the model runs you want to compare - you are allowed up to 20. Just enter the name of each of the runs separated by a space. You will then be asked to enter a grid location at which to extract data - specify the required $x$ and $y$ values (space-separated) based on the domain coordinates, not the Lat / Lon coordinates. (Plotting your original map with the 'rectangular' grid option will help with finding appropriate values). The final prompt then is to specify a name for your output data-table - once again you do not need to specify the file extension, it will automatically add .txt and save the file in the ./archive/ directory. If the file doesn't already exist, a new file will be written. If it does exist, you have the option of overwriting, moving, or appending data to the file. All being well the script will then generate a table with all your input parameters from the input.nml file for each of your specified runs, together with the values of each of the gridded datasets (total accumulation, air temperature, air density, shear velocity, entrainment velocity, total $(10 \mathrm{~m})$ wind velocity, and the $x$ and $y$ (' $\mathrm{U}$ ' and ' $\mathrm{V}$ ') components of the wind field) at the grid location requested. A header 
line at the top of the file informs you as to which parameter is in each column. To plot your own graphs of any combination of these parameters, just open / import the table into a spreadsheet program as a space-delimited text file.

\section{Experimentation \& future development}

Your main aim in using this model will be to run sensitivity experiments under constant wind fields, to gain an understanding of 1) the key parameters influencing the pattern and magnitude of sediment fluxes, and 2) the natural variability of the system (i.e. how much do 'natural' changes in wind strength / direction influence the patterns of sediment dispersal?). What can we learn from these experiments with respect to the observed pattern of aeolian sediment distribution in McMurdo Sound (i.e. your field data) - is it best explained by 'average' wind fields, or are episodic storm events more important?

In the future we can look at running longer simulations with changing windfields to see what sort of complexities that might introduce in the geological record. I've already implemented a tracking algorithm that will build a 'virtual' stratigraphy at chosen sites so that we can compare timeseries model outputs with ice/firn core records. To refine this we still need to acquire high-resolution sea-ice boundaries at frequent temporal intervals and use these to define where and when sediments are released to the ocean. Other modifications we could implement might include a spatially-variable retention factor, to reflect differences in surface (i.e. blue-ice vs. deep snow). Similarly we could incorporate additional sediment sources, perhaps based on the GNS mapping. If the climate, sea-ice and geological data exist we could also expand the model domain to consider the whole Ross Sea region, at a lower resolution (e.g. $10 \mathrm{~km}$ ). 


\section{References}

Abbott, P. and Wardle, M. (1970). Teach Yourself Calculus. Hodder and Stoughton Educational, Great Britain, revised edition.

Aitken, A. R. A., Wilson, G. S., Jordan, T., Tinto, K., and Blakemore, H. (2012). Flexural controls on late Neogene basin evolution in southern McMurdo Sound, Antarctica. Global and Planetary Change, 80-81:99-112.

Albani, S., Mahowald, N. M., Delmonte, B., Maggi, V., and Winckler, G. (2012). Comparing modeled and observed changes in mineral dust transport and deposition to Antarctica between the Last Glacial Maximum and current climates. Climate Dynamics, 38(9-10):1731-1755.

Alderkamp, A.-C., Mills, M. M., van Dijken, G. L., Laan, P., Thuroczy, C.-E., Gerringa, L. J. A., de Baar, H. J. W., Payne, C. D., Visser, Ronald, J. W., Buma, A. G. J., and Arrigo, K. R. (2012). Iron from melting glaciers fuels phytoplankton blooms in the Amundsen Sea (Southern Ocean): Phytoplankton characteristics and productivity. Deep Sea Research Part II, 71-76:32-48.

Allen, J. R. L. (1994). Fundamental properties of fluids and their relation to sediment transport processes. Sediment transport and depositional processes., chapter 2, pages 25-60. Blackwell Scientific Publications, United Kingdom.

Anderson, J. B., Brake, C. F., and Myers, N. C. (1984). Sedimentation on the Ross Sea Continental Shelf, Antarctica. Marine Geology, 57((1-4)):295-333.

Anderson, R. S. and Hallet, B. (1986). Sediment transport by wind: Toward a general model. Geological Society of America Bulletin, 97:523-535.

Armand, L. K. and Zielinski, U. (2001). Diatom species of the genus Rhizosolenia from Southern Ocean sediments: distribution and taxonomic notes. Diatom Research, 16(2):259-294.

Arrigo, K. R., Lowry, K. E., and van Dijken, G. L. (2012). Annual changes in sea ice and phytoplankton in polynyas of the Amundsen Sea, Antarctica. Deep Sea Research Part II, 71-76:5-15. 
Arrigo, K. R., Mills, M. M., Kropuenske, L. R., van Dijken, G. L., Alderkamp, A.-C., and Robinson, D. H. (2010). Photophysiology in two major Southern Ocean phytoplankton taxa: Photosynthesis and growth of Phaeocystis antarctica and Fragilariopsis cylindrus under different irradiance levels. Integrative and Comparative Biology, 50(6):950-966.

Arrigo, K. R., van Dijken, G. L., and Bushinsky, S. (2008). Primary production in the Southern Ocean 1997-2006. Journal of Geophysical Research, 113(C08004).

Arrigo, K. R., Worthen, D. L., and Robinson, D. H. (2003). A coupled ocean-ecosystem model of the Ross Sea: 2. Iron regulation of phytoplankton taxonomic variability and primary production. Journal of Geophysical Research, 108(C7, 3231):24:1-17.

Atkins, C. B., Barrett, P. J., and Hicock, S. R. (2002). Cold glaciers erode and deposit: Evidence from Allan Hills, Antarctica. Geology, 30(7):659-662.

Atkins, C. B. and Dickinson, W. W. (2007). Landscape modification by meltwater channels at the margins of cold-based glaciers, Dry Valleys, Antarctica. Boreas, 36(1):4755 .

Atkins, C. B. and Dunbar, G. B. (2009). Aeolian sediment flux from sea ice into Southern McMurdo Sound, Antarctica. Global and Planetary Change, 69(3):133-141.

Ayling, B. F. (2001). Dust accumulation on the Victoria Lower Glacier and Wilson Piedmont, coastal South Victoria Land, Antarctica, and its potential as a paleowind indicator. Victoria University of Wellington. BSc Hons, 109pp.

Ayling, B. F. and McGowan, H. A. (2006). Niveo-eolian sediment deposits coastal South Victoria Land, Antarctica: Indicators of regional variability in weather and climate. Arctic, Antarctic, and Alpine Research, 38(3):313-324.

Bagnold, R. A. (1941). The Physics of Blown Sand and Desert Dunes. Methuen and Co. Ltd, London.

Barber, D. G. and Masson, R. A. (2007). The Role of Sea Ice in Arctic and Antarctic Polynyas. volume 74 of Elsevier Oceanography Series, chapter 1, pages 1-54. Elsevier.

Barnes, C. G., Barrett, P. J., Brady, H. T., Bucher, G., Kaminuma, K., McCormick, S. A., McGinnis, L. D., McKelvey, B. C., Miller, G. H., Nakai, N., Oliver, J., Parker, Bruce, C., Sillars, K. J., Treves, S. B., Webb, P. N., and Wrenn, J. (1976). Dry Valleys Drilling Project (DVDP) Bulletin No. 7. Technical report, National Science Foundation Office of Polar Programs New Zealand Department of Scientific and Industrial Research Antarctic Division Japan National Institute for Polar Research. 
Barrett, P. J. (1986). Antarctic Cenozoic history from the MSSTS-1 drillhole, McMurdo Sound. DSIR Bulletin NZ, 237. New Zealand Department of Scientific and Industrial Research.

Barrett, P. J. (1989). Antarctic Cenozoic history from the CIROS-1 drillhole, McMurdo Sound. DSIR Bulletin NZ, 245. New Zealand Department of Scientific and Industrial Research.

Barrett, P. J. (2007). Cenozoic climate and sea level history from glacimarine strata off Victoria Land coast, Cape Roberts Project, Antarctica. In Hambrey, M. J., Christoffersen, P., Glasser, N. F., and Hubbard, B., editors, Glacial Processes and Products, International Association of Sedimentologists Special Publication, volume 39.

Barrett, P. J., Henrys, S. A., Bartek, L. R., Brancolini, G., Busett, M., Davey, F. J., Hannah, M. J., and Pyne, A. R. (1995). Geology of the margin of the Victoria Land off Cape Roberts, southwest Ross Sea. In Geology and Seismic Stratigraphy of the Antarctic Margin, volume 68 of Antarctic Research Series, pages 183-207. American Geophysical Union, Washington, D.C.

Barrett, P. J., Pyne, A. R., and Ward, B. L. (1983). Modern sedimentation in McMurdo Sound, Antarctica. Antarctic Earth Science, pp. 550-554. Australian Academy of Science, Canberra, A.C.T.

Barrett, P. J. and Treves, S. B. (1981). Sedimentology and petrology of core from DVDP 15, western McMurdo Sound. In McGinnis, L. D., editor, Dry Valley Drilling Project, volume 33, pages 281-315. Americal Geophysical Union, Washington D.C.

Barrett, P. J., Treves, S. B., Behling, R. E., Brady, H., Cartwright, K., Glodich, S. S., Bodkin, J. L., Hall, S. A., Hendy, C., Healy, T. H., Rayner, E. R., Wilson, A. T., Jackson, J. K., McGinnis, L. D., Mudrey Jr., M. G., Kaminuma, K., Kear, D., Kusonoki, K., Kyle, P. R., Ling, H. Y., McCollum, D., Miagkov, S. M., Nakai, N., Nishiyama, T., Kurasawa, H., Park, J., Powell, R., Stuckless, J. S., Ericksen, R. L., Stuiver, M., Yang, I. C., Sun, S., Hanson, G. N., Thompson, R. B., Torii, T., Yamagata, N., Ossaka, J., Turner, J., and Vucetich, C. G. (1975). Dry Valleys Drilling Project (DVDP) Bulletin No. 6. Technical report, National Science Foundation Office of Polar Programs New Zealand Department of Scientific and Industrial Research Antarctic Division Japan National Institute for Polar Research.

Bartek, L. R. and Anderson, J. B. (1991). Facies distribution resulting from sedimentation under polar interglacial climatic conditions within a high-latitude marginal basin, McMurdo Sound, Antarctica. Technical report, Geological Society of America. 
Basile, I., Grousset, F., Revel, M., Petit, J. R., Biscaye, P. E., and Barkov, N. I. (1997). Patgonian origin of glacial dust deposited in East Antarctica (Vostok and Dome C) during glacial stages 2, 4 and 6. Earth and Planetary Science Letters, 146:573-589.

Bauer, E. and Ganopolski, A. (2010). Aeolian dust modeling over the past four glacial cycles with CLIMBER-2. Global and Planetary Change, 74(2):49-60.

Beckman Coulter, I. (2011). LS 13320 Laser Diffraction Particle Size Analyzer - Instructions for Use. www.beckmancoulter.com.

Bentley, P. N. (1979). Characteristics and distribution of wind blown sediment, western McMurdo Sound, Antarctica. Victoria University of Wellington. BSc Hons thesis, 46pp.

Bertler, N. A. N., Naish, T. R., Oerter, H., Kipfstuhl, S., Barrett, P. J., Mayewski, P. A., and Kreutz, K. (2006). The effects of joint ENSO-Antarctic Oscillation forcing on the McMurdo Dry Valleys, Antarctica. Antarctic Science, 18(04):507.

Bloemendal, J. and deMenocal, P. (1989). Evidence for a change in the periodicity of tropical climate cycles at 2.4 Myr from whole-core magnetic susceptibility measurements. Nature, 342:897-900.

Boggs, S. (2006). Principles of Sedimentology and Stratigraphy. Pearson Prentice Hall, Pearson Education, Inc., New Jersey, fourth edition edition.

Bory, A., Wolff, E., Mulvaney, R., Jagoutz, E., Wegner, A., Ruth, U., and Elderfield, H. (2010). Multiple sources supply eolian mineral dust to the Atlantic sector of coastal Antarctica: Evidence from recent snow layers at the top of Berkner Island ice sheet. Earth and Planetary Science Letters, 291(1-4):138-148.

Bowie, A. R., Lannuzel, D., Remenyi, T. A., Wagener, T., Lam, P. J., Boyd, P. W., Guieu, C., Townsend, A. T., and Trull, T. W. (2009). Biogeochemical iron budgets of the Southern Ocean south of Australia: Decoupling of iron and nutrient cycles in the subantarctic zone by the summertime supply. Global Biogeochemical Cycles, 23(4).

Boyd, P. W., Arrigo, K. R., Strzepek, R., and van Dijken, G. L. (2012). Mapping phytoplankton iron utilization: Insights into Southern Ocean supply mechanisms. Journal of Geophysical Research, 117(C06009):1-18.

Bristow, C. S., Augustinus, P. C., Wallis, I. C., Jol, H. M., and Rhodes, E. J. (2010). Investigation of the age and migration of reversing dunes in Antarctica using GPR and OSL, with implications for GPR on Mars. Earth and Planetary Science Letters, 289:30-42. 
Bromwich, D. H. (1989). An extraordinary katabatic wind regime at Terra Nova Bay, Antarctica. Monthly Weather Review, 117:688-695.

Brook, E. J., Brown, E. T., Kurtz, M. D., Ackert, R. P., Raisbeck, G. M., and Yiou, F. (1995). Constraints on the age, erosion, and uplift of Neogene glacial deposits in the Transantarctic Mountains determined from in situ cosmogenic 10Be and 26Al. Geology, 23:1063-1066.

Brookfield, M. E. (2011). Aeolian processes and features in cool climates., volume 354, pages 241-258. Geological Society, London, Special Publications, United Kingdom.

Bull, J. R. (2009). Stable isotope, major and trace element chemistry of modern snow from Evans Piedmont Glacier, Antarctica: insights into potential source regions and relationship of glaciochemistry to atmospheric circulation and vigour. Victoria University of Wellington. MSc thesis, 113pp.

Bullard, J. E. and Livingstone, I. (2009). Dust. Geomorphology of Desert Environments., chapter 20, pages 629-654. Springer Science and Business Media B. V.

Carson, M. A. (1971). The mechanics of erosion, volume 4 of Monographs in spatial and environmental systems analysis. Pion Limited, United Kingdom.

Cefarelli, A. O., Ferrario, M. E., Almandoz, G. O., Atencio, A. G., Akselman, R., and Vernet, M. (2010). Diversity of the diatom genus Fragilariopsis in the Argentine Sea and Antarctic waters: morphology, distribution and abundance. Polar Biology, 33:1463-1484.

Chalmers, M. O., Harper, M. A., and Marshall, W. A. (1996). An Illustrated Catalogue of Airborne Microbiota from the Maritime Antarctic. British Antarctic Survey, Natural Environment Research Council, Cambridge, Great Britain.

Chenoli, S., Turner, J., and Samah, A. A. (2012). A climatology of strong wind events at McMurdo station, Antarctica. International Journal of Climatology.

Comiso, J. C., Kwok, R., Martin, S., and Gordon, A. L. (2011). Variability and trends in sea ice extent and ice production in the Ross Sea. Journal of Geophysical Research, 116(C04021).

Cox, S. C., Turnbull, I. M., Isaac, M. J., Townsend, D. B., Smith Lyttle, B., and (compilers) (2012). Geology of southern Victoria Land, Antarctica. Institute of Geological and Nuclear Sciences 1:250,000 geological map 22. 1 sheet + map text.

Craddock, C. (1970). Geological maps of Antarctica. Antarctic Map Folio Series 12. American Geographical Society, (p.6). 
Cremer, H., Gore, D., Hultzsch, N., Melles, M., and Wagner, B. (2004). The diatom flora and limnology of lakes in the Amery Oasis, East Antarctica. Polar Biology, 27(9).

Crosta, X., Romero, O., Armand, L. K., and Pichon, J.-J. (2005). The biogeography of major diatom taxa in Southern Ocean sediments: 2. Open ocean related species. Palaeogeography, Palaeoclimatology, Palaeoecology, 223:66-92.

Cuffey, K. M., Conway, H., Gades, A. M., Hallet, B., Lorrain, R., Severinghaus, J. P., Steig, E. J., Vaughn, B., and White, J. W. C. (2000). Entrainment at cold glacier beds. Geology, 28:351-354.

Debenham, F. (1920). A new mode of transportation by ice: the raised marine muds of South Victoria Land (Antarctica). Quarterly Journal of the Geological Society of London, 2(75):51-76.

Delmonte, B., Andersson, P. S., Hansson, M., Schöberg, H., Petit, J. R., Basile-Doelsch, I., and Maggi, V. (2008). Aeolian dust in East Antarctica (EPICA-Dome C and Vostok): Provenance during glacial ages over the last 800 kyr. Geophysical Research Letters, 35(L07703).

Delmonte, B., Andersson, P. S., Schöberg, H., Hansson, M., Petit, J. R., Delmas, R., Gaiero, D. M., Maggi, V., and Frezzotti, M. (2010a). Geographic provenance of aeolian dust in East Antarctica during Pleistocene glaciations: preliminary results from Talos Dome and comparison with East Antarctica and new Andean ice core data. Quaternary Science Reviews, 29:256-264.

Delmonte, B., Baroni, C., Andersson, P. S., Narcisi, B., Salvatore, M. C., Petit, J. R., Scarchilli, C., Frezzotti, M., Albani, S., and Maggi, V. (2013). Modern and Holocene aeolian dust variability from Talos Dome (Northern Victoria Land) to the interior of the Antarctic ice sheet. Quaternary Science Reviews, 64:76-89.

Delmonte, B., Baroni, C., Andersson, P. S., Schoberg, H., Hansson, M., Aciego, S., Petit, J.-R., Albani, S., Mazzola, C., Maggi, V., and Frezzotti, M. (2010b). Aeolian dust in the Talos Dome ice core (East Antarctica, Pacific/Ross Sea sector): Victoria Land versus remote sources over the last two climate cycles. Journal of Quaternary Science.

Delmonte, B., Basile-Doelsch, I., Petit, J. R., Maggi, V., Revel-Rolland, M., Michard, A., Jagoutz, E., and Grousset, F. (2004a). Comparing the Epica and Vostok dust records during the last 220,000 years: stratigraphical correlation and provenance in glacial periods. Earth-Science Reviews, 66:63-87. 
Delmonte, B., Petit, J. R., Anderson, K. K., Basile-Doelsch, I., Maggi, V., and Ya Lipenkov, V. (2004b). Dust size evidence for opposite regional atmospheric circulation changes over east Antarctica during the last climate transition. Climate Dynamics, 23:427-438.

Denton, G. H. and Hughes, T. J. (2000). Reconstruction of the Ross Ice Drainage System, Antarctica, at the Last Glacial Maximum. Geografiska Annaler, 82 A(2-3):143166.

Denton, G. H. and Marchant, D. R. (2000). The geological basis for a reconstruction of a grounded ice sheet in McMurdo Sound, Antarctica, at the Last Glacial Maximum. Geografiska Annaler, 82 A(2-3):167-211.

Deuerling, K. M. (2010). Aeolian sediments of the McMurdo Dry Valleys, Antarctica. Ohio State University. PhD thesis, 144pp.

Domack, E. W., Jacobson, E. A., Shipp, S., and Anderson, J. B. (1999). Late PleistoceneHolocene retreat of the West Antarctic Ice-Sheet system in the Ross Sea: Part 2 Sedimentologic and stratigraphic signature. Geological Society of America Bulletin, 111(10):1517-1536.

Dong, Z., Lu, J., Man, D., Lv, P., Qian, G., Zhang, Z., and Luo, W. (2011). Equations for the near-surface mass flux density profile of wind-blown sediments. Earth Surface Processes and Landforms, 36:1292-1299.

Doran, P. T. (2002). Valley floor climate observations from the McMurdo Dry Valleys, Antarctica, 1986-2000. Journal of Geophysical Research, 107(D24).

Dover, S.-J. E. (1993). Numerical modelling of blowing snow. University of Leeds. PhD thesis, 213pp.

Drewry, D. J., Jordan, S. R., and Jankowski, E. (1982). Measured properties of the Antarctic ice sheet: surface configuration, ice thickness, volume and bedrock characteristics. Annals of Glaciology, 3:83-91.

Drucker, R., Martin, S., and Kwok, R. (2011). Sea ice production and export from coastal polynyas in the Weddell and Ross Seas. Geophysical Research Letters, 38(L17502).

Duce, R. A., Liss, P. S., Merril, J. T., Atlas, E. L., Buat-Menard, P., Hicks, B. B., Miller, J. M., Prospero, J. M., Arimoto, R., Church, T. M., Ellis, W., Galloway, J. N., Hansen, L., Jickells, T. D., Knap, A. H., Reinhardt, K. H., Schneider, B., Soudine, A., Tokos, J. J., Tsunogai, S., Wollast, R., and Zhou, M. (1991). The atmospheric input of trace species to the world ocean. Global Biogeochemical Cycles, 5(3):193-259. 
Dunbar, G. B. and Barrett, P. J. (2004). A compilation of textural data for modern and ancient sediments in the McMurdo Sound area, Antarctica. In Antarctic Data Series No. 24. Antarctic Research Centre, Victoria University of Wellington, New Zealand.

Dunbar, G. B., Bertler, N. A. N., and McKay, R. M. (2009). Sediment flux through the McMurdo Ice Shelf in Windless Bight, Antarctica. Global and Planetary Change, 69(3):87-93.

Dunbar, R. B., Leventer, A. R., and Stockton, W. L. (1989). Biogenic sedimentation in McMurdo Sound, Antarctica. Marine Geology, 85((2-4)):155-179.

Ellis, J. T., Sherman, D. J., Farrell, E. J., and Li, B. (2012). Temporal and spatial variability of aeolian sand transport: Implications for field measurements. Aeolian Research, 3:379-387.

Esposito, R. M. M., Spaulding, S. A., McKnight, D. M., Van der Vijver, B., Kopalová, K., Lubinski, D., Hall, B., and Whittaker, T. (2008). Inland diatoms from the McMurdo Dry Valleys and James Ross Island, Antarctica. Botany, 86:1378-1392.

Falconer, T. R. and Pyne, A. R. (2000). Sea ice analysis for proposed hydrographic survey - Cape Hallett, Cape Adare and Possession Islands (LINZ Project number 1017).

Falconer, T. R. and Pyne, A. R. (2004). Ice breakout history in southern McMurdo Sound, Antarctica (1988-2002). In Antarctic Data Series No. 27. Antarctic Research Centre, Victoria University of Wellington, New Zealand.

Fischer, H., Fundel, F., Ruth, U., Twarloh, B., Wegner, A., Udisti, R., Becagli, S., Castellano, E., Morganti, A., Severi, M., Wolff, E. W., Littot, G. C., Röthlisberger, R., Mulvaney, R., Hutterli, M. A., Kaufmann, P., Federer, U., Lambert, F., Bigler, M., Hansson, M., Jonsell, U., de Angelis, M., Boutron, C. F., Siggaard-Andersen, M.-L., Steffensen, J. P., Barbante, C., Gaspari, V., Gabrielli, P., and Wagenbach, D. (2007). Reconstruction of millennial changes in dust emission, transport and regional sea ice coverage using the deep EPICA ice cores from the Atlantic and Indian Ocean sector of Antarctica. Earth and Planetary Science Letters, 260:340-354.

Fortner, S. K., Berry Lyons, W., and Olesik, J. W. (2011). Eolian deposition of trace elements onto Taylor Valley Antarctic glaciers. Applied Geochemistry, 26(11):18971904.

Fountain, A. G., Nylen, T. H., Monaghan, A. J., Basagic, H. J., and Bromwich, D. H. (2010). Snow in the McMurdo Dry Valleys, Antarctica. International Journal of Climatology, 30:633-642. 
Frignani, M., Giglio, F., Accornero, A., Langone, L., and Ravaioli, M. (2003). Sediment characteristics at selected sites of the Ross Sea continental shelf: does the sedimentary record reflect water column fluxes? Antarctic Science, 15:133-139.

Gaiero, D. M. (2007). Dust provenance in Antarctic ice during glacial periods: From where in southern South America? Geophysical Research Letters, 34(17).

Gassó, S. and Stein, A. F. (2007). Does dust from Patagonia reach the sub-Antarctic Atlantic Ocean? Geophysical Research Letters, 34(L01801).

Genthon, C. (1992). Simulations of desert dust and sea-salt aerosols in Antarctica with a general circulation model of the atmosphere. Tellus, Series B: Chemical and Physical Meteorology, 44(4):371-389.

Gerringa, L. J. A., Alderkamp, A.-C., Laan, P., Thuroczy, C.-E., de Baar, H. J. W., Mills, M. M., van Dijken, G. L., van Haren, H., and Arrigo, K. R. (2012). Iron from melting glaciers fuels the phytoplankton blooms in Amundsen Sea (Southern Ocean): Iron biogeochemistry. Deep Sea Research Part II, 71-76:16-31.

Glasser, N., Goodsell, B., Copland, L., and Lawson, W. (2006). Debris characteristics and ice-shelf dynamics in the ablation region of the McMurdo Ice Shelf, Antarctica. Journal of Glaciology, 52(177):223-234.

Golledge, N. (2012). Numerical Model for Aeolian Sediment Transport and Evolution (NaMASTE) - user manual. (Unpublished).

Greeley, R. and Iversen, J. D. (1985). Wind as a geological process: on Earth, Mars, Venus, and Titan. Cambridge planetary science series. Cambridge University Press, Cambridge, United Kingdom.

Grousset, F. E. and Biscaye, P. E. (2005). Tracing dust sources and transport patterns using Sr, Nd and Pb isotopes. Chemical Geology, 222(3-4):149-167.

Gunn, B. M. and Warren, G. (1962). Geology of Victoria Land between the Mawson and Mulock Glaciers, Antarctica.

Hawes, I. and Howard-Williams, C. (2003). Coastal Ecosystems: Pond life on the McMurdo Ice Shelf, one of the world's strangest ecosystem. Water and Atmosphere, 11(3):18-19.

Hinkley, T. K. and Matsumoto, A. (2001). Atmospheric regime of dust and salt through 75,000 years of Taylor Dome ice core: Refinement by measurement of major, minor, and trace metal suites. Journal of Geophysical Research, 106(D16):18487-18493. 
Holmes, R. E., Stearns, C. R., Weidner, G. A., and Keller, L. M. (2000). Utilization of automatic weather station data for forecasting high wind speeds at Pegasus Runway, Antarctica. Weather and Forecasting, 15:137-151.

Howard-Williams, C., Hawes, I., and Gordon, S. (2010). The environmental basis of ecosystem variability in Antarctica: research in the Latitudinal Gradient Project. Antarctic Science, 22(06):591-602.

Hsü, K. J. (1989). Physical Principles of Sedimentology: A readable textbook for beginners and experts. Springer-Verlag Berlin Heidelberg, Germany.

Hughes, P. and Krissek, L. A. (1985). Modern sediments of the Terra Nova Bay polynya, Ross Sea, Antarctica. Antarctic Journal, (1985 Review):107-108.

Iriondo, M. (2000). Patagonian dust in Antarctica. Quaternary International, 68-71:8386.

Jickells, T. D., An, Z. S., Anderson, K. K., Baker, A. R., Bergametti, G., Brooks, N., Cao, J. J., Boyd, P. W., Duce, R. A., Hunter, K. A., Kawahata, H., Kubilay, N., laRoche, J., Liss, P. S., Mahowald, N. M., Prospero, J. M., Ridgwell, A. J., Tegen, I., and Torres, R. (2005). Global iron connections between desert dust, ocean biogeochemistry, and climate. Science, 308:67-71.

Johnson, M. S., Meskhidze, N., Solmon, F., Gassó, S., Chuang, P. Y., Gaiero, D. M., Yantosca, R. M., Wu, S., Wang, Y., and Carouge, C. (2010). Modeling dust and soluble iron deposition to the South Atlantic Ocean. Journal of Geophysical Research. Atmospheres, 115(D15202).

Kellogg, D. E. and Kellogg, T. B. (1987). Diatoms of the McMurdo Ice Shelf, Antarctica: Implications for sediment and biotic reworking. Palaeogeography, Palaeoclimatology, Palaeoecology, 60:77-96.

Kellogg, D. E., Stuiver, M., Kellogg, T. B., and Denton, G. H. (1980). Non-marine diatoms from Late Wisconsin perched deltas in Taylor Valley, Antarctica. Palaeogeography, Palaeoclimatology, Palaeoecology, 30:157-189.

Kellogg, T. B., Kellogg, D. E., and Stuiver, M. (1990). Late Quaternary history of the southwestern Ross Sea: Evidence from debris bands on the McMurdo Ice Shelf, Antarctica. In Contributions to Antarctic Research I, volume 50 of Antarctic Research Series, pages 25-56. American Geophysical Union.

Kelly, W. C. and Zumberge, J. H. (1961). Weathering of a Quartz Dolerite at Marble Point, McMurdo Sound, Antarctica. The Journal of Geology, 69(4):433-446. 
Keys, J. R. (1980). Air temperature, wind, precipitation and atmospheric humidity in the McMurdo region. In Antarctic Data Series No. 9. Department of Geology Publication No. 17. Antarctic Research Centre, Victoria University of Wellington, New Zealand.

Knuth, S. L., Tripoli, G. J., Thom, J. E., and Weidner, G. A. (2010). The influence of blowing snow and precipitation on snow depth change across the Ross Ice Shelf and Ross Sea regions of Antarctica. Journal of Applied Meteorology and Climatology, 49(6):1306-1321.

Kohfeld, K. and Tegen, I. (2007). Record of mineral aerosols and their role in the Earth System, volume 4 - The Atmosphere, chapter 4.13, pages 1-26. Elsevier Ltd.

Kwok, R. (2005). Ross Sea ice motion, area flux, and deformation. Journal of Climate, 18:3761-3776.

Kyle, P. R., McIntosh, W., Schmidt-Thomé, M., Mueller, P., Tessensohn, F., Noll, M., Wörner, G., Wörner, G., Viereck, L., Behrendt, J., Ellerman, P., Wright, A., Moore, J., Stump, E., Borg, S., and Sheridan, M. (1990). A. McMurdo Volcanic Group Western Ross embayment. In LeMasurier, W., Thomson, J., Baker, P., Kyle, P. R., Rowley, P., Smellie, J., and Verwoerd, W., editors, Volcanoes of the Antarctic Plate and Southern Oceans, volume 48 of Antarctic Research Series, chapter A. III., pages 18-145. American Geophysical Union.

Lambert, F., Delmonte, B., Petit, J. R., Bigler, M., Kaufmann, P. R., Hutterli, M. A., Stocker, T. F., Ruth, U., Steffensen, J. P., and Maggi, V. (2008). Dust-climate couplings over the past 800,000 years from the EPICA Dome C ice core. Nature, 452(7187):616-9.

Lancaster, N. (2002). Flux of eolian sediment in the McMurdo Dry Valleys, Antarctica: a preliminary assessment. Arctic, Antarctic, and Alpine Research, 34(3):318-323.

Lancaster, N., Nickling, W. G., and Gillies, J. A. (2010). Sand transport by wind on complex surfaces: Field studies in the McMurdo Dry Valleys, Antarctica. Journal of Geophysical Research, 115(F3).

Ledford-Hoffman, P. A., DeMaster, D. J., and Nittrouer, C. A. (1986). Biogenic-silica accumulation in the Ross Sea and the importance of Antarctic continental-shelf deposits in the marine silica budget. Geochimica et Cosmochimica Acta, 50:2099-2110.

Leventer, A. (2003). Particulate Flux from Sea Ice in Polar Waters. Blackwell Science Ltd., UK. 
Li, B. and McKenna-Neuman, C. (2012). Boundary-layer turbulence characteristics during aeolian saltation. Geophysical Research Letters, 39(L11402).

Li, F., Ginoux, P., and Ramaswamy, V. (2008). Distribution, transport, and deposition of mineral dust in the Southern Ocean and Antarctica: Contribution of major sources. Journal of Geophysical Research, 113(D10207).

Li, F., Ramaswamy, V., Ginoux, P., Broccoli, A. J., Delworth, T., and Zeng, F. (2010). Toward understanding the dust deposition in Antarctica during the Last Glacial Maximum: sensitivity studies on plausible causes. Journal of Geophysical Research, 115(D24120).

Lindsay, J. F. (1973). Reversed barchan dunes in Lower Victoria Valley, Antarctica. GSA Bulletin, 84(5):1799-1806.

Lunt, D. J. and Valdes, P. J. (2001). Dust transport to Dome C, Antarctica at the Last Glacial Maximum and present day. Geophysical Research Letters, 28(2):295-298.

Macpherson, A. J. (1987). The Mackay Glacier/Granite Harbour system (Ross Dependency, Antarctica) - a study in nearshore glacial marine sedimentation. Victoria University of Wellington. PhD thesis, 85pp.

Mahowald, N. M., Baker, A. R., Bergametti, G., Brooks, N., Duce, R. A., Jickells, T. D., Kubilay, N., Prospero, J. M., and Tegan, I. (2005). Atmospheric global dust cycle and iron inputs to the ocean. Global Biogeochemical Cycles, 19(GB4025):1 -15.

Mahowald, N. M., Engelstaedter, S., Luo, C., Sealy, A., Artaxo, P., Benitez-Nelson, C., Bonnet, S., Chen, Y., Chuang, P. Y., Cohen, D. D., Dulac, F., Herut, B., Johansen, A. M., Kubilay, N., Losno, R., Maenhaut, W., Paytan, A., Prospero, J. M., Shank, L. M., and Siefert, R. L. (2009). Atmospheric Iron Deposition: Global Distribution, Variability, and Human Perturbations. Annual Review of Marine Science, 1(1):245-278.

Mahowald, N. M., Kohfeld, K. E., Hansson, M., Balkanski, Y., Harrison, S. P., Prentice, I. C., Schulz, M., and Rodhe, H. (1999). Dust sources and deposition during the last glacial maximum and current climate: A comparison of model results with paleodata from ice cores and marine sediments. Journal of Geophysical Research, 104(D13):15,195-15,916.

Mahowald, N. M., Muhs, D. R., Levis, S., Rasch, P. J., Yoshioka, M., Zender, C. S., and Luo, C. (2006). Change in atmospheric mineral aerosols in response to climate: Last glacial period, preindustrial, modern, and doubled carbon dioxide climates. Journal of Geophysical Research, 111(D10202). 
Mahowald, N. M., Ward, D. S., Kloster, S., Flanner, M. G., Heald, C. L., Heavens, N. G., Hess, P. G., Lamarque, J.-F., and Chuang, P. Y. (2011). Aerosol impacts on climate and biogeochemistry. Annual Review of Environment and Resources, 36:45-74.

Malin, M. C. (1986). Rates of geomorphic modification in ice-free areas southern Victoria Land, Antarctica. Antarctic Journal of the United States, 20(5):18-21.

Malin, M. C. (1992). Short-term variations in the rate of eolian processes, southern Victoria Land, Antarctica. Antarctic Journal of the United States, 26(5):27-29.

Marchant, D. R. and Head, J. W. (2007). Antarctic dry valleys: Microclimate zonation, variable geomorphic processes, and implications for assessing climate change on Mars. Icarus, 192(1):187-222.

McKay, R. M., Barrett, P. J., Harper, M. A., and Hannah, M. J. (2008a). Atmospheric transport and concentration of diatoms in surficial and glacial sediments of the Allan Hills, Transantarctic Mountains. Palaeogeography, Palaeoclimatology, Palaeoecology, 260:168-183.

McKay, R. M., Dunbar, G. B., Naish, T. R., Barrett, P. J., Carter, L., and Harper, M. (2008b). Retreat history of the Ross Ice Sheet (Shelf) since the Last Glacial Maximum from deep-basin sediment cores around Ross Island. Palaeogeography, Palaeoclimatology, Palaeoecology, 260(1-2):245-261.

McKendry, I. G. and Lewthwaite, E. W. D. (1992). Summertime along-valley wind variations in the Wright Valley Antarctica. International Journal of Climatology, 12:587596.

McKenna-Neuman, C. (1993). A review of aeolian transport processes in cold environments. Progress in Physical Geography, 17(2):137-155.

McKenna-Neuman, C. (2003). Effects of temperature and humidity upon the entrainment of sedimentary particles by wind. Boundary-Layer Meteorology, 108:61-89.

McTainsh, G. H. and Strong, C. (2007). The role of aeolian dust in ecosystems. Geomorphology, 89:37-54.

Medlin, L. K. and Priddle, J. (1990). Polar Marine Diatoms. British Antarctic Survey, Natural Environment Research Council, Cambridge, Great Britain.

Middleton, N. J. (1989). Desert dust. Arid Zone Geomorphology., chapter 12, pages 262-283. Halsted Press, United Kingdom. 
Miller, M. C., McCave, I. N., and Komar, P. D. (1977). Threshold of sediment motion under unidirectional currents. Sedimentology, 24:507-527.

Monaghan, A. J., Bromwich, D. H., Powers, J. G., and Manning, K. W. (2005). The climate of the McMurdo, Antarctica, region as represented by one year of forecasts from the Antarctic Mesoscale Prediction System. Journal of Climate, 18:11741189.

Murray, K. T., Miller, M. F., and Bowser, S. S. (2012). Depositional processes beneath coastal multi-year sea ice. Sedimentology, In Press.

Naish, T. R., Powell, R., Levy, R., Wilson, G., Scherer, R. P., Talarico, F. M., Krissek, L. A., Niessen, F., Pompilio, M., Wilson, T., Carter, L., DeConto, R., Huybers, P., McKay, R. M., Pollard, D., Ross, J., Winter, D., Barrett, P. J., Browne, G., Cody, R., Cowan, E., Crampton, J., Dunbar, G. B., Dunbar, N., Florindo, F., Gebhardt, C., Graham, I., Hannah, M. J., Hansaraj, D., Harwood, D., Helling, D., Henrys, S. A., Hinnov, L., Kuhn, G., Kyle, P. R., Läufer, A., Maffioli, P., Magens, D., Mandernack, K., McIntosh, W., Millan, C., Morin, R., Ohneiser, C., Paulsen, T., Persico, D., Raine, I., Reed, J., Riesselman, C., Sagnotti, L., Schmitt, D., Sjunneskog, C., Strong, P., Taviani, M., Vogel, S., Wilch, T., and Williams, T. (2009). Obliquity-paced Pliocene West Antarctic ice sheet oscillations. Nature, 489:322-329.

Nichols, G. (2009). Sedimentology and Stratigraphy. Wiley-Blackwell, second edition.

Nickling, W. G. (1994). Aeolian sediment transport and deposition. Sediment transport and depositional processes., chapter 9, pages 293-350. Blackwell Scientific Publications.

Nickling, W. G. and McKenna-Neuman, C. (2009). Aeolian sediment transport. Geomorphology of Desert Environments., chapter 17, pages 517-554. Springer Science and Business Media B. V., second edition.

Nylen, T. H., Fountain, A. G., and Doran, P. T. (2004). Climatology of katabatic winds in the McMurdo dry valleys, southern Victoria Land, Antarctica. Journal of Geophysical Research, 109(D03114):1-9.

Oke, T. R. (1978). Boundary Layer Climates. Methuen, New York.

Parish, T. R. and Bromwich, D. H. (1987). The surface windfield over the Antarctic ice sheets. Nature, 328:51-54.

Parish, T. R. and Bromwich, D. H. (2007). Reexamination of the near-surface airflow over the Antarctic continent and implications on atmospheric circulations at high southern latitudes. Monthly Weather Review, 135:1961-1973. 
Parish, T. R., Cassano, J. J., and Seefeldt, M. W. (2006). Characteristics of the Ross Ice Shelf air stream as depicted in Antarctic Mesoscale Prediction System simulations. Journal of Geophysical Research, 111(D12).

Petit, J. R. and etal (1999). Climate and atmospheric history of the past 420,000 years from the Vostok ice core, Antarctica. Nature, 399:429-436.

Pike, J., Crosta, X., Maddison, E. J., Stickley, C. E., Denis, D., Barbara, L., and Renssen, H. (2009). Observations on the relationship between the Antarctic coastal diatoms Thalassiosira antarctica Comber and Porosira glacialis (Grunow) Jorgensen and sea ice concentrations during the late Quaternary. Marine Micropaleontology, 73:14-25.

Priddle, J. and Fryxell, G. (1985). Handbook of the Common Plankton Diatoms of the Southern Ocean: Centrales except the genus Thalassiosira. British Antarctic Survey, Natural Enivironment Research Council, University Press, Cambridge, Great Britain.

Prospero, J. M., Charlson, R. J., Mohnen, V., Jaenicke, R., Delany, A. C., Moyers, J., Zoller, W., and Rahn, K. (1983). The atmospheric aerosol system: an overview. Review of Geophysics and Space Physics, 21:1607-1629.

Prospero, J. M., Ginoux, P., Torres, O., Nicholson, S. E., and Gill, T. E. (2002). Environmental characterization of global sources of atmospheric soil dust identified with the NIMBUS 7 Total Ozone Mapping Spectrometer (TOMS) absorbing aerosol product. Reviews of Geophysics, 40(1):1002.

Pye, K. (1987). Aeolian dust and dust deposits. Academic Press, London, UK.

Raiswell, R., Benning, L. G., Tranter, M., and Tulaczyk, S. (2008). Bioavailable iron in the Southern Ocean: the significance of the iceberg conveyor belt. Geochemical Transactions, 9:7.

Raupach, M. and Lu, H. (2004). Representation of land-surface processes in aeolian transport models. Environmental Modelling and Software, 19(2):93-112.

Raupach, M. R. (1994). Simplified expressions for vegetation roughness length and zero-plane displacement as functions of canopy height and area index. BoundaryLayer Meteorology, 71:211-216.

Ravi, S., D’Odorico, P., Breshears, D. D., Field, J. P., Goudie, A. S., Huxman, T. E., Li, J., Okin, G. S., Swap, R. J., Thomas, A. D., Pelt, S. V., Whicker, J. J., and Zobeck, T. M. (2011). Aeolian processes and the biosphere. Review of Geophysics and Space Physics, 49(RG3001):1-45. 
Reddy, T. E. and Arrigo, K. R. (2006). Constraints on the extent of the Ross Sea phytoplankton bloom. Journal of Geophysical Research, 111(C07005):1-8.

Rickard, G. J., Roberts, M. J., Williams, M. J. M., Dunn, A., and Smith, M. H. (2010). Mean circulation and hydrography in the Ross Sea sector, Southern Ocean: representation in numerical models. Antarctic Science, 22(05):533-558.

Robinson, N. J. (2004). An oceanographic study of the cavity beneath the McMurdo Ice Shelf, Antarctica. Victoria University of Wellington. MSc thesis, 100pp.

Robinson, N. J., Williams, M. J. M., Barrett, P. J., and Pyne, A. R. (2010). Observations of flow and ice-ocean interaction beneath the McMurdo Ice Shelf, Antarctica. Journal of Geophysical Research, 115(C03025).

Šabacká, M., Priscu, J. C., Basagic, H. J., Fountain, A. G., Wall, D. H., Virginia, R. A., and Greenwood, M. C. (2012). Aeolian flux of biotic and abiotic material in Taylor Valley, Antarctica. Geomorphology, 155-156:102-111.

Schlichting, H. (1979). Boundary-layer Theory. McGraw-Hill, New York, 7th edition.

Schuck, I. (2009). Mineralogical characterisation and geographic provenance of atmospheric particles in coastal Antarctic ice cores: indicators of past climatic variability. Universitat Karlsruhe. Diploma thesis, 87pp.

Schulz, M., Prospero, J. M., Baker, A. R., Dentener, F., Ickes, L., Liss, P. S., Mahowald, N. M., Nickovic, S., García-Pando, C. P., Rodríguez, S., Sarin, M., Tegan, I., and Duce, R. A. (2012). Atmospheric transport and deposition of mineral dust to the ocean: Implications for research needs. Environmental Science and Technology, 46:1039010404.

Scott, W. D., Hopwood, J. M., and Summers, K. J. (1995). A mathematical model of suspension with saltation. Acta Mechanica, 108:1-22.

Sedwick, P., Marsay, C., Sohst, B., Aguilar-Islas, A., Lohan, M., Long, M., Arrigo, K. R., Dunbar, R., Saito, M., Smith, W., and DiTullio, G. (2011). Early season depletion of dissolved iron in the Ross Sea polynya: Implications for iron dynamics on the Antarctic continental shelf. Journal of Geophysical Research, 116(C12019).

Sedwick, P. N. and DiTullio, G. R. (1997). Regulation of algal blooms in Antarctic shelf waters by the release of iron from melting sea ice. Geophysical Research Letters, 24(20):2515-2518. 
Seefeldt, M. W., Cassano, J. J., and Parish, T. R. (2007). Dominant regimes of the Ross Ice Shelf surface wind field during austral autumn 2005. Journal of Applied Meteorology and Climatology, 46(11):1933-1955.

Seefeldt, M. W., Tripoli, G. J., and Stearns, C. R. (2003). A high-resolution numerical simulation of the wind flow in the Ross Island region, Antarctica. American Metereological Society, 131:435-458.

Seppälä, M. (2004). Wind as a geomorphic agent in cold climates. Studies in Polar Research. Cambridge University Press, UK.

Shao, Y. and Lu, H. (2000). A simple expression for wind erosion threshold friction velocity. Journal of Geophysical Research, 105(D17):22,437-22,443.

Shao, Y., Wyrwoll, K.-H., Chappell, A., Huang, J., Lin, Z., McTainsh, G. H., Mikami, M., Tanaka, T. Y., Wang, X., and Yoon, S. (2011). Dust cycle: An emerging core theme in Earth system science. Aeolian Research, 2(4):181-204.

Sherman, D. J. and Li, B. (2012). Predicting aeolian sand transport rates: A reevaluation of models. Aeolian Research, 3(371-378).

Sinclair, M. R. (1982). Weather observations in the Ross Island area, Antarctica. Technical report, New Zealand Meteorological Service.

Smetacek, V., Klaas, C., Strass, V. H., Assmy, P., Montresor, M., Cisewski, B., Savoye, N., Webb, A., d'Ovidio, F., Arrieta, J. M., Bathmann, U., Bellerby, R., Berg, G. M., Croot, P., Gonzalez, S., Henjes, J., Herndl, G. J., Hoffmann, L. J., Leach, H., Losch, M., Mills, M. M., Neill, C., Peeken, I., Rottgers, R., Sachs, O., Sauter, E., Schmidt, M. M., Schwarz, J., Terbruggen, A., and Wolf-Gladrow, D. (2012). Deep carbon export from a Southern Ocean iron-fertilized diatom bloom. Nature, 487(7407):313-319.

Smith, J. O. (2010). 'Finite Difference Schemes' in Physical Audio Signal Processing, http://ccrma.stanford.edu/ jos/pasp/, online book,.

Spaulding, S., Esposito, R., Lubinski, D., Horn, S., Cox, M., McKnight, D., Alger, A., Hall, B., Mayernick, M., Whittaker, T., and Yang, C. (2013). Antarctic Freshwater Diatoms. McMurdo Dry Valleys Long Term Ecological Research. http://huey.colorado.edu/diatoms/.

Speirs, J. C., McGowan, H. A., and Neil, D. T. (2008). Meteorological controls on sand transport and dune morphology in a polar-desert: Victoria Valley, Antarctica. Earth Surface Processes and Landforms, 33(12):1875-1891. 
Speirs, J. C., McGowan, H. A., Steinhoff, D. F., and Bromwich, D. H. (2012). Regional climate variability driven by foehn winds in the McMurdo Dry Valleys, Antarctica. International Journal of Climatology, pages n/a-n/a.

Speirs, J. C., Steinhoff, D. F., McGowan, H. A., Bromwich, D. H., and Monaghan, A. J. (2010). Foehn winds in the McMurdo Dry Valleys, Antarctica: The origin of extreme warming events. Journal of Climate, 23:3577-3598.

Stearns, C. R. (1997). Ross Island area wind field. Antarctic Journal of the United States, 33:181-182.

Steinhoff, D. F., Bromwich, D. H., Lambertson, M., Knuth, S. L., and Lazzara, M. A. (2008). A dynamical investigation of the May 2004 McMurdo Antarctica severe wind event using AMPS. Monthly Weather Review, 136:7-26.

Steinhoff, D. F., Bromwich, D. H., and Monaghan, A. J. (2012). Dynamics of the foehn mechanism in the McMurdo Dry Valleys of Antarctica from Polar WRF. Quarterly Journal of the Royal Meteorological Society.

Sugden, D. E. and Denton, G. H. (2004). Cenozoic landscape evolution of the Convoy Range to Mackay glacier area, Transantarctic Mountains: onshore to offshores synthesis. . Geological Society of America Bulletin, 116:840-857.

Sugden, D. E., Summerfield, M. A., Denton, G. H., Wilch, T. I., McIntosh, W. C., Marchant, D. R., and Rutford, R. H. (1999). Landscape development in the Royal Society Range, southern Victoria Land, Antarctica: stability since the mid-Miocene. Geomorphology, 28:181-200.

Summerfield, M. A., Stuart, F. M., Cockburn, H. A. P., Sugden, D. E., Denton, G. H., Dunai, T., and Marchant, D. R. (1999). Long-term rates of denudation in the Dry Valleys, Transantarctic Mountains, southern Victoria Land, Antarctica based on insitu-produced cosmogenic 21Ne. Geomorphology, 27:113-129.

Tagliabue, A., Mtshali, T., Aumont, O., Bowie, A. R., Klunder, M. B., Roychoudhury, A. N., and Swart, S. (2011). A global compilation of over 13000 dissolved iron measurements: focus on distributions and processes in the Southern Ocean. Biogeosciences Discussions, 8(6):11489-11527.

Tsoar, H. and Pye, K. (1987). Dust transport and the question of desert loess formation. Sedimentology, 34:139-153.

Turner, J., Colwell, S. R., Marshall, G. J., Lachlan-Cope, T. A., Carleton, A. M., Jones, P. D., Lagun, V., Reid, P. A., and Iagovkina, S. (2005). Antarctic climate change during the last 50 years. International Journal of Climatology, 25(3):279-294. 
Turpin, C., Badr, T., and Harion, J. L. (2010). Numerical modelling of aeolian erosion over rough surfaces. Earth Surface Processes and Landforms, 35(12):1418-1429.

USGS (1970). Ross Island and Vicinity, Antarctica 1:250,000-scale topographic map. US Geological Survey in cooperation with the National Science Foundation.

Vallelonga, P., Gabrielli, P., Balliana, E., Wegner, A., Delmonte, B., Turetta, C., Burton, G., Vanhaecke, F., Rosman, K. J. R., Hong, S., Boutron, C. F., Cescon, P., and Barbante, C. (2010). Lead isotopic compositions in the EPICA Dome C ice core and Southern Hemisphere Potential Source Areas. Quaternary Science Reviews, 29:247-255.

van den Broeke, M. R. and van Lipzig, N. P. M. (2003). Factors controlling the nearsurface wind field in Antarctica. Monthly Weather Review, 131:733-743.

Van der Vijver, B., Tavernier, I., Kellogg, T. B., Gibson, J., Verleyen, E., Vyverman, W., and Sabbe, K. (2012). Revision of type materials of Antarctic diatom species (Bacillariophyta) described by West and West (1911), with the description of two new species. Fottea, Olomounc, 12(2):149-169.

Volk, T. and Hoffert, M. I. (1985). Ocean carbon pumps: Analysis of relative strengths and efficiencies in ocean-driven atmospheric CO2 changes. In Broeker, W. S. and Sundquist, E. T., editors, The Carbon Cycle and Atmospheric CO2: Natural Variations Archean to Present, Geophysical Monograph Series., volume 32, pages 99-110. AGU, Washington.

Wagener, T., Guieu, C., Losno, R., Bonnet, S., and Mahowald, N. M. (2008). Revisiting atmospheric dust export to the Southern Hemisphere ocean: Biogeochemical implications. Global Biogeochemical Cycles, 22(GB2006).

Warren, A. (1979). Aeolian processes. Process in Geomorphology, chapter 10, pages 325-351. Edward Arnold (Publishers) Ltd., United Kingdom.

Watson, A. (1989). Windflow characteristics and aeolian entrainment. Arid Zone Geomorphology., chapter 10, pages 209-231. Halsted Press., United Kingdom.

Wilson, N. (2003). The movement and origin of the sand dunes in the Victoria Valley, Antarctica. Victoria University of Wellington. BSc Hons, 64pp.

Windom, H. L. (1969). Atmospheric dust records in permanent snowfields: Implications to marine sedimentation. Geological Society of America Bulletin, 80:761-782.

Winton, V. H. L. (2011). Aeolian iron variability and its contribution to primary production in McMurdo Sound, SW Ross Sea, Antarctica. Victoria University of Wellington. MSc thesis, 228pp. 
Witherow, R. A., Lyons, W. B., Bertler, N. A. N., Welch, K. A., Mayewski, P. A., Sneed, S. B., Nylen, T., Handley, M. J., and Fountain, A. (2006). The aeolian flux of calcium, chloride and nitrate to the McMurdo Dry Valleys landscape: evidence from snow pit analysis. Antarctic Science, 18(04):497. 